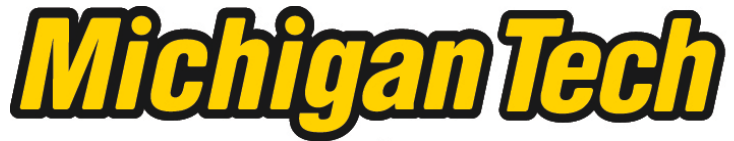 \\ Michigan Technological University Create the Future Digital Commons @ Michigan Tech
}

Dissertations, Master's Theses and Master's Reports - Open

Dissertations, Master's Theses and Master's

Reports

2012

\section{Evaluation of flood risk in response to climate variability}

Casey E. Fritsch

Michigan Technological University

Follow this and additional works at: https://digitalcommons.mtu.edu/etds

Part of the Civil and Environmental Engineering Commons

Copyright 2012 Casey E. Fritsch

\section{Recommended Citation}

Fritsch, Casey E., "Evaluation of flood risk in response to climate variability", Master's Thesis, Michigan Technological University, 2012.

https://doi.org/10.37099/mtu.dc.etds/237

Follow this and additional works at: https://digitalcommons.mtu.edu/etds

3 Part of the Civil and Environmental Engineering Commons 
Casey E. Fritsch

\begin{abstract}
A THESIS
Submitted in partial fulfillment of the requirements for the degree of MASTER OF SCIENCE

(Civil Engineering)
\end{abstract}

MICHIGAN TECHNOLOGICAL UNIVERSITY

2012

Copyright (C) Casey E. Fritsch 2012 

This thesis, "Evaluation of Flood Risk in Response to Climate Variability," is hereby approved in partial fulfillment of the requirements for the Degree of MASTER OF SCIENCE IN CIVIL ENGINEERING.

Department of Civil and Environmental Engineering

Signatures:

Thesis Advisor

Dr. Veronica W. Griffis

Department Chair

Dr. David Hand

Date 



\section{TABLE OF CONTENTS}

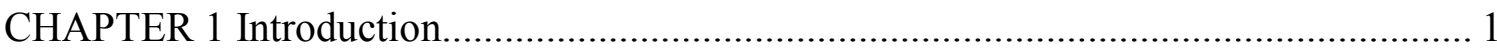

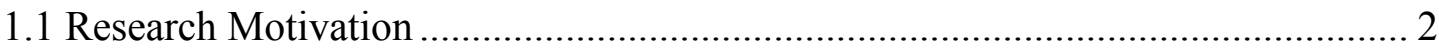

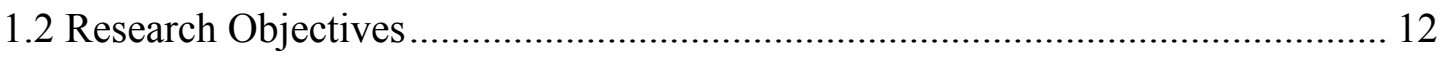

CHAPTER 2 Identification of Nonstationarity in Hydroclimatic Data Series ................ 13

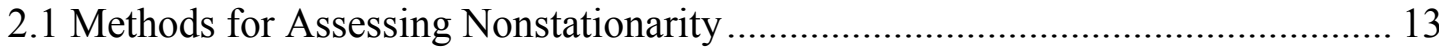

2.1.1 Mann-Kendall Trend Test.......................................................................... 15

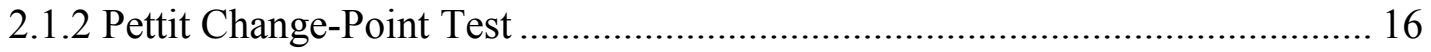

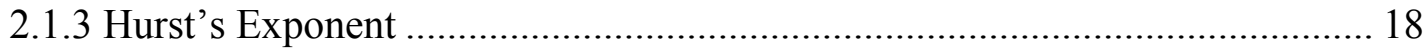

2.2 Nonstationarity in Annual Maximum Flood Series .......................................... 19

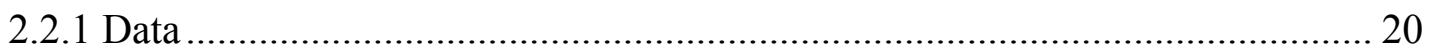

2.2.2 Trends in Magnitude of Annual Maximum Flood Series ............................. 21

2.2.3 Change-Points in Magnitude of Annual Maximum Flood Series................... 23

2.2.4 Long-Term Persistence in AMF Series..................................................... 28

2.2.5 Nonstationarity in the Timing of Flood Peaks .............................................. 29

2.3 Nonstationarity in Flood Generating Meteorological Series ............................. 31

2.3.1 Trends in Flood Generating Precipitation Series ........................................ 33 
2.3.2 Change-Points in Flood Generating Precipitation Series.

2.3.3 Trends in Flood Generating Temperature Series

2.3.4 Change-Points in Flood Generating Temperature Series.

CHAPTER 3 Sources of Nonstationarity in Annual Maximum Flood Series.

3.1 Methods for Evaluating Correlation

3.1.1 Pearson's Correlation. 44

3.1.2 Kendall's Tau Correlation. 45

3.1.3 Spearman's Rho Correlation

3.2 Climatic Causes of Nonstationarity..... 48

3.2.1 Frequency of Annual Maximum Discharge. 50

3.2.2 Evaluation of Teleconnections with Flood Flows 53

3.2.3 Common Shifts between Flood Flows and Climatic Phases 60

3.3 Meteorological Connections to Flood Peaks

3.3.1 Association among Precipitation and AMF Series 64

3.3.2 Association among Temperature and AMF Series 69

3.4 Physical Causes of Nonstationarity .76

CHAPTER 4 Climate Informed Flood Risk Projections 83

4.1 Current Procedures 83

4.2 Proposed Modification to Bulletin 17B 88 
4.3 Climate Informed Flood Risk Projection

CHAPTER 5 Conclusions.

APPENDIX A Results of Nonstationarity Tests on Series of Flood Magnitude. 113

APPENDIX B Trend and Change-Point Results for Timing of Flood Peaks. 125

APPENDIX C Trend and Change-Point Results for Flood Generating Precipitation Series

C.1 Results for Precipitation Series Based on 1/8-Degree Gridded Data 130

C.2 Results for Precipitation Series Based on 1/4-Degree Gridded Data. 135

APPENDIX D Trend and Change-Point Results for Flood Generating Temperature Series

D.1 Results for Minimum Temperature Series 142

D.2 Results for Maximum Temperature Series 147

APPENDIX E Correlation Analysis Results Between 10 Year Moving Average of Logs of Flood Flows and Climate Anomalies .............................................................. 153

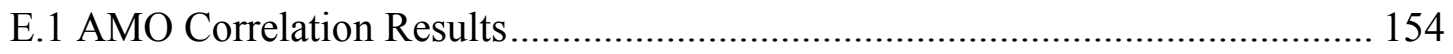

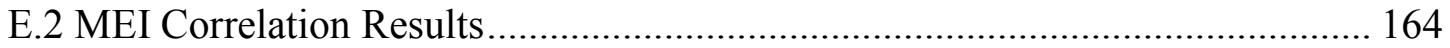

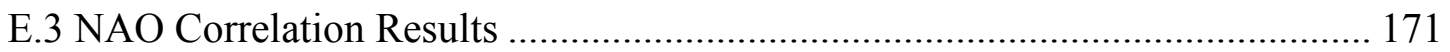

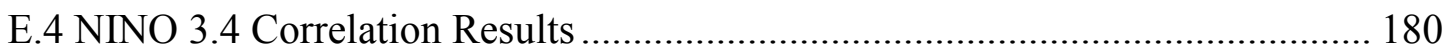


E.5 PDO Correlation Results

APPENDIX F Correlation Anaylsis Results Between 10 Year Moving Standard deviation of Logs of Flood Flows and Climate Anomalies ............................................. 195

F.1 AMO Correlation Results ............................................................................. 196

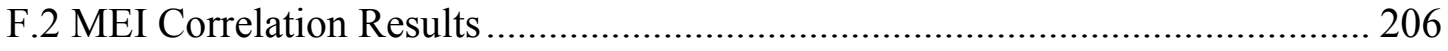

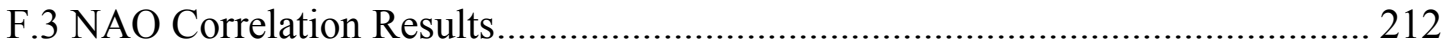

F.4 NINO 3.4 Correlation Results .................................................................. 219

F.5 PDO Correlation Results ............................................................................. 223

APPENDIX G Correlation Anaylsis Results Between Annual Maximum Flood Series and Flood Generating Hydroclimatic Series......................................................... 233 


\section{LIST OF FIGURES}

Figure 2.1 Example graph illustrating nonstationarity in an AMF series in the form of a linear trend and an abrupt shift in the mean (USGS Station No. 05340500)....... 14

Figure 2.2 Water-resources regions (gray-scale polygons) and major rivers (blue lines) of the continental U.S as defined by the USGS. 20

Figure 2.3 Location of 569 unimpaired USGS streamflow gauging stations within the continental U.S. selected from the HCDN having at minimum a continuous annual maximum flow record from 1940-2005. 21

Figure 2.4 Results of traditional Mann-Kendall trend tests on magnitude of AMF series (neglecting possible autocorrelation). Upright (inverted) triangles represent sites with a positive/increasing (negative/decreasing) trend. 22

Figure 2.5 Results of modified Mann-Kendall trend tests on magnitude of AMF series (accounting for autocorrelation). Upright (inverted) triangles represent sites with a positive/increasing (negative/decreasing) trend................................................ 23

Figure 2.6 Locations of sites with a change-point in the mean annual maximum flood magnitude significant at 5\% and $10 \%$ levels................................................... 24

Figure 2.7 Time period in which a change-point in the mean annual maximum flood magnitude was identified by the Pettitt test ( $10 \%$ significance level)................. 25

Figure 2.8 Results of Mann-Kendall trend tests on annual maximum flood subseries before identified change-point in mean flood magnitude. 27

Figure 2.9 Results of Mann-Kendall trend tests on annual maximum flood subseries after identified change-point in mean flood magnitude.

Figure 2.10 Magnitude of Hurst exponent for annual maximum flood series in the contiguous U.S. with continuous record lengths of at least 66 years. 28

Figure 2.11 Results of Mann-Kendall trend tests on the day of occurrence of annual maximum flood peaks. 29

Figure 2.12 Locations of sites with a significant change-point in the mean day of occurrence of the annual maximum flood peak. 30 
Figure 2.13 Time period of change-points in the mean day of occurrence of flood peaks as identified by the Pettitt test (10\% significance level).

Figure 2.14 Locations of 235 streamflow gauging stations used to create flood associated precipitation and temperature series. 32

Figure 2.15 Results of Mann-Kendall trend tests on flood generating precipitation series with 5-day lead time constructed using 1/8-degree gridded data. 35

Figure 2.16 Results of Pettitt tests on flood generating precipitation series with a 5-day lead constructed using $1 / 8$-degree gridded data. 36

Figure 2.17 Results of Mann-Kendall tests on flood generating maximum temperature

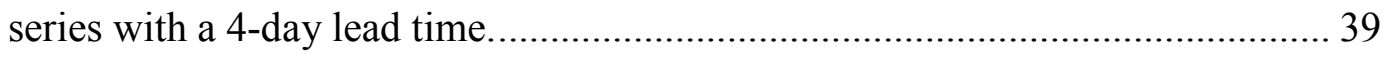

Figure 2.18 Results of Mann-Kendall tests on flood generating minimum temperature

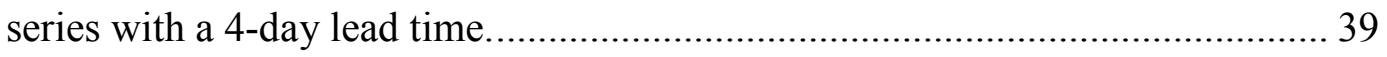

Figure 2.19 Results of Pettitt tests on flood generating maximum temperature series with a 4-day lead time.

Figure 2.20 Results of Pettitt tests on flood generating minimum temperature series with a 4-day lead time.

Figure 3.1 Location of 14,835 USGS stations with a minimum 12 years of AMF record.

Figure 3.2 Most common (mode) month of occurrence of AMF peaks........................... 51

Figure 3.3 Frequency of occurrence of AMF peaks in identified mode month................ 51

Figure 3.4 Combined frequency of occurrence of AMF peaks in three month seasons (A. Dec-Jan-Feb, B. Mar-Apr-May, C. Jun-July-Aug, D. Sep-Oct-Nov)..................... 52

Figure 3.5 Locations of sites with significant correlation between 10-year moving average of log-transformed flood flows and 3-month average AMO anomalies with 6-month lead. 55

Figure 3.6 Locations of sites with significant correlation between 10-year moving average of log-transformed flood flows and 3-month average MEI anomalies with 9-month lead. 55 
Figure 3.7 Locations of sites with significant correlation between 10-year moving average of log-transformed flood flows and 3-month average NAO anomalies with 3-month lead. 56

Figure 3.8 Locations of sites with significant correlation between 10-year moving average of log-transformed flood flows and 3-month average PDO anomalies

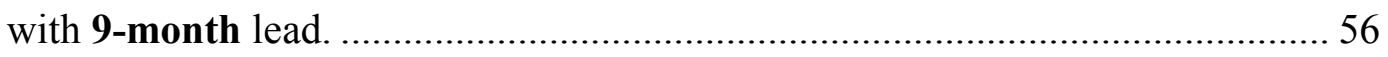

Figure 3.9 Locations of sites with significant correlation between 10-year moving standard deviation of log-transformed flood flows and 3-month average AMO anomalies with 3-month lead. 58

Figure 3.10 Locations of sites with significant correlation between 10-year moving standard deviation of log-transformed flood flows and 3-month average MEI

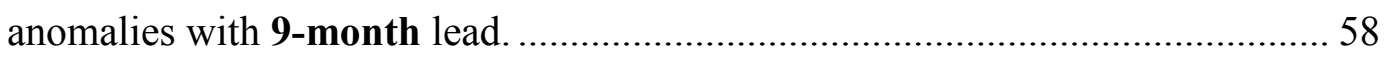

Figure 3.11 Locations of sites with significant correlation between 10-year moving standard deviation of log-transformed flood flows and 3-month average NAO anomalies with 3-month lead.

Figure 3.12 Locations of sites with significant correlation between 10-year moving standard deviation of log-transformed flood flows and 3-month average PDO anomalies with 9-month lead.

Figure 3.13 X-day lead time yielding most significant Pearson's correlation coefficient between AMF series and the associated flood generating precipitation series constructed using 1/8-degree gridded data. 65

Figure 3.14 Location of sites with trends in both the AMF series and the best X-day flood generating precipitation series constructed using 1/8-degree gridded data. 66

Figure 3.15 Location of sites with shifts in both the AMF series and the best X-day flood generating precipitation series constructed using 1/8-degree gridded data. 66

Figure 3.16 X-day lead time yielding the most significant Pearson's correlation coefficient between the AMF peaks and associated minimum temperature series.

Figure 3.17 X-day lead time yielding the most significant Pearson's correlation coefficient between the AMF peaks and associated maximum temperature series. 
Figure 3.18 Location of sites with trends in both the best X-day flood generating minimum temperature and the AMF series.

Figure 3.19 Location of sites with trends in both the best X-day flood generating maximum temperature and the AMF series.

Figure 3.20 Location of sites with change-points in both the best X-day flood generating minimum temperature series and the AMF series. .73

Figure 3.21 Location of sites with change-points in both the best X-day flood generating maximum temperature series and the AMF series. .73

Figure 3.22 X-day lead time yielding the most significant Pearson's correlation coefficient between the day of occurrence of AMF peaks and associated minimum temperature series. 75

Figure 3.23 X-day lead time yielding the most significant Pearson's correlation coefficient between the day of occurrence of AMF peaks and associated maximum temperature series. .76

Figure 4.1 Location of six USGS stations used to compare current flood risk projection procedures to proposed climate informed flood risk projection model.

Figure 4.2 One-year ahead forecast of flood risk for Sheepscot River at North Whitefield, Maine (USGS Station No. 01038000) obtained using the Bulletin 17B LP3 model and the proposed modification to incorporate climate variability. 93

Figure 4.3 One-year ahead forecast of flood risk for Swift River near Roxbury, Maine (USGS Station No. 01055000) obtained using the Bulletin 17B LP3 model and the proposed modification to incorporate climate variability.

Figure 4.4 One-year ahead forecast of flood risk for Saco River near Conway, NH (USGS Station No. 01064500) obtained using the Bulletin 17B LP3 model and the proposed modification to incorporate climate variability. 94

Figure 4.5 One-year ahead forecast of flood risk for Oyster River near Durham, NH (USGS Station No. 01073000) obtained using the Bulletin 17B LP3 model and the proposed modification to incorporate climate variability.

Figure 4.6 One-year ahead forecast of flood risk for Smith River near Bristol, NH (USGS Station No. 01078000) obtained using the Bulletin 17B LP3 model and the proposed modification to incorporate climate variability. 95 
Figure 4.7 One-year ahead forecast of flood risk for Ammonoosuc River at Bethlehem Junction, NH (USGS Station No. 01137500) obtained using the Bulletin 17B LP3 model and the proposed modification to incorporate climate variability. 96

Figure C.1 Results of Mann-Kendall trend tests on flood generating precipitation series with 2-day lead constructed using 1/8-degree gridded data 130

Figure C.2 Results of Pettitt tests on flood generating precipitation series with 2-day lead constructed using $1 / 8$-degree gridded data. 130

Figure C.3 Results of Mann-Kendall trend tests on flood generating precipitation series with 3-day lead constructed using 1/8-degree gridded data. 131

Figure C.4 Results of Pettitt tests on flood generating precipitation series with 3-day lead constructed using $1 / 8$-degree gridded data. 131

Figure C.5 Results of Mann-Kendall trend tests on flood generating precipitation series with 4-day lead constructed using 1/8-degree gridded data. 132

Figure C.6 Results of Pettitt tests on flood generating precipitation series with 4-day lead constructed using $1 / 8$-degree gridded data. 132

Figure C.7 Results of Mann-Kendall trend tests on flood generating precipitation series with 6-day lead constructed using 1/8-degree gridded data. 133

Figure C.8 Results of Pettitt tests on flood generating precipitation series with 6-day lead constructed using $1 / 8$-degree gridded data. 133

Figure C.9 Results of Mann-Kendall trend tests on flood generating precipitation series with 7-day lead constructed using 1/8-degree gridded data. 134

Figure C.10 Results of Pettitt tests on flood generating precipitation series with 7-day lead constructed using 1/8-degree gridded data. 134

Figure C.11 Results of Mann-Kendall trend tests on flood generating precipitation series with 2-day lead constructed using 1/4-degree gridded data. 135

Figure C.12 Results of Pettitt tests on flood generating precipitation series with 2-day lead constructed using 1/4-degree gridded data. 135

Figure C.13 Results of Mann-Kendall trend tests on flood generating precipitation series with 3-day lead constructed using 1/4-degree gridded data 136 
Figure C.14 Results of Pettitt tests on flood generating precipitation series with 3-day lead constructed using 1/4-degree gridded data.

Figure C.15 Results of Mann-Kendall trend tests on flood generating precipitation series with 4-day lead constructed using 1/4-degree gridded data.

Figure C.16 Results of Pettitt tests on flood generating precipitation series with 4-day lead constructed using 1/4-degree gridded data.......

Figure C.17 Results of Mann-Kendall trend tests on flood generating precipitation series with 5-day lead constructed using 1/4-degree gridded data. 138

Figure C.18 Results of Pettitt tests on flood generating precipitation series with 5-day lead constructed using 1/4-degree gridded data. 138

Figure C.19 Results of Mann-Kendall trend tests on flood generating precipitation series with 6-day lead constructed using 1/4-degree gridded data.

Figure C.20 Results of Pettitt tests on flood generating precipitation series with 6-day lead constructed using 1/4-degree gridded data......

Figure C.21 Results of Mann-Kendall trend tests on flood generating precipitation series with 7-day lead constructed using 1/4-degree gridded data. 140

Figure C.22 Results of Pettitt tests on flood generating precipitation series with 7-day lead constructed using 1/4-degree gridded data. 140

Figure D.1 Results of Mann-Kendall tests on flood generating minimum temperature series with 2-day lead.

Figure D.2 Results of Pettitt tests on flood generating minimum temperature series with 2-day lead.

Figure D.3 Results of Mann-Kendall tests on flood generating minimum temperature series with 3-day lead.

Figure D.4 Results of Pettitt tests on flood generating minimum temperature series with 3-day lead.

Figure D.5 Results of Mann-Kendall tests on flood generating minimum temperature series with 5-day lead. 144 
Figure D.6 Results of Pettitt tests on flood generating minimum temperature series with 5-day lead. 144

Figure D.7 Results of Mann-Kendall tests on flood generating minimum temperature series with 6-day lead. 145

Figure D.8 Results of Pettitt tests on flood generating minimum temperature series with 6-day lead. 145

Figure D.9 Results of Mann-Kendall tests on flood generating minimum temperature

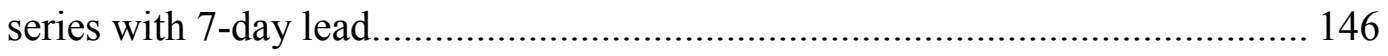

Figure D.10 Results of Pettitt tests on flood generating minimum temperature series with 7-day lead. 146

Figure D.11 Results of Mann-Kendall tests on flood generating maximum temperature series with 2-day lead.. 147

Figure D.12 Results of Pettitt tests on flood generating maximum temperature series with 2-day lead.

Figure D.13 Results of Mann-Kendall tests on flood generating maximum temperature

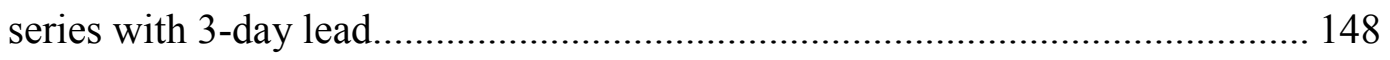

Figure D.14 Results of Pettitt tests on flood generating maximum temperature series with

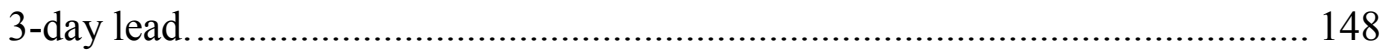

Figure D.15 Results of Mann-Kendall tests on flood generating maximum temperature

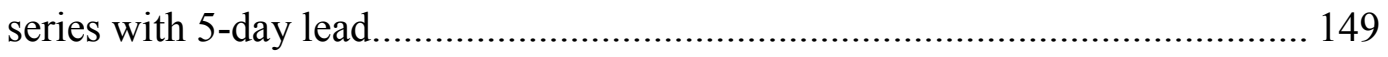

Figure D.16 Results of Pettitt tests on flood generating maximum temperature series with 5-day lead. 149

Figure D.17 Results of Mann-Kendall tests on flood generating maximum temperature

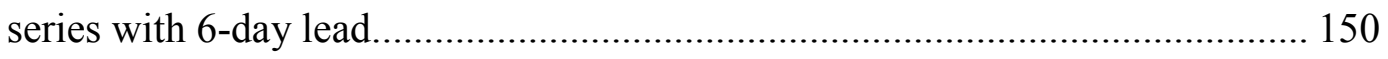

Figure D.18 Results of Pettitt tests on flood generating maximum temperature series with

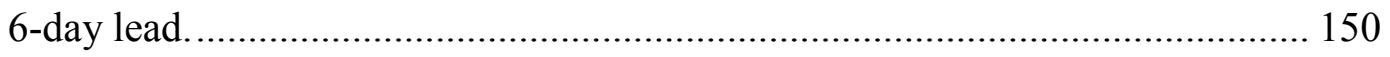

Figure D.19 Results of Mann-Kendall tests on flood generating maximum temperature

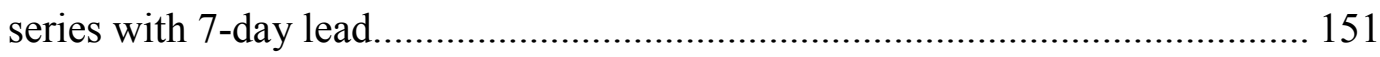


Figure D.20 Results of Pettitt tests on flood generating maximum temperature series with 7-day lead.

Figure E.1 Locations of sites with significant Kendall's tau correlation between 10-year moving average of log-transformed flood flows and 3-month average AMO anomalies with 3-month lead. 162

Figure E.2 Locations of sites with significant Kendall's tau correlation between 10-year moving average of log-transformed flood flows and 3-month average AMO anomalies with 9 -month lead.................................................................... 162

Figure E.1 Locations of sites with significant Pearson's r correlation between 10-year moving average of log-transformed flood flows and 3-month average AMO anomalies with 6-month lead. 163

Figure E.2 Locations of sites with significant Spearman's rho correlation between 10year moving average of log-transformed flood flows and 3-month average AMO anomalies with 6-month lead. 163

Figure E.3 Locations of sites with significant Kendall's tau correlation between 10-year moving average of log-transformed flood flows and 3-month average MEI anomalies with 3-month lead.

Figure E.4 Locations of sites with significant Kendall's tau correlation between 10-year moving average of log-transformed flood flows and 3-month average MEI anomalies with 6-month lead. 170

Figure E.5 Locations of sites with significant Pearson's r correlation between 10-year moving average of log-transformed flood flows and 3-month average MEI anomalies with 9-month lead. 170

Figure E.6 Locations of sites with significant Spearman's rho correlation between 10year moving average of log-transformed flood flows and 3-month average MEI anomalies with 9-month lead.

Figure E.9 Locations of sites with significant Pearson's r correlation between 10-year moving average of log-transformed flood flows and 3-month average NAO anomalies with 3-month lead. 
Figure E.10 Locations of sites with significant Spearman's rho correlation between 10year moving average of log-transformed flood flows and 3-month average NAO anomalies with 3-month lead.

Figure E.11 Locations of sites with significant Kendall's tau correlation between 10-year moving average of log-transformed flood flows and 3-month average Nino3.4 anomalies with 3-month lead.

Figure E.12 Locations of sites with significant Kendall's tau correlation between 10-year moving average of log-transformed flood flows and 3-month average Nino3.4 anomalies with 6-month lead.

Figure E.13 Locations of sites with significant Kendall's tau correlation between 10-year moving average of log-transformed flood flows and 3-month average Nino3.4 anomalies with 9-month lead.

Figure E.14 Locations of sites with significant Pearson's $r$ correlation between 10-year moving average of log-transformed flood flows and 3-month average Nino3.4 anomalies with 9-month lead.

Figure E.15 Locations of sites with significant Spearman's rho correlation between 10year moving average of log-transformed flood flows and 3-month average Nino3.4 anomalies with 9-month lead. 184

Figure E.16 Locations of sites with significant Kendall's tau correlation between 10-year moving average of log-transformed flood flows and 3-month average PDO anomalies with 3-month lead.

Figure E.17 Locations of sites with significant Kendall's tau correlation between 10-year moving average of log-transformed flood flows and 3-month average PDO anomalies with 6-month lead.

Figure E.18 Locations of sites with significant Pearson's $r$ correlation between 10-year moving average of log-transformed flood flows and 3-month average PDO anomalies with 9-month lead. 194

Figure E.19 Locations of sites with significant Spearman's rho correlation between 10year moving average of log-transformed flood flows and 3-month average PDO anomalies with 9-month lead. 
Figure F.1 Locations of sites with significant Kendall's tau correlation between 10-year moving standard deviation of log-transformed flood flows and 3-month average AMO anomalies with 6-month lead. 204

Figure F.2 Locations of sites with significant Kendall's tau correlation between 10-year moving standard deviation of log-transformed flood flows and 3-month average AMO anomalies with 9-month lead. 204

Figure F.3 Locations of sites with significant Pearson's r correlation between 10-year moving standard deviation of log-transformed flood flows and 3-month average AMO anomalies with 6-month lead. 205

Figure F.4 Locations of sites with significant Spearman's rho correlation between 10-year moving standard deviation of log-transformed flood flows and 3-month average AMO anomalies with 3-month lead. 205

Figure F 5 Locations of sites with significant Kendall's tau correlation between 10-year moving standard deviation of log-transformed flood flows and 3-month average MEI anomalies with 3-month lead. 210

Figure F 6 Locations of sites with significant Kendall's tau correlation between 10-year moving standard deviation of log-transformed flood flows and 3-month average MEI anomalies with 6-month lead.

Figure F.7 Locations of sites with significant Pearson's r correlation between 10-year moving standard deviation of log-transformed flood flows and 3-month average MEI anomalies with 9-month lead. 211

Figure F.8 Locations of sites with significant Spearman's rho correlation between 10-year moving standard deviation of log-transformed flood flows and 3-month average MEI anomalies with 9-month lead.

Figure F.11 Locations of sites with significant Pearson's $r$ correlation between 10-year moving standard deviation of log-transformed flood flows and 3-month average NAO anomalies with 3-month lead. 218

Figure F.12 Locations of sites with significant Spearman's rho correlation between 10year moving standard deviation of log-transformed flood flows and 3-month average NAO anomalies with 3-month lead. 
Figure F.16 Locations of sites with significant Pearson's $r$ correlation between 10-year moving standard deviation of log-transformed flood flows and 3-month average Nino3.4 anomalies with 9-month lead. 222

Figure F.17 Locations of sites with significant Spearman's rho correlation between 10year moving standard deviation of log-transformed flood flows and 3-month average Nino3.4 anomalies with 9-month lead................................................. 223

Figure F.20 Locations of sites with significant Pearson's r correlation between 10-year moving standard deviation of log-transformed flood flows and 3-month average PDO anomalies with 9-month lead. 232

Figure F.21 Locations of sites with significant Spearman's rho correlation between 10year moving standard deviation of log-transformed flood flows and 3-month average PDO anomalies with 9-month lead........................................................ 232 



\section{LIST OF TABLES}

Table 2.1 Number of trends identified in the complete record and/or subseries with respect to identified change-points in mean flood magnitude.

Table 2.2 Number of sites with significant negative and positive trends in flood generating precipitation series identified using Mann-Kendall trend tests........... 34

Table 2.3 Number of sites with significant change-points in the mean of flood generating precipitation identified using the Pettitt test with 5\% and 10\% significance levels. 36

Table 2.4 Number of sites with significant trends (negative or positive) in flood generating maximum and minimum temperature series with X-days lead times identified using Mann-Kendall tests. 38

Table 2.5 Number of sites with change-points in the mean of flood associated minimum and maximum temperature series identified using the Pettitt test with $5 \%$ and $10 \%$ significance levels.

Table 3.1 Sources of climatic indices used to identify teleconnections with flood flows.

Table 3.2 Number of sites with significant Kendall's tau correlation (5 and 10\% levels) between 10-year moving average of log-transformed flood peaks and AMO, MEI, NINO 3.4, NAO, and PDO indices with specified lead times. 53

Table 3.3 Number of sites with significant Kendall's tau correlation (5 and 10\% levels) between 10-year moving standard deviation of log-transformed flood peaks and AMO, MEI, NINO 3.4, NAO, and PDO indices with specified lead times. 54

Table 3.4 Timing of Cold/Negative and Warm/Positive phases of AMO, PDO, and NAO.

Table 3.5 Coincidental timing of AMO phase changes and identified change-points in the mean of AMF series; including respective Kendall's tau values and associated p-values for correlation between the 10-year moving average of AMF series and AMO climate anomalies with 6-month lead.

Table 3.6 Coincidental timing of PDO phase changes and identified change-points in the mean of AMF series; including respective Kendall's tau values and associated p- 
values for correlation between the 10-year moving average of AMF series and PDO climate anomalies with 9-month lead.

Table 3.7 Coincidental timing of NAO phase changes and identified change-points in the mean of AMF series; including respective Kendall's tau values and associated pvalues for correlation between the 10-year moving average of AMF series and NAO climate anomalies with 3-month lead

Table 3.8 Number of sites yielding significant Pearson's correlation coefficients for AMF series relative to precipitation series with X-day lead times constructed using $1 / 8$ and $1 / 4$ degree gridded data. 64

Table 3.9 Summary results for sites with trends in both the magnitude of AMF series and the best X-day flood generating precipitation series

Table 3.10 Summary results for sites with significant shifts in both the magnitude of AMF series and the best $\mathrm{X}$-day flood generating precipitation series. 68

Table 3.11 Summary results for sites with trends in both the magnitude of AMF series and the best $\mathrm{X}$-day flood generating minimum and maximum temperature series.

Table 3.12 Summary results for sites with significant shifts in both the magnitude of $\mathrm{AMF}$ series and the best $\mathrm{X}$-day flood generating minimum/maximum temperature series. 74

Table 3.13 Summary results for sites with significant shifts in AMF magnitude for which water report remarks pertinent to hydrologic modifications exist within Falcone et al. [2011]. .78

Table 3.14 Summary results for sites with shifts in the magnitude of AMF series and corresponding changes in amount of storage (megaliters total storage per square $\mathrm{km})$ in each basin. 80

Table 4.1 Three-month averaged values of climate indices with specified lead time relative to April flood peak used in regression models to obtain one-year ahead forecasts $\mu(2009)$ and $\sigma(2009)$ : observed values for 2009 and extreme scenario. 91

Table 4.2 Regression coefficients obtained for the model of the log space mean at six sample sites. Coefficients reported are all significant at the $10 \%$ level. 92 
Table 4.3 Regression coefficients obtained for the model of the log space standard deviation at six sample sites. Coefficients reported are all significant on the $10 \%$ level.

Table 4.4 Moments of the log-transformed flood peaks based on stationary P3 model through 2008, proposed model with observed climate indices for 2009 and hypothetical extreme climate indices. 92

Table A.1 Results of Pettitt and Mann-Kendall tests on flood magnitude (significant on the $10 \%$ level), including the year of the identified shift in the mean, and the direction of significant trends, either positive $(+)$ and negative (-). 113

Table A.2 Results of Mann-Kendall tests (10\% significance level) on AMF subseries for sites exhibiting a significant change-point in the mean flood magnitude at the $10 \%$ level. The mean flood magnitude in the complete series, and each subseries are also reported.

Table A.3 Hurst exponents for AMF series for all 569 sites considered. Values in red indicate sites characterized by a random walk or anti-persistence.

Table B.1 Mann-Kendall results for sites exhibiting a significant trend whether positive $(+)$ or negative (-), in the day of occurrence of flood peaks on the $10 \%$ level... 125

Table B.2 Change-point results indicating year of identified shift in the day of occurrence of flood peaks and associated p-value. 126

Table E.1 Number of sites with significant Pearson's $r$ and Spearman's rho correlations ( 5 and 10\% levels) between 10-yr moving mean of log-transformed flood peaks and for AMO, MEI, NINO 3.4, NAO, and PDO indices with specified lead times. 153

Table E.2 Results of Kendall's tau analyses (significant 10\% level) between 10-year moving average of log-transformed flood flows and 3-month average AMO anomalies with 3-, 6-, and 9-month leads. 154

Table E.3 Results of Kendall's tau analyses (significant 10\% level) between 10-year moving average of log-transformed flood flows and 3-month average MEI anomalies with 3-, 6-, and 9-month leads. 164 
Table E.4 Results of Kendall's tau analyses (significant 10\% level) between 10-year moving average of log-transformed flood flows and 3-month average NAO anomalies with 3-, 6-, and 9-month leads.

Table E.5 Results of Kendall's tau analyses (significant at 10\% level) between 10-year moving average of log-transformed flood flows and 3-month average Nino3.4 anomalies with 3-, 6-, and 9-month leads. 180

Table E.6 Results of Kendall's tau analyses (significant 10\% level) between 10-year moving average of log-transformed flood flows and 3-month average PDO anomalies with 3-, 6-, 9-month leads. 184

Table F.1 Number of sites with significant Pearson's $r$ and Spearman's rho correlations (5 and 10\% levels) between 10-yr moving standard deviation of log-transformed flood peaks and for AMO, MEI, NINO 3.4, NAO, and PDO indices with specified lead times. 195

Table F.2 Results of Kendall's tau analyses (significant 10\% level) between 10-year moving standard deviation of log-transformed flood flows and 3-month average AMO anomalies with 3-, 6-, and 9-month leads.

Table F.3 Results of Kendall's tau analyses (significant at 10\% level) between 10-year moving standard deviation of log-transformed flood flows and 3-month average MEI anomalies with 3-, 6-, and 9-month leads. 206

Table F.4 Results of Kendall's tau analyses (significant at 10\% level) between 10-year moving standard deviation of log-transformed flood flows and 3-month average NAO anomalies with 3-, 6-, and 9-month leads.

Table F.5 Results of Kendall's tau analyses (significant at 10\% level) between 10-year moving standard deviation of log-transformed flood flows and 3-month average Nino3.4 anomalies with 3-, 6-, and 9-month leads.

Table F.6 Results of Kendall's tau analyses (significant at 10\% level) between 10-year moving standard deviation of log-transformed flood flows and 3-month average PDO anomalies with 3-, 6-, and 9-month leads.

Table G.1 Results of Pearson's correlation analyses between magnitude of AMF peaks and associated flood generating hydroclimatic series with best lead times........ 233

Table G.2 Results of Pearson's correlation analyses between timing of AMF peaks and associated flood generating temperature (minimum and maximum) series with best lead times. 


\section{ACKNOWLEDGEMENTS}

Foremost, I would like to express my sincere gratitude to Dr. Veronica Griffis for her immense patience, constructive advice, and her willingness to allow me to get involved with her research as an undergraduate student. This project would never have been possible without her support, words of enthusiasm, and immense knowledge. The past year has been filled with up and downs or should I say "abrupt shifts," but Dr. Griffis still supported me, and working with her as my advisor has been a rewarding experience.

My thanks also go to the members of my major committee Dr. Veronica Griffis, Dr. Ann Maclean and Dr. Watkins for their time and contribution to this research.

Further, I wish to thank Dr. Ann Maclean for her invaluable contributions and guidance with GIS, and her willingness to allow me to be a GIS teaching assistant.

I would like to thank my fellow classmate Karl Meingast, for the countless stimulating discussions in the duck blind about my research and how to get my MATLAB code to run, and for all the fun we have had in the last year in and out of class. On this note, I would also like to recognize my dog "Wigeon" who was always by my side whether on the water duck hunting or just taking a walk to "escape" the labs.

My parents, Denice and Joe, receive my deepest gratitude and love for their dedication and the many years of support during my undergraduate studies that provided the foundation for this work. Had it not been for them and their continuous words of encouragement, I would not be where I am today. Special thanks to my siblings, Jeremiah and Jonathan, who have been my true role models.

Last, but not least, I would like to thank my girlfriend Stephanie Mayer for her understanding and love during the past few years. Her support and encouragement was in the end what made this thesis possible. 


\begin{abstract}
Standard procedures for forecasting flood risk (Bulletin 17B) assume annual maximum flood (AMF) series are stationary, meaning the distribution of flood flows is not significantly affected by climatic trends/cycles, or anthropogenic activities within the watershed. Historical flood events are therefore considered representative of future flood occurrences, and the risk associated with a given flood magnitude is modeled as constant over time. However, in light of increasing evidence to the contrary, this assumption should be reconsidered, especially as the existence of nonstationarity in AMF series can have significant impacts on planning and management of water resources and relevant infrastructure. Research presented in this thesis quantifies the degree of nonstationarity evident in AMF series for unimpaired watersheds throughout the contiguous U.S., identifies meteorological, climatic, and anthropogenic causes of this nonstationarity, and proposes an extension of the Bulletin $17 B$ methodology which yields forecasts of flood risk that reflect climatic influences on flood magnitude.
\end{abstract}

To appropriately forecast flood risk, it is necessary to consider the driving causes of nonstationarity in AMF series. Herein, large-scale climate patterns-including El NiñoSouthern Oscillation (ENSO), Pacific Decadal Oscillation (PDO), North Atlantic Oscillation (NAO), and Atlantic Multidecadal Oscillation (AMO) - are identified as influencing factors on flood magnitude at numerous stations across the U.S. Strong relationships between flood magnitude and associated precipitation series were also observed for the majority of sites analyzed in the Upper Midwest and Northeastern regions of the U.S. Although relationships between flood magnitude and associated temperature series are not apparent, results do indicate that temperature is highly correlated with the timing of flood peaks. Despite consideration of watersheds classified as unimpaired, analyses also suggest that identified change-points in AMF series are due to dam construction, and other types of regulation and diversion. Although not explored herein, trends in AMF series are also likely to be partially explained by changes in land use and land cover over time. 
Results obtained herein suggest that improved forecasts of flood risk may be obtained using a simple modification of the Bulletin $17 B$ framework, wherein the mean and standard deviation of the log-transformed flows are modeled as functions of climate indices associated with oceanic-atmospheric patterns (e.g. AMO, ENSO, NAO, and PDO) with lead times between 3 and 9 months. Herein, one-year ahead forecasts of the mean and standard deviation, and subsequently flood risk, are obtained by applying site specific multivariate regression models, which reflect the phase and intensity of a given climate pattern, as well as possible impacts of coupling of the climate cycles. These forecasts of flood risk are compared with forecasts derived using the existing Bulletin $17 B$ model; large differences in the one-year ahead forecasts are observed in some locations. The increased knowledge of the inherent structure of AMF series and an improved understanding of physical and/or climatic causes of nonstationarity gained from this research should serve as insight for the formulation of a physical-casual based statistical model, incorporating both climatic variations and human impacts, for flood risk over longer planning horizons (e.g., 10-, 50, 100-years) necessary for water resources design, planning, and management. 



\section{CHAPTER 1 INTRODUCTION}

During the 2010 water year, within the United States alone, flood damages bolstered $\$ 5.04$ billion in accumulation - 67\% the cost of the previous thirty years' average (1980 2009), totaling $\$ 7.56$ billion [NOAA, 2011]. These figures, in themselves, raise reason for concern of attaining an accurate approach for flood frequency analysis and estimation

of flood risk. Standard procedures for forecasting flood risk [IACWD, 1982] entail employing an assumed theoretical probability distribution to estimate the recurrence interval associated with observed annual maximum discharges. Hydraulic structures are then designed to withstand and/or accommodate the flood magnitude corresponding to a designated recurrence interval (e.g., the 100-year event). Similarly, the resulting magnitude of design events may be utilized in a variety of water resources applications (e.g., floodplain delineation, land-use planning/management, design/operation of wateruse and water-control structures, and design of transportation infrastructure like bridges and roadways), thus indicating the importance of accurate flood risk estimation.

Current procedures presuppose instantaneous annual maximum flood (AMF) flow series as stationary, thereby assuming parameters of the fitted probability distribution as constant over time, and disregarding any possible influence of climatic cycles and/or trends [Olsen et al., 1999; Hirschboeck et al., 2000]. Otherwise stated, standard procedures assume historical events are representative of future flood events over any time horizon. This assumption, however, is increasingly being debated in the hydrologic literature; results of studies already executed suggest AMF series are nonstationary [e.g. National Research Council, 1998; Franks and Kuczera, 2002; Kashelikar and Griffis, 2008; Petrow and Merz, 2009; Villarini et al., 2009, 2011]. This thesis provides further evidence that AMF series in relatively unimpaired watersheds within the U.S. are nonstationary, and considers how to incorporate sources of nonstationarity in annual maximum flood flows into standard flood frequency analysis procedures to improve oneyear ahead estimates of flood risk. This research provides the groundwork for needed advances in water resources planning and management, and stochastic hydrology. 


\subsection{Research Motivation}

In light of natural climate variability and potential climate change, a vast amount of research has been dedicated to investigating nonstationarity in hydroclimatic data series. Results of previous studies reveal that trends and/or change-points are evident in multiple hydroclimatic data series including precipitation and streamflow [e.g., Lettenmaier et al., 1994; Lins and Slack, 1999; Olsen et al., 1999; Perreault et al., 1999; Rasmussen, 2001; Burn and Hag Elnur, 2002; McCabe and Wolock, 2002; Kalra et al., 2006, 2008; Small et al., 2006; Seidou and Ouarda, 2007; Ehsanzadeh et al., 2010; Walter and Vogel, 2010 and references therein]. With respect to streamflow series, the majority of these studies have considered annual and seasonal minimum, median, and average quantities. In the U.S., Douglas et al. [2000] and Small et al. [2006] considered nonstationarity in high flows defined as the annual maximum average daily streamflow. Only a few studies have considered existence of nonstationarity in instantaneous annual maximum flood (AMF) series within the U.S. [Olsen et al., 1999; Kashelikar and Griffis, 2008; Collins, 2009; Villarini et al., 2009, 2011], as are evaluated herein. Outside of the U.S., others have investigated trends in flood series comprised of peaks-over threshold and annual maximum events [e.g., Petrow and Merz, 2009; Burn and Hag Elnur, 2002; Yue et al., 2002].

Nonstationarity in the form of trends has been investigated in annual average daily streamflow series (not AMF series) by means of a non-parametric Mann-Kendall trend test [e.g., Small et al., 2006; Lins and Slack, 1999; Douglas et al., 2000; Hodgkins and Dudley, 2005]. While the focus herein is on AMF series, results of these studies are discussed briefly as they illustrate what changes might be occurring within the hydrologic cycle over time, and indicate what trends might exist in AMF series. Hodgkins and Dudley [2005] analyzed trends in annual average daily streamflow series at 27 stations in New England. They did not identify any significant trends in annual average daily streamflows; however, significant increases were identified in various percentiles of annual streamflow (minimum, $25^{\text {th }}$ percentile, median, $75^{\text {th }}$ percentile, and maximum) at the majority of the stations analyzed. Small et al. [2006] analyzed annual average daily flow series of 218 basins across the eastern half of the U.S.; only a small portion of sites 
were found to exhibit trends. Lins and Slack [1999] appraised trends in quantiles of annual average daily streamflows across the U.S. They observed upward trends in minimum and median quantiles, but relatively few in maximum quantiles, thereby indicating that "the U.S. is getting wetter, but less extreme" [Lins and Slack, 1999, p.227]. Results of Douglas et al. [2000] indicate that significant trends in maximum annual average daily flows do not exist when accounting for cross-correlation. Overall, these results suggest trends would not exist in AMF series, i.e. instantaneous annual maximum peak discharge series.

In the U.S., only a few studies have focused attention on identifying trends in AMF series [Olsen et al., 1999; Kashelikar and Griffis, 2008; Villarini et al., 2009, 2010, 2011]. Olsen et al. [1999] identified significant upward trends in flood series in the Upper Mississippi and Missouri Rivers by performing linear regression on AMF series over time; Spearman rank correlation tests further reinforced their findings. Kashelikar and Griffis [2008] performed Mann-Kendall trend tests on 396 relatively unimpaired basins across the U.S. Their results show most sites exhibiting a significant trend in flood flows are located in the North Pacific, the Midwest and the Eastern U.S. Several studies have identified significant trends (both positive and negative) in the Northeastern quadrant of the U.S. on a site-by-site basis [Olsen et al, 1999; Kashelikar and Griffis, 2008; Villarini et al., 2010]. Overall, results of trend analyses in flood series have been mixed in the U.S., as noted by Walter and Vogel [2010]. Discrepancies in the existence (or attained significance) of trends in peak flows are due to conflicting methodologies as well as record lengths employed [Villarini et al., 2009].

A number of studies pertaining to nonstationarity in flood flows have been conducted outside the U.S. Across the UK, Robson et al. [1998] investigated two types of flood series-AMF and peaks-over-threshold (POT) — for trends by employing three standard statistical tests-linear regression, normal scores regression, and Spearman's rho; no significant trends in flood behavior were identified. Others investigated trends in flood series using a Mann-Kendall test. In Germany, Petrow and Merz [2009] accounted for serial correlation when investigating trends in AMF and POT series, and observed that 
basins exhibiting significant trends in flood series tended to be spatially clustered. In Canada, Burn and Hag Elnur [2002] identified spatial differences in both occurrence and direction of trends in AMF series. Yue et al. [2002] utilized both Mann-Kendall and Spearman's rho tests to detect trends in AMF series of 20 pristine basins in Ontario, Canada; they observed negative trends, or a general decrease in flood magnitudes. Though outside the U.S., these studies raise concern as to the validity of the assumption of nonstationarity in flood series.

Others have investigated nonstationarity in streamflows in the form of change-points (abrupt shifts) rather than gradual trends [e.g., McCabe and Wolock, 2002; Kalra et al., 2006; Seidou and Ouarda, 2007; Ehsanzadeh et al., 2010]. Results of these studies indicate the need to couple trend and change-point tests when investigating nonstationarity in hydroclimatic series to limit false detection of trends. Ehsanzadeh et al. [2010] investigated the presence of gradual and abrupt changes in Canadian low flows using a Mann-Kendall trend test combined with a Bayesian change-point detection methodology proposed by Seidou and Ouarda [2007]. Kalra et al. [2006] examined average annual and monthly streamflow quantities for trends using Spearman's rho, Mann-Kendall, and linear regression analyses. Their results indicate streamflow quantities are increasing in the Upper and Middle Mississippi regions. These results were corroborated using rank sum and student $\mathrm{t}$ tests to evaluate step changes in streamflow quantity [Kalra et al., 2006]. McCabe and Wolock [2002] discovered a mixed pattern of increases and decreases in average annual daily maximum flows throughout the U.S. when using a Mann-Kendall trend test, but results of a standard departures test revealed that the apparent linear monotonic trends actually occur as abrupt shifts.

The importance of investigating nonstationarity in the form of both trends (gradual changes) and abrupt shifts is evident based on the studies discussed above; however, only a few studies have completed this type of analysis for AMF series [e.g., Collins, 2009; Armstrong et al., 2011; Villarini et al., 2009, 2010, 2011]. Armstrong et al. [2011] investigated changes in the number of peaks-over-threshold per water year in New England. They compared pre- and post-1970 records using the Wilcoxon Rank-Sum test, 
and found a median increase of one flood per year for the post-1970 period. Villarini et al. [2009] investigated the presence of monotonic trends in AMF series by applying Mann-Kendall and Spearman's rho tests. Abrupt change-points in the mean and variance of AMF series were also investigated by means of the Pettitt change-point test [Villarini et al., 2009, 2011]. Results throughout the Midwest and Northeastern U.S. indicate that observed increases in flood magnitude are due to an abrupt shift (change-point), the presence of which results in spurious results of the Mann-Kendall test when not accounted for [Villarini et al., 2009, 2011]. Similarly, using a standard departures test, Collins [2009] identified increasing magnitudes of instantaneous peak flows in New England which occurred as abrupt shifts rather than gradual changes. These limited results for AMF series further illustrate the need to couple tests when trying to identify nonstationarity.

Not only have the methods employed for trend detection been under debate, but also whether the trends themselves will continue unabated into the future or if they are the result of long term persistence, and thus only part of a longer-term cycle not apparent in the available record [e.g., Villarini et al., 2009; Stedinger and Griffis, 2011]. Hurst [1951] investigated dependence properties of water levels in the Nile River, and concluded that the data exhibited signs of long-term persistence or dependence that is beyond what one could explain by assuming independent and identically distributed observations. Others have since applied the Hurst phenomenon to a variety of hydrologic variables [e.g., Sakalauskiene, 2003; Koutsoyiannis, 2003]. In order to improve our understanding of nonstationarity in flood series, persistence in AMF series is investigated herein in addition to trends and change-points. Moreover, in the context of water resources applications, it is necessary to move beyond simply assessing the degree of nonstationarity in AMF series, and consider the driving causes, whether climatic and/or human-induced, of the observed changes in flood magnitude and the associated flood risk.

With respect to climatic influences on flood flows, Robson et al. [1998] observed strong year-to-year variations in UK floods (POT and AMF series), noting that the flows 
displayed systematic behavior (fluctuations), with emergence of some possible cyclic tendencies when smoothed using locally weighted regression. The observed behavior suggests that fluctuations in flood flows are driven climatically. Climate variability and its relation to streamflows is often investigated through teleconnections-large and persistent oceanic-atmospheric patterns which occur over large areas, displaying causal effects on regional climate conditions in adjacent and often remote areas [Piechota and Dracup, 1999]. Examples of large scale oceanic patterns include the El Nino-Southern Oscillation (ENSO), North Atlantic Oscillation (NAO), and Pacific Decadal Oscillation (PDO). These large scale patterns have either inter-annual variations (2-10 years) or inter-decadal variations (10-50 years) [Piechota and Dracup, 1999]. Interannual climate variability occurs when large scale oceanic-atmospheric patterns result in extremely large climate anomalies, i.e. departures from a long-term average. Several studies have demonstrated how these well-organized spatial and temporal climatic patterns have high correlations with other hydroclimatic data series, such as precipitation and streamflows [e.g., Dettinger et al., 2000; Chiew and McMahon, 2002; Twine et al., 2005].

Others have attempted to explain natural variation and identified shifts in the magnitudes of floods by relating the timing of the shifts to phase changes in climatic patterns. Jain and Lall [2000] performed nonlinear regression on AMF records for a site on the Black Fork River in Utah; their results indicate ENSO and PDO could potentially explain 40\% of the variation in AMF peaks at this one location. Hamlet and Lettenmaier [2007] investigated changes in flood risk in the western U.S. associated with both century-scale warming and interannual climate variations. Their results indicate climate variations associated with PDO and ENSO have strong effects on flood risk, especially when they are in phase with each other. In addition, they observe that a recent increase in flood risk in the western U.S. has resulted from changes in variability of cool season precipitation after 1973 [Hamlet and Lettenmaier, 2007]. Similarly, Collins [2009] observed that step increases in New England flood magnitudes occurred around 1970, in conjunction with a well-documented phase change in the low-frequency variability of NAO. Further, his results indicate a statistically significant, positive lagged correlation between indices of NAO and flood magnitudes. 
In the context of water resources planning and management, these identified relationships have the potential to be incorporated into streamflow forecasting [e.g., Dettinger et al., 2000; Chiew and McMahon, 2002; Twine et al., 2005]. Dettinger et al. [2000] found strong correlations between average monthly streamflow series and winter averages (December-February) of SOI across North America. Chiew and McMahon [2002] investigated global ENSO-streamflow relationships to allude to the idea of using these identified relationships to potentially forecast monthly streamflow several months in advance. A number of papers provide examples of site specific applications of ENSO indicators in probabilistic streamflow forecasts [e.g., Hamlet et al., 1999; Piechota and Dracup, 1999; Grantz et al., 2005]. With respect to AMF peaks, knowledge of strong teleconnections has led to the use of climate anomalies to improve year-specific estimates of flood risk [e.g., Kiem et al., 2003; Kashelikar and Griffis, 2008; Kwon et al., 2008; Kashelikar, 2009].

In a similar fashion, the existence of trends in flood series could be due to trends in relevant climate variables such as precipitation. Several studies have investigated precipitation series for trends [e.g., Knight and Karl, 1998; Kunkel et al., 1999; Groisman et al., 2001; Balling and Goodrich, 2010]. Knight and Karl [1998] explored trends in precipitation by employing a variety of methods to fully characterize changes in quantity, frequency, and intensity of precipitation in the U.S. Their results indicate precipitation has increased by $10 \%$ across the continental U.S. since 1910. The driving force behind this observed increase in annual precipitation depth is due to identified trends in extreme precipitation series, resulting from an increase in heavy and intense rain events [Knight and Karl, 1998; Kunkel et al., 1999; Groisman et al., 2001]. However, mixed results are identified in Canada; the frequency of rare extreme events has not increased, but less extreme events have become more regular [Kunkel et al., 1999]. Balling and Goodrich [2010] investigated trends and variations in precipitation intensity over the contiguous U.S. Only two regions within the U.S. exhibited a spatially coherent change in intensity - an increase in the Northeastern quadrant of the U.S., and a decrease in the center portion of the Western U.S - while the rest of the U.S. exhibits high spatial entropy (disorder) [Balling and Goodrich, 2010]. 
Beyond investigating nonstationarity in precipitation series as discussed above, it is necessary to understand how changes in precipitation series could partially or fully explain identified gradual and/or abrupt changes in streamflow series. Small et al. [2006] associated trends in annual average and 7-day low flows with trends in average fall precipitation in basins within the Upper Mississippi and Great Lakes regions. Further, they note that spring precipitation series in the Eastern U.S. do not exhibit strong increasing trends, thereby providing evidence to the lack of identified trends in AMF series in that region. Lettenmaier et al. [1994] identified strong trends in average monthly precipitation across the U.S. using a seasonal Kendall's test, and applied a bivariate test to evaluate changes in streamflow relative to precipitation and temperature series. Their results indicate observed trends in average monthly streamflow are not completely consistent with trends in climatic variables, implying that observed trends in streamflow quantities are caused by a mixture of climatic and anthropogenic effects.

The recent increased understanding of climate variability and its connections to streamflows and flood flows as discussed above holds promise for improved estimation of flood risk, and will thereby have a significant impact on the design of water resources infrastructure, as well as water resources management. However, to improve flood frequency forecasts for long-term planning and management, it is also necessary to quantify the impacts of anthropogenic activities relative to those of natural climate variability [e.g., Juckem et al., 2008]. Changes in the mean or variance of hydroclimatic time series can be caused by several mechanisms, including land cover changes (e.g., fire, urbanization, deforestation and changing agricultural practices), channel modifications (e.g., construction of dams and levees), and water withdrawals [Ehsanzadeh et al., 2010].

Many of the aforementioned studies considered unimpaired watersheds in an attempt to isolate the impacts of climate variability on streamflow. The term unimpaired is used to describe a watershed relatively free of anthropogenic influences such as water source regulation, diversion, water withdrawals and land use changes [Slack and Landwehr, 1992]. For example, Kashelikar [2009] used unimpaired flood series for sites contained in the Hydro-Climatic Data Network (HCDN) Streamflow Dataset [Slack et al., 1993]. 
For a site to be included in the $\mathrm{HCDN}$, unimpaired basin conditions were defined as follows:

\begin{abstract}
"At least with respect to the computation of a monthly mean discharge value -- There should be no overt adjustment of "natural" streamflow, such as flow diversion or augmentation, regulation of the streamflow by some containment structure, or reduction of base flow by extreme ground-water pumping, nor should the degree of human activity in the watershed, such as changes in land use during the period of record, be so large as to significantly affect the value of monthly mean discharge (computed on the basis of the daily mean discharge) at the station."
\end{abstract}

[Slack et al., 1993]

In addition, sites could be included in the HCDN if a river was regulated by a low-head hydropower dam which only produced temporary effects on high and low streamflows.

Records for sites contained within the HCDN should be used with caution, because not all sites included were considered unimpaired for the entire time period analyzed [Slack et al., 1993]. Moreover, the status quo of an "unimpaired" watershed could have been jeopardized at any time since 1988 when it was originally classified. For example, abrupt or gradual land use/land cover changes can affect streamflow; if a basin has undergone changes from forest to agriculture to urban, it would no longer be considered unimpaired, and thus would not be included in the HCDN at present.

Prior to 2010, when the Geospatial Attributes of Gages for Evaluating Streamflow (GAGES) was published, no updates to the $1988 \mathrm{HCDN}$ had been made and an alternative large scale database containing basins which represent hydrologic conditions least disturbed by human influences ("reference gages") did not exist [Falcone et al., 2010]. In 2011, GAGES II (updated version of GAGES) was published. The dataset was created to provide users with a comprehensive set of geospatial characteristics for a large number of gaged watersheds, and to provide reference watersheds representative of hydrologic conditions which are least affected by anthropogenic effects [Falcone et al., 2010]. A total of 9,322 sites were analyzed, and 2,057 are classified as reference sites. The dataset also includes a new "HCDN-2009" consisting of 743 sites defined as having potential for hydro-climatic studies following criteria based on continuous flow record 
length and activity, and basin characteristics ( $<5 \%$ imperviousness). Additional details are provided by Falcone et al. [2011].

Undoubtedly, the U.S. has become more urbanized in the last century. The removal of vegetation and soil, grading of the land surface, and construction of drainage networks typically results in an increased magnitude and frequency of floods [Konrad, 2003]. Significant river engineering projects have also been related to observed trends in flooding [Pinter et al., 2008; Villiarini et al., 2009, 2011]. Villiarini et al. [2009, 2011] related change-points in the mean of AMF series to USGS qualification code " 6 ""discharge affected by regulation or diversion." Pinter et al. [2008] explored the effects of river engineering on the Mississippi River system with respect to observed trends in flood series. They concluded that climate and/or land use changes have played a role in observed increases in flood risk; however, these increases could also be associated with major engineering infrastructure (dikes, navigational structures, and levees).

Unimpaired watersheds predominantly consisting of forest cover can also experience increased flood risk by human effects. Storck et al. [1998] examined forest harvest effects on peak streamflows in the Pacific Northwest U.S. by employing a GIS-based distributed hydrologic model to simulate discrete (single storm) events for several watersheds. All results indicate clear-cutting can increase the magnitude of flows resulting from rain-on-snow events. Results of Jones and Grant [1996] reveal that the installation of logging roads increases streamflows to the same degree as clear-cutting.

Potter [1991] investigated a relatively unimpaired agricultural watershed in southwestern Wisconsin and related an observed decrease in the magnitude of flood flows to changing land management practices (i.e., adoption of conservation tillage and treatment of gullies) rather than climatic variations, reservoir construction, or major land use changes. However, Juckem et al. [2008] observe that changes in baseflows and stormflows in southwestern Wisconsin coincide with changes in precipitation in the 1970's, and note that both were likely amplified by changing agricultural practices in the 1930's. 
Despite the cause, the existence of trends or change-points in AMF series can have a significant impact on the planning and management of water infrastructure. Several studies have proposed methods for coping with nonstationarity when forecasting flood risk. Strupczewski et al. [2001] and Olsen et al. [1999] incorporated hydrological nonstationarity into at-site flood frequency estimation by projecting observed trends in AMF series. Sveinsson et a1. [2005] considered modeling variation in AMF series by incorporating shifting mean models that assume a constant long-term mean about which the stochastic model moves from one "stationary" state to another. For prediction of nonstationary hydrological time series, a dynamic recurrent neural network was proposed by Coulibaly and Baldwin [2005]. Generalized additive models have been proposed for modeling time series under nonstationary conditions by employing time-dependent parameters which take into account both trends and abrupt shifts [Villarini et al., 2009, 2011]. The abilities of these models to forecast flood risk under changing climate and land use/land cover are limited, however, as they are merely a function of time.

On the contrary, Kashelikar and Griffis [2008] and Kashelikar [2009] propose a physicalcausal model of flood risk which reflects observed nonstationarity in flood series. They used a regression model to incorporate effects of climate variability associated with ENSO events into updated estimates of the mean of AMF series to improve one-year ahead forecasts of flood risk. Their model appropriately increases/decreases expected flood risk relative to the phase and intensity of forecasted ENSO anomalies. Still, to be useful in the design of large-scale water control projects, models are needed which can provide accurate forecasts of flood risk over relevant planning/construction horizons of at least 50 years. Before these models can be developed, increased understanding of the prevalence of nonstationarity in flood series, and knowledge of the climatic, meteorologic, and anthropogenic causes of identified nonstationarity is needed. 


\subsection{Research Objectives}

The objectives of this thesis are to identify causes of nonstationarity in AMF series, and to provide insight as to how traditional statistical models of flood risk can be adapted to better estimate flood risk by incorporating effects of nonstationary related to climate variability. To accomplish this, the thesis has been divided into three main tasks:

(1) Identify hydroclimatic data series that exhibit nonstationarity in the form of gradual monotonic trends, abrupt shifts, and/or long-term persistence using standard statistical procedures.

(2) Identify climatic, meteorologic, and/or human-induced causes of nonstationarity in AMF time series.

(3) Develop site specific regression models to forecast flood risk one-year ahead as a function of forecasted climate anomalies.

Although the assumption of stationarity is considered "dead," as inferred by Milly et al. [2008], there exists no need to reinvent the overall process for flood risk estimation; rather, traditional statistical models of flood risk may be adapted to incorporate sources of nonstationarity, and thereby allow for generation of more accurate flood risk estimates. It is imperative that we disregard all presuppositions that variables of flood frequency are unaffected over time, and transform our models to reflect identified causes of nonstationarity for which there exists a physical-causal basis for flood risk projection [Stedinger and Griffis, 2011]. 


\section{CHAPTER 2 IDENTIFICATION OF NONSTATIONARITY IN HYDROCLIMATIC DATA SERIES}

Previous studies have provided evidence of nonstationarity in hydroclimatic series, including precipitation, streamflow and temperature at various time scales. Results of studies already executed for various parts of the U.S. also suggest annual maximum flood (AMF) series are nonstationary [e.g. National Research Council, 1998; Franks and Kuczera, 2002; Kashelikar and Griffis, 2008; Petrow and Merz, 2009; Villarini et al., 2009, 2011]. These findings provide motivation to challenge current flood frequency analysis procedures which presuppose AMF series as stationary, and thereby assume parameters of the fitted probability distribution are unassociated with time, and disregard any possible influence of climatic cycles and/or trends [Olsen et al., 1999; Hirschboeck et $a l ., 2000]$. This chapter presents results of an investigation of nonstationarity in AMF series at unimpaired sites throughout the contiguous U.S., as well as other associated hydroclimatic data series including flood-associated total daily precipitation series, and average daily maximum and minimum temperature series. Nonstationarity in the AMF series is considered with respect to both the magnitude of flood peaks and the day of occurrence. Sources of the nonstationarity identified in flood series will be investigated in Chapter 3.

\subsection{Methods for Assessing Nonstationarity}

The most common methods of investigating possible nonstationarity in hydroclimatic series are trend and change-point analyses. The existence of linear, temporal trends in annual maximum flood series is frequently evaluated using the non-parametric MannKendall (MK) test [e.g., Helsel and Hirsch, 1993; Douglas et al., 2000; Kashelikar and Griffis, 2008; Villarini et al., 2009, 2011]. Change-point analyses are frequently used to test for abrupt shifts in either the mean or variance of the flood peaks [e.g., Seidou and Ouarda, 2007; Kalra et al., 2008; Villarini et al., 2009, 2011]. Per Villarini et al. [2009], AMF series and flood associated hydroclimatic series considered herein were first 
checked for change-points in the mean using the non-parametric Pettitt test [Pettit, 1979], and then checked for temporal trends using the Mann-Kendall test. In the instance a change-point is detected in an AMF series, the sub-series before and after the shift will be checked independently for temporal trends. Each flood series was also checked for autocorrelation, and appropriate modifications of the Mann-Kendall test were used to avoid spurious results [Hamad and Rao, 1998; Yue et al., 2003; Cohn and Lins, 2005; Hamad, 2009]. Figure 2.1 shows the results of change-point and trend tests for a sample station's AMF series. The figure indicates a significant change-point in the mean occurred in 1940 and shows the series is better characterized by an abrupt shift rather than a linear monotonic trend. Further, as a trend identified as statistically significant could be part of a long-term cycle not apparent in the analyzed time series [Hamad, 2009], the Hurst exponent [Hurst, 1951] will be estimated to test for the presence of longterm persistence. Additional details of the methods used herein to identify nonstationarity are provided below.

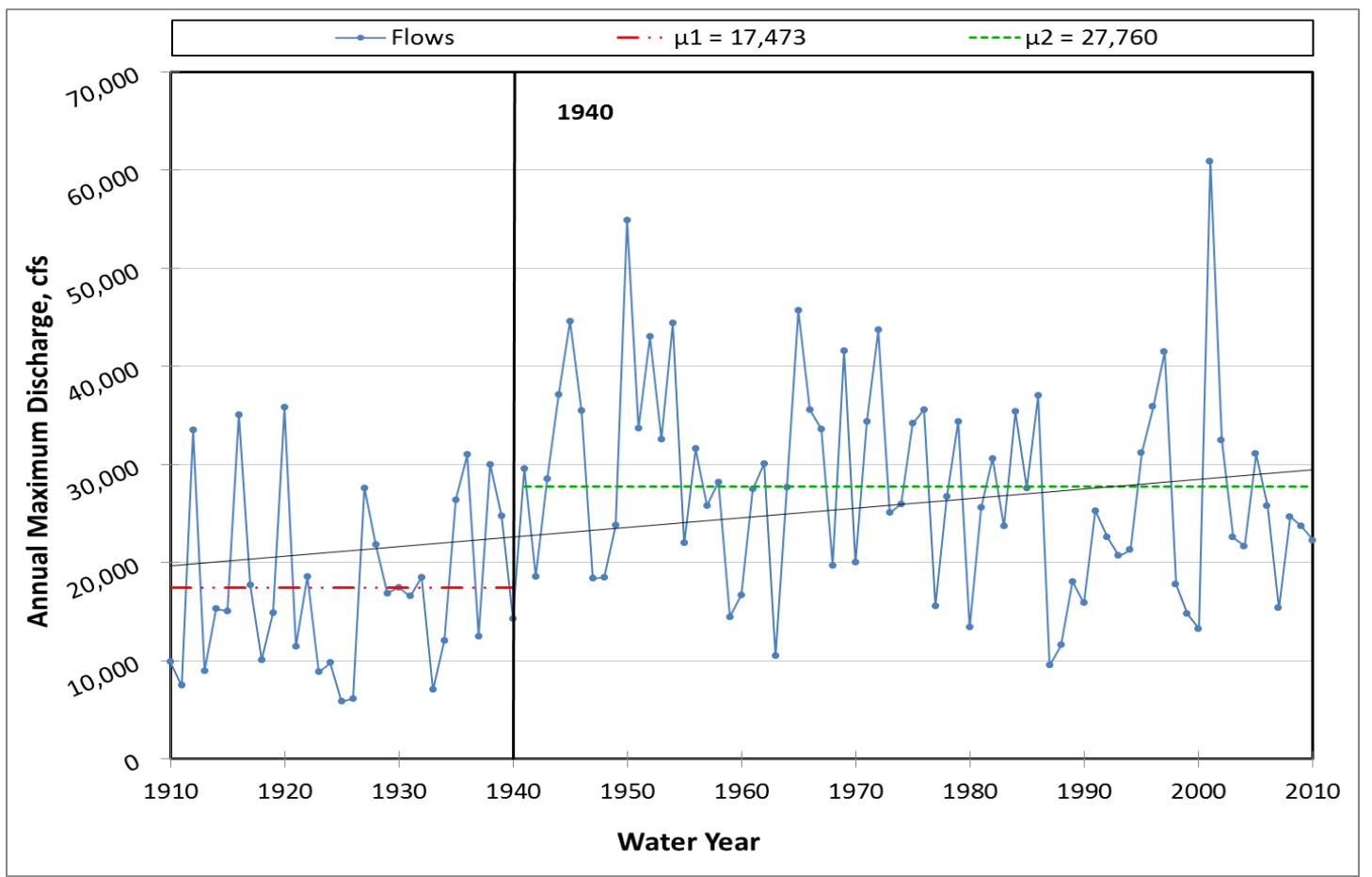

Figure 2.1 Example graph illustrating nonstationarity in an AMF series in the form of a linear trend and an abrupt shift in the mean (USGS Station No. 05340500). 


\subsubsection{Mann-Kendall Trend Test}

Standard statistical trend tests used to identify monotonic trends include the MannKendall test, Spearman's rho and linear regression with time as an independent variable. Several studies have investigated trends in streamflow quantities including annual and seasonal minimum, median, and averages by employing such tests [Lettenmaier et al., 1994; Lins and Slack, 1999; Olsen et al., 1999; Douglas et al., 2000; Burn and Hag Elnur, 2002; McCabe and Wolock, 2002; Yue et al., 2002; Hodgkins and Dudley, 2005; Small et al., 2006; Collins, 2009; Petrow and Merz, 2009; Villarini et al., 2009, 2011]. Yue et al. [2002] investigated the power of Mann-Kendall (MK) and Spearman's rho tests for detecting monotonic trends in time series data; their findings indicate both tests provide indistinguishable results when used in practice. They also note the power depends on the magnitude of the trend, sample size, and the amount of variation within the time series. Only the MK test will be utilized in this study to investigate trends in hydroclimatic series as it provides similar results as the Spearman's rho test, and it is routinely used to identify trends in hydroclimatic time series.

The MK test is a non-parametric, rank based method, therefore it is more robust given outliers in the data set, and is advantageous in that it does not assume an underlying distribution of the data (in particular, normality is not required). The MK test is used to detect monotonic trends by evaluating whether there is an increase or decrease in values with respect to time. The test is completed by considering each observation as its own datum, and differences between the datum and successive observations are computed across a triangular table. The test statistic $\mathrm{S}$ is computed by taking the difference between the number of positive $(\mathrm{P})$ and negative differences $(\mathrm{N})$ :

$$
S=P-N
$$

To evaluate the significance of the trend, when the sample size (n) is greater than 10, the test statistic $\mathrm{S}$ is transformed to define a standard normal $\mathrm{Z}$ statistic as follows:

$$
Z= \begin{cases}(S-1) / \sigma_{s} & \text { If } S>0 \\ 0 & \text { If } S=0 \\ (S+1) / \sigma_{s} & \text { If } S<0\end{cases}
$$


where,

$$
\sigma_{s}^{2}=\frac{n(n-1)(2 n+5)}{18}
$$

in the instance that no ties are observed. When data values are tied, the following correction is applied to $\sigma_{s}^{2}$ :

$$
\sigma_{s}^{2}=\frac{n(n-1)(2 n+5)-\sum_{i=1}^{n} t_{i}(i)(i-1)(2 i+5)}{18}
$$

where $t_{i}$ symbolizes the number of ties of extent $i$.

A trend is apparent in a time series when the absolute value of the Z-statistic computed in equation (2) is greater than $\mathrm{z}_{\alpha / 2}=\phi^{-1}(1-\alpha / 2)$ for a defined significance level $(\alpha)$, and thus the null hypothesis (no trend) is rejected. A detailed discussion of the MannKendall test and its application to evaluate hydrological time series is provided by Douglas et al. [2000].

\subsubsection{Pettit Change-Point Test}

Nonstationarity in time series can also be characterized by abrupt shifts in the mean or variance of the series. To identify possible shifts, standard change-point procedures have been applied to multiple time series in earth sciences including precipitation and temperature [Tome et al., 2004]. One type of homogeneity (change-point) test is the Pettitt test [Pettitt, 1979], which is a non-parametric test-requiring no assumption of the underlying distribution.

The Pettitt test is a version of the Mann-Whitney two-sample test which allows for identification of the time $t$ at which a possible abrupt shift may occur. Under the null hypothesis, the time series is composed of homogeneous variables which follow the same distribution (with same location parameter, but not necessarily equal variance). Under the alternative hypothesis, the mean of the subseries prior to time $t$ is statistically different from the mean of the subseries after time t. In order to test for 
shifts in the variance of the distribution, the data set is first transformed such that identified shifts are inferred from changes in average variance between the two subseries [e.g., Villarini et al., 2009].

To perform the two-tailed hypothesis test on the location parameter (mean), the Pettitt test statistic is calculated as:

$$
D_{i j}= \begin{cases}-1 & \left(x_{i}-x_{j}\right)<0 \\ 0 & \left(x_{i}-x_{j}\right)=0 \\ 1 & \left(x_{i}-x_{j}\right)>0\end{cases}
$$

where $x_{i}$ and $x_{j}$ correspond to the magnitude of the hydroclimatic variable under consideration, and $x_{i}$ precedes $x_{j}$ in time. For evaluation over the entire sample (T years), these $\mathrm{D}$ statistics are combined as follows:

$$
U_{t, T}=\sum_{i=1}^{t} \sum_{j=t+1}^{T} D_{i j}
$$

The statistic $U_{t, T}$ is equivalent to a Mann-Whitney statistic for testing that the two samples $\mathrm{X}_{1}, \ldots, \mathrm{X}_{\mathrm{t}}$ and $\mathrm{X}_{\mathrm{t}+1} \ldots, \mathrm{X}_{\mathrm{T}}$ come from the same population. The test statistic $U_{t, T}$ is evaluated for all possible values of $t$ ranging from 1 to $T$. The most probable year of a change-point occurring is evaluated using a two-tailed test on the following statistic:

$$
K_{T}=\max _{1 \leq t<T}\left|U_{t, T}\right|
$$

If the statistic $\mathrm{K}_{\mathrm{T}}$ is significantly different from 0 , then a change-point occurs in the year $\mathrm{t}$ corresponding to the point in time for which the absolute value of $U_{t, T}$ is obtained. To evaluate the significance of the test, a Monte Carlo resampling procedure within XLSTAT was applied to calculate corresponding p-values [XLSTAT, 2011]. The statistic $\mathrm{K}_{\mathrm{T}}$ is significantly different from 0 , and thus a change-point is said to occur, when the $\mathrm{p}$ value is less than the desired level of significance $(\alpha)$. 


\subsubsection{Hurst's Exponent}

The Hurst exponent, $\mathrm{H}$, is a common indicator of long-term persistence in hydrologic data [Hurst, 1951]. Evaluation of the presence of long-term persistence is particularly important as gauged records are often relatively short, and thus identified trends could be part of a long-term cycle not apparent in the available record [Hamad, 2009]. The Hurst exponent is estimated using a rescaled range $(\mathrm{R} / \mathrm{S})$ analysis wherein the range of partial sums of departures of a time series from its mean is rescaled by its standard deviation [Sakalauskiene, 2003]. For a representative time series, $\left(X=X_{1}, X_{2}, \ldots, X_{n}\right)$ and $[t=$ $1,2, \ldots, n]$, the $\mathrm{R} / \mathrm{S}$ analysis is performed as follows. First, the mean (m) of the $\mathrm{n}$ observations in the total time series is computed:

$$
m=\frac{1}{n} \sum_{i=1}^{n} X_{i}
$$

The mean adjusted series, $\mathrm{Y}$, is then obtained as

$$
Y_{t}=X_{t}-m
$$

Summing over the mean adjusted series through time $\mathrm{t}$ (for $\mathrm{t}=1, \ldots, \mathrm{n}$ ) yields the cumulative deviate series $\mathrm{Z}$ :

$$
Z_{t}=\sum_{i=1}^{t} Y_{i}
$$

The range series, $R$, is defined as

$$
R_{t}=\max \left(Z_{1}, Z_{2}, \ldots, Z_{t}\right)-\min \left(Z_{1}, Z_{2}, \ldots, Z_{t}\right)
$$

where $\max \left(Z_{1}, Z_{2}, \ldots, Z_{t}\right)$ is the adjusted surplus and $\min \left(Z_{1}, Z_{2}, \ldots, Z_{t}\right)$ is the adjusted deficit. The standard deviation, $S$, for observations through time $t$ is calculated as

$$
S_{t}=\sqrt{\frac{1}{t} \sum_{i=1}^{t}\left(X_{i}-u\right)^{2}}
$$


where $u$ is the mean value of the observations $\left\{X_{1}, \ldots, X_{t}\right\}$. The standard deviation for time $t$ is then used to scale the corresponding sample range for time $t$ to yield the rescaled range series $(\mathrm{R} / \mathrm{S})$ :

$$
(R / S)_{t}=R_{t} / S_{t}
$$

By analyzing long term storage requirements of the Nile River, Hurst [1951] found that $(\mathrm{R} / \mathrm{S})$ scales by the power-law as time increases:

$$
(R / S)_{t}=(c) t^{H}
$$

where $\mathrm{c}$ is a scaling constant. The expected value of the rescaled range, or $E\left[\frac{R_{t}}{S_{t}}\right]$, is determined over partial time series (subseries of the overall record) and converges on the Hurst exponent power function [Bras and Rodriquez-Iturbe, 1985]:

$$
E\left[\frac{R_{t}}{S_{t}}\right]=c n^{H} \text { as } n \rightarrow \infty
$$

When the time series is truly random, i.e. representing a random walk, the expected value is described by the power $\mathrm{H}=0.5$ [Sakalauskiene, 2003]. If the Hurst exponent is between $0.5<H \leq 1$, the time series shows signs of long-term persistence [Sakalauskiene, 2003]. For $0 \leq H<0.5$, the time series exhibits signs of anti-persistent behavior, or a mean reverting system - the assumption that extremes within the data set are temporary, and that values will return to the average over time [Sakalauskiene, 2003].

\subsection{Nonstationarity in Annual Maximum Flood Series}

Identification of nonstationarity in both the magnitude and timing of AMF series is analyzed in the form of trends and abrupt shifts by means of standard statistical tests. In particular, Mann-Kendall trend and Pettitt change-point tests are employed as discussed above. The magnitude of AMF peaks are also analyzed for indications of long-term persistence using the Hurst exponent. 


\subsubsection{Data}

Data used in this research includes AMF series for streamflow gauging stations throughout the continental United States selected from the USGS Hydro Climatological Data Network (HCDN) [Slack et al., 1993]. The 1,659 sites included in the HCDN are scattered across 21 water resources regions of the U.S.; only the first 18 regions delineated for the continental U.S. are considered in this study (Figure 2.2). A total of 569 stations were used in this study, based on the criteria of having at least a continuous record for the period of 1940-2005 (Figure 2.3). As the HCDN only contains data through 1988, updated flood records were obtained from the U.S. Geological Survey (USGS) website (http://nwis.waterdata.usgs.gov/usa/nwis/peak). The minimum record length of 66 years is long enough to test for trends and other forms of nonstationarity in the flood series with reasonable certainty, as well as to identify physical and/or climatic causes of the nonstationarity as discussed in Chapter 3.

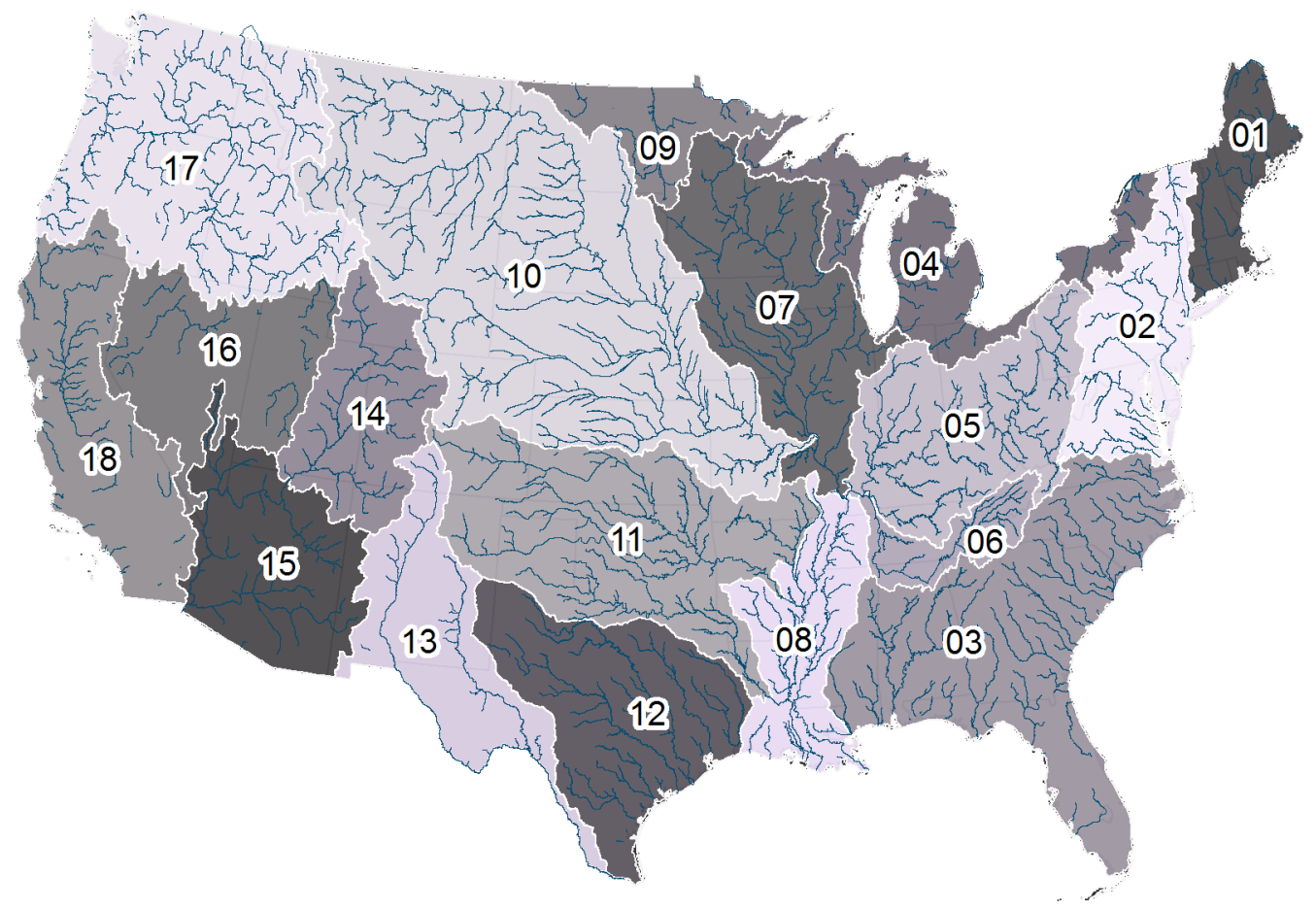

Figure 2.2 Water-resources regions (gray-scale polygons) and major rivers (blue lines) of the continental U.S as defined by the USGS. 


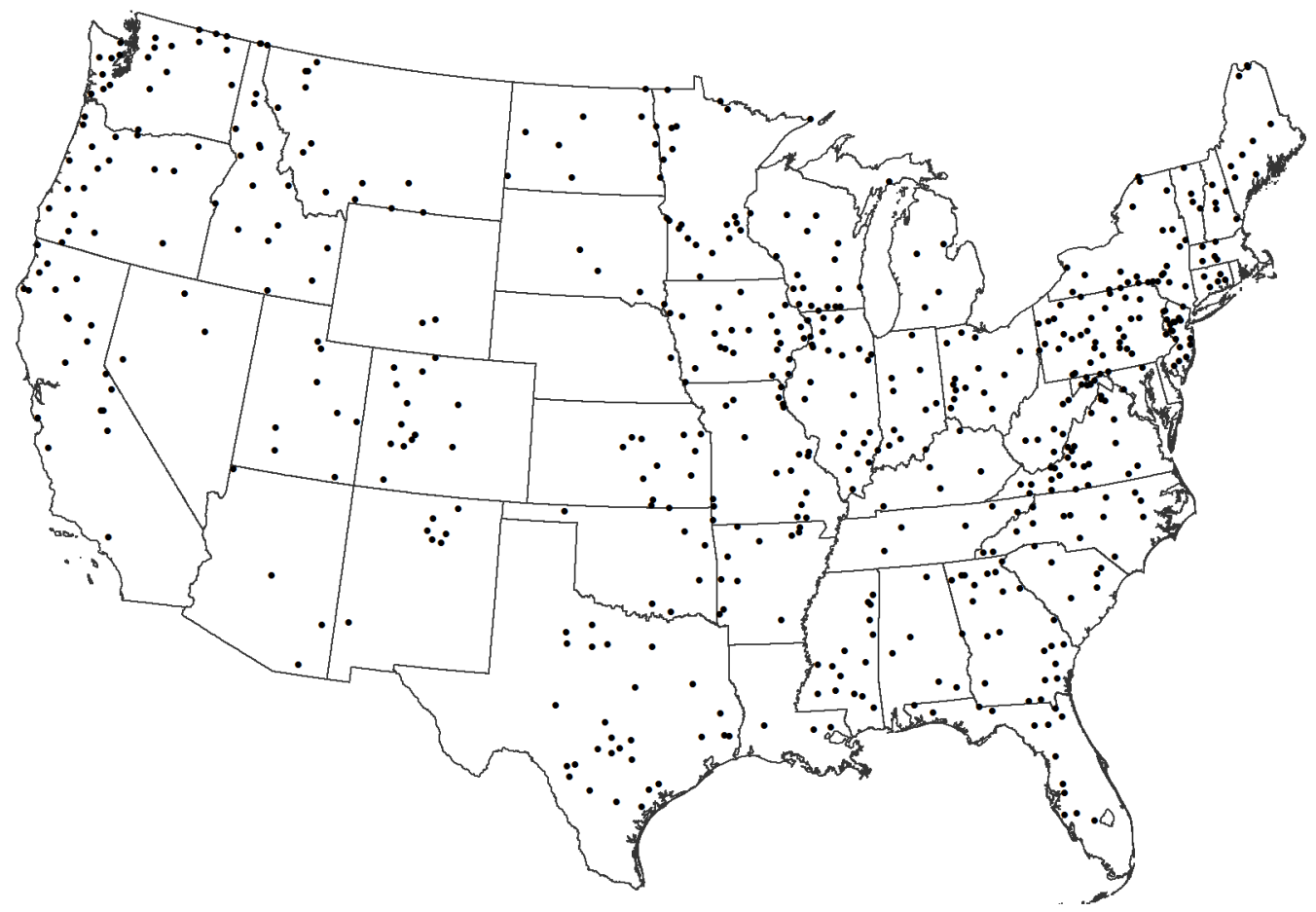

Figure 2.3 Location of 569 unimpaired USGS streamflow gauging stations within the continental U.S. selected from the HCDN having at minimum a continuous annual maximum flow record from 1940-2005.

\subsubsection{Trends in Magnitude of Annual Maximum Flood Series}

Trends in the magnitude of AMF series at each site in Figure 2.3 were identified by employing two versions of a standard MK test-both neglecting autocorrelation, and accounting for autocorrelation. In the latter case, each flood series was checked for autocorrelation, and appropriate modifications of the MK test were employed to avoid possible spurious results [Hamad and Rao, 1998; Yue et al., 2002; Cohn and Lins, 2005; Hamad, 2009]. For significance levels of 5\% and 10\%, Figure 2.4 illustrates the location of sites for which significant trends were identified when autocorrelation is neglected; results of the MK tests when accounting for autocorrelation are shown in Figure 2.5. Herein, parenthesized values within figure legends correspond to the number of sites illustrated for their respective categories (e.g., (48) in Figure 2.4 indicates 48 stations were identified to have a negative trend significant on the $5 \%$ level). Considering results 
at the $10 \%$ level, if possible autocorrelation is ignored (Figure 2.4), 59 of the 569 sites analyzed exhibit an upward trend indicating increasing flood risk over time; 70 sites exhibit a downward trend indicating decreasing flood risk over time. When accounting for the effects of autocorrelation using the procedure of Yue and Wang [2002, 2004], 53 sites exhibit a positive trend, and 58 sites exhibit a negative trend in the magnitude of flood peaks at the $10 \%$ level. A total of 129 significant trends (10\% significance level) were identified when effects of autocorrelation were not accounted for, 111 trends were identified as significant when accounting for autocorrelation; only 69 of the trends identified in both analyses were found at common sites. These numbers exceed what would be expected due to random variability (i.e., 57 trends identified on 10\% level), and thus the results do imply that trends exist in AMF series. After applying the Bonferroni correction to the results in Figure 2.4, 63 sites are still observed to exhibit a significant trend.

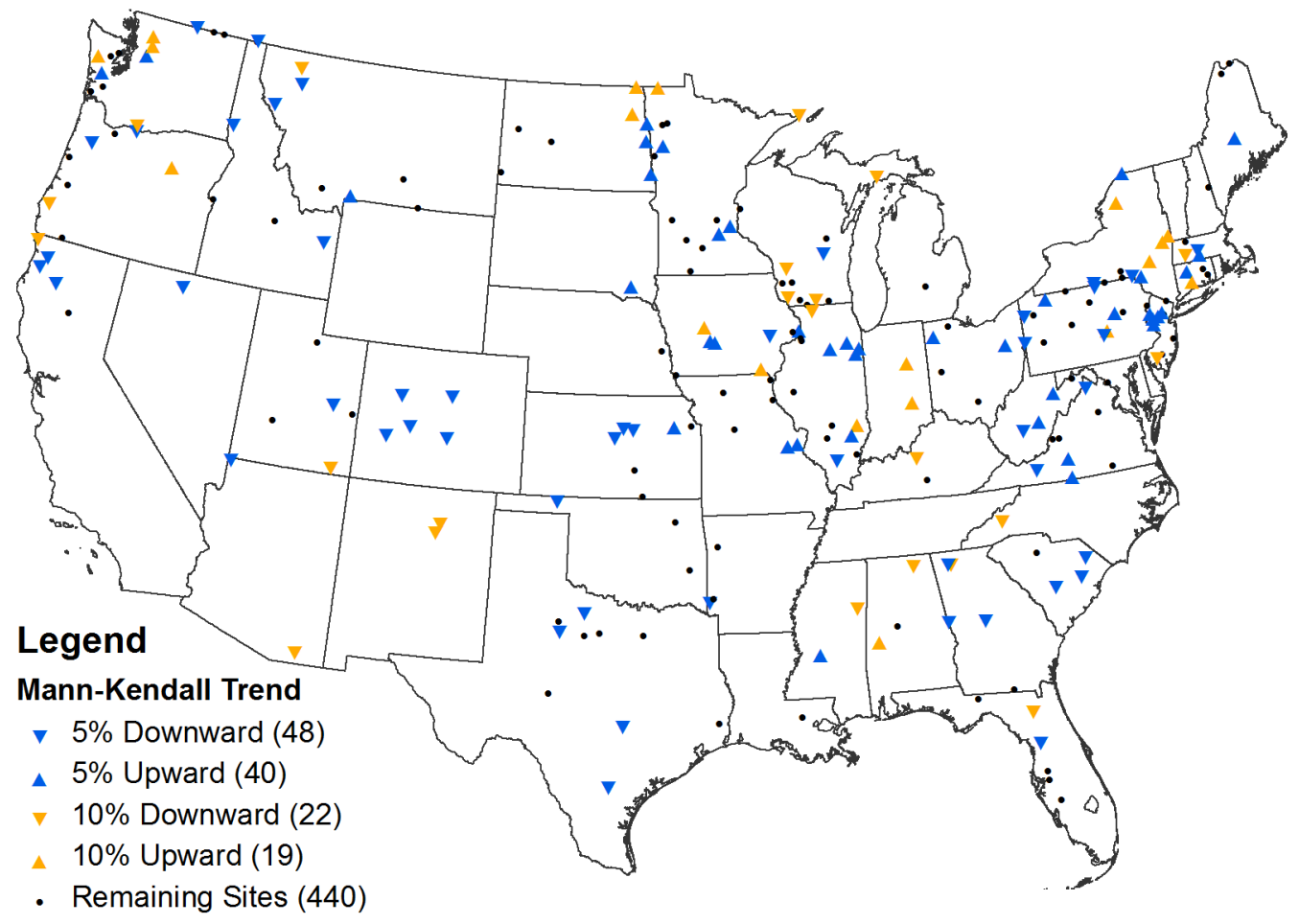

Figure 2.4 Results of traditional Mann-Kendall trend tests on magnitude of AMF series (neglecting possible autocorrelation). Upright (inverted) triangles represent sites with a positive/increasing (negative/decreasing) trend. 


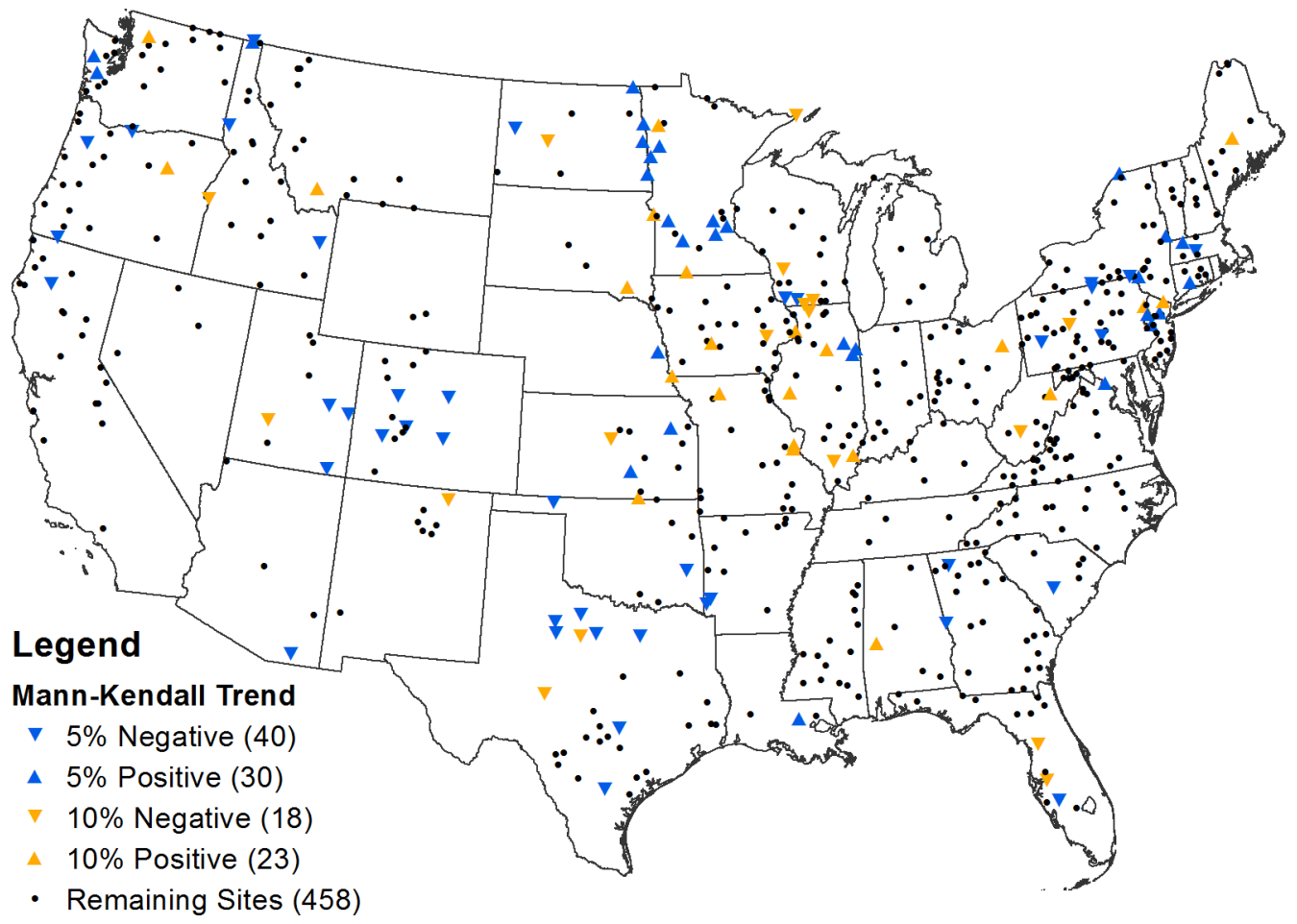

Figure 2.5 Results of modified Mann-Kendall trend tests on magnitude of AMF series (accounting for autocorrelation). Upright (inverted) triangles represent sites with a positive/increasing (negative/decreasing) trend.

Trends are evident across the U.S. both when neglecting and accounting for effects of autocorrelation in the magnitude of AMF series. Clusters of sites containing mixtures of negative and positive trends are found throughout areas of the U.S (Figure 2.4, Figure 2.5). Similar patterns of identified trends in the Eastern and Midwestern U.S. were reported in previous studies [e.g., Villarini and Smith, 2010; and Villarini et al., 2011]. APPENDIX A provides additional details of the trend analyses, reporting the direction of trends and corresponding $\mathrm{p}$-values for sites with significant results at the $10 \%$ level.

\subsubsection{Change-Points in Magnitude of Annual Maximum Flood Series}

The Pettitt change-point test was used to identify potential shifts in the mean of the AMF series for each of the 569 sites in Figure 2.3. As illustrated in Figure 2.6, 202 stations were found to have a significant change-point in the mean of the AMF series at the $10 \%$ level. The years in which these abrupt shifts occurred are indicated in Figure 2.7. Sites 
exhibiting a significant change-point in the mean flood magnitude tend to be scattered throughout the U.S., although sites in close proximity often show shifts around the same time period. The timing of these change-points is especially important when considering the causes of nonstationarity, whether human induced or due to natural climate variability, as is discussed in Chapter 3. In the Eastern and Midwestern U.S., identified patterns of change-points in the mean of AMF series support previous findings [e.g., Villarini and Smith, 2010; Villarini et al., 2011]. APPENDIX A provides additional details of the change-point analyses, reporting the timing and corresponding p-values for sites with significant results at the $10 \%$ level.

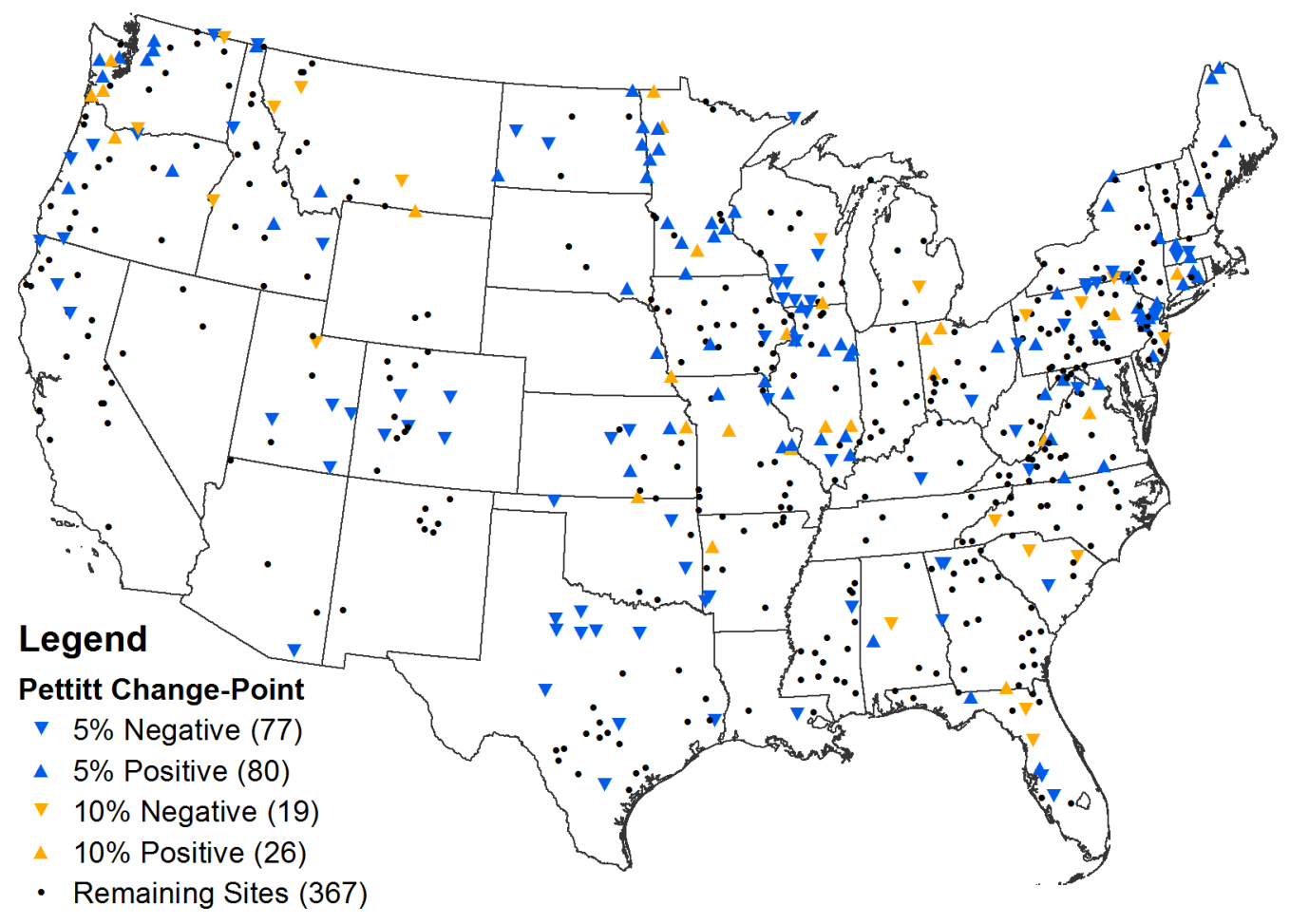

Figure 2.6 Locations of sites with a change-point in the mean annual maximum flood magnitude significant at $5 \%$ and $10 \%$ levels. 


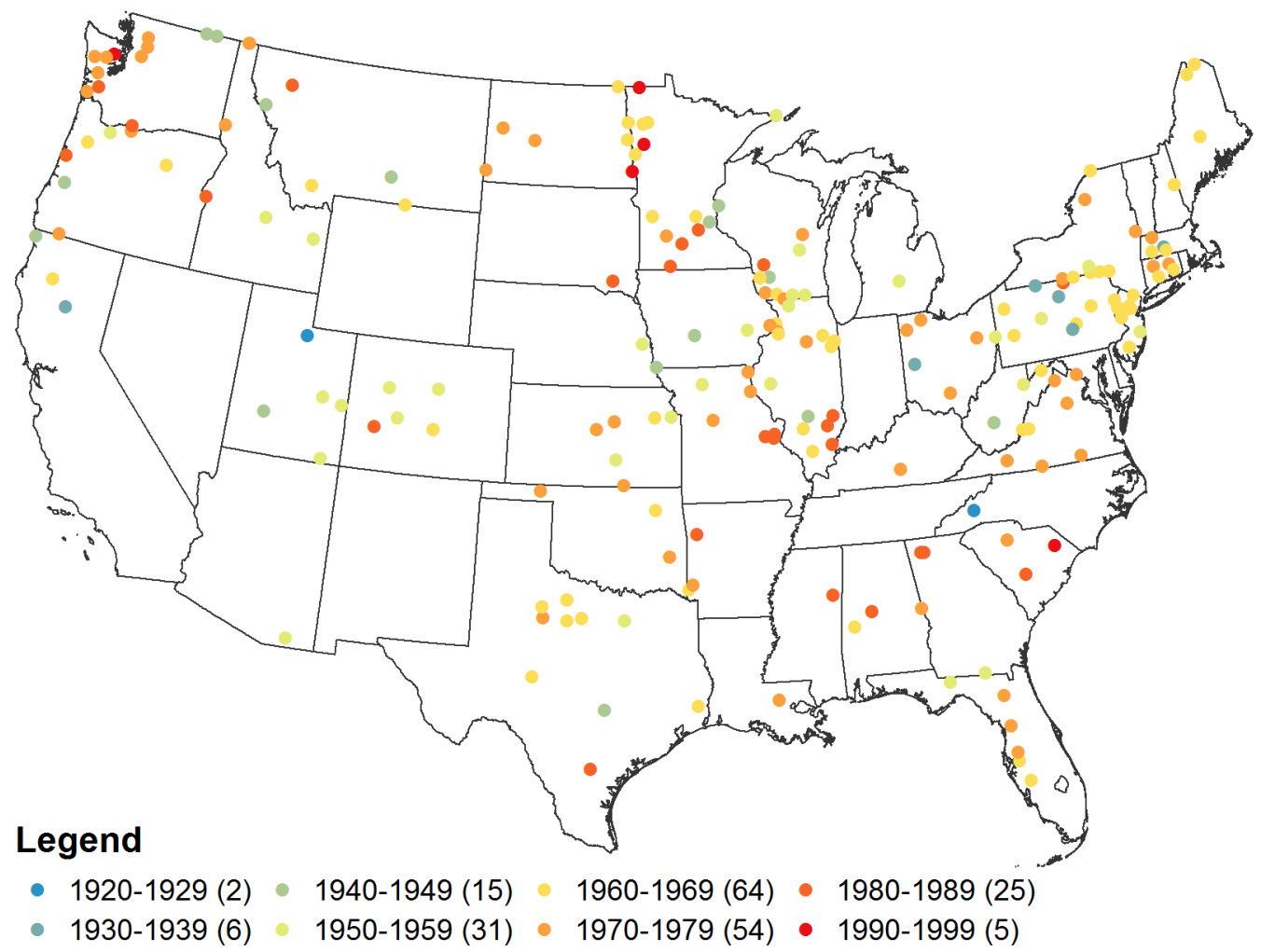

Figure 2.7 Time period in which a change-point in the mean annual maximum flood magnitude was identified by the Pettitt test (10\% significance level).

Of the 202 sites identified to contain a change-point, 98 sites also exhibit a significant trend over the entire period of record; thus, of the 129 sites determined to exhibit a trend as shown in Figure 2.4, only 31 sites show signs of nonstationarity only in the form of trends. As the presence of change-points (abrupt shifts) in the mean of AMF series can produce spurious results of the MK trend test, the remaining 98 sites should be further investigated. Herein, for all 202 sites identified to have a significant change-point in the mean flood magnitude, the subseries before and after the shift were checked independently for temporal trends using Mann-Kendall tests. This type of analysis is in line with recommendations of others who indicate the need to couple trend and changepoint tests when investigating nonstationarity in hydroclimatic series to limit false detection of trends [e.g., McCabe and Wolock, 2002; Kalra et al., 2006; Seidou and Ouarda, 2007; Ehsanzadeh et al., 2010]. 
The MK test results for each subseries of the 202 sites in question are illustrated in Figure 2.8 and Figure 2.9. A substantial reduction in the number of significant trends is observed when evaluating trends in subseries based on respective change-point dates. A breakdown of the results is provided in Table 2.1. Of the 98 sites observed to exhibit a trend in the complete record, 68 sites do not exhibit trends once the change-points are accounted for. Overall, significant trends were not identified in either subseries (before or after change-point) for 152 of the 202 sites analyzed. In addition to significant trends in the complete series, subseries at 15 sites were identified to exhibit a trend before the identified change-point, and 13 sites exhibit a trend in the subseries after the identified change-point. Only 2 sites exhibit trends in all series analyzed. These results are again consistent with findings of Villarini and Smith [2010], and Villarini et al. [2011]. APPENDIX A provides additional details of the trend analyses performed on the subseries, reporting the direction of trends and corresponding $\mathrm{p}$-values.

Table 2.1

Number of trends identified in the complete record and/or subseries with respect to identified change-points in mean flood magnitude.

\begin{tabular}{|c|c|}
\hline Trend Identification & Count \\
\hline \hline Before, After, Complete & 2 \\
Before, Complete & 15 \\
After, Complete & 13 \\
Before & 13 \\
After & 7 \\
Complete & 68 \\
No Trend & 84 \\
\hline
\end{tabular}




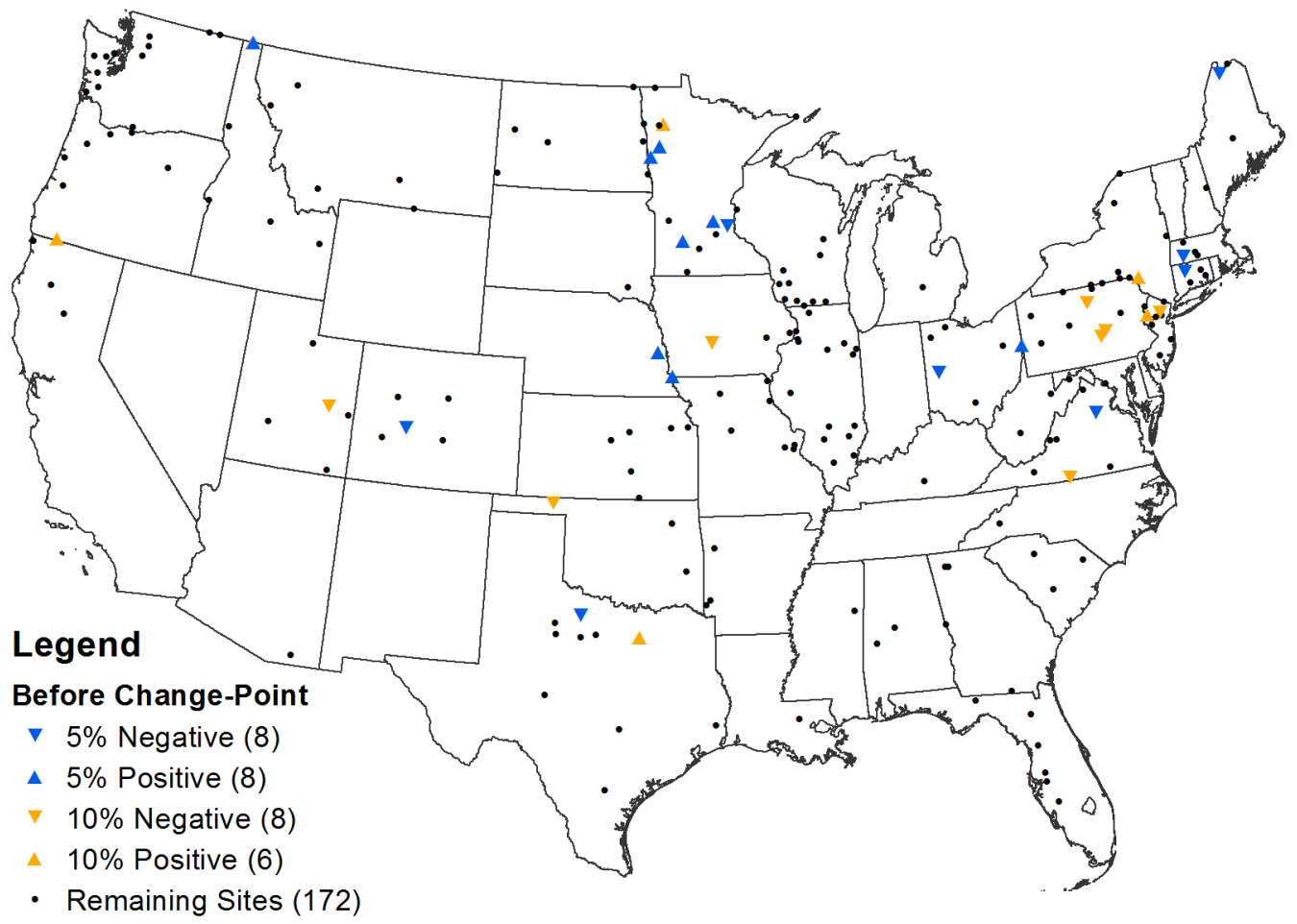

Figure 2.8 Results of Mann-Kendall trend tests on annual maximum flood subseries before identified change-point in mean flood magnitude.

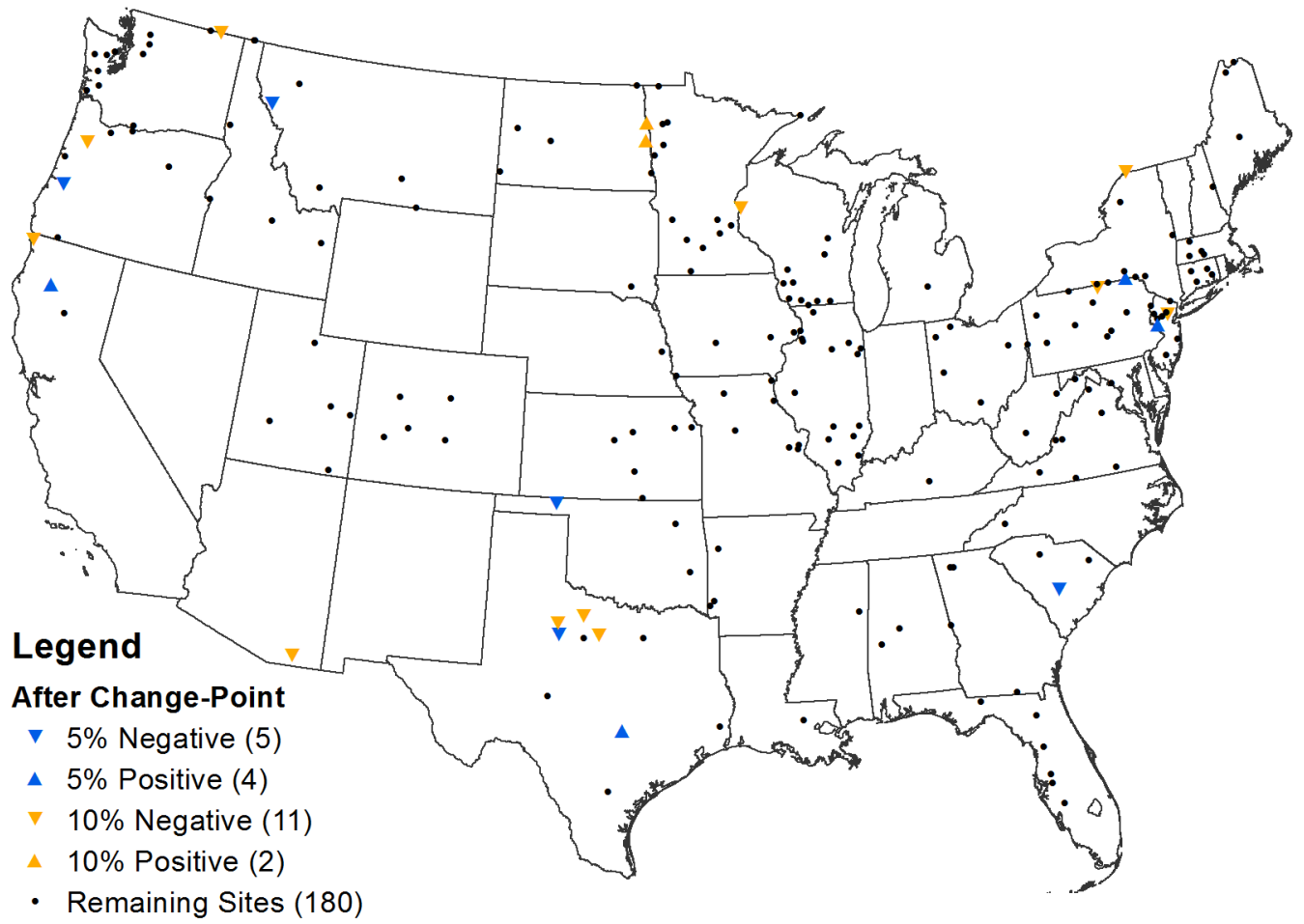

Figure 2.9 Results of Mann-Kendall trend tests on annual maximum flood subseries after identified change-point in mean flood magnitude. 


\subsubsection{Long-Term Persistence in AMF Series}

As a trend and/or change-point identified as statistically significant could be part of a long-term cycle not apparent in the available record [Hamad, 2009], the Hurst exponent [Hurst, 1951] was used as an indicator of long-term persistence in AMF series. Of the 569 sites analyzed, 537 sites show signs of long-term persistence with $\mathrm{H}$ values greater than 0.5; the locations of these sites are illustrated in Figure 2.10. APPENDIX A includes tables of the estimated Hurst coefficients for all sites showing signs of long-term persistence at the $10 \%$ significance level. As the majority of the sites analyzed show signs of persistence, these results suggest that hydroclimatic time series may be affected by large-scale climatic patterns (e.g., PDO, AMO or NAO) with variations on decadal time scales, contrary to assumptions made in Bulletin 17B. Therefore, it is suggested that future work apply spectral analyses to identify the possible timing of cyclical oscillatory behavior in flood series [Baldwin and Lall, 1999].

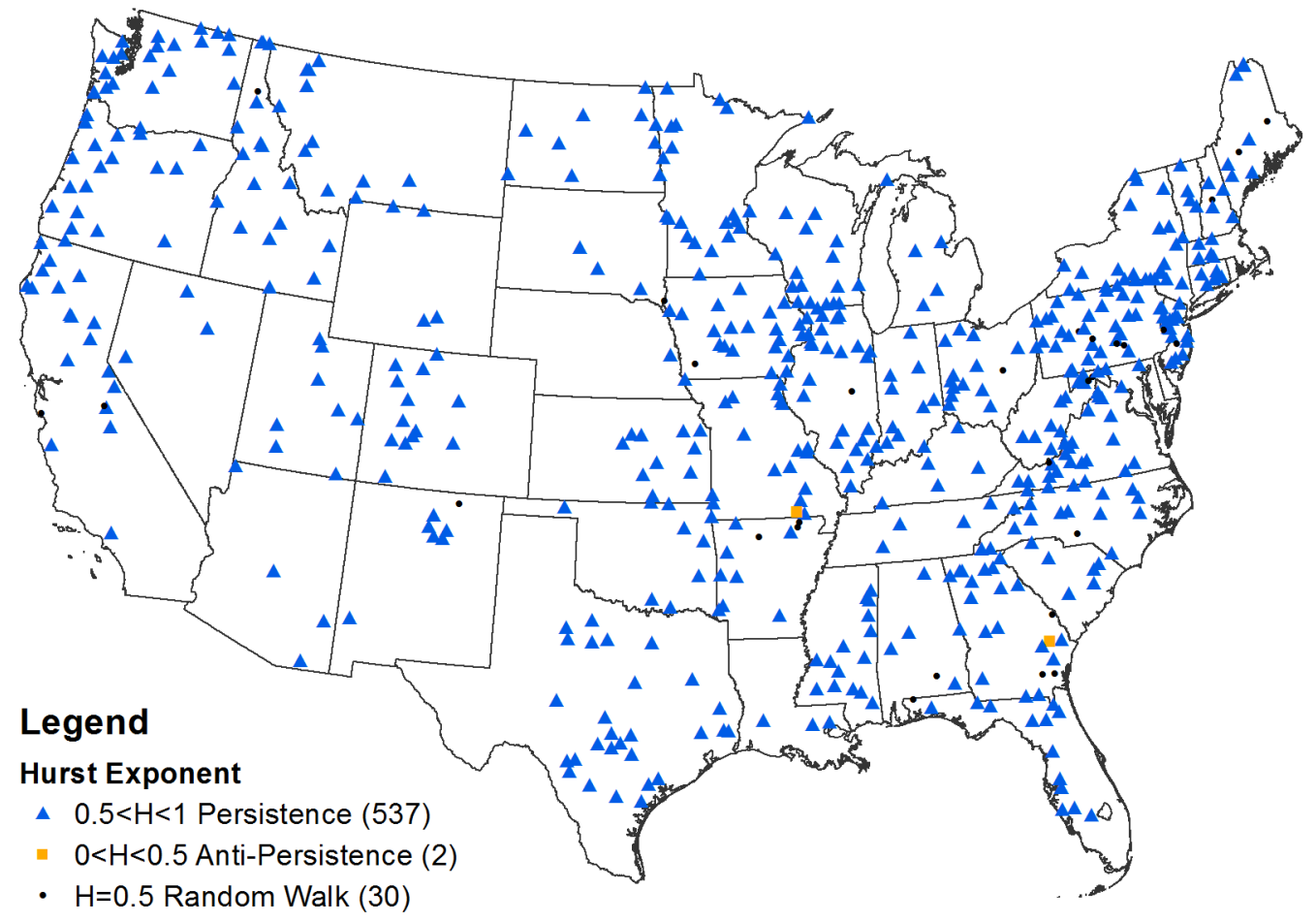

Figure 2.10 Magnitude of Hurst exponent for annual maximum flood series in the contiguous U.S. with continuous record lengths of at least 66 years. 


\subsubsection{Nonstationarity in the Timing of Flood Peaks}

Nonstationarity in AMF series may also be exhibited in the form of changes in the timing of flood peaks, either as an abrupt shift (change-point) or a linear trend indicating, for instance, a steady change towards an earlier spring. Possible shifts in the timing of flood peaks in the form of linear trends were investigated at each station in Figure 2.3 by performing a MK test on the day of the water year the AMF peaks occurred (day $1=$ October 1). The locations of sites with significant trends identified at both the $5 \%$ and 10\% significance levels are shown in Figure 2.11. Of the 569 sites analyzed, only 29 stations exhibit an upward trend potentially indicating floods are occurring later in the water year; 43 stations exhibit a downward trend suggesting floods are occurring earlier in the water year. However, as the number of trends identified is less than what would be expected due to random variability, few conclusions can be made based on these results. Also, as no spatial patterns are evident in the data, it is unclear whether or not there are regional influences causing these trends.

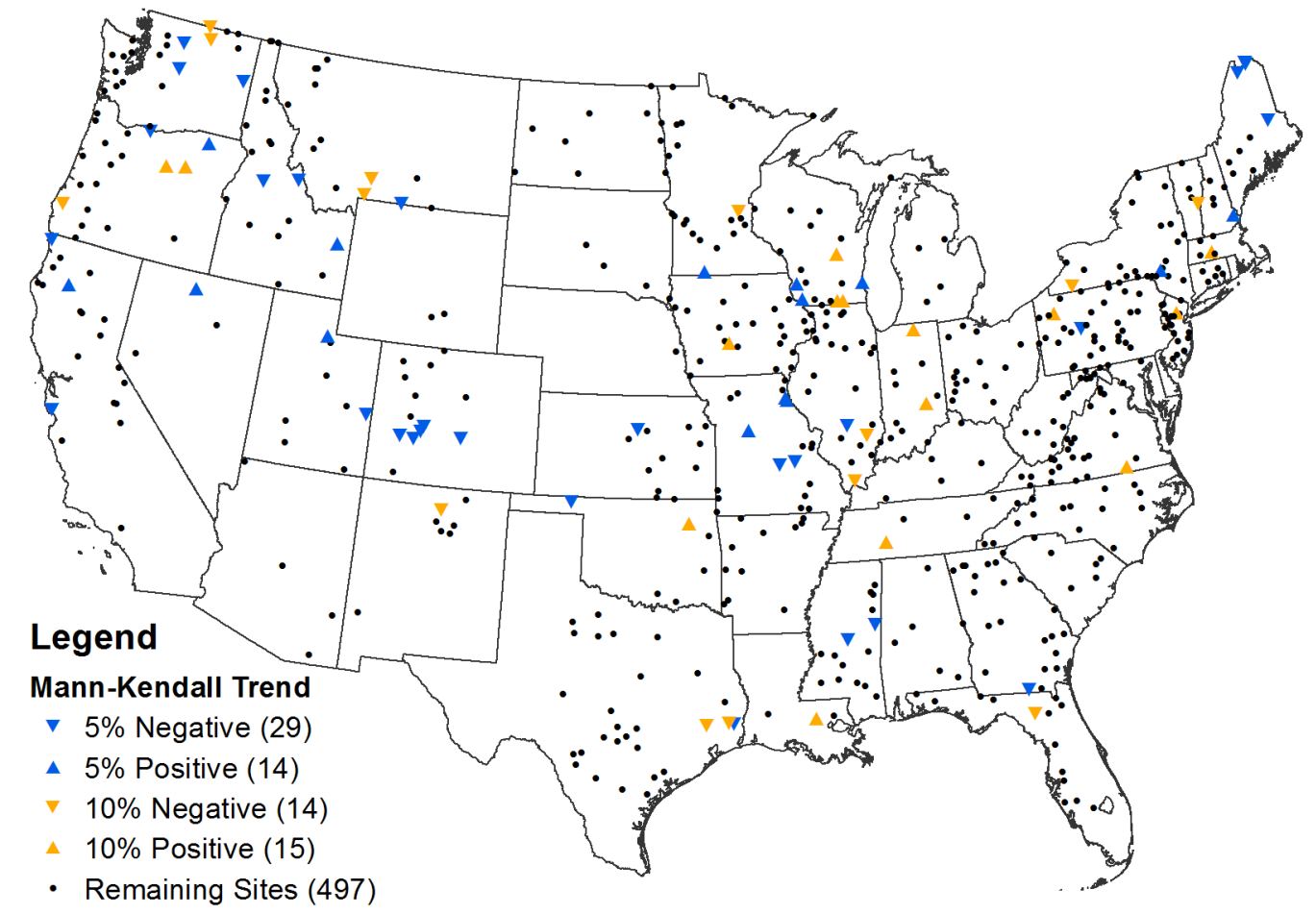

Figure 2.11 Results of Mann-Kendall trend tests on the day of occurrence of annual maximum flood peaks. 
To confirm whether identified trends in the timing of flood peaks are truly gradual over time, or a spurious result due to an abrupt shift, the Pettitt change-point test was also applied to the day of occurrence series for each site in Figure 2.3. Of the 569 sites analyzed, 66 stations were identified to have a significant change-point in the mean day of occurrence of AMF peaks at the 10\% level (Figure 2.12). The years in which these abrupt shifts occurred are indicated in Figure 2.13. Of the 66 stations, 33 had been identified to exhibit a trend in the complete record using the MK test; thus, nonstationarity in the time of occurrence at these sites may be better characterized by an abrupt shift rather than a gradual trend. However, the remaining 39 stations in Figure 2.11 only exhibit a gradual trend in the time of occurrence of flood peaks. Many of the trends and abrupt shifts identified in the time of occurrence of flood peaks occur in the Midwest and Western U.S., potentially due to dam installation in these areas (see CHAPTER 3). APPENDIX B provides additional results for the trend and change-point analyses on the time of occurrence of AMF peaks.

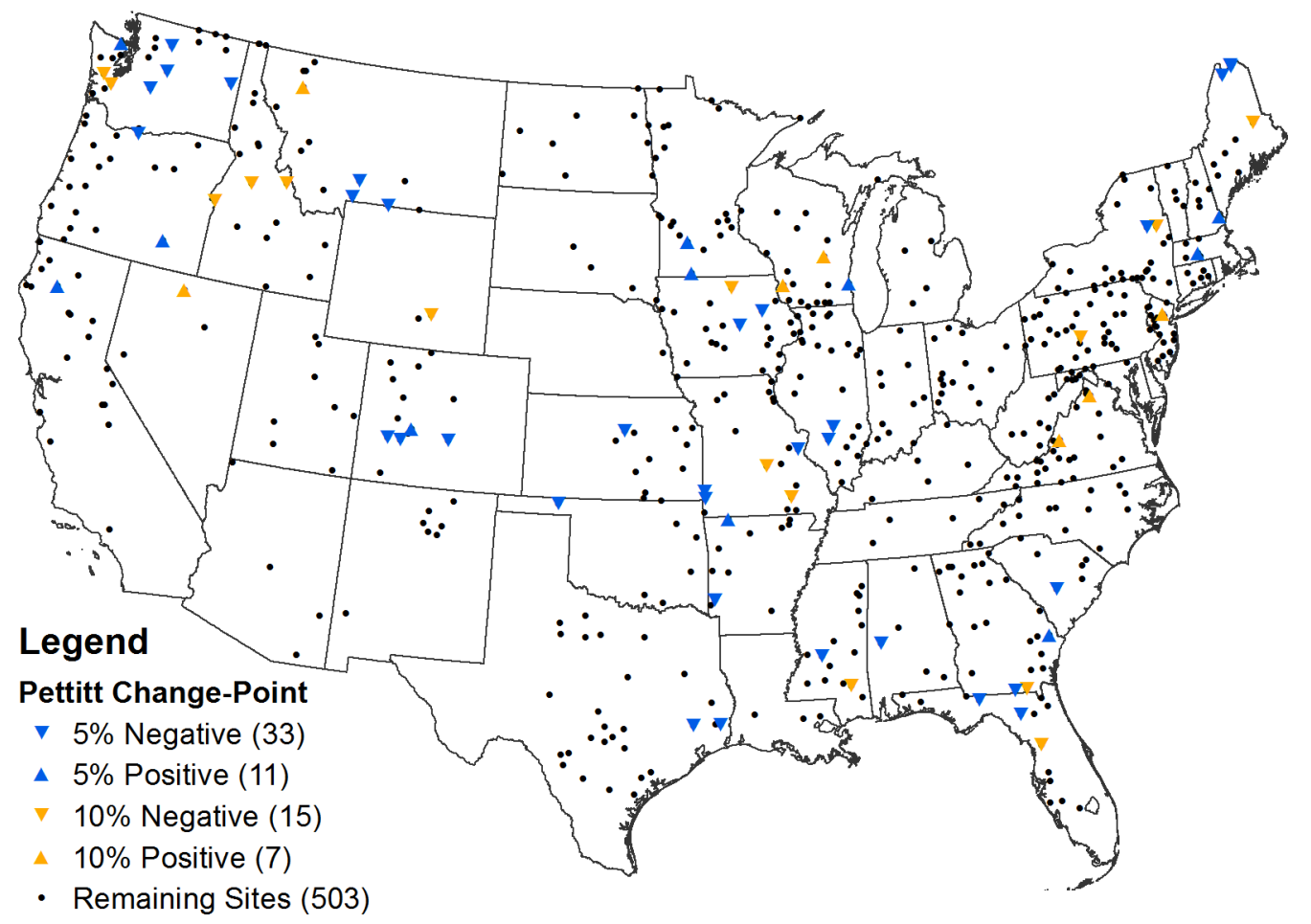

Figure 2.12 Locations of sites with a significant change-point in the mean day of occurrence of the annual maximum flood peak. 


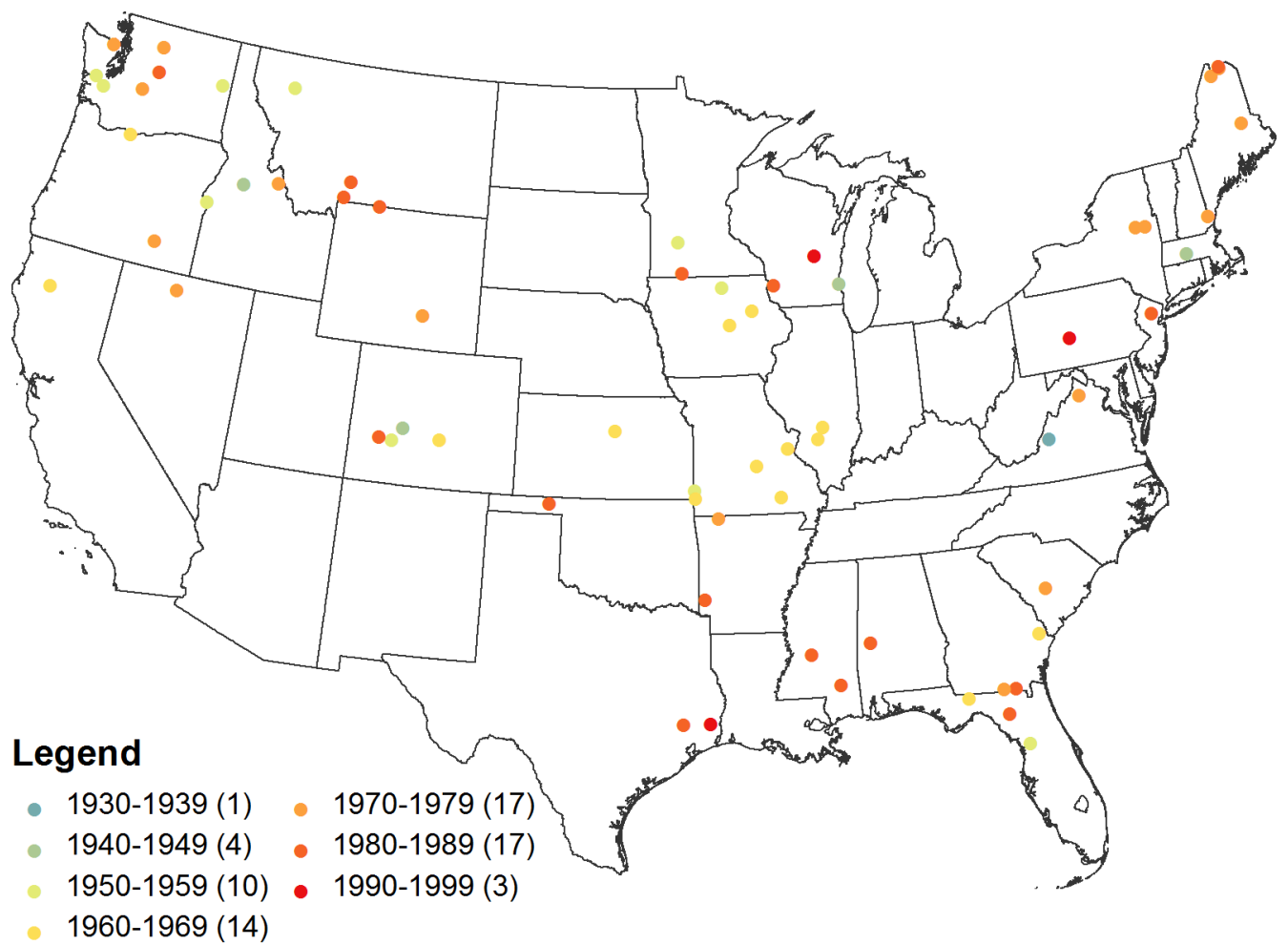

Figure 2.13 Time period of change-points in the mean day of occurrence of flood peaks as identified by the Pettitt test (10\% significance level).

\subsection{Nonstationarity in Flood Generating Meteorological Series}

The results above indicate that flood series corresponding to relatively unimpaired watersheds throughout the U.S. are nonstationary in terms of both flood magnitude, exhibiting either a trend, abrupt shift, or long-term persistence. Possible sources of this nonstationarity will be investigated in Chapter 3. However, because the identified nonstationarity in flood series could be due to nonstationarity in associated precipitation and/or temperature series, the remainder of this chapter seeks to identify nonstationarity in relevant meteorological series. To this end, peak flood associated precipitation and annual temperature series were constructed using gridded daily precipitation and temperature data. Further, as significant effort will be required to identify sources of nonstationarity in the individual flood series, the remaining analyses will be conducted for a smaller region of the U.S. (see Figure 2.14). 


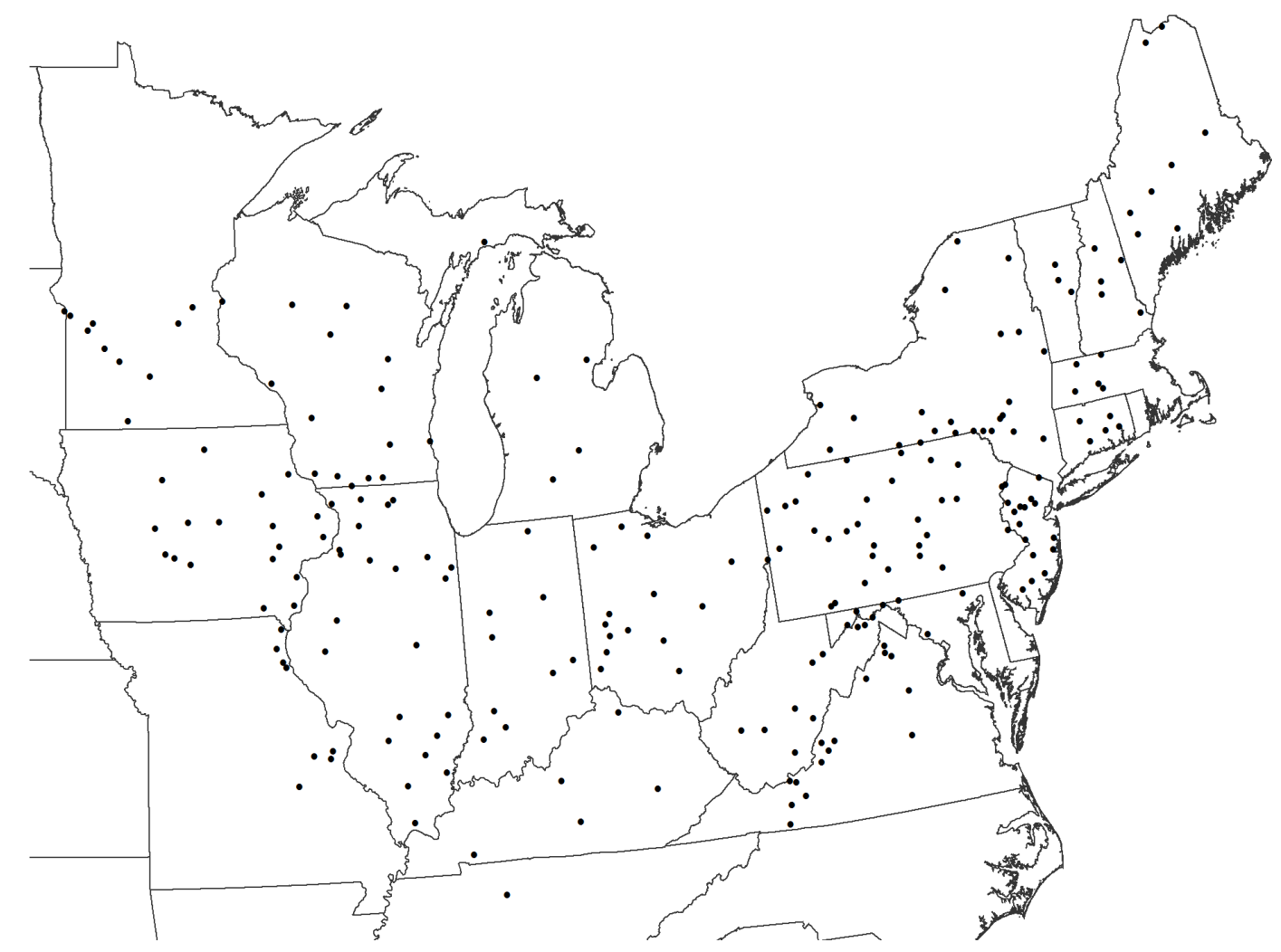

Figure 2.14 Locations of 235 streamflow gauging stations used to create flood associated precipitation and temperature series.

Based on the results of previous studies conducted in the Midwest [e.g., Changnon and Kunkel, 1995; Changnon and Demissie, 1996], flood generating precipitation series consisting of the total precipitation that occurred within X-days prior to the annual maximum flood peak were constructed for each of the 235 streamflow gauging stations in Figure 2.14. Similarly, flood generating temperature series consisting of the average daily maximum and minimum temperatures over $\mathrm{X}$-days prior to the annual peak flow were constructed. For lead times of $\mathrm{X}=2,3,4,5,6$, and 7 days, 235 watershed specific precipitation and temperature series were constructed using 1/8 degree gridded daily precipitation (mm/day), and daily maximum and minimum temperatures (C) recorded from 1950 to 2006 (57 years) [Maurer et al., 2002]. For each watershed, precipitation and temperature series were assembled by averaging the daily gridded data relative to the watershed boundary. The daily averages were then summed over the X-days to obtain a total precipitation depth prior to the flood peak, or averaged over the X-days to define the 
temperature series. In addition, a coarser resolution precipitation dataset- $25 \mathrm{x} .25$ Daily US UNIFIED Precipitation-was obtained from the National Oceanic \& Atmospheric Administration Climate Prediction Center (NOAA CPC) website (http://www.esrl.noaa.gov/psd/data/gridded/), and used to construct a second set of flood generating precipitation series. Comparison of results using the 1/8-degree gridded data versus the 1/4-degree gridded data provides insight as to how the spatial resolution of data may influence analyses of nonstationarity.

\subsubsection{Trends in Flood Generating Precipitation Series}

Mann-Kendall trend tests were employed to investigate trends in the flood generating precipitation series corresponding to the streamflow gauging stations illustrated in Figure 2.14. A positive trend would indicate an increase in the total precipitation series over time, thus one would expect to see similar increases in the magnitude of AMF peaks. Conversely, a negative trend would indicate a decrease in the total precipitation series with respect to time, and thus a decrease in the corresponding flood magnitudes would be expected. The trend analyses for precipitation series were performed on two general categories of data to determine if the spatial scale of data used to construct precipitation series has an effect on trend results:

Category A: Flood generating precipitation series based on 1/8-degree gridded precipitation data.

Category B: Flood generating precipitation series based on 1/4-degree gridded precipitation data.

These analyses include a total of 6 data series (with 2-, 3-, 4-, 5-, 6-, and 7-day lead times) each for Category A and Category B. Table 2.2 provides a summary of the number of sites found to exhibit significant trends at both $5 \%$ and $10 \%$ significance levels for all series (lead times) considered. 
Table 2.2

Number of sites with significant negative and positive trends in flood generating precipitation series identified using Mann-Kendall trend tests.

\begin{tabular}{|c|c|c|c|c|}
\hline \multirow{2}{*}{$\begin{array}{l}\text { Lead Time } \\
\text { (days) }\end{array}$} & \multicolumn{2}{|c|}{ 5\% Significance Level } & \multicolumn{2}{|c|}{$10 \%$ Significance Level } \\
\hline & Negative & Positive & Negative & Positive \\
\hline \multicolumn{5}{|c|}{ Category A: 1/8-degree generated precipitation series } \\
\hline 2 & 5 & 20 & 6 & 36 \\
\hline 3 & 0 & 21 & 0 & 32 \\
\hline 4 & 0 & 25 & 0 & 43 \\
\hline 5 & 0 & 21 & 1 & 45 \\
\hline 6 & 0 & 25 & 1 & 43 \\
\hline 7 & 2 & 28 & 3 & 49 \\
\hline \multicolumn{5}{|c|}{ Category B: 1/4-degree generated precipitation series } \\
\hline 2 & 8 & 16 & 10 & 32 \\
\hline 3 & 7 & 17 & 10 & 34 \\
\hline 4 & 8 & 15 & 9 & 29 \\
\hline 5 & 3 & 16 & 11 & 33 \\
\hline 6 & 2 & 18 & 7 & 35 \\
\hline 7 & 3 & 18 & 5 & 36 \\
\hline
\end{tabular}

The results in Table 2.2 indicate that both scales of data yield significantly more positive trends than negative trends in all precipitation series analyzed. In general, a greater number of negative trends are identified using coarser scale data (Category B), whereas more significant positive trends are identified with the finer scale data (Category A). Figure 2.15 illustrates the locations of the streamflow gauging stations for which the Mann-Kendall test identified significant trends in the flood generating precipitation series with a 5-day lead time constructed based on 1/8-degree gridded data. Of the 235 series analyzed, 45 sites exhibit an upward trend at the 10\% level, indicating an increase in the flood associated precipitation depth; only 1 site exhibits a downward trend indicating a decrease in precipitation depth. The identified increases in flood generating precipitation series are consistent with the expectations of the IPCC [2007a, 2007b]: global warming is anticipated to result in increased precipitation and a higher frequency of heavy 
precipitation events in many regions, including the northeastern quadrant of the U.S. The small number of negative trends in the flood generating precipitation series is inconsistent with the number of negative trends identified in AMF series (Figure 2.4); however, there are many other factors such as decreased snow pack or increased dam density/storage which could offset the effects of precipitation, as will be discussed in CHAPTER 3. For the remaining daily precipitation series considered in both categories, figures showing the location of sites with significant results are provided in APPENDIX C.

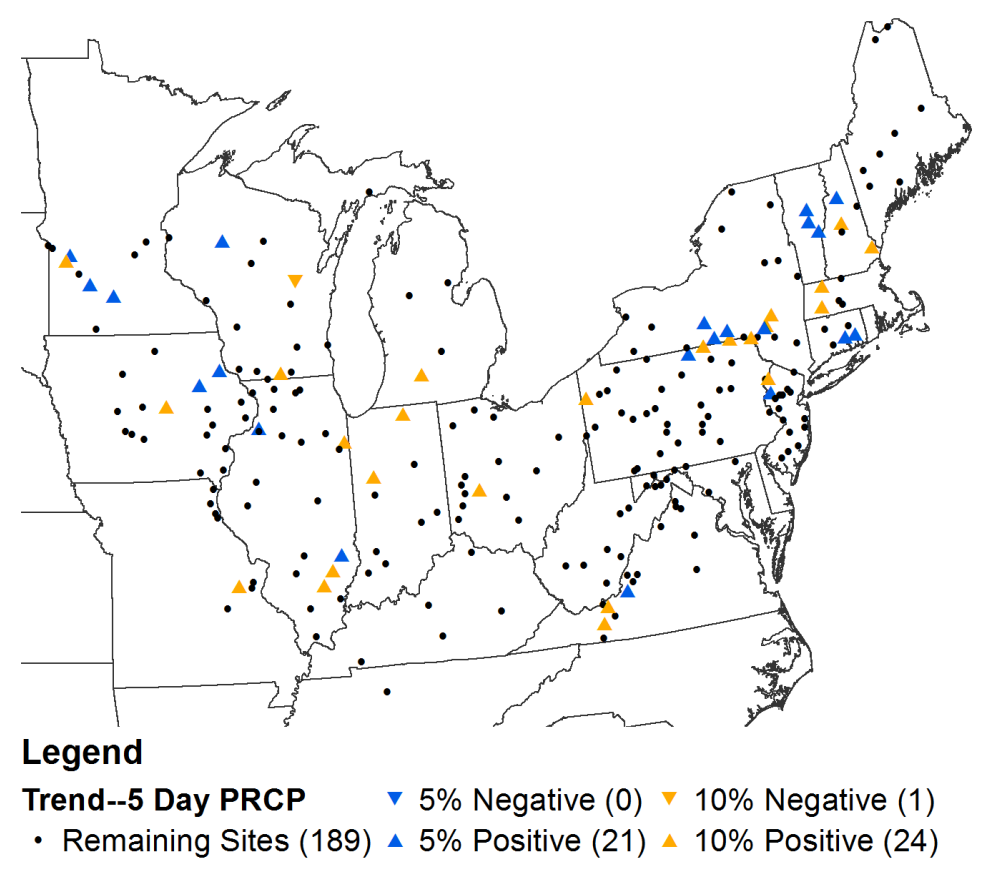

Figure 2.15 Results of Mann-Kendall trend tests on flood generating precipitation series with 5-day lead time constructed using 1/8-degree gridded data.

\subsubsection{Change-Points in Flood Generating Precipitation Series}

Pettitt change-point tests were conducted to investigate the possible presence of abrupt shifts in the mean of flood generating precipitation series with respect to time. Abrupt changes were investigated for both Categories A and B as previously described. Table 2.3 provides a summary of the number of sites where significant change-points were identified at both 5\% and 10\% significance levels for all flood generating precipitation series (2- to 7-day lead times) considered. Figure 2.16 shows results of the change-point 
tests for precipitation series with a 5 -day lead time based on 1/8-degree gridded data (Category A). Of the 235 series analyzed, a total of 62 sites exhibit a shift in the mean of their respective precipitation series. Figures showing the location of sites with significant results are provided in APPENDIX $\mathrm{C}$ for the remaining flood generating precipitation series considered in both categories.

Table 2.3

Number of sites with significant change-points in the mean of flood generating precipitation identified using the Pettitt test with 5\% and 10\% significance levels.

\begin{tabular}{|c|cc|cc|}
\hline $\begin{array}{c}\text { Lead Time } \\
\text { (days) }\end{array}$ & \multicolumn{2}{|c|}{ Category A } & \multicolumn{2}{c|}{ Category B } \\
\hline \hline 2 & $5 \%$ & $10 \%$ & $5 \%$ & $10 \%$ \\
3 & 38 & 53 & 26 & 40 \\
4 & 27 & 40 & 27 & 48 \\
5 & 32 & 55 & 24 & 47 \\
6 & 35 & 62 & 28 & 49 \\
7 & 40 & 62 & 28 & 48 \\
\hline
\end{tabular}

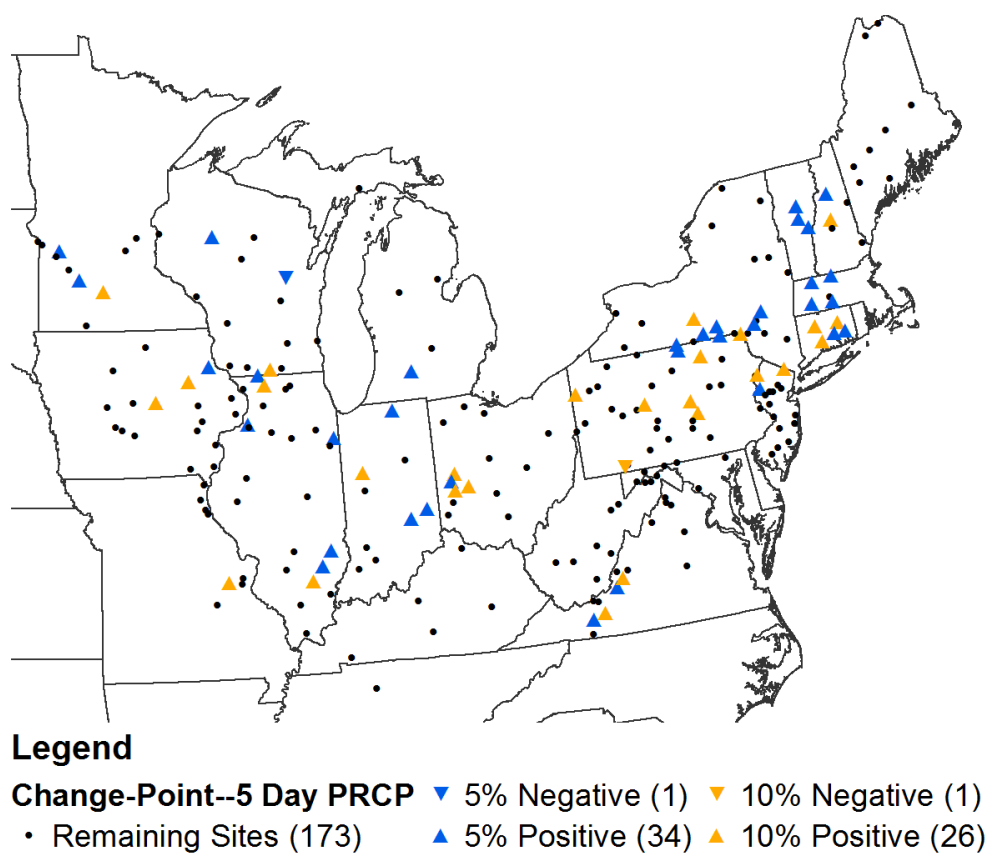

Figure 2.16 Results of Pettitt tests on flood generating precipitation series with a 5-day lead constructed using 1/8-degree gridded data. 
The results in Table 2.3 indicate that more change-points were identified on both significance levels for flood generating precipitation series in Category A than those in Category B with the same lead time, except for series with a 3-day lead for which both resolutions of data yielded the same number of significant results at the $5 \%$ level. The precipitation series with a 7-day lead exhibit the most change-points on the $10 \%$ level compared to other $\mathrm{X}$-day series considered. The increase in the number of identified shifts in the Category A series relative to Category B, as well as the differences observed in Table 2.3 with respect to trends, indicate the importance of the resolution of the data when considering nonstationarity in precipitation data.

\subsubsection{Trends in Flood Generating Temperature Series}

In response to climate change, future flood risk will likely be influenced by the potential changes in flood generating precipitation series as previously discussed, as well as possible changes in temperature. Projected increases in temperature could lead to decreased snow pack, earlier spring, and drier antecedent moisture conditions, all of which could lead to a decrease in AMF magnitude and/or a change in the timing of peak flood events. Therefore, this section summarizes results of Mann-Kendall tests conducted to investigate trends in flood-generating temperature series. Two types of temperature series (average daily maximum and average daily minimum) were constructed from 1/8-degree data with lead times of 2- to 7-days for the 235 previously described watersheds. Table 2.4 provides a summary of the number of sites where significant trends were identified at both $5 \%$ and $10 \%$ levels for all series considered. The results for average maximum temperature series indicate that the number of trends identified at the $10 \%$ level is relatively independent of the X-day lead time. On the other hand, average minimum temperature series exhibit fewer trends, both negative and positive, as $\mathrm{X}$ increases. Both average maximum and minimum temperature series show more increasing (positive) trends than decreasing (negative) trends; this is similar to the findings for trends in precipitation series. The identified increases (warming) in possible flood generating temperature is consistent with IPCC findings [2007a, 2007b]: in general 
cold days, cold nights, and frost have become less frequent, while hot days, hot nights, and heat waves have become more frequent in the U.S.

Table 2.4

Number of sites with significant trends (negative or positive) in flood generating maximum and minimum temperature series with $\mathrm{X}$-days lead times identified using Mann-Kendall tests.

\begin{tabular}{|c|c|c|c|c|}
\hline \multirow{2}{*}{$\begin{array}{c}\text { Lead Time } \\
\text { [days] }\end{array}$} & \multicolumn{2}{|c|}{$5 \%$} & \multicolumn{2}{|c|}{$10 \%$} \\
\hline & Negative & Positive & Negative & Positive \\
\hline \multicolumn{5}{|c|}{ Average Maximum Temperature } \\
\hline 2 & 2 & 17 & 3 & 27 \\
\hline 3 & 2 & 16 & 4 & 29 \\
\hline 4 & 1 & 10 & 5 & 24 \\
\hline 5 & 1 & 9 & 4 & 25 \\
\hline 6 & 1 & 13 & 3 & 28 \\
\hline 7 & 1 & 13 & 2 & 29 \\
\hline \multicolumn{5}{|c|}{ Average Minimum Temperature } \\
\hline 2 & 3 & 36 & 4 & 56 \\
\hline 3 & 4 & 35 & 4 & 61 \\
\hline 4 & 4 & 32 & 4 & 60 \\
\hline 5 & 2 & 27 & 4 & 52 \\
\hline 6 & 2 & 25 & 2 & 50 \\
\hline 7 & 2 & 24 & 3 & 47 \\
\hline
\end{tabular}

Figure 2.17 and Figure 2.18 show the locations of the streamflow gauging stations for which the Mann-Kendall test identified significant trends in the flood generating maximum and minimum temperature series with a 4-day lead time, respectively. Of the 235 series analyzed, 24 sites exhibit an upward trend in maximum temperature; only 5 sites exhibit a downward trend in maximum temperature. A greater portion of sites (60) exhibit an upward trend in minimum temperature; only 4 sites exhibit a downward trend. Overall, these results indicate a warming trend in this region, although no spatially coherent patterns or clustering of significant results are evident. Figures showing the location of sites with significant results for the remaining minimum and maximum temperatures series are provided in APPENDIX D. 


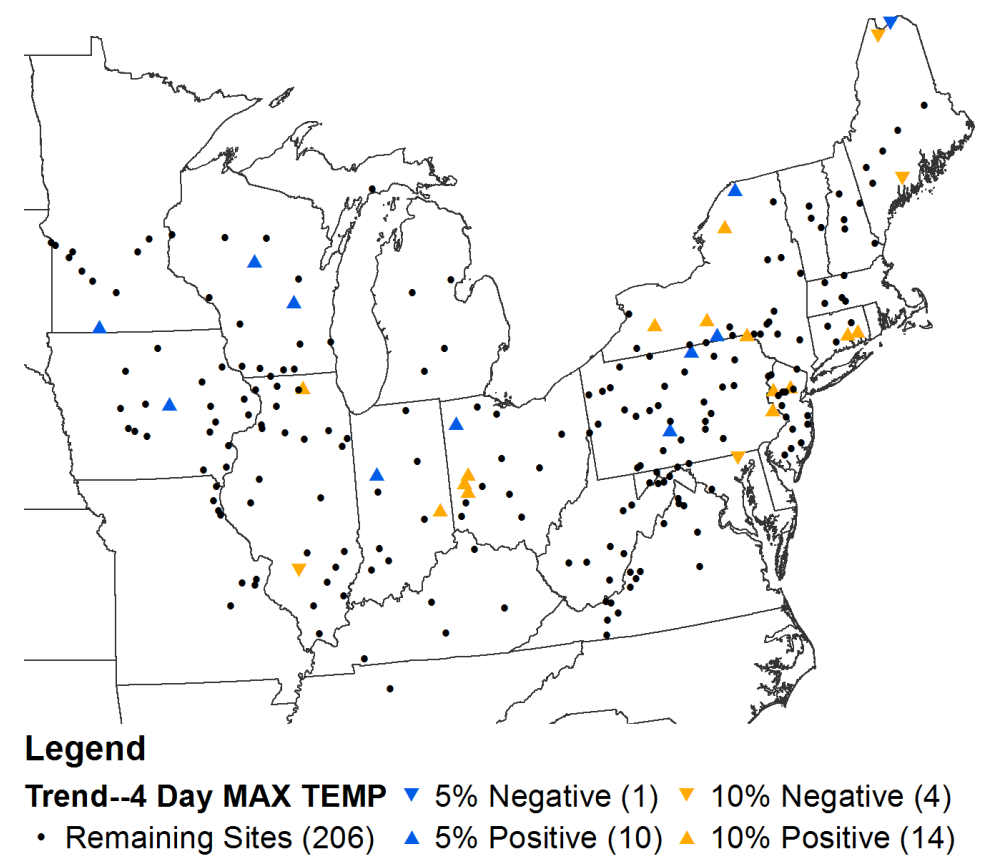

Figure 2.17 Results of Mann-Kendall tests on flood generating maximum temperature series with a 4-day lead time.

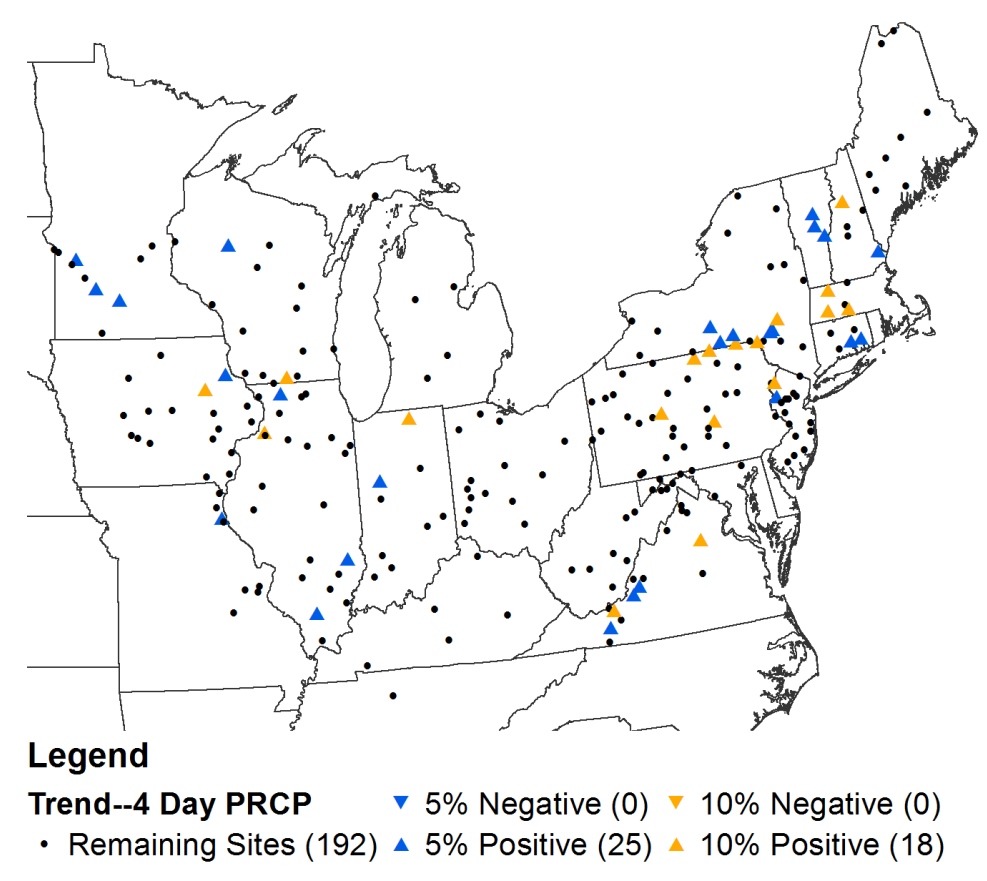

Figure 2.18 Results of Mann-Kendall tests on flood generating minimum temperature series with a 4-day lead time. 


\subsubsection{Change-Points in Flood Generating Temperature Series}

Pettitt change-point tests were conducted to investigate abrupt shifts in temperature series. Identification of a change-point would indicate an abrupt shift in the mean of the flood associated temperature series with respect to time. Both average minimum and maximum temperature flood associated series were considered as previously described. Table 2.5 provides a summary of the number of sites where significant change-points were identified at both $5 \%$ and $10 \%$ levels for all series considered (lead times of 2- to 7days). Overall, more change-points were identified for the minimum temperature series as compared to the maximum temperature series for each X-day lead time considered.

Table 2.5

Number of sites with change-points in the mean of flood associated minimum and maximum temperature series identified using the Pettitt test with 5\% and 10\% significance levels.

\begin{tabular}{|c|cc|cc|}
\hline $\begin{array}{c}\text { Lead Time } \\
\text { (days) }\end{array}$ & \multicolumn{2}{|c|}{$\begin{array}{c}\text { Minimum } \\
\text { Temperature }\end{array}$} & \multicolumn{2}{c|}{$\begin{array}{c}\text { Maximum } \\
\text { Temperature }\end{array}$} \\
& $5 \%$ & $10 \%$ & $5 \%$ & $10 \%$ \\
\hline \hline 2 & 33 & 51 & 22 & 29 \\
3 & 31 & 58 & 20 & 29 \\
4 & 29 & 49 & 13 & 28 \\
5 & 27 & 48 & 12 & 26 \\
6 & 29 & 48 & 17 & 33 \\
7 & 28 & 51 & 17 & 38 \\
\hline
\end{tabular}

Figure 2.19 and Figure 2.20 show the locations of the streamflow gauging stations where significant change-points were identified for the maximum and minimum temperature series with 4-day lead times, respectively. No spatial pattern is evident in these results. For the remaining lead times employed to define minimum and maximum temperatures series, figures showing the location of sites with significant results are provided in APPENDIX D. 


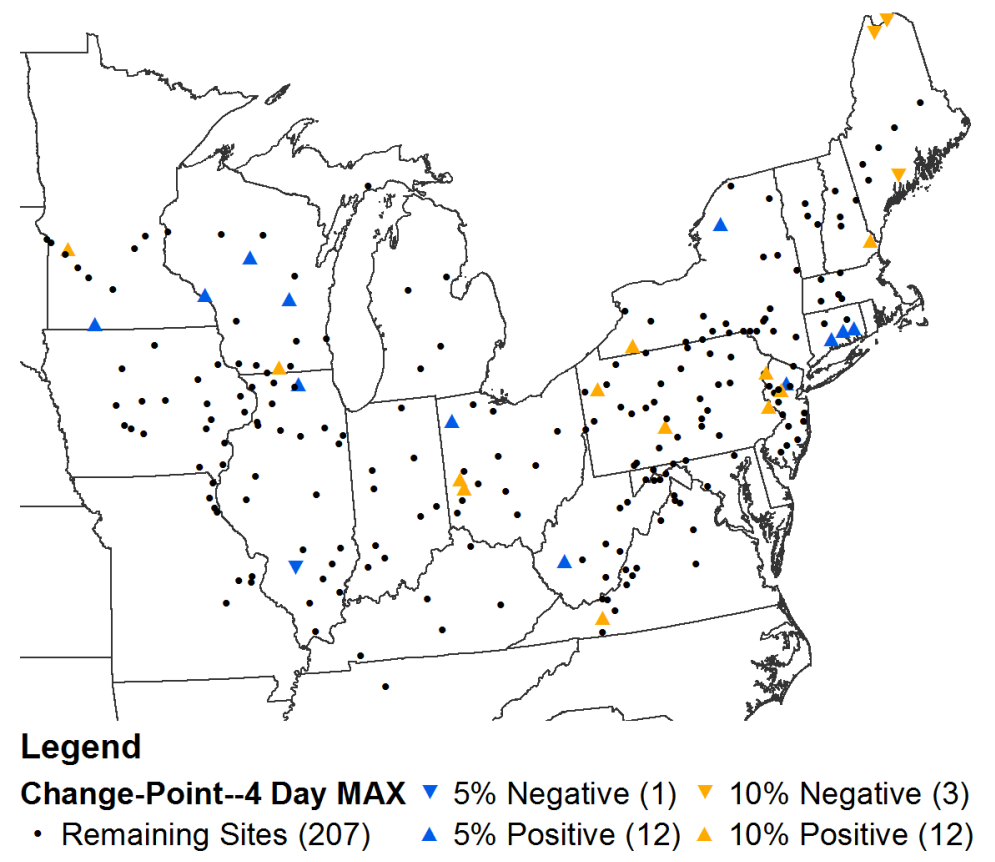

Figure 2.19 Results of Pettitt tests on flood generating maximum temperature series with a 4-day lead time.

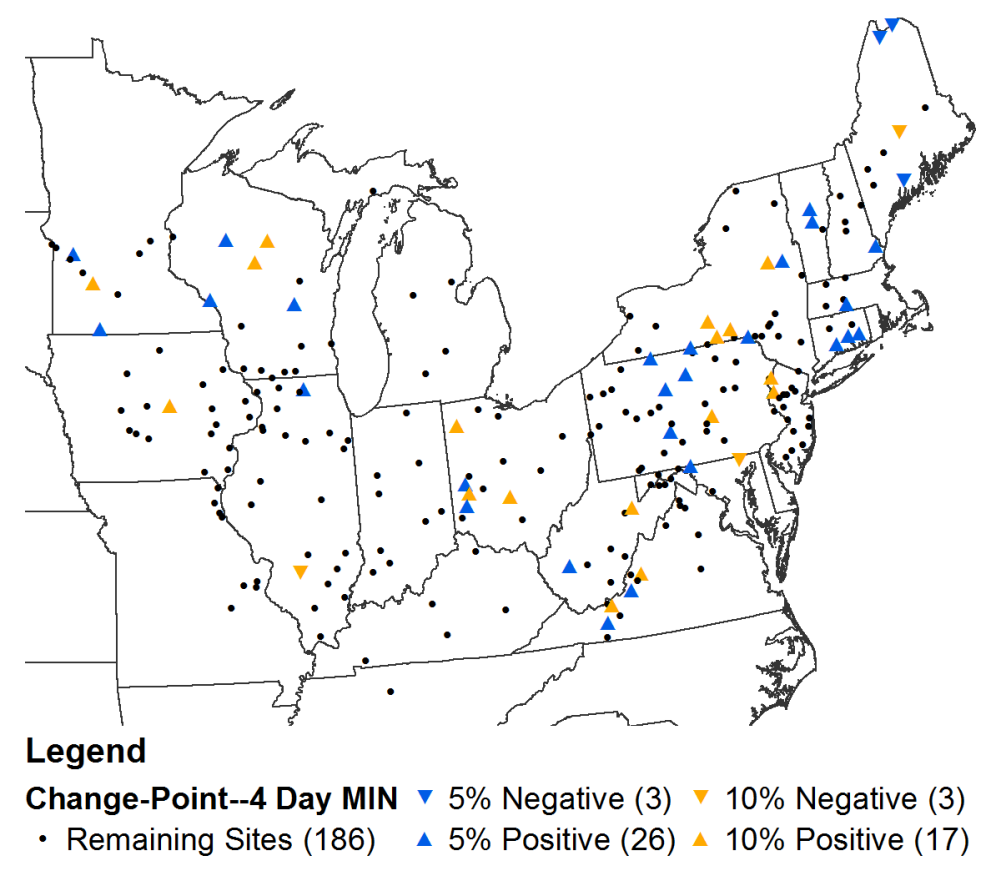

Figure 2.20 Results of Pettitt tests on flood generating minimum temperature series with a 4-day lead time. 



\section{CHAPTER 3 SOURCES OF NONSTATIONARITY IN ANNUAL MAXIMUM FLOOD SERIES}

Results presented in CHAPTER 2 reveal that some annual maximum flood (AMF) series throughout the U.S. exhibit nonstationarity in the form of monotonic trends, changepoints and/or long-term persistence. In the context of water resources applications, it is necessary to move beyond simply assessing the degree of nonstationarity in these series, to consider the driving causes of these observed changes in flood magnitude and the associated flood risk. Due to the variety of forms of nonstationarity exhibited in flood series and numerous possible climatic and human-induced causes of this nonstationarity, a mixture of statistical and inferential methods are employed herein to identify the causes of nonstationarity. Correlation analyses are used to assess the strength of association between flood series and climatic variables; correlation analyses are not conducted with respect to physical parameters (e.g., land cover and dam storage), due to the limited availability of relevant data over time. The influences of climatic shifts are assessed by comparing the timing of identified change-points in the AMF series to those of documented phase changes in oceanic-atmospheric patterns. Similar comparisons are made between the timing of change-points in AMF series and those in climatic series (precipitation and temperature), as well as documented modifications of the watershed and the channel. These results are indicative of the primary causes of nonstationarity in AMF series for unimpaired watersheds in the U.S.; however, more detailed analyses on a site specific basis are needed before this information could be used to increase the accuracy of forecasts of future flood risk.

\subsection{Methods for Evaluating Correlation}

Correlation analyses have been employed extensively in the hydrologic literature to increase understanding of the relationships between various streamflow quantities and climate parameters [e.g., Jain and Lall, 2000; Stewart et al., 2005; Tootle et al., 2005; Kashelikar, 2009]. Several studies have also investigated physical and/or climatic 
relationships with streamflow quantities by means of linear regression analyses [Changnon and Kunkel, 1995; Changnon and Demissie, 1996; Olsen et al., 1999; Regonda et al., 2005], for which the significance of model coefficients is based on the strength of the correlation between the response variable and each independent variable. In general, these analyses reveal trends and patterns amongst climate/meteorological parameters common to those identified in streamflow series. To investigate the relationship between climate variables and flood magnitude, three common measures of correlation-Pearson's r, Kendall's tau, and Spearman's rho - are employed herein to measure the strength of association between the variables. These methods are described in further detail below.

\subsubsection{Pearson's Correlation}

The most common measure of dependence is Pearson's correlation coefficient, $\rho_{X Y}$, which measures the degree of linear correlation between two variables $\mathrm{X}$ and $\mathrm{Y}$. The correlation coefficient ranges from -1 (strong negative correlation) to +1 (strong positive correlation); $\rho_{X Y}=0$ when no discernible linear relationship exists between the two variables. The equation describing the linear relationship between $\mathrm{X}$ and $\mathrm{Y}$ can be obtained by performing a regression analysis. The correlation coefficient is calculated as:

$$
\rho_{X Y}=\frac{\operatorname{cov}(X, Y)}{\sigma_{X} \sigma_{Y}}
$$

where $\operatorname{cov}(X, Y)$ is the covariance between the two variables, and $\sigma_{X}$ and $\sigma_{Y}$ are the standard deviations of $\mathrm{X}$ and $\mathrm{Y}$, respectively. Pearson's correlation is a dimensionless value and is invariant to changes in units of either variable. However, this measure of correlation is sensitive to outliers, and is not robust if $\mathrm{X}$ and $\mathrm{Y}$ exhibit a nonlinear relationship [Helsel and Hirsch, 2002].

The Pearson product-moment correlation coefficient ( $\mathrm{r}$ ) is a maximum likelihood estimator of $\rho_{X Y}$, and is calculated as:

$$
\mathrm{r}=\frac{\sum_{\mathrm{i}=1}^{\mathrm{n}}\left(x_{i}-\bar{x}\right)\left(y_{i}-\bar{y}\right)}{\left[\sum_{\mathrm{i}=1}^{\mathrm{n}}\left(x_{i}-\bar{x}\right)^{2} \sum_{\mathrm{i}=1}^{\mathrm{n}}\left(y_{i}-\bar{y}\right)^{2}\right]^{1 / 2}}
$$


where $x_{i}$ and $y_{i}$ are the values of the $\mathrm{i}^{\text {th }}$ observations, $\bar{x}$ and $\bar{y}$ are the sample means of $\mathrm{X}$ and $\mathrm{Y}$, respectively, and $\mathrm{n}$ is the number of concurrent observations within the dataset. The significance of the observed correlation (pattern) is assessed by means of a twotailed hypothesis test to determine if the correlation is statistically different from zero. The test assumes the data follows a bivariate normal distribution, and thus the test statistic follows a t-distribution with $\mathrm{n}-2$ degrees of freedom. The test statistic is calculated as:

$$
t^{*}=r \sqrt{\frac{n-2}{1-r^{2}}}
$$

The null hypothesis that $\rho_{X Y}=0$ (no linear relationship between $\mathrm{X}$ and $\mathrm{Y}$ ) is rejected if $\left|t^{*}\right| \geq t_{\frac{\alpha}{2}, n-2}$, or if the associated $\mathrm{p}$-value is less than the desired significance level $\alpha$. Additional details of the Pearson correlation test are provided by Helsel and Hirsch [2002].

\subsubsection{Kendall's Tau Correlation}

Kendall's tau $(\tau)$ is a non-parametric measure of the degree of monotonic correlation, whether linear or nonlinear, between two variables, $\mathrm{X}$ and $\mathrm{Y}$. The Kendall $\tau$ coefficient depends only on the ranks of the data, not the actual observed values. As such, $\tau$ is resistant to the effects of outliers, and is not affected by power transformations of one or both variables. These properties of Kendall's tau make it more powerful than the Pearson's correlation coefficient for use in discerning the strength of relationships between two variables.

The $\tau$ coefficient is computed as a function of the degree of agreement/disagreement amongst pairs of observations $\left(\mathrm{x}_{\mathrm{i}}, \mathrm{y}_{\mathrm{i}}\right)$ and $\left(\mathrm{x}_{\mathrm{j}}, \mathrm{y}_{\mathrm{j}}\right)$. Agreement, or concordance, among pairs is observed when the ranks of $y$ increase (or decrease) with the ranks of x. Conversely, disagreement, or discordant pairs are those in which the ranks of $y$ decrease as those of $x$ increase, or vice versa. The test statistic $\mathrm{S}$, which measures the monotonic dependence of 
$\mathrm{Y}$ on $\mathrm{X}$, and is computed by taking the difference between the number of discordant pairs (M) and the number of concordant pairs $(\mathrm{P})$ :

$$
S=P-M
$$

The $\tau$ coefficient is then calculated as follows:

$$
\tau=\frac{S}{n(n-1) / 2}
$$

where $\mathrm{n}$ is the sample size, and the denominator represents the total number of pairs. As with Pearson's r, Kendall's $\tau$ must be in the range $(-1,+1)$ where $\tau=+1$ for perfect agreement, $\tau=-1$ for perfect disagreement, and $\tau=0$ when $\mathrm{X}$ and $\mathrm{Y}$ are independent [Helsel and Hirsch, 2002].

The significance of $\tau$ is evaluated using a two-tailed hypothesis test to determine if $\mathrm{S}$ (and thus $\tau$ )is statistically different from zero. For $\mathrm{n}$ greater than $10, \mathrm{~S}$ is transformed to define a standard normal $\mathrm{Z}$ statistic as follows:

$$
Z= \begin{cases}(S-1) / \sigma_{S} & \text { if } S>0 \\ 0 & \text { if } S=0 \\ (S+1) / \sigma_{S} & \text { if } S<0\end{cases}
$$

where

$$
\sigma_{s}^{2}=\frac{n(n-1)(2 n+5)}{18}
$$

in the instance that no ties are observed. When data values are tied, the following correction is applied to $\sigma_{s}^{2}$ :

$$
\sigma_{s}^{2}=\frac{n(n-1)(2 n+5)-\sum_{i=1}^{n} t_{i}(i)(i-1)(2 i+5)}{18}
$$

where $t_{i}$ symbolizes the number of ties of extent $i$. 
A significant measure of correlation is apparent in a time series when the absolute value of $Z$ computed using equation (21) is greater than $z_{\alpha / 2}=\phi^{-1}(1-\alpha / 2)$ for a desired significance level $(\alpha)$, and the null hypothesis that $\mathrm{S}=0$ is rejected. Additional details of the Kendall's correlation test are provided by Helsel and Hirsch [2002].

\subsubsection{Spearman's Rho Correlation}

An alternative non-parametric measure of correlation (linear or nonlinear) between two variables is Spearman's rho. As with Kendall's tau, Spearman's rho is a function of the ranks of the data, and thus is resistant to the effects of outliers. However, where Kendall's tau ignores the magnitude of differences between data pairs, Spearman's rho weights differences between data values ranked further apart more heavily. Ranks are assigned to the observations comprising each set of variables ( $\mathrm{X}$ and $\mathrm{Y}$ ) separately. Spearman's rho is then calculated as:

$$
\text { rho }=\frac{\sum_{i=1}^{n}\left(R x_{i} R y_{i}\right)-n\left(\frac{n+1}{2}\right)^{2}}{n\left(n^{2}-1\right) / 12}
$$

where $R x_{i}$ and $R y_{i}$ are the ranks of observations $\mathrm{x}_{\mathrm{i}}$ and $\mathrm{y}_{\mathrm{i}}$, respectively, $(n+1) / 2$ is the mean rank of both $\mathrm{X}$ and $\mathrm{Y}$ given a set of $\mathrm{n}$ concurrent observations, and the denominator reflects their variance.

Spearman's rho can be interpreted as Pearson's linear correlation coefficient computed based on the ranks of the data, instead of the data values themselves. As such, the significance of rho can be assessed using a two-tailed hypothesis test using the test statistic presented in equation (18) [Helsel and Hirsch, 2002]. Alternative formulations of the test statistic - exact and large sample approximations - for Spearman's rho are presented by Bhattacharyya and Johnson [1977]. Unfortunately, these approximations do not work well for small samples ( $<20$ ), and thus use of Kendall's tau is typically preferred over Spearman's rho [Helsel and Hirsch, 2002]. As such, the discussions below focus on analysis of results using Kendall's tau correlations. 


\subsection{Climatic Causes of Nonstationarity}

Cyclical patterns in flood series, whether evident in the historical flood record, or part of some unforeseen long-term persistence, could result from variation in the large-scale climate forcing of oceanic-atmospheric patterns, such as the Atlantic Multidecadal Oscillation (AMO), El Nino-Southern Oscillation (ENSO), North Atlantic Oscillation (NAO), or Pacific Decadal Oscillation (PDO). Correlation analyses, as described above, were performed herein to investigate these possible teleconnections with AMF series. These results provide insight as to how current methodologies for assessing flood risk could be updated in view of possible climate change, as discussed in greater detail in Chapter 4.

The strength of teleconnections with AMF series throughout the contiguous U.S. are assessed below using output of correlation analyses performed for two general categories of data:

Category A: 10-year moving averages of the log-transformed flood peaks and associated 3-month averaged climate indices representing AMO, ENSO, NAO, and PDO with 3-, 6-, and 9-month leads relative to the most common month of flood peak occurrence.

Category B: 10-year moving standard deviations of the log-transformed flood peaks and associated 3-month averaged climate indices representing AMO, ENSO, NAO, and PDO with 3-, 6-, and 9-month leads relative to the most common month of flood peak occurrence.

In both categories, moving windows are defined over the time period 1942 to 2010, such that the first 10-year window is computed using data from 1942 to 1951 . The correlation analyses consider the relationship between the value of the mean or standard deviation computed using AMF peaks within the 10-year window ending in year $t$ and the associated climate index with a lead time relative to year $t$. Sources for monthly climate index anomalies (available for the period 1950-2010) used herein are shown in Table 3.1. The smoothed time series resulting from use of a 10-year moving window reduces 
(filters) the effects of random variations, thereby allowing for trends and/or cyclical patterns to be more easily distinguished. The 10-year interval in particular was chosen for two primary reasons: (1) shorter time intervals were not sufficient to clearly show trends or cyclical patterns, whereas longer windows result in too much dampening of the signal, and (2) the 10-year window is commensurate with climate patterns that follow cyclical patterns on decadal scales (e.g., AMO, PDO). Similarly, for each climate pattern, a three-month average of the relevant climate anomalies leading the AMF peak in year $t$ was used to reduce effects of random monthly variations in respective indices.

Table 3.1

Sources of climatic indices used to identify teleconnections with flood flows.

\begin{tabular}{cl}
\hline \multicolumn{1}{c}{ Parameters } & \multicolumn{1}{c}{ Source } \\
\hline \hline \multirow{2}{*}{ AMO anomalies } & $\begin{array}{l}\text { NOAA Earth System Research Laboratory } \\
\text { http://www.esrl.noaa.gov/psd/data/timeseries/AMO/ }\end{array}$ \\
\hline MEI anomalies & $\begin{array}{l}\text { NOAA Earth System Research Laboratory } \\
\text { http://www.esrl.noaa.gov/psd/enso/mei/table.html }\end{array}$ \\
\hline NINO3.4 anomalies & $\begin{array}{l}\text { NOAA Earth System Research Laboratory } \\
\text { http://www.esrl.noaa.gov/psd/data/climateindices/list/ }\end{array}$ \\
\hline NAO anomalies & $\begin{array}{l}\text { NOAA Earth System Research Laboratory Prediction } \\
\text { http://www.cpc.ncep.noaa.gov/data/teledoc/nao.shtml }\end{array}$ \\
\hline \multirow{2}{*}{ PDO anomalies } & $\begin{array}{l}\text { Joint Institute for the Study of the Atmosphere and Oceans, } \\
\text { University of Washington } \\
\text { http://www.atmos.washington.edu/ mantua/abst.PDO.html }\end{array}$ \\
\hline
\end{tabular}

Similar analyses were performed by Kashelikar [2009], wherein relationships between oceanic-atmospheric patterns and flood series were assessed using Pearson's correlation coefficients computed using the observed magnitude of the flood peaks (real space), as well as the base-10 logarithmically transformed flood peaks (log space). The latter case is of interest as the standard guidelines employed for flood frequency analysis in the U.S. [IACWD, 1982] employ parameter values computed as a function of the log-transformed data. Kashelikar [2009] observed that the tests in both real space and log space produce similar results, and thus herein, correlations are investigated using only the logtransformed flood flows. It should be noted that the results provided by Kashelikar [2009] provide a more direct measure of how oceanic-atmospheric patterns influence flood risk in that she considered the correlation between the magnitude of flood peaks 
and the associated climate indices with lead times relative to the actual date of flood peak occurrence. Herein, lead times are relative to the most common month of flood peak occurrence at a given site so that results can be used to improve one-year ahead forecasts of flood risk, wherein the actual date on which the flood peak will occur is unknown. The subsection below provides additional details for the selection of the mode month of flood peak occurrence as the baseline.

\subsubsection{Frequency of Annual Maximum Discharge}

To broaden current understanding of the timing of AMF peaks, a total of 14,835 AMF series across the U.S. (Figure 3.1) with a minimum 12 years of record were used to construct general frequency maps indicating the probability of a flood peak occurring within a given month/season. Figure 3.2 shows the general distribution of the most common (mode) month of occurrence of AMF peaks across the U.S. upon which lead times of climate indices for correlation analyses presented below, and subsequent models to forecast flood risk (CHAPTER 4), will be based. Figure 3.3 shows the frequency with which AMF peaks occur during the identified mode month of occurrence. Comparison of Figure 3.2 and Figure 3.3 suggests that the mode month of occurrence may not be the most appropriate baseline throughout the Eastern and South Central portions of the U.S. This may be due to the presence of a bimodal distribution in the time of occurrence (i.e., AMF peaks caused by multiple flood generating mechanisms).

To determine the extent to which bimodality exists, the frequencies of AMF peaks occurring within three-month seasons (Dec-Jan-Feb, Mar-Apr-May, Jun-July-Aug, SepOct-Nov) were evaluated (Figure 3.4). Comparison of results across the four seasons suggests that the distribution for the time of flood peak occurrence is reasonably unimodal in many areas of the U.S. Although future floods may occur one month prior to or following the identified mode month, it is anticipated that use of a three-month average climate index as an indicator of flood risk would help offset these discrepancies. However, in the Eastern U.S. where floods tend to be generated by spring rains and fall hurricanes with relatively equal frequency, basing correlation analyses on the mode month of occurrence may not be the most appropriate procedure to follow. Future 
developments of the flood risk forecasting framework proposed in CHAPTER 4 should include methods to account for this bimodality.

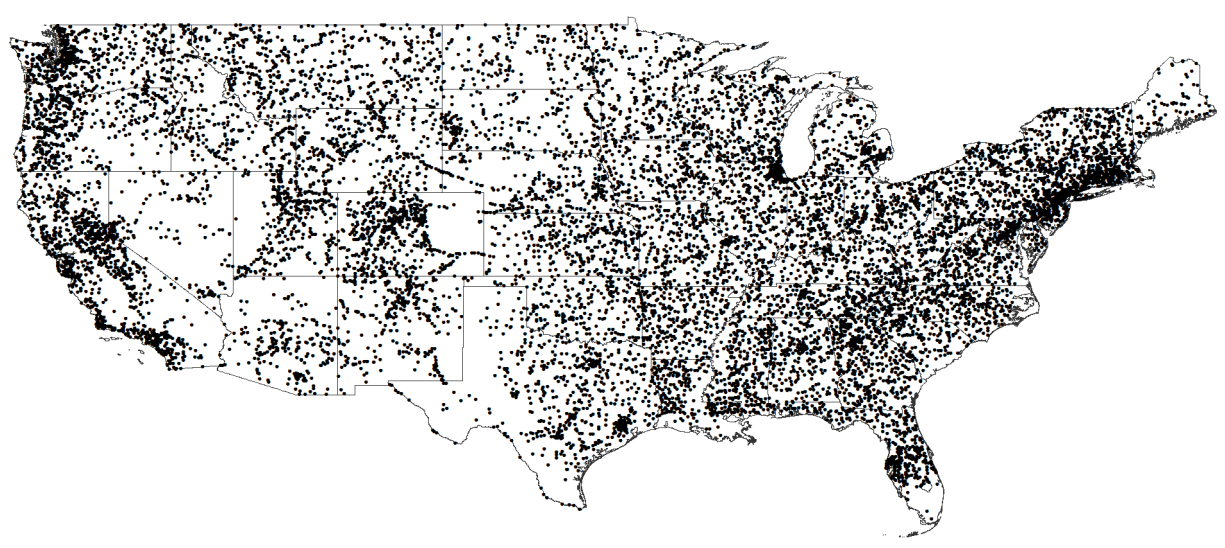

Figure 3.1 Location of 14,835 USGS stations with a minimum 12 years of AMF record.

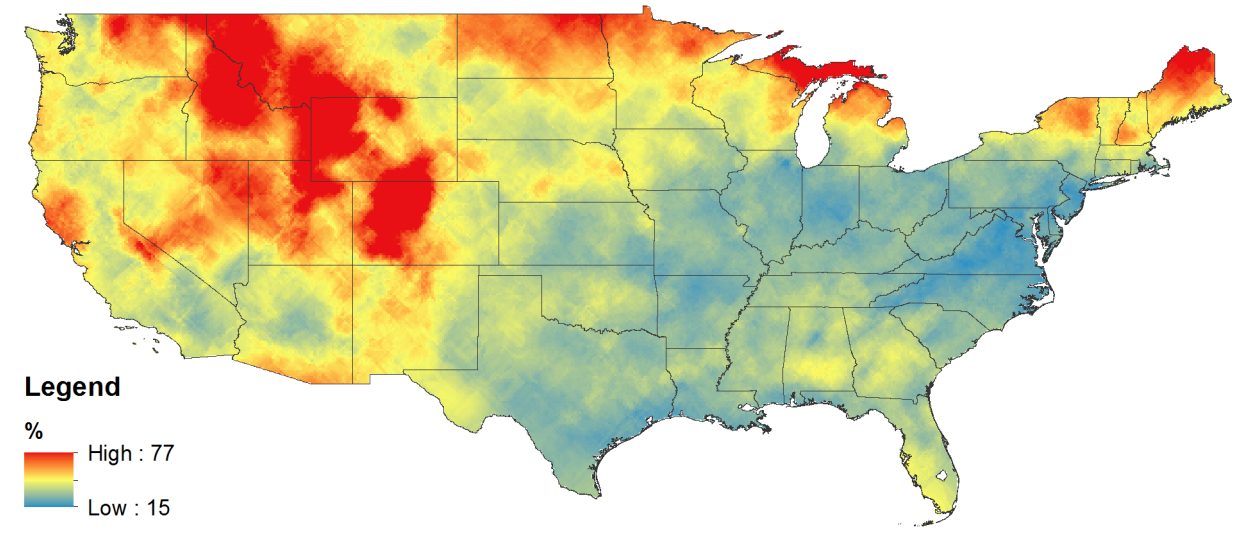

Figure 3.2 Most common (mode) month of occurrence of AMF peaks.

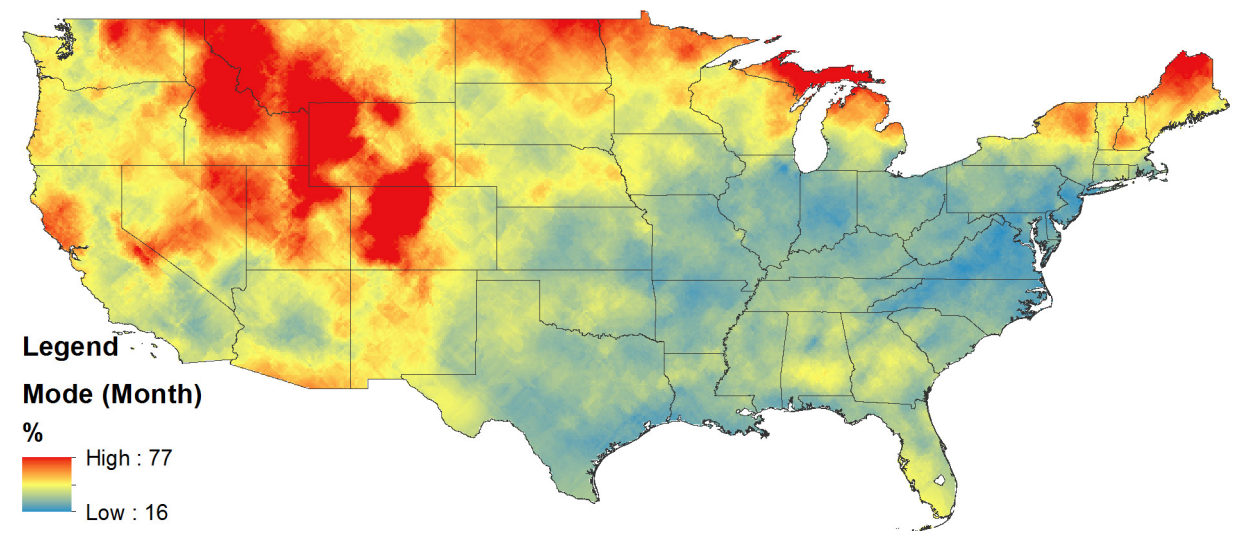

Figure 3.3 Frequency of occurrence of AMF peaks in identified mode month. 
A.

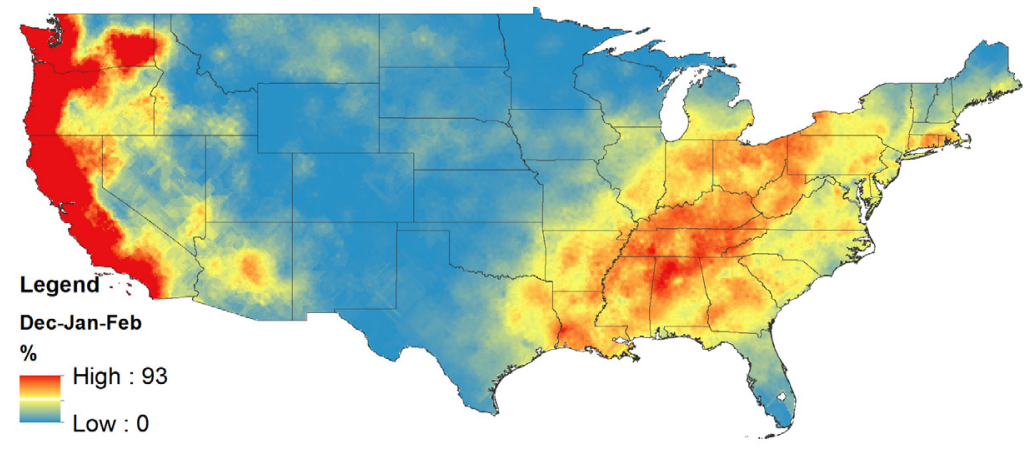

B.

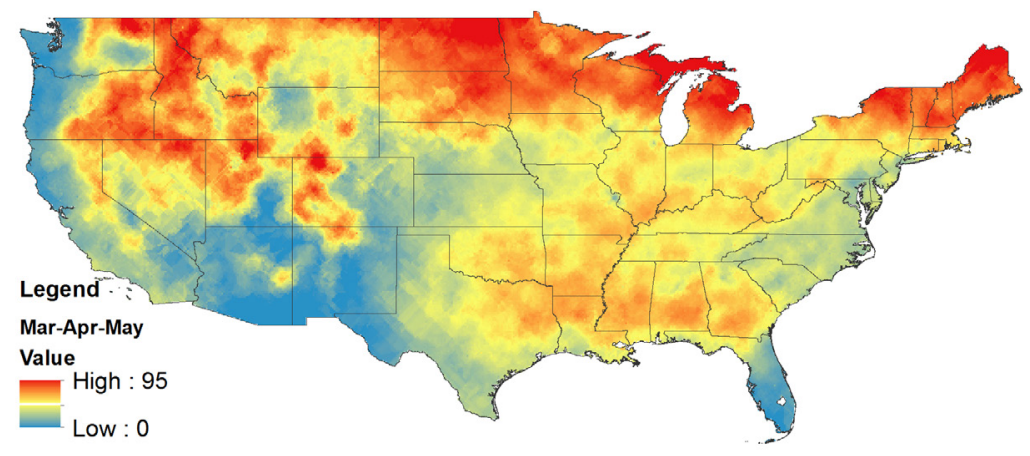

C.

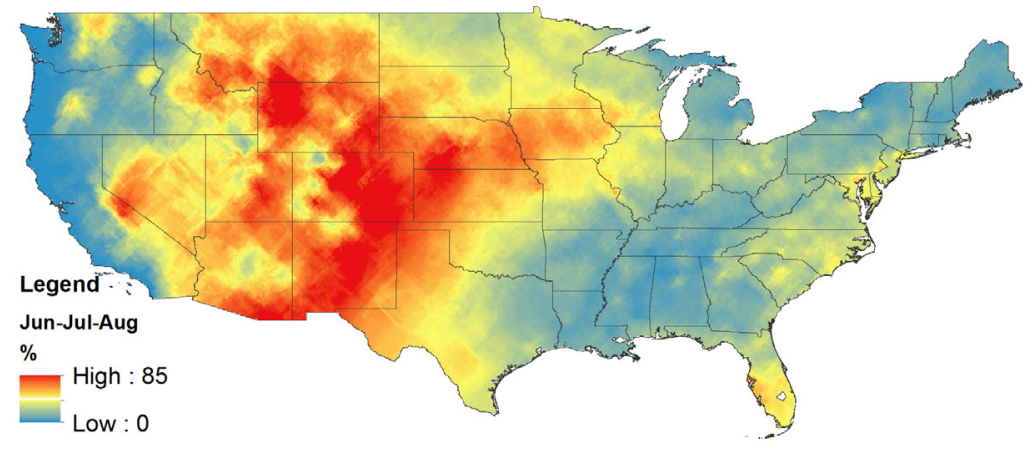

D.

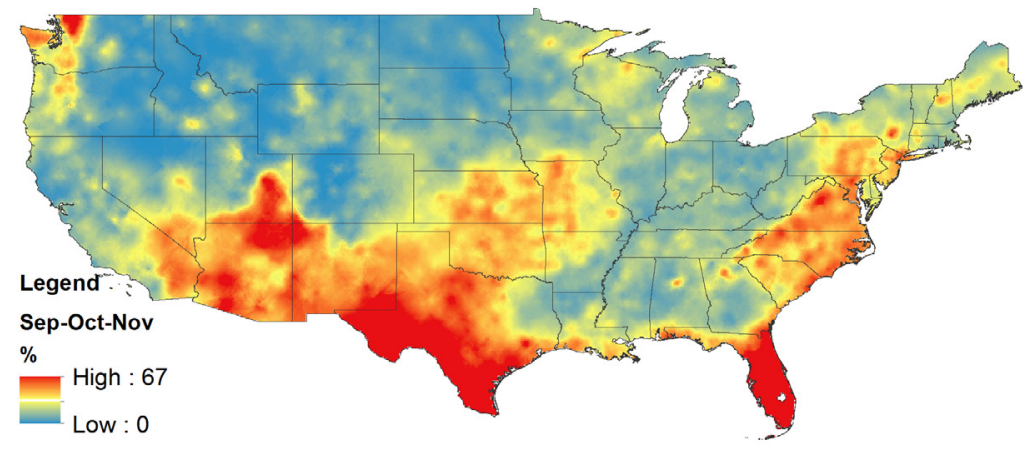

Figure 3.4 Combined frequency of occurrence of AMF peaks in three month seasons (A. Dec-Jan-Feb, B. Mar-Apr-May, C. JunJuly-Aug, D. Sep-Oct-Nov). 


\subsubsection{Evaluation of Teleconnections with Flood Flows}

Overall, fifteen cases were considered within each category (A and B), resulting from use of three lead times (3-, 6-, and 9-months) for each of the five climatic indices used in this study: AMO, NAO, PDO, MEI, and NINO 3.4. The latter two indices are both indicators of ENSO. All three common measures of correlation-Pearson's r, Kendall's tau, and Spearman's rho-were applied for each of the 569 sites in Figure 2.3. However, only results for Kendall's tau are discussed herein, as it is generally considered more robust than Spearman's rho, and is more powerful than Pearson's r. Table 3.2 and Table 3.3 summarize the number of sites where significant results were obtained using Kendall's tau at both $5 \%$ and $10 \%$ levels for all cases under consideration in Categories $\mathrm{A}$ and $\mathrm{B}$, respectively. These results reveal that strong relationships between AMF series and Nino3.4 anomalies are nonexistent; however, MEI shows a much stronger relationship with AMF series. Results of the Kendall's tau tests for each category are discussed in more detail below. Additional results for Kendall's tau, as well as those for the Spearman's rho and Pearson's $r$ tests, are provided in APPENDIX E and APPENDIX F for Categories A and B, respectively. Caution should be used when viewing these results as the correlation coefficient is a quality measure of the direction of the relationships between variables under consideration; however, by no means does it indicate a causal relationship.

Table 3.2

Number of sites with significant Kendall's tau correlation (5 and 10\% levels) between 10-year moving average of log-transformed flood peaks and AMO, MEI, NINO 3.4, $\mathrm{NAO}$, and PDO indices with specified lead times.

\begin{tabular}{|c|cc|cc|cc|cc|cc|}
\hline Lead Time & \multicolumn{2}{|c|}{ AMO } & \multicolumn{2}{c|}{ MEI } & \multicolumn{2}{c|}{ Nino 3.4 } & \multicolumn{2}{c|}{ NAO } & \multicolumn{2}{c|}{ PDO } \\
(months) & $5 \%$ & $10 \%$ & $5 \%$ & $10 \%$ & $5 \%$ & $10 \%$ & $5 \%$ & $10 \%$ & $5 \%$ & $10 \%$ \\
\hline 3 & 226 & 265 & 43 & 87 & 1 & 7 & 97 & 135 & 175 & 230 \\
6 & 224 & 271 & 64 & 130 & 8 & 24 & 39 & 83 & 192 & 253 \\
9 & 184 & 243 & 126 & 186 & 11 & 43 & 51 & 80 & 232 & 286 \\
\hline
\end{tabular}


Table 3.3

Number of sites with significant Kendall's tau correlation (5 and 10\% levels) between 10-year moving standard deviation of log-transformed flood peaks and AMO, MEI, NINO 3.4, NAO, and PDO indices with specified lead times.

\begin{tabular}{|c|cc|cc|cc|cc|cc|}
\hline Lead Time & \multicolumn{2}{|c|}{ AMO } & \multicolumn{2}{c|}{ MEI } & \multicolumn{2}{c|}{ Nino 3.4 } & \multicolumn{2}{c|}{ NAO } & \multicolumn{2}{c|}{ PDO } \\
(months) & $5 \%$ & $10 \%$ & $5 \%$ & $10 \%$ & $5 \%$ & $10 \%$ & $5 \%$ & $10 \%$ & $5 \%$ & $10 \%$ \\
\hline \hline 3 & 228 & 285 & 40 & 72 & 3 & 8 & 75 & 102 & 153 & 198 \\
6 & 232 & 280 & 46 & 94 & 6 & 18 & 26 & 47 & 174 & 220 \\
9 & 198 & 246 & 100 & 148 & 16 & 36 & 38 & 77 & 198 & 246 \\
\hline
\end{tabular}

The results in Table 3.2 suggest that the mean of the log-transformed flood peaks (Category A) could be modeled as variable over time, expressed as functions of the 3month averaged AMO, MEI, NAO, and PDO indices with 6-, 9-, 3-, and 9-month lead times, respectively. For these four cases, the spatial representation of sites for which significant correlations were obtained are illustrated in the figures below. Figures illustrating results for other cases (lead times) considered, as well as with the Nino3.4 anomalies, are provided in APPENDIX E. Both AMO and PDO anomalies show significant relationships with AMF peaks across the U.S., as illustrated in Figure 3.5 and Figure 3.8, respectively. Significant relationships between the MEI anomalies and AMF peaks are also evident throughout the U.S. (Figure 3.6), although the teleconnections with ENSO are not as strong as for AMO and PDO, with fewer sites overall exhibiting significant correlations with MEI. Figure 3.7 suggests more regionally coherent teleconnections exist with NAO in the Pacific Northwest, South Central, and New England portions of the U.S. In general, these results suggest that teleconnections could be used to at least partially explain observed trends and/or possible cyclical behavior in AMF series. 


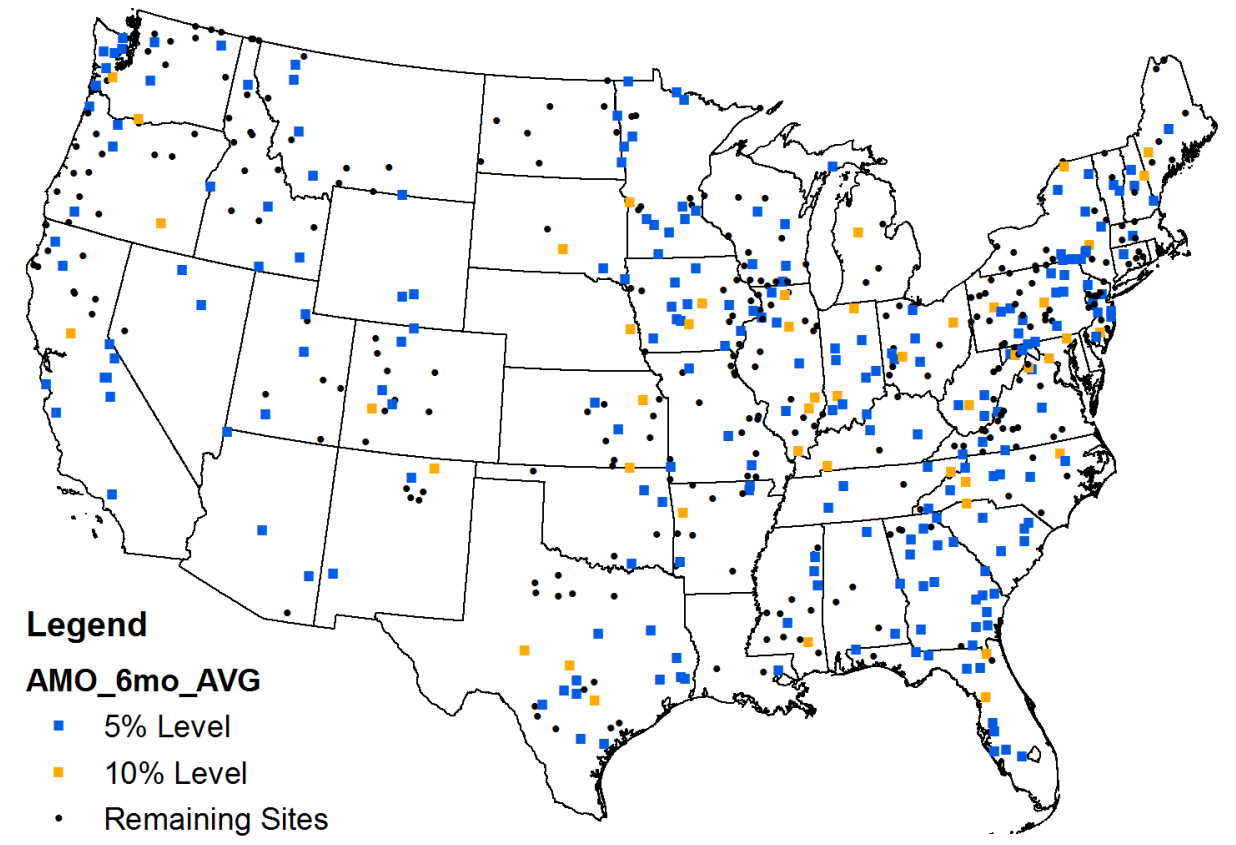

Figure 3.5 Locations of sites with significant correlation between 10-year moving average of log-transformed flood flows and 3-month average AMO anomalies with 6month lead.

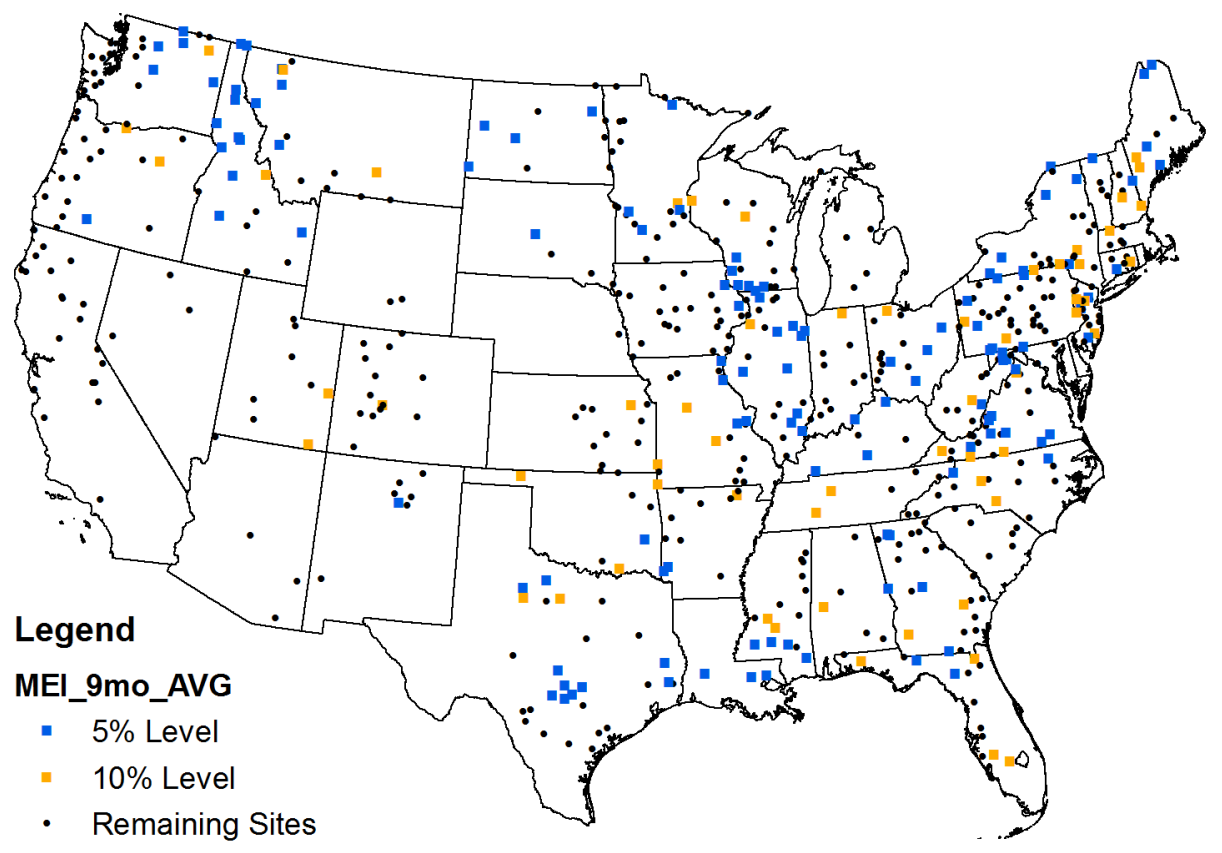

Figure 3.6 Locations of sites with significant correlation between 10-year moving average of log-transformed flood flows and 3-month average MEI anomalies with 9month lead. 


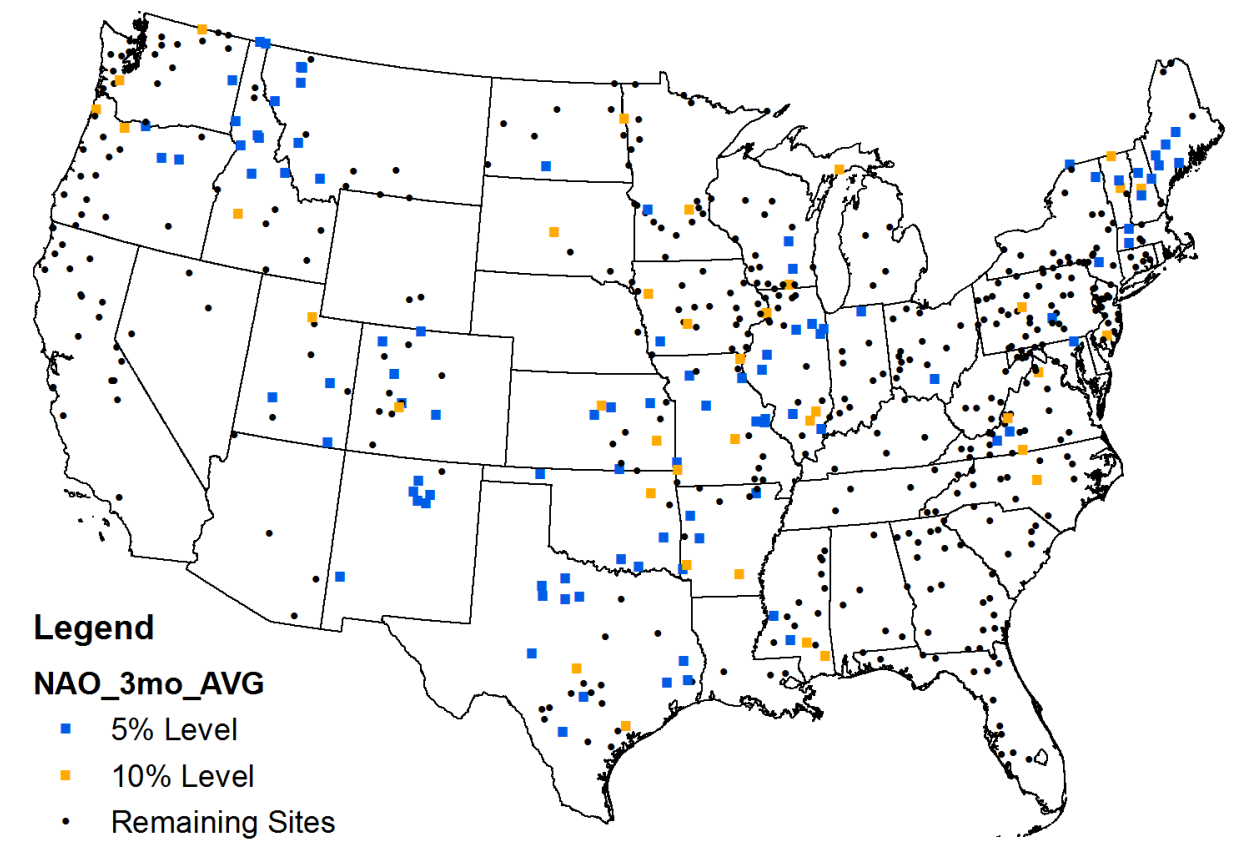

Figure 3.7 Locations of sites with significant correlation between 10-year moving average of log-transformed flood flows and 3-month average NAO anomalies with 3month lead.

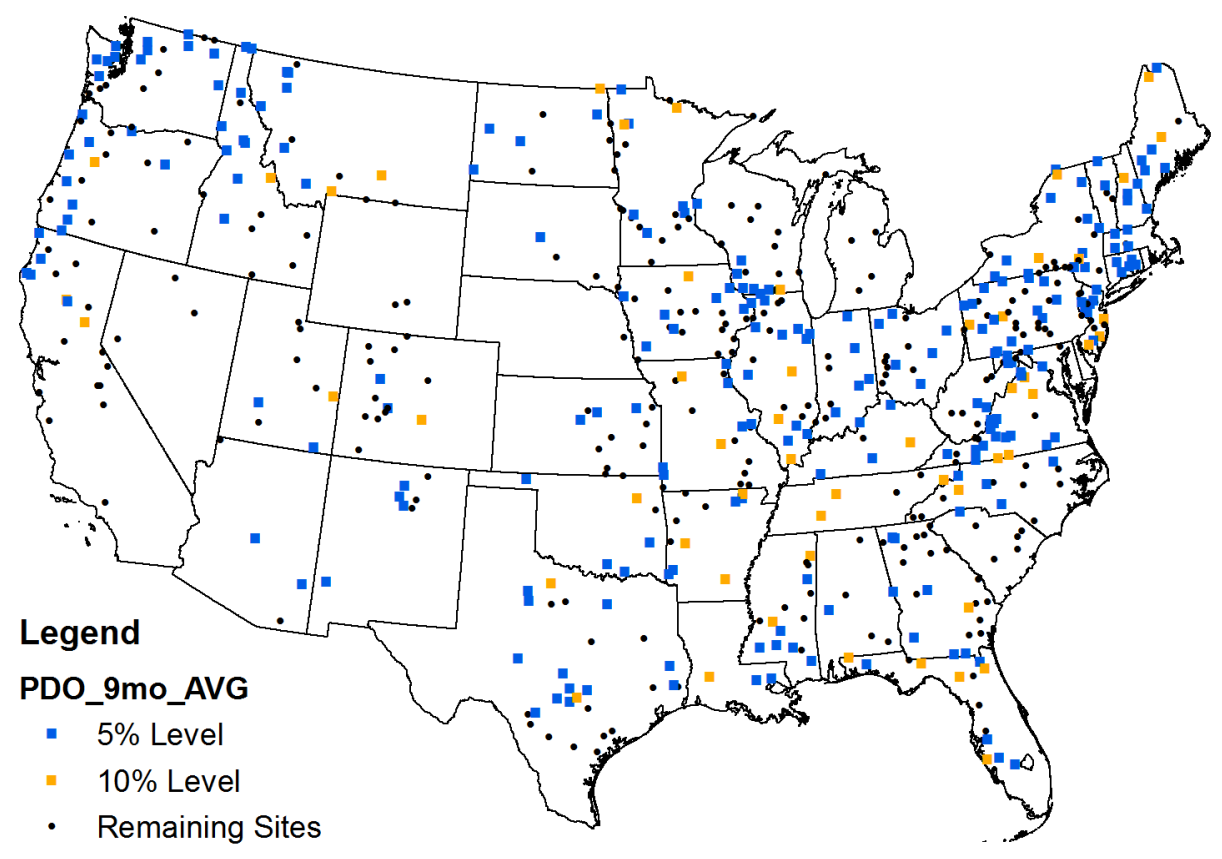

Figure 3.8 Locations of sites with significant correlation between 10-year moving average of log-transformed flood flows and 3-month average PDO anomalies with 9month lead. 
With respect to Category $\mathrm{B}$, the results in Table 3.2 suggest that the standard deviation of the log-transformed flows could be modeled as variable over time, expressed as a function of the 3-month averaged AMO, MEI, NAO, and PDO indices with 3-, 9-, 3-, and 9-month lead times, respectively. Except for AMO, the selected lead times are consistent with those for the 10-year moving averages. For these four cases, the spatial representation of sites for which significant correlations were obtained are illustrated in the figures below. Figures illustrating results for other cases (lead times) considered, as well as with the Nino3.4 anomalies, are provided in APPENDIX F. As was observed for the mean, both AMO and PDO anomalies show significant relationships with the variability in AMF series for sites across the U.S., as shown in Figure 3.9 and Figure 3.12, respectively. Significant relationships between the MEI anomalies and AMF peaks are also evident throughout the U.S. (Figure 3.10), although again, the teleconnections with ENSO are not as strong as for AMO and PDO, with fewer sites overall exhibiting significant correlations. Overall, the strength of teleconnections between NAO and the standard deviation (Figure 3.11) do not appear to be as strong, and certainly not as regionally coherent, as the results for the mean (Figure 3.7). 


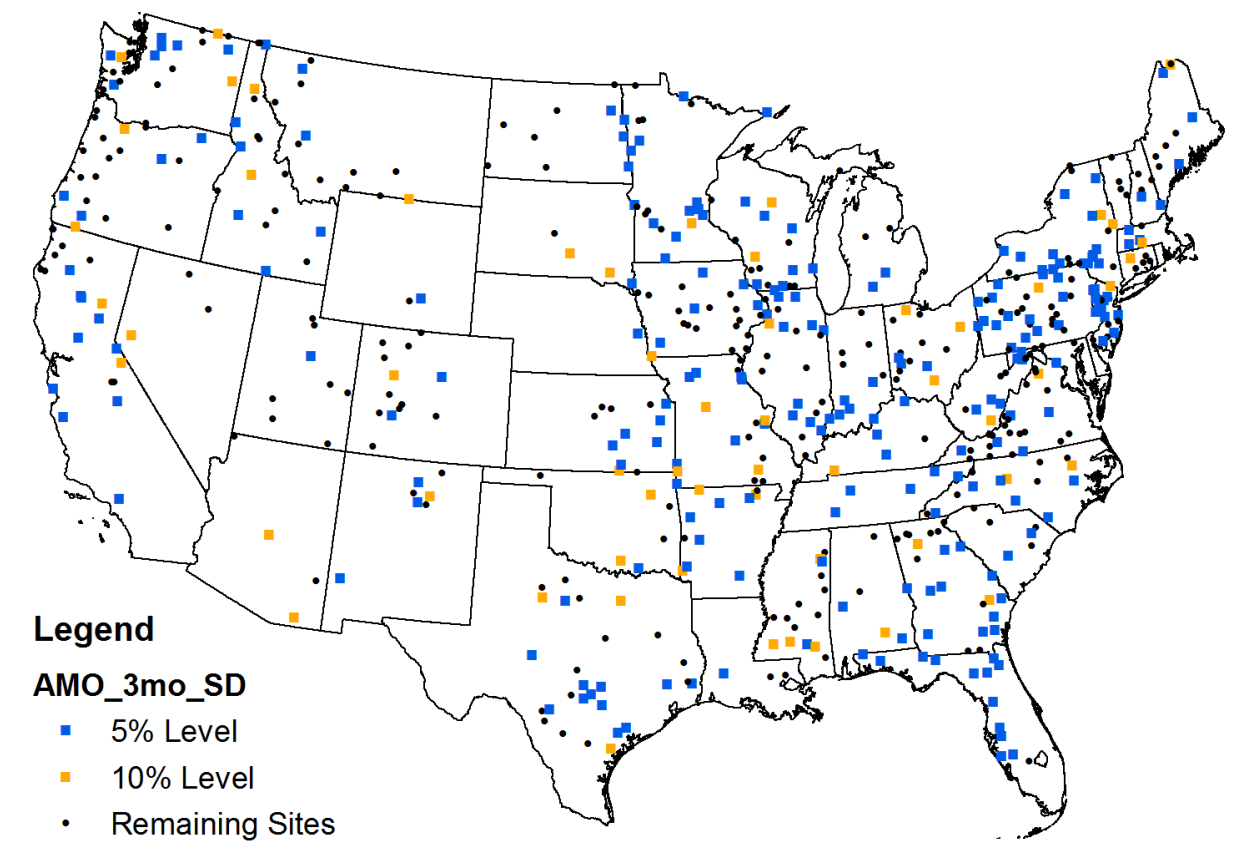

Figure 3.9 Locations of sites with significant correlation between 10-year moving standard deviation of log-transformed flood flows and 3-month average AMO anomalies with 3-month lead.

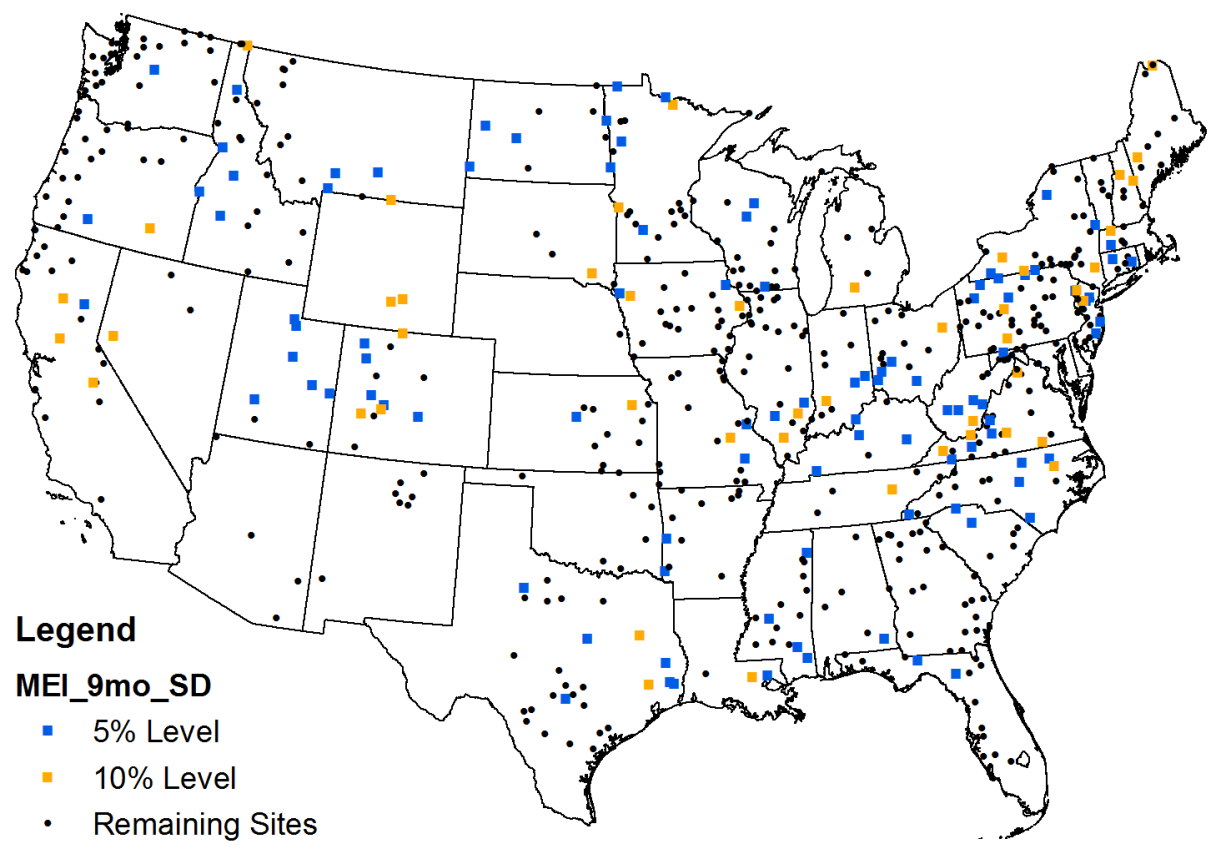

Figure 3.10 Locations of sites with significant correlation between 10-year moving standard deviation of log-transformed flood flows and 3-month average MEI anomalies with 9-month lead. 


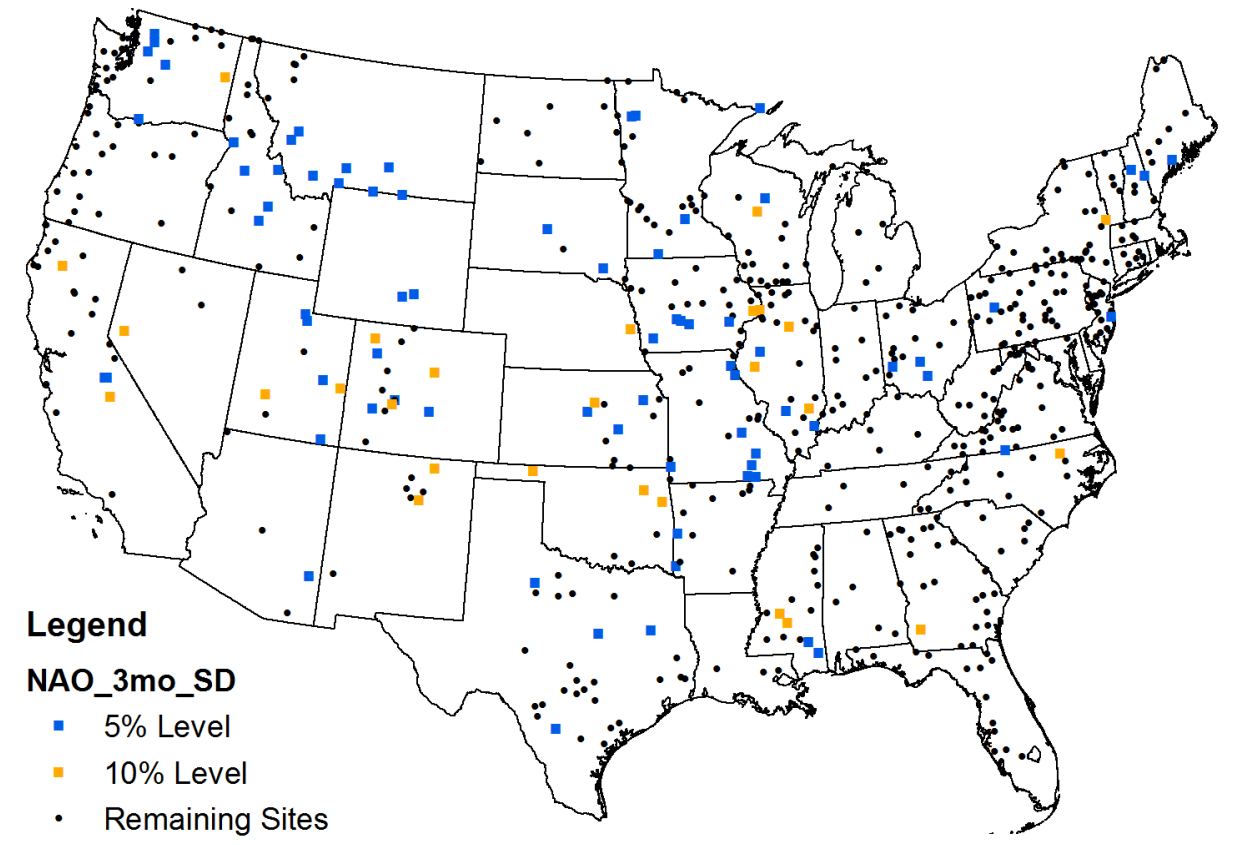

Figure 3.11 Locations of sites with significant correlation between 10-year moving standard deviation of log-transformed flood flows and 3-month average NAO anomalies with 3-month lead.

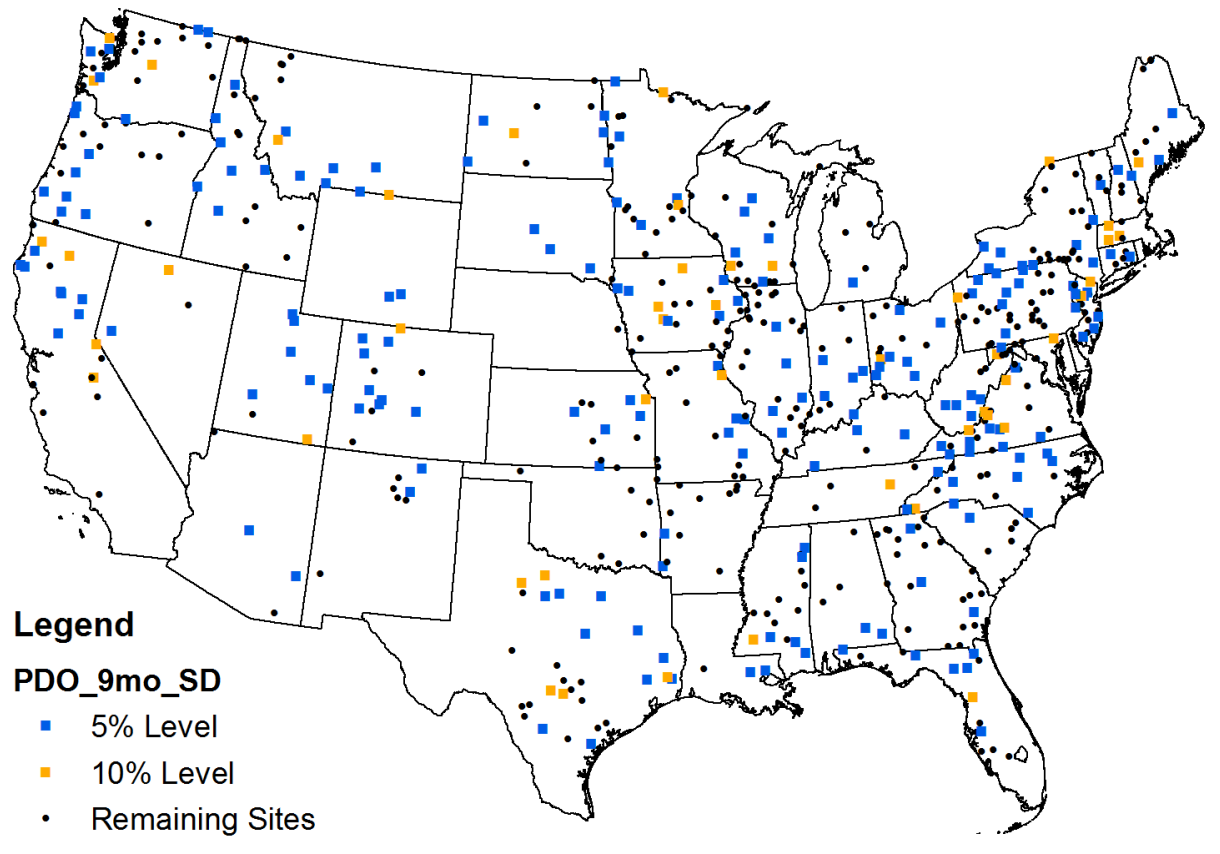

Figure 3.12 Locations of sites with significant correlation between 10-year moving standard deviation of log-transformed flood flows and 3-month average PDO anomalies with 9-month lead. 


\subsubsection{Common Shifts between Flood Flows and Climatic Phases}

Abrupt shifts (change-points) in the mean of AMF series could occur in response to abrupt shifts in the climate. The possible influence of climatic shifts was assessed by comparing the timing of identified change-points in AMF series (CHAPTER 2) to that of documented phase changes in oceanic-atmospheric patterns, such as AMO, NAO, and PDO [e.g., Tootle et al., 2005]. Phases of AMO and NAO were classified as per Tootle et al. [2005]; phases of PDO were classified using information obtained from the Climate Impacts Group of the University of Washington (http://cses.washington.edu/cig/pnwc/compensopdo.shtml). Table 3.4 summarizes the warm/cold phases of the three climate cycles on an annual time scale.

Table 3.4

Timing of Cold/Negative and Warm/Positive phases of AMO, PDO, and NAO.

\begin{tabular}{lccc}
\hline & AMO & PDO & NAO \\
\hline \hline Cold (Negative) & $1964-1994$ & $1900-1924$ & $1952-1972$ \\
& & $1947-1976$ & $1977-1980$ \\
& & $1999-2002$ & \\
& & $2006-2009$ & \\
\hline Warm (Positive) & $1950-1963$ & $1925-1946$ & $1950-1951$ \\
& $1995-2001$ & $1977-1998$ & $1973-1976$ \\
& & $2003-2005$ & $1981-2001$ \\
\hline
\end{tabular}

Of the 569 sites analyzed for change-points in the mean of respective AMF series, 202 sites were identified to contain a significant change-point at the 10\% level (Figure 2.6). To determine if these change-points were induced by shifts in climate, the timing of change-points in AMF series were related to the respective years when a climate pattern switched phases. For example, AMO switched from the warm phase to the cold phase in 1963. As the climatic shift should lead the shift in the mean of the AMF series for a causal relationship to exist, sites with change-points occurring in 1963, 1964, or 1965 are noted for further consideration. A total of 12 stations were identified to have common shifts with AMO; as shown in Table 3.5, of the 12 stations, only 5 had significant measures of correlation between the AMO climate anomalies and the 10-year moving 
average of the AMF series at the $10 \%$ level. Similarly, Table 3.6 provides results for common shifts between flood series and PDO; 12 stations exhibit a common shift, and only 6 show significant measures of correlation. Identified common shifts between flood series and NAO are shown in Table 3.7. Results indicate a total of 55 stations have a common time of shift with $\mathrm{NAO}$, but the number reduces to 22 stations when considering only stations with significant correlations. Overall, only 31 stations identified to have an abrupt shift in the mean flood magnitude were observed to have a common shift with at least one of the climate patterns considered. Two stations exhibit common shifts with both NAO and PDO (USGS Stations 05555300 and 13342500). As such, these results provide possible explanations of the observed shifts in relatively few AMF series, thereby giving reason to investigate other meteorological and physical causes of nonstationarity in AMF series.

Table 3.5

Coincidental timing of AMO phase changes and identified change-points in the mean of AMF series; including respective Kendall's tau values and associated p-values for correlation between the 10-year moving average of AMF series and AMO climate anomalies with 6-month lead.

\begin{tabular}{|c|cc|cc||c|cc|cc|}
\hline $\begin{array}{c}\text { Site } \\
\text { Number }\end{array}$ & \multicolumn{2}{|c|}{ Change-Point } & \multicolumn{2}{|c|}{ Correlation } \\
Year & $\begin{array}{c}\text { p- } \\
\text { value }\end{array}$ & tau & $\begin{array}{c}\text { Site } \\
\text { value }\end{array}$ & Number & Yhange-Point & \multicolumn{2}{|c|}{$\begin{array}{c}\text { Correlation } \\
\text { p- } \\
\text { value }\end{array}$} & tau & $\begin{array}{c}\text { p- } \\
\text { value }\end{array}$ \\
\hline \hline 01426500 & 1963 & $\mathbf{0 . 0 0 0}$ & 0.221 & $\mathbf{0 . 0 1 3}$ & 05280000 & 1964 & $\mathbf{0 . 0 1 2}$ & 0.276 & $\mathbf{0 . 0 0 2}$ \\
01503000 & 1964 & 0.066 & 0.328 & $\mathbf{0 . 0 0 0}$ & 05304500 & 1964 & $\mathbf{0 . 0 0 5}$ & 0.116 & 0.193 \\
01531000 & 1964 & $\mathbf{0 . 0 2 4}$ & 0.118 & 0.185 & 05420500 & 1964 & $\mathbf{0 . 0 0 3}$ & 0.097 & 0.278 \\
05066500 & 1964 & $\mathbf{0 . 0 0 0}$ & 0.106 & 0.235 & 05520500 & 1965 & $\mathbf{0 . 0 0 0}$ & 0.049 & 0.588 \\
05082500 & 1964 & $\mathbf{0 . 0 0 0}$ & 0.179 & $\mathbf{0 . 0 4 4}$ & 05597000 & 1964 & $\mathbf{0 . 0 0 3}$ & 0.142 & 0.111 \\
05100000 & 1964 & $\mathbf{0 . 0 1 7}$ & 0.145 & 0.103 & 08128000 & 1964 & $\mathbf{0 . 0 1 0}$ & 0.167 & 0.060 \\
\hline
\end{tabular}


Table 3.6

Coincidental timing of PDO phase changes and identified change-points in the mean of AMF series; including respective Kendall's tau values and associated p-values for correlation between the 10-year moving average of AMF series and PDO climate anomalies with 9-month lead.

\begin{tabular}{|c|cc|cc||c|cc|cc|}
\hline \multirow{2}{*}{$\begin{array}{c}\text { Site } \\
\text { Number }\end{array}$} & \multicolumn{2}{|c|}{ Change-Point } & \multicolumn{2}{|c|}{ Correlation } & \multirow{2}{*}{$\begin{array}{c}\text { Site } \\
\text { Year }\end{array}$} & \multicolumn{2}{|c|}{$\begin{array}{c}\text { Change-Point } \\
\text { value }\end{array}$} & tau & \multicolumn{2}{|c|}{$\begin{array}{c}\text { Correlation } \\
\text { value }\end{array}$} & Number & Year & $\begin{array}{c}\text { p- } \\
\text { value }\end{array}$ & tau & $\begin{array}{c}\text { p- } \\
\text { value }\end{array}$ \\
\hline \hline 03167000 & 1978 & $\mathbf{0 . 0 1 0}$ & -0.274 & $\mathbf{0 . 0 0 2}$ & 12010000 & 1977 & 0.087 & 0.084 & 0.348 \\
04079000 & 1976 & 0.076 & -0.068 & 0.452 & 12035000 & 1978 & $\mathbf{0 . 0 0 6}$ & 0.327 & $\mathbf{0 . 0 0 0}$ \\
05407000 & 1946 & $\mathbf{0 . 0 1 7}$ & 0.062 & 0.492 & 12354500 & 1946 & 0.082 & -0.225 & $\mathbf{0 . 0 1 1}$ \\
05555300 & 1978 & $\mathbf{0 . 0 1 1}$ & 0.266 & $\mathbf{0 . 0 0 3}$ & 12401500 & 1947 & $\mathbf{0 . 0 3 0}$ & 0.110 & 0.218 \\
06335500 & 1978 & $\mathbf{0 . 0 1 1}$ & -0.383 & $\mathbf{0 . 0 0 0}$ & 12404500 & 1947 & 0.067 & 0.046 & 0.605 \\
06810000 & 1946 & 0.053 & 0.051 & 0.570 & 13342500 & 1976 & $\mathbf{0 . 0 0 0}$ & -0.261 & $\mathbf{0 . 0 0 3}$ \\
\hline
\end{tabular}

Table 3.7

Coincidental timing of NAO phase changes and identified change-points in the mean of AMF series; including respective Kendall's tau values and associated p-values for correlation between the 10-year moving average of AMF series and NAO climate anomalies with 3-month lead.

\begin{tabular}{|c|c|c|c|c|c|c|c|c|c|}
\hline \multirow{2}{*}{$\begin{array}{c}\text { Site } \\
\text { Number }\end{array}$} & \multicolumn{2}{|c|}{$\begin{array}{c}\text { Change- } \\
\text { Point }\end{array}$} & \multicolumn{2}{|c|}{ Correlation } & \multirow{2}{*}{$\begin{array}{c}\text { Site } \\
\text { Number }\end{array}$} & \multicolumn{2}{|c|}{ Change-Point } & \multicolumn{2}{|c|}{ Correlation } \\
\hline & Year & $\begin{array}{c}\mathrm{p}- \\
\text { value }\end{array}$ & tau & $\begin{array}{c}\mathrm{p}- \\
\text { value }\end{array}$ & & Year & $\begin{array}{c}\text { p- } \\
\text { value }\end{array}$ & tau & $\begin{array}{c}\mathrm{p}- \\
\text { value }\end{array}$ \\
\hline 01169000 & 1972 & 0.000 & 0.275 & 0.002 & 05495000 & 1972 & 0.036 & 0.164 & 0.064 \\
\hline 01334500 & 1972 & 0.000 & 0.077 & 0.386 & 05501000 & 1972 & 0.011 & 0.321 & 0.000 \\
\hline 01518000 & 1980 & 0.000 & 0.079 & 0.379 & 0555 & 1978 & 0.011 & 0.176 & 0.048 \\
\hline 02173500 & 1980 & 0.001 & 0.033 & 0.716 & 06335500 & 1978 & 0.011 & 0.022 & 0.808 \\
\hline 02321500 & 1973 & 0.100 & 0.053 & 0.553 & 06337000 & 1972 & 0.000 & 0.039 & 0.664 \\
\hline 02383500 & 1980 & 0.000 & 0.016 & 0.858 & 06340500 & 1972 & 0.050 & 0.109 & 0.221 \\
\hline 02387500 & 1980 & 0.010 & -0.001 & 1.000 & 06478500 & 1982 & 0.010 & 0. & 0.101 \\
\hline 03118500 & 1974 & 0.022 & 0.080 & 0.368 & 06908000 & 1972 & 0.073 & 0.227 & 0.011 \\
\hline 03167000 & 1978 & 0.010 & -0.046 & 0.610 & 07016500 & 1980 & 0.011 & 0.225 & 0.011 \\
\hline 03234500 & 1972 & 0.034 & -0.247 & 0.006 & 07018500 & 1981 & 0.058 & 0.225 & 0.011 \\
\hline 03307000 & 1973 & 0.006 & -0.031 & 0.734 & 07019000 & 1980 & 0.010 & 0.204 & 0.022 \\
\hline 03345500 & 1981 & 0.078 & -0.099 & 0.267 & 07146500 & 1972 & 0.065 & 0.216 & 0.015 \\
\hline 03379500 & 1981 & 0.036 & 0.152 & 0.087 & 07234000 & 1973 & 0.000 & -0.304 & 0.001 \\
\hline
\end{tabular}


Table 3.7, continued

\begin{tabular}{|c|cc|cc||cc|cc|cc|}
\hline $\begin{array}{c}\text { Site } \\
\text { Number }\end{array}$ & \multicolumn{2}{|c|}{$\begin{array}{c}\text { Change- } \\
\text { Point }\end{array}$} & \multicolumn{2}{|c||}{$\begin{array}{c}\text { Correlation } \\
\text { Year }\end{array}$} & $\begin{array}{c}\text { p- } \\
\text { value }\end{array}$ & tau & $\begin{array}{c}\text { p- } \\
\text { value }\end{array}$ & \multicolumn{2}{|c|}{ Change-Point } & \multicolumn{2}{|c|}{ Correlation } \\
03381500 & 1981 & $\mathbf{0 . 0 4 0}$ & 0.257 & $\mathbf{0 . 0 0 4}$ & 07247500 & 1974 & $\mathbf{0 . 0 0 0}$ & -0.251 & $\mathbf{0 . 0 0 5}$ \\
04073500 & 1953 & $\mathbf{0 . 0 2 1}$ & 0.187 & $\mathbf{0 . 0 3 7}$ & 07252000 & 1981 & 0.073 & 0.199 & $\mathbf{0 . 0 2 5}$ \\
04079000 & 1976 & 0.076 & -0.060 & 0.509 & 07340500 & 1974 & $\mathbf{0 . 0 0 0}$ & -0.151 & 0.089 \\
04191500 & 1973 & 0.063 & 0.028 & 0.759 & 08080500 & 1972 & $\mathbf{0 . 0 0 0}$ & -0.278 & $\mathbf{0 . 0 0 2}$ \\
04193500 & 1973 & 0.078 & -0.017 & 0.853 & 12010000 & 1977 & 0.087 & -0.013 & 0.888 \\
04262500 & 1973 & $\mathbf{0 . 0 4 8}$ & 0.140 & 0.117 & 12035000 & 1978 & $\mathbf{0 . 0 0 6}$ & -0.024 & 0.794 \\
05316500 & 1974 & $\mathbf{0 . 0 0 3}$ & 0.031 & 0.731 & 12134500 & 1973 & $\mathbf{0 . 0 4 0}$ & 0.044 & 0.628 \\
05317000 & 1982 & 0.094 & -0.005 & 0.959 & 12186000 & 1973 & $\mathbf{0 . 0 3 1}$ & -0.004 & 0.969 \\
05330000 & 1982 & $\mathbf{0 . 0 0 5}$ & 0.110 & 0.216 & 12189500 & 1973 & $\mathbf{0 . 0 1 6}$ & 0.073 & 0.414 \\
05422000 & 1972 & 0.053 & -0.050 & 0.575 & 12321500 & 1952 & $\mathbf{0 . 0 0 7}$ & 0.066 & 0.463 \\
05431486 & 1953 & 0.092 & 0.145 & 0.103 & 12322000 & 1972 & $\mathbf{0 . 0 0 0}$ & -0.331 & $\mathbf{0 . 0 0 0}$ \\
05435500 & 1953 & $\mathbf{0 . 0 0 6}$ & -0.012 & 0.898 & 13342500 & 1976 & $\mathbf{0 . 0 0 0}$ & -0.289 & $\mathbf{0 . 0 0 1}$ \\
05436500 & 1953 & $\mathbf{0 . 0 1 4}$ & 0.009 & 0.922 & 14105700 & 1972 & $\mathbf{0 . 0 0 0}$ & -0.369 & $\mathbf{0 . 0 0 0}$ \\
05454500 & 1953 & $\mathbf{0 . 0 0 4}$ & 0.083 & 0.355 & 14137000 & 1952 & 0.075 & 0.159 & 0.074 \\
05476000 & 1982 & $\mathbf{0 . 0 4 6}$ & 0.091 & 0.307 & & & & & \\
\hline
\end{tabular}

\subsection{Meteorological Connections to Flood Peaks}

Observed trends in flood series could be due to trends in associated precipitation and/or temperature series. Previous studies have documented the influence of temperature changes on shifts in the timing of spring snowmelt and corresponding runoff events in the western U.S. [e.g., Cayan et al., 2001; Stewart et al., 2005; Moore et al., 2007]. For the 235 sites under consideration in the Northeastern quadrant of the U.S. (Figure 2.14), the presence of common trends between the AMF series and the flood generating precipitation and temperature series were investigated using Pearson's correlation analyses. In addition, relationships between temperature series and timing of flood peaks were analyzed. These analyses only consider the Pearson's correlation coefficient as the interest herein is to determine the extent to which changes in the AMF series over time are explained by changes in associated meteorological series. The Pearson's correlation coefficient appropriately describes the direction and degree to which one variable is 
linearly related to another, and thus will indicate the proportion of variability within the AMF series explained by either precipitation or temperature. Conversely, Kendall's tau represents the probability that the observed data are similarly ranked (agreement) versus the probability that the observed data are not in agreement with respect to rank [Bolboaca and Jantschi, 2006]. The presence of coincidental shifts in the meteorologic and AMF series are also investigated.

\subsubsection{Association among Precipitation and AMF Series}

Flood generating precipitation series consisting of the total precipitation that occurred within X-days prior to the annual maximum flow were constructed for each of the 235 streamflow gauging stations. For lead times of $\mathrm{X}=2,3,4,5,6$, and 7 days, these watershed specific precipitation series were constructed for 1950-2006 (57 years) using two different spatial scales of gridded data-1/8 and 1/4 degree. (See CHAPTER 2 for details.) Correlation analyses were performed between the AMF peaks and X-day precipitation totals for both spatial scales of data. Table 3.8 provides a summary of the number of sites where significant measures of correlation (Pearson's $r$ ) were identified on both $5 \%$ and $10 \%$ levels for all cases considered. Overall, a large portion of the 235 AMF series considered exhibit a significant degree of correlation with associated precipitation series. The discussion below pertains to results obtained using the finer scale precipitation data (1/8-degree). Additional results are provided in Appendix G.

Table 3.8

Number of sites yielding significant Pearson's correlation coefficients for AMF series relative to precipitation series with $\mathrm{X}$-day lead times constructed using $1 / 8$ and $1 / 4$ degree gridded data.

\begin{tabular}{|c|cc|cc|}
\hline \multirow{2}{*}{$\begin{array}{c}\text { Lead Time } \\
\text { (days) }\end{array}$} & \multicolumn{2}{|c|}{ 1/8 Degree Gridded Data } & \multicolumn{2}{c|}{ 1/4 Degree Gridded Data } \\
5\% Level & 10\% Level & 5\% Level & 10\% Level \\
\hline \hline 2 & 165 & 181 & 186 & 190 \\
3 & 186 & 200 & 188 & 198 \\
4 & 195 & 203 & 195 & 199 \\
5 & 199 & 206 & 189 & 199 \\
6 & 195 & 205 & 192 & 200 \\
7 & 198 & 204 & 193 & 200 \\
\hline
\end{tabular}


For a given site, only the precipitation series constructed using the $\mathrm{X}$-day lead time (1/8degree gridded data) which exhibited the highest measure of correlation with the AMF peaks was used to evaluate the presence of common trends and/or shifts between the two respective series. The most significant (best) X-day lead time chosen for each site, provided Pearson's $\mathrm{r}$ was significant at the $10 \%$ significance level, is presented in Figure 3.13. Of the 235 sites analyzed, 221 sites exhibit a significant measure of correlation between flood magnitude and the associated precipitation depth. The locations of sites where the best X-day precipitation series and the AMF series both exhibit trends and shifts (as identified in CHAPTER 2) are illustrated in Figure 3.14 and Figure 3.15, respectively. In the latter case, it should be noted that both the precipitation and AMF series were observed to contain a significant change-point, but they do not necessarily occur at the same time.

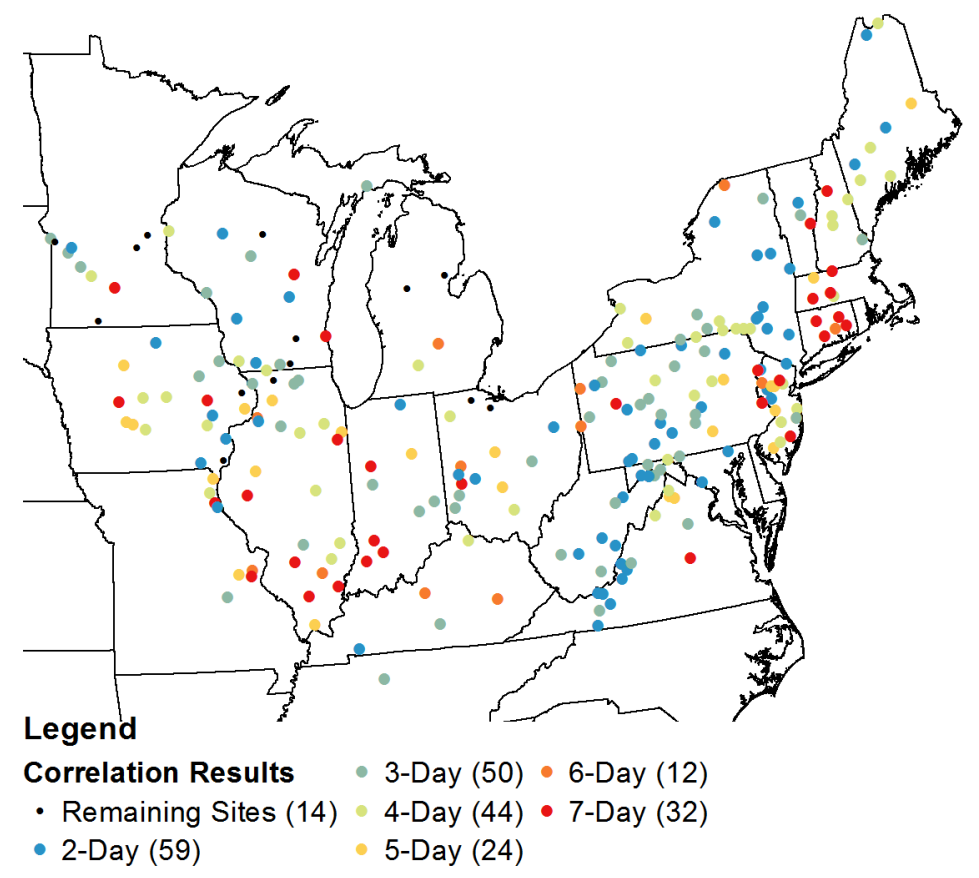

Figure $3.13 \mathrm{X}$-day lead time yielding most significant Pearson's correlation coefficient between AMF series and the associated flood generating precipitation series constructed using 1/8-degree gridded data. 


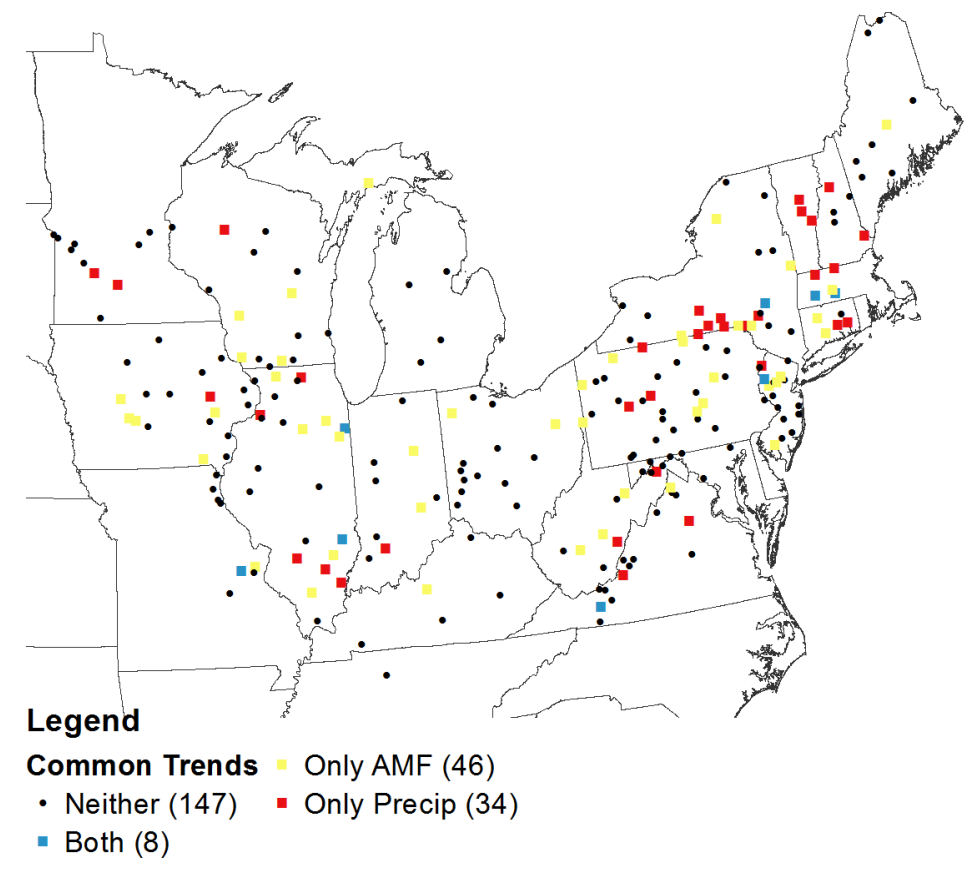

Figure 3.14 Location of sites with trends in both the AMF series and the best X-day flood generating precipitation series constructed using 1/8-degree gridded data.

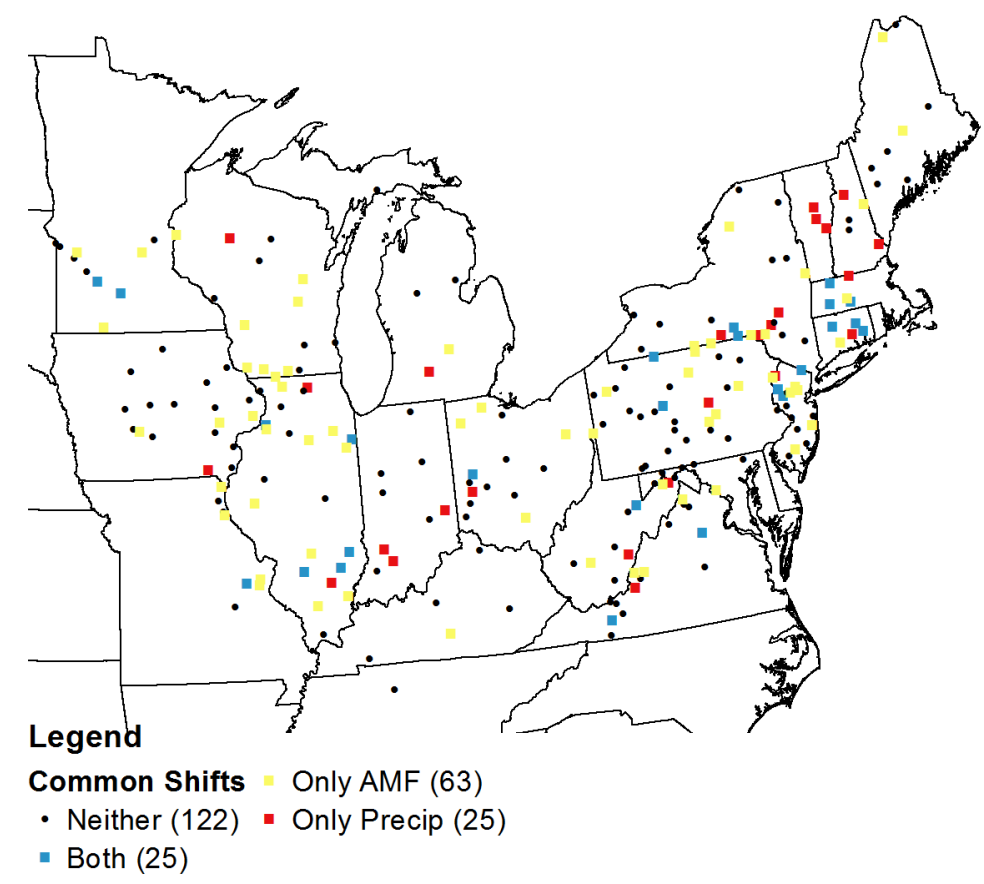

Figure 3.15 Location of sites with shifts in both the AMF series and the best X-day flood generating precipitation series constructed using 1/8-degree gridded data. 
Table 3.9 summarizes the trend results in both precipitation and AMF series for the 8 sites in Figure 3.14 determined to have a common trend. Of the 8 sites, two exhibit decreasing trends in the magnitude of AMF series, and increasing trends in flood generating precipitation series. As such, the significant Pearson's correlation is actually indicative of a strong inverse relationship between precipitation and flood magnitude, and thus a causal relationship does not exist.

Table 3.10 summarizes the change-point results for the 25 sites in Figure 3.15 which exhibit shifts in both the X-day precipitation and AMF series, though not necessarily at the same time. The last column in the table reports the difference between the year in which the shift in the AMF series occurs and the year in which the shift in the precipitation series occurs. Thus, a positive difference indicates that the shift in the precipitation series leads the shift in flood magnitude. Further, a small difference would indicate a possible causative effect of the shift in precipitation on flood magnitude. Sites for which further analysis is warranted are indicated in bold font. Overall, relatively few sites are identified; however, this analysis may be limited by the robustness of the Pettitt test, as well as the inability of the test to identify multiple shifts which may occur if the time series exhibits cyclical behavior.

Table 3.9

Summary results for sites with trends in both the magnitude of AMF series and the best $\mathrm{X}$-day flood generating precipitation series.

\begin{tabular}{|c|c|c|c|c|c|c|}
\hline \multirow[t]{2}{*}{$\begin{array}{l}\text { Station } \\
\text { Number }\end{array}$} & \multicolumn{2}{|c|}{$\begin{array}{l}\text { AMF Trend } \\
\text { Results }\end{array}$} & \multicolumn{2}{|c|}{ Pearson's r Correlation } & \multicolumn{2}{|c|}{$\begin{array}{l}\text { Precipitation } \\
\text { Trend Results }\end{array}$} \\
\hline & tau & $\mathrm{p}$-value & Lead Time (days) & p-value & tau & p-value \\
\hline 01176000 & 0.193 & 0.010 & 4 & 0.000 & 0.167 & 0.068 \\
\hline 01181000 & -0.192 & 0.092 & 7 & 0.000 & 0.183 & 0.045 \\
\hline 01350000 & 0.177 & 0.069 & 2 & 0.000 & 0.169 & 0.064 \\
\hline 01445500 & 0.353 & 0.000 & 6 & 0.000 & 0.216 & 0.018 \\
\hline 03167000 & -0.267 & 0.004 & 3 & 0.000 & 0.219 & 0.016 \\
\hline 03345500 & 0.143 & 0.058 & 4 & 0.000 & 0.229 & 0.012 \\
\hline 05520500 & 0.415 & 0.000 & 5 & 0.049 & 0.155 & 0.089 \\
\hline 07016500 & 0.166 & 0.034 & 5 & 0.000 & 0.174 & 0.057 \\
\hline
\end{tabular}


Table 3.10

Summary results for sites with significant shifts in both the magnitude of AMF series and the best X-day flood generating precipitation series.

\begin{tabular}{|c|cc|cc|c|}
\hline $\begin{array}{c}\text { Station } \\
\text { Number }\end{array}$ & \multicolumn{2}{|c|}{ AMF Series } & \multicolumn{2}{c|}{ Precipitation Series } & Difference \\
\hline \hline 01119500 & Year & p-value & Year & p-value & \\
01127500 & 1971 & 0.038 & 1972 & 0.0551 & -1 \\
01169000 & 1972 & 0.020 & 1977 & 0.0298 & -10 \\
01176000 & 1967 & 0.036 & 1973 & 0.0132 & -6 \\
01181000 & 1968 & 0.018 & 1968 & 0.0149 & $\mathbf{0}$ \\
01188000 & 1971 & 0.069 & 1970 & 0.0584 & $\mathbf{1}$ \\
01387500 & 1967 & 0.003 & 1967 & 0.0987 & $\mathbf{0}$ \\
01396500 & 1969 & 0.002 & 1966 & 0.0953 & 3 \\
01445500 & 1966 & 0.000 & 1966 & 0.0429 & $\mathbf{0}$ \\
01503000 & 1964 & 0.066 & 1971 & 0.0497 & -7 \\
01512500 & 1950 & 0.031 & 1974 & 0.0296 & -24 \\
01541500 & 1956 & 0.017 & 1982 & 0.0743 & -26 \\
01667500 & 1971 & 0.056 & 1970 & 0.0116 & $\mathbf{1}$ \\
03010500 & 1939 & 0.003 & 1960 & 0.015 & -21 \\
03069500 & 1954 & 0.002 & 1970 & 0.0934 & -16 \\
03167000 & 1978 & 0.010 & 1971 & 0.0116 & 7 \\
03262000 & 1930 & 0.064 & 1986 & 0.0491 & -56 \\
03345500 & 1981 & 0.078 & 1982 & 0.002 & -1 \\
03379500 & 1981 & 0.036 & 1983 & 0.0582 & -2 \\
05316500 & 1974 & 0.003 & 1989 & 0.0249 & -15 \\
05317000 & 1982 & 0.094 & 1982 & 0.0169 & $\mathbf{0}$ \\
05446500 & 1970 & 0.049 & 1969 & 0.0158 & $\mathbf{1}$ \\
05520500 & 1965 & 0.000 & 1985 & 0.0289 & -20 \\
05593000 & 1962 & 0.003 & 1963 & 0.0288 & -1 \\
07016500 & 1980 & 0.011 & 1982 & 0.0554 & -2 \\
\hline
\end{tabular}




\subsubsection{Association among Temperature and AMF Series}

Flood generating temperature series consisting of the average daily maximum and minimum temperatures over X-days prior to the annual peak flow were constructed using 1/8-degree gridded data. (See CHAPTER 2 for details.) For a given site, only the minimum and maximum temperature series constructed using the $\mathrm{X}$-day lead time which exhibited the highest measure of correlation with the magnitude of AMF peaks was used to evaluate the presence of common trends and/or shifts between the two respective series. The most significant (best) X-day lead times chosen for each site, provided Pearson's $r$ was significant at the $10 \%$ significance level, are presented in Figure 3.16 and Figure 3.17 for the minimum and maximum temperature series, respectively. Only a few sites show a significant measure of correlation between flood magnitude and the temperature series analyzed. Additional results for the correlation analyses are provided in Appendix G.

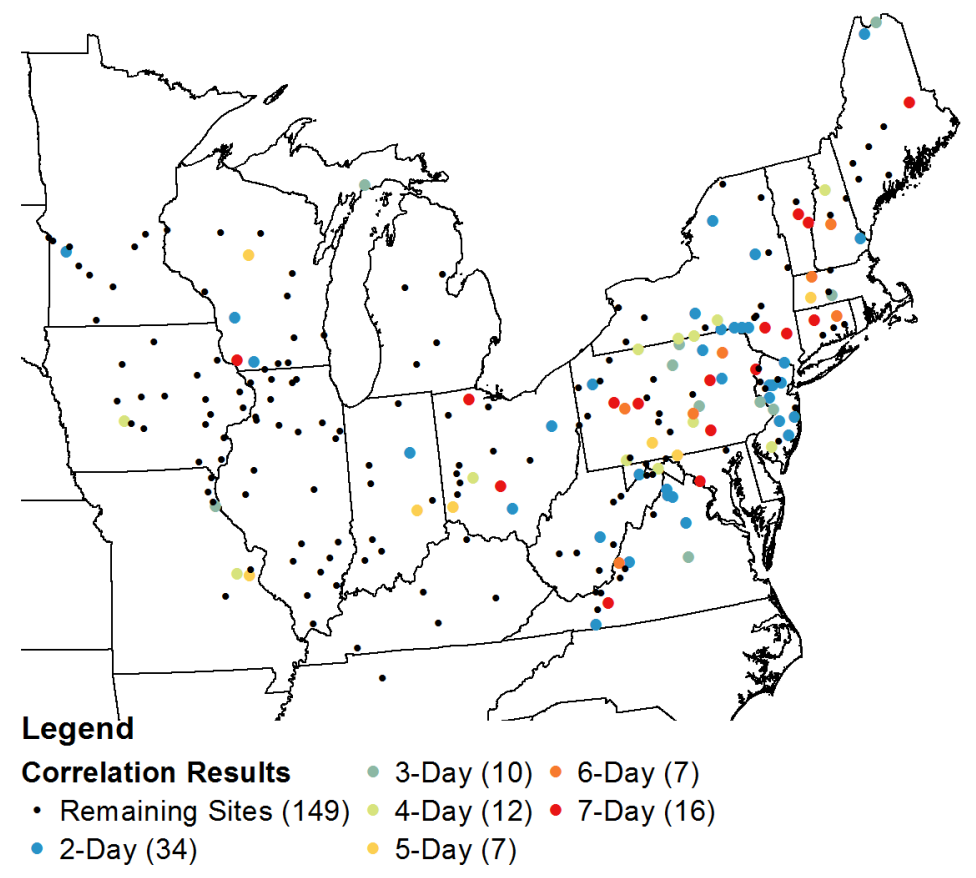

Figure 3.16 X-day lead time yielding the most significant Pearson's correlation coefficient between the AMF peaks and associated minimum temperature series. 


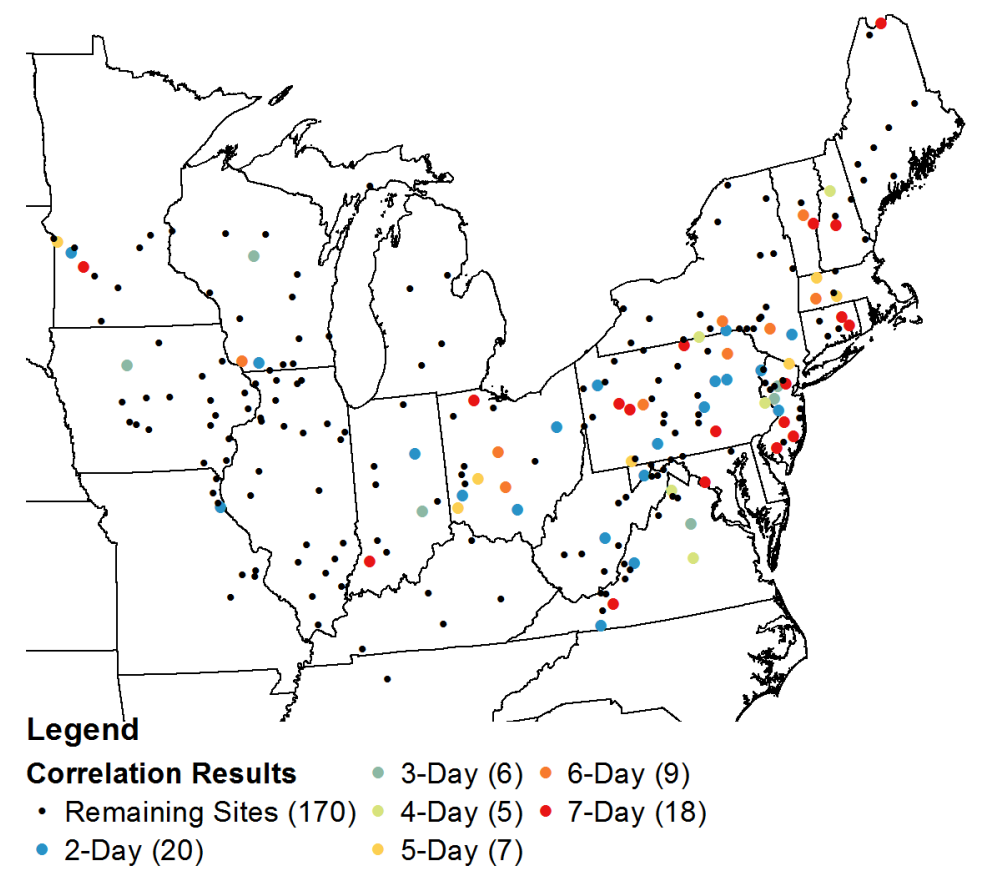

Figure 3.17 X-day lead time yielding the most significant Pearson's correlation coefficient between the AMF peaks and associated maximum temperature series.

Figure 3.18 and Figure 3.19 show sites at which trends were identified in both the AMF series and the best $\mathrm{X}$-day minimum and maximum flood generating temperature series, respectively. Table 3.11 summarizes the trend results for the 6 sites in Figure 3.18 and the 2 sites in Figure 3.19 determined to have both a trend in the AMF series and the respective temperature series. For these 8 sites, each of the flood generating temperature (minimum/maximum) series show signs of increasing trends at the 10\% level; however, 4 of the corresponding AMF series exhibit decreasing trends in the magnitude despite significant correlation with the respective temperature series. Therefore, the causative effects of temperature on flood magnitude are unclear. 


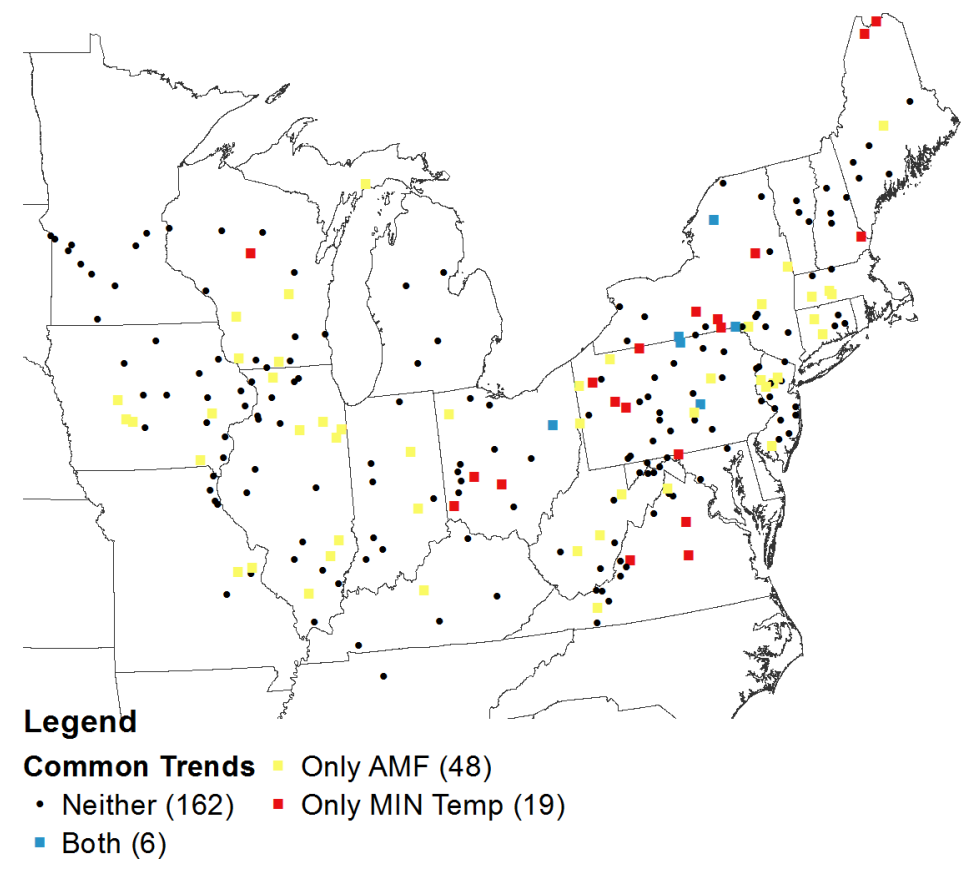

Figure 3.18 Location of sites with trends in both the best X-day flood generating minimum temperature and the AMF series.

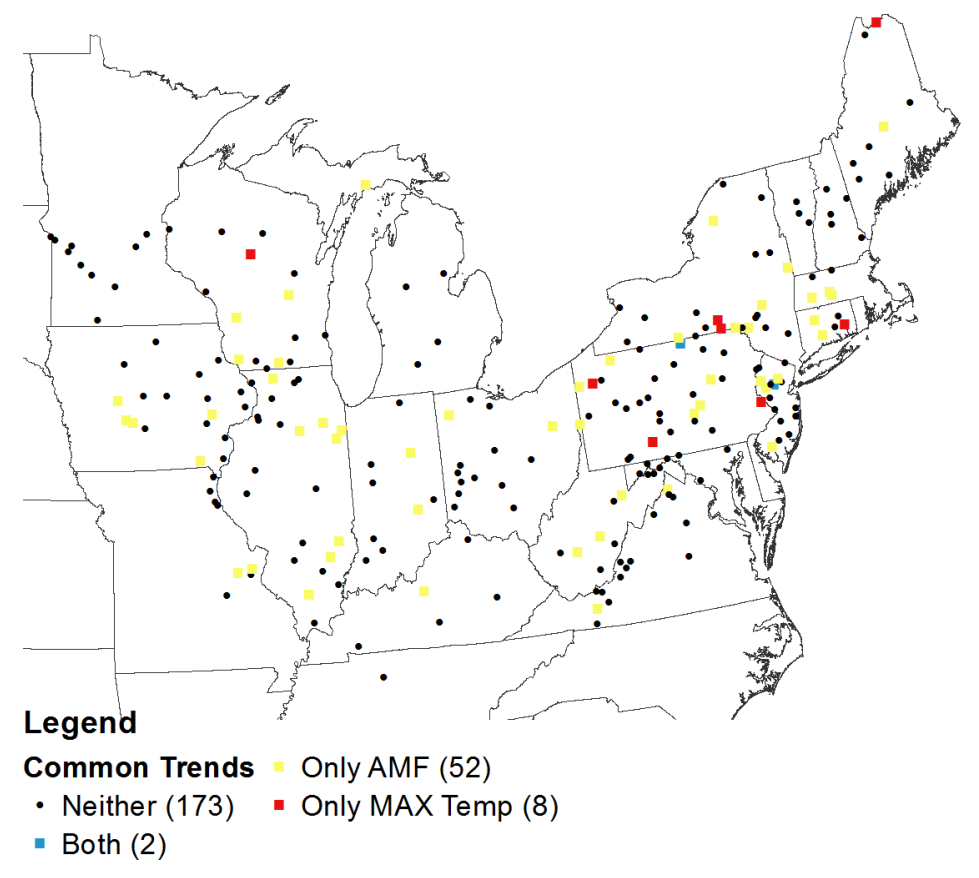

Figure 3.19 Location of sites with trends in both the best X-day flood generating maximum temperature and the AMF series. 
Table 3.11

Summary results for sites with trends in both the magnitude of AMF series and the best $\mathrm{X}$-day flood generating minimum and maximum temperature series.

\begin{tabular}{|c|cc|cc|cc|}
\hline $\begin{array}{c}\text { Station } \\
\text { Number }\end{array}$ & $\begin{array}{c}\text { AMF Trend } \\
\text { Results } \\
\text { tau }\end{array}$ & \multicolumn{2}{c|}{$\begin{array}{c}\text { Pearson's r } \\
\text { Correlation } \\
\text { Lead Time } \\
\text { (days) }\end{array}$} & \multicolumn{2}{c|}{$\begin{array}{c}\text { Temperature Trend } \\
\text { Results } \\
\text { tau }\end{array}$} & p-value \\
\hline \hline \multicolumn{7}{|c|}{ Minimum Temperature Series } \\
\hline 01426500 & -0.277 & $\mathbf{0 . 0 0 0}$ & 2 & $\mathbf{0 . 0 5 0}$ & 0.174 & 0.057 \\
01518000 & -0.313 & $\mathbf{0 . 0 1 1}$ & 3 & $\mathbf{0 . 0 3 0}$ & 0.187 & $\mathbf{0 . 0 4 1}$ \\
01520500 & -0.406 & $\mathbf{0 . 0 0 0}$ & 4 & 0.079 & 0.209 & $\mathbf{0 . 0 2 2}$ \\
01555500 & 0.171 & 0.078 & 3 & $\mathbf{0 . 0 3 7}$ & 0.167 & 0.068 \\
03118500 & 0.174 & $\mathbf{0 . 0 3 7}$ & 2 & $\mathbf{0 . 0 1 0}$ & 0.169 & 0.064 \\
04262500 & 0.144 & 0.064 & 2 & $\mathbf{0 . 0 2 5}$ & 0.221 & $\mathbf{0 . 0 1 6}$ \\
\hline \multicolumn{7}{|c|}{ Maximum Temperature Series } \\
\hline 01398500 & 0.199 & $\mathbf{0 . 0 1 8}$ & 3 & $\mathbf{0 . 0 3 5}$ & 0.182 & $\mathbf{0 . 0 4 7}$ \\
01518000 & -0.313 & $\mathbf{0 . 0 1 1}$ & 7 & 0.070 & 0.237 & $\mathbf{0 . 0 0 9}$ \\
\hline
\end{tabular}

Sites at which shifts are identified in both the AMF series and the minimum/maximum temperature series, though not necessarily at the same time, are shown in Figure 3.20 and Figure 3.21, respectively. Table 3.12 summarizes the change-point results for the 14 sites in Figure 3.20 and the 6 sites in Figure 3.21 which exhibit shifts in both the X-day minimum/maximum temperature series and AMF magnitude. The last column in the table reports the difference between the year in which the shift in the AMF series occurs and the year in which the shift in the temperature series occurs. Overall, the differences are large enough that it is unlikely that shifts in temperature alone would lead to the observed shifts in the AMF series. However, this analysis may be limited as discussed above with respect to the influence of precipitation series. 


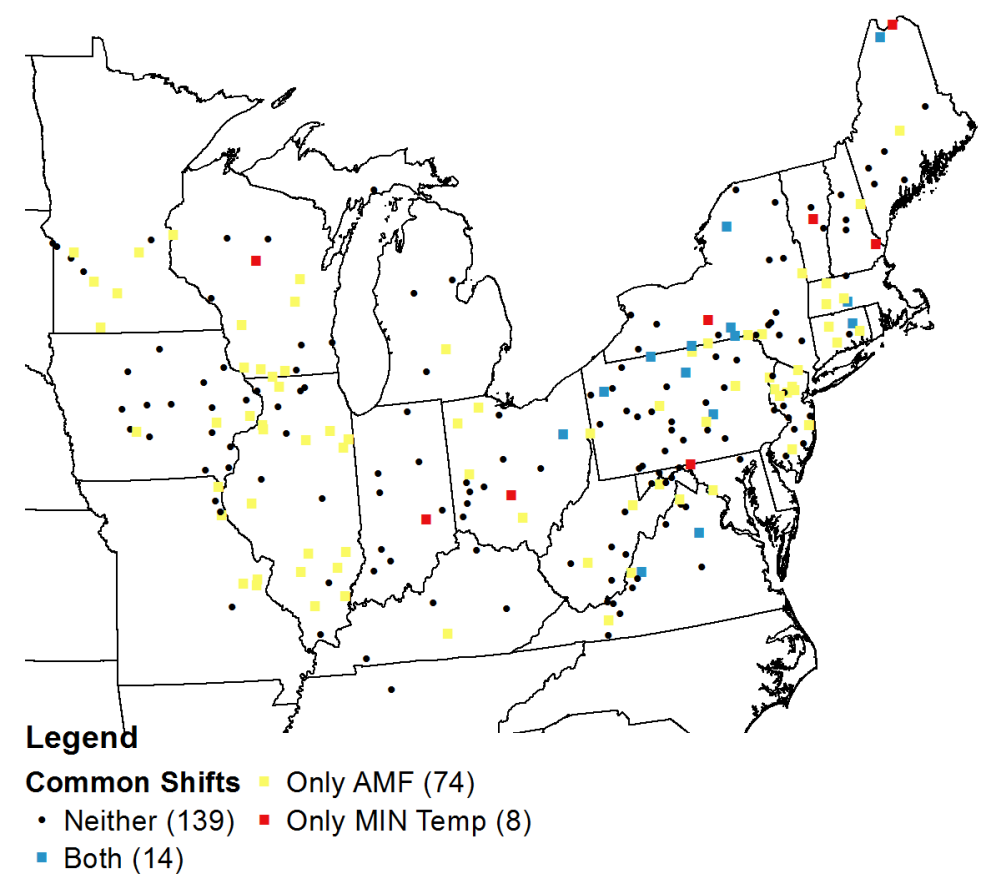

Figure 3.20 Location of sites with change-points in both the best X-day flood generating minimum temperature series and the AMF series.

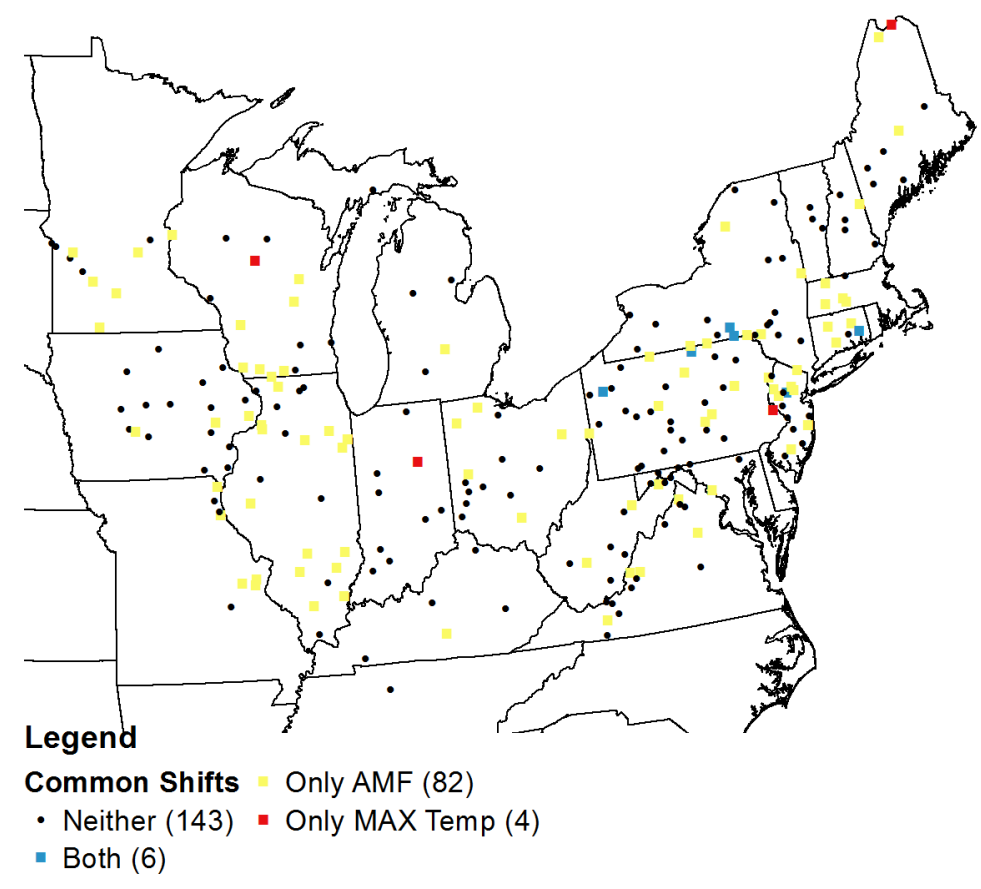

Figure 3.21 Location of sites with change-points in both the best X-day flood generating maximum temperature series and the AMF series. 
Table 3.12

Summary results for sites with significant shifts in both the magnitude of AMF series and the best X-day flood generating minimum/maximum temperature series.

Table 3.12, continued

\begin{tabular}{|c|c|c|c|c|c|}
\hline \multirow{2}{*}{$\begin{array}{c}\text { Station } \\
\text { Number }\end{array}$} & \multicolumn{2}{|c|}{ AMF Series } & \multicolumn{2}{|c|}{ Temperature Series } & \multirow{2}{*}{ Difference } \\
\hline & Year & p-value & Year & p-value & \\
\hline \multicolumn{6}{|c|}{ Minimum Temperature Series } \\
\hline 1011000 & 1968 & 0.040 & 1979 & 0.002 & -11 \\
\hline 1119500 & 1971 & 0.038 & 1979 & 0.089 & -8 \\
\hline 1176000 & 1967 & 0.036 & 1978 & 0.033 & -11 \\
\hline 1503000 & 1964 & 0.066 & 1970 & 0.007 & -6 \\
\hline 1512500 & 1950 & 0.031 & 1971 & 0.058 & -21 \\
\hline 1520500 & 1979 & 0.000 & 1971 & 0.01 & 8 \\
\hline 1548500 & 1935 & 0.069 & 1968 & 0.014 & -33 \\
\hline 1555500 & 1969 & 0.007 & 1981 & 0.056 & -12 \\
\hline 1667500 & 1971 & 0.056 & 1978 & 0.077 & -7 \\
\hline 2016000 & 1968 & 0.040 & 1979 & 0.064 & -11 \\
\hline 3010500 & 1939 & 0.003 & 1971 & 0.002 & -32 \\
\hline 3024000 & 1969 & 0.057 & 1971 & 0.062 & -2 \\
\hline 3118500 & 1974 & 0.022 & 1968 & 0.099 & 6 \\
\hline 4262500 & 1973 & 0.048 & 1968 & 0.023 & 5 \\
\hline \multicolumn{6}{|c|}{ Maximum Temperature Series } \\
\hline 1127500 & 1967 & 0.020 & 1979 & 0.004 & -12 \\
\hline 1398500 & 1969 & 0.002 & 1982 & 0.067 & -13 \\
\hline 1503000 & 1964 & 0.066 & 1987 & 0.018 & -23 \\
\hline 1512500 & 1950 & 0.031 & 1971 & 0.057 & -21 \\
\hline 1518000 & 1980 & 0.000 & 1970 & 0.079 & 10 \\
\hline 3024000 & 1969 & 0.057 & 1981 & 0.016 & -12 \\
\hline
\end{tabular}

Moving past the few commonalities identified between temperature series and flood magnitude, relationships between temperature series and timing of flood flows, if any, would potentially be useful in improving forecasts of flood risk by considering when a future flood might occur. In particular, the ability to reasonably forecast the month in which a future flood was most likely to occur would be advantageous in areas of the U.S. 
where timing of AMF peaks are better represented by a bimodal distribution. The strength of the relationship between temperature and the day of occurrence of AMF peaks for each site in Figure 2.14 was assessed using Pearson's correlation. The most significant (best) X-day lead times chosen for each site, provided Pearson's $r$ was significant at the $10 \%$ significance level, for the minimum and maximum temperature series are presented in Figure 3.22 and Figure 3.23, respectively. These results in themselves illustrate the prevalence of significant relationships between temperature and timing of AMF peaks. Additional test results are provided in APPENDIX G.

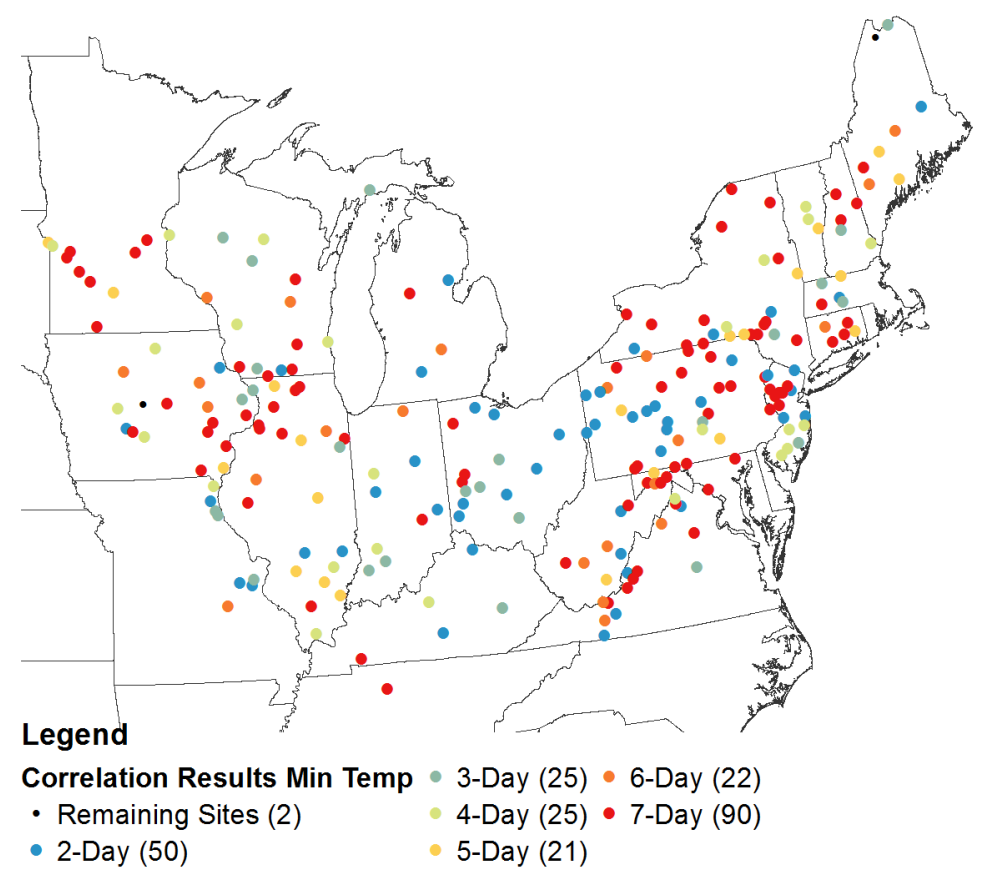

Figure 3.22 X-day lead time yielding the most significant Pearson's correlation coefficient between the day of occurrence of AMF peaks and associated minimum temperature series. 


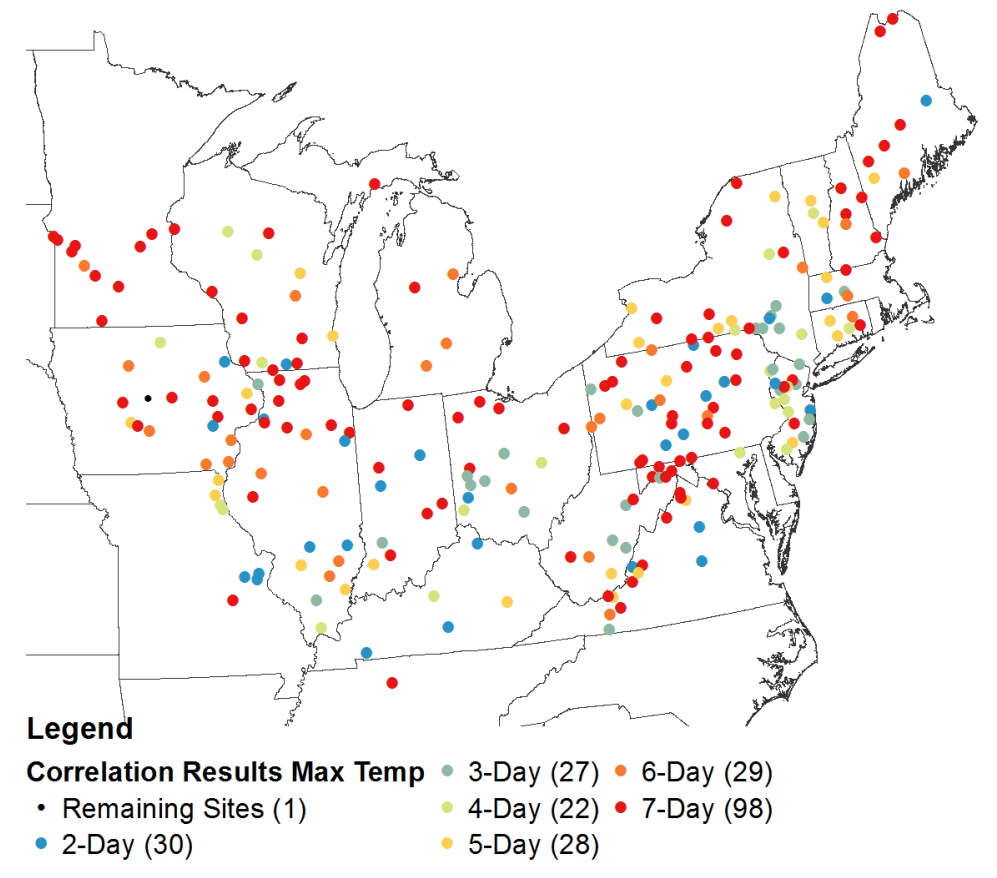

Figure 3.23 X-day lead time yielding the most significant Pearson's correlation coefficient between the day of occurrence of AMF peaks and associated maximum temperature series.

\subsection{Physical Causes of Nonstationarity}

An abrupt shift (change-point) in the mean or variance of annual maximum flood series could occur in response to a regime shift such as regulation, channelization, gauge movement, or land use change (e.g., wildfire or changing agricultural practices) [e.g., Ehsanzadeh et al., 2010]. The correlation analyses discussed above work well to identify common patterns or trends between climate parameters and flood series; however, these analyses cannot be completed with respect to physical parameters due to the limited availability of relevant data over time. Thus, physical causes of nonstationarity are considered by relating identified trends and/or change-points to documented changes in land use/land cover, changes in agricultural practices, and the installation of major reservoirs. These analyses are conducted for the same 235 stations used to investigate precipitation/temperature relationships with flood series (see Figure 2.14). 
The GAGES-II database, which identifies sites to be part of the 2009 HCDN, and reports water data remarks and hydraulic modifications on a site-by-site basis, was used to assess possible physical causes of nonstationarity. As the sites included in Figure 2.14 were chosen for their inclusion in the original HCDN [Slack et al., 1993], an initial check was performed to see if they were also part of the 2009-HCDN. As for the original HCDN, the 2009-HCDN consists of sites defined as having potential for use in hydro-climatic studies following criteria based on continuous flow record length, activity within the watershed, and basin characteristics ( $<5 \%$ imperviousness); additional details are provided by Falcone et al. [2011]. Therefore, if the sites were included in the 2009HCDN, this would suggest that anthropogenic effects on flood flows were minor over the duration of the record, and thus any nonstationarity in the flood series should be due to climate/meteorological influences, as previously discussed. Of the 235 sites under consideration, only 55 sites are contained within the 2009-HCDN. Of the 55 sites, 11 were identified to have a significant trend, and 15 have a significant change-point (see Chapter 2), which would presumably be due to climatic/meteorologic influences as discussed above.

For the remaining 180 sites under consideration, which are not included in the 2009HCDN, the fore mentioned investigation of climatic/meteorologic causes does not explain all of the identified trends and/or shifts in AMF peaks series, thus suggesting structural/anthropogenic effects may play a role in the observed nonstationarity. Table 3.13 reports summary results for 18 sites which were identified to contain a significant shift in the magnitude of AMF series, and for which water report remarks pertinent to hydrologic modifications were obtained from the Annual Data Report [Falcone et al., 2011]. The last column in the table reports the difference between the year in which the Water Report remark was made and the year in which the shift in the AMF series occurs. Thus, a negative difference indicates that the hydrologic modification leads the shift in flood magnitude. Further, a small difference would indicate a possible causative effect on flood magnitude. Sites for which further analysis is warranted are indicated in bold font. For example, USGS \#03193000 was identified to have a shift in the mean of the AMF series in 1939, which was consistent with a water resources remark indicating that 
flow has been regulated since 1939 by Claytor Lake [Falcone et al., 2011]. This method was used because the water report remarks are more specific to the timing of the hydrologic modification than alternative informational databases, such as the USGS qualification codes indicating the degree of regulation or diversion previously employed by others for similar assessments of anthropogenic influences [e.g., Villiarini et al., 2009, Villarini et al., 2011].

Table 3.13

Summary results for sites with significant shifts in AMF magnitude for which water report remarks pertinent to hydrologic modifications exist within Falcone et al. [2011].

Table 3.13, continued

\begin{tabular}{|c|cc|cc|cc|}
\hline $\begin{array}{c}\text { Station } \\
\text { Number }\end{array}$ & \multicolumn{2}{|c|}{$\begin{array}{c}\text { Mann-Kendall } \\
\text { Trend Results } \\
\text { Direction }\end{array}$} & \multicolumn{2}{c|}{$\begin{array}{c}\text { Pettitt Change-Point } \\
\text { Results }\end{array}$} & \multicolumn{2}{c|}{$\begin{array}{c}\text { Water Report } \\
\text { Remarks }\end{array}$} \\
& of Trend & p-value & p-value & Year & Year & Difference \\
\hline 01011000 & & & 0.040 & 1968 & 1969 & 1 \\
01175500 & - & 0.004 & 0.000 & 1939 & 1939 & $\mathbf{0}$ \\
01176000 & + & 0.010 & 0.036 & 1967 & 1965 & $-\mathbf{- 2}$ \\
01408500 & & & 0.081 & 1957 & 1990 & 33 \\
01426500 & - & 0.000 & 0.000 & 1963 & 1963 & $\mathbf{0}$ \\
01512500 & & & 0.031 & 1950 & 1942 & -8 \\
01518000 & - & 0.011 & 0.000 & 1980 & 1979 & $-\mathbf{1}$ \\
01520500 & - & 0.000 & 0.000 & 1979 & 1979 & $\mathbf{0}$ \\
01541500 & & & 0.017 & 1956 & 1960 & 4 \\
01567000 & - & 0.001 & 0.006 & 1937 & 1973 & 36 \\
03024000 & & & 0.057 & 1969 & 1970 & 1 \\
03193000 & - & 0.002 & 0.003 & 1940 & 1939 & $-\mathbf{1}$ \\
03262000 & & & 0.064 & 1930 & 1921 & -9 \\
04112500 & & & 0.051 & 1957 & 1975 & 18 \\
04262500 & + & 0.064 & 0.048 & 1973 & 1985 & 12 \\
05592500 & & & 0.069 & 1942 & 1969 & 27 \\
05593000 & & & 0.003 & 1962 & 1967 & 5 \\
05597000 & - & 0.021 & 0.003 & 1964 & 1970 & 6 \\
\hline
\end{tabular}

Change in dam storage could also cause changes in the magnitude of AMF peaks. Estimates of dam storage (megaliters total storage per square $\mathrm{km}$ ) for each watershed pre- 
$1940,-1950,-1960,-1970,-1980$ and -1990 were obtained from the GAGES II database ([Falcone et al., 2011 and references therein]. For relevant sites, the decade within which the largest change in storage was observed is reported in Table 3.14. The year reported is the last year of the decade in which the largest change occurred. For instance, for USGS Station No. 01011000, the largest change occurred in the period 1961 to 1970. The table also reports results of the Pettitt tests performed on the AMF series as discussed in CHAPTER 2. For each site, the last column of the table reports the difference between the end year of the decade in which the largest change in storage was observed and the year in which the shift in the AMF series occurs. Thus, positive differences on the order of 0-10 years and small negative differences would suggest a possible causative effect of the change in storage on flood magnitude. Based on this cursory analysis, a number of the AMF series could be influenced by change in dam storage. However, as the change in storage is computed on a decadal time scale, further analyses should be conducted to link increasing dam storage over time with the gradual trends observed in AMF series, or perhaps step changes therein which could be identified using an alternative homogeneity test, such as the Bayesian change-point test proposed by Seidou and Ouarda [2007].

The analysis of anthropogenic effects presented herein provides a general direction for future research, as more detailed analyses are needed on a site-by-site basis. In addition, to improve flood frequency forecasts for long-term planning and management, it will be necessary to quantify the impacts of anthropogenic activities relative to those of natural climate variability [e.g., Juckem et al., 2008]. To quantify the impacts of nonstationarity due to anthropogenic effects, AMF series could be regressed on their respective flood generating hydroclimatic series to determine the amount of flow individually explained by precipitation and temperature. The residual flow values after removing the effects of precipitation and temperature could then be tested for trends; any remaining trends could be attributed to land use changes, or other anthropogenic influences. 
Table 3.14

Summary results for sites with shifts in the magnitude of AMF series and corresponding changes in amount of storage (megaliters total storage per square $\mathrm{km}$ ) in each basin.

\begin{tabular}{|c|c|c|c|c|c|}
\hline $\begin{array}{l}\text { Station } \\
\text { Number }\end{array}$ & Year & p-value & Year & $\begin{array}{c}\text { Max } \\
\text { Change }\end{array}$ & Difference \\
\hline 01011000 & 1968 & 0.040 & 1970 & 38.3 & 2 \\
\hline 01031500 & 1966 & 0.022 & 1960 & 5.75 & -6 \\
\hline 01064500 & 1966 & 0.035 & 1980 & 1.54 & 14 \\
\hline 01119500 & 1971 & 0.038 & 1970 & 44.5 & -1 \\
\hline 01127500 & 1967 & 0.020 & 1970 & 0.29 & 3 \\
\hline 01169000 & 1972 & 0.000 & 1980 & 1.63 & 8 \\
\hline 01175500 & 1939 & 0.000 & 1980 & 0.20 & 41 \\
\hline 01176000 & 1967 & 0.036 & 1970 & 12.2 & 3 \\
\hline 01181000 & 1968 & 0.018 & 1970 & 13.5 & 2 \\
\hline 01196500 & 1968 & 0.000 & 1960 & 7.77 & -8 \\
\hline 01334500 & 1972 & 0.000 & 1990 & 1.96 & 18 \\
\hline 01379500 & 1966 & 0.010 & 1950 & 0.58 & -16 \\
\hline 01387500 & 1967 & 0.003 & 1960 & 3.13 & -7 \\
\hline 01396500 & 1969 & 0.002 & 1980 & 0.47 & 11 \\
\hline 01398500 & 1969 & 0.002 & 1950 & 1.09 & -19 \\
\hline 01408500 & 1957 & 0.081 & 1960 & 2.14 & 3 \\
\hline 01411000 & 1966 & 0.027 & 1960 & 2.17 & -6 \\
\hline 01420500 & 1968 & 0.000 & 1950 & 1.24 & -18 \\
\hline 01426500 & 1963 & 0.000 & 1970 & 360.9 & 7 \\
\hline 01439500 & 1967 & 0.014 & 1960 & 14.6 & -7 \\
\hline 01445500 & 1966 & 0.000 & 1980 & 6.59 & 14 \\
\hline 01503000 & 1964 & 0.066 & 1960 & 12.9 & -4 \\
\hline 01512500 & 1950 & 0.031 & 1950 & 56.7 & 0 \\
\hline 01518000 & 1980 & 0.000 & 1980 & 243.9 & 0 \\
\hline 01520500 & 1979 & 0.000 & 1980 & 173.5 & 1 \\
\hline 01531000 & 1964 & 0.024 & 1980 & 53.8 & 16 \\
\hline 01541500 & 1956 & 0.017 & 1970 & 87.6 & 14 \\
\hline 01548500 & 1935 & 0.069 & 1970 & 3.82 & 35 \\
\hline 01567000 & 1937 & 0.006 & 1980 & 125.3 & 43 \\
\hline 01604500 & 1967 & 0.039 & 1970 & 58.1 & 3 \\
\hline 01634500 & 1970 & 0.000 & 1980 & 1.79 & 10 \\
\hline 01645000 & 1970 & 0.000 & 1990 & 116.7 & 20 \\
\hline 01667500 & 1971 & 0.056 & 1970 & 4.32 & -1 \\
\hline 02016000 & 1968 & 0.040 & 1980 & 1.08 & 12 \\
\hline 03010500 & 1939 & 0.003 & 1970 & 0.05 & 31 \\
\hline 03024000 & 1969 & 0.057 & 1980 & 60.1 & 11 \\
\hline 03069500 & 1954 & 0.002 & 1960 & 0.55 & 6 \\
\hline 03109500 & 1959 & 0.002 & 1960 & 6.91 & 1 \\
\hline 03167000 & 1978 & 0.010 & 1970 & 4.50 & -8 \\
\hline
\end{tabular}


Table 3.14, continued

\begin{tabular}{|c|c|c|c|c|c|}
\hline $\begin{array}{l}\text { Station } \\
\text { Number }\end{array}$ & Year & p-value & Year & $\begin{array}{c}\text { Max } \\
\text { Change }\end{array}$ & Difference \\
\hline 03193000 & 1940 & 0.003 & 1950 & 35.9 & 10 \\
\hline 03234500 & 1972 & 0.034 & 1980 & 26.8 & 8 \\
\hline 03262000 & 1930 & 0.064 & 1980 & 0.30 & 50 \\
\hline 03307000 & 1973 & 0.006 & 1970 & 0.35 & -3 \\
\hline 03345500 & 1981 & 0.078 & 1990 & 3.39 & 9 \\
\hline 03379500 & 1981 & 0.036 & 1980 & 21.4 & -1 \\
\hline 03381500 & 1981 & 0.040 & 1980 & 11.6 & -1 \\
\hline 04073500 & 1953 & 0.021 & 1970 & 9.43 & 17 \\
\hline 04079000 & 1976 & 0.076 & 1970 & 5.12 & -6 \\
\hline 04112500 & 1957 & 0.051 & 1980 & 0.50 & 23 \\
\hline 04191500 & 1973 & 0.063 & 1980 & 7.76 & 7 \\
\hline 04193500 & 1973 & 0.078 & 1980 & 3.49 & 7 \\
\hline 05280000 & 1964 & 0.012 & 1950 & 12.7 & -14 \\
\hline 05304500 & 1964 & 0.005 & 1970 & 52.7 & 6 \\
\hline 05316500 & 1974 & 0.003 & 1990 & 0.46 & 16 \\
\hline 05317000 & 1982 & 0.094 & 1950 & 1.09 & -32 \\
\hline 05340500 & 1940 & 0.000 & 1970 & 5.03 & 30 \\
\hline 05408000 & 1984 & 0.012 & 1980 & 4.38 & -4 \\
\hline 05414000 & 1979 & 0.000 & 1980 & 0.20 & 1 \\
\hline 05422000 & 1972 & 0.053 & 1970 & 0.56 & -2 \\
\hline 05432500 & 1969 & 0.001 & 1980 & 2.04 & 11 \\
\hline 05434500 & 1975 & 0.008 & 1960 & 2.95 & -15 \\
\hline 05435500 & 1953 & 0.006 & 1960 & 2.66 & 7 \\
\hline 05436500 & 1953 & 0.014 & 1960 & 0.27 & 7 \\
\hline 05446500 & 1970 & 0.049 & 1970 & 2.38 & 0 \\
\hline 05447500 & 1968 & 0.001 & 1960 & 0.36 & -8 \\
\hline 05454500 & 1953 & 0.004 & 1960 & 61.6 & 7 \\
\hline 05476000 & 1982 & 0.046 & 1950 & 2.21 & -32 \\
\hline 05484500 & 1943 & 0.006 & 1970 & 10.1 & 27 \\
\hline 05495000 & 1972 & 0.036 & 1990 & 2.84 & 18 \\
\hline 05501000 & 1972 & 0.011 & 1960 & 3.83 & -12 \\
\hline 05520500 & 1965 & 0.000 & 1980 & 2.21 & 15 \\
\hline 05526000 & 1967 & 0.002 & 1960 & 3.17 & -7 \\
\hline 05527500 & 1967 & 0.000 & 1980 & 4.24 & 13 \\
\hline 05555300 & 1978 & 0.011 & 1970 & 0.17 & -8 \\
\hline 05585000 & 1958 & 0.019 & 1950 & 1.84 & -8 \\
\hline 05592500 & 1942 & 0.069 & 1980 & 252.2 & 38 \\
\hline 05593000 & 1962 & 0.003 & 1980 & 179.5 & 18 \\
\hline 05597000 & 1964 & 0.003 & 1980 & 367.4 & 16 \\
\hline 07016500 & 1980 & 0.011 & 1970 & 8.69 & -10 \\
\hline 07018500 & 1981 & 0.058 & 1970 & 39.8 & -11 \\
\hline 07019000 & 1980 & 0.010 & 1970 & 13.8 & -10 \\
\hline
\end{tabular}





\section{CHAPTER 4 CLIMATE INFORMED FLOOD RISK PROJECTIONS}

Standard procedures for forecasting flood risk (e.g., Bulletin 17B) assume AMF series are stationary, meaning the distribution of flood flows is not significantly affected by climatic trends or cycles. However, in light of surmounting evidence to the contrary [e.g. Olsen et al., 1999; Kashelikar and Griffis, 2008; Collins, 2009; Villarini et al., 2009, 2011], including results presented in Chapters 2 and 3 herein, this assumption deserves reconsideration. This chapter provides an overview of the current procedures for flood frequency analysis within the U.S. as outlined in Bulletin 17B [IACWD, 1982], and recommends an extension of those procedures to account for nonstationarity in flood peaks caused by large-scale oceanic-atmospheric patterns (AMO, PDO, and ENSO). The proposed extension is a modified version of the model proposed by Kashelikar and Griffis [2008] and Kashelikar [2009] for improved one-year ahead forecasts of flood risk. Their model only incorporated effects of ENSO on flood risk, and was based on the assumption that flood peaks throughout the U.S. tend to occur in April.

\subsection{Current Procedures}

Water resources planning and management requires coordination between various levels of government (e.g., local, state and federal), as well as the private sector. Thus, a set of uniform flood frequency analysis procedures for use across agencies has been sought after since the U.S. Water Resources Council published their first attempt, Bulletin 15 in 1967 [WRC, 1967]. Several updates were published thereafter to create a more unified and accurate set of guidelines, culminating with the publication of Bulletin 17B in 1982 [IACWD, 1982]. Despite recognized discrepancies within and limitations of those procedures [see Thomas, 1985], as well as subsequent advances in statistics and computing capabilities over the last 30 years [see Griffis and Stedinger, 2007a; Stedinger and Griffis, 2008], a new update to the Bulletin has yet to be published. Griffis and Stedinger [2007a] provide an in-depth review of the development/evolution of the Bulletin, an evaluation of its procedures, and recommendations for improvements. 
A primary limitation of the procedures outlined in Bulletin $17 B$ is that they are based on the assumption that AMF series are stationary, and thus the distribution of flood flows is assumed to be unaffected by climatic trends and/or cycles. Historical flood events are thus considered representative of future flood occurrences, and the flood risk associated with a given magnitude of flow is modeled as constant over time. In addition, Bulletin $17 B$ procedures assume AMF series are composed of independent and identically distributed events. Thereby, it is inherently assumed that gradual land use/land cover changes have little to no effect on flood peaks despite evidence of anthropogenic-induced nonstationarity in flood peaks [e.g., Potter, 1991; Pinter et al., 2008; Villiarini et al. 2009, 2011]. Although evidence of both climatic and anthropogenic effects on AMF series is mounting, Bulletin $17 B$ remains the standard for flood frequency analysis in the U.S. Stedinger and Griffis [2011] comment on the need to adapt the traditional B17 model to incorporate parameters which reflect climatic/physical causes of nonstationarity in AMF series. The use of parameters which reflect influences of oceanic-atmospheric patterns on flood magnitude is discussed herein.

Bulletin 17B procedures employ the log-Pearson type III (LP3) distribution to model the frequency associated with annual maximum flood peaks. The LP3 distribution is a three parameter distribution which describes a random variable whose logarithms are Pearson type III (P3) distributed with shape, scale, and location parameters $\alpha, \beta$ and $\xi$, respectively. The $\mathrm{P} 3$ distribution is defined by the probability density function:

$$
f_{x}(x)=\frac{1}{|\beta| \Gamma(\alpha)}\left(\frac{x-\xi}{\beta}\right)^{\alpha-1} \exp \left(\frac{x-\xi}{\beta}\right)
$$

for $\alpha>0$ and $(x-\xi) / \beta>0$, where $\Gamma(\alpha)$ is the gamma function:

$$
\Gamma(\alpha)=\int_{0}^{\infty} t^{\alpha-1} e^{-t} d t
$$

Given a record of $\mathrm{n}$ years at an individual station, Bulletin $17 B$ procedures involve fitting a LP3 distribution to the annual maximum flood series $\left\{Q_{1}, Q_{2} \ldots \ldots, Q_{n}\right\}$ by fitting a P3 
distribution to the base-10 logarithms of the flood peaks $\left\{X_{1}, X_{2} \ldots \ldots, X_{n}\right\}$ using the method of moments $(\mathrm{MOM})$. The population mean $\left(\mu_{\mathrm{x}}\right)$, standard deviation $\left(\sigma_{\mathrm{x}}\right)$ and skew $\left(\gamma_{\mathrm{x}}\right)$ of the logarithms are estimated using traditional moment estimators:

$$
\begin{aligned}
& \hat{\mu}_{x}=\frac{1}{n} \sum_{i=1}^{n} x_{i} \\
& \hat{\sigma}_{x}=\sqrt{\frac{1}{n-1} \sum_{i=1}^{n}\left(x_{i}-\hat{\mu}_{x}\right)^{2}} \\
& \hat{\gamma}_{x}=\frac{n}{(n-1)(n-2)} \sum_{i=1}^{n}\left(\frac{x_{i}-\hat{\mu}_{x}}{\hat{\sigma}_{x}}\right)^{3}
\end{aligned}
$$

Using MOM, the parameters of the P3 distribution $(\alpha, \beta, \xi)$ are then estimated using the following equations wherein the population moments are equated to the sample moments:

$$
\begin{aligned}
& \hat{\alpha}=\frac{4}{\hat{\gamma}_{x}{ }^{2}} \\
& \hat{\beta}=\frac{\hat{\sigma}_{x} \hat{\gamma}_{x}}{2} \\
& \hat{\xi}=\hat{\mu}_{x}-2 \frac{\hat{\sigma}_{x}}{\hat{\gamma}_{x}}
\end{aligned}
$$

The statistical reliability of $\hat{\alpha}, \hat{\beta}, \hat{\xi}$, and therefore, the accuracy of the fitted LP3 distribution and subsequent quantile estimators, are highly dependent on the accuracy of $\hat{\mu}_{x}, \hat{\sigma}_{x}$ and $\hat{\gamma}_{x}$. The traditional moment estimators are functions of at-site data, and due to limited record lengths, often less than 30 years, the skewness estimator can be unstable. Instability in the at-site skewness estimator is improved by using a regional skewness estimator which combines data from nearby sites [IACWD, 1982]. The use of the LP3 distribution in flood frequency analysis and the value of weighted skew estimators are discussed in detail by Griffis and Stedinger [2007b,c, 2009].

A closed-form expression for the cumulative distribution function (CDF) of the P3 distribution and its inverse are not available. To account for this, the $\mathrm{p}^{\text {th }}$ quantile of the fitted P3 distribution is computed as follows: 


$$
\hat{X}_{p}=\log \left(\hat{Q}_{p}\right)=\hat{\mu}_{x}+\hat{\sigma}_{x} K_{p}\left(\hat{\gamma}_{x}\right)
$$

where the frequency factor $K_{p}\left(\hat{\gamma}_{x}\right)$ is the $\mathrm{p}^{\text {th }}$ quantile of a standard P3 distribution with mean zero, variance 1 and skew $\hat{\gamma}_{x}\left[I A C W D, 1982\right.$; Chow et al., 1988]. For $\left|\gamma_{x}\right|<$ $2, \gamma_{x} \neq 0$ and $0.01<\mathrm{p}<0.99, K_{p}\left(\hat{\gamma}_{x}\right)$ is well approximated by the Wilson-Hilferty transformation [Kirby, 1972]:

$$
K_{p}\left(\hat{\gamma}_{x}\right)=\frac{2}{\hat{\gamma}_{x}}\left\{\left[\left(z_{p}-\frac{\hat{\gamma}_{x}}{6}\right) \frac{\hat{\gamma}_{x}}{6}+1\right]^{3}-1\right\}
$$

where $z_{p}$ is the $p^{\text {th }}$ quantile of a standard normal distribution. As $\gamma_{x}$ goes to zero, the P3 distribution converges to the normal distribution. As a result, P3 quantiles for $\left|\gamma_{x}\right|<$ 0.01 are given by:

$$
\hat{X}_{p}=\hat{\mu}_{x}+\hat{\sigma}_{x} z_{p}=\hat{\mu}_{x}+\hat{\sigma}_{x} \Phi^{-1}(p)
$$

where $\Phi()$ represents the CDF of the standard normal distribution. Quantiles obtained using equations (33) and (35) must subsequently be converted back to real space using a base-10 antilogarithmic transformation to yield the magnitude of discharge associated with the desired exceedance probability (i.e., magnitude of a design event).

Quantiles computed using the equations above, and the associated frequency curve, are only approximations of the population distribution/quantiles based on a limited sample of observations. To account for the presence of sampling variability, confidence intervals can be constructed to provide a measure of the uncertainty in the estimated discharge [design magnitude] at a selected exceedance probability (E). Bulletin 17B (Appendix 9) presents a procedure to approximate the uncertainty in the $\mathrm{P} 3$ quantile estimates [IACWD, 1982]. Confidence limits are computed as follows:

$$
\begin{aligned}
& U_{E, C}(X)=\bar{X}+S\left(k_{E, C}^{U}\right) \\
& L_{E, C}(X)=\bar{X}+S\left(k_{E, C}^{L}\right)
\end{aligned}
$$


where $\bar{X}$ and $\mathrm{S}$ are the log base-10 mean and standard deviation corresponding to the final estimated LP3 density function representing the AMF series. The upper and lower confidence coefficients $k_{E, C}^{U}$ and $k_{E, C}^{L}$ are based on a large sample approximation using the non-central t-distribution:

$$
\begin{aligned}
k_{E, C}^{U}= & \frac{K_{G_{w}, E}+\sqrt{K_{G_{w}, E}^{2}-a b}}{a} \\
k_{E, C}^{L}= & \frac{K_{G_{w}, E}-\sqrt{K_{G_{w}, E}^{2}-a b}}{a}
\end{aligned}
$$

where

$$
\begin{aligned}
& a=1-\frac{Z_{c}^{2}}{2(n-1)} \\
& b=K_{G_{w}, E}^{2}-\frac{Z_{c}^{2}}{n}
\end{aligned}
$$

and $Z_{c}$ is the standard normal deviate with cumulative probability, $C$. The value of $C$ employed reflects the desired level of confidence with which the computed bounds should contain the true quantile of the P3 distribution. The record length, $\mathrm{n}$, controls the statistical reliability (accuracy) of the estimated function [IACWD, 1982]. Thus, the accuracy of quantile estimates increases with the availability of additional flood peak occurrences. 


\subsection{Proposed Modification to Bulletin 17B}

Several studies have proposed methods for coping with nonstationarity when forecasting flood risk. Strupczewski et al. [2001] and Olsen et al. [1999] incorporated hydrological nonstationarity into at-site flood frequency estimation by projecting observed trends in AMF series. Severe limitations arise with this proposed method; identified linear monotonic trends may be better characterized as an abrupt shift, or could be part of a larger cycle not evident in the period of record. Other methods which account for nonstationarity in flood frequency analysis by employing time-dependent distribution parameters have also been proposed [e.g., Coulibaly and Baldwin, 2005; Sveinsson et al., 2005; Villarini et al., 2009, 2011]. Unfortunately, the ability of models such as these, which consider variations in flood risk only as a function of time, to accurately forecast flood risk under changing climate and/or land use/land cover is questionable. On the contrary, Kiem et al. [2003], Kashelikar and Griffis [2008], Kwon et al. [2008], and Kashelikar [2009] propose models of flood risk which reflect observed nonstationarity in flood series due to influences of oceanic-atmospheric patterns. Stedinger and Griffis [2011] further comment on the need to adapt traditional flood frequency analysis procedures to incorporate parameters which can vary over time in response to climatic/physical causes of nonstationarity in AMF series.

A model is proposed herein which incorporates the coupled effects of multiple climate patterns on flood magnitude to provide one-year ahead forecasts of both the mean and standard deviation of the log-transformed flood peaks. This work extends the model proposed by Kashelikar [2009], wherein nonstationarity in flood peaks was accounted for by updating (shifting) the mean year to year in response to climate variability associated strictly with ENSO events. The model proposed herein also corrects a major limitation of that proposed by Kashelikar [2009]. Her forecasts (updates) of the mean were computed as a function of ENSO indices obtained with a specified lead time based on the assumption that flood peaks across the U.S. tend to occur in the month of April. Results provided in CHAPTER 3 herein demonstrate that this assumption is not valid for many areas of the U.S. (see Figure 3.2). Instead, model parameters based on climate indices relative to the mode month of flood peak occurrence for a given site would provide a 
more appropriate framework for forecasting flood risk wherein the time occurrence of the future flood peak is unknown. The correlation analyses presented in CHAPTER 3 indicate that the mean of the log-transformed flows can be modeled as functions of the AMO, MEI, NAO, and PDO indices with 6-, 9-, 3-, and 9-month lead times, respectively, relative to the mode month of occurrence. Similarly, the standard deviation of the logtransformed flows can be modeled as functions of the AMO, MEI, NAO, and PDO indices with 3-, 9-, 3-, and 9-month lead times, respectively.

For each site in Figure 2.3, climate informed P3 parameters are obtained using a regression model of the following form:

$$
\begin{aligned}
& \mu[\mathrm{t}]=\alpha_{1}+\beta_{11} \mathrm{C}_{\mathrm{t} \_\mathrm{AMO}}+\beta_{12} \mathrm{C}_{\mathrm{t} \_\mathrm{MEI}}+\beta_{13} \mathrm{C}_{\mathrm{t} \_\mathrm{NAO}}+\beta_{14} \mathrm{C}_{\mathrm{t} \_\mathrm{PDO}}+\varepsilon_{\mathrm{t}} \\
& \sigma[\mathrm{t}]=\alpha_{2}+\beta_{21} \mathrm{C}_{\mathrm{t} \_\mathrm{AMO}}+\beta_{22} \mathrm{C}_{\mathrm{t} \_\mathrm{MEI}}+\beta_{23} \mathrm{C}_{\mathrm{t} \_\mathrm{NAO}}+\beta_{24} \mathrm{C}_{\mathrm{t} \_\mathrm{PDO}}+\varepsilon_{\mathrm{t}}
\end{aligned}
$$

where $\mu(t)$ and $\sigma(t)$ are the mean and standard deviation of the log-transformed flows computed using a 10-year moving window ending in time $t, \mathrm{C}_{\mathrm{t}_{-} \mathrm{i}}$ is a three-month average of climate index $\mathrm{i}$ observed in time $\mathrm{t}$ with an appropriate lead time relative to the mode month of occurrence of AMF peaks at the site in question, $\alpha$ and $\beta$ are regression parameters, and $\varepsilon_{\mathrm{t}}$ is the independent model error. The logarithms of the AMF peaks are subsequently modeled as:

$$
X_{t} \sim P 3\left[\mu_{x}(t), \sigma_{x}(t), \gamma\right]
$$

in which the skew of the logarithms $(\gamma)$ is independent of time (i.e., stationary). Yearspecific quantile estimates (for year $t$ ) which reflect the influence of climate patterns can then be obtained using equation (33) or (35) as a function of the updated (or climateinformed) mean $\mu(\mathrm{t})$ and standard deviation $\sigma(\mathrm{t})$. The proposed model does not consider the skew estimator to be a function of time due to present challenges in the standard stationary procedure to estimate the skew well with limited data [Reis et al., 2005; Gruber and Stedinger, 2008; Griffis and Stedinger, 2009]. In addition, Bulletin 17B procedures to improve quantile estimates by using regional skew information, accounting for low outliers, or the addition of historical flood data are not considered herein. 


\subsection{Climate Informed Flood Risk Projection}

The extension of the Bulletin $17 B$ framework proposed above can be used to obtain oneyear ahead forecasts of flood risk which reflect the influence of large-scale climate patterns (AMO, NOA, ENSO, or PDO). To do so, the site specific regression models of the form in equation (42) would be used to forecast the mean and standard deviation oneyear ahead in time $(\mathrm{t}+1)$ using forecasts of relevant climate indices obtained from (http://www.cpc.ncep.noaa.gov/products/analysis_monitoring/lanina/ensoforecast.shtml). To illustrate how accounting for nonstationarity due to climate variability impacts projected flood risk, one-year ahead estimates of flood risk corresponding to various cumulative probabilities were computed for six sample USGS gauging stations (Figure 4.1) using the proposed model and compared against estimates computed under the assumption of stationarity (i.e., the traditional Bulletin 17B model). The parameters of the regression models for $\mu(t)$ and $\sigma(t)$ for each station were obtained using the logarithms of annual maximum flood data through $t=2008$. The values of the regression parameters obtained for the model of the mean and standard deviation at each site are reported in Table 4.2 and Table 4.3, respectively. One-year ahead forecasts of the mean and standard deviation for $\mathrm{t}=2009$ obtained for each of the stations are reported in Table 4.4; the parameters of the traditional (stationary) Bulletin 17B LP3 model obtained using all available data through 2008 are also provided. The mode month of occurrence was April for all sites considered; thus, respective climate indices used to forecast $\mu(2009)$ and $\sigma(2009)$ were the same. The historical (observed) three-month averaged climate indices with the appropriate lead times for 2009 are reported in Table 4.1. With the exception of PDO, the climate patterns were reasonably neutral in 2009, therefore, a hypothetical extreme scenario was also considered, assuming all climate indices were in the positive (warm) phase. For each climate pattern, the extreme value employed is the maximum value of the three-month averaged climate index with the appropriate lead observed over the period of record. 


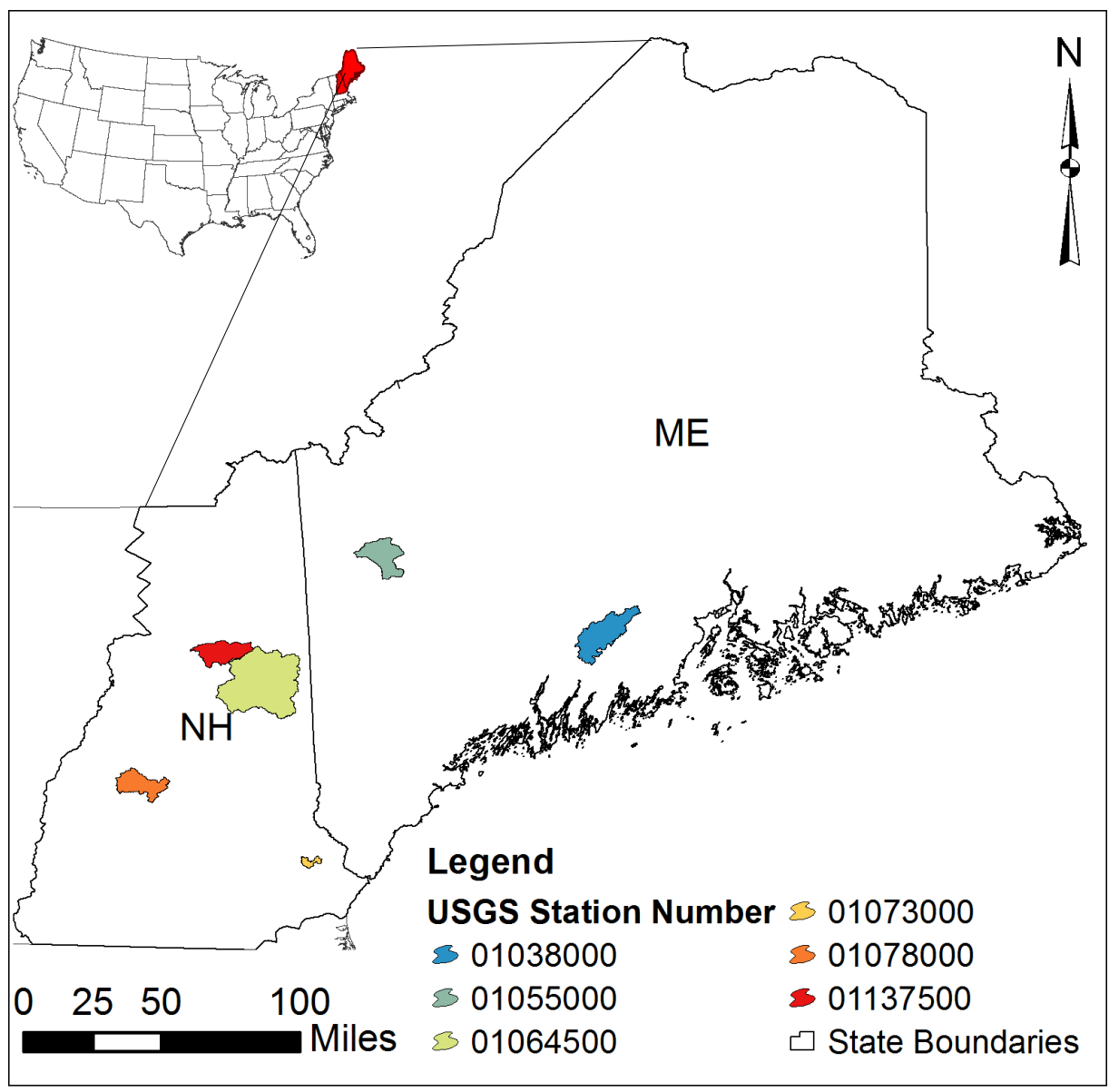

Figure 4.1 Location of six USGS stations used to compare current flood risk projection procedures to proposed climate informed flood risk projection model.

Table 4.1

Three-month averaged values of climate indices with specified lead time relative to April flood peak used in regression models to obtain one-year ahead forecasts $\mu(2009)$ and $\sigma(2009)$ : observed values for 2009 and extreme scenario.

\begin{tabular}{|c|cccc|}
\hline Parameters & $\begin{array}{c}\text { AMO } \\
(6 \mathrm{~m} \text { lead })\end{array}$ & $\begin{array}{c}\text { MEI } \\
(9 \mathrm{~m} \text { lead })\end{array}$ & $\begin{array}{c}\text { NAO } \\
(3 \mathrm{~m} \text { lead })\end{array}$ & $\begin{array}{c}\text { PDO } \\
(9 \mathrm{~m} \text { lead })\end{array}$ \\
\hline \hline Extreme Scenario & 0.300 & 2.140 & 1.720 & 2.557 \\
Observed & 0.027 & -0.104 & -0.203 & -1.460 \\
\hline
\end{tabular}


Table 4.2

Regression coefficients obtained for the model of the log space mean at six sample sites. Coefficients reported are all significant at the $10 \%$ level.

\begin{tabular}{|c|ccccc|c|}
\hline $\begin{array}{c}\text { Site } \\
\text { Number }\end{array}$ & $\begin{array}{c}\text { Intercept } \\
\left(\alpha_{1}\right)\end{array}$ & $\begin{array}{c}\text { AMO } \\
\left(\beta_{11}\right)\end{array}$ & $\begin{array}{c}\text { MEI } \\
\left(\beta_{12}\right)\end{array}$ & $\begin{array}{c}\text { NAO } \\
\left(\beta_{13}\right)\end{array}$ & $\begin{array}{c}\text { PDO } \\
\left(\beta_{14}\right)\end{array}$ & $\mathbf{R}^{2}$ \\
\hline \hline 01038000 & 3.313 & -0.073 & & 0.020 & 0.023 & 0.330 \\
01055000 & 3.793 & 0.075 & & 0.035 & 0.019 & 0.359 \\
01064500 & 4.245 & 0.068 & & 0.041 & 0.026 & 0.467 \\
01073000 & 2.482 & 0.125 & & & 0.028 & 0.447 \\
01078000 & 3.226 & & & 0.021 & 0.017 & 0.322 \\
01137500 & 3.651 & 0.141 & -0.016 & 0.027 & 0.012 & 0.544 \\
\hline
\end{tabular}

Table 4.3

Regression coefficients obtained for the model of the log space standard deviation at six sample sites. Coefficients reported are all significant on the $10 \%$ level.

\begin{tabular}{|c|ccccc|c|}
\hline Site Number & $\begin{array}{c}\text { Intercept } \\
\left(\alpha_{2}\right)\end{array}$ & $\begin{array}{c}\text { AMO } \\
\left(\beta_{21}\right)\end{array}$ & $\begin{array}{c}\text { MEI } \\
\left(\beta_{22}\right)\end{array}$ & $\begin{array}{c}\text { NAO } \\
\left(\beta_{23}\right)\end{array}$ & $\begin{array}{c}\text { PDO } \\
\left(\beta_{24}\right)\end{array}$ & $\mathbf{R}^{2}$ \\
\hline \hline 01038000 & 0.184 & -0.097 & & 0.014 & 0.012 & 0.376 \\
01055000 & 0.252 & 0.053 & & & & 0.169 \\
01064500 & 0.235 & & -0.031 & -0.013 & 0.234 \\
01073000 & 0.235 & 0.068 & & & & 0.146 \\
01078000 & 0.175 & & & & & 0.203 \\
01137500 & 0.189 & & & -0.017 & -0.010 & 0.204 \\
\hline
\end{tabular}

Table 4.4

Moments of the log-transformed flood peaks based on stationary P3 model through 2008, proposed model with observed climate indices for 2009 and hypothetical extreme climate indices.

\begin{tabular}{|c|cccc|cc|cc|}
\hline \multirow{2}{*}{$\begin{array}{c}\text { Site } \\
\text { Number }\end{array}$} & \multicolumn{3}{|c|}{ Stationary P3 Model } & \multicolumn{2}{c|}{$\begin{array}{c}\text { Proposed Model } \\
\text { (2009 Indices) }\end{array}$} & \multicolumn{2}{c|}{$\begin{array}{c}\text { Proposed Model } \\
\text { (Extreme Indices) }\end{array}$} \\
& Years & $\boldsymbol{\mu}$ & $\boldsymbol{\sigma}$ & $\boldsymbol{\gamma}$ & $\boldsymbol{\mu}(\mathbf{t})$ & $\boldsymbol{\sigma}(\mathbf{t})$ & $\boldsymbol{\mu}(\mathbf{t})$ & $\boldsymbol{\sigma}(\mathbf{t})$ \\
\hline \hline 01038000 & 72 & 3.323 & 0.197 & 0.569 & 3.261 & 0.161 & 3.372 & 0.210 \\
01055000 & 81 & 3.784 & 0.243 & -0.280 & 3.773 & 0.253 & 3.938 & 0.268 \\
01064500 & 81 & 4.231 & 0.225 & -0.255 & 4.213 & 0.260 & 4.415 & 0.148 \\
01073000 & 74 & 2.494 & 0.234 & 0.158 & 2.466 & 0.236 & 2.613 & 0.255 \\
01078000 & 91 & 3.255 & 0.194 & 0.448 & 3.197 & 0.176 & 3.306 & 0.195 \\
01137500 & 70 & 3.643 & 0.183 & 0.254 & 3.657 & 0.208 & 3.760 & 0.132 \\
\hline
\end{tabular}


The sample moments $(\mu, \sigma, \gamma)$ of the log-transformed data through 2008 are reported in Table 4.4. These moments define the P3 distribution used to forecast flood risk under the assumption that flood series are stationary (i.e., Bulletin 17B model). The P3 distribution used to forecast flood risk under the proposed model is defined by the values of $\mu(2009)$ and $\sigma(2009)$ reported in Table 4.4, for either the historical (observed) indices or the extreme scenario, combined with the skew $\gamma$ computed assuming stationarity. Figure 4.2 through Figure 4.7 show one-year ahead forecasts of flood risk obtained using these three models. Overall, these examples demonstrate that the modified (proposed) LP3 model can yield significantly different flood risk estimates than the traditional Bulletin 17B model. The proposed modification of the Bulletin 17B LP3 model yields one-year ahead forecasts of flood risk which are consistent with the phase and intensity of climate patterns, and thus the observed differences in flood risk forecasts are enhanced when climate indices are more extreme. Similar observations were made by Kashelikar [2009] who only considered the mean to be variable over time, modeled as a function of the Nino3.4 index. However, before the model can be adopted in practice, analyses must be performed to validate the model performance for projection of flood risk.

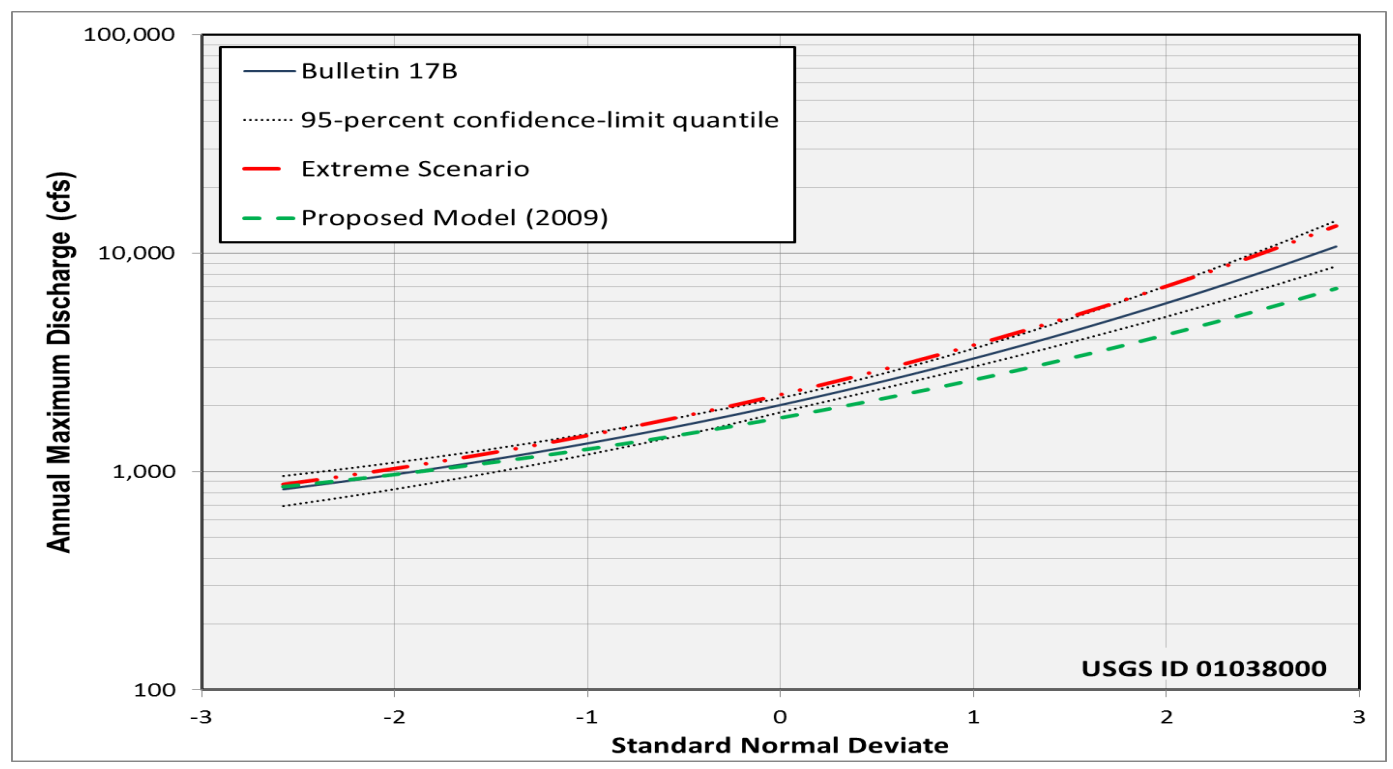

Figure 4.2 One-year ahead forecast of flood risk for Sheepscot River at North Whitefield, Maine (USGS Station No. 01038000) obtained using the Bulletin 17B LP3 model and the proposed modification to incorporate climate variability. 


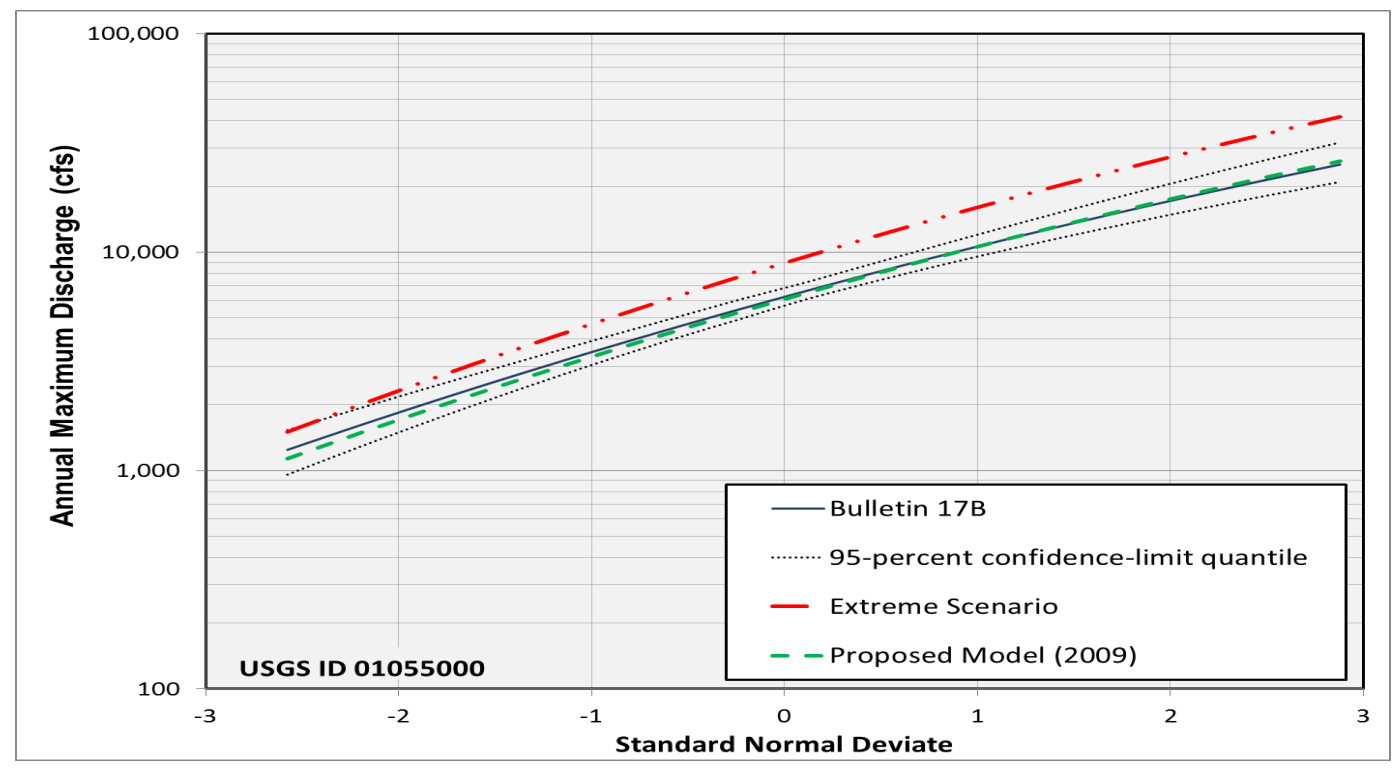

Figure 4.3 One-year ahead forecast of flood risk for Swift River near Roxbury, Maine (USGS Station No. 01055000) obtained using the Bulletin 17B LP3 model and the proposed modification to incorporate climate variability.

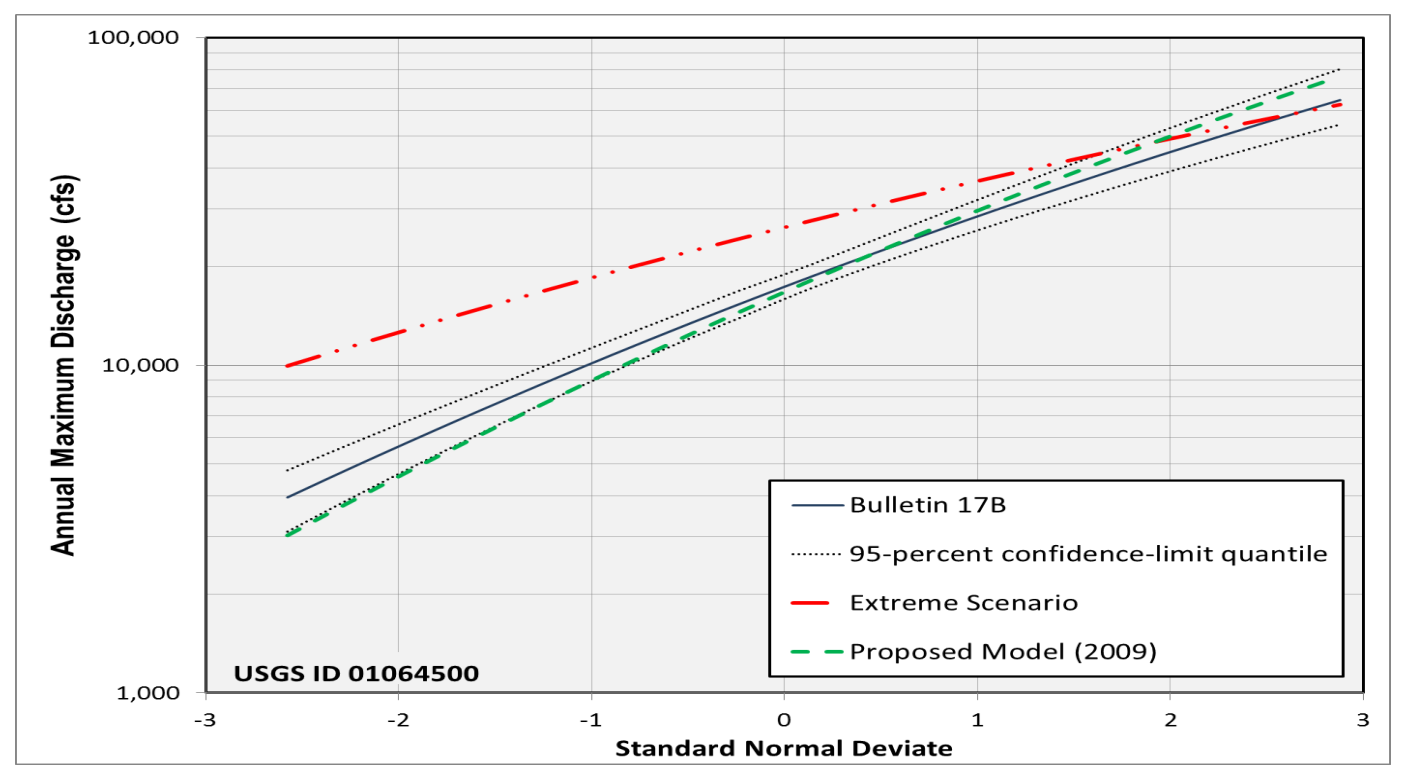

Figure 4.4 One-year ahead forecast of flood risk for Saco River near Conway, NH (USGS Station No. 01064500) obtained using the Bulletin 17B LP3 model and the proposed modification to incorporate climate variability. 


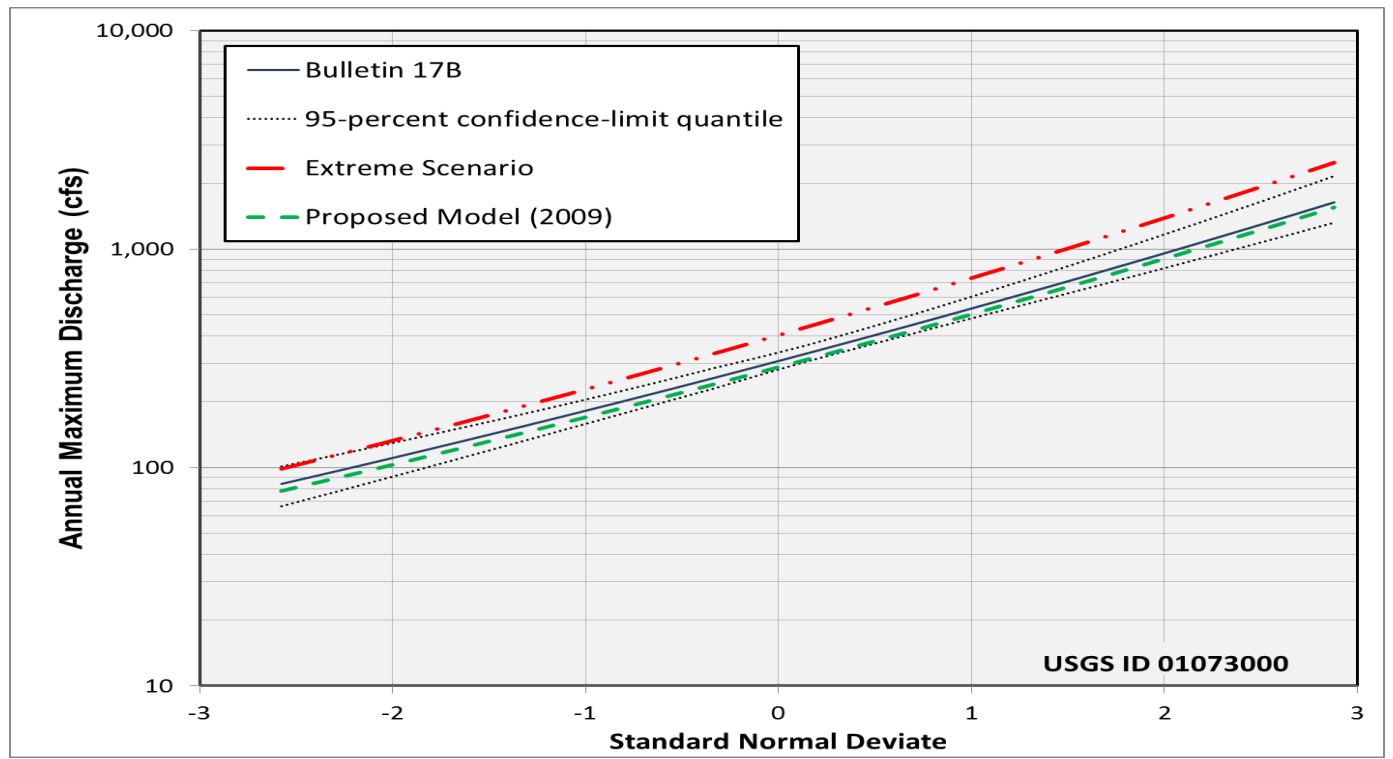

Figure 4.5 One-year ahead forecast of flood risk for Oyster River near Durham, NH (USGS Station No. 01073000) obtained using the Bulletin 17B LP3 model and the proposed modification to incorporate climate variability.

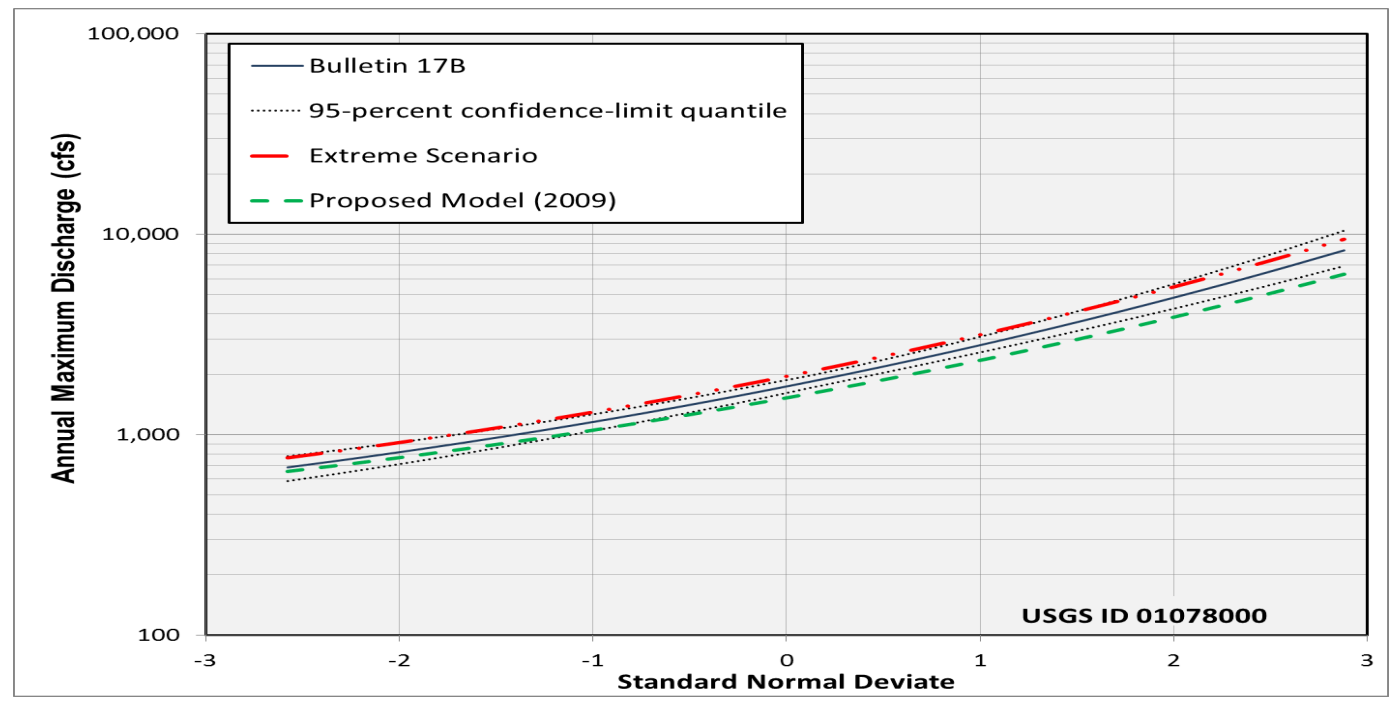

Figure 4.6 One-year ahead forecast of flood risk for Smith River near Bristol, NH (USGS Station No. 01078000) obtained using the Bulletin 17B LP3 model and the proposed modification to incorporate climate variability. 


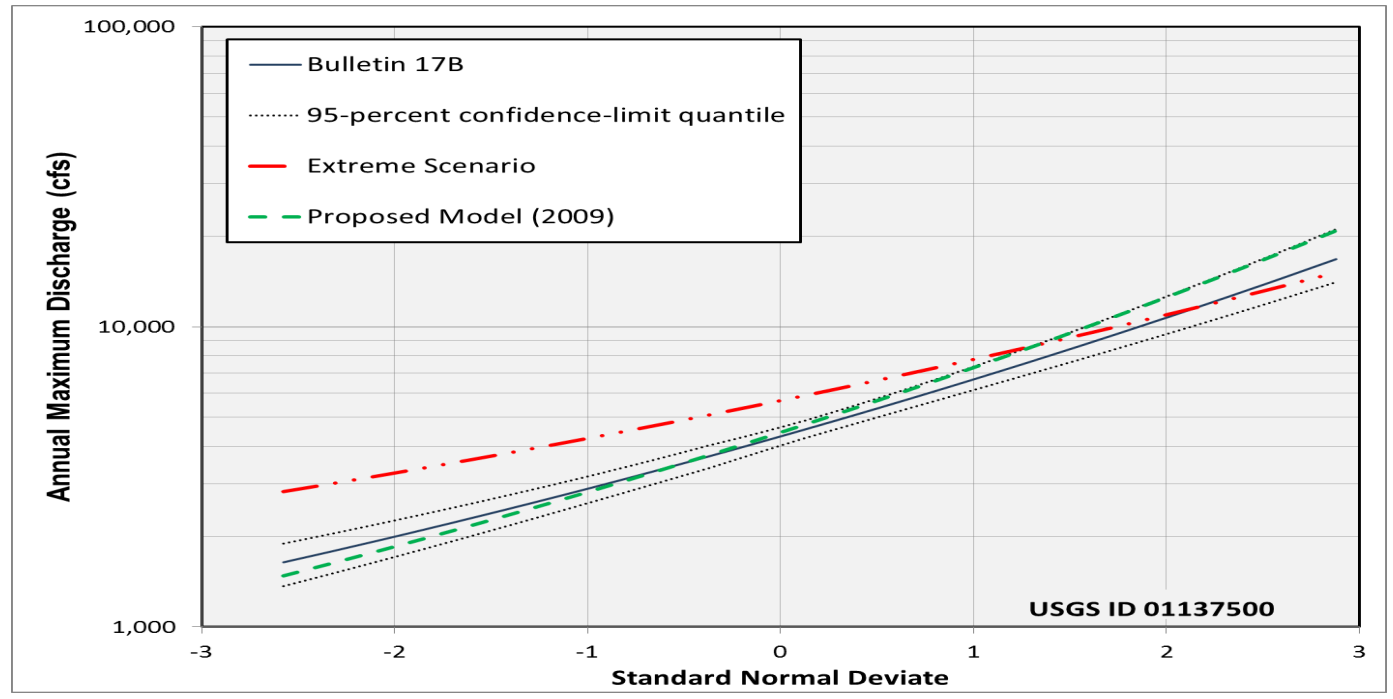

Figure 4.7 One-year ahead forecast of flood risk for Ammonoosuc River at Bethlehem Junction, NH (USGS Station No. 01137500) obtained using the Bulletin 17B LP3 model and the proposed modification to incorporate climate variability.

\subsection{Model Limitations and Future Work}

The proposed modification of Bulletin $17 B$ procedures appropriately increases/decreases expected flood risk relative to the phase and intensity of forecasted anomalies indicative of climate indices (e.g., AMO, MEI, NAO and PDO) for the upcoming year. However, estimates of $\mu(t)$ and $\sigma(t)$ could possibly be improved by employing non-linear or nonparametric models instead of a multiple linear regression model as proposed in equation (42). Additionally, cyclical patterns in AMF series could be better understood by applying spectral analyses, thereby providing insight as to the appropriate model form for $\mu(t)$ and $\sigma(t)$.

The model proposed herein would be particularly useful for long-term planning and/or construction horizons (e.g., 10-, 50-, 100-years), but how to forecast the needed climate indices with sufficient accuracy is not clear at this time. One possible solution would be to model the log space mean, and perhaps the standard deviation, as a function of appropriately downscaled GCM outputs. Results presented in CHAPTER 3 indicate that strong relationships exist between the magnitude of AMF peaks and the associated flood generating precipitation series. Although flood generating series could not be obtained 
directly, the use of the monthly precipitation forecasted within the mode month of flood peak occurrence could be investigated as a possible substitute. In addition, as the timing of flood peaks is highly correlated with temperature, GCM outputs could be used to forecast the timing of the flood peak in a future year instead of using the mode month of occurrence as a reference. The forecasted time (month) of occurrence could then be combined with a model of magnitude based on precipitation to indicate overall flood risk in the future. Along these lines, meteorological inputs such as quantity and timing of precipitation events, as well as storm type, should be further investigated to understand changes in hydrological extremes.

Beyond impacts of climate variability and potential climate change, the influence of human activities within the watershed on future flood risk must also be considered. Several USGS studies provide insight for modeling flood risk as a function of physical, observable watershed characteristics. Regional regression equations have been developed for the estimation of peak discharges with various recurrence intervals for rural watersheds as a function of characteristics, such as drainage area and percent forest cover [Jennings et al., 1994]. A procedure is also available to estimate peak discharges in urban watersheds as a function of the rural equivalent peak discharge and physical characteristics including percent impervious surface and a basin development factor used to quantify manmade changes to the drainage system [Sauer et al., 1983]. Although these procedures assume flood series are stationary, a recent extension by Moglen and Shivers [2006] accounts for nonstationarity in flood series resulting from urbanization via annual time series of percent impervious surface, or population density as a surrogate where data is limited [e.g., Stankowski, 1972]. A comprehensive analysis of how flood risk could be forecasted in the presence of both climatic and anthropogenic changes has yet to be conducted. But, the fore mentioned studies provide insight to how a physicalcausal based statistical model for flood risk projection can be created based on knowledge of the inherent structure of AMF series, and the physical and/or climatic causes of nonstationarity therein. Thus:

"The issue is how to use all the information available to reliably forecast flood risk in the future: "Where do we go from here?"," [Stedinger and Griffis, 2011] 



\section{CHAPTER 5 CONCLUSIONS}

Flooding is the most common occurring natural disaster, and a large portion of the U.S. population, infrastructure, and industry is located in flood prone areas. However, the structural and nonstructural strategies (e.g., the National Flood Insurance Program) used to reduce the economic, social and environmental impacts of floods continue to be based on static estimates of flood risk. The standard procedures for flood frequency analysis (i.e., Bulletin 17B) assume annual maximum flood (AMF) peaks are independent, identically distributed, and stationary over time; thus, AMF peaks are assumed to be unaffected by climate cycles and/or trends, or by human activities within the watershed. However, in light of surmounting evidence to the contrary, these assumptions deserve reconsideration.

The research presented herein investigated the presence of nonstationarity in AMF series for relatively unimpaired watersheds throughout the contiguous U.S. Standard statistical tests reveal AMF series exhibit nonstationarity in the form of monotonic trends, abrupt shifts, and/or long-term persistence in terms of flood magnitude. Sites exhibiting either positive or negative trends in AMF magnitude tend to be clustered throughout the U.S. However, half of these sites also contain a significant change-point, and thus, the nonstationarity in these AMF series would likely be better characterized by an abrupt shift, rather than a gradual monotonic change. Further, as the majority of the sites considered displayed signs of long-term persistence by means of the Hurst exponent, it is possible that the identified trend/change-points in the flood series are part of a long-term cycle not evident in the available record. Thus, future work should include a more indepth analysis of the possible cyclical behavior of AMF series using methods such as spectral analysis. The time of occurrence of flood peaks was also investigated for signs

of nonstationarity as an identified shift (change-point) or a linear trend could be indicative of a steady change towards an earlier/later spring; however, few sites yielded significant results. 
Watersheds are deemed unimpaired when human activities have insignificant impacts on the distribution of flows; therefore, for the purposes of this study, any nonstationarity identified in corresponding flood series should be primarily due to meteorological and/or climatic forcing, although modest trends could be observed in response to land use/land cover changes over time. Driving causes of nonstationarity in AMF series were investigated herein by relating observed changes in flood magnitude and timing to that of associated flood generating hydroclimatic series (total precipitation and average temperature series prior to occurrence of flood peak), as well as climate anomalies indicative of the large-scale climate forcing of oceanic-atmospheric patterns. Climate patterns - including the El Niño-Southern Oscillation (ENSO), North Atlantic Oscillation (NAO), Pacific Decadal Oscillation (PDO), and Atlantic Multidecadal Oscillation (AMO) - were identified as influencing factors on AMF magnitudes at numerous unimpaired gauging stations throughout the contiguous U.S. Strong relationships between AMF magnitudes and flood generating precipitation series were observed for the majority of sites analyzed in the northeast quadrant of the U.S. Although significant relationships were not identified between flood magnitude and associated temperature series, results indicate that flood generating temperature series are highly correlated with the timing of AMF peaks.

Despite the fact that the watersheds considered were classified as unimpaired, analyses herein suggest possible anthropogenic causes (e.g., regulation, dams, land use/land cover changes) of nonstationarity in AMF series. However, more in-depth investigations on a site-by-site basis are needed. To move past qualitatively assessing physical causes of nonstationarity in AMF series, and to further quantify the relative impacts of climatic variation versus anthropogenic activities on flood risk, future work should involve the regression of AMF peaks on annual flood generating meteorological series to determine the amount of variability in flood peaks individually explained by precipitation and temperature. The residual flow values after removing the effects of these meteorological variables could then be tested for trends. Any remaining trends could then be attributed to land use/land cover changes or other human effects, which could be subsequently identified. 
The existence of nonstationarity in AMF series can have a significant impact on the planning and management of water resources and relevant infrastructure; thus, the prevalence of nonstationarity in AMF series for unimpaired watersheds dictates that Bulletin $17 B$ procedures be modified to produce forecasts of flood risk which reflect the meteorological/climatic influences on flood magnitude and timing. A modification is proposed herein which accounts for nonstationarity in AMF series due to the large-scale climatic forcing of ocean-atmospheric patterns. Site specific regression models were developed to forecast flood risk one-year ahead as a function of forecasted climate pattern anomalies, which reflect the phase and intensity of climate patterns. Large differences in the one-year ahead forecasts are obtained in some locations relative to estimates obtained using the standard Bulletin $17 B$ procedures, which would potentially have significant impacts on water resources planning and management (e.g., reservoir operation). However, additional analyses to validate the proposed model are needed. A further extension of the proposed model would be particularly useful for long-term planning horizons (e.g., 10-, 50-, 100-years) and design, but how to forecast the needed indices is not particularly clear at this time. However, similar models could be derived which relate flood distribution parameters to meteorological variables, such as precipitation, for which future forecasts could be obtained using outputs of General Circulation Models. Overall, the increased knowledge of the inherent structure of AMF series and the improved understanding of physical and/or climatic causes of nonstationarity gained from this research should serve as insight for the future development of a statistical model for flood risk which incorporates impacts of both climate change (natural and/or anthropogenic) and human activities within the watershed. 



\section{REFERENCES}

Addinsoft (2011), XLSTAT (Time), Computer Software, New York, New York, retrieved May 2011, available from http://www.xlstat.com/.

Armstrong, W. H., M.J. Collins, and N.P. Snyder (2011), Increased frequency of low-magnitude floods in New England, Journal of the American Water Resources Association, 1-15. doi:10.1111/j.1752-1688.2011.00613.x.

Baldwin, C. K., and U. Lall (1999), Seasonality of streamflow: The upper Mississippi River, Water Resouces Research, 35, 1143-1154.

Balling, R., and G. Goodrich (2010), Increasing frought in the American Southwest? A continental perspective using a spatial analytical evaluation of recent trends, Physical Geography, 31(4), 293-306.

Bhattacharyya, G., and R. Johnson (1977), Statistical Concepts and Methods, John Wiley and Sons, New York, New York.

Bolboaca S.D., and L. Ja“ntschi (2006), Pearson versus Spearman, Kendall's Tau correlation analysis on structure-activity relationships of biologic active compounds, Leonardo Journal of Science, 9, 179-200.

Bras, R. L., and I. Rodriquez-Iturbe (1985), Random Functions and Hydrology, Addison-Wesley, Reading, Massachusetts.

Burn, D. H., and M.A. Hag Elnur (2002), Detection of hydrologic trends and variability. Journal of Hydrology, 255, 107-22.

Cayan, D. R., S. A. Kammerdiener, M. D. Dettinger, J. M. Caprio, D. H. Peterson (2001), Changes in the onset of spring in the western United States, American Meteorological Society, 82(3).

Changnon, S.A. and K.E. Kunkel (1995), Climate-related fluctuations in midwestern floods during 1921-1985, Journal of Water Resources Planning and Management, 121, 326-334.

Changnon, S.A. and M. Demissie (1996), Detection of changes in streamflow and floods resulting from climate fluctuations and land use-drainage changes, Climatic Change, 32, 411-421.

Chiew F.H.S., and T.A. McMahon (2002), Global ENSO-streamflow teleconnection, streamflow forecasting and interannual variability, Hydrological Sciences Journal, 47(3), 505-522.

Chow, Ven Te, D.R. Maidment, and L.W. Mays (1988), Applied Hydrology, McGraw-Hill, Columbus, Ohio. 
Cohn T.A., and H.F. Lins (2005), Nature's style: Naturally trendy, Geophysical Research Letters, 32, doi:10.1029/2005GL024476.

Collins, M. J. (2009), Evidence for changing flood risk in New England since the late 20th Century, Journal of the American Water Resources Association, 45(2), 279-90.

Coulibaly, P. and C. K. Baldwin (2005), Nonstationary hydrological time series forecasting using nonlinear dynamic methods, Journal of Hydrology, 307, 164-174.

Dettinger, M. D., D. R. Cayan, G.J. McCabe, and J.A. Marengo (2000), Multiscale hydrologic variability associated with El Niño/Southern Oscillation, in El Niño and the Southern Oscillation--Multiscale Variability, Global and Regional Impacts, edited by Diaz, H.F., and V. Markgraf, pp. 113-146, Cambridge University Press, United Kingdom, and New York, New York.

Douglas, E. M., R. M. Vogel, and C. N. Kroll (2000), Trends in floods and low flows in the United States: Impact of spatial correlation, Journal of Hydrology, 240, 90-105.

Ehsanzadeh, E., T. Ouarda, and H.M. Saley (2011), A simultaneous analysis of gradual and abrupt changes in Canadian low streamflows, Hydrological Processes, 25, 727-739.

Falcone, J.A., D.M. Carlisle, D.M. Wolock, and M.R. Meador (2010), Gages: A stream gage database for evaluating natural and altered flow conditions in the conterminous United States, Ecology.

Falcone, J.A., D.M. Carlisle, D.M. Wolock, and M.R. Meador (2011), Gages: A stream gage database for evaluating natural and altered flow conditions in the conterminous United States, Ecology, 91, 621.

Franks, S. W., and G. Kuczera (2002), Flood frequency analysis: Evidence and implications of secular climate variability, New South Wales, Water Resources Research, 38(5), doi:10.1029/2001WR000232.

Grantz, K., B. Rajagopalan, M. Clark, and E. Zagona (2005), A technique for incorporating large-scale climate information in basin-scale ensemble streamflow forecasts, Water Resources Research, 41, W10410, doi:10.1029/2004WR003467.

Griffis V. W., and J. R. Stedinger (2007), Evolution of flood frequency analysis with Bulletin 17, Journal of Hydrologic Engineering, 12(3).

Griffis, V. W. and J. R. Stedinger (2007b) The log-Pearson type 3 distribution and its application in flood frequency analysis, 1 . Distribution characteristics. Journal of Hydrologic Engineering, 12(5), 482-491. 
Griffis, V. W. and J. R. Stedinger (2007c) The log-Pearson type 3 distribution and its application in flood frequency analysis, 2. Parameter estimation methods. Journal of Hydrologic Engineering, 12(5), 492-500.

Griffis, V. W., and J. R. Stedinger (2009), The log-Pearson type 3 distribution and its application in flood frequency analysis, III: Sample skew and weighted skew estimators, Journal of Hydrologic Engineering, 14(2), 209-212.

Groisman, P. Y., R. W. Knight, and T. R. Karl (2001), Heavy precipitation and high streamflow in the contiguous United States: Trends in the twentieth century, Bulletin of the American Meteorological Society, 82(2), 219-46.

Gruber, A.M., and J.R. Stedinger (2008), Models of LP3 regional skew, data selection, and bayesian GLS regression, paper presented at World Environmental and Water Resources Conference, American Society of Civil Engineers, edited by Babcock, R.W., and R. Walton, Honolulu, Hawaii.

Hamad, K.H.(2009), Trend detection in hydrologic data: The Mann-Kendall trend test under the scaling hypothesis, Journal of Hydrology, 349, 350-363.

Hamad, K.H., and A.R. Rao (1998), A modified Mann-Kendall trend test for autocorrelated data, Journal of Hydrology, 204, 182-196.

Hamlet, A.F., and D. P. Lettenmaier (1999), Columbia River forecasting based on ENSO and PDO climate signals, Journal of Water Resources Planning. and Managment, 125(6).

Hamlet, A.F., and D.P. Lettenmaier (2007), Effects of 20th century warming and climate variability on flood risk in the western U.S., Water Resources Research, 43, W06427, doi:10.1029/2006WR005099.

Helsel D.R., and R.M. Hirsch (1993), Statistical methods in water resources, Elsevier, 522.

Helsel, D.R., and R.M. Hirsch (2002), Statistical methods in water resources, in Techniques of Water-Resource Investigations of the United States Geological Survey, Book 4, http://pubs.usgs.gov/twri/, accessed May 2010.

Hirschboeck, K.K., L.L. Ely, and R.A. Maddox (2000), Hydroclimatology of Meteorologic Foods, Inland Flood Hazards, edited by E.E. Wohl, pp. 3972, Cambridge University Press, United Kingdom, and New York, New York.

Hodgkins, G. A., and R. W. Dudley (2005), Changes in the magnitude of annual and monthly streamflows in New England, 1902-2002, in U.S. Geological Survey Scientific Investigations Report 44, Report 2005-5135, U.S. Geological Survey, Washington, D.C. 
Hurst, H.E. (1951), Long-term storage capacity of reservoirs, Transactions of the American Society of Civil Engineers, 116, 770-779.

Interagency Committee on Water Data (1982), Bulletin 17B (revised and corrected), in Guidelines For Determining Flood Flow Fequency, 28, Hydrologic Subcommission, Washington, D.C.

Intergovernmental Panel on Climate Change, Climate Change 2007: The Physical Science Basis, contribution of Working Group I to the Fourth Assessment Report of the IPCC (2007a), edited by Solomon, S., D. Qin, M. Manning, Z. Chen, M. Marquis, K.B. Averyt, M. Tignor, and H.L. Miller, Cambridge University Press, Cambridge, United Kingdom and New York, New York.

Intergovernmental Panel on Climate Change, Summary for Policy Makers in: Climate Change 2007: The Physical Science Basis, contribution of Working Group I to the Fourth Assessment Report of the IPCC (2007b), edited by Solomon, S., D. Qin, M. Manning, Z. Chen, M. Marquis, K.B. Averyt, M. Tignor, and H.L. Miller, Cambridge University Press, Cambridge, United Kingdom and New York, New York.

Jain S., and U. Lall (2000), Magnitude and timing of annual maximum floods: Trends and large-scale climate associations for the Blacksmith Fork River, Utah, Water Resources Research, 36(12), 3641-3651.

Jennings, M.E., W.O. Thomas Jr., and H.C. Riggs (1994), Nationwide Summary of U.S. Geological Survey Regional Regression Equations for Estimating Magnitude and Frequency of Floods for Ungaged Sites, 1993, in WaterResources Investigations, Report 94-4002, p. 196, superseded by WRIR 02-4168, U.S. Geological Survey, Washington, D.C.

Jones J.A., and G.E. Grant (1996), Peak flow responses to clearcutting and roads in small and large basins, Western Cascades, Oregon, Water Resources Research, 32, 959-74.

Juckem, P., R.J. Hunt, M.P. Anderson, and D.M. Robertson (2008), Effects of climate and land management change on streamflowi $\mathrm{n}$ the driftless area of Wisconsin, Journal of Hydrology, 355, 123-130.

Kalra, A., T.C. Piechota, R. Davies, and G.A. Tootle (2008), Changes in the U.S. streamflow and western U.S. snowpack, Journal of Hydrological Engineering, 13, 156-163.

Kalra, A., T.C. Piechota., R. Davies, G. A. Tootle (2006), Is climate change evident in U.S. streamflow? Examing the confluence of environmental and water concerns, paper presented at World Environmental and Water Resources Congress, American Society of Civil Engineers, edited by R. Graham, Reston, Virginia. 
Karl T. R., and R. W. Knight (1998), Secular trends of precipitation amount, frequency, and intensity in the United States., Bulletin of the American Meteorological Society, 79, 231-241.

Kashelikar, A.S. (2009), Identification of teleconnections and improved flood risk forecasts using Bulletin 17B, MS thesis, Department of Civil \& Environmental Engineering, Michigan Technological University, Houghton, MI.

Kashelikar, A.S. and,V.W. Griffis (2008), Forecasting flood risk with Bulletin 17B LP3 model and climate variability, paper presented at World Water and Environmental Resources Congress, American Society of Civl Engineers, edited by Babcock, R.W., and R. Walton, Honolulu, Hawaii.

Kiem, A.S., S.W. Franks, and G. Kuczera (2003), Multi-decadal variability of flood risk, Geophysical Research Letters, 30(2), 1035, doi:10.1029/2002GL015992.

Kirby, W. (1972), Computer-oriented Wilson-Hilferty transformation that preserves the first three moments and the lower bound of the Pearson type 3 distribution, Water Resources Research, 8(5), 1251-1254.

Konrad, C.P. (2003), Effects of Urban Development on Floods: U.S.Geological Survey Fact Sheet 076-03, 4, http://pubs.usgs.gov/fs/fs07603/, accessed March 8, 2011.

Koutsoyiannis, D. (2003), Climate change, the Hurst phenomenon, and hydrological statistics, Hydrological Sciences Journal, 48(1), 3- 24.

Kunkel, K.E., K. Andsager, and D.R. Easterling (1999), Long-term trends in extreme precipitation events over the coterminous United States and Canada, Journal of Climate, 12, 2515-2527.

Kwon, H.H., C. Brown, and U. Lall (2008), Climate informed flood frequency analysis and prediction in Montana using hierarchical Bayesian modeling, Geophysical Research Letters, 35, L05404, doi:10.1029/2007GL032220.

Lettenmaier, D. P., E. F. Wood, and J. R.Wallis (1994), Hydro-climatological trends in the continental United States, 1948-88, Journal of Climate, 7 , 586-607.

Lins, H.F., and J.R. Slack (1999), Streamflow trends in the United States, Geophysical Research Letters, 26(2), 227-230.

Maurer, E.P., A.W. Wood, J.C. Adam, D.P. Lettenmaier, and B. Nijssen (2002), A long-term hydrologically-based data set of land surface fluxes and states for the conterminous United States, Journal of Climate, 15, 32373251. 
McCabe, G.J., and D.M. Wolock (2002), A step increase in streamflow in the conterminous United States, Geophysical Research Letters 29(24), 2185, doi:10.1029/2002GL015999.

Milly, P. C. D., J. Betancourt, M. Falkenmark, R. M. Hirsch, Z. W. Kundzewicz, D. P. Lettenmaier, and R. J. Stouffer (2008), Stationarity is dead: Whiter water management?, Science, 319, 573- 574.

Moglen, G.E., and D.E. Shivers (2006), Methods for adjusting U.S. Geological Survey rural regression peak discharges in an urban setting, in U.S. Geological Survey Scientific Investigations Report 2006, Report 5270, p. 55, U.S. Geological Survey, Washington, D.C.

Moore, J. N., J. T. Harper, and M. C. Greenwood (2007), Significance of trends toward earlier snowmelt runoff, Columbia and Missouri Basin headwaters, western United States, Geophysical Research Lett.ers, 34, L16402, doi:10.1029/2007GL031022.

National Research Council (1998), Decade-to-Century-Scale Climate Variability and Change: A Science Strategy, in Panel on Climate Variability on Decade-to-Century Time Scales, National Academy Press, Washington, D.C.

NOAA (2011), Hydrologic Information Center - Flood Loss Data, in National Oceanic and Atmospheric Administration's, National Weather Service, http://www.nws.noaa.gov/oh/hic/, accessed Dec 2011.

Olsen, J. R., J. R. Stedinger, N. C. Matalas, and E.Z. Stakhiv (1999), Climate variability and flood frequency estimation for the Upper Mississippi and Lower Missouri Rivers, Journal of the American Water Resources Association, 35(6), 1509-1524.

Perreault, L., M. Hache', M. Slivitsky, and B. Bobe'e (1999), Detection of changes in precipitation and runoff over eastern Canada and U.S. using a Bayesian approach, Stochastic Research and Risk Assessment, 13, 201216.

Petrow, T., and B. Merz (2009), Trends in flood magnitude, frequency and seasonality in Germany in the period 1951-2002, Journal of Hydrology, $371,129-41$.

Pettitt, A. N. (1979), A non-parametric approach to the change-point problem, Journal of Applied Statistics, 28, 126- 135.

Piechota, T. C., and J. A. Dracup (1999), Long-range streamflow forecasting using El Niño-Southern Oscillation indicators, Journal of Hydrologic Engineering, 4(2), 144-151. 
Pinter, N., A. Jemberie, J.W.F. Remo, and R.A. Heine, (2008), Flood trends and river engineering on the Mississippi River system, Geophysical Research Letters, 35, L23404, doi: 10.1029/2008GL035987.

Potter, K. W. (1991), Hydrological impacts of changing land management practices in a moderate-sized agricultural catchment, Water Resources Research, 27(5), 845-855.

Rasmussen, P. (2001), Bayesian estimation of change points using general linear model, Water Resources Research, 37(11), 2723-2731.

Regonda, S. K., B. Rajagopalan, M. Clark, and J. Pitlick (2005), Seasonal cycle shifts in hydroclimatology over the western United States, Journal of Climate, 18(2), 372-384.

Reis, D.S. Jr., J.R. Stedinger, and E.S. Martins (2005), Bayesian GLS regression with application to LP3 regional skew estimation, Water Resources Research, 41,W10419, doi: 10.1029/2004WR00344.

Robson, A. J., T. K. Jones, D. W. Reed, and A. C. Bayliss, (1998), A study of national trend and variation in UK floods, International Journal of Climatology, 18, 165-82.

Sakalauskienè, G. (2003), The Hurst Phenomenon in hydrology, Environmental Research, Engineering and Management, 3(25), 16-20.

Sauer, V. B., W. O. Thomas, V. A. Stricker, and K. V. Wilson (1983), Flood characteristics of urban watersheds in the United States, in U.S. Geological Water Supply Paper, 2207.

Seidou, O., and T. B. M. J. Ouarda (2007), Recursion-based multiple changepoint detection in multiple linear regression and application to river streamflows, Water Resources Research, 43, W07404, doi:10.1029/2006WR005021.

Slack, J. R., A. M. Lumb, and J. M. Landwehr, Hydro-Climactic Data Network (1993), Water-Resource Investigations Report 93-4076, U.S. Geological Survey, Washington, D.C.

Slack, J.R., and J.M. Landwehr (1992), Hydro-Climatic Data Metwork: A U.S. Geological Survey Streamflow Data Set for the United States for the study of Climate Variations, 1874-1988, Open-File Report 2-129, U.S. Geological Survey, Washington, D.C.

Small, D., S. Islam, and R. M. Vogel (2006), Trends in precipitation and streamflow in the eastern U.S.: Paradox or perception?, Geophysical Research Letters, 33, L03403. 
Stankowski, S.J. (1972), Population desnity as an indirect indicator of urban and suburban land-surface modification, Rep. 800B, B219-B224, U.S. Geological Survey, Washington, D.C.

Stedinger, J. R., and V. W. Griffis (2008), Flood frequency analysis in the United States: Time to update, Journal of Hydrological Engineering, 4, 199-204.

Stedinger, J. R., and V.W. Griffis (2011), Getting from here to where? Flood frequency analysis and climate, Journal of the American Water Resources Association, 47, 506-513. doi: 10.1111/j.1752-1688.2011.00545.x

Stewart, I.T., D.R. Cayan, and M.D. Dettinger (2005), Changes toward earlier streamsflow timing across western North America, Journal of Climate, $18,1136-1155$.

Storck, P., L. Bowling, P. Wetherbee, and D. Lettenmaier (1998), Application of a GIS-based distirbution hydrology model for prediction of forest harvest effects on peak stream flow in the Pacific Northwest, Hydrological Processes, 12, 889-904.

Strupczewski, W. G., V. P. Singh, and W. Feluch (2001), Non-stationary approach to at-site flood frequency modeling I. maximum likelihood estimation, Journal of Hydrology, 248, 123-142.

Sveinsson, O. G. B., J. D. Salas, and D. C. Boes (2005), Prediction of extreme events in hydrologic processes that exhibit abrupt shifting patterns, Journal of Hydrologic Engineering, 10(4), 315-326.

Thomas, W. O. Jr. (1985), A uniform technique for flood frequency analysis, Journal of Water Resources Planning and Management, 111(3), 321-337.

Tomé, A. R., and P.M.A. Miranda (2004), Piecewise linear fitting and trend changing points of climate parameters, Geophysical Research Letters, 31, L02207, doi:10.1029/2003GL019100.

Tootle, G. A., T. C. Piechota, and A. Singh (2005), Coupled oceanic-atmospheric variability and U.S. streamflow, Water Resources Research, 41, W12408, doi:10.1029/2005WR004381.

Twine, T. E., C. J. Kucharik, and J. A. Foley (2005), Effects of El Niño-Southern Oscillation on the climate, water balance, and streamflow of the Mississippi River Basin, Journal of Climate, 18(22), 4840-4861.

Villarini, G., and J.A. Smith (2010), Flood peak distributions for the eastern United States, Water Resources Research, 46, W06504, doi: 10.1029/2009WR008395. 
Villarini, G., F. Serinaldi, J. A. Smith, and W. F. Krajewski (2009), On the stationarity of annual flood peaks in the continental united states during the 20th century, Water Resources Research, 45, W08417.

Villarini, G., G.A. Vecchi, and J.A. Smith (2010), Modeling of the dependence of tropical storm counts in the North Atlantic Basin on climate indices, Monthly Weather Review, 138, 2681-2705, doi:10.1175/2010MWR33151

Villarini, G., G.A. Vecchi, T.R. Knutson, M. Zhao, and J.A. Smith (2011), North Atlantic tropical storm frequency response to anthropogenic forcing: Projections and sources of uncertainty, Journal of Climate, doi: 10.1175/2011JCLI3853.1, in press.

Walter, M., and R.M. Vogel (2010), Increasing trends in peak flow in the northeastern United States and their impacts on design, paper presented at 2nd Joint Federal Interagency Conference, Las Vegas, Nevada.

Water Resources Council (1967), A uniform technique for determining flood flow frequencies, in Bulletin 15, Hydrologic Commission., Washington, D.C.

Yue, S., and C. Wang (2004), The Mann-Kendall test modified by effective sample size to detect trend in serially correlated hydrological series, Water Resources Management, 18(3), 201-218

Yue, S., and C.Y. Wang (2002), The applicability of pre-whitening to eliminate the influence of serial correlation on the Mann-Kendall test, Water Resources. Research, 38(6), doi:10.1029/2001WR000861, 4-1-7.

Yue, S., P. Pilon, and B. Phinney (2003), Canadian streamflow trend detection: impacts of serial and cross-correlation, Hydrologic Science. Journal, $48(1), 51-64$.

Yue, S., P. Pilon, and G. Cavadias (2002), Power of the Mann-Kendall and Spearman's Rho tests for detecting monotonic trends in hydrological series, Journal of Hydrology, 259, 254-271. 



\section{APPENDIX A RESULTS OF NONSTATIONARITY TESTS ON SERIES OF FLOOD MAGNITUDE}

This appendix contains tables of results for the tests for trends, change-points, and longterm persistence in annual maximum flood series as discussed in CHAPTER 2. Results are presented for both the traditional Mann-Kendall test (neglecting autocorrelation) and the modified Mann-Kendall test to account for autocorrelation. The length of continuous data $(\mathrm{N})$ analyzed for each site is also reported. Only sites for which results are significant on the $10 \%$ level are included in the following tables (results significant on the $5 \%$ level are in bold). Results are omitted (blank spaces) when p-values greater than $10 \%$ obtained. A table of Hurst exponents computed for all 569 sites is provided.

Table A.1

Results of Pettitt and Mann-Kendall tests on flood magnitude (significant on the $10 \%$ level), including the year of the identified shift in the mean, and the direction of significant trends, either positive $(+)$ and negative $(-)$.

\begin{tabular}{|c|c|c|c|c|c|c|c|}
\hline \multirow{2}{*}{$\begin{array}{l}\text { Station } \\
\text { Number }\end{array}$} & \multirow{2}{*}{$\begin{array}{c}\text { Years of } \\
\text { Record } \\
\mathrm{N} \\
\end{array}$} & \multicolumn{2}{|c|}{ Pettitt Test } & \multicolumn{2}{|c|}{$\begin{array}{c}\text { Traditional } \\
\text { Mann-Kendall }\end{array}$} & \multicolumn{2}{|c|}{$\begin{array}{c}\text { Modified } \\
\text { Mann-Kendall }\end{array}$} \\
\hline & & Year & $\mathrm{p}$-value & $\mathrm{p}$-value & Trend & $\mathrm{p}$-value & Trend \\
\hline 01011000 & 79 & 1968 & 0.040 & & & & \\
\hline 01014000 & 84 & 1967 & 0.014 & & & & \\
\hline 01031500 & 108 & 1966 & 0.022 & 0.038 & + & 0.077 & + \\
\hline 01064500 & 81 & 1966 & 0.035 & & & & \\
\hline 01119500 & 78 & 1971 & 0.038 & & & & \\
\hline 01127500 & 79 & 1967 & 0.020 & & & & \\
\hline 01169000 & 70 & 1972 & 0.000 & & & 0.026 & + \\
\hline 01175500 & 99 & 1939 & 0.000 & 0.004 & - & 0.008 & - \\
\hline 01176000 & 97 & 1967 & 0.036 & 0.010 & + & & \\
\hline 01181000 & 74 & 1968 & 0.018 & 0.092 & - & & \\
\hline 01188000 & 78 & 1971 & 0.069 & 0.036 & + & & \\
\hline 01196500 & 79 & 1968 & 0.000 & 0.091 & + & 0.004 & + \\
\hline 01334500 & 87 & 1972 & 0.000 & 0.053 & + & 0.049 & + \\
\hline 01350000 & & & & 0.069 & + & & \\
\hline 01357500 & & & & 0.058 & + & & \\
\hline 01379500 & 73 & 1966 & 0.010 & & & & \\
\hline 01381500 & 89 & 1969 & 0.000 & 0.000 & + & 0.041 & + \\
\hline 01387500 & 88 & 1967 & 0.003 & & & 0.077 & + \\
\hline 01396500 & 91 & 1969 & 0.002 & 0.032 & + & & \\
\hline 01397500 & 74 & 1968 & 0.000 & 0.001 & + & 0.000 & + \\
\hline
\end{tabular}


Table A.1, continued

\begin{tabular}{|c|c|c|c|c|c|c|c|}
\hline \multirow{2}{*}{$\begin{array}{l}\text { Station } \\
\text { Number }\end{array}$} & \multirow{2}{*}{$\begin{array}{c}\text { Years of } \\
\text { Record } \\
\text { N } \\
\end{array}$} & \multicolumn{2}{|c|}{ Pettitt Test } & \multicolumn{2}{|c|}{$\begin{array}{c}\text { Traditional } \\
\text { Mann-Kendall }\end{array}$} & \multicolumn{2}{|c|}{$\begin{array}{c}\text { Modified } \\
\text { Mann-Kendall }\end{array}$} \\
\hline & & Year & $\mathrm{p}$-value & p-value & Trend & $\mathrm{p}$-value & Trend \\
\hline 01398500 & 89 & 1969 & 0.002 & 0.018 & + & & \\
\hline 01408500 & 82 & 1957 & 0.081 & & & & \\
\hline 01411000 & 85 & 1966 & 0.027 & & & & \\
\hline 01411500 & & & & 0.092 & - & & \\
\hline 01420500 & 97 & 1968 & 0.000 & 0.001 & + & 0.003 & + \\
\hline 01426500 & 98 & 1963 & 0.000 & 0.000 & - & 0.002 & - \\
\hline 01439500 & 102 & 1967 & 0.014 & & & 0.084 & + \\
\hline 01445500 & 89 & 1966 & 0.000 & 0.000 & + & 0.000 & + \\
\hline 01503000 & 98 & 1964 & 0.066 & & & & \\
\hline 01512500 & 98 & 1950 & 0.031 & & & & \\
\hline 01518000 & 72 & 1980 & 0.000 & 0.011 & - & 0.001 & - \\
\hline 01520500 & 81 & 1979 & 0.000 & 0.000 & - & 0.002 & - \\
\hline 01531000 & 107 & 1964 & 0.024 & & & & \\
\hline 01538000 & 91 & 1969 & 0.065 & & & & \\
\hline 01539000 & & & & 0.011 & + & & \\
\hline 01541500 & 97 & 1956 & 0.017 & & & 0.057 & - \\
\hline 01548500 & 92 & 1935 & 0.069 & & & & \\
\hline 01555500 & 81 & 1969 & 0.007 & 0.078 & + & & \\
\hline 01567000 & 111 & 1937 & 0.006 & 0.001 & - & 0.023 & - \\
\hline 01604500 & 72 & 1967 & 0.039 & & & & \\
\hline 01634500 & 73 & 1970 & 0.000 & 0.026 & - & & \\
\hline 01645000 & 81 & 1970 & 0.000 & & & 0.005 & + \\
\hline 01667500 & 80 & 1971 & 0.056 & & & & \\
\hline 02013000 & 82 & 1968 & 0.096 & & & & \\
\hline 02016000 & 85 & 1968 & 0.040 & & & & \\
\hline 02051500 & 83 & 1971 & 0.039 & & & & \\
\hline 02059500 & & & & 0.047 & + & & \\
\hline 02074500 & 81 & 1971 & 0.003 & 0.016 & + & & \\
\hline 02131000 & 72 & 1993 & 0.100 & 0.036 & - & & \\
\hline 02136000 & & & & 0.021 & - & & \\
\hline 02156500 & 71 & 1979 & 0.090 & & & & \\
\hline 02173500 & 72 & 1980 & 0.001 & 0.002 & - & 0.021 & - \\
\hline 02213500 & & & & 0.017 & - & & \\
\hline 02296750 & 80 & 1960 & 0.001 & & & 0.031 & - \\
\hline 02301500 & 79 & 1968 & 0.011 & & & 0.068 & - \\
\hline 02303000 & 71 & 1970 & 0.044 & & & & \\
\hline 02313000 & 79 & 1971 & 0.054 & 0.015 & - & 0.065 & - \\
\hline 02317500 & 83 & 1957 & 0.074 & & & & \\
\hline 02321500 & 79 & 1973 & 0.100 & 0.088 & - & & \\
\hline 02329000 & 85 & 1957 & 0.012 & & & & \\
\hline 02339500 & 110 & 1975 & 0.001 & 0.000 & - & 0.009 & - \\
\hline 02383500 & 73 & 1980 & 0.000 & 0.069 & - & 0.006 & - \\
\hline 02387500 & 110 & 1980 & 0.010 & 0.028 & - & & \\
\hline
\end{tabular}


Table A.1, continued

\begin{tabular}{|c|c|c|c|c|c|c|c|}
\hline \multirow{2}{*}{$\begin{array}{l}\text { Station } \\
\text { Number }\end{array}$} & \multirow{2}{*}{$\begin{array}{c}\text { Years of } \\
\text { Record } \\
\mathrm{N} \\
\end{array}$} & \multicolumn{2}{|c|}{ Pettitt Test } & \multicolumn{2}{|c|}{$\begin{array}{c}\text { Traditional } \\
\text { Mann-Kendall }\end{array}$} & \multicolumn{2}{|c|}{$\begin{array}{c}\text { Modified } \\
\text { Mann-Kendall }\end{array}$} \\
\hline & & Year & p-value & $\mathrm{p}$-value & Trend & $\mathrm{p}$-value & Trend \\
\hline 02424000 & 83 & 1984 & 0.057 & & & & \\
\hline 02441000 & 71 & 1985 & 0.025 & 0.077 & - & & \\
\hline 02467000 & 82 & 1969 & 0.002 & 0.067 & + & 0.058 & + \\
\hline 02486000 & & & & 0.047 & + & & \\
\hline 03010500 & 95 & 1939 & 0.003 & & & & \\
\hline 03015500 & & & & 0.033 & + & & \\
\hline 03024000 & 78 & 1969 & 0.057 & & & & \\
\hline 03049500 & 72 & 1966 & 0.003 & & & 0.020 & - \\
\hline 03069500 & 97 & 1954 & 0.002 & 0.008 & + & 0.076 & + \\
\hline 03102500 & & & & 0.040 & - & & \\
\hline 03109500 & 94 & 1959 & 0.002 & 0.009 & - & & \\
\hline 03118500 & 90 & 1974 & 0.022 & 0.037 & + & 0.099 & + \\
\hline 03167000 & 84 & 1978 & 0.010 & 0.004 & - & & \\
\hline 03186500 & & & & 0.046 & + & & \\
\hline 03193000 & 111 & 1940 & 0.003 & 0.002 & - & 0.052 & - \\
\hline 03234500 & 79 & 1972 & 0.034 & & & & \\
\hline 03262000 & 94 & 1930 & 0.064 & & & & \\
\hline 03301500 & & & & 0.083 & - & & \\
\hline 03307000 & 70 & 1973 & 0.006 & & & & \\
\hline 03326500 & & & & 0.064 & + & & \\
\hline 03345500 & 97 & 1981 & 0.078 & 0.058 & + & & \\
\hline 03363500 & & & & 0.085 & + & & \\
\hline 03379500 & 96 & 1981 & 0.036 & 0.010 & + & & \\
\hline 03381500 & 71 & 1981 & 0.040 & & & 0.096 & + \\
\hline 03451500 & 111 & 1920 & 0.059 & 0.050 & - & & \\
\hline 03574500 & & & & 0.083 & - & & \\
\hline 04010500 & 87 & 1954 & 0.018 & 0.065 & - & 0.079 & - \\
\hline 04056500 & & & & 0.057 & - & & \\
\hline 04073500 & 110 & 1953 & 0.021 & 0.025 & - & & \\
\hline 04079000 & 73 & 1976 & 0.076 & & & & \\
\hline 04112500 & 100 & 1957 & 0.051 & & & & \\
\hline 04191500 & 95 & 1973 & 0.063 & 0.044 & + & & \\
\hline 04193500 & 73 & 1973 & 0.078 & & & & \\
\hline 04262500 & 94 & 1973 & 0.048 & 0.064 & + & & \\
\hline 04264331 & 93 & 1968 & 0.000 & 0.001 & + & 0.002 & + \\
\hline 05053000 & 78 & 1992 & 0.002 & 0.010 & + & 0.031 & + \\
\hline 05062000 & 80 & 1961 & 0.007 & & & 0.008 & + \\
\hline 05062500 & 80 & 1992 & 0.000 & 0.020 & + & 0.003 & + \\
\hline 05066500 & 77 & 1964 & 0.000 & 0.042 & + & 0.003 & + \\
\hline 05078000 & 72 & 1961 & 0.056 & & & & \\
\hline 05078500 & 76 & 1961 & 0.006 & & & 0.052 & + \\
\hline 05082500 & 111 & 1964 & 0.000 & 0.000 & + & 0.006 & + \\
\hline 05084000 & & & & 0.064 & + & & \\
\hline
\end{tabular}


Table A.1, continued

\begin{tabular}{|c|c|c|c|c|c|c|c|}
\hline \multirow{2}{*}{$\begin{array}{l}\text { Station } \\
\text { Number }\end{array}$} & \multirow{2}{*}{$\begin{array}{c}\text { Years of } \\
\text { Record } \\
\text { N } \\
\end{array}$} & \multicolumn{2}{|c|}{ Pettitt Test } & \multicolumn{2}{|c|}{$\begin{array}{c}\text { Traditional } \\
\text { Mann-Kendall }\end{array}$} & \multicolumn{2}{|c|}{$\begin{array}{c}\text { Modified } \\
\text { Mann-Kendall }\end{array}$} \\
\hline & & Year & $\mathrm{p}$-value & p-value & Trend & $\mathrm{p}$-value & Trend \\
\hline 05100000 & 91 & 1964 & 0.017 & 0.072 & + & 0.043 & + \\
\hline 05112000 & 91 & 1991 & 0.050 & 0.087 & + & & \\
\hline 05280000 & 81 & 1964 & 0.012 & & & 0.014 & + \\
\hline 05291000 & & & & & & 0.096 & + \\
\hline 05304500 & 74 & 1964 & 0.005 & & & 0.024 & + \\
\hline 05316500 & 81 & 1974 & 0.003 & & & 0.011 & + \\
\hline 05317000 & 80 & 1982 & 0.094 & & & & \\
\hline 05330000 & 76 & 1982 & 0.005 & 0.010 & + & 0.025 & + \\
\hline 05331000 & 110 & 1942 & 0.000 & 0.001 & + & 0.018 & + \\
\hline 05340500 & 101 & 1940 & 0.000 & & & & \\
\hline 05407000 & 96 & 1946 & 0.017 & & & & \\
\hline 05408000 & 72 & 1984 & 0.012 & 0.083 & - & 0.080 & - \\
\hline 05410490 & 77 & 1967 & 0.024 & & & & \\
\hline 05414000 & 76 & 1979 & 0.000 & 0.086 & - & 0.005 & - \\
\hline 05420500 & 111 & 1964 & 0.003 & 0.007 & + & 0.067 & + \\
\hline 05422000 & 76 & 1972 & 0.053 & & & & \\
\hline 05431486 & 71 & 1953 & 0.092 & & & & \\
\hline 05432500 & 71 & 1969 & 0.001 & & & 0.021 & - \\
\hline 05434500 & 71 & 1975 & 0.008 & & & 0.053 & - \\
\hline 05435500 & 97 & 1953 & 0.006 & 0.051 & - & 0.062 & - \\
\hline 05436500 & 96 & 1953 & 0.014 & 0.058 & - & 0.061 & - \\
\hline 05446500 & 71 & 1970 & 0.049 & & & & \\
\hline 05447500 & 75 & 1968 & 0.001 & & & & \\
\hline 05454500 & 108 & 1953 & 0.004 & 0.014 & - & 0.083 & - \\
\hline 05476000 & 80 & 1982 & 0.046 & & & 0.059 & + \\
\hline 05482500 & & & & 0.077 & + & & \\
\hline 05484000 & & & & 0.032 & + & & \\
\hline 05484500 & 96 & 1943 & 0.006 & 0.018 & + & 0.092 & + \\
\hline 05490500 & & & & 0.088 & + & & \\
\hline 05495000 & 89 & 1972 & 0.036 & & & & \\
\hline 05501000 & 76 & 1972 & 0.011 & & & & \\
\hline 05520500 & 96 & 1965 & 0.000 & 0.000 & + & 0.001 & + \\
\hline 05526000 & 87 & 1967 & 0.002 & 0.006 & + & 0.014 & + \\
\hline 05527500 & 96 & 1967 & 0.000 & 0.000 & + & 0.003 & + \\
\hline 05555300 & 80 & 1978 & 0.011 & 0.044 & + & 0.071 & + \\
\hline 05585000 & 90 & 1958 & 0.019 & & & 0.073 & + \\
\hline 05592500 & 95 & 1942 & 0.069 & & & & \\
\hline 05593000 & 81 & 1962 & 0.003 & & & & \\
\hline 05597000 & 96 & 1964 & 0.003 & 0.021 & - & 0.053 & - \\
\hline 06019500 & 72 & 1966 & 0.010 & & & 0.079 & + \\
\hline 06191500 & & & & 0.010 & + & & \\
\hline 06214500 & 83 & 1941 & 0.096 & & & & \\
\hline 06289000 & 72 & 1962 & 0.095 & & & & \\
\hline
\end{tabular}


Table A.1, continued

\begin{tabular}{|c|c|c|c|c|c|c|c|}
\hline \multirow{2}{*}{$\begin{array}{l}\text { Station } \\
\text { Number }\end{array}$} & \multirow{2}{*}{$\begin{array}{c}\text { Years of } \\
\text { Record } \\
\mathrm{N}\end{array}$} & \multicolumn{2}{|c|}{ Pettitt Test } & \multicolumn{2}{|c|}{$\begin{array}{c}\text { Traditional } \\
\text { Mann-Kendall }\end{array}$} & \multicolumn{2}{|c|}{$\begin{array}{c}\text { Modified } \\
\text { Mann-Kendall }\end{array}$} \\
\hline & & Year & $\mathrm{p}$-value & $\mathrm{p}$-value & Trend & $\mathrm{p}$-value & Trend \\
\hline 06335500 & 72 & 1978 & 0.011 & & & & \\
\hline 06337000 & 76 & 1972 & 0.000 & & & 0.025 & - \\
\hline 06340500 & 73 & 1972 & 0.050 & & & 0.096 & - \\
\hline 06478500 & 82 & 1982 & 0.010 & 0.013 & + & 0.095 & + \\
\hline 06710500 & 88 & 1958 & 0.000 & 0.034 & - & 0.024 & - \\
\hline 06800500 & 82 & 1957 & 0.009 & & & 0.020 & + \\
\hline 06810000 & 81 & 1946 & 0.053 & & & 0.058 & + \\
\hline 06864500 & 84 & 1975 & 0.004 & 0.044 & - & 0.065 & - \\
\hline 06869500 & & & & 0.013 & - & & \\
\hline 06876900 & 93 & 1975 & 0.036 & 0.004 & - & & \\
\hline 06889500 & 82 & 1966 & 0.000 & 0.027 & + & 0.014 & + \\
\hline 06892000 & 82 & 1957 & 0.085 & & & & \\
\hline 06899500 & 83 & 1958 & 0.006 & & & 0.059 & + \\
\hline 06908000 & 73 & 1972 & 0.073 & & & & \\
\hline 07016500 & 94 & 1980 & 0.011 & 0.034 & + & & \\
\hline 07018500 & 88 & 1981 & 0.058 & & & 0.071 & + \\
\hline 07019000 & 89 & 1980 & 0.010 & 0.030 & + & 0.070 & + \\
\hline 07096000 & 111 & 1966 & 0.002 & 0.001 & - & 0.034 & - \\
\hline 07144200 & 90 & 1956 & 0.009 & & & 0.036 & + \\
\hline 07146500 & 89 & 1972 & 0.065 & & & 0.077 & + \\
\hline 07176000 & 75 & 1961 & 0.000 & & & & \\
\hline 07203000 & & & & & & 0.092 & - \\
\hline 07218000 & & & & 0.055 & - & & \\
\hline 07234000 & 73 & 1973 & 0.000 & 0.000 & - & 0.000 & - \\
\hline 07247500 & 72 & 1974 & 0.000 & & & 0.014 & - \\
\hline 07252000 & 72 & 1981 & 0.073 & & & & \\
\hline 07340000 & 81 & 1969 & 0.000 & 0.019 & - & 0.005 & - \\
\hline 07340500 & 73 & 1974 & 0.000 & & & 0.000 & - \\
\hline 07378500 & 73 & 1971 & 0.005 & & & 0.038 & + \\
\hline 08041000 & 90 & 1962 & 0.006 & & & & \\
\hline 08055500 & 88 & 1950 & 0.000 & & & 0.031 & - \\
\hline 08080500 & 73 & 1972 & 0.000 & 0.004 & - & 0.004 & - \\
\hline 08082000 & 73 & 1961 & 0.000 & & & 0.001 & - \\
\hline 08082500 & 88 & 1967 & 0.000 & 0.000 & - & 0.000 & - \\
\hline 08085500 & 87 & 1962 & 0.020 & & & 0.059 & - \\
\hline 08088000 & 73 & 1969 & 0.003 & & & 0.009 & - \\
\hline 08128000 & 81 & 1964 & 0.010 & & & 0.090 & - \\
\hline 08158000 & 111 & 1941 & 0.000 & 0.000 & - & 0.014 & - \\
\hline 08210000 & 95 & 1983 & 0.000 & 0.001 & - & 0.041 & - \\
\hline 08380500 & & & & 0.073 & - & & \\
\hline 09085000 & 100 & 1959 & 0.000 & 0.000 & - & 0.001 & - \\
\hline 09110000 & 102 & 1958 & 0.000 & 0.000 & - & 0.000 & - \\
\hline 09147500 & 90 & 1987 & 0.013 & 0.032 & - & 0.047 & - \\
\hline
\end{tabular}


Table A.1, continued

\begin{tabular}{|c|c|c|c|c|c|c|c|}
\hline \multirow{2}{*}{$\begin{array}{l}\text { Station } \\
\text { Number }\end{array}$} & \multirow{2}{*}{$\begin{array}{c}\text { Years of } \\
\text { Record } \\
\text { N } \\
\end{array}$} & \multicolumn{2}{|c|}{ Pettitt Test } & \multicolumn{2}{|c|}{$\begin{array}{c}\text { Traditional } \\
\text { Mann-Kendall }\end{array}$} & \multicolumn{2}{|c|}{$\begin{array}{c}\text { Modified } \\
\text { Mann-Kendall }\end{array}$} \\
\hline & & Year & $\mathrm{p}$-value & p-value & Trend & $\mathrm{p}$-value & Trend \\
\hline 09180500 & 88 & 1958 & 0.001 & & & 0.009 & - \\
\hline 09315000 & 104 & 1958 & 0.000 & 0.000 & - & 0.003 & - \\
\hline 09379500 & 84 & 1958 & 0.000 & 0.093 & - & 0.010 & - \\
\hline 09415000 & & & & 0.026 & - & & \\
\hline 09471000 & 76 & 1959 & 0.001 & 0.088 & - & 0.002 & - \\
\hline 10128500 & 102 & 1923 & 0.089 & & & & \\
\hline 10234500 & 97 & 1949 & 0.003 & & & 0.096 & - \\
\hline 10329500 & & & & 0.031 & - & & \\
\hline 11383500 & 90 & 1937 & 0.022 & & & & \\
\hline 11522500 & & & & 0.035 & - & & \\
\hline 11525500 & 99 & 1960 & 0.000 & 0.000 & - & 0.013 & - \\
\hline 11530000 & & & & 0.024 & - & & \\
\hline 11532500 & 79 & 1949 & 0.031 & 0.059 & - & & \\
\hline 12010000 & 81 & 1977 & 0.087 & & & & \\
\hline 12020000 & 71 & 1985 & 0.055 & & & & \\
\hline 12035000 & 81 & 1978 & 0.006 & 0.021 & + & 0.013 & + \\
\hline 12039500 & 85 & 1979 & 0.027 & 0.097 & + & 0.035 & + \\
\hline 12054000 & 72 & 1993 & 0.015 & & & & \\
\hline 12056500 & 86 & 1979 & 0.082 & & & & \\
\hline 12134500 & 82 & 1973 & 0.040 & 0.027 & + & & \\
\hline 12186000 & 82 & 1973 & 0.031 & 0.069 & + & & \\
\hline 12189500 & 82 & 1973 & 0.016 & 0.097 & + & 0.060 & + \\
\hline 12321500 & 82 & 1952 & 0.007 & & & 0.033 & + \\
\hline 12322000 & 83 & 1972 & 0.000 & 0.000 & - & 0.004 & - \\
\hline 12354500 & 82 & 1946 & 0.082 & 0.041 & - & & \\
\hline 12355500 & & & & 0.071 & - & & \\
\hline 12370000 & 89 & 1986 & 0.086 & 0.031 & - & & \\
\hline 12401500 & 82 & 1947 & 0.030 & & & & \\
\hline 12404500 & 81 & 1947 & 0.067 & & & & \\
\hline 12442500 & & & & 0.029 & - & & \\
\hline 13037500 & 100 & 1956 & 0.001 & 0.033 & - & 0.017 & - \\
\hline 13120500 & 91 & 1950 & 0.031 & & & & \\
\hline 13269000 & 101 & 1986 & 0.056 & & & 0.086 & - \\
\hline 13342500 & 87 & 1976 & 0.000 & 0.000 & - & 0.012 & - \\
\hline 14044000 & 81 & 1969 & 0.020 & 0.087 & + & 0.097 & + \\
\hline 14105700 & 110 & 1972 & 0.000 & 0.000 & - & 0.000 & - \\
\hline 14113000 & 82 & 1983 & 0.091 & 0.083 & - & & \\
\hline 14137000 & 99 & 1952 & 0.075 & & & & \\
\hline 14191000 & 111 & 1966 & 0.000 & 0.000 & - & 0.000 & - \\
\hline 14306500 & 71 & 1983 & 0.037 & & & & \\
\hline 14321000 & 103 & 1945 & 0.045 & & & & \\
\hline 14325000 & & & & 0.093 & - & & \\
\hline 14362000 & 72 & 1975 & 0.001 & & & 0.030 & - \\
\hline
\end{tabular}


Table A.2

Results of Mann-Kendall tests (10\% significance level) on AMF subseries for sites exhibiting a significant change-point in the mean flood magnitude at the $10 \%$ level. The mean flood magnitude in the complete series, and each subseries are also reported.

\begin{tabular}{|c|c|c|c|c|c|c|c|}
\hline \multirow{2}{*}{$\begin{array}{c}\text { Site } \\
\text { Number }\end{array}$} & \multirow{2}{*}{$\begin{array}{c}\text { Complete } \\
\text { Series } \\
\text { Mean }\end{array}$} & \multicolumn{3}{|c|}{ Before Change-Point } & \multicolumn{3}{|c|}{ After Change-point } \\
\hline & & Mean & Trend & $\mathrm{p}$-value & Mean & Trend & p-value \\
\hline 1011000 & 16,305 & 14,307 & - & 0.018 & & & \\
\hline 1181000 & 6,926 & 5,947 & - & 0.030 & & & \\
\hline 1188000 & 362 & 305 & - & 0.013 & & & \\
\hline 1379500 & 1,370 & & & & 1,506 & - & 0.080 \\
\hline 1381500 & 1,048 & 851 & - & 0.064 & & & \\
\hline 1397500 & 561 & & & & 808 & + & 0.004 \\
\hline 1420500 & 14,142 & 10,599 & + & 0.062 & & & \\
\hline 1445500 & 997 & 780 & + & 0.051 & & & \\
\hline 1503000 & 32,940 & & & & 31,026 & + & 0.045 \\
\hline 1518000 & 10,081 & & & & 5,578 & - & 0.086 \\
\hline 1548500 & 14,687 & 9,861 & - & 0.087 & & & \\
\hline 1555500 & 6,368 & 4,534 & - & 0.056 & & & \\
\hline 1567000 & 49,251 & 57,038 & - & 0.080 & & & \\
\hline 1667500 & 13,812 & 11,724 & - & 0.033 & & & \\
\hline 2074500 & 5,183 & 4,224 & - & 0.059 & & & \\
\hline 2173500 & 2,632 & & & & 2,023 & - & 0.010 \\
\hline 3109500 & 10,123 & 11,824 & + & 0.026 & & & \\
\hline 3262000 & 4,501 & 5,934 & - & 0.014 & & & \\
\hline 4264331 & 282,581 & & & & 306,977 & - & 0.090 \\
\hline 5062000 & 2,567 & 1,431 & + & 0.002 & & & \\
\hline 5062500 & 2,410 & 1,721 & + & 0.029 & & & \\
\hline 5066500 & 2,570 & & & & 3,432 & + & 0.081 \\
\hline 5078000 & 1,709 & 1,334 & + & 0.092 & & & \\
\hline 5082500 & 23,342 & & & & 34,260 & + & 0.065 \\
\hline 5280000 & 5,035 & 3,790 & + & 0.007 & & & \\
\hline 5316500 & 2,576 & 2,282 & + & 0.020 & & & \\
\hline 5331000 & 47,228 & 33,631 & - & 0.025 & & & \\
\hline 5340500 & 24,603 & & & & 27,571 & - & 0.094 \\
\hline 5484500 & 17,783 & 12,197 & - & 0.069 & & & \\
\hline 6800500 & 18,459 & 14,276 & + & 0.048 & & & \\
\hline 6810000 & 18,573 & 12,210 & + & 0.015 & & & \\
\hline 7234000 & 6,896 & 13,201 & - & 0.078 & 1,088 & - & 0.000 \\
\hline 8055500 & 13,709 & 28,596 & + & 0.078 & & & \\
\hline 8080500 & 16,792 & & & & 10,706 & - & 0.016 \\
\hline 8082000 & 11,057 & & & & 6,908 & - & 0.069 \\
\hline 8082500 & 22,685 & 33,227 & - & 0.020 & 12,613 & - & 0.077 \\
\hline 8088000 & 21,664 & & & & 16,907 & - & 0.082 \\
\hline 8158000 & 39,858 & & & & 15,819 & + & 0.015 \\
\hline
\end{tabular}


Table A.2, continued

\begin{tabular}{|c|c|ccc|ccc|}
\hline $\begin{array}{c}\text { Site } \\
\text { Number }\end{array}$ & $\begin{array}{c}\text { Complete } \\
\text { Series }\end{array}$ & \multicolumn{2}{|c|}{ Before Change-Point } & \multicolumn{3}{c|}{ After Change-point } \\
& Mean & Mean & Trend & p-value & Mean & Trend & p-value \\
\hline \hline 9110000 & 1,451 & 1,878 & - & $\mathbf{0 . 0 0 2}$ & & & \\
9315000 & 27,511 & 32,891 & - & 0.051 & & & \\
9471000 & 6,934 & & & & 5,594 & - & 0.066 \\
11525500 & 11,132 & & & & 4,139 & + & $\mathbf{0 . 0 0 3}$ \\
11532500 & 82,656 & & & & 88,773 & - & 0.054 \\
12321500 & 2,116 & 1,732 & + & 0.057 & & & \\
12322000 & 60,141 & 78,575 & + & $\mathbf{0 . 0 2 4}$ & & & \\
12354500 & 36,243 & & & & 38,240 & - & $\mathbf{0 . 0 0 2}$ \\
12404500 & 21,313 & & & & 22,145 & - & 0.088 \\
14191000 & 148,611 & & & & 111,416 & - & 0.053 \\
14321000 & 101,671 & & & & & & \\
14362000 & 6,400 & 8,977 & + & 0.074 & & & $\mathbf{0 . 0 1 7}$ \\
\hline
\end{tabular}

Table A.3

Hurst exponents for AMF series for all 569 sites considered. Values in red indicate sites characterized by a random walk or anti-persistence.

\begin{tabular}{|c|c|c|c|c|c|c|c|}
\hline $\begin{array}{c}\text { Station } \\
\text { Number }\end{array}$ & H & $\begin{array}{c}\text { Station } \\
\text { Number }\end{array}$ & H & $\begin{array}{l}\text { Station } \\
\text { Number }\end{array}$ & H & $\begin{array}{c}\text { Station } \\
\text { Number }\end{array}$ & $\mathbf{H}$ \\
\hline 01011000 & 0.71 & 02317500 & 0.64 & 05293000 & 0.69 & 08041500 & 0.65 \\
\hline 01013500 & 0.63 & 02320500 & 0.56 & 05300000 & 0.52 & 08055500 & 0.82 \\
\hline 01014000 & 0.70 & 02321500 & 0.71 & 05304500 & 0.68 & 08070000 & 0.68 \\
\hline 01030500 & 0.53 & 02329000 & 0.59 & 05313500 & 0.58 & 08080500 & 0.80 \\
\hline 01031500 & 0.66 & 02331600 & 0.62 & 05316500 & 0.62 & 08082000 & 0.86 \\
\hline 01038000 & 0.65 & 02333500 & 0.71 & 05317000 & 0.58 & 08082500 & 0.84 \\
\hline 01047000 & 0.54 & 02337000 & 0.57 & 05330000 & 0.63 & 08085500 & 0.58 \\
\hline 01055000 & 0.59 & 02339500 & 0.75 & 05331000 & 0.74 & 08088000 & 0.73 \\
\hline 01057000 & 0.60 & 02347500 & 0.57 & 05340500 & 0.78 & 08095000 & 0.67 \\
\hline 01064500 & 0.64 & 02353500 & 0.62 & 05362000 & 0.60 & 08128000 & 0.69 \\
\hline 01073000 & 0.66 & 02358000 & 0.59 & 05379500 & 0.66 & 08151500 & 0.60 \\
\hline 01076500 & 0.51 & 02361000 & 0.65 & 05394500 & 0.60 & 08153500 & 0.60 \\
\hline 01078000 & 0.69 & 02369000 & 0.61 & 05399500 & 0.62 & 08158000 & 0.82 \\
\hline 01119500 & 0.56 & 02371500 & 0.50 & 05407000 & 0.70 & 08164000 & 0.67 \\
\hline 01127500 & 0.70 & 02375500 & 0.54 & 05408000 & 0.67 & 08167000 & 0.64 \\
\hline 01137500 & 0.56 & 02383500 & 0.79 & 05410490 & 0.67 & 08167500 & 0.64 \\
\hline 01142500 & 0.62 & 02387500 & 0.74 & 05412500 & 0.59 & 08171000 & 0.61 \\
\hline 01144000 & 0.64 & 02392000 & 0.60 & 05414000 & 0.74 & 08172000 & 0.61 \\
\hline 01162500 & 0.65 & 02398000 & 0.57 & 05418500 & 0.64 & 08176500 & 0.63 \\
\hline 01169000 & 0.75 & 02424000 & 0.68 & 05419000 & 0.59 & 08189500 & 0.62 \\
\hline 01175500 & 0.87 & 02431000 & 0.68 & 05420500 & 0.73 & 08190000 & 0.56 \\
\hline 01176000 & 0.57 & 02436500 & 0.57 & 05421000 & 0.57 & 08192000 & 0.59 \\
\hline 01181000 & 0.66 & 02437000 & 0.57 & 05422000 & 0.68 & 08195000 & 0.70 \\
\hline
\end{tabular}


Table A.3, continued

\begin{tabular}{|c|c|c|c|c|c|c|c|}
\hline $\begin{array}{c}\text { Station } \\
\text { Number }\end{array}$ & $\mathbf{H}$ & $\begin{array}{c}\text { Station } \\
\text { Number }\end{array}$ & H & $\begin{array}{c}\text { Station } \\
\text { Number }\end{array}$ & $\mathbf{H}$ & $\begin{array}{c}\text { Station } \\
\text { Number }\end{array}$ & $\mathbf{H}$ \\
\hline 01188000 & 0.62 & 02441000 & 0.73 & 05426000 & 0.57 & 08205500 & 0.58 \\
\hline 01193500 & 0.69 & 02448000 & 0.67 & 05430500 & 0.67 & 08210000 & 0.70 \\
\hline 01196500 & 0.80 & 02467000 & 0.75 & 05431486 & 0.60 & 08276500 & 0.68 \\
\hline 01318500 & 0.60 & 02472500 & 0.59 & 05432500 & 0.72 & 08291000 & 0.70 \\
\hline 01321000 & 0.59 & 02474500 & 0.62 & 05434500 & 0.74 & 08378500 & 0.66 \\
\hline 01334500 & 0.63 & 02475500 & 0.61 & 05435500 & 0.72 & 08380500 & 0.64 \\
\hline 01350000 & 0.58 & 02479000 & 0.67 & 05436500 & 0.73 & 09085000 & 0.83 \\
\hline 01357500 & 0.60 & 02484500 & 0.72 & 05438500 & 0.68 & 09110000 & 0.84 \\
\hline 01365000 & 0.63 & 02486000 & 0.63 & 05440000 & 0.67 & 09112500 & 0.55 \\
\hline 01372500 & 0.59 & 02487500 & 0.61 & 05444000 & 0.60 & 09119000 & 0.64 \\
\hline 01379500 & 0.73 & 02488500 & 0.72 & 05446500 & 0.70 & 09124500 & 0.61 \\
\hline 01381500 & 0.80 & 03010500 & 0.69 & 05447500 & 0.77 & 09132500 & 0.57 \\
\hline 01387500 & 0.68 & 03011020 & 0.62 & 05451500 & 0.57 & 09147500 & 0.71 \\
\hline 01396500 & 0.75 & 03015500 & 0.62 & 05454500 & 0.74 & 09180500 & 0.78 \\
\hline 01397500 & 0.86 & 03020500 & 0.58 & 05455500 & 0.61 & 09239500 & 0.63 \\
\hline 01398000 & 0.62 & 03024000 & 0.73 & 05459500 & 0.59 & 09251000 & 0.62 \\
\hline 01398500 & 0.73 & 03032500 & 0.70 & 05464500 & 0.62 & 09304500 & 0.59 \\
\hline 01399500 & 0.68 & 03034500 & 0.55 & 05465500 & 0.65 & 09310500 & 0.69 \\
\hline 01408000 & 0.57 & 03049500 & 0.77 & 05470000 & 0.61 & 09315000 & 0.79 \\
\hline 01408500 & 0.63 & 03051000 & 0.61 & 05474000 & 0.64 & 09361500 & 0.67 \\
\hline 01410000 & 0.69 & 03069500 & 0.69 & 05476000 & 0.60 & 09379500 & 0.76 \\
\hline 01411000 & 0.58 & 03079000 & 0.60 & 05479000 & 0.59 & 09415000 & 0.56 \\
\hline 01411500 & 0.61 & 03080000 & 0.67 & 05482500 & 0.66 & 09430500 & 0.69 \\
\hline 01413500 & 0.63 & 03102500 & 0.73 & 05484000 & 0.61 & 09448500 & 0.69 \\
\hline 01414500 & 0.72 & 03106000 & 0.55 & 05484500 & 0.70 & 09471000 & 0.71 \\
\hline 01420500 & 0.77 & 03109500 & 0.78 & 05486490 & 0.58 & 09508500 & 0.64 \\
\hline 01421000 & 0.72 & 03118500 & 0.64 & 05490500 & 0.63 & 10128500 & 0.69 \\
\hline 01426500 & 0.86 & 03144000 & 0.54 & 05495000 & 0.63 & 10131000 & 0.65 \\
\hline 01439500 & 0.58 & 03164000 & 0.64 & 05497000 & 0.62 & 10174500 & 0.59 \\
\hline 01440000 & 0.63 & 03167000 & 0.68 & 05500000 & 0.64 & 10234500 & 0.72 \\
\hline 01445500 & 0.87 & 03170000 & 0.55 & 05501000 & 0.72 & 10296000 & 0.69 \\
\hline 01459500 & 0.48 & 03173000 & 0.59 & 05520500 & 0.82 & 10310000 & 0.63 \\
\hline 01463500 & 0.69 & 03175500 & 0.52 & 05526000 & 0.73 & 10312000 & 0.61 \\
\hline 01467000 & 0.54 & 03182500 & 0.64 & 05527500 & 0.79 & 10322500 & 0.65 \\
\hline 01503000 & 0.70 & 03183500 & 0.69 & 05555300 & 0.70 & 10329500 & 0.60 \\
\hline 01512500 & 0.69 & 03186500 & 0.73 & 05556500 & 0.66 & 10396000 & 0.62 \\
\hline 01514000 & 0.61 & 03193000 & 0.78 & 05570000 & 0.58 & 11098000 & 0.59 \\
\hline 01518000 & 0.78 & 03198500 & 0.61 & 05572000 & 0.53 & 11152000 & 0.59 \\
\hline 01520500 & 0.82 & 03219500 & 0.57 & 05585000 & 0.74 & 11160500 & 0.55 \\
\hline 01531000 & 0.72 & 03230500 & 0.67 & 05592500 & 0.62 & 11237500 & 0.60 \\
\hline 01532000 & 0.67 & 03234500 & 0.75 & 05593000 & 0.80 & 11264500 & 0.57 \\
\hline 01534000 & 0.55 & 03253500 & 0.65 & 05597000 & 0.70 & 11266500 & 0.55 \\
\hline 01538000 & 0.69 & 03262000 & 0.75 & 06019500 & 0.72 & 11367500 & 0.64 \\
\hline 01539000 & 0.62 & 03265000 & 0.60 & 06191500 & 0.67 & 11381500 & 0.61 \\
\hline
\end{tabular}


Table A.3, continued

\begin{tabular}{|c|c|c|c|c|c|c|c|}
\hline $\begin{array}{c}\text { Station } \\
\text { Number }\end{array}$ & H & $\begin{array}{l}\text { Station } \\
\text { Number }\end{array}$ & H & $\begin{array}{c}\text { Station } \\
\text { Number }\end{array}$ & H & $\begin{array}{c}\text { Station } \\
\text { Number }\end{array}$ & $\mathbf{H}$ \\
\hline 01541000 & 0.55 & 03266000 & 0.55 & 06192500 & 0.59 & 11383500 & 0.69 \\
\hline 01541500 & 0.64 & 03269500 & 0.64 & 06207500 & 0.62 & 11402000 & 0.59 \\
\hline 01543500 & 0.57 & 03272000 & 0.62 & 06214500 & 0.69 & 11413000 & 0.55 \\
\hline 01548500 & 0.61 & 03274000 & 0.62 & 06289000 & 0.64 & 11425500 & 0.59 \\
\hline 01555000 & 0.58 & 03275000 & 0.60 & 06335500 & 0.75 & 11477000 & 0.70 \\
\hline 01555500 & 0.65 & 03281500 & 0.74 & 06337000 & 0.75 & 11478500 & 0.70 \\
\hline 01556000 & 0.59 & 03294500 & 0.65 & 06340500 & 0.69 & 11501000 & 0.68 \\
\hline 01558000 & 0.48 & 03301500 & 0.69 & 06354000 & 0.65 & 11522500 & 0.71 \\
\hline 01560000 & 0.67 & 03307000 & 0.69 & 06441500 & 0.60 & 11525500 & 0.88 \\
\hline 01564500 & 0.59 & 03326500 & 0.71 & 06452000 & 0.61 & 11530000 & 0.71 \\
\hline 01567000 & 0.63 & 03335500 & 0.60 & 06478500 & 0.77 & 11532500 & 0.78 \\
\hline 01568000 & 0.54 & 03339500 & 0.66 & 06485500 & 0.52 & 12010000 & 0.66 \\
\hline 01570500 & 0.51 & 03345500 & 0.59 & 06600500 & 0.61 & 12020000 & 0.69 \\
\hline 01574000 & 0.66 & 03360500 & 0.63 & 06606600 & 0.62 & 12027500 & 0.61 \\
\hline 01580000 & 0.63 & 03363500 & 0.61 & 06620000 & 0.61 & 12035000 & 0.73 \\
\hline 01599000 & 0.66 & 03373500 & 0.57 & 06630000 & 0.64 & 12039500 & 0.68 \\
\hline 01601500 & 0.60 & 03374000 & 0.59 & 06635000 & 0.69 & 12048000 & 0.66 \\
\hline 01604500 & 0.71 & 03377500 & 0.58 & 06710500 & 0.72 & 12054000 & 0.75 \\
\hline 01608500 & 0.54 & 03379500 & 0.70 & 06800500 & 0.62 & 12056500 & 0.56 \\
\hline 01610000 & 0.52 & 03380500 & 0.66 & 06809500 & 0.53 & 12134500 & 0.71 \\
\hline 01613000 & 0.64 & 03381500 & 0.65 & 06810000 & 0.63 & 12186000 & 0.68 \\
\hline 01614500 & 0.60 & 03434500 & 0.59 & 06864500 & 0.66 & 12189500 & 0.72 \\
\hline 01631000 & 0.59 & 03438000 & 0.60 & 06869500 & 0.67 & 12306500 & 0.77 \\
\hline 01632000 & 0.57 & 03451500 & 0.64 & 06876900 & 0.62 & 12321500 & 0.72 \\
\hline 01634000 & 0.56 & 03465500 & 0.62 & 06889500 & 0.79 & 12322000 & 0.93 \\
\hline 01634500 & 0.72 & 03473000 & 0.65 & 06892000 & 0.59 & 12330000 & 0.69 \\
\hline 01645000 & 0.73 & 03479000 & 0.58 & 06897500 & 0.66 & 12332000 & 0.69 \\
\hline 01667500 & 0.67 & 03488000 & 0.72 & 06899500 & 0.67 & 12354500 & 0.80 \\
\hline 02013000 & 0.72 & 03504000 & 0.67 & 06908000 & 0.65 & 12355500 & 0.69 \\
\hline 02016000 & 0.68 & 03524000 & 0.70 & 06913500 & 0.65 & 12358500 & 0.65 \\
\hline 02017500 & 0.60 & 03528000 & 0.68 & 06933500 & 0.61 & 12370000 & 0.69 \\
\hline 02018000 & 0.67 & 03540500 & 0.61 & 07013000 & 0.66 & 12401500 & 0.73 \\
\hline 02035000 & 0.68 & 03550000 & 0.73 & 07016500 & 0.72 & 12404500 & 0.74 \\
\hline 02045500 & 0.69 & 03574500 & 0.67 & 07018500 & 0.69 & 12409000 & 0.68 \\
\hline 02051500 & 0.72 & 03604000 & 0.59 & 07019000 & 0.69 & 12413000 & 0.48 \\
\hline 02055000 & 0.65 & 03612000 & 0.58 & 07050500 & 0.56 & 12414500 & 0.57 \\
\hline 02059500 & 0.63 & 04010500 & 0.71 & 07056000 & 0.55 & 12422500 & 0.71 \\
\hline 02061500 & 0.73 & 04056500 & 0.59 & 07061500 & 0.61 & 12442500 & 0.77 \\
\hline 02070000 & 0.60 & 04073500 & 0.71 & 07067000 & 0.61 & 12445000 & 0.75 \\
\hline 02074500 & 0.72 & 04079000 & 0.68 & 07068000 & 0.60 & 12451000 & 0.67 \\
\hline 02083000 & 0.65 & 04087000 & 0.68 & 07069500 & 0.54 & 12459000 & 0.66 \\
\hline 02083500 & 0.63 & 04100500 & 0.64 & 07071500 & 0.44 & 12488500 & 0.72 \\
\hline 02085500 & 0.59 & 04105000 & 0.66 & 07072000 & 0.54 & 13037500 & 0.77 \\
\hline 02091500 & 0.60 & 04112500 & 0.65 & 07074000 & 0.56 & 13073000 & 0.71 \\
\hline
\end{tabular}


Table A.3, continued

\begin{tabular}{|c|c|c|c|c|c|c|c|}
\hline $\begin{array}{c}\text { Station } \\
\text { Number }\end{array}$ & H & $\begin{array}{c}\text { Station } \\
\text { Number }\end{array}$ & H & $\begin{array}{c}\text { Station } \\
\text { Number }\end{array}$ & $\mathbf{H}$ & $\begin{array}{c}\text { Station } \\
\text { Number }\end{array}$ & $\mathbf{H}$ \\
\hline 02102000 & 0.56 & 04121500 & 0.67 & 07096000 & 0.74 & 13082500 & 0.70 \\
\hline 02116500 & 0.57 & 04142000 & 0.60 & 07144200 & 0.70 & 13120500 & 0.72 \\
\hline 02118000 & 0.57 & 04191500 & 0.65 & 07146500 & 0.68 & 13139510 & 0.64 \\
\hline 02126000 & 0.51 & 04193500 & 0.68 & 07147800 & 0.60 & 13185000 & 0.58 \\
\hline 02131000 & 0.60 & 04198000 & 0.66 & 07172000 & 0.60 & 13269000 & 0.65 \\
\hline 02132000 & 0.57 & 04214500 & 0.66 & 07176000 & 0.80 & 13302500 & 0.68 \\
\hline 02134500 & 0.64 & 04223000 & 0.56 & 07180500 & 0.61 & 13313000 & 0.64 \\
\hline 02136000 & 0.56 & 04234000 & 0.55 & 07183000 & 0.65 & 13317000 & 0.73 \\
\hline 02138500 & 0.60 & 04262500 & 0.75 & 07186000 & 0.62 & 13336500 & 0.75 \\
\hline 02154500 & 0.63 & 04264331 & 0.89 & 07187000 & 0.69 & 13337000 & 0.74 \\
\hline 02156500 & 0.62 & 04269000 & 0.62 & 07189000 & 0.61 & 13342500 & 0.81 \\
\hline 02173500 & 0.71 & 04275000 & 0.63 & 07196500 & 0.67 & 14020000 & 0.69 \\
\hline 02177000 & 0.57 & 04287000 & 0.62 & 07203000 & 0.52 & 14044000 & 0.68 \\
\hline 02192000 & 0.69 & 04293500 & 0.71 & 07218000 & 0.61 & 14046500 & 0.62 \\
\hline 02198000 & 0.54 & 05014500 & 0.61 & 07234000 & 0.84 & 14105700 & 0.86 \\
\hline 02202500 & 0.60 & 05053000 & 0.75 & 07247000 & 0.65 & 14113000 & 0.59 \\
\hline 02203000 & 0.45 & 05062000 & 0.71 & 07247500 & 0.77 & 14137000 & 0.73 \\
\hline 02213500 & 0.59 & 05062500 & 0.75 & 07252000 & 0.66 & 14154500 & 0.58 \\
\hline 02217500 & 0.73 & 05066500 & 0.75 & 07261500 & 0.62 & 14178000 & 0.56 \\
\hline 02225500 & 0.58 & 05078000 & 0.70 & 07290000 & 0.65 & 14185000 & 0.69 \\
\hline 02226000 & 0.63 & 05078500 & 0.72 & 07291000 & 0.70 & 14191000 & 0.80 \\
\hline 02226500 & 0.45 & 05082500 & 0.81 & 07331000 & 0.64 & 14301000 & 0.56 \\
\hline 02228000 & 0.50 & 05084000 & 0.64 & 07332500 & 0.59 & 14301500 & 0.57 \\
\hline 02231000 & 0.67 & 05100000 & 0.73 & 07340000 & 0.83 & 14306500 & 0.75 \\
\hline 02246000 & 0.60 & 05112000 & 0.73 & 07340500 & 0.86 & 14308000 & 0.66 \\
\hline 02256500 & 0.72 & 05120500 & 0.57 & 07363500 & 0.69 & 14321000 & 0.78 \\
\hline 02296750 & 0.72 & 05131500 & 0.73 & 07375500 & 0.68 & 14325000 & 0.68 \\
\hline 02298830 & 0.63 & 05133500 & 0.64 & 07378500 & 0.76 & 14359000 & 0.70 \\
\hline 02301500 & 0.71 & 05280000 & 0.66 & 08013500 & 0.58 & 14362000 & 0.80 \\
\hline 02303000 & 0.65 & 05286000 & 0.70 & 08032000 & 0.66 & & \\
\hline 02313000 & 0.69 & 05288500 & 0.65 & 08033500 & 0.66 & & \\
\hline 02314500 & 0.64 & 05291000 & 0.68 & 08041000 & 0.77 & & \\
\hline
\end{tabular}





\section{APPENDIX B TREND AND CHANGE-POINT RESULTS FOR TIMING OF FLOOD PEAKS}

This appendix contains tables of results for the trend and change-point tests on series of the day of occurrence of flood peaks as discussed in CHAPTER 2. The length of continuous data $(\mathrm{N})$ analyzed for each site is also reported. Only results significant on the $10 \%$ level are reported in the following tables (sites significant on the $5 \%$ level are in bold). Results are omitted (blank spaces) when p-values greater than $10 \%$ were obtained.

Table B.1

Mann-Kendall results for sites exhibiting a significant trend whether positive $(+)$ or negative (-), in the day of occurrence of flood peaks on the $10 \%$ level.

\begin{tabular}{|cccc|cccc|}
\hline $\begin{array}{c}\text { Station } \\
\text { Number }\end{array}$ & N & Trend & P-Value & $\begin{array}{c}\text { Station } \\
\text { Number }\end{array}$ & N & Trend & P-Value \\
\hline \hline 01011000 & 79 & - & $\mathbf{0 . 0 1 3}$ & 06207500 & 89 & - & $\mathbf{0 . 0 0 3}$ \\
01013500 & 81 & - & $\mathbf{0 . 0 0 7}$ & 06869500 & 92 & - & $\mathbf{0 . 0 4 4}$ \\
01014000 & 84 & - & $\mathbf{0 . 0 0 2}$ & 06908000 & 73 & + & $\mathbf{0 . 0 2 0}$ \\
01030500 & 108 & - & $\mathbf{0 . 0 0 4}$ & 06933500 & 88 & - & $\mathbf{0 . 0 4 1}$ \\
01073000 & 75 & + & $\mathbf{0 . 0 3 8}$ & 07013000 & 94 & - & $\mathbf{0 . 0 2 0}$ \\
01144000 & 94 & - & 0.065 & 07096000 & 111 & - & $\mathbf{0 . 0 0 0}$ \\
01175500 & 99 & + & 0.054 & 07176000 & 75 & + & 0.071 \\
01381500 & 89 & + & 0.082 & 07234000 & 73 & - & $\mathbf{0 . 0 4 1}$ \\
01414500 & 74 & + & $\mathbf{0 . 0 3 7}$ & 07378500 & 73 & + & 0.094 \\
01541000 & 97 & - & $\mathbf{0 . 0 4 7}$ & 08041000 & 90 & - & $\mathbf{0 . 0 3 9}$ \\
02051500 & 83 & + & 0.057 & 08041500 & 71 & - & 0.096 \\
02317500 & 83 & - & $\mathbf{0 . 0 0 8}$ & 08070000 & 72 & - & 0.086 \\
02320500 & 79 & - & 0.080 & 08276500 & 85 & - & 0.074 \\
02448000 & 72 & - & $\mathbf{0 . 0 1 9}$ & 09112500 & 77 & - & $\mathbf{0 . 0 0 0}$ \\
02484500 & 73 & - & $\mathbf{0 . 0 4 8}$ & 09119000 & 73 & - & $\mathbf{0 . 0 1 8}$ \\
03011020 & 107 & - & 0.087 & 09124500 & 73 & - & $\mathbf{0 . 0 0 2}$ \\
03020500 & 101 & + & 0.096 & 09147500 & 90 & - & $\mathbf{0 . 0 2 2}$ \\
03363500 & 80 & + & 0.083 & 09180500 & 88 & - & $\mathbf{0 . 0 1 3}$ \\
03379500 & 96 & - & 0.085 & 10131000 & 84 & + & $\mathbf{0 . 0 1 1}$ \\
03604000 & 90 & + & 0.050 & 10329500 & 76 & + & $\mathbf{0 . 0 3 9}$ \\
03612000 & 87 & - & 0.088 & 11160500 & 73 & - & $\mathbf{0 . 0 1 5}$ \\
04073500 & 110 & + & 0.100 & 11525500 & 99 & + & $\mathbf{0 . 0 0 1}$ \\
04087000 & 96 & + & $\mathbf{0 . 0 0 5}$ & 11532500 & 79 & - & $\mathbf{0 . 0 2 5}$ \\
04100500 & 79 & + & 0.088 & 12422500 & 111 & - & $\mathbf{0 . 0 0 5}$ \\
05286000 & 81 & - & 0.068 & 12442500 & 82 & - & 0.075 \\
05410490 & 77 & + & $\mathbf{0 . 0 4 2}$ & 12445000 & 82 & - & 0.084 \\
05414000 & 76 & + & $\mathbf{0 . 0 3 9}$ & 12451000 & 84 & - & $\mathbf{0 . 0 0 9}$
\end{tabular}


Table B.1, continued

\begin{tabular}{|c|c|c|c|c|c|c|c|}
\hline $\begin{array}{l}\text { Station } \\
\text { Number }\end{array}$ & $\mathbf{N}$ & Trend & P-Value & $\begin{array}{c}\text { Station } \\
\text { Number }\end{array}$ & $\mathbf{N}$ & Trend & P-Value \\
\hline 05430500 & 96 & + & 0.082 & 12459000 & 82 & - & $\overline{0.004}$ \\
\hline 05431486 & 71 & + & 0.080 & 13037500 & 100 & + & 0.011 \\
\hline 05476000 & 80 & + & 0.014 & 13302500 & 91 & - & 0.046 \\
\hline 05484500 & 96 & + & 0.077 & 13313000 & 82 & - & 0.007 \\
\hline 05500000 & 76 & + & 0.048 & 14020000 & 78 & + & 0.012 \\
\hline 05501000 & 76 & + & 0.022 & 14044000 & 81 & + & 0.058 \\
\hline 05592500 & 95 & - & 0.004 & 14046500 & 81 & + & 0.050 \\
\hline 06191500 & 100 & - & 0.065 & 14105700 & 110 & - & 0.007 \\
\hline 06192500 & 73 & - & 0.066 & 14325000 & 82 & - & 0.062 \\
\hline
\end{tabular}

Table B. 2

Change-point results indicating year of identified shift in the day of occurrence of flood peaks and associated $\mathrm{p}$-value.

\begin{tabular}{|cccc|cccc|}
\hline $\begin{array}{c}\text { Station } \\
\text { Number }\end{array}$ & N & Year & P-Value & $\begin{array}{c}\text { Station } \\
\text { Number }\end{array}$ & N & Year & P-Value \\
\hline \hline 01011000 & 79 & 1975 & $\mathbf{0 . 0 0 0}$ & 06192500 & 73 & 1983 & $\mathbf{0 . 0 0 3}$ \\
01013500 & 81 & 1975 & 0.050 & 06207500 & 89 & 1984 & $\mathbf{0 . 0 3 2}$ \\
01014000 & 84 & 1982 & $\mathbf{0 . 0 0 2}$ & 06635000 & 71 & 1972 & 0.064 \\
01030500 & 108 & 1975 & 0.063 & 06869500 & 92 & 1969 & $\mathbf{0 . 0 0 1}$ \\
01073000 & 75 & 1979 & $\mathbf{0 . 0 3 3}$ & 06933500 & 88 & 1967 & 0.085 \\
01175500 & 99 & 1942 & $\mathbf{0 . 0 0 0}$ & 07018500 & 88 & 1963 & $\mathbf{0 . 0 4 8}$ \\
01318500 & 89 & 1979 & 0.070 & 07050500 & 72 & 1970 & $\mathbf{0 . 0 3 3}$ \\
01321000 & 99 & 1972 & $\mathbf{0 . 0 2 8}$ & 07067000 & 98 & 1965 & 0.067 \\
01381500 & 89 & 1982 & 0.091 & 07096000 & 111 & 1966 & $\mathbf{0 . 0 0 0}$ \\
01558000 & 72 & 1990 & 0.063 & 07186000 & 87 & 1958 & $\mathbf{0 . 0 0 7}$ \\
01631000 & 80 & 1972 & 0.064 & 07187000 & 87 & 1964 & $\mathbf{0 . 0 1 3}$ \\
02016000 & 85 & 1939 & 0.078 & 07234000 & 73 & 1984 & $\mathbf{0 . 0 2 5}$ \\
02173500 & 72 & 1976 & $\mathbf{0 . 0 0 5}$ & 07340500 & 73 & 1984 & $\mathbf{0 . 0 2 0}$ \\
02202500 & 75 & 1964 & $\mathbf{0 . 0 0 9}$ & 08041000 & 90 & 1993 & $\mathbf{0 . 0 2 3}$ \\
02313000 & 79 & 1955 & 0.085 & 08070000 & 72 & 1987 & $\mathbf{0 . 0 3 7}$ \\
02314500 & 73 & 1985 & 0.089 & 09110000 & 102 & 1940 & $\mathbf{0 . 0 2 5}$ \\
02317500 & 83 & 1976 & $\mathbf{0 . 0 0 7}$ & 09124500 & 73 & 1957 & $\mathbf{0 . 0 0 7}$ \\
02320500 & 79 & 1985 & $\mathbf{0 . 0 0 6}$ & 09147500 & 90 & 1983 & $\mathbf{0 . 0 1 2}$ \\
02329000 & 85 & 1962 & $\mathbf{0 . 0 0 9}$ & 10329500 & 76 & 1974 & 0.062 \\
02467000 & 82 & 1983 & $\mathbf{0 . 0 2 0}$ & 10396000 & 73 & 1972 & 0.050 \\
02474500 & 71 & 1981 & 0.083 & 11525500 & 99 & 1964 & $\mathbf{0 . 0 0 0}$ \\
02486000 & 109 & 1983 & $\mathbf{0 . 0 4 6}$ & 12027500 & 82 & 1957 & 0.067 \\
04073500 & 110 & 1992 & 0.072 & 12035000 & 81 & 1953 & 0.075 \\
04087000 & 96 & 1948 & $\mathbf{0 . 0 0 1}$ & 12048000 & 73 & 1977 & $\mathbf{0 . 0 4 2}$ \\
05316500 & 81 & 1955 & $\mathbf{0 . 0 1 5}$ & 12370000 & 89 & 1958 & 0.078 \\
05410490 & 77 & 1989 & 0.076 & 12422500 & 111 & 1957 & $\mathbf{0 . 0 2 3}$ \\
05421000 & 77 & 1966 & $\mathbf{0 . 0 2 7}$ & 12451000 & 84 & 1978 & $\mathbf{0 . 0 1 4}$ \\
05451500 & 78 & 1965 & $\mathbf{0 . 0 0 2}$ & 12459000 & 82 & 1986 & $\mathbf{0 . 0 0 9}$
\end{tabular}


Table B.2, continued

\begin{tabular}{|cccc|cccc|}
\hline $\begin{array}{c}\text { Station } \\
\text { Number }\end{array}$ & N & Year & P-Value & $\begin{array}{c}\text { Station } \\
\text { Number }\end{array}$ & N & Year & P-Value \\
\hline \hline 05459500 & 78 & 1952 & 0.076 & 12488500 & 71 & 1972 & $\mathbf{0 . 0 1 9}$ \\
05476000 & 80 & 1980 & $\mathbf{0 . 0 0 3}$ & 13269000 & 101 & 1959 & 0.085 \\
05592500 & 95 & 1966 & $\mathbf{0 . 0 2 7}$ & 13302500 & 91 & 1978 & 0.088 \\
05593000 & 81 & 1966 & $\mathbf{0 . 0 1 1}$ & 13313000 & 82 & 1949 & 0.098 \\
06191500 & 100 & 1983 & $\mathbf{0 . 0 0 1}$ & 14105700 & 110 & 1968 & $\mathbf{0 . 0 0 6}$ \\
\hline
\end{tabular}





\section{APPENDIX C TREND AND CHANGE-POINT RESULTS FOR FLOOD GENERATING PRECIPITATION SERIES}

This appendix contains figures presenting results of Mann-Kendall and Pettitt tests conducted on flood generating precipitation series with lead times of 2- to 7-days constructed based on both 1/8-degree and 1/4-degree gridded precipitation data as discussed in CHAPTER 2. Note that results for precipitation series with a 5-day lead time based on 1/8-degree gridded data are included in Chapter 2. 


\section{C.1 Results for Precipitation Series based on 1/8-Degree Gridded Data}

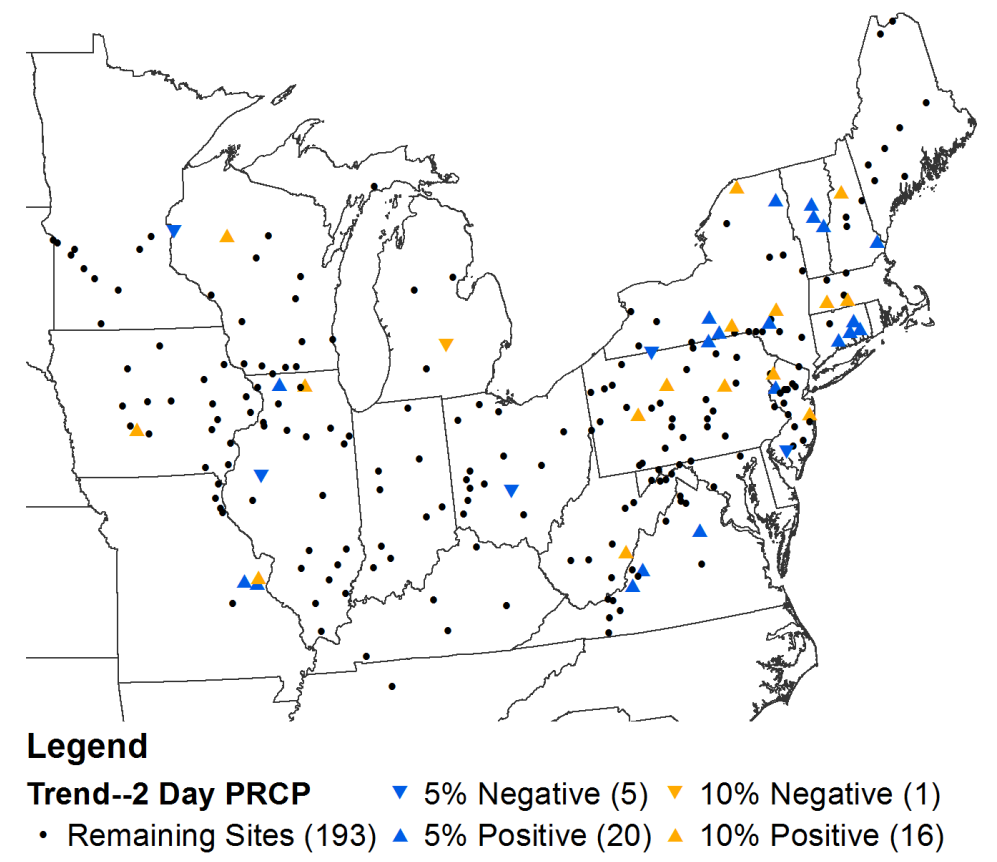

Figure C.1 Results of Mann-Kendall trend tests on flood generating precipitation series with 2-day lead constructed using 1/8-degree gridded data.

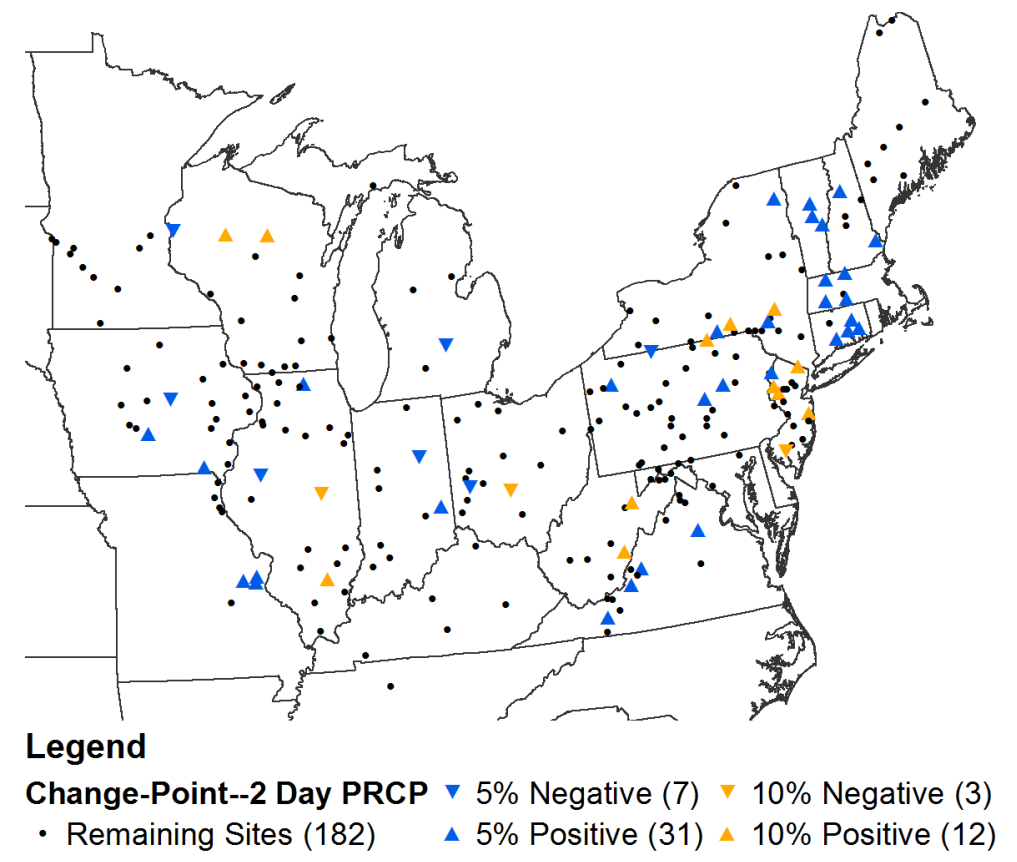

Figure C.2 Results of Pettitt tests on flood generating precipitation series with 2-day lead constructed using 1/8-degree gridded data. 


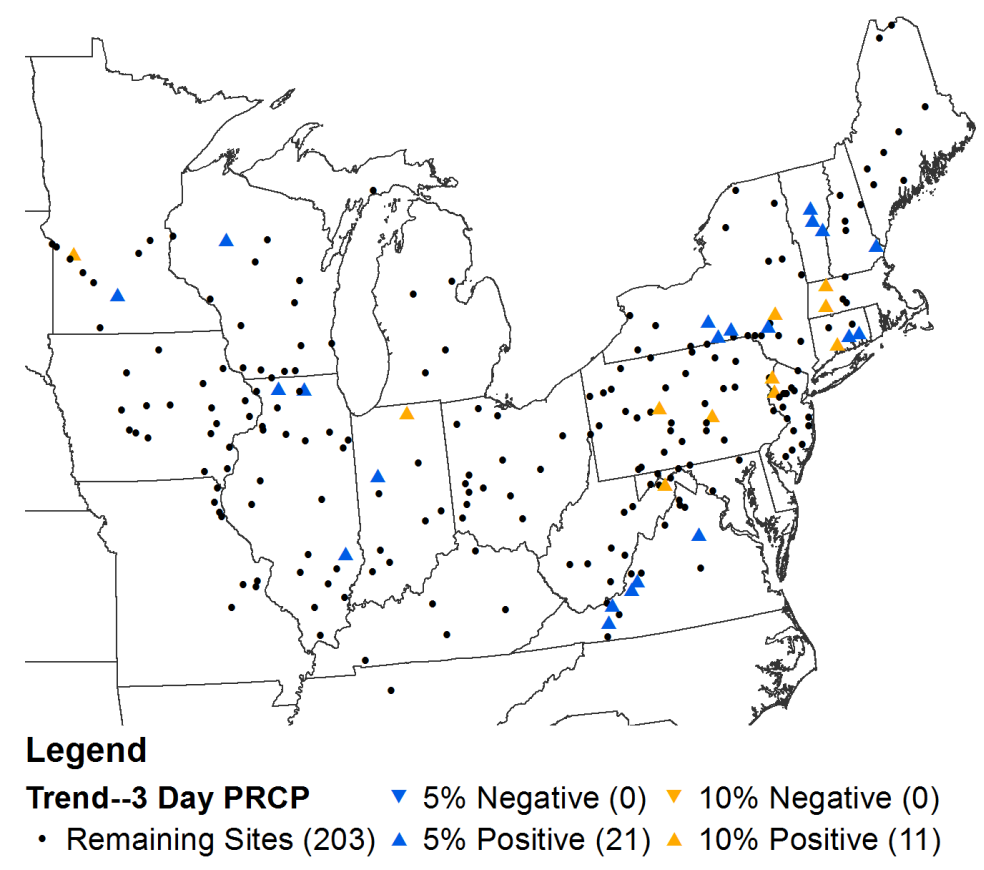

Figure C.3 Results of Mann-Kendall trend tests on flood generating precipitation series with 3-day lead constructed using 1/8-degree gridded data.

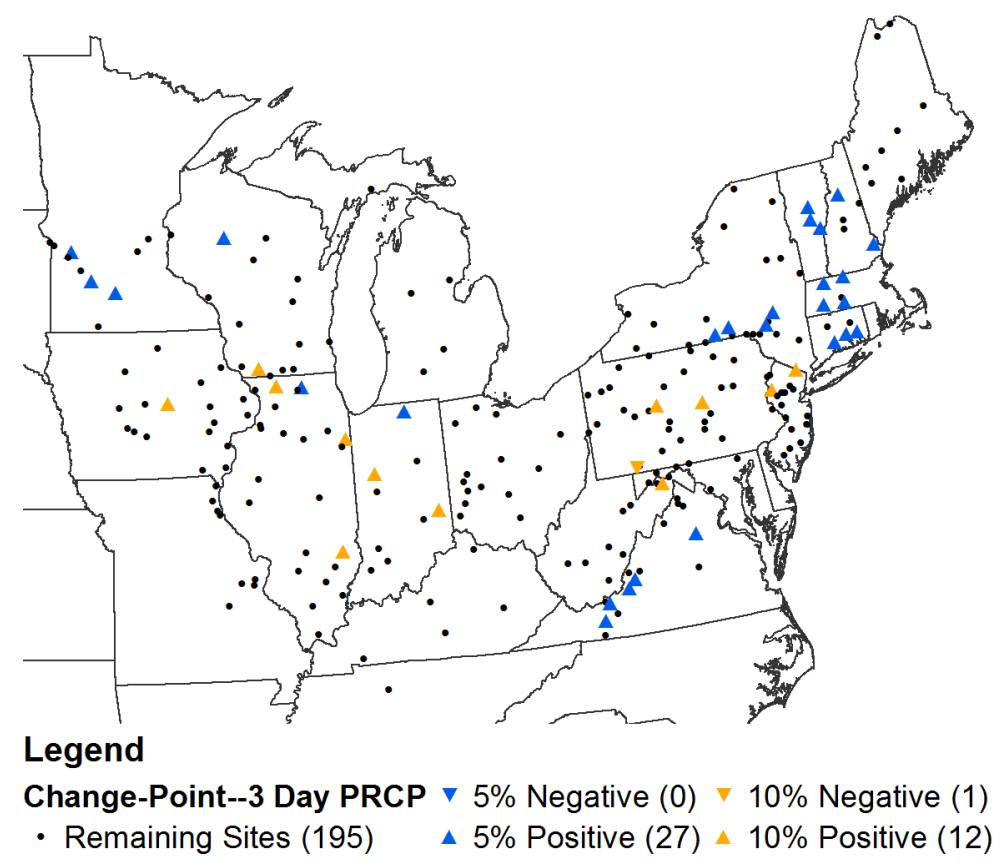

Figure C.4 Results of Pettitt tests on flood generating precipitation series with 3-day lead constructed using $1 / 8$-degree gridded data. 


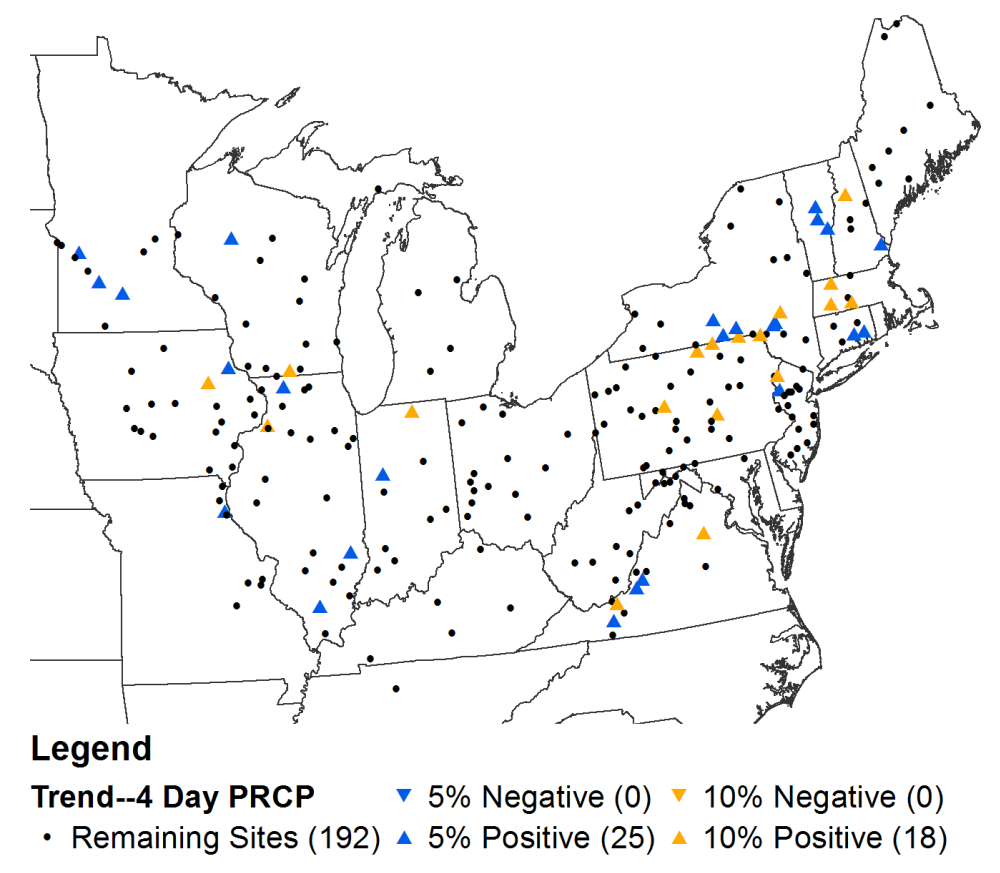

Figure C.5 Results of Mann-Kendall trend tests on flood generating precipitation series with 4-day lead constructed using 1/8-degree gridded data.

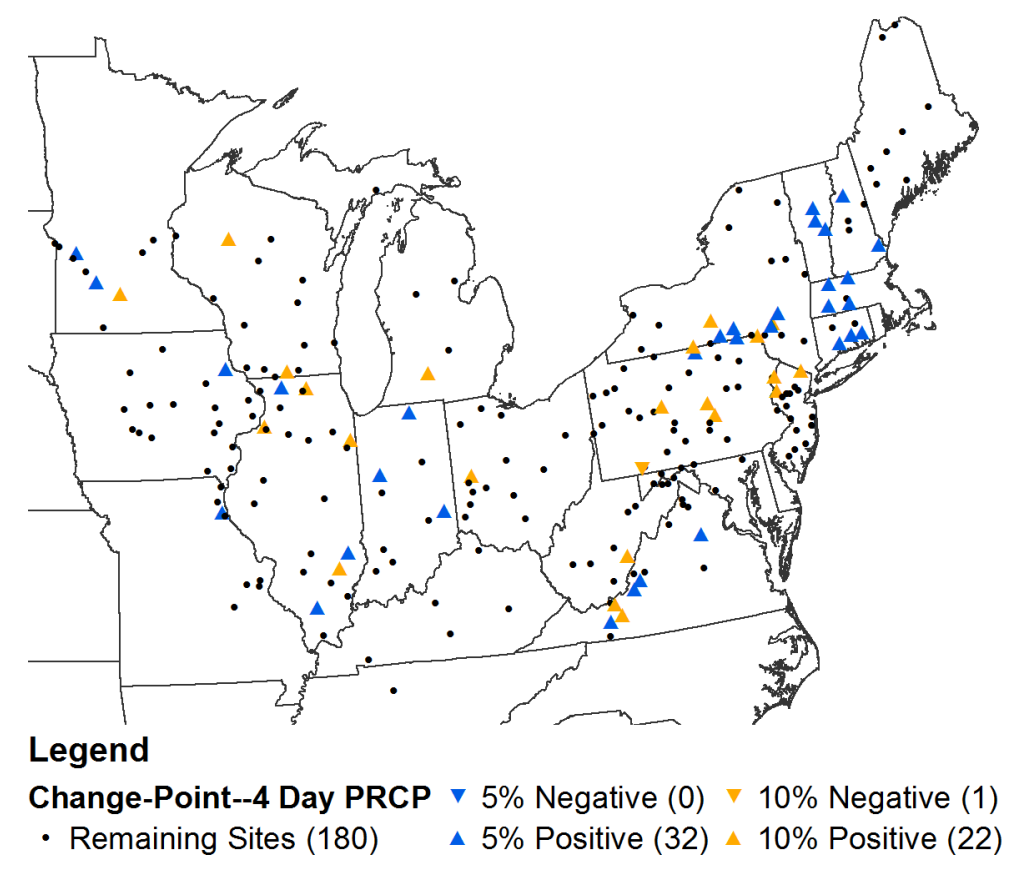

Figure C.6 Results of Pettitt tests on flood generating precipitation series with 4-day lead constructed using 1/8-degree gridded data. 


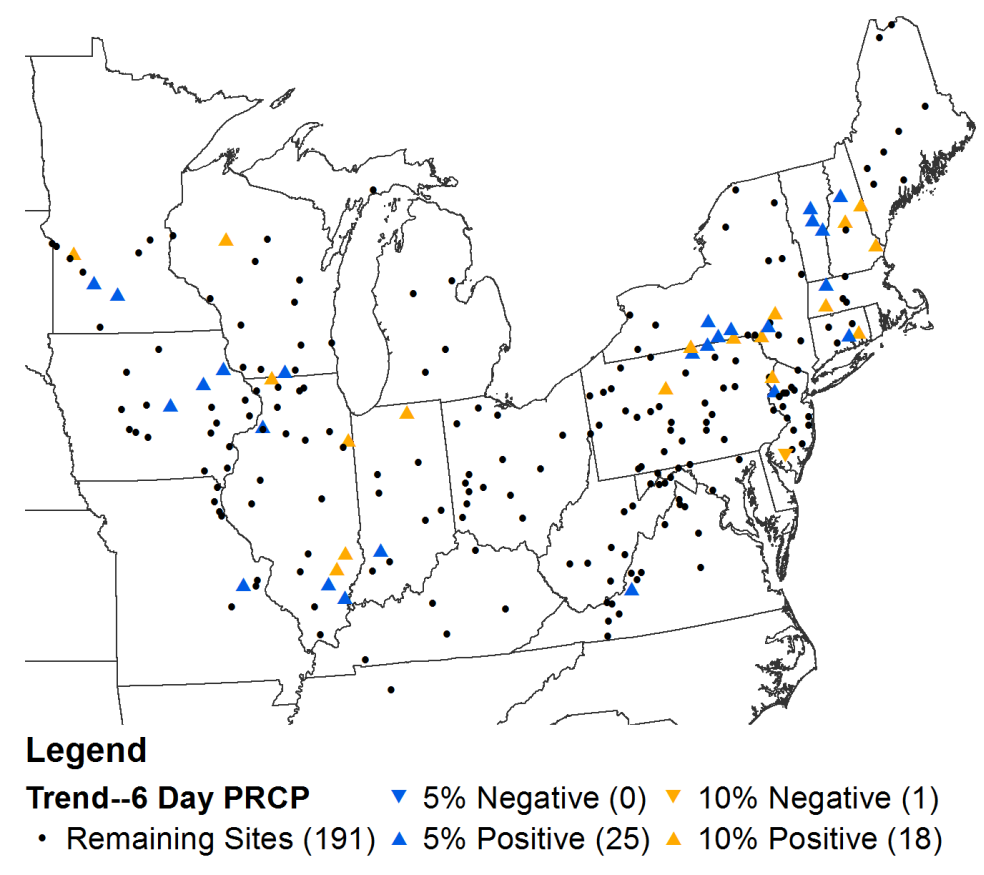

Figure C.7 Results of Mann-Kendall trend tests on flood generating precipitation series with 6-day lead constructed using 1/8-degree gridded data.

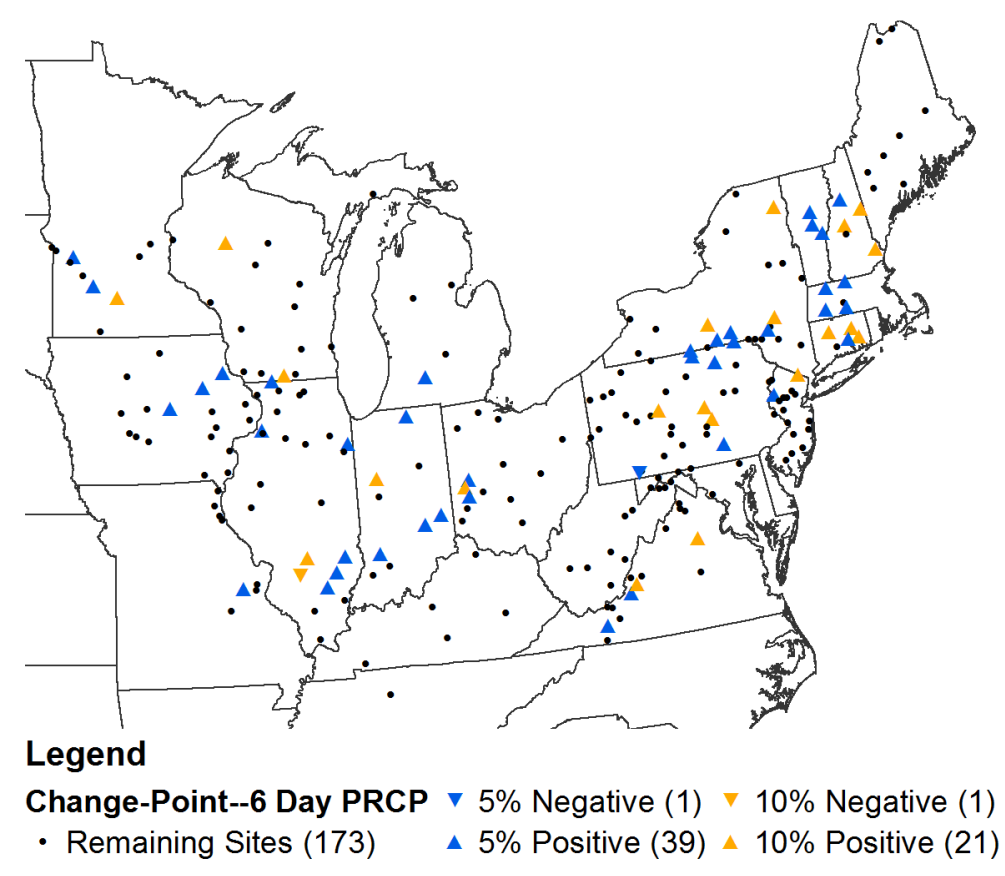

Figure C.8 Results of Pettitt tests on flood generating precipitation series with 6-day lead constructed using $1 / 8$-degree gridded data. 


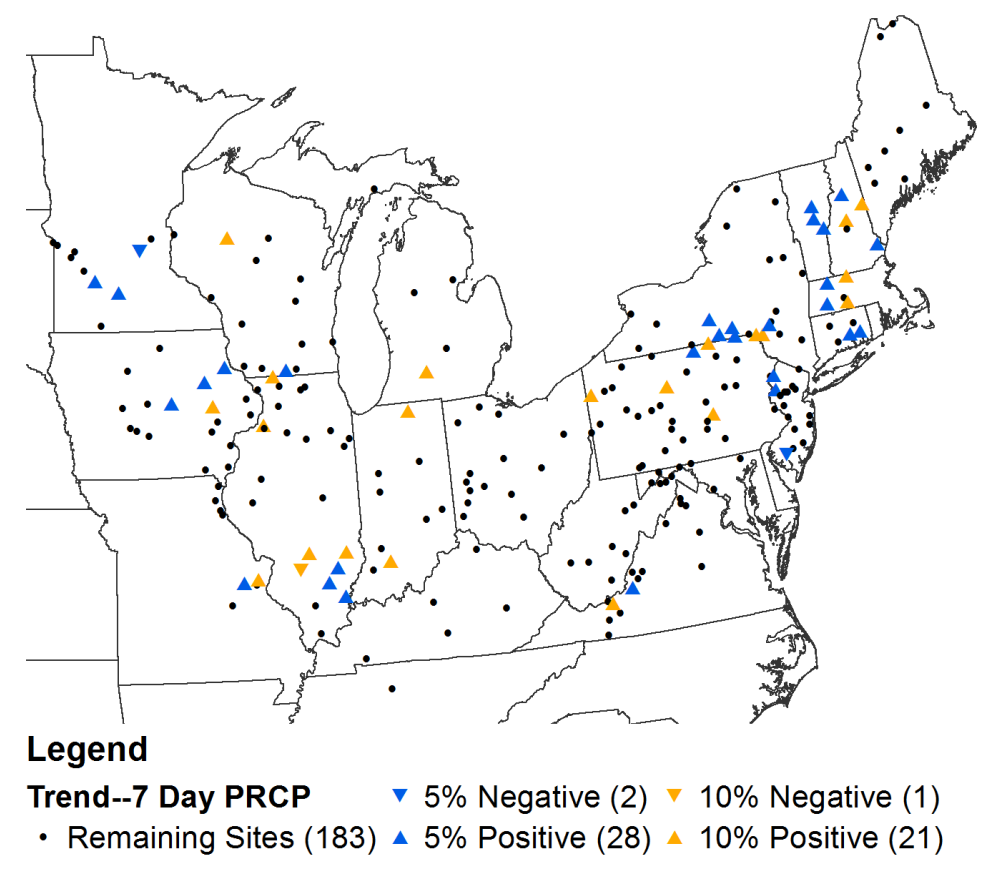

Figure C.9 Results of Mann-Kendall trend tests on flood generating precipitation series with 7-day lead constructed using 1/8-degree gridded data.

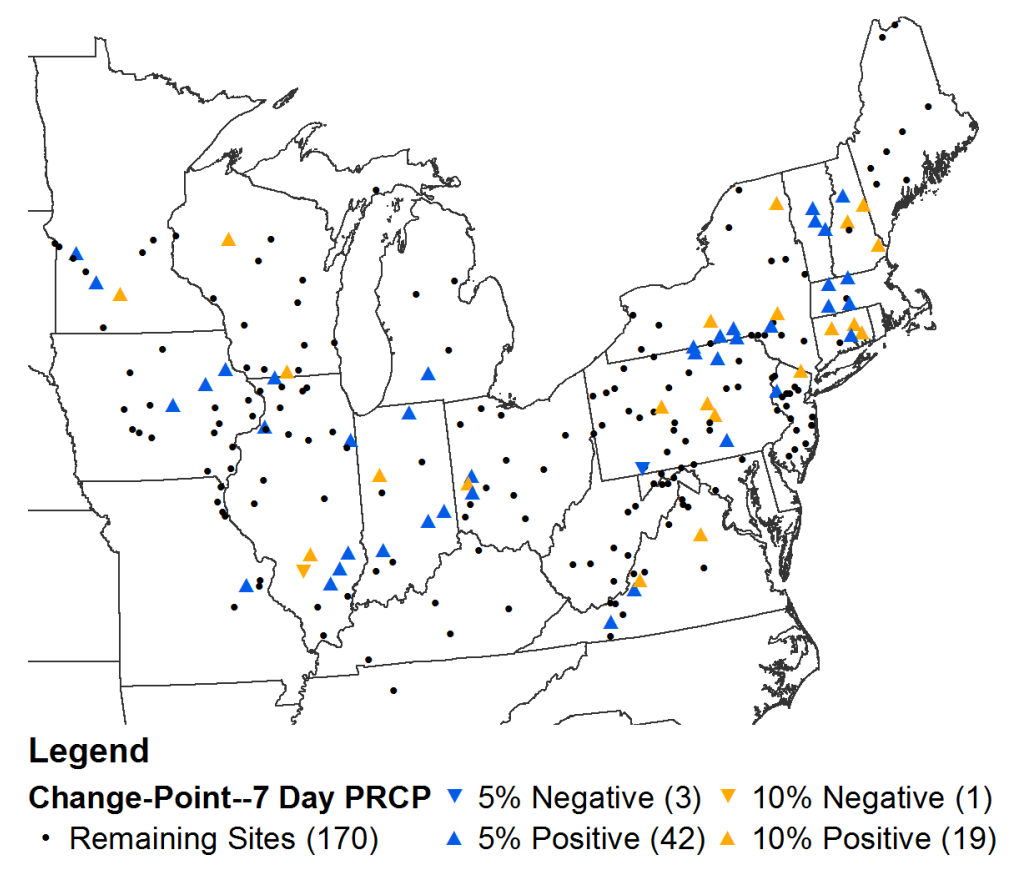

Figure C.10 Results of Pettitt tests on flood generating precipitation series with 7-day lead constructed using 1/8-degree gridded data. 


\section{C.2 Results for Precipitation Series Based on 1/4-Degree Gridded Data}

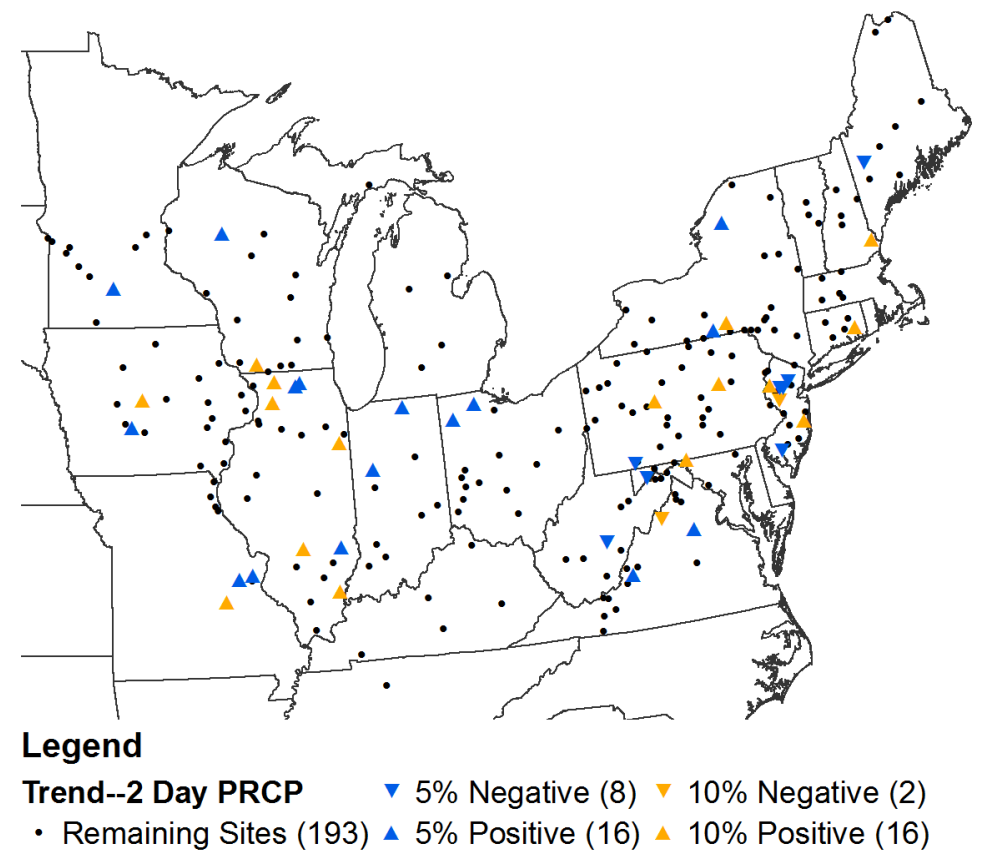

Figure C.11 Results of Mann-Kendall trend tests on flood generating precipitation series with 2-day lead constructed using 1/4-degree gridded data.

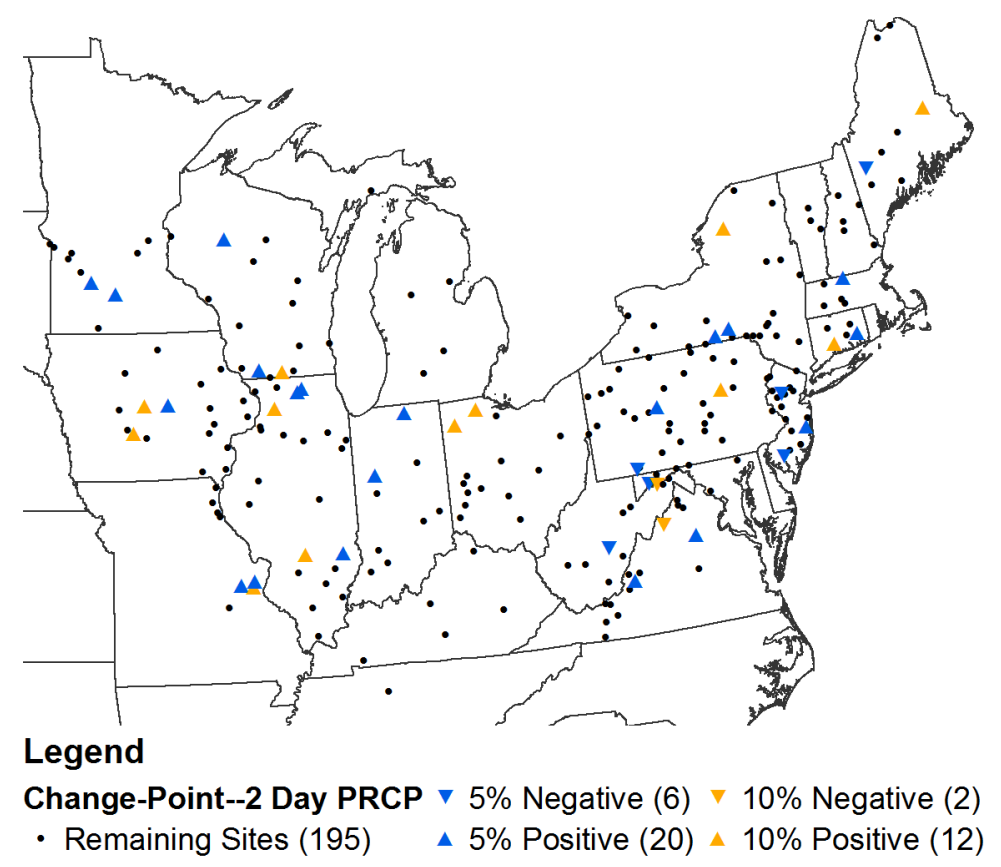

Figure C.12 Results of Pettitt tests on flood generating precipitation series with 2-day lead constructed using 1/4-degree gridded data. 


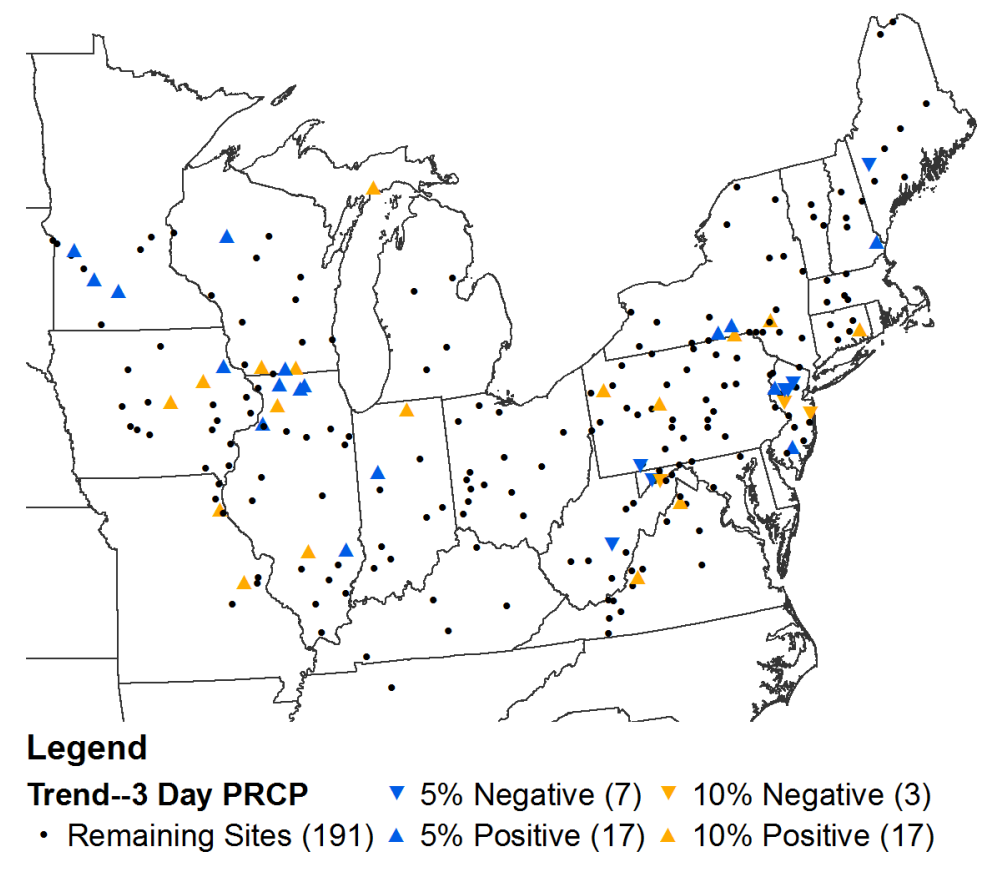

Figure C.13 Results of Mann-Kendall trend tests on flood generating precipitation series with 3-day lead constructed using 1/4-degree gridded data.

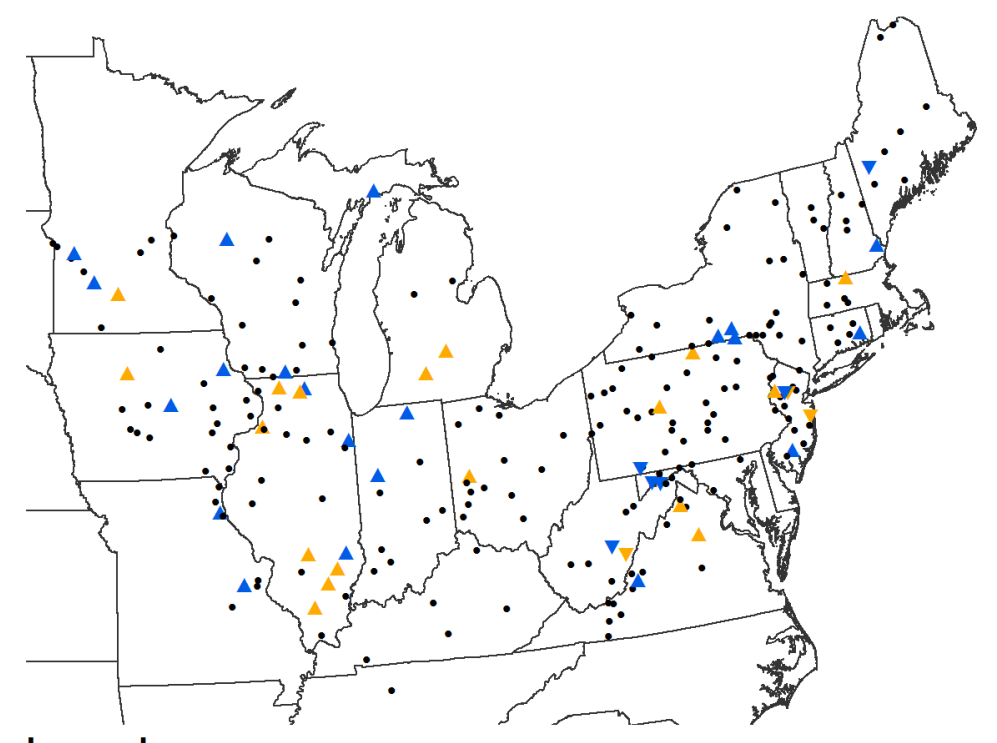

Legend

Change-Point--3 Day PRCP $\vee 5 \%$ Negative (6) $>10 \%$ Negative (3)

- Remaining Sites (187) \5\% Positive (21) $\triangle 10 \%$ Positive (18)

Figure C.14 Results of Pettitt tests on flood generating precipitation series with 3-day lead constructed using 1/4-degree gridded data. 


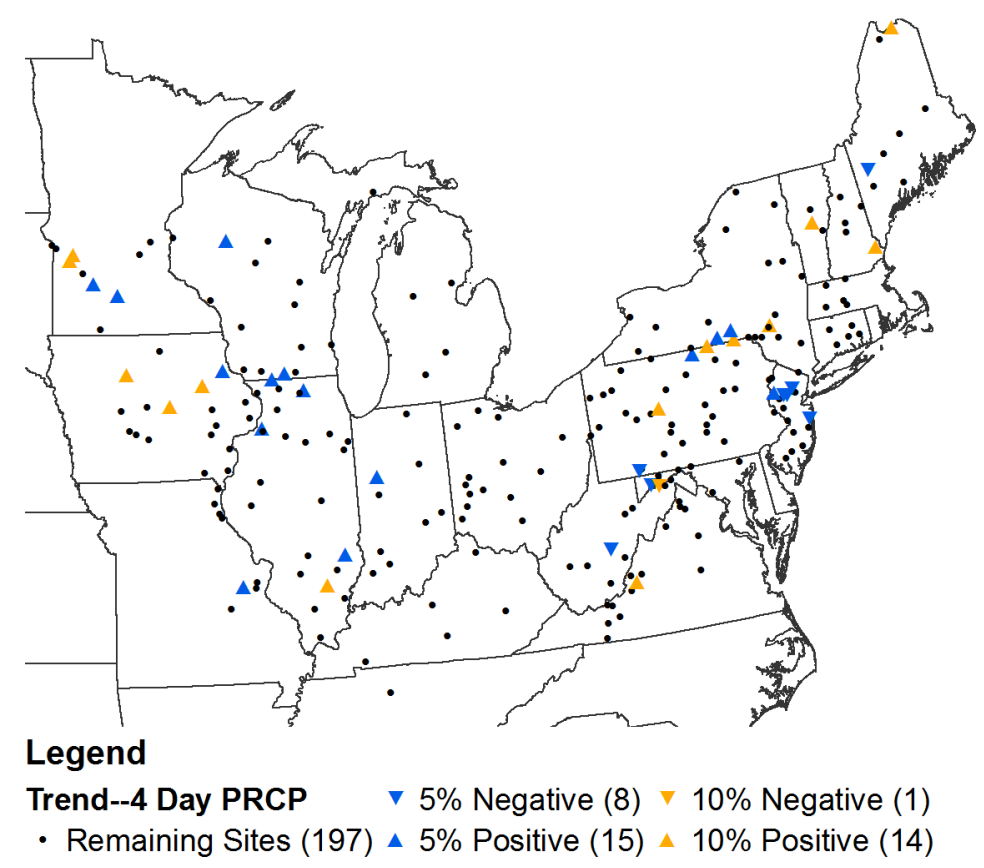

Figure C.15 Results of Mann-Kendall trend tests on flood generating precipitation series with 4-day lead constructed using 1/4-degree gridded data.

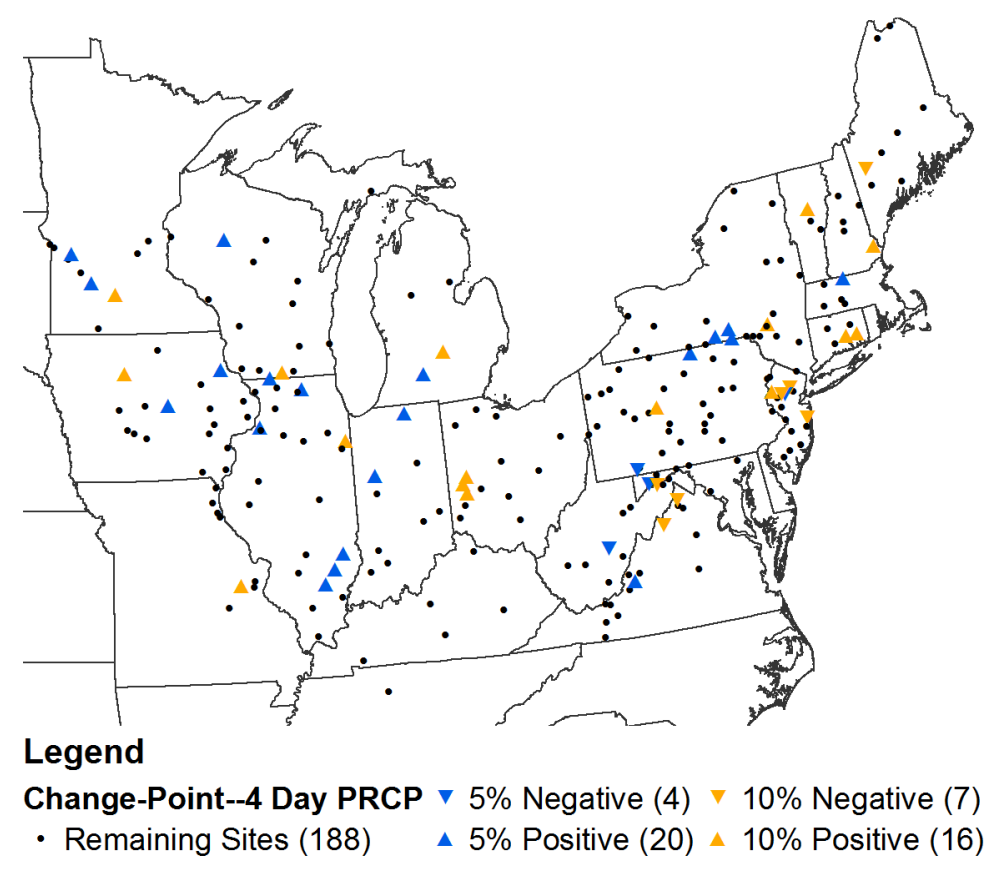

Figure C.16 Results of Pettitt tests on flood generating precipitation series with 4-day lead constructed using 1/4-degree gridded data. 


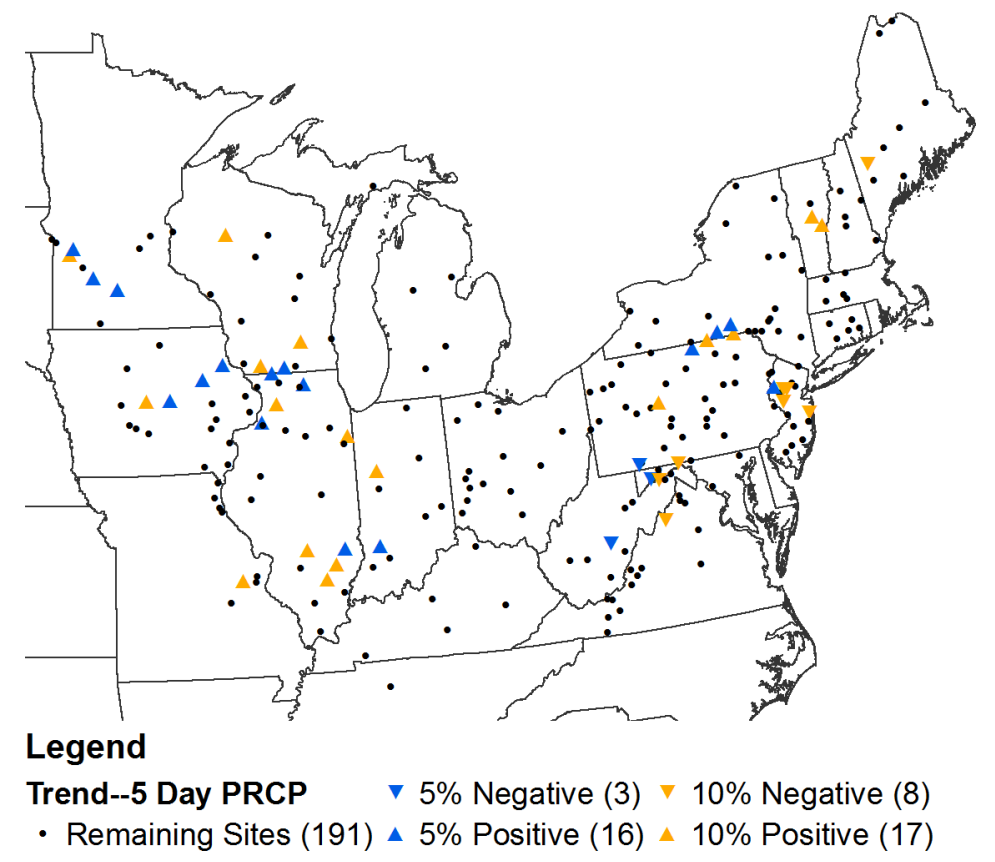

Figure C.17 Results of Mann-Kendall trend tests on flood generating precipitation series with 5-day lead constructed using 1/4-degree gridded data.

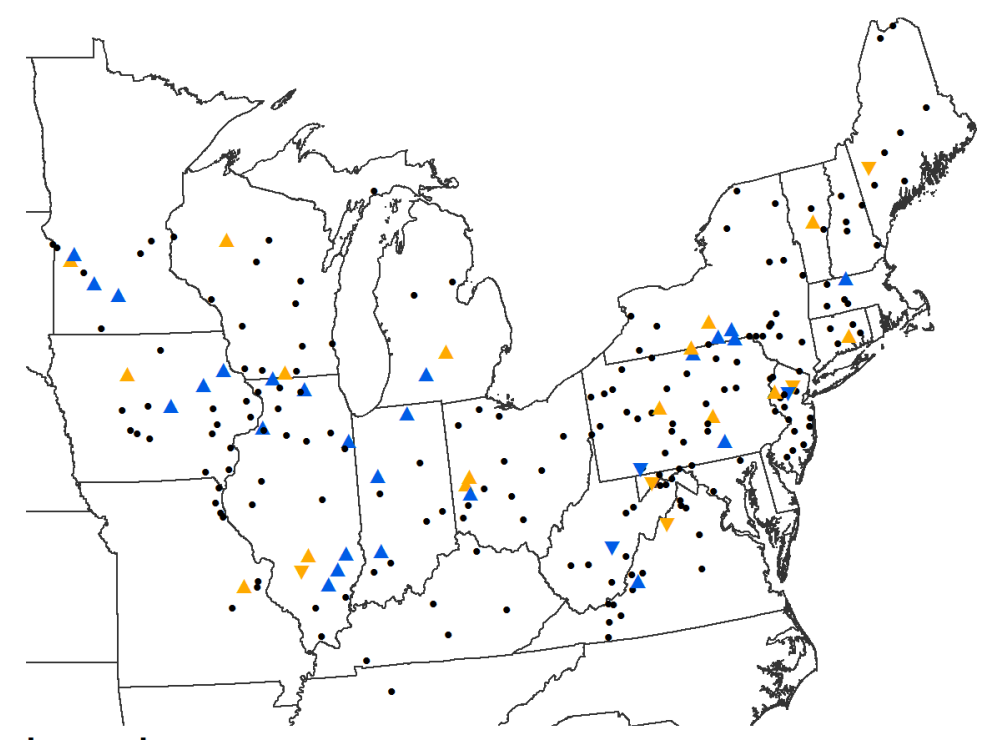

Legend

Change-Point--5 Day PRCP $\vee 5 \%$ Negative (3) $\vee 10 \%$ Negative (5)

- Remaining Sites (186) \5\% Positive (25) $\triangle 10 \%$ Positive (16)

Figure C.18 Results of Pettitt tests on flood generating precipitation series with 5-day lead constructed using 1/4-degree gridded data. 


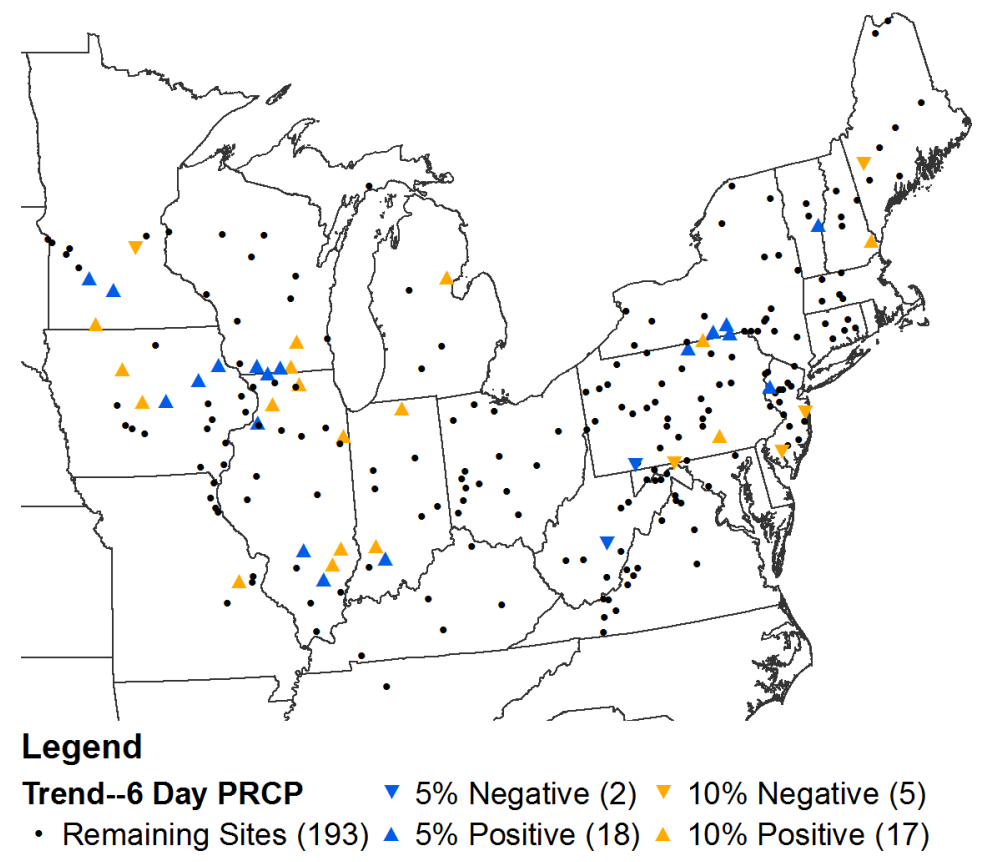

Figure C.19 Results of Mann-Kendall trend tests on flood generating precipitation series with 6-day lead constructed using 1/4-degree gridded data.

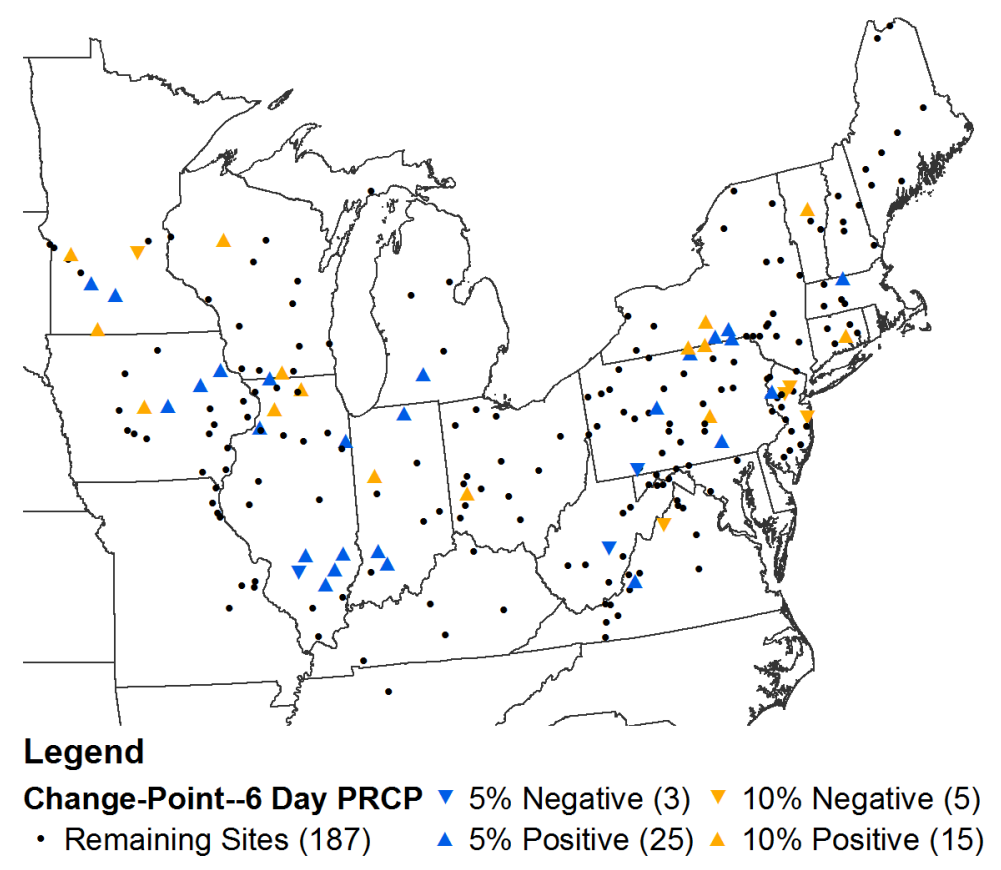

Figure C.20 Results of Pettitt tests on flood generating precipitation series with 6-day lead constructed using 1/4-degree gridded data. 


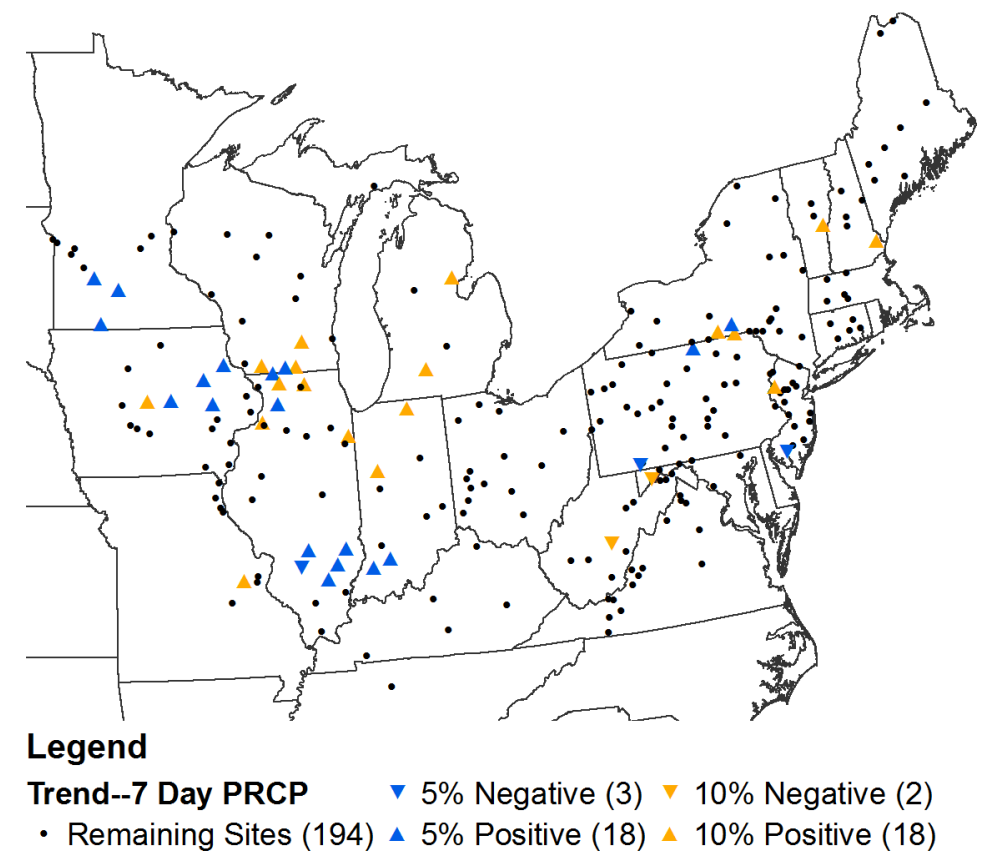

Figure C.21 Results of Mann-Kendall trend tests on flood generating precipitation series with 7-day lead constructed using 1/4-degree gridded data.

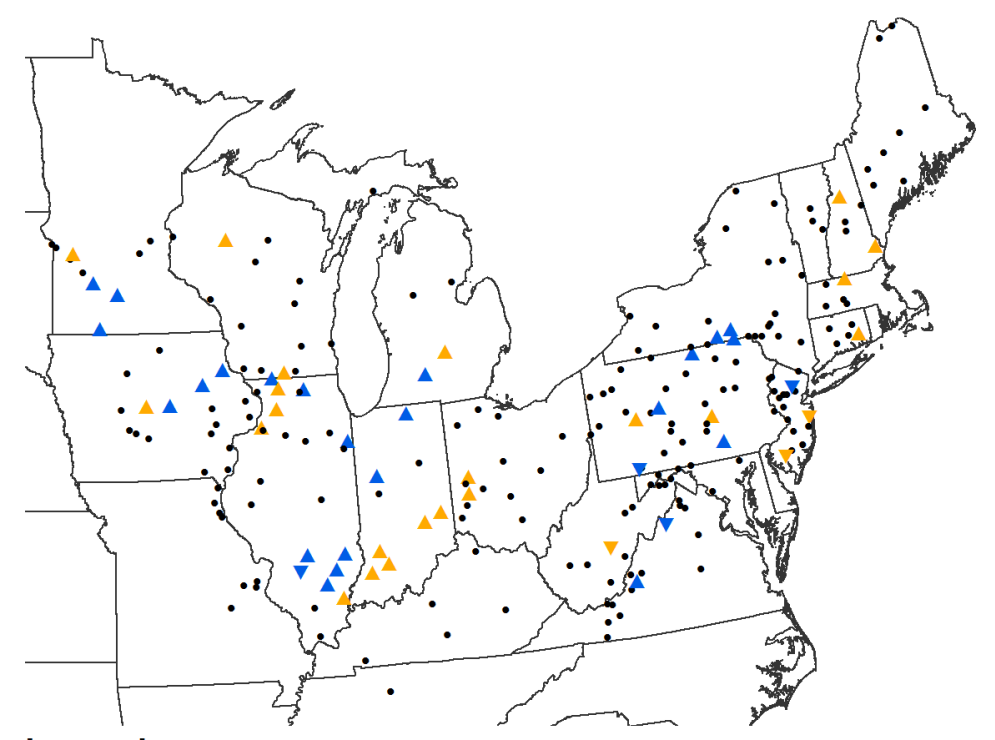

Legend

Change-Point--7 Day PRCP $\vee 5 \%$ Negative (4) $>10 \%$ Negative (3)

- Remaining Sites (183) \5\% Positive (23) $\triangle 10 \%$ Positive (22)

Figure C.22 Results of Pettitt tests on flood generating precipitation series with 7-day lead constructed using 1/4-degree gridded data. 


\section{APPENDIX D TREND AND CHANGE-POINT RESULTS FOR FLOOD GENERATING TEMPERATURE SERIES}

This appendix contains figures presenting results of Mann-Kendall and Pettitt tests on flood generating minimum and maximum temperature series constructed with 2- to 7-day lead times based on 1/8-degree gridded data as discussed in CHAPTER 2. Note that results for both minimum and maximum temperatu4re series with a 4-day lead time are included in Chapter 2. 


\section{D.1 Results for Minimum Temperature Series}

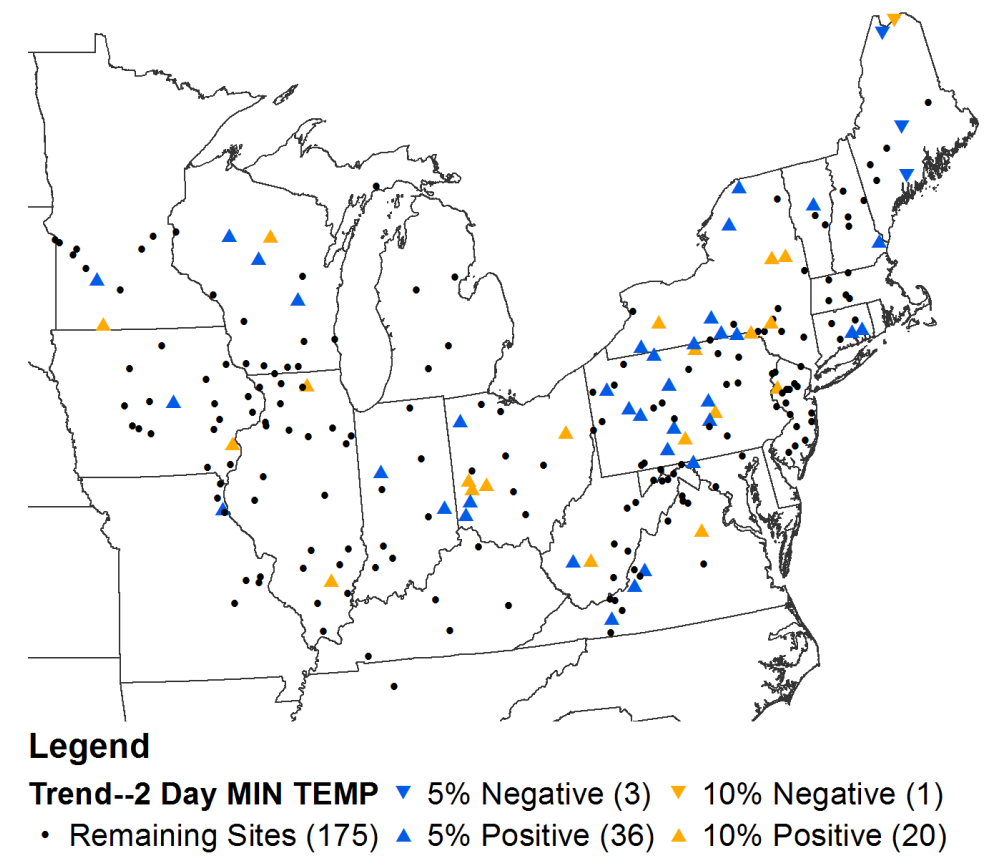

Figure D.1 Results of Mann-Kendall tests on flood generating minimum temperature series with 2-day lead.

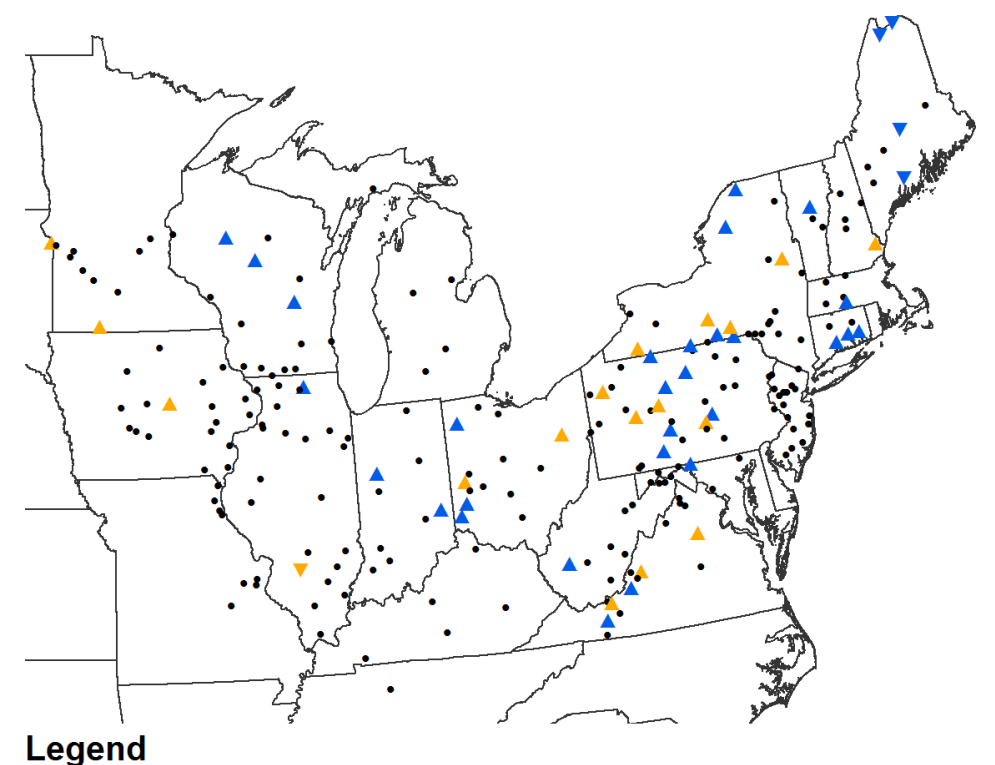

Legend

Change-Point--2 Day MIN $\vee 5 \%$ Negative (4) $\vee 10 \%$ Negative (1)

- Remaining Sites (184) ^ 5\% Positive (29) ^ 10\% Positive (17)

Figure D.2 Results of Pettitt tests on flood generating minimum temperature series with 2-day lead. 


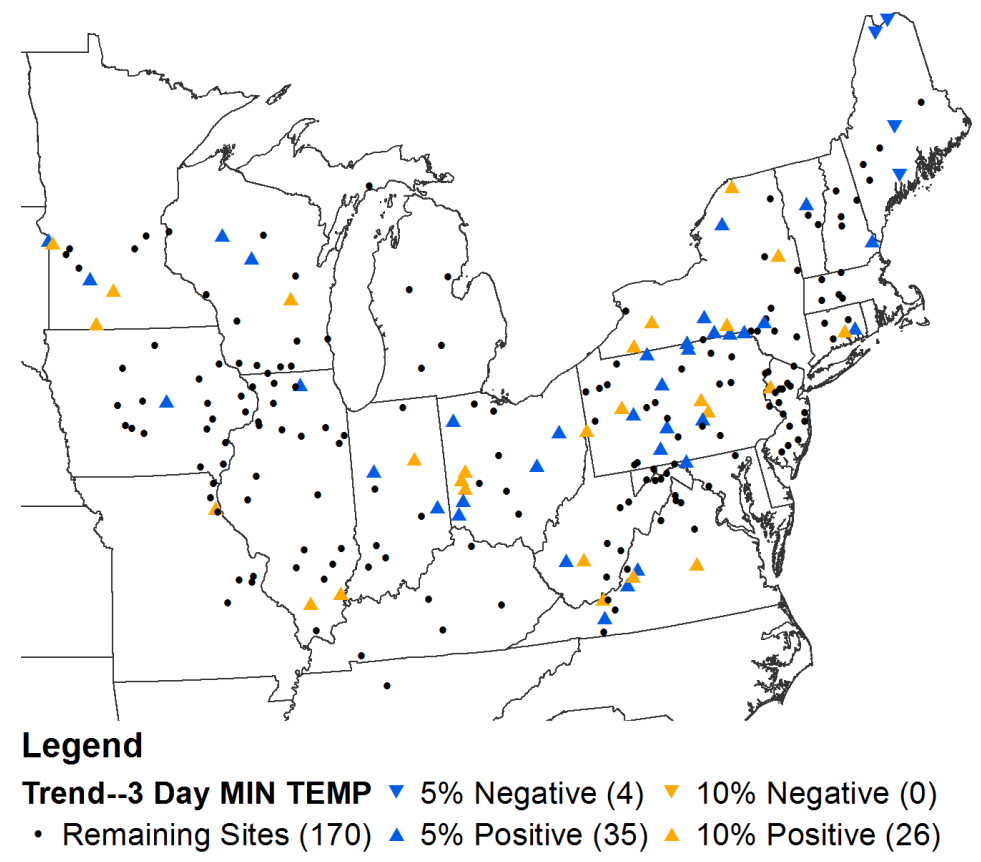

Figure D.3 Results of Mann-Kendall tests on flood generating minimum temperature series with 3-day lead.

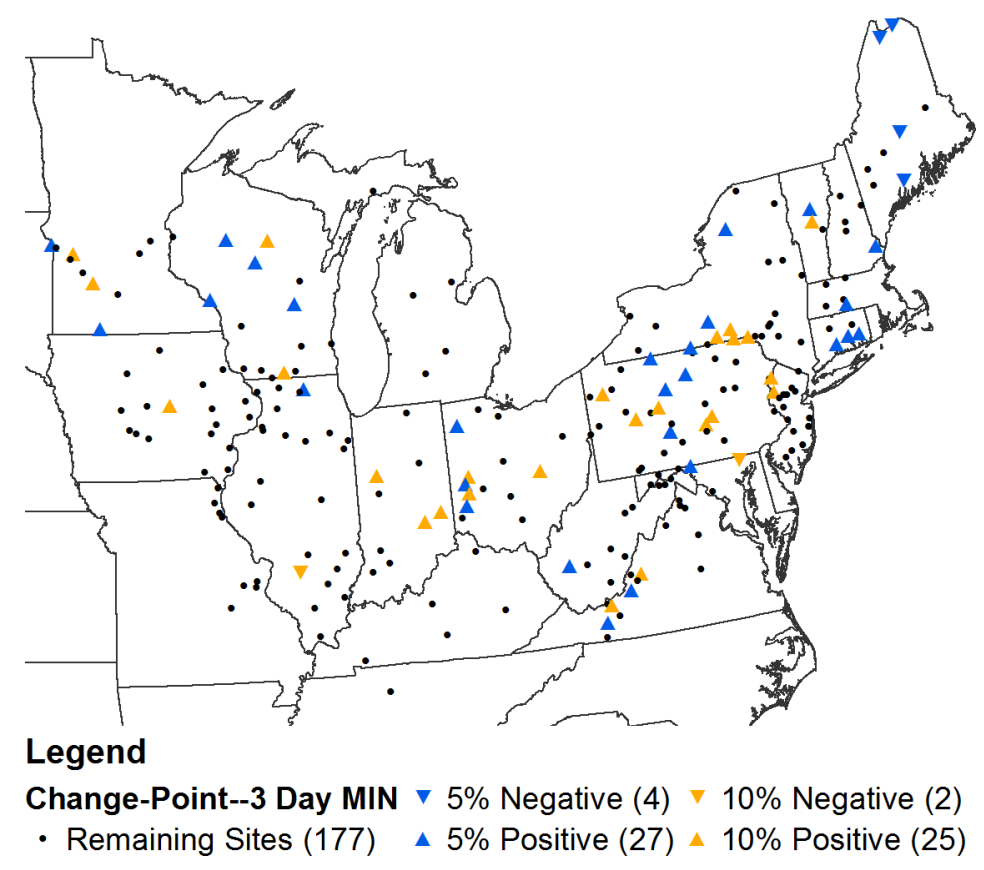

Figure D.4 Results of Pettitt tests on flood generating minimum temperature series with 3-day lead. 


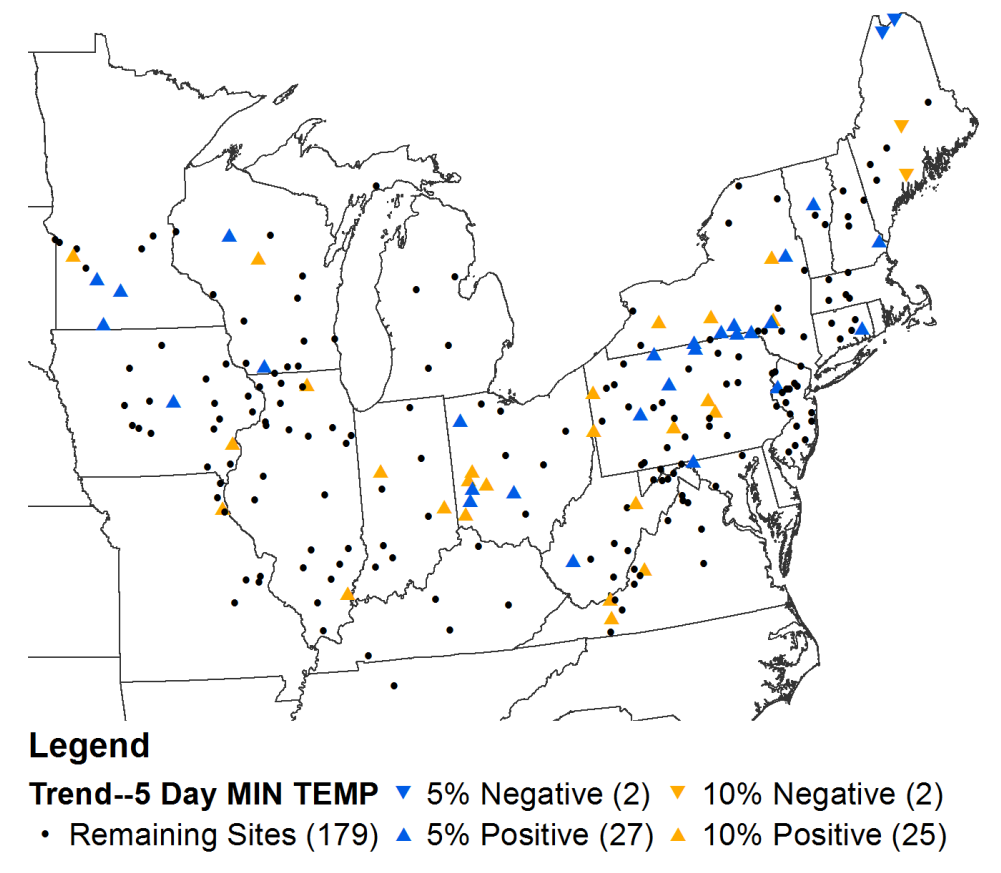

Figure D.5 Results of Mann-Kendall tests on flood generating minimum temperature series with 5-day lead.

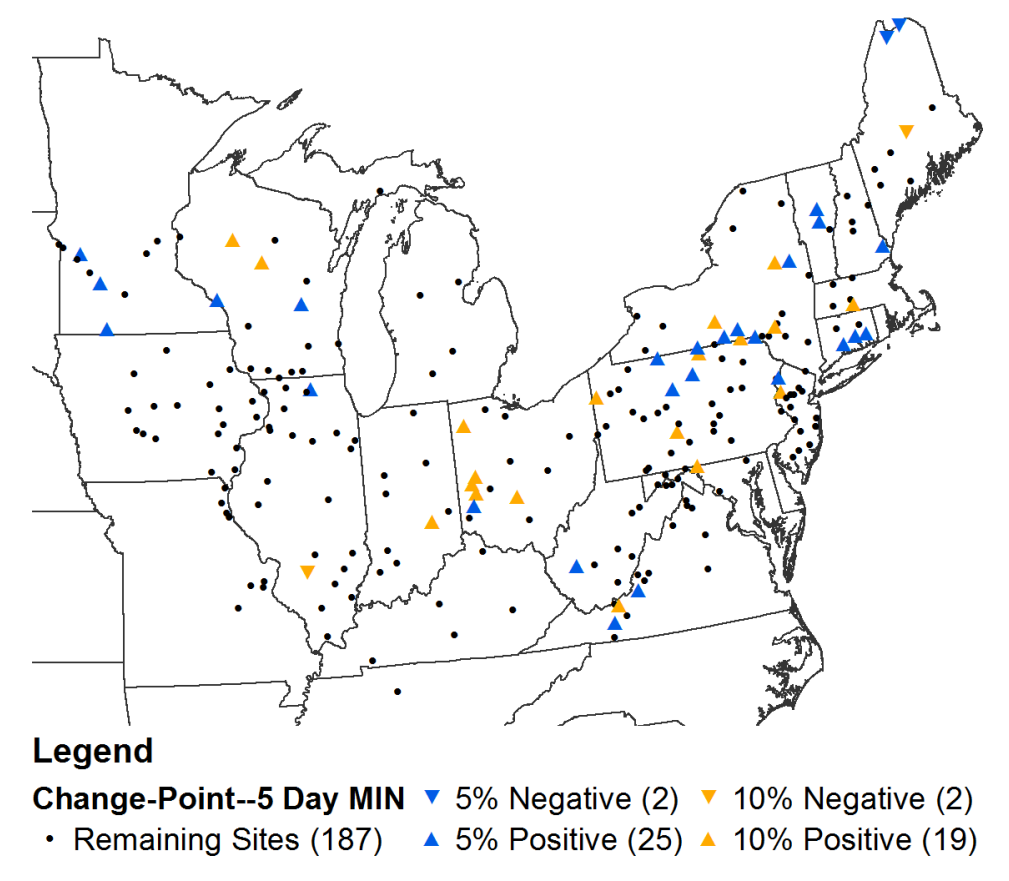

Figure D.6 Results of Pettitt tests on flood generating minimum temperature series with 5-day lead. 


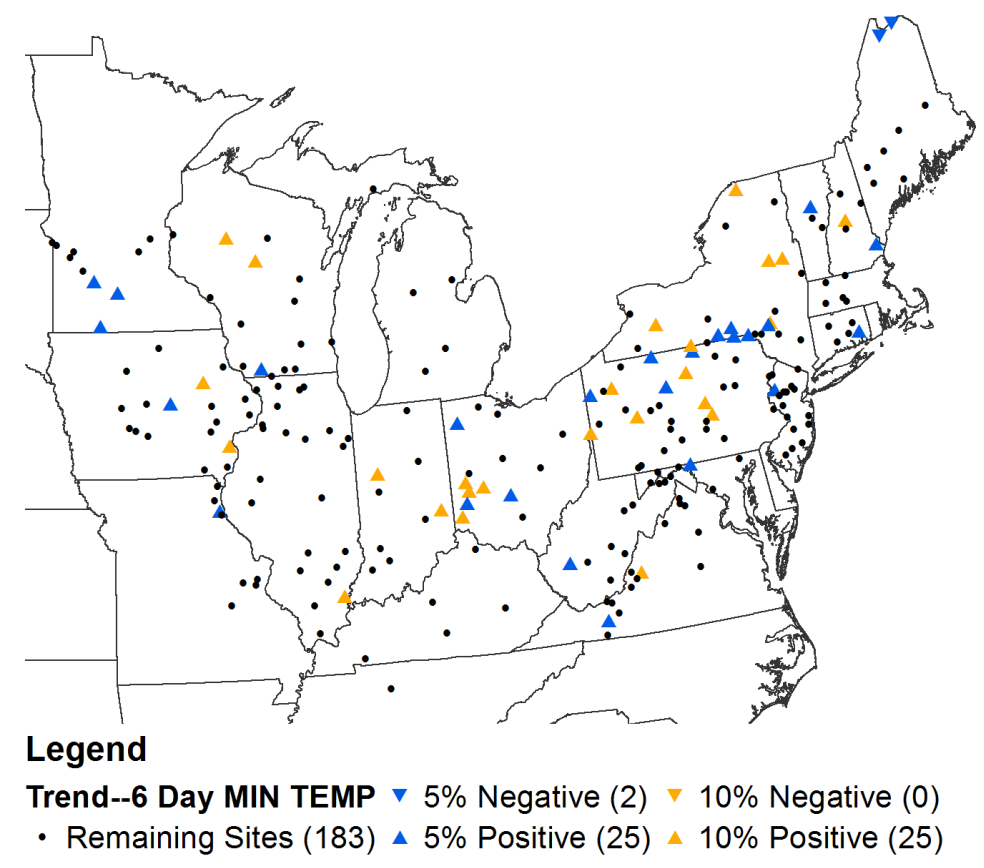

Figure D.7 Results of Mann-Kendall tests on flood generating minimum temperature series with 6-day lead.

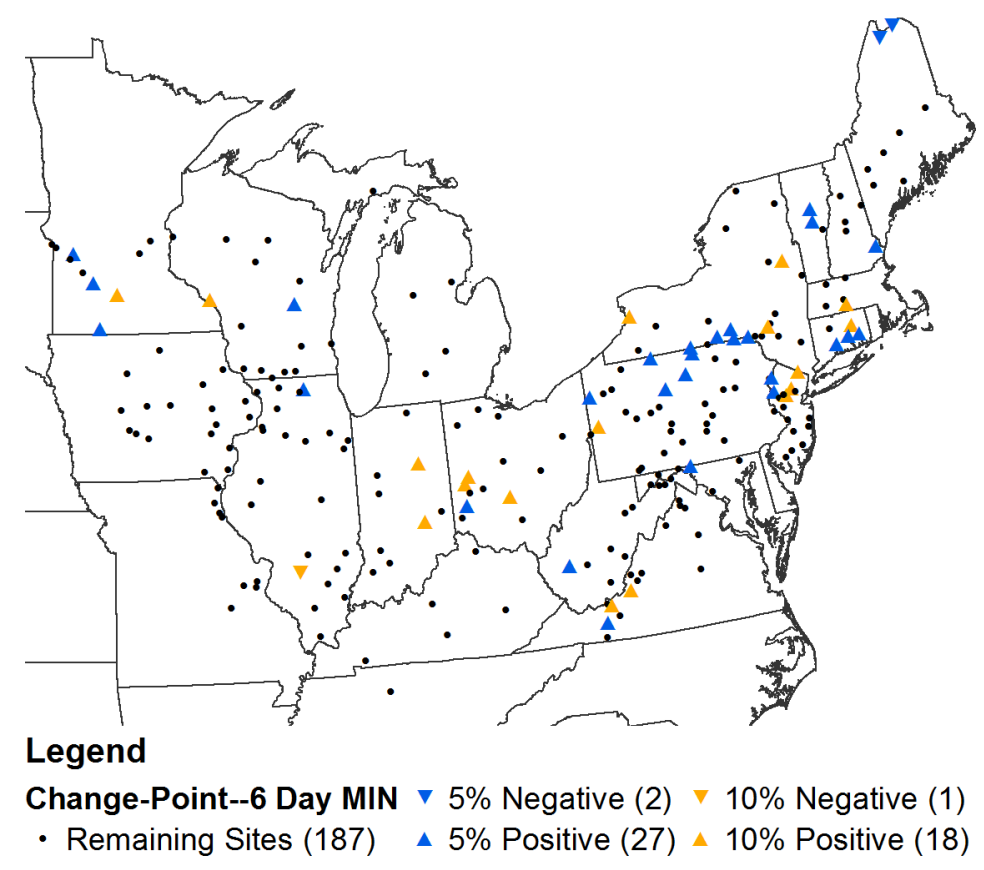

Figure D. 8 Results of Pettitt tests on flood generating minimum temperature series with 6-day lead. 


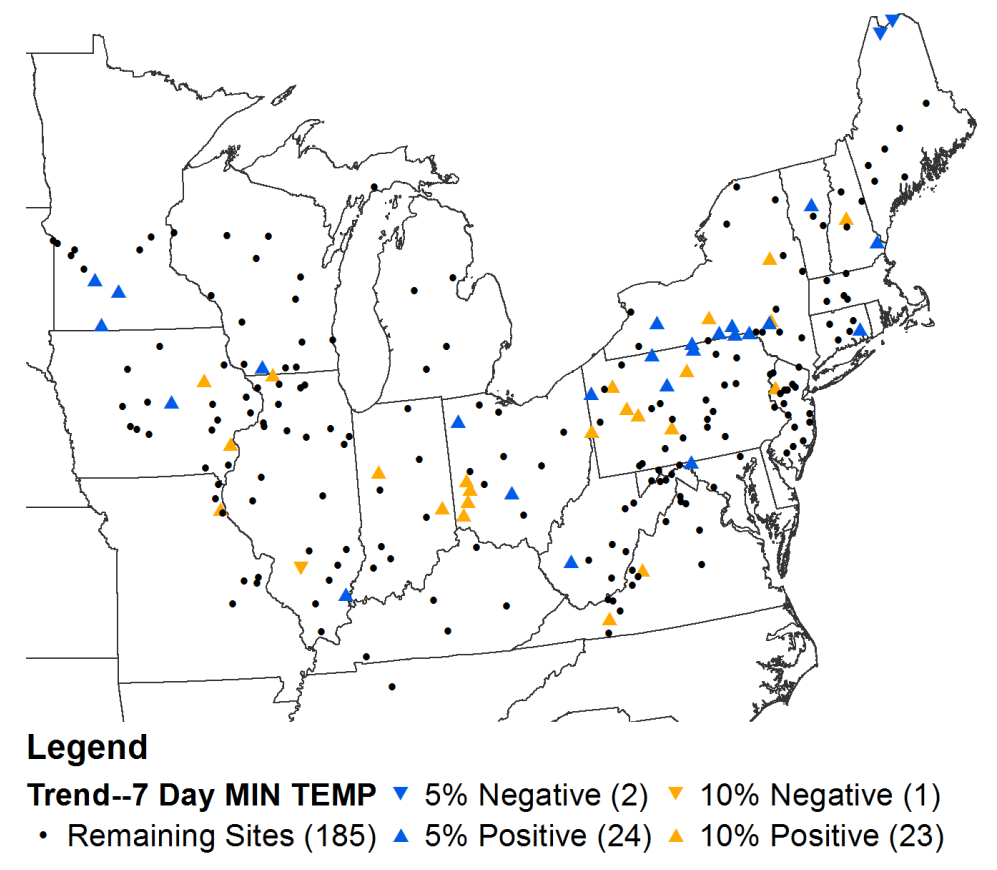

Figure D.9 Results of Mann-Kendall tests on flood generating minimum temperature series with 7-day lead.

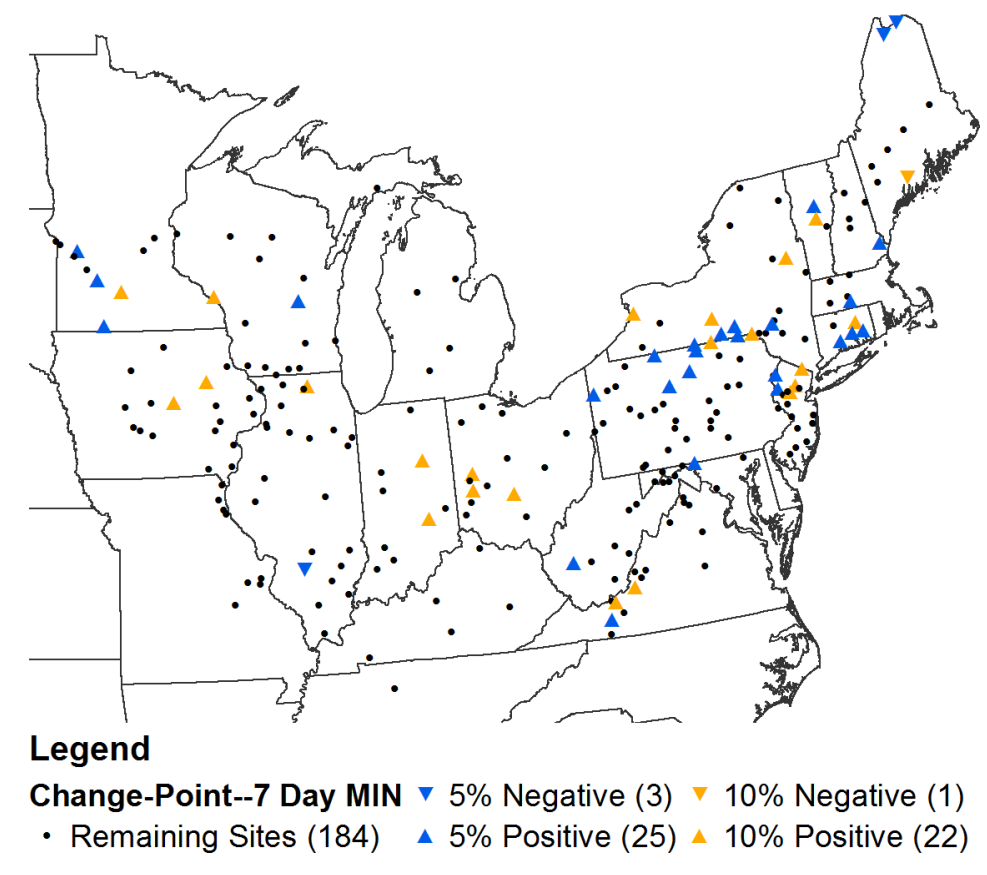

Figure D.10 Results of Pettitt tests on flood generating minimum temperature series with 7-day lead. 


\section{D.2 Results for Maximum Temperature Series}

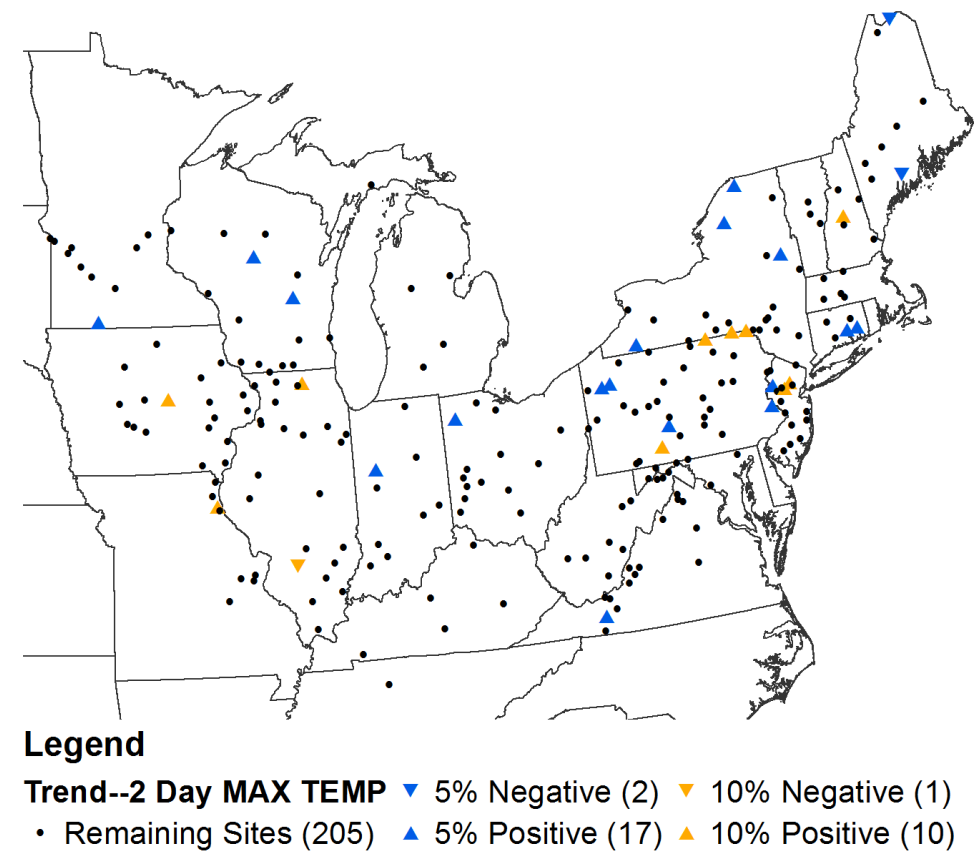

Figure D.11 Results of Mann-Kendall tests on flood generating maximum temperature series with 2-day lead.

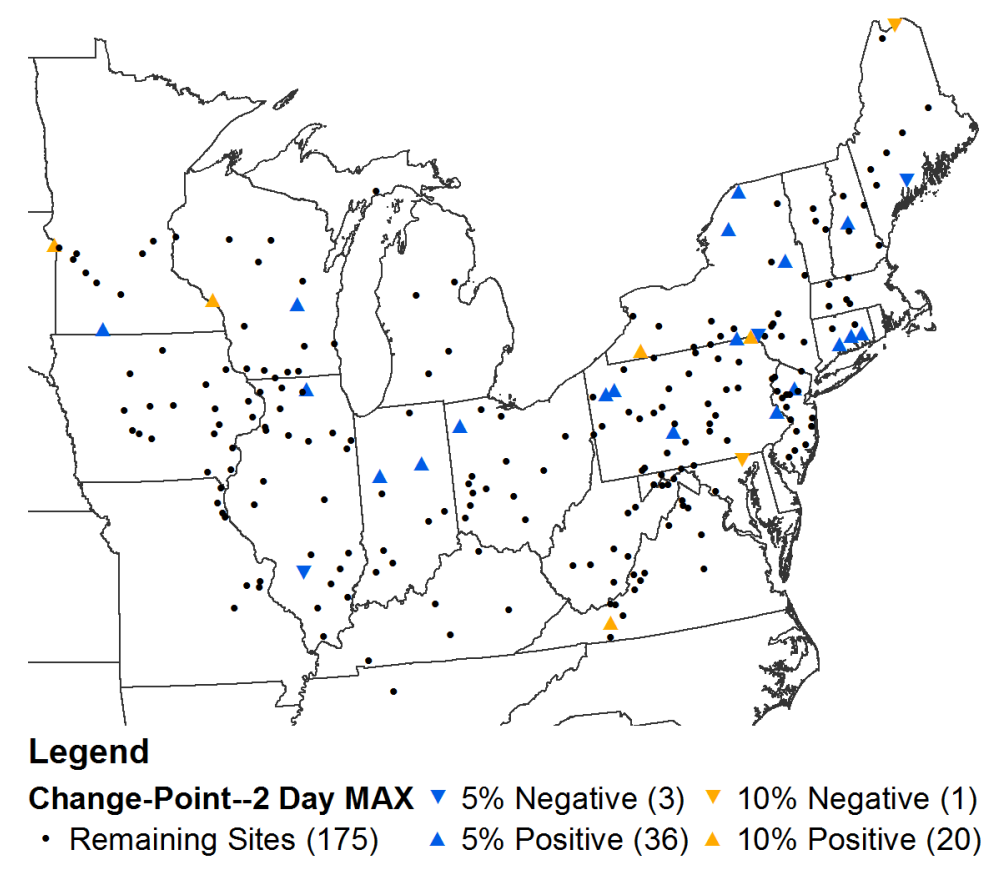

Figure D.12 Results of Pettitt tests on flood generating maximum temperature series with 2-day lead. 


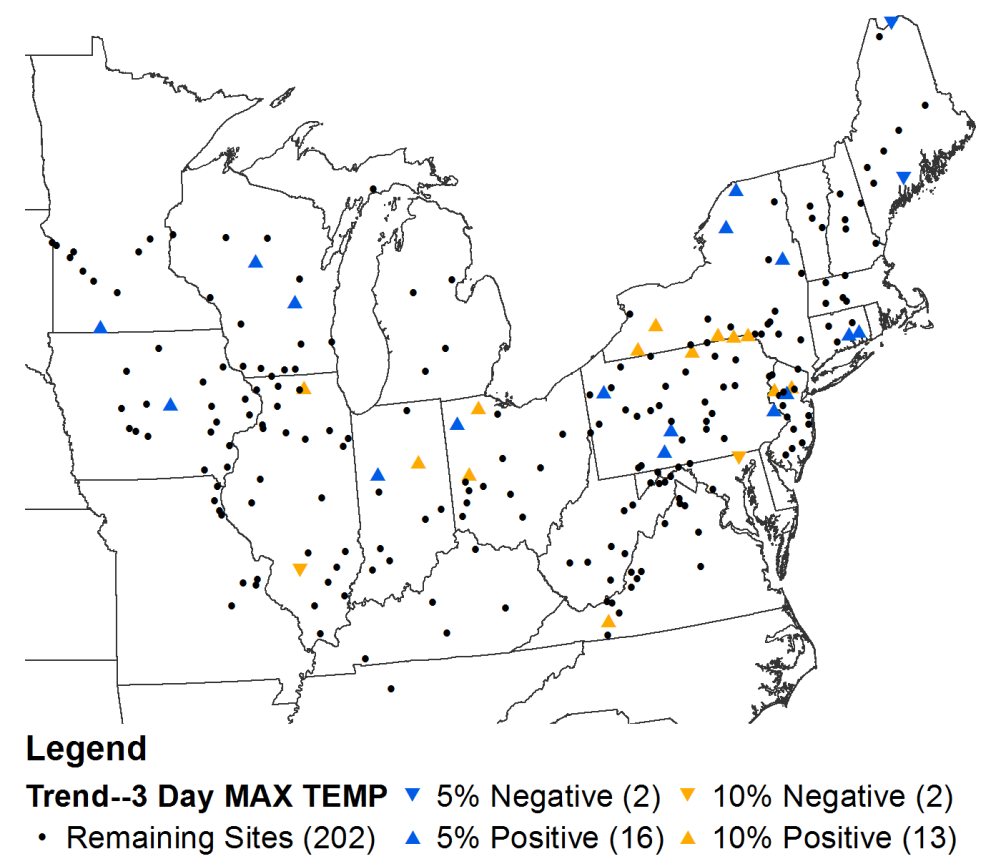

Figure D.13 Results of Mann-Kendall tests on flood generating maximum temperature series with 3-day lead.

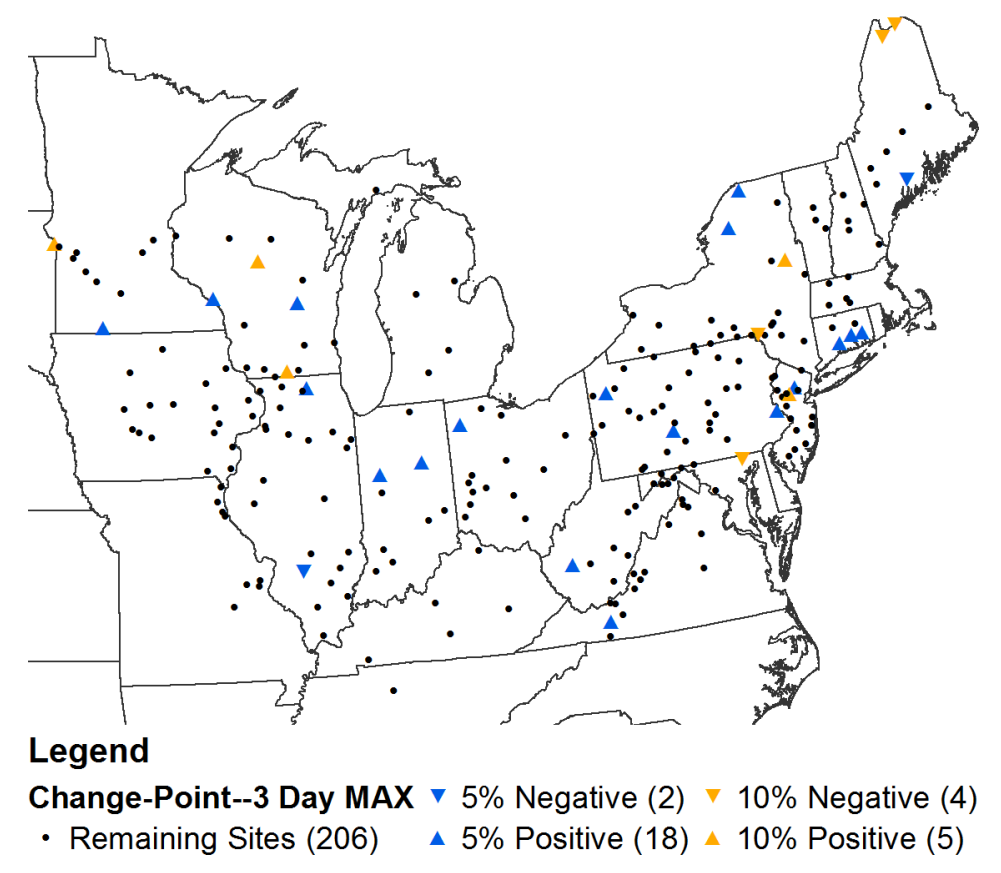

Figure D.14 Results of Pettitt tests on flood generating maximum temperature series with 3-day lead. 


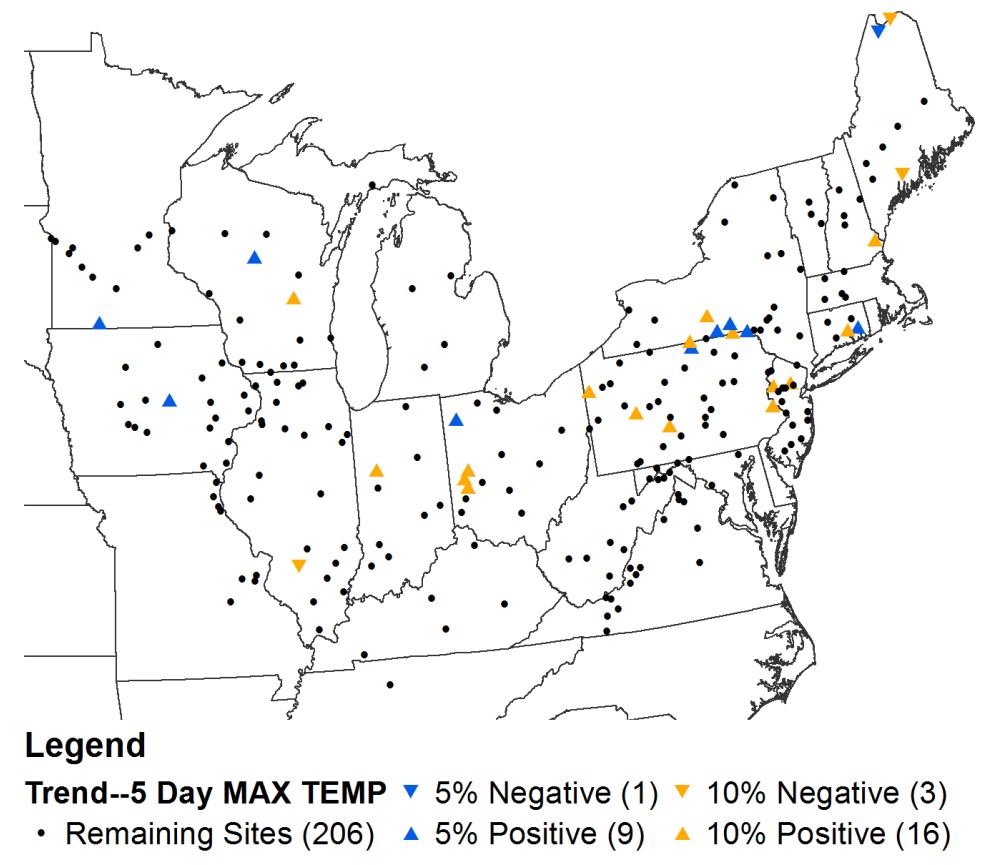

Figure D.15 Results of Mann-Kendall tests on flood generating maximum temperature series with 5-day lead.

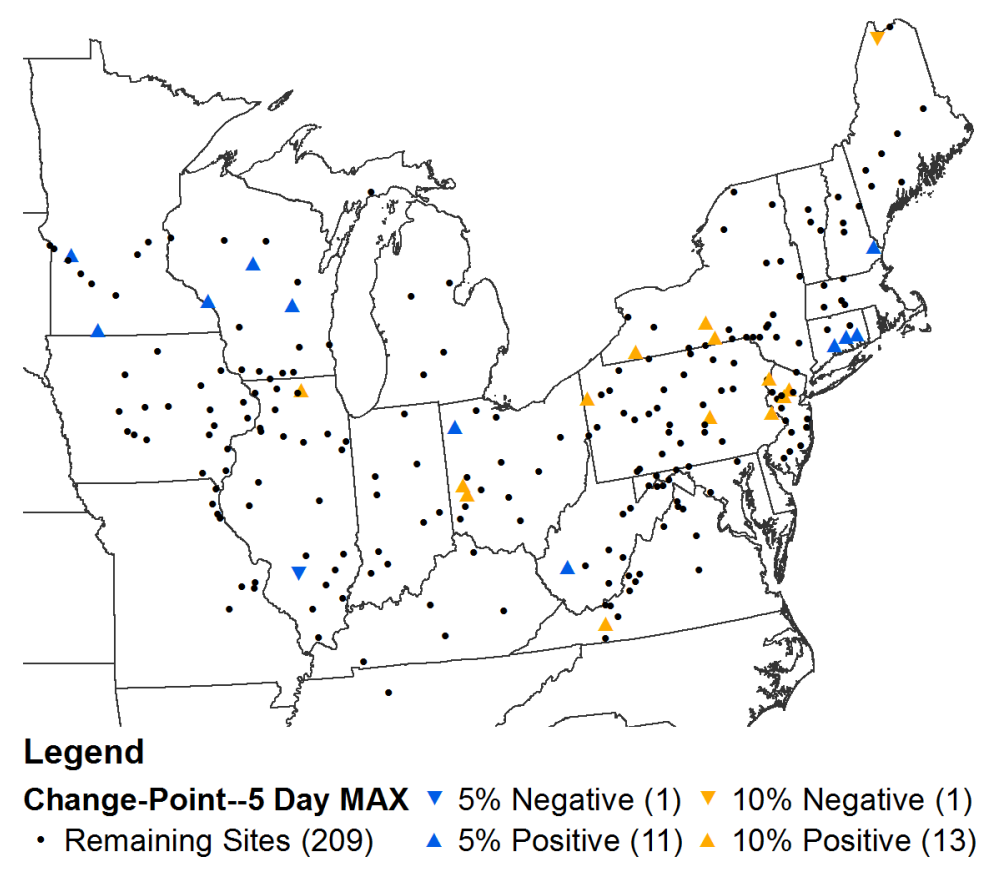

Figure D.16 Results of Pettitt tests on flood generating maximum temperature series with 5-day lead. 


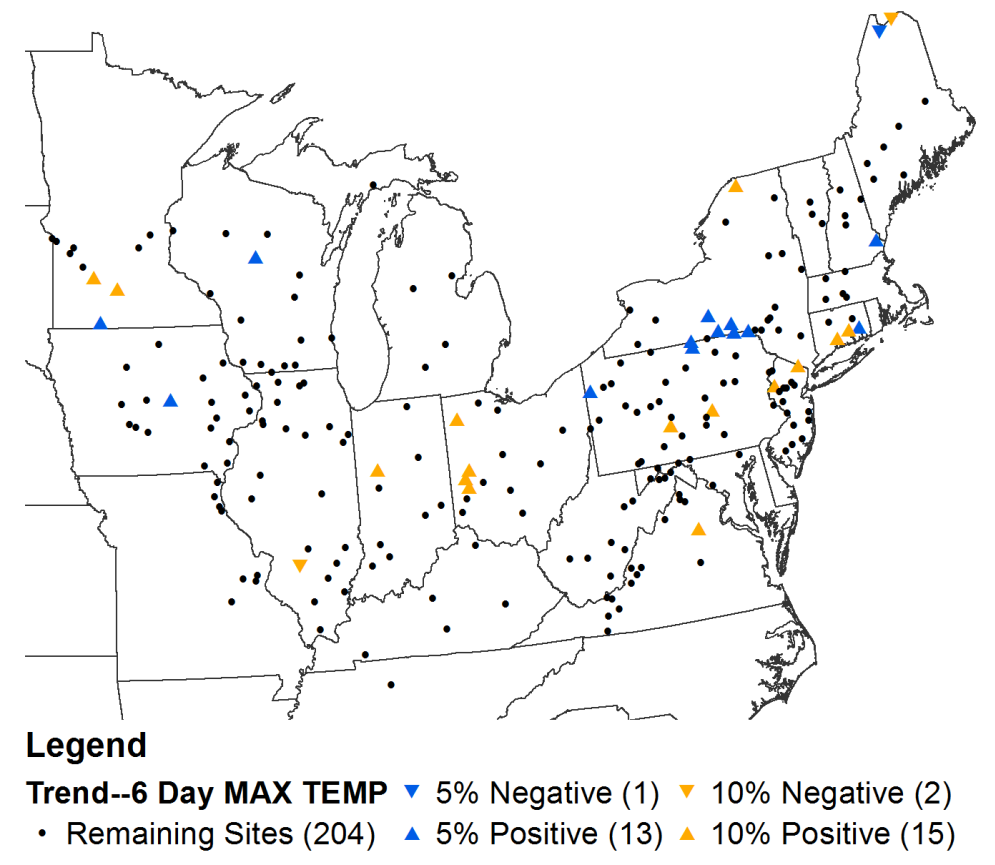

Figure D.17 Results of Mann-Kendall tests on flood generating maximum temperature series with 6-day lead.

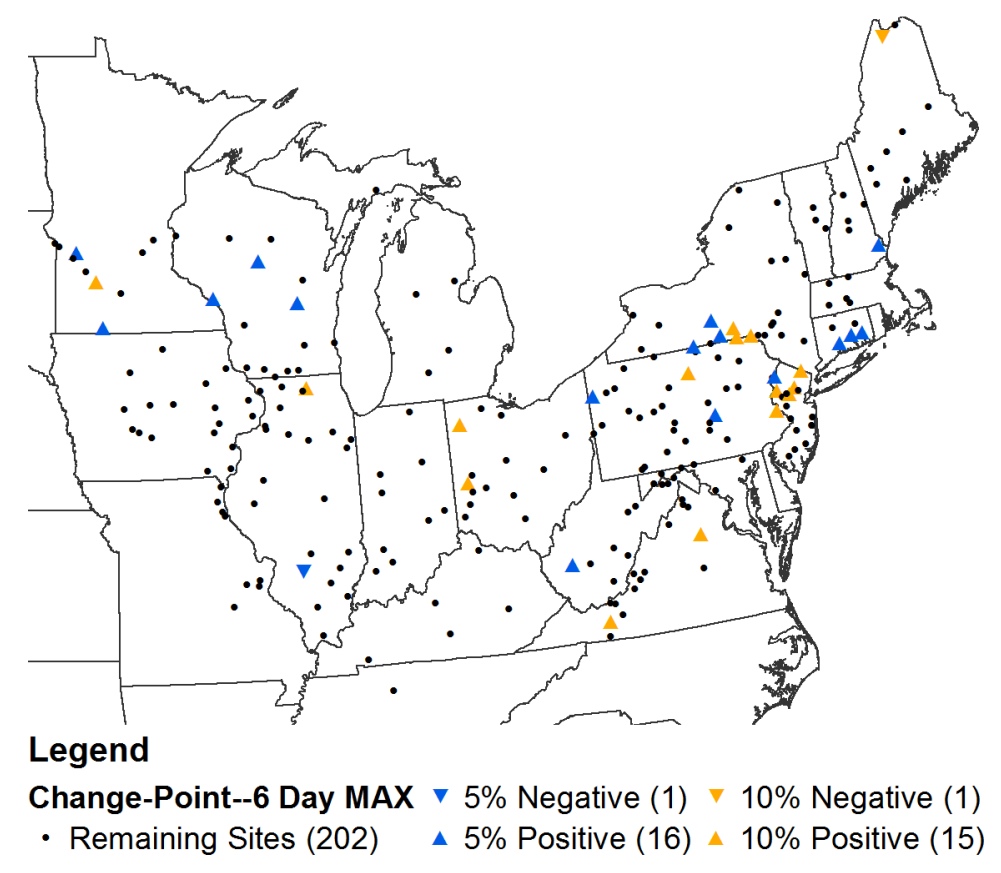

Figure D.18 Results of Pettitt tests on flood generating maximum temperature series with 6-day lead. 


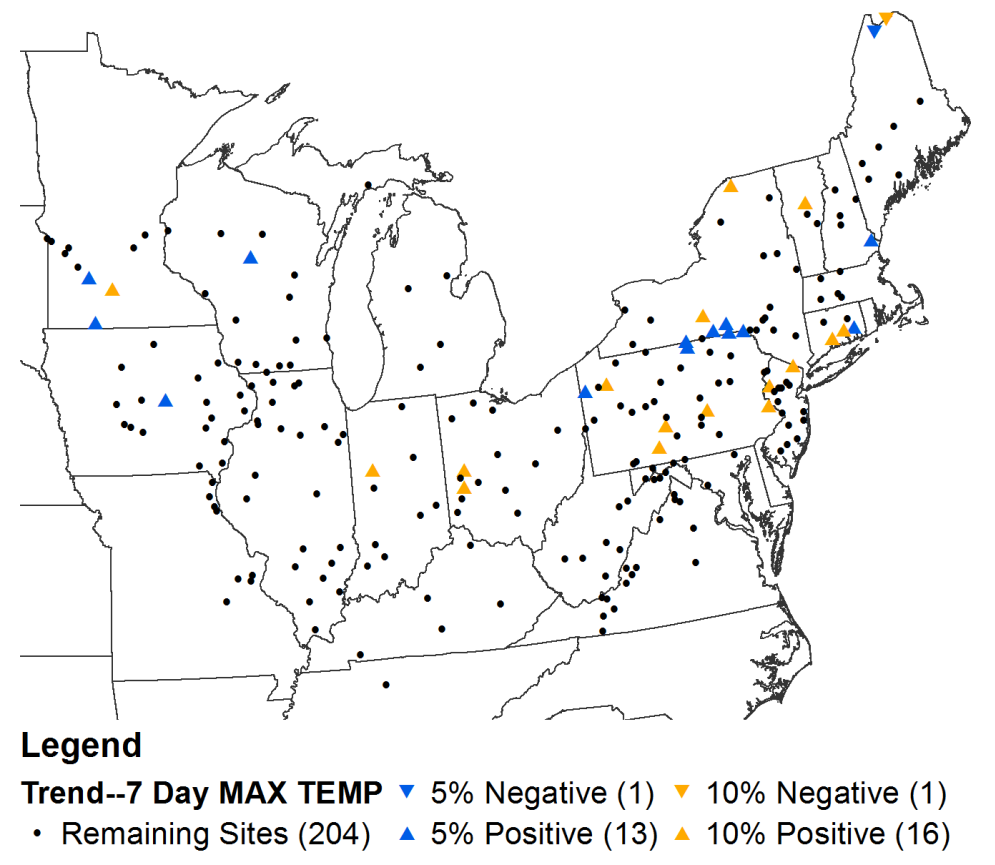

Figure D.19 Results of Mann-Kendall tests on flood generating maximum temperature series with 7-day lead.

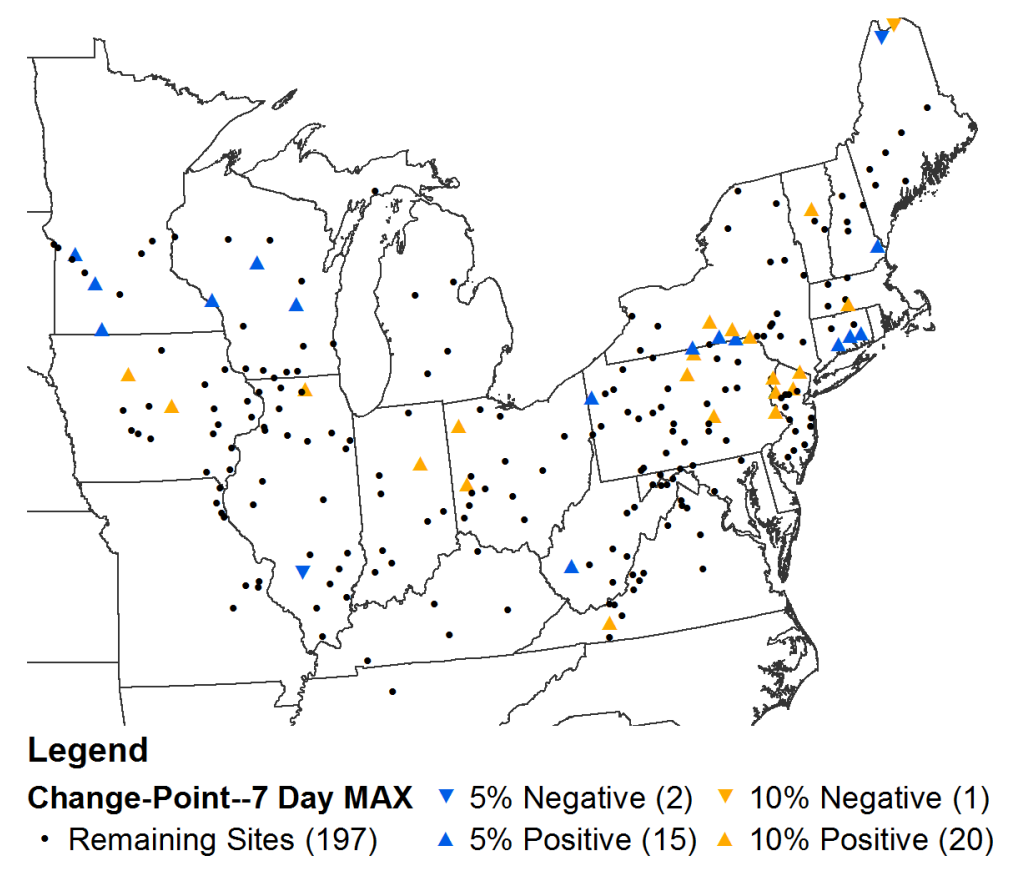

Figure D.20 Results of Pettitt tests on flood generating maximum temperature series with 7-day lead. 


\section{APPENDIX E CORRELATION ANALYSIS RESULTS BETWEEN 10 YEAR MOVING AVERAGE OF LOGS OF FLOOD FLOWS AND CLIMATE ANOMALIES}

This appendix contains tables and figures summarizing Kendall's tau correlation analyses between the 10-year moving average of log-transformed flood flows and 3-month average AMO, MEI, NAO, Nino3.4, and PDO anomalies with 3-, 6-, and 9-month leads. Tables include results only for sites with significant relationships on the $10 \%$ level (sites significant on the 5\% level are in bold). Results are omitted (blank spaces) when pvalues greater than $10 \%$ were obtained. Note that results of the Kendall's tau analyses for AMO, MEI, NAO, and PDO with lead times of 6-, 9-, 3-, and 9-months, respectively, are illustrated in Chapter 3. Figures for Pearson's r and Spearman's rho with the same lead times are included herein. The table below summarizes the number of sites where significant results were obtained using the Pearson's $r$ and Spearman's rho analyses for all cases considered.

Table E.1

Number of sites with significant Pearson's $r$ and Spearman's rho correlations ( 5 and 10\% levels) between 10-yr moving mean of log-transformed flood peaks and for AMO, MEI, NINO 3.4, NAO, and PDO indices with specified lead times.

\begin{tabular}{|c|c|c|c|c|c|c|c|c|c|c|}
\hline \multirow{2}{*}{$\begin{array}{c}\text { Lead Time } \\
\text { (months) }\end{array}$} & \multicolumn{2}{|c|}{ AMO } & \multicolumn{2}{|c|}{ MEI } & \multicolumn{2}{|c|}{ Nino 3.4} & \multicolumn{2}{|c|}{ NAO } & \multicolumn{2}{|c|}{ PDO } \\
\hline & $5 \%$ & $10 \%$ & $5 \%$ & $10 \%$ & $5 \%$ & $10 \%$ & $5 \%$ & $10 \%$ & $5 \%$ & $10 \%$ \\
\hline \multicolumn{11}{|c|}{ Pearson's r Correlation } \\
\hline 3 & 233 & 282 & 48 & 107 & 1 & 6 & 110 & 144 & 174 & 235 \\
\hline 6 & 247 & 297 & 90 & 162 & 4 & 16 & 48 & 81 & 204 & 254 \\
\hline 9 & 213 & 265 & 159 & 214 & 14 & 35 & 48 & 85 & 251 & 296 \\
\hline \multicolumn{11}{|c|}{ Spearman's rho Correlation } \\
\hline 3 & 234 & 271 & 44 & 90 & 1 & 7 & 99 & 138 & 180 & 239 \\
\hline 6 & 234 & 281 & 69 & 134 & 6 & 20 & 47 & 85 & 197 & 248 \\
\hline 9 & 192 & 252 & 135 & 188 & 14 & 42 & 52 & 82 & 236 & 285 \\
\hline
\end{tabular}




\section{E.1 AMO Correlation Results}

Table E. 2

Results of Kendall's tau analyses (significant 10\% level) between 10-year moving average of log-transformed flood flows and 3-month average AMO anomalies with 3-, 6, and 9-month leads.

\begin{tabular}{|c|c|c|c|c|c|c|}
\hline \multirow{2}{*}{$\begin{array}{c}\text { Station } \\
\text { Number }\end{array}$} & \multicolumn{2}{|c|}{ 3-Month Lead } & \multicolumn{2}{|c|}{ 6-Month Lead } & \multicolumn{2}{|c|}{ 9-Month Lead } \\
\hline & tau & p-value & tau & $\mathrm{p}$-value & tau & $\mathrm{p}$-value \\
\hline 1011000 & -0.185 & 0.038 & & & & \\
\hline 1014000 & -0.196 & 0.027 & & & & \\
\hline 1031500 & -0.274 & 0.002 & -0.196 & 0.027 & & \\
\hline 1038000 & -0.224 & 0.012 & & & & \\
\hline 1055000 & & & 0.166 & 0.062 & & \\
\hline 1064500 & & & 0.146 & 0.100 & & \\
\hline 1073000 & 0.220 & 0.014 & 0.353 & 0.000 & 0.344 & 0.000 \\
\hline 1076500 & 0.173 & 0.054 & 0.254 & 0.005 & 0.202 & 0.024 \\
\hline 1127500 & -0.226 & 0.012 & & & & \\
\hline 1137500 & 0.353 & 0.000 & 0.452 & 0.000 & 0.349 & 0.000 \\
\hline 1142500 & 0.355 & 0.000 & 0.436 & 0.000 & 0.337 & 0.000 \\
\hline 1144000 & 0.178 & 0.047 & 0.222 & 0.013 & 0.173 & 0.054 \\
\hline 1175500 & 0.379 & 0.000 & 0.360 & 0.000 & 0.363 & 0.000 \\
\hline 1188000 & & & 0.255 & 0.004 & 0.195 & 0.029 \\
\hline 1193500 & -0.157 & 0.080 & & & & \\
\hline 1196500 & -0.164 & 0.067 & & & & \\
\hline 1321000 & 0.361 & 0.000 & 0.381 & 0.000 & 0.366 & 0.000 \\
\hline 1350000 & & & 0.160 & 0.072 & & \\
\hline 1357500 & 0.177 & 0.046 & 0.220 & 0.013 & 0.227 & 0.011 \\
\hline 1379500 & -0.417 & 0.000 & -0.317 & 0.000 & -0.386 & 0.000 \\
\hline 1381500 & -0.148 & 0.096 & & & & \\
\hline 1397500 & & & 0.207 & 0.020 & & \\
\hline 1398500 & -0.218 & 0.014 & & & -0.178 & 0.045 \\
\hline 1399500 & -0.198 & 0.026 & & & -0.189 & 0.033 \\
\hline 1408000 & -0.368 & 0.000 & -0.334 & 0.000 & -0.315 & 0.000 \\
\hline 1408500 & -0.237 & 0.008 & -0.264 & 0.003 & -0.276 & 0.002 \\
\hline 1411000 & -0.242 & 0.006 & -0.151 & 0.090 & & \\
\hline 1411500 & -0.316 & 0.000 & -0.301 & 0.001 & -0.357 & 0.000 \\
\hline 1413500 & 0.256 & 0.004 & 0.249 & 0.005 & 0.245 & 0.006 \\
\hline 1414500 & 0.539 & 0.000 & 0.504 & 0.000 & 0.498 & 0.000 \\
\hline 1420500 & & & 0.201 & 0.024 & & \\
\hline 1421000 & 0.304 & 0.001 & 0.319 & 0.000 & 0.285 & 0.001 \\
\hline 1426500 & 0.285 & 0.001 & 0.221 & 0.013 & 0.259 & 0.003 \\
\hline 1440000 & 0.178 & 0.045 & 0.213 & 0.016 & 0.208 & 0.019 \\
\hline 1463500 & 0.247 & 0.005 & 0.227 & 0.011 & 0.204 & 0.022 \\
\hline 1503000 & 0.369 & 0.000 & 0.328 & 0.000 & 0.360 & 0.000 \\
\hline 1512500 & 0.252 & 0.005 & 0.231 & 0.009 & 0.270 & 0.002 \\
\hline 1531000 & 0.203 & 0.022 & & & & \\
\hline
\end{tabular}


Table E.2, continued

\begin{tabular}{|c|c|c|c|c|c|c|}
\hline \multirow{2}{*}{$\begin{array}{c}\text { Station } \\
\text { Number }\end{array}$} & \multicolumn{2}{|c|}{ 3-Month Lead } & \multicolumn{2}{|c|}{ 6-Month Lead } & \multicolumn{2}{|c|}{ 9-Month Lead } \\
\hline & tau & $\mathrm{p}$-value & tau & $\mathrm{p}$-value & tau & $\mathrm{p}$-value \\
\hline 1532000 & 0.249 & ב0.005 & 0.281 & 0.002 & 0.225 & $\overline{0.011}$ \\
\hline 1534000 & & & 0.227 & 0.011 & & \\
\hline 1538000 & & & 0.187 & 0.035 & & \\
\hline 1539000 & 0.296 & 0.001 & 0.315 & 0.000 & 0.262 & 0.003 \\
\hline 1541000 & -0.174 & 0.050 & -0.213 & 0.016 & -0.157 & 0.078 \\
\hline 1548500 & 0.149 & 0.093 & & & & \\
\hline 1555000 & & & 0.160 & 0.072 & & \\
\hline 1555500 & -0.177 & 0.046 & & & -0.149 & 0.095 \\
\hline 1556000 & 0.419 & 0.000 & 0.294 & 0.001 & 0.282 & 0.001 \\
\hline 1560000 & & & 0.181 & 0.041 & & \\
\hline 1574000 & -0.436 & 0.000 & -0.359 & 0.000 & -0.407 & 0.000 \\
\hline 1580000 & & & -0.163 & 0.066 & & \\
\hline 1599000 & 0.366 & 0.000 & 0.309 & 0.000 & 0.296 & 0.001 \\
\hline 1604500 & & & -0.155 & 0.081 & & \\
\hline 1610000 & -0.349 & 0.000 & -0.354 & 0.000 & -0.345 & 0.000 \\
\hline 1613000 & -0.336 & 0.000 & -0.362 & 0.000 & -0.361 & 0.000 \\
\hline 1614500 & -0.345 & 0.000 & -0.288 & 0.001 & -0.325 & 0.000 \\
\hline 1631000 & -0.240 & 0.007 & -0.189 & 0.033 & -0.258 & 0.004 \\
\hline 1634000 & -0.205 & 0.021 & -0.154 & 0.083 & -0.228 & 0.010 \\
\hline 1645000 & & & -0.172 & 0.053 & & \\
\hline 2013000 & -0.273 & 0.002 & -0.183 & 0.040 & -0.279 & 0.002 \\
\hline 2016000 & -0.181 & 0.042 & & & -0.202 & 0.023 \\
\hline 2035000 & -0.327 & 0.000 & -0.261 & 0.003 & -0.329 & 0.000 \\
\hline 2055000 & -0.174 & 0.050 & & & -0.149 & 0.095 \\
\hline 2070000 & -0.303 & 0.001 & -0.246 & 0.006 & -0.283 & 0.001 \\
\hline 2083000 & & & 0.151 & 0.090 & & \\
\hline 2083500 & 0.353 & 0.000 & 0.276 & 0.002 & 0.283 & 0.001 \\
\hline 2085500 & 0.173 & 0.051 & & & 0.156 & 0.079 \\
\hline 2091500 & 0.198 & 0.026 & & & 0.162 & 0.068 \\
\hline 2102000 & 0.303 & 0.001 & 0.255 & 0.004 & 0.238 & 0.007 \\
\hline 2116500 & -0.342 & 0.000 & -0.387 & 0.000 & -0.298 & 0.001 \\
\hline 2118000 & -0.231 & 0.009 & -0.260 & 0.003 & -0.207 & 0.020 \\
\hline 2131000 & -0.303 & 0.001 & -0.348 & 0.000 & -0.281 & 0.002 \\
\hline 2132000 & -0.363 & 0.000 & -0.377 & 0.000 & -0.326 & 0.000 \\
\hline 2136000 & -0.373 & 0.000 & -0.370 & 0.000 & -0.358 & 0.000 \\
\hline 2138500 & & & -0.167 & 0.060 & -0.167 & 0.060 \\
\hline 2154500 & & & -0.167 & 0.061 & & \\
\hline 2156500 & -0.259 & 0.004 & -0.339 & 0.000 & -0.289 & 0.001 \\
\hline 2173500 & -0.376 & 0.000 & -0.408 & 0.000 & -0.334 & 0.000 \\
\hline 2177000 & -0.253 & 0.004 & -0.261 & 0.003 & -0.237 & 0.008 \\
\hline 2192000 & -0.333 & 0.000 & -0.340 & 0.000 & -0.326 & 0.000 \\
\hline 2198000 & -0.337 & 0.000 & -0.371 & 0.000 & -0.293 & 0.001 \\
\hline 2202500 & -0.360 & 0.000 & -0.378 & 0.000 & -0.314 & 0.000 \\
\hline 2203000 & -0.389 & 0.000 & -0.454 & 0.000 & -0.361 & 0.000 \\
\hline
\end{tabular}


Table E.2, continued

\begin{tabular}{|c|c|c|c|c|c|c|}
\hline \multirow{2}{*}{$\begin{array}{l}\text { Station } \\
\text { Number }\end{array}$} & \multicolumn{2}{|c|}{ 3-Month Lead } & \multicolumn{2}{|c|}{ 6-Month Lead } & \multicolumn{2}{|c|}{ 9-Month Lead } \\
\hline & tau & $\mathrm{p}$-value & tau & $\mathrm{p}$-value & tau & $\mathrm{p}$-value \\
\hline 2213500 & -0.289 & 0.001 & -0.224 & 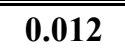 & -0.224 & 0.012 \\
\hline 2217500 & -0.318 & 0.000 & -0.346 & 0.000 & -0.299 & 0.001 \\
\hline 2225500 & -0.403 & 0.000 & -0.400 & 0.000 & -0.327 & 0.000 \\
\hline 2226000 & -0.314 & 0.000 & -0.288 & 0.001 & -0.272 & 0.002 \\
\hline 2226500 & -0.327 & 0.000 & -0.361 & 0.000 & -0.289 & 0.001 \\
\hline 2228000 & -0.276 & 0.002 & -0.308 & 0.001 & -0.242 & 0.006 \\
\hline 2231000 & & & 0.150 & 0.092 & 0.149 & 0.093 \\
\hline 2256500 & 0.218 & 0.014 & 0.308 & 0.001 & 0.325 & 0.000 \\
\hline 2296750 & 0.262 & 0.003 & 0.395 & 0.000 & 0.372 & 0.000 \\
\hline 2298830 & 0.336 & 0.000 & 0.466 & 0.000 & 0.407 & 0.000 \\
\hline 2301500 & 0.202 & 0.023 & 0.286 & 0.001 & 0.294 & 0.001 \\
\hline 2303000 & & & 0.219 & 0.014 & 0.197 & 0.027 \\
\hline 2313000 & -0.207 & 0.020 & -0.152 & 0.087 & -0.160 & 0.071 \\
\hline 2314500 & -0.255 & 0.004 & -0.320 & 0.000 & -0.248 & 0.005 \\
\hline 2317500 & -0.151 & 0.089 & & & & \\
\hline 2320500 & -0.340 & 0.000 & -0.287 & 0.001 & -0.259 & 0.003 \\
\hline 2321500 & -0.192 & 0.031 & -0.215 & 0.015 & -0.206 & 0.021 \\
\hline 2329000 & -0.301 & 0.001 & -0.248 & 0.005 & -0.263 & 0.003 \\
\hline 2333500 & -0.233 & 0.009 & -0.208 & 0.019 & & \\
\hline 2337000 & -0.192 & 0.031 & -0.188 & 0.034 & -0.157 & 0.078 \\
\hline 2339500 & & & -0.204 & 0.022 & & \\
\hline 2347500 & -0.335 & 0.000 & -0.366 & 0.000 & -0.286 & 0.001 \\
\hline 2353500 & -0.316 & 0.000 & -0.285 & 0.001 & -0.263 & 0.003 \\
\hline 2358000 & -0.345 & 0.000 & -0.374 & 0.000 & -0.337 & 0.000 \\
\hline 2361000 & -0.221 & 0.013 & -0.259 & 0.003 & -0.213 & 0.016 \\
\hline 2375500 & -0.352 & 0.000 & -0.308 & 0.001 & -0.328 & 0.000 \\
\hline 2392000 & -0.166 & 0.063 & -0.248 & 0.005 & -0.164 & 0.065 \\
\hline 2437000 & 0.254 & 0.004 & 0.239 & 0.007 & 0.202 & 0.023 \\
\hline 2441000 & -0.268 & 0.003 & -0.297 & 0.001 & -0.228 & 0.010 \\
\hline 2448000 & -0.168 & 0.058 & -0.197 & 0.027 & -0.202 & 0.023 \\
\hline 2474500 & & & -0.169 & 0.057 & -0.163 & 0.067 \\
\hline 2487500 & 0.183 & 0.039 & 0.221 & 0.013 & 0.158 & 0.076 \\
\hline 3010500 & 0.214 & 0.016 & & & 0.150 & 0.092 \\
\hline 3020500 & 0.169 & 0.057 & & & & \\
\hline 3032500 & 0.171 & 0.055 & 0.171 & 0.054 & & \\
\hline 3034500 & 0.193 & 0.030 & 0.229 & 0.010 & 0.289 & 0.001 \\
\hline 3051000 & & & & & -0.169 & 0.057 \\
\hline 3109500 & 0.219 & 0.014 & & & 0.205 & 0.022 \\
\hline 3118500 & & & 0.170 & 0.057 & & \\
\hline 3167000 & & & -0.230 & 0.010 & & \\
\hline 3175500 & 0.172 & 0.053 & & & & \\
\hline 3183500 & -0.259 & 0.004 & -0.245 & 0.006 & -0.288 & 0.001 \\
\hline 3186500 & 0.195 & 0.028 & 0.281 & 0.002 & 0.199 & 0.025 \\
\hline 3193000 & 0.223 & 0.012 & 0.151 & 0.090 & 0.154 & 0.083 \\
\hline
\end{tabular}


Table E.2, continued

\begin{tabular}{|c|c|c|c|c|c|c|}
\hline \multirow{2}{*}{$\begin{array}{c}\text { Station } \\
\text { Number }\end{array}$} & \multicolumn{2}{|c|}{ 3-Month Lead } & \multicolumn{2}{|c|}{ 6-Month Lead } & \multicolumn{2}{|c|}{ 9-Month Lead } \\
\hline & tau & $\mathrm{p}$-value & tau & p-value & tau & p-value \\
\hline 3198500 & -0.337 & 0.000 & -0.320 & 0.000 & -0.297 & 0.001 \\
\hline 3219500 & -0.248 & 0.006 & -0.189 & 0.035 & -0.153 & 0.088 \\
\hline 3230500 & 0.458 & 0.000 & 0.415 & 0.000 & 0.366 & 0.000 \\
\hline 3262000 & 0.171 & 0.056 & & & 0.154 & 0.085 \\
\hline 3265000 & 0.350 & 0.000 & 0.317 & 0.000 & 0.308 & 0.001 \\
\hline 3266000 & 0.254 & 0.005 & 0.229 & 0.011 & 0.402 & 0.000 \\
\hline 3269500 & 0.292 & 0.001 & 0.156 & 0.083 & 0.215 & 0.016 \\
\hline 3274000 & 0.151 & 0.092 & & & 0.159 & 0.076 \\
\hline 3275000 & 0.310 & 0.000 & 0.237 & 0.008 & 0.270 & 0.002 \\
\hline 3281500 & & & -0.194 & 0.030 & & \\
\hline 3294500 & & & -0.213 & 0.018 & -0.170 & 0.059 \\
\hline 3301500 & -0.451 & 0.000 & -0.398 & 0.000 & -0.392 & 0.000 \\
\hline 3326500 & 0.193 & 0.030 & 0.207 & 0.020 & 0.221 & 0.013 \\
\hline 3335500 & 0.192 & 0.031 & 0.185 & 0.038 & 0.197 & 0.026 \\
\hline 3339500 & 0.376 & 0.000 & 0.306 & 0.001 & 0.361 & 0.000 \\
\hline 3345500 & & & 0.150 & 0.092 & & \\
\hline 3360500 & 0.185 & 0.037 & 0.166 & 0.063 & 0.154 & 0.083 \\
\hline 3363500 & 0.388 & 0.000 & 0.354 & 0.000 & 0.359 & 0.000 \\
\hline 3373500 & 0.271 & 0.002 & 0.214 & 0.016 & 0.224 & 0.012 \\
\hline 3374000 & 0.162 & 0.068 & 0.196 & 0.027 & 0.197 & 0.027 \\
\hline 3379500 & & & 0.162 & 0.068 & 0.162 & 0.069 \\
\hline 3381500 & & & & & 0.164 & 0.064 \\
\hline 3434500 & 0.273 & 0.002 & 0.250 & 0.005 & 0.221 & 0.013 \\
\hline 3438000 & & & 0.157 & 0.081 & & \\
\hline 3451500 & -0.236 & 0.008 & -0.302 & 0.001 & -0.228 & 0.010 \\
\hline 3465500 & & & -0.147 & 0.097 & & \\
\hline 3473000 & & & -0.209 & 0.019 & & \\
\hline 3479000 & -0.181 & 0.042 & -0.190 & 0.032 & & \\
\hline 3504000 & -0.258 & 0.004 & -0.227 & 0.011 & -0.159 & 0.073 \\
\hline 3528000 & -0.218 & 0.014 & -0.223 & 0.012 & & \\
\hline 3540500 & 0.168 & 0.059 & & & 0.155 & 0.082 \\
\hline 3574500 & -0.256 & 0.004 & -0.276 & 0.002 & -0.235 & 0.008 \\
\hline 3604000 & 0.304 & 0.001 & 0.298 & 0.001 & 0.245 & 0.006 \\
\hline 3612000 & -0.153 & 0.089 & -0.158 & 0.079 & & \\
\hline 4056500 & -0.222 & 0.012 & -0.184 & 0.039 & -0.214 & 0.016 \\
\hline 4079000 & -0.265 & 0.003 & -0.333 & 0.000 & -0.338 & 0.000 \\
\hline 4100500 & & & 0.147 & 0.097 & 0.156 & 0.079 \\
\hline 4121500 & & & -0.147 & 0.097 & & \\
\hline 4198000 & -0.353 & 0.000 & -0.228 & 0.010 & -0.250 & 0.005 \\
\hline 4214500 & 0.188 & 0.035 & & & & \\
\hline 4262500 & & & 0.186 & 0.036 & 0.169 & 0.057 \\
\hline 4269000 & & & 0.173 & 0.051 & & \\
\hline 4275000 & & & 0.186 & 0.036 & 0.192 & 0.031 \\
\hline 5053000 & 0.276 & 0.002 & 0.289 & 0.001 & 0.215 & 0.016 \\
\hline
\end{tabular}


Table E.2, continued

\begin{tabular}{|c|c|c|c|c|c|c|}
\hline \multirow{2}{*}{$\begin{array}{l}\text { Station } \\
\text { Number }\end{array}$} & \multicolumn{2}{|c|}{ 3-Month Lead } & \multicolumn{2}{|c|}{ 6-Month Lead } & \multicolumn{2}{|c|}{ 9-Month Lead } \\
\hline & tau & $\mathrm{p}$-value & tau & p-value & tau & $\mathrm{p}$-value \\
\hline 5062000 & 0.211 & 0.018 & 0.262 & 0.003 & 0.271 & 0.002 \\
\hline 5062500 & & & 0.177 & 0.047 & & \\
\hline 5078000 & -0.155 & 0.082 & & & -0.192 & 0.031 \\
\hline 5082500 & & & 0.179 & 0.044 & & \\
\hline 5100000 & 0.150 & 0.092 & & & & \\
\hline 5112000 & 0.194 & 0.029 & 0.188 & 0.034 & & \\
\hline 5131500 & -0.226 & 0.011 & -0.300 & 0.001 & -0.276 & 0.002 \\
\hline 5133500 & -0.288 & 0.001 & -0.259 & 0.004 & -0.236 & 0.008 \\
\hline 5280000 & 0.233 & 0.009 & 0.276 & 0.002 & 0.181 & 0.042 \\
\hline 5293000 & 0.157 & 0.077 & 0.147 & 0.097 & & \\
\hline 5313500 & 0.199 & 0.025 & 0.187 & 0.035 & & \\
\hline 5316500 & & & 0.175 & 0.049 & & \\
\hline 5317000 & 0.269 & 0.002 & 0.293 & 0.001 & 0.218 & 0.014 \\
\hline 5330000 & 0.227 & 0.011 & 0.257 & 0.004 & 0.194 & 0.029 \\
\hline 5331000 & 0.177 & 0.047 & 0.209 & 0.019 & & \\
\hline 5394500 & & & & & -0.171 & 0.054 \\
\hline 5399500 & -0.218 & 0.014 & -0.288 & 0.001 & -0.256 & 0.004 \\
\hline 5407000 & -0.300 & 0.001 & -0.247 & 0.006 & -0.261 & 0.004 \\
\hline 5419000 & & & & & -0.159 & 0.074 \\
\hline 5422000 & & & 0.240 & 0.007 & & \\
\hline 5426000 & & & 0.197 & 0.026 & 0.159 & 0.074 \\
\hline 5430500 & & & 0.219 & 0.015 & 0.154 & 0.085 \\
\hline 5435500 & 0.263 & 0.003 & 0.192 & 0.031 & 0.175 & 0.049 \\
\hline 5436500 & 0.213 & 0.017 & & & 0.166 & 0.064 \\
\hline 5440000 & & & 0.150 & 0.092 & & \\
\hline 5446500 & & & 0.228 & 0.010 & & \\
\hline 5451500 & & & -0.158 & 0.076 & & \\
\hline 5455500 & -0.160 & 0.071 & & & -0.161 & 0.070 \\
\hline 5459500 & 0.180 & 0.043 & 0.186 & 0.036 & 0.223 & 0.012 \\
\hline 5464500 & & & 0.187 & 0.035 & & \\
\hline 5465500 & 0.181 & 0.042 & 0.222 & 0.012 & & \\
\hline 5470000 & -0.209 & 0.019 & -0.229 & 0.010 & & \\
\hline 5476000 & & & 0.188 & 0.034 & 0.153 & 0.086 \\
\hline 5479000 & 0.244 & 0.006 & 0.224 & 0.012 & 0.264 & 0.003 \\
\hline 5482500 & 0.360 & 0.000 & 0.348 & 0.000 & 0.308 & 0.001 \\
\hline 5484000 & 0.208 & 0.020 & 0.224 & 0.012 & 0.204 & 0.022 \\
\hline 5484500 & 0.262 & 0.003 & 0.259 & 0.004 & 0.151 & 0.090 \\
\hline 5486490 & & & -0.147 & 0.099 & & \\
\hline 5490500 & 0.234 & 0.009 & 0.207 & 0.020 & 0.233 & 0.009 \\
\hline 5495000 & & & & & 0.150 & 0.091 \\
\hline 5501000 & -0.155 & 0.081 & & & & \\
\hline 5555300 & & & 0.173 & 0.051 & 0.182 & 0.041 \\
\hline 5556500 & & & 0.186 & 0.036 & & \\
\hline 5572000 & -0.167 & 0.060 & -0.190 & 0.033 & & \\
\hline
\end{tabular}


Table E.2, continued

\begin{tabular}{|c|c|c|c|c|c|c|}
\hline \multirow{2}{*}{$\begin{array}{l}\text { Station } \\
\text { Number }\end{array}$} & \multicolumn{2}{|c|}{ 3-Month Lead } & \multicolumn{2}{|c|}{ 6-Month Lead } & \multicolumn{2}{|c|}{ 9-Month Lead } \\
\hline & tau & $\mathrm{p}$-value & tau & $\mathrm{p}$-value & tau & $\mathrm{p}$-value \\
\hline 5593000 & 0.362 & 0.000 & 0.231 & 0.009 & 0.206 & 0.021 \\
\hline 5597000 & 0.226 & 0.011 & & & 0.195 & 0.028 \\
\hline 6019500 & -0.301 & 0.001 & -0.220 & 0.013 & & \\
\hline 6207500 & & & & & -0.169 & 0.057 \\
\hline 6214500 & & & & & -0.160 & 0.072 \\
\hline 6289000 & -0.352 & 0.000 & -0.372 & 0.000 & -0.353 & 0.000 \\
\hline 6441500 & 0.163 & 0.067 & & & & \\
\hline 6452000 & & & 0.155 & 0.082 & & \\
\hline 6478500 & 0.299 & 0.001 & 0.309 & 0.000 & 0.339 & 0.000 \\
\hline 6485500 & 0.270 & 0.002 & 0.273 & 0.002 & 0.334 & 0.000 \\
\hline 6606600 & & & & & -0.171 & 0.054 \\
\hline 6620000 & -0.168 & 0.059 & -0.235 & 0.008 & -0.254 & 0.004 \\
\hline 6630000 & -0.220 & 0.013 & -0.200 & 0.024 & -0.162 & 0.068 \\
\hline 6635000 & -0.410 & 0.000 & -0.445 & 0.000 & -0.407 & 0.000 \\
\hline 6800500 & 0.197 & 0.026 & 0.158 & 0.075 & 0.180 & 0.043 \\
\hline 6809500 & 0.237 & 0.008 & 0.209 & 0.019 & & \\
\hline 6864500 & & & & & -0.185 & 0.038 \\
\hline 6869500 & 0.320 & 0.000 & 0.225 & 0.011 & 0.148 & 0.096 \\
\hline 6889500 & -0.187 & 0.035 & -0.173 & 0.052 & & \\
\hline 6899500 & -0.148 & 0.096 & -0.203 & 0.022 & -0.209 & 0.019 \\
\hline 6933500 & -0.193 & 0.030 & -0.193 & 0.030 & & \\
\hline 7018500 & & & & & 0.148 & 0.096 \\
\hline 7067000 & -0.241 & 0.007 & -0.247 & 0.005 & -0.241 & 0.007 \\
\hline 7069500 & -0.244 & 0.006 & -0.231 & 0.009 & -0.198 & 0.026 \\
\hline 7072000 & -0.354 & 0.000 & -0.385 & 0.000 & -0.366 & 0.000 \\
\hline 7096000 & & & & & -0.159 & 0.074 \\
\hline 7146500 & & & & & 0.157 & 0.078 \\
\hline 7172000 & 0.171 & 0.054 & 0.163 & 0.067 & 0.184 & 0.039 \\
\hline 7176000 & 0.280 & 0.002 & 0.212 & 0.017 & 0.173 & 0.051 \\
\hline 7180500 & -0.345 & 0.000 & -0.351 & 0.000 & -0.272 & 0.002 \\
\hline 7187000 & 0.345 & 0.000 & 0.288 & 0.001 & 0.225 & 0.011 \\
\hline 7196500 & 0.201 & 0.024 & 0.267 & 0.003 & 0.224 & 0.012 \\
\hline 7203000 & -0.215 & 0.017 & -0.170 & 0.060 & -0.255 & 0.005 \\
\hline 7234000 & & & & & -0.163 & 0.066 \\
\hline 7252000 & & & 0.155 & 0.081 & & \\
\hline 7291000 & -0.210 & 0.018 & & & -0.177 & 0.047 \\
\hline 7332500 & -0.317 & 0.000 & -0.256 & 0.004 & -0.211 & 0.017 \\
\hline 7340500 & -0.170 & 0.057 & -0.253 & 0.004 & -0.287 & 0.001 \\
\hline 7375500 & -0.238 & 0.007 & -0.186 & 0.036 & -0.289 & 0.001 \\
\hline 8032000 & 0.349 & 0.000 & 0.322 & 0.000 & 0.254 & 0.004 \\
\hline 8033500 & 0.258 & 0.004 & 0.307 & 0.001 & 0.341 & 0.000 \\
\hline 8041000 & 0.444 & 0.000 & 0.368 & 0.000 & 0.338 & 0.000 \\
\hline 8041500 & 0.187 & 0.035 & 0.294 & 0.001 & 0.276 & 0.002 \\
\hline 8070000 & 0.398 & 0.000 & 0.380 & 0.000 & 0.349 & 0.000 \\
\hline
\end{tabular}


Table E.2, continued

\begin{tabular}{|c|c|c|c|c|c|c|}
\hline \multirow{2}{*}{$\begin{array}{c}\text { Station } \\
\text { Number }\end{array}$} & \multicolumn{2}{|c|}{ 3-Month Lead } & \multicolumn{2}{|c|}{ 6-Month Lead } & \multicolumn{2}{|c|}{ 9-Month Lead } \\
\hline & tau & p-value & tau & p-value & tau & p-value \\
\hline 8080500 & & & & & -0.173 & 0.051 \\
\hline 8088000 & & & & & -0.182 & 0.041 \\
\hline 8095000 & 0.200 & 0.024 & 0.210 & 0.018 & & \\
\hline 8128000 & 0.280 & 0.002 & 0.167 & 0.060 & & \\
\hline 8151500 & -0.207 & 0.020 & -0.158 & 0.075 & & \\
\hline 8153500 & -0.197 & 0.027 & -0.193 & 0.030 & -0.155 & 0.082 \\
\hline 8167000 & -0.238 & 0.007 & -0.326 & 0.000 & -0.336 & 0.000 \\
\hline 8167500 & -0.341 & 0.000 & -0.294 & 0.001 & -0.228 & 0.010 \\
\hline 8172000 & 0.159 & 0.073 & 0.171 & 0.055 & & \\
\hline 8189500 & -0.176 & 0.047 & -0.245 & 0.006 & -0.265 & 0.003 \\
\hline 8192000 & -0.203 & 0.022 & & & & \\
\hline 8195000 & -0.252 & 0.005 & -0.330 & 0.000 & -0.393 & 0.000 \\
\hline 8205500 & 0.162 & 0.069 & & & & \\
\hline 8210000 & -0.234 & 0.008 & -0.200 & 0.024 & -0.228 & 0.010 \\
\hline 8276500 & -0.252 & 0.005 & -0.212 & 0.017 & & \\
\hline 9110000 & 0.151 & 0.090 & & & & \\
\hline 9119000 & -0.204 & 0.022 & -0.190 & 0.033 & & \\
\hline 9132500 & -0.186 & 0.037 & -0.234 & 0.008 & & \\
\hline 9147500 & & & -0.173 & 0.052 & -0.158 & 0.076 \\
\hline 9239500 & -0.153 & 0.086 & -0.175 & 0.049 & & \\
\hline 9251000 & -0.151 & 0.090 & & & & \\
\hline 9310500 & -0.336 & 0.000 & -0.342 & 0.000 & -0.259 & 0.004 \\
\hline 9379500 & & & & & -0.152 & 0.087 \\
\hline 9415000 & -0.358 & 0.000 & -0.331 & 0.000 & -0.399 & 0.000 \\
\hline 9430500 & -0.258 & 0.004 & -0.369 & 0.000 & -0.297 & 0.001 \\
\hline 9448500 & -0.280 & 0.002 & -0.332 & 0.000 & -0.375 & 0.000 \\
\hline 9508500 & -0.386 & 0.000 & -0.427 & 0.000 & -0.456 & 0.000 \\
\hline 10131000 & -0.227 & 0.011 & -0.184 & 0.038 & & \\
\hline 10174500 & -0.374 & 0.000 & -0.427 & 0.000 & -0.323 & 0.000 \\
\hline 10234500 & & & & & 0.157 & 0.077 \\
\hline 10296000 & 0.356 & 0.000 & 0.368 & 0.000 & 0.320 & 0.000 \\
\hline 10310000 & 0.350 & 0.000 & 0.311 & 0.000 & 0.259 & 0.004 \\
\hline 10312000 & 0.147 & 0.099 & & & & \\
\hline 10322500 & -0.225 & 0.011 & -0.196 & 0.027 & & \\
\hline 10329500 & -0.405 & 0.000 & -0.391 & 0.000 & -0.353 & 0.000 \\
\hline 10396000 & -0.221 & 0.013 & -0.166 & 0.063 & -0.236 & 0.008 \\
\hline 11098000 & -0.350 & 0.000 & -0.328 & 0.000 & -0.295 & 0.001 \\
\hline 11152000 & 0.200 & 0.024 & 0.186 & 0.036 & 0.205 & 0.021 \\
\hline 11160500 & 0.351 & 0.000 & 0.336 & 0.000 & 0.320 & 0.000 \\
\hline 11237500 & 0.301 & 0.001 & 0.292 & 0.001 & 0.274 & 0.002 \\
\hline 11264500 & 0.226 & 0.011 & 0.229 & 0.010 & 0.202 & 0.023 \\
\hline 11266500 & 0.293 & 0.001 & 0.282 & 0.001 & 0.263 & 0.003 \\
\hline 11381500 & -0.164 & 0.064 & & & & \\
\hline 11425500 & 0.171 & 0.055 & 0.155 & 0.082 & 0.235 & 0.008 \\
\hline
\end{tabular}


Table E.2, continued

\begin{tabular}{|c|c|c|c|c|c|c|}
\hline \multirow{2}{*}{$\begin{array}{c}\text { Station } \\
\text { Number }\end{array}$} & \multicolumn{2}{|c|}{ 3-Month Lead } & \multicolumn{2}{|c|}{ 6-Month Lead } & \multicolumn{2}{|c|}{ 9-Month Lead } \\
\hline & tau & $\mathrm{p}$-value & tau & $\mathrm{p}$-value & tau & $\mathrm{p}$-value \\
\hline 11522500 & -0.264 & ב0.003 & -0.210 & 0.018 & & \\
\hline 11525500 & 0.538 & 0.000 & 0.467 & 0.000 & 0.431 & 0.000 \\
\hline 11532500 & -0.203 & 0.022 & & & & \\
\hline 12010000 & 0.352 & 0.000 & 0.246 & 0.006 & 0.170 & 0.056 \\
\hline 12020000 & 0.236 & 0.008 & & & & \\
\hline 12027500 & & & -0.156 & 0.079 & -0.214 & 0.016 \\
\hline 12035000 & 0.280 & 0.002 & 0.206 & 0.021 & & \\
\hline 12039500 & 0.351 & 0.000 & 0.365 & 0.000 & 0.386 & 0.000 \\
\hline 12048000 & 0.377 & 0.000 & 0.336 & 0.000 & 0.356 & 0.000 \\
\hline 12054000 & 0.375 & 0.000 & 0.370 & 0.000 & 0.360 & 0.000 \\
\hline 12056500 & 0.433 & 0.000 & 0.395 & 0.000 & 0.396 & 0.000 \\
\hline 12134500 & 0.186 & 0.036 & & & & \\
\hline 12186000 & 0.270 & 0.002 & 0.218 & 0.014 & & \\
\hline 12322000 & 0.226 & 0.011 & & & & \\
\hline 12330000 & -0.193 & 0.030 & -0.221 & 0.013 & -0.220 & 0.013 \\
\hline 12354500 & & & & & -0.148 & 0.096 \\
\hline 12355500 & & & & & -0.179 & 0.044 \\
\hline 12358500 & -0.192 & 0.031 & -0.278 & 0.002 & -0.332 & 0.000 \\
\hline 12370000 & & & -0.189 & 0.034 & -0.216 & 0.015 \\
\hline 12409000 & 0.430 & 0.000 & 0.369 & 0.000 & 0.296 & 0.001 \\
\hline 12413000 & 0.361 & 0.000 & 0.284 & 0.001 & 0.227 & 0.011 \\
\hline 12414500 & & & & & -0.146 & 0.100 \\
\hline 12488500 & -0.294 & 0.001 & -0.238 & 0.007 & -0.177 & 0.046 \\
\hline 13073000 & -0.362 & 0.000 & -0.468 & 0.000 & -0.391 & 0.000 \\
\hline 13082500 & -0.252 & 0.005 & -0.341 & 0.000 & -0.289 & 0.001 \\
\hline 13120500 & -0.282 & 0.001 & -0.275 & 0.002 & -0.297 & 0.001 \\
\hline 13185000 & 0.180 & 0.043 & & & & \\
\hline 13269000 & -0.158 & 0.076 & -0.187 & 0.035 & & \\
\hline 13302500 & & & & & -0.227 & 0.011 \\
\hline 13317000 & & & & & -0.150 & 0.091 \\
\hline 13336500 & & & & & -0.172 & 0.053 \\
\hline 14113000 & -0.214 & 0.016 & -0.171 & 0.055 & -0.155 & 0.081 \\
\hline 14137000 & -0.368 & 0.000 & -0.282 & 0.001 & -0.336 & 0.000 \\
\hline 14178000 & 0.219 & 0.014 & 0.185 & 0.038 & 0.157 & 0.078 \\
\hline 14185000 & & & & & 0.162 & 0.069 \\
\hline 14301000 & -0.282 & 0.002 & -0.292 & 0.001 & -0.234 & 0.008 \\
\hline 14306500 & -0.223 & 0.012 & & & & \\
\hline 14325000 & -0.207 & 0.020 & & & & \\
\hline 14359000 & -0.261 & 0.003 & -0.179 & 0.044 & & \\
\hline 14362000 & -0.205 & 0.021 & & & & \\
\hline
\end{tabular}




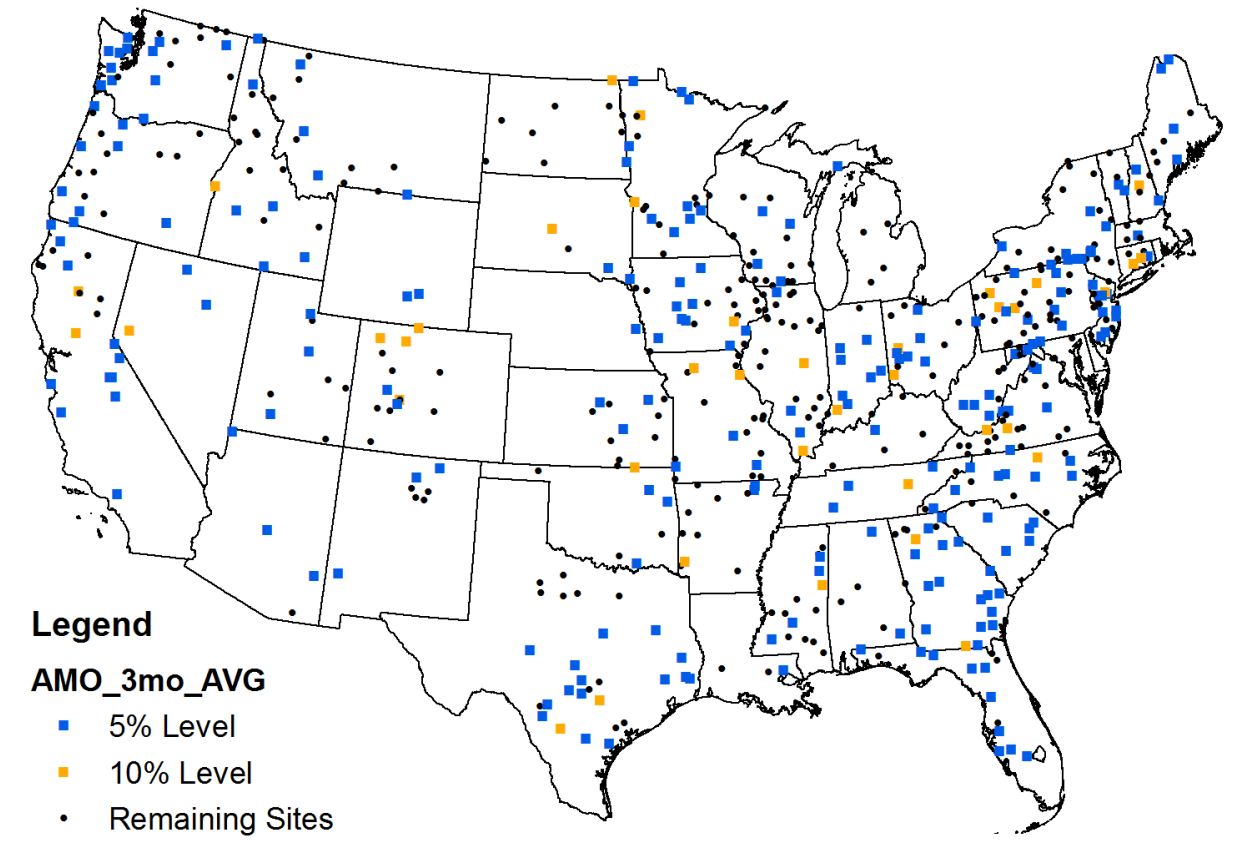

Figure E.1 Locations of sites with significant Kendall's tau correlation between 10-year moving average of log-transformed flood flows and 3-month average AMO anomalies with 3-month lead.

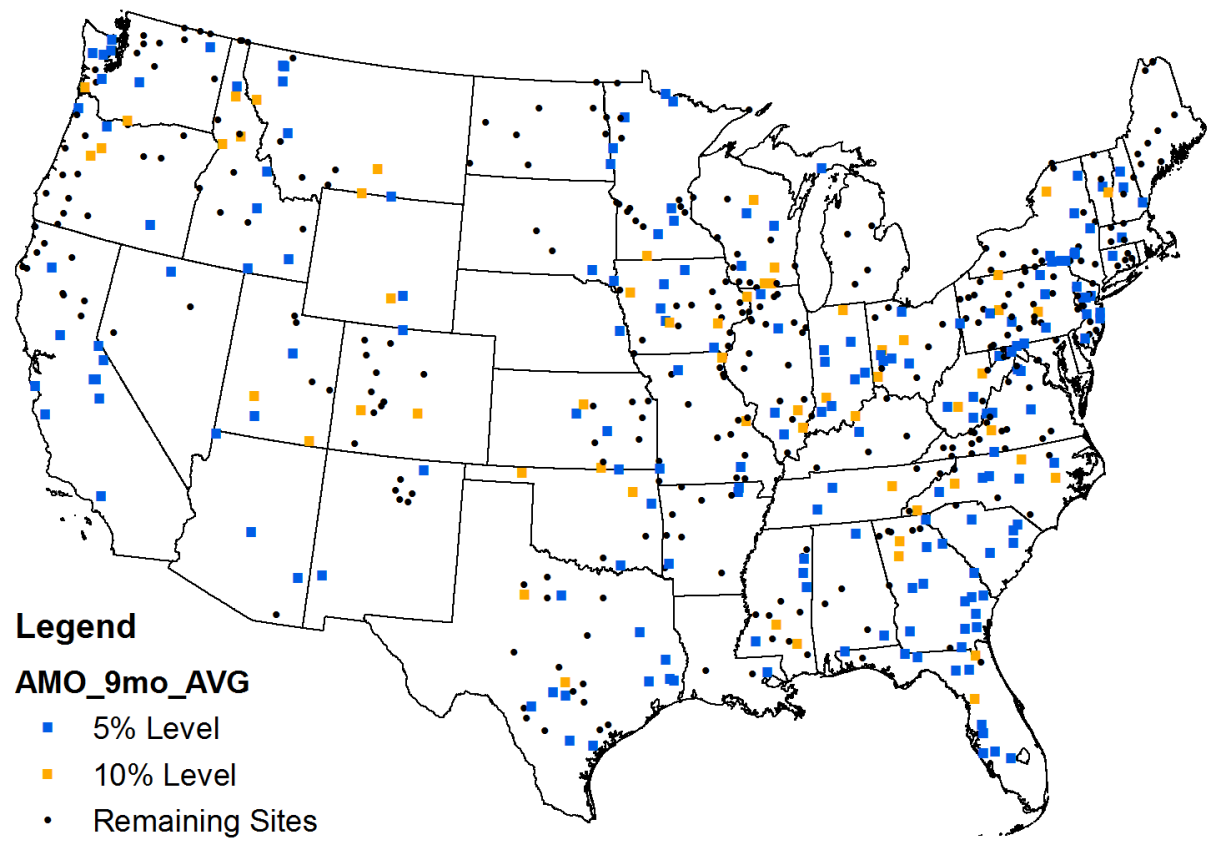

Figure E.2 Locations of sites with significant Kendall's tau correlation between 10-year moving average of log-transformed flood flows and 3-month average AMO anomalies with 9-month lead. 


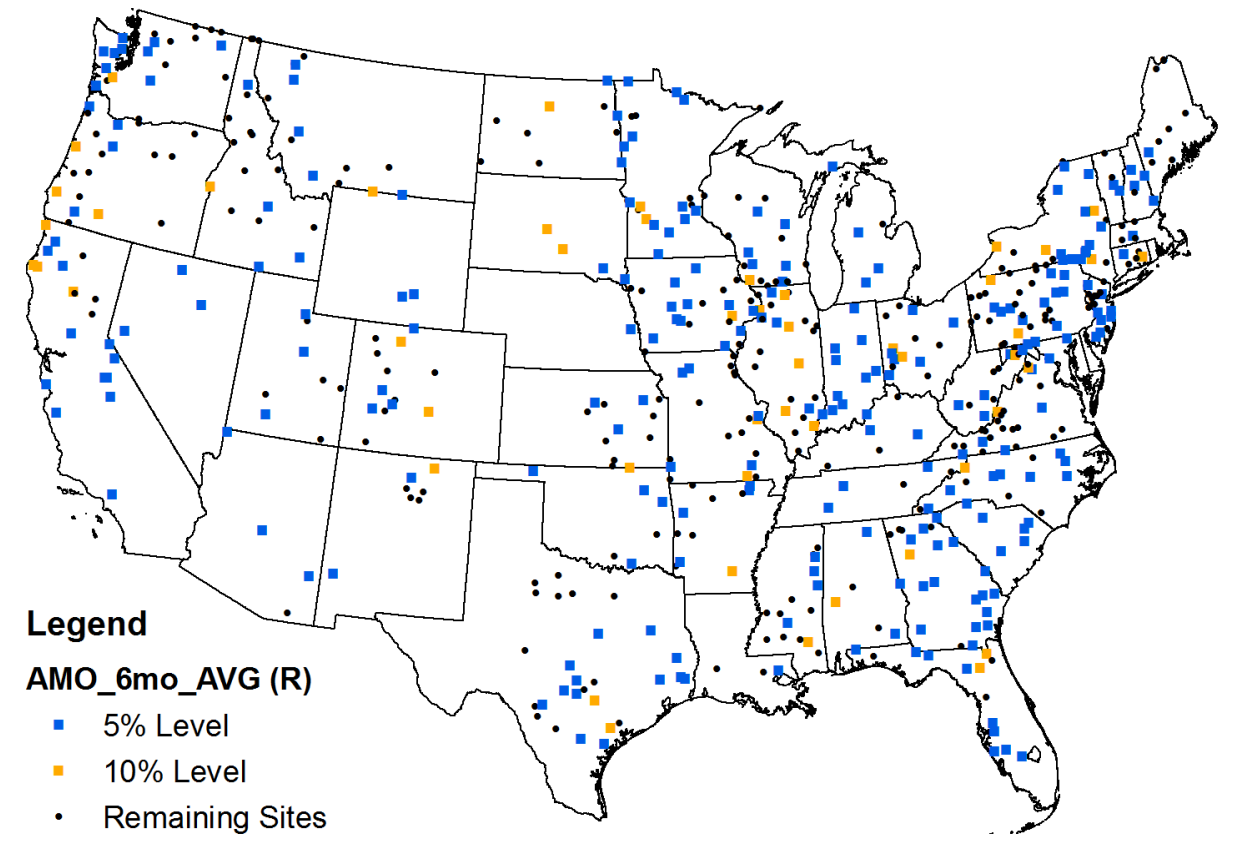

Figure E.1 Locations of sites with significant Pearson's $r$ correlation between 10-year moving average of log-transformed flood flows and 3-month average AMO anomalies with 6-month lead.

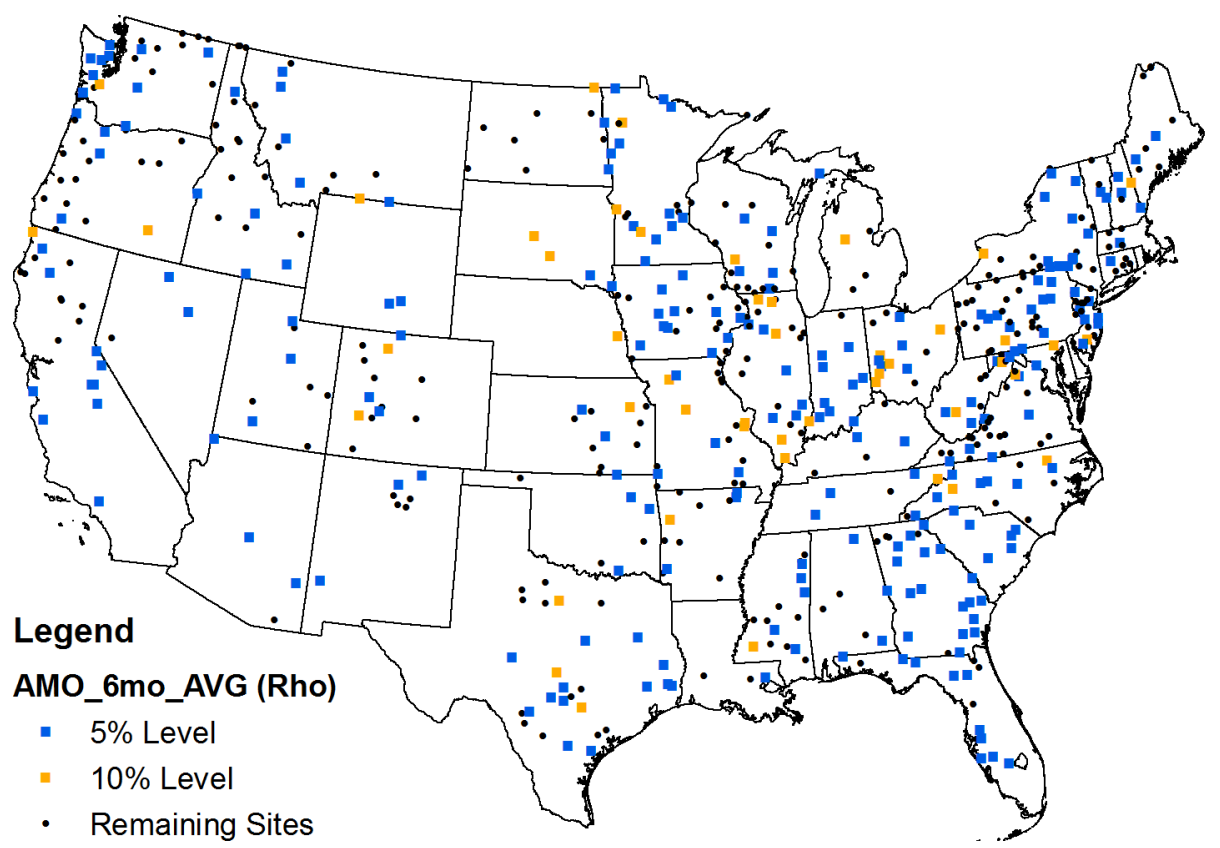

Figure E.2 Locations of sites with significant Spearman's rho correlation between 10year moving average of log-transformed flood flows and 3-month average AMO anomalies with 6-month lead. 


\section{E.2 MEI Correlation Results}

Table E.3

Results of Kendall's tau analyses (significant 10\% level) between 10-year moving average of log-transformed flood flows and 3-month average MEI anomalies with 3-, 6-, and 9-month leads.

\begin{tabular}{|c|c|c|c|c|c|c|}
\hline \multirow{2}{*}{$\begin{array}{c}\text { Station } \\
\text { Number }\end{array}$} & \multicolumn{2}{|c|}{ 3-Month Lead } & \multicolumn{2}{|c|}{ 6-Month Lead } & \multicolumn{2}{|c|}{ 9-Month Lead } \\
\hline & tau & p-value & tau & p-value & tau & $\mathrm{p}$-value \\
\hline 1011000 & & & & & 0.189 & 0.034 \\
\hline 1014000 & & & & & 0.180 & 0.043 \\
\hline 1038000 & 0.154 & 0.084 & 0.157 & 0.077 & 0.201 & 0.024 \\
\hline 1047000 & & & & & 0.181 & 0.042 \\
\hline 1055000 & & & & & 0.160 & 0.072 \\
\hline 1057000 & & & & & 0.158 & 0.075 \\
\hline 1064500 & 0.148 & 0.096 & 0.176 & 0.047 & 0.275 & 0.002 \\
\hline 1073000 & & & & & 0.150 & 0.094 \\
\hline 1078000 & & & & & 0.172 & 0.055 \\
\hline 1127500 & & & & & 0.165 & 0.066 \\
\hline 1169000 & & & & & 0.175 & 0.051 \\
\hline 1196500 & & & 0.179 & 0.045 & 0.262 & 0.003 \\
\hline 1350000 & & & & & 0.154 & 0.083 \\
\hline 1365000 & & & & & 0.158 & 0.075 \\
\hline 1381500 & & & 0.173 & 0.052 & 0.248 & 0.005 \\
\hline 1396500 & & & & & 0.168 & 0.059 \\
\hline 1397500 & & & & & 0.188 & 0.034 \\
\hline 1398500 & & & & & 0.167 & 0.061 \\
\hline 1410000 & & & & & 0.159 & 0.074 \\
\hline 1411000 & & & & & 0.183 & 0.039 \\
\hline 1420500 & & & 0.201 & 0.024 & 0.229 & 0.010 \\
\hline 1426500 & & & & & -0.147 & 0.097 \\
\hline 1445500 & & & 0.158 & 0.075 & 0.147 & 0.097 \\
\hline 1459500 & & & -0.174 & 0.050 & -0.160 & 0.072 \\
\hline 1518000 & & & & & -0.222 & 0.012 \\
\hline 1520500 & & & & & -0.238 & 0.007 \\
\hline 1531000 & & & & & -0.157 & 0.078 \\
\hline 1560000 & & & 0.153 & 0.086 & 0.155 & 0.081 \\
\hline 1601500 & & & & & 0.183 & 0.040 \\
\hline 1604500 & & & & & -0.224 & 0.012 \\
\hline 1608500 & 0.169 & 0.057 & 0.169 & 0.057 & 0.176 & 0.048 \\
\hline 1614500 & & & & & 0.195 & 0.028 \\
\hline 1634000 & & & & & 0.157 & 0.078 \\
\hline 1634500 & 0.155 & 0.082 & 0.195 & 0.028 & 0.259 & 0.003 \\
\hline 1667500 & 0.221 & 0.013 & & & & \\
\hline 2016000 & & & & & 0.176 & 0.048 \\
\hline 2018000 & & & 0.160 & 0.071 & 0.253 & 0.004 \\
\hline 2045500 & 0.177 & 0.046 & 0.202 & 0.023 & 0.253 & 0.004 \\
\hline
\end{tabular}


Table E.3, continued

\begin{tabular}{|c|c|c|c|c|c|c|}
\hline \multirow{2}{*}{$\begin{array}{l}\text { Station } \\
\text { Number }\end{array}$} & \multicolumn{2}{|c|}{ 3-Month Lead } & \multicolumn{2}{|c|}{ 6-Month Lead } & \multicolumn{2}{|c|}{ 9-Month Lead } \\
\hline & tau & $\mathrm{p}$-value & tau & $\mathrm{p}$-value & tau & p-value \\
\hline 2051500 & 0.159 & 0.074 & 0.181 & 0.041 & 0.249 & 0.005 \\
\hline 2055000 & 0.175 & 0.049 & 0.193 & 0.030 & 0.238 & 0.007 \\
\hline 2059500 & 0.267 & 0.003 & & & & \\
\hline 2061500 & & & & & 0.220 & 0.013 \\
\hline 2074500 & 0.245 & 0.006 & 0.159 & 0.074 & 0.167 & 0.061 \\
\hline 2083000 & & & & & 0.250 & 0.005 \\
\hline 2118000 & & & 0.151 & 0.090 & 0.167 & 0.060 \\
\hline 2126000 & & & & & 0.157 & 0.078 \\
\hline 2138500 & & & 0.206 & 0.021 & & \\
\hline 2213500 & 0.186 & 0.036 & 0.204 & 0.022 & 0.237 & 0.008 \\
\hline 2225500 & 0.159 & 0.073 & & & 0.173 & 0.051 \\
\hline 2228000 & 0.149 & 0.093 & & & & \\
\hline 2231000 & -0.258 & 0.004 & -0.159 & 0.074 & -0.169 & 0.057 \\
\hline 2246000 & & & -0.147 & 0.097 & & \\
\hline 2256500 & -0.233 & 0.009 & -0.149 & 0.095 & -0.149 & 0.093 \\
\hline 2296750 & -0.259 & 0.003 & -0.161 & 0.070 & -0.150 & 0.091 \\
\hline 2298830 & -0.193 & 0.030 & -0.154 & 0.083 & & \\
\hline 2301500 & -0.209 & 0.019 & & & & \\
\hline 2303000 & -0.157 & 0.078 & & & & \\
\hline 2313000 & -0.220 & 0.013 & & & & \\
\hline 2317500 & 0.215 & 0.016 & 0.233 & 0.009 & 0.285 & 0.001 \\
\hline 2320500 & 0.171 & 0.055 & 0.148 & 0.096 & 0.215 & 0.015 \\
\hline 2321500 & -0.172 & 0.053 & & & & \\
\hline 2329000 & 0.210 & 0.018 & 0.183 & 0.039 & 0.236 & 0.008 \\
\hline 2333500 & & & -0.156 & 0.079 & & \\
\hline 2339500 & & & & & -0.226 & 0.011 \\
\hline 2353500 & & & & & 0.160 & 0.072 \\
\hline 2369000 & & & & & 0.170 & 0.056 \\
\hline 2383500 & & & & & -0.232 & 0.009 \\
\hline 2387500 & & & & & -0.206 & 0.020 \\
\hline 2467000 & & & 0.188 & 0.035 & 0.162 & 0.069 \\
\hline 2472500 & 0.172 & 0.053 & 0.207 & 0.020 & 0.244 & 0.006 \\
\hline 2479000 & 0.180 & 0.043 & 0.233 & 0.009 & 0.275 & 0.002 \\
\hline 2486000 & & & 0.174 & 0.050 & 0.162 & 0.069 \\
\hline 2487500 & & & & & 0.159 & 0.074 \\
\hline 2488500 & 0.173 & 0.052 & 0.226 & 0.011 & 0.304 & 0.001 \\
\hline 3010500 & -0.150 & 0.091 & -0.155 & 0.082 & -0.264 & 0.003 \\
\hline 3011020 & -0.160 & 0.071 & -0.169 & 0.057 & -0.249 & 0.005 \\
\hline 3024000 & & & & & -0.227 & 0.011 \\
\hline 3049500 & & & & & -0.237 & 0.008 \\
\hline 3079000 & & & -0.154 & 0.084 & -0.246 & 0.006 \\
\hline 3080000 & -0.151 & 0.089 & -0.165 & 0.063 & -0.332 & 0.000 \\
\hline 3102500 & & & -0.168 & 0.058 & & \\
\hline 3106000 & & & & & -0.167 & 0.061 \\
\hline
\end{tabular}


Table E.3, continued

\begin{tabular}{|c|c|c|c|c|c|c|}
\hline \multirow{2}{*}{$\begin{array}{c}\text { Station } \\
\text { Number }\end{array}$} & \multicolumn{2}{|c|}{ 3-Month Lead } & \multicolumn{2}{|c|}{ 6-Month Lead } & \multicolumn{2}{|c|}{ 9-Month Lead } \\
\hline & tau & $\mathrm{p}$-value & tau & $\mathrm{p}$-value & tau & $\mathrm{p}$-value \\
\hline 3118500 & 0.203 & 0.022 & 0.237 & 0.008 & 0.233 & 0.009 \\
\hline 3144000 & 0.226 & 0.012 & 0.279 & 0.002 & 0.277 & 0.002 \\
\hline 3164000 & & & 0.216 & 0.015 & 0.163 & 0.067 \\
\hline 3167000 & & & & & -0.206 & 0.020 \\
\hline 3170000 & 0.156 & 0.079 & & & & \\
\hline 3182500 & & & & & 0.178 & 0.045 \\
\hline 3186500 & & & & & 0.167 & 0.061 \\
\hline 3234500 & & & & & -0.247 & 0.006 \\
\hline 3253500 & & & & & -0.182 & 0.043 \\
\hline 3262000 & & & 0.174 & 0.053 & & \\
\hline 3269500 & & & & & -0.195 & 0.029 \\
\hline 3294500 & & & & & -0.192 & 0.032 \\
\hline 3307000 & 0.161 & 0.073 & 0.216 & 0.016 & 0.244 & 0.007 \\
\hline 3326500 & & & 0.197 & 0.027 & & \\
\hline 3379500 & & & & & 0.193 & 0.030 \\
\hline 3380500 & 0.158 & 0.075 & 0.173 & 0.052 & 0.221 & 0.013 \\
\hline 3381500 & & & 0.147 & 0.097 & 0.215 & 0.015 \\
\hline 3434500 & & & 0.147 & 0.099 & 0.169 & 0.057 \\
\hline 3438000 & & & 0.165 & 0.065 & 0.196 & 0.028 \\
\hline 3479000 & & & & & 0.198 & 0.026 \\
\hline 3524000 & & & & & -0.164 & 0.064 \\
\hline 3604000 & & & & & 0.163 & 0.066 \\
\hline 4100500 & & & & & 0.154 & 0.084 \\
\hline 4193500 & & & 0.158 & 0.076 & 0.167 & 0.060 \\
\hline 4223000 & & & & & -0.176 & 0.047 \\
\hline 4262500 & & & & & 0.203 & 0.022 \\
\hline 4264331 & & & 0.162 & 0.068 & 0.219 & 0.014 \\
\hline 4275000 & & & & & 0.219 & 0.014 \\
\hline 4293500 & & & & & 0.211 & 0.019 \\
\hline 5084000 & -0.147 & 0.099 & -0.155 & 0.082 & -0.267 & 0.003 \\
\hline 5131500 & & & & & -0.238 & 0.007 \\
\hline 5286000 & & & & & -0.151 & 0.089 \\
\hline 5288500 & -0.156 & 0.079 & -0.155 & 0.082 & -0.185 & 0.037 \\
\hline 5304500 & & & & & 0.231 & 0.009 \\
\hline 5316500 & & & 0.173 & 0.052 & 0.259 & 0.003 \\
\hline 5340500 & & & & & -0.172 & 0.053 \\
\hline 5379500 & & & -0.153 & 0.086 & & \\
\hline 5399500 & & & & & -0.171 & 0.055 \\
\hline 5408000 & & & -0.164 & 0.065 & -0.230 & 0.010 \\
\hline 5410490 & -0.162 & 0.069 & -0.184 & 0.038 & -0.253 & 0.004 \\
\hline 5412500 & -0.166 & 0.062 & -0.164 & 0.065 & -0.232 & 0.009 \\
\hline 5414000 & & & & & -0.179 & 0.044 \\
\hline 5418500 & & & & & -0.201 & 0.024 \\
\hline 5432500 & -0.155 & 0.082 & -0.175 & 0.049 & -0.257 & 0.004 \\
\hline
\end{tabular}


Table E.3, continued

\begin{tabular}{|c|c|c|c|c|c|c|}
\hline \multirow{2}{*}{$\begin{array}{l}\text { Station } \\
\text { Number }\end{array}$} & \multicolumn{2}{|c|}{ 3-Month Lead } & \multicolumn{2}{|c|}{ 6-Month Lead } & \multicolumn{2}{|c|}{ 9-Month Lead } \\
\hline & tau & $\mathrm{p}$-value & tau & $\mathrm{p}$-value & tau & $\mathrm{p}$-value \\
\hline 5434500 & $2-0.163$ & "0.067 & -0.194 & 0.029 & -0.272 & 0.002 \\
\hline 5435500 & -0.186 & 0.036 & -0.186 & 0.036 & -0.214 & 0.016 \\
\hline 5436500 & -0.160 & 0.075 & -0.168 & 0.061 & -0.234 & 0.009 \\
\hline 5447500 & & & & & 0.162 & 0.068 \\
\hline 5495000 & & & 0.160 & 0.071 & 0.202 & 0.023 \\
\hline 5501000 & 0.155 & 0.081 & 0.180 & 0.043 & 0.211 & 0.017 \\
\hline 5520500 & & & 0.150 & 0.092 & 0.219 & 0.014 \\
\hline 5526000 & & & 0.158 & 0.075 & 0.237 & 0.008 \\
\hline 5527500 & 0.159 & 0.073 & 0.201 & 0.024 & 0.302 & 0.001 \\
\hline 5555300 & & & 0.179 & 0.045 & 0.252 & 0.005 \\
\hline 5572000 & & & 0.159 & 0.073 & 0.195 & 0.028 \\
\hline 5585000 & & & 0.153 & 0.086 & 0.184 & 0.038 \\
\hline 6214500 & & & & & -0.149 & 0.093 \\
\hline 6335500 & -0.165 & 0.063 & -0.181 & 0.042 & -0.272 & 0.002 \\
\hline 6337000 & -0.157 & 0.077 & -0.171 & 0.055 & -0.280 & 0.002 \\
\hline 6340500 & & & & & -0.235 & 0.008 \\
\hline 6441500 & -0.163 & 0.067 & -0.182 & 0.041 & -0.209 & 0.019 \\
\hline 6864500 & -0.153 & 0.086 & & & & \\
\hline 6889500 & & & & & 0.157 & 0.077 \\
\hline 6908000 & & & & & 0.172 & 0.053 \\
\hline 6933500 & & & & & 0.154 & 0.084 \\
\hline 7016500 & & & 0.159 & 0.074 & 0.250 & 0.005 \\
\hline 7019000 & & & & & 0.210 & 0.018 \\
\hline 7067000 & 0.164 & 0.065 & 0.160 & 0.071 & & \\
\hline 7069500 & & & & & -0.153 & 0.086 \\
\hline 7072000 & 0.155 & 0.082 & & & & \\
\hline 7186000 & & & & & 0.156 & 0.079 \\
\hline 7189000 & & & & & 0.174 & 0.055 \\
\hline 7234000 & & & & & -0.155 & 0.082 \\
\hline 7247500 & & & & & -0.217 & 0.015 \\
\hline 7291000 & 0.224 & 0.012 & 0.233 & 0.009 & 0.303 & 0.001 \\
\hline 7332500 & & & & & 0.149 & 0.093 \\
\hline 7340000 & & & & & -0.179 & 0.045 \\
\hline 7340500 & & & & & -0.205 & 0.021 \\
\hline 7375500 & & & 0.149 & 0.093 & 0.234 & 0.008 \\
\hline 7378500 & 0.157 & 0.077 & 0.186 & 0.036 & 0.307 & 0.001 \\
\hline 8013500 & & & 0.183 & 0.040 & 0.241 & 0.007 \\
\hline 8033500 & & & 0.148 & 0.096 & 0.211 & 0.017 \\
\hline 8041500 & 0.147 & 0.099 & 0.164 & 0.065 & 0.258 & 0.004 \\
\hline 8080500 & & & & & -0.173 & 0.052 \\
\hline 8082000 & & & & & -0.199 & 0.025 \\
\hline 8082500 & & & & & -0.182 & 0.041 \\
\hline 8088000 & & & & & -0.156 & 0.079 \\
\hline 8151500 & 0.160 & 0.071 & 0.164 & 0.065 & 0.186 & 0.036 \\
\hline
\end{tabular}


Table E.3, continued

\begin{tabular}{|c|c|c|c|c|c|c|}
\hline \multirow{2}{*}{$\begin{array}{l}\text { Station } \\
\text { Number }\end{array}$} & \multicolumn{2}{|c|}{ 3-Month Lead } & \multicolumn{2}{|c|}{ 6-Month Lead } & \multicolumn{2}{|c|}{ 9-Month Lead } \\
\hline & tau & p-value & tau & p-value & tau & p-value \\
\hline 8153500 & 0.245 & 0.006 & 0.255 & 0.004 & 0.271 & 0.002 \\
\hline 8158000 & 0.154 & 0.084 & 0.180 & 0.043 & 0.243 & 0.006 \\
\hline 8167000 & 0.207 & 0.020 & 0.255 & 0.004 & 0.192 & 0.032 \\
\hline 8167500 & 0.203 & 0.022 & 0.207 & 0.020 & 0.223 & 0.012 \\
\hline 8171000 & 0.219 & 0.014 & 0.234 & 0.008 & 0.175 & 0.049 \\
\hline 8195000 & 0.223 & 0.012 & 0.188 & 0.035 & & \\
\hline 8210000 & -0.188 & 0.035 & & & & \\
\hline 8291000 & 0.264 & 0.003 & & & & \\
\hline 8378500 & & & 0.171 & 0.056 & 0.247 & 0.006 \\
\hline 9110000 & & & -0.165 & 0.063 & -0.169 & 0.057 \\
\hline 9180500 & & & & & -0.155 & 0.082 \\
\hline 9379500 & & & & & -0.173 & 0.052 \\
\hline 9430500 & 0.205 & 0.021 & & & & \\
\hline 9471000 & -0.147 & 0.099 & & & & \\
\hline 11381500 & & & -0.214 & 0.016 & & \\
\hline 11383500 & & & -0.174 & 0.050 & & \\
\hline 11402000 & & & -0.198 & 0.026 & & \\
\hline 11477000 & -0.199 & 0.025 & -0.272 & 0.002 & & \\
\hline 11478500 & -0.179 & 0.045 & -0.184 & 0.038 & & \\
\hline 11501000 & & & -0.171 & 0.055 & -0.188 & 0.035 \\
\hline 11522500 & -0.163 & 0.067 & -0.189 & 0.033 & & \\
\hline 11530000 & -0.175 & 0.049 & -0.269 & 0.002 & & \\
\hline 11532500 & -0.221 & 0.013 & -0.218 & 0.014 & & \\
\hline 12035000 & & & 0.207 & 0.020 & & \\
\hline 12048000 & & & 0.152 & 0.087 & & \\
\hline 12134500 & 0.180 & 0.043 & 0.180 & 0.043 & & \\
\hline 12189500 & 0.159 & 0.073 & 0.158 & 0.076 & & \\
\hline 12306500 & -0.179 & 0.045 & -0.218 & 0.014 & -0.284 & 0.001 \\
\hline 12322000 & -0.163 & 0.067 & -0.193 & 0.030 & -0.261 & 0.003 \\
\hline 12332000 & & & -0.151 & 0.089 & -0.188 & 0.035 \\
\hline 12354500 & & & -0.163 & 0.067 & -0.242 & 0.006 \\
\hline 12355500 & & & -0.167 & 0.061 & -0.216 & 0.015 \\
\hline 12358500 & & & & & -0.164 & 0.065 \\
\hline 12370000 & & & & & -0.188 & 0.035 \\
\hline 12409000 & & & & & -0.169 & 0.057 \\
\hline 12413000 & & & -0.149 & 0.095 & -0.193 & 0.030 \\
\hline 12414500 & & & & & -0.175 & 0.049 \\
\hline 12422500 & & & -0.184 & 0.038 & -0.286 & 0.001 \\
\hline 12442500 & & & -0.156 & 0.079 & -0.228 & 0.010 \\
\hline 12445000 & & & & & -0.203 & 0.022 \\
\hline 12451000 & -0.179 & 0.045 & -0.214 & 0.016 & -0.209 & 0.019 \\
\hline 12459000 & -0.185 & 0.037 & -0.209 & 0.019 & -0.182 & 0.041 \\
\hline 13037500 & -0.159 & 0.074 & -0.208 & 0.019 & -0.190 & 0.033 \\
\hline 13185000 & & & -0.163 & 0.066 & -0.210 & 0.018 \\
\hline
\end{tabular}


Table E.3, continued

\begin{tabular}{|c|cc|cc|cc|}
\hline $\begin{array}{c}\text { Station } \\
\text { Number }\end{array}$ & \multicolumn{2}{|c|}{ 3-Month Lead } & \multicolumn{2}{c|}{ 6-Month Lead } & \multicolumn{2}{c|}{ 9-Month Lead } \\
tau & p-value & tau & p-value & tau & p-value \\
\hline \hline 13302500 & & & -0.148 & 0.096 & -0.168 & 0.058 \\
13313000 & & & -0.197 & $\mathbf{0 . 0 2 7}$ & -0.271 & $\mathbf{0 . 0 0 2}$ \\
13317000 & & & -0.169 & 0.057 & -0.246 & $\mathbf{0 . 0 0 6}$ \\
13336500 & & & -0.151 & 0.090 & -0.239 & $\mathbf{0 . 0 0 7}$ \\
13337000 & & & -0.154 & 0.084 & -0.233 & $\mathbf{0 . 0 0 9}$ \\
13342500 & & & & & -0.201 & $\mathbf{0 . 0 2 4}$ \\
14044000 & & & & & 0.174 & 0.050 \\
14105700 & & & & & -0.168 & 0.058 \\
14113000 & & & -0.185 & $\mathbf{0 . 0 3 7}$ & & \\
14154500 & -0.149 & 0.093 & -0.220 & $\mathbf{0 . 0 1 3}$ & & \\
14178000 & -0.190 & $\mathbf{0 . 0 3 3}$ & -0.152 & 0.087 & & \\
14185000 & & & -0.174 & 0.050 & & \\
14191000 & -0.199 & $\mathbf{0 . 0 2 5}$ & -0.327 & $\mathbf{0 . 0 0 0}$ & & \\
14301000 & -0.175 & $\mathbf{0 . 0 4 9}$ & -0.175 & $\mathbf{0 . 0 4 9}$ & & \\
14306500 & -0.220 & $\mathbf{0 . 0 1 3}$ & -0.250 & $\mathbf{0 . 0 0 5}$ & & \\
14308000 & -0.180 & $\mathbf{0 . 0 4 3}$ & -0.249 & $\mathbf{0 . 0 0 5}$ & & \\
14321000 & -0.168 & 0.058 & -0.264 & $\mathbf{0 . 0 0 3}$ & & \\
14325000 & -0.224 & $\mathbf{0 . 0 1 2}$ & -0.240 & $\mathbf{0 . 0 0 7}$ & & \\
14359000 & -0.193 & $\mathbf{0 . 0 3 0}$ & -0.253 & $\mathbf{0 . 0 0 4}$ & & \\
14362000 & -0.210 & $\mathbf{0 . 0 1 8}$ & -0.258 & $\mathbf{0 . 0 0 4}$ & & \\
\hline
\end{tabular}

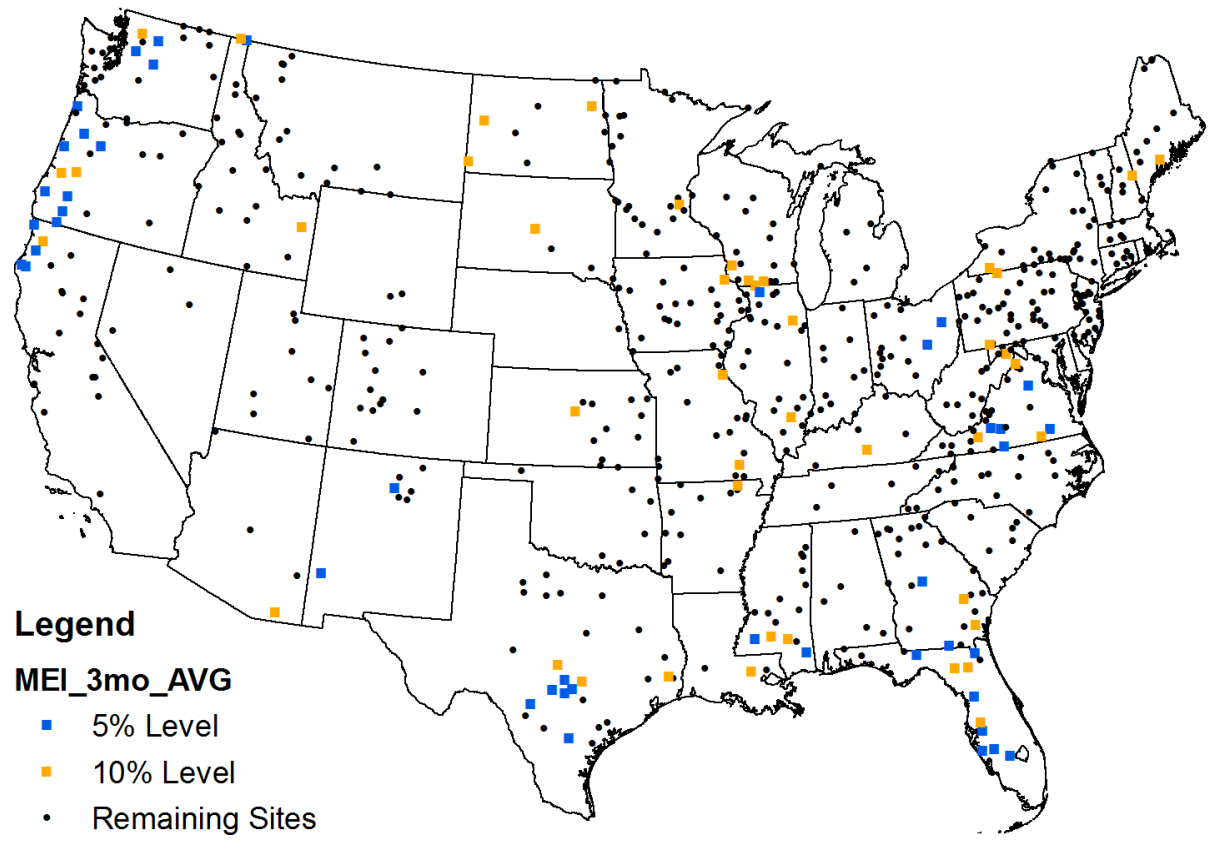

Figure E.3 Locations of sites with significant Kendall's tau correlation between 10-year moving average of log-transformed flood flows and 3-month average MEI anomalies with 3-month lead. 


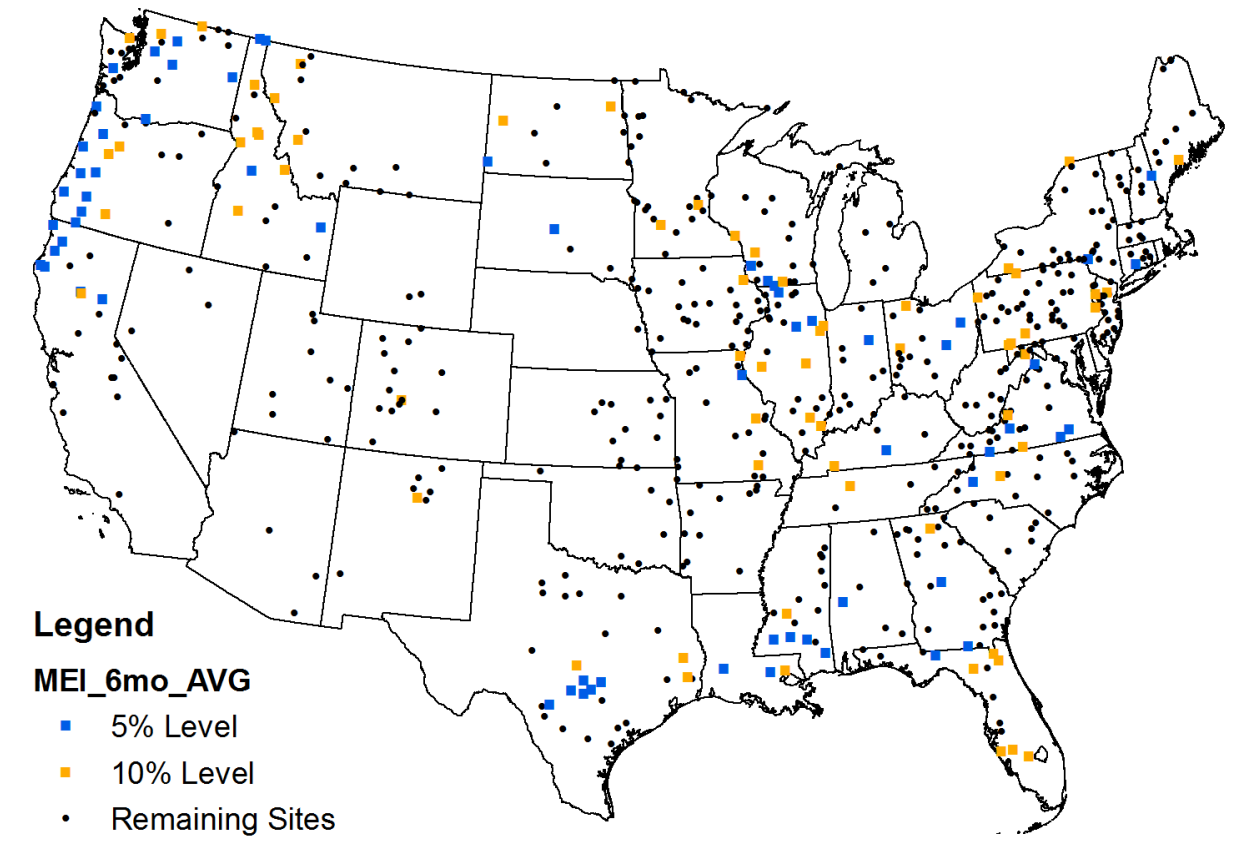

Figure E.4 Locations of sites with significant Kendall's tau correlation between 10-year moving average of log-transformed flood flows and 3-month average MEI anomalies with 6-month lead.

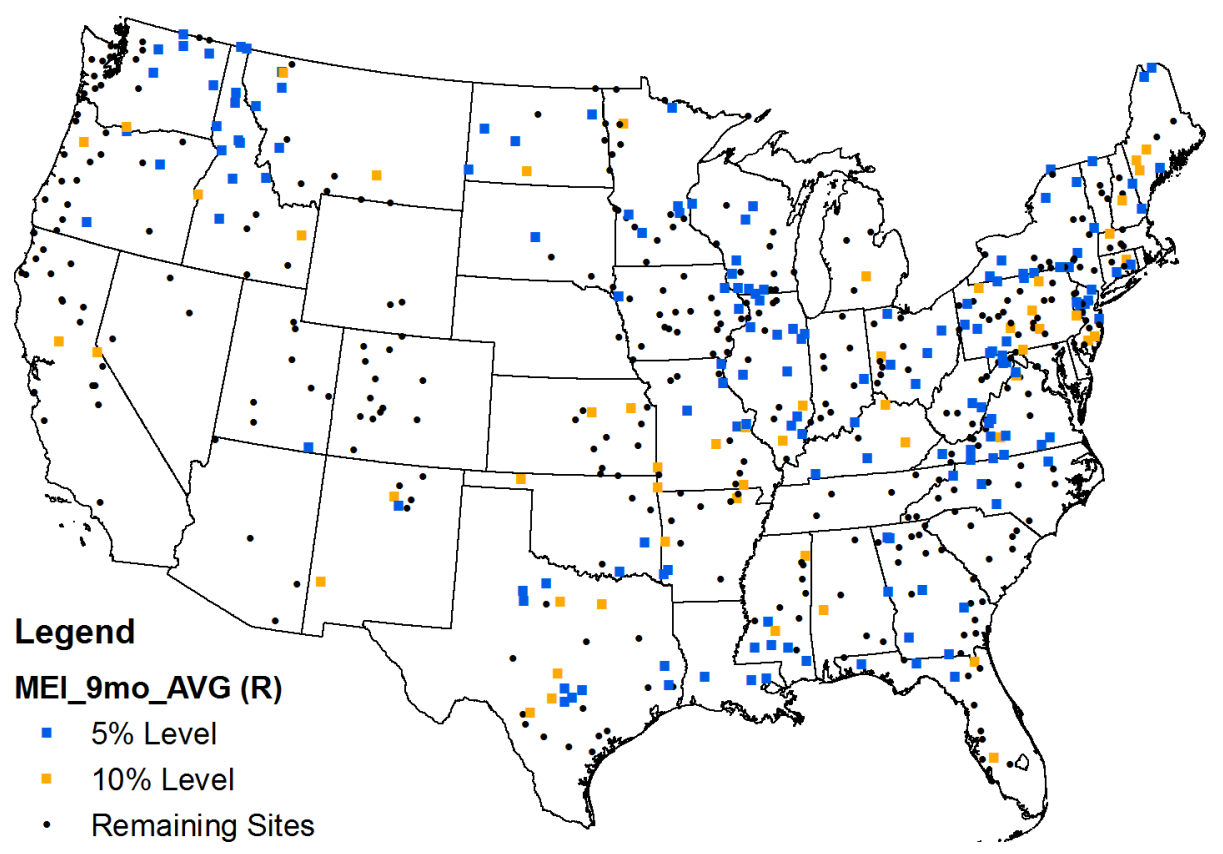

Figure E.5 Locations of sites with significant Pearson's $r$ correlation between 10-year moving average of log-transformed flood flows and 3-month average MEI anomalies with 9-month lead. 


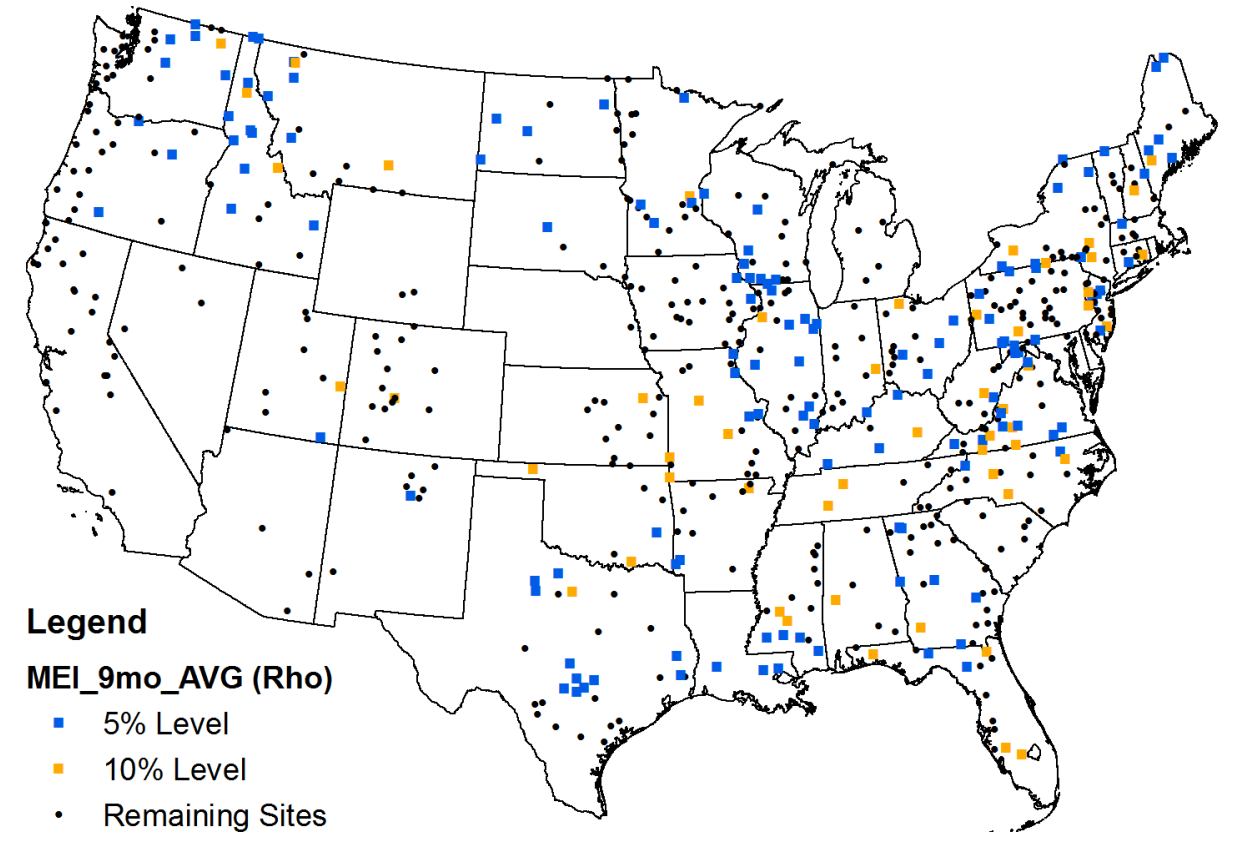

Figure E.6 Locations of sites with significant Spearman's rho correlation between 10year moving average of log-transformed flood flows and 3-month average MEI anomalies with 9-month lead.

\section{E.3 NAO Correlation Results}

Table E.4

Results of Kendall's tau analyses (significant 10\% level) between 10-year moving average of log-transformed flood flows and 3-month average NAO anomalies with 3-, 6-, and 9-month leads.

\begin{tabular}{|c|cc|cc|cc|}
\hline $\begin{array}{c}\text { Station } \\
\text { Number }\end{array}$ & \multicolumn{2}{|c|}{ 3-Month Lead } & \multicolumn{2}{|c|}{ 6-Month Lead } & \multicolumn{2}{|c|}{ 9-Month Lead } \\
tau & p-value & tau & p-value & tau & p-value \\
\hline \hline 1031500 & 0.228 & $\mathbf{0 . 0 1 0}$ & & & & \\
1038000 & 0.189 & $\mathbf{0 . 0 3 3}$ & & & & \\
1047000 & 0.246 & $\mathbf{0 . 0 0 6}$ & & & & \\
1055000 & 0.271 & $\mathbf{0 . 0 0 2}$ & & & & \\
1057000 & 0.323 & $\mathbf{0 . 0 0 0}$ & & & & \\
1064500 & 0.327 & $\mathbf{0 . 0 0 0}$ & & & & \\
1076500 & 0.154 & 0.085 & & & & \\
1078000 & 0.237 & $\mathbf{0 . 0 0 8}$ & & & & \\
1137500 & 0.185 & $\mathbf{0 . 0 3 9}$ & -0.230 & $\mathbf{0 . 0 1 0}$ & & \\
1142500 & 0.152 & 0.090 & -0.164 & 0.067 & -0.189 & \\
1169000 & 0.275 & $\mathbf{0 . 0 0 2}$ & & & & \\
1181000 & 0.198 & $\mathbf{0 . 0 2 8}$ & & & &
\end{tabular}


Table E.4, continued

\begin{tabular}{|c|c|c|c|c|c|c|}
\hline \multirow{2}{*}{$\begin{array}{c}\text { Station } \\
\text { Number }\end{array}$} & \multicolumn{2}{|c|}{ 3-Month Lead } & \multicolumn{2}{|c|}{ 6-Month Lead } & \multicolumn{2}{|c|}{ 9-Month Lead } \\
\hline & tau & $\mathrm{p}$-value & tau & $\mathrm{p}$-value & tau & $\mathrm{p}$-value \\
\hline 1321000 & & & & & -0.160 & 0.072 \\
\hline 1365000 & 0.184 & 0.039 & & & & \\
\hline 1379500 & & & 0.148 & 0.097 & & \\
\hline 1408500 & & & 0.149 & 0.095 & & \\
\hline 1411000 & 0.171 & 0.054 & & & & \\
\hline 1411500 & & & & & 0.190 & 0.033 \\
\hline 1413500 & & & -0.154 & 0.083 & & \\
\hline 1414500 & & & -0.204 & 0.022 & & \\
\hline 1421000 & & & & & -0.194 & 0.029 \\
\hline 1426500 & & & -0.153 & 0.085 & & \\
\hline 1532000 & & & & & -0.182 & 0.041 \\
\hline 1538000 & & & & & -0.162 & 0.069 \\
\hline 1541000 & & & 0.159 & 0.074 & & \\
\hline 1541500 & 0.154 & 0.083 & & & & \\
\hline 1548500 & & & & & -0.178 & 0.046 \\
\hline 1555500 & & & & & -0.154 & 0.084 \\
\hline 1567000 & 0.175 & 0.049 & & & & \\
\hline 1568000 & & & & & -0.171 & 0.055 \\
\hline 1574000 & & & 0.182 & 0.041 & & \\
\hline 1580000 & -0.194 & 0.029 & & & & \\
\hline 1631000 & 0.146 & 0.100 & & & & \\
\hline 1667500 & & & 0.315 & 0.000 & & \\
\hline 2017500 & & & & & -0.158 & 0.075 \\
\hline 2018000 & 0.168 & 0.059 & & & & \\
\hline 2055000 & 0.211 & 0.018 & & & & \\
\hline 2059500 & & & 0.254 & 0.004 & & \\
\hline 2074500 & 0.154 & 0.084 & 0.287 & 0.001 & & \\
\hline 2102000 & 0.146 & 0.100 & & & & \\
\hline 2132000 & & & 0.193 & 0.030 & & \\
\hline 2198000 & & & 0.165 & 0.064 & & \\
\hline 2217500 & & & 0.180 & 0.043 & & \\
\hline 2231000 & & & -0.288 & 0.001 & & \\
\hline 2256500 & & & -0.315 & 0.000 & & \\
\hline 2296750 & & & -0.360 & 0.000 & & \\
\hline 2298830 & & & -0.222 & 0.012 & & \\
\hline 2301500 & & & -0.231 & 0.009 & & \\
\hline 2303000 & & & -0.252 & 0.005 & & \\
\hline 2313000 & & & -0.213 & 0.016 & & \\
\hline 2321500 & & & & & 0.169 & 0.057 \\
\hline 2331600 & & & & & -0.230 & 0.010 \\
\hline 2333500 & & & & & -0.213 & 0.017 \\
\hline 2337000 & & & 0.170 & 0.056 & & \\
\hline 2347500 & & & 0.150 & 0.091 & & \\
\hline 2358000 & & & 0.150 & 0.092 & & \\
\hline
\end{tabular}


Table E.4, continued

\begin{tabular}{|c|c|c|c|c|c|c|}
\hline \multirow{2}{*}{$\begin{array}{l}\text { Station } \\
\text { Number }\end{array}$} & \multicolumn{2}{|c|}{ 3-Month Lead } & \multicolumn{2}{|c|}{ 6-Month Lead } & \multicolumn{2}{|c|}{ 9-Month Lead } \\
\hline & tau & $\mathrm{p}$-value & tau & $\mathrm{p}$-value & tau & $\mathrm{p}$-value \\
\hline 2369000 & & & 0.151 & 0.090 & & \\
\hline 2375500 & & & 0.162 & 0.069 & & \\
\hline 2398000 & & & & & -0.186 & 0.036 \\
\hline 2437000 & & & & & -0.205 & 0.021 \\
\hline 2441000 & & & & & -0.179 & 0.044 \\
\hline 2472500 & 0.162 & 0.068 & & & & \\
\hline 2475500 & & & & & -0.215 & 0.016 \\
\hline 2479000 & 0.154 & 0.083 & & & & \\
\hline 2487500 & & & & & -0.216 & 0.015 \\
\hline 2488500 & 0.177 & 0.047 & & & & \\
\hline 3020500 & & & & & -0.182 & 0.041 \\
\hline 3102500 & & & & & -0.342 & 0.000 \\
\hline 3170000 & 0.209 & 0.019 & & & & \\
\hline 3173000 & & & & & -0.156 & 0.079 \\
\hline 3234500 & -0.247 & 0.006 & & & & \\
\hline 3253500 & & & & & -0.258 & 0.004 \\
\hline 3266000 & & & & & -0.223 & 0.013 \\
\hline 3275000 & & & -0.159 & 0.074 & -0.149 & 0.095 \\
\hline 3301500 & & & 0.159 & 0.076 & & \\
\hline 3339500 & & & -0.189 & 0.034 & & \\
\hline 3363500 & & & -0.173 & 0.051 & & \\
\hline 3377500 & & & & & -0.170 & 0.056 \\
\hline 3379500 & 0.152 & 0.087 & & & & \\
\hline 3380500 & 0.146 & 0.100 & & & & \\
\hline 3381500 & 0.257 & 0.004 & & & & \\
\hline 3434500 & & & & & -0.198 & 0.026 \\
\hline 3488000 & & & & & -0.215 & 0.016 \\
\hline 3504000 & & & & & -0.218 & 0.014 \\
\hline 3528000 & & & & & -0.290 & 0.001 \\
\hline 3550000 & & & & & -0.171 & 0.054 \\
\hline 3604000 & & & & & -0.218 & 0.014 \\
\hline 4056500 & 0.172 & 0.053 & & & & \\
\hline 4073500 & 0.187 & 0.037 & & & & \\
\hline 4100500 & 0.202 & 0.023 & & & -0.162 & 0.069 \\
\hline 4112500 & & & -0.174 & 0.050 & & \\
\hline 4191500 & & & & & -0.175 & 0.051 \\
\hline 4193500 & & & & & -0.161 & 0.070 \\
\hline 4264331 & 0.291 & 0.001 & & & & \\
\hline 4275000 & 0.215 & 0.015 & & & & \\
\hline 4287000 & 0.194 & 0.030 & & & & \\
\hline 4293500 & 0.165 & 0.066 & & & & \\
\hline 5062000 & & & -0.178 & 0.045 & & \\
\hline 5082500 & 0.164 & 0.064 & & & & \\
\hline 5280000 & 0.151 & 0.090 & -0.159 & 0.074 & -0.151 & 0.089 \\
\hline
\end{tabular}


Table E.4, continued

\begin{tabular}{|c|c|c|c|c|c|c|}
\hline \multirow{2}{*}{$\begin{array}{c}\text { Station } \\
\text { Number }\end{array}$} & \multicolumn{2}{|c|}{ 3-Month Lead } & \multicolumn{2}{|c|}{ 6-Month Lead } & \multicolumn{2}{|c|}{ 9-Month Lead } \\
\hline & tau & $\mathrm{p}$-value & tau & $\mathrm{p}$-value & tau & $\mathrm{p}$-value \\
\hline 5304500 & 0.247 & 0.005 & & & & \\
\hline 5330000 & & & -0.170 & 0.056 & & \\
\hline 5419000 & & & & & -0.162 & 0.068 \\
\hline 5420500 & 0.150 & 0.092 & & & & \\
\hline 5426000 & 0.202 & 0.023 & -0.152 & 0.087 & & \\
\hline 5430500 & 0.170 & 0.059 & & & & \\
\hline 5446500 & & & & & -0.149 & 0.095 \\
\hline 5454500 & & & & & -0.176 & 0.048 \\
\hline 5459500 & & & -0.149 & 0.095 & & \\
\hline 5465500 & & & & & -0.172 & 0.053 \\
\hline 5479000 & & & & & -0.167 & 0.061 \\
\hline 5484500 & -0.162 & 0.068 & & & & \\
\hline 5495000 & 0.164 & 0.064 & & & & \\
\hline 5501000 & 0.321 & 0.000 & & & & \\
\hline 5520500 & 0.222 & 0.013 & & & & \\
\hline 5526000 & 0.188 & 0.035 & & & & \\
\hline 5527500 & 0.287 & 0.001 & & & & \\
\hline 5555300 & 0.176 & 0.048 & & & & \\
\hline 5570000 & 0.175 & 0.049 & & & & \\
\hline 5585000 & 0.178 & 0.046 & & & & \\
\hline 5593000 & -0.214 & 0.016 & & & & \\
\hline 6019500 & 0.197 & 0.027 & & & 0.188 & 0.034 \\
\hline 6354000 & 0.219 & 0.014 & & & & \\
\hline 6441500 & -0.155 & 0.082 & & & & \\
\hline 6478500 & & & & & -0.165 & 0.063 \\
\hline 6485500 & & & & & -0.163 & 0.066 \\
\hline 6606600 & -0.150 & 0.092 & & & & \\
\hline 6620000 & -0.235 & 0.008 & & & & \\
\hline 6630000 & & & 0.228 & 0.010 & & \\
\hline 6809500 & -0.192 & 0.031 & & & & \\
\hline 6864500 & -0.258 & 0.004 & -0.236 & 0.008 & & \\
\hline 6869500 & -0.156 & 0.079 & & & & \\
\hline 6876900 & -0.295 & 0.001 & & & & \\
\hline 6889500 & 0.389 & 0.000 & & & & \\
\hline 6897500 & 0.195 & 0.028 & & & & \\
\hline 6908000 & 0.227 & 0.011 & & & & \\
\hline 6933500 & 0.170 & 0.057 & & & & \\
\hline 7016500 & 0.225 & 0.011 & & & & \\
\hline 7018500 & 0.225 & 0.011 & & & & \\
\hline 7019000 & 0.204 & 0.022 & & & & \\
\hline 7056000 & & & & & -0.158 & 0.075 \\
\hline 7069500 & 0.241 & 0.007 & & & -0.173 & 0.052 \\
\hline 7096000 & -0.251 & 0.005 & & & & \\
\hline 7146500 & 0.216 & 0.015 & & & & \\
\hline
\end{tabular}


Table E.4, continued

\begin{tabular}{|c|c|c|c|c|c|c|}
\hline \multirow{2}{*}{$\begin{array}{l}\text { Station } \\
\text { Number }\end{array}$} & \multicolumn{2}{|c|}{ 3-Month Lead } & \multicolumn{2}{|c|}{ 6-Month Lead } & \multicolumn{2}{|c|}{ 9-Month Lead } \\
\hline & tau & $\mathrm{p}$-value & tau & $\mathrm{p}$-value & tau & $p$-value \\
\hline 7176000 & -0.170 & 0.056 & & & & \\
\hline 7183000 & 0.168 & 0.058 & & & & \\
\hline 7186000 & 0.354 & 0.000 & & & & \\
\hline 7187000 & -0.174 & 0.051 & & & & \\
\hline 7203000 & & & -0.229 & 0.011 & & \\
\hline 7218000 & -0.258 & 0.004 & -0.228 & 0.011 & & \\
\hline 7234000 & -0.304 & 0.001 & & & & \\
\hline 7247500 & -0.251 & 0.005 & & & & \\
\hline 7252000 & 0.199 & 0.025 & & & -0.174 & 0.050 \\
\hline 7261500 & 0.342 & 0.000 & & & & \\
\hline 7290000 & 0.190 & 0.032 & & & & \\
\hline 7331000 & 0.190 & 0.033 & & & & \\
\hline 7332500 & 0.181 & 0.042 & & & & \\
\hline 7340000 & -0.196 & 0.028 & & & & \\
\hline 7340500 & -0.151 & 0.089 & & & & \\
\hline 7363500 & -0.172 & 0.053 & & & & \\
\hline 7375500 & & & 0.146 & 0.100 & & \\
\hline 8013500 & & & & & 0.212 & 0.017 \\
\hline 8033500 & 0.251 & 0.005 & -0.206 & 0.021 & & \\
\hline 8041500 & 0.249 & 0.005 & -0.219 & 0.014 & & \\
\hline 8070000 & -0.188 & 0.035 & & & & \\
\hline 8080500 & -0.278 & 0.002 & & & & \\
\hline 8082000 & -0.205 & 0.021 & 0.161 & 0.071 & & \\
\hline 8082500 & -0.190 & 0.033 & & & & \\
\hline 8085500 & -0.251 & 0.005 & & & & \\
\hline 8088000 & -0.295 & 0.001 & & & & \\
\hline 8095000 & & & -0.186 & 0.037 & & \\
\hline 8128000 & -0.336 & 0.000 & & & & \\
\hline 8151500 & 0.151 & 0.089 & & & & \\
\hline 8153500 & & & & & 0.151 & 0.090 \\
\hline 8164000 & 0.173 & 0.052 & -0.155 & 0.082 & & \\
\hline 8167500 & 0.235 & 0.008 & & & 0.152 & 0.087 \\
\hline 8190000 & & & & & -0.205 & 0.022 \\
\hline 8192000 & & & -0.158 & 0.075 & -0.272 & 0.002 \\
\hline 8195000 & & & 0.165 & 0.063 & & \\
\hline 8205500 & -0.200 & 0.024 & & & & \\
\hline 8210000 & & & -0.256 & 0.004 & & \\
\hline 8276500 & 0.284 & 0.001 & & & & \\
\hline 8291000 & 0.190 & 0.035 & 0.226 & 0.012 & & \\
\hline 8378500 & 0.256 & 0.004 & -0.168 & 0.061 & & \\
\hline 8380500 & -0.228 & 0.011 & -0.224 & 0.012 & & \\
\hline 9085000 & -0.214 & 0.016 & 0.154 & 0.083 & & \\
\hline 9110000 & -0.190 & 0.033 & & & & \\
\hline 9112500 & & & 0.155 & 0.081 & & \\
\hline
\end{tabular}


Table E.4, continued

\begin{tabular}{|c|c|c|c|c|c|c|}
\hline \multirow{2}{*}{$\begin{array}{c}\text { Station } \\
\text { Number }\end{array}$} & \multicolumn{2}{|c|}{ 3-Month Lead } & \multicolumn{2}{|c|}{ 6-Month Lead } & \multicolumn{2}{|c|}{ 9-Month Lead } \\
\hline & tau & $\mathrm{p}$-value & tau & $\mathrm{p}$-value & tau & $\mathrm{p}$-value \\
\hline 9119000 & 0.155 & 0.082 & & & & \\
\hline 9124500 & & & 0.203 & 0.022 & & \\
\hline 9239500 & & & 0.200 & 0.024 & & \\
\hline 9251000 & 0.243 & 0.006 & & & & \\
\hline 9304500 & & & 0.178 & 0.046 & & \\
\hline 9315000 & -0.216 & 0.015 & 0.174 & 0.051 & & \\
\hline 9361500 & & & 0.179 & 0.044 & & \\
\hline 9379500 & -0.269 & 0.002 & & & & \\
\hline 9430500 & 0.201 & 0.024 & 0.251 & 0.005 & & \\
\hline 9471000 & & & -0.215 & 0.016 & 0.176 & 0.047 \\
\hline 10128500 & & & 0.236 & 0.011 & & \\
\hline 10131000 & 0.163 & 0.067 & & & & \\
\hline 10234500 & 0.242 & 0.006 & & & & \\
\hline 10296000 & & & & & -0.189 & 0.034 \\
\hline 11160500 & & & -0.188 & 0.036 & & \\
\hline 11237500 & & & & & -0.157 & 0.081 \\
\hline 11477000 & & & 0.172 & 0.053 & -0.260 & 0.003 \\
\hline 11478500 & & & & & -0.149 & 0.093 \\
\hline 11501000 & & & & & 0.200 & 0.024 \\
\hline 11522500 & & & & & -0.379 & 0.000 \\
\hline 11525500 & & & & & -0.239 & 0.007 \\
\hline 11530000 & & & 0.172 & 0.053 & -0.314 & 0.000 \\
\hline 11532500 & & & & & -0.358 & 0.000 \\
\hline 12010000 & & & & & 0.317 & 0.000 \\
\hline 12020000 & & & -0.156 & 0.079 & 0.319 & 0.000 \\
\hline 12027500 & 0.168 & 0.059 & & & & \\
\hline 12035000 & & & & & 0.324 & 0.000 \\
\hline 12056500 & & & & & 0.151 & 0.090 \\
\hline 12134500 & & & & & 0.324 & 0.000 \\
\hline 12186000 & & & & & 0.218 & 0.014 \\
\hline 12189500 & & & & & 0.274 & 0.002 \\
\hline 12306500 & -0.235 & 0.008 & & & & \\
\hline 12322000 & -0.331 & 0.000 & & & & \\
\hline 12332000 & -0.312 & 0.000 & & & & \\
\hline 12354500 & -0.241 & 0.007 & 0.171 & 0.055 & & \\
\hline 12355500 & -0.215 & 0.015 & & & & \\
\hline 12358500 & -0.179 & 0.045 & 0.156 & 0.079 & & \\
\hline 12370000 & -0.261 & 0.003 & 0.164 & 0.065 & & \\
\hline 12404500 & & & 0.148 & 0.096 & & \\
\hline 12422500 & -0.275 & 0.002 & 0.147 & 0.099 & & \\
\hline 12442500 & -0.171 & 0.055 & 0.158 & 0.075 & & \\
\hline 13037500 & & & 0.163 & 0.066 & & \\
\hline 13073000 & & & & & 0.179 & 0.044 \\
\hline 13139510 & & & 0.183 & 0.040 & & \\
\hline
\end{tabular}


Table E.4, continued

\begin{tabular}{|c|cc|cc|cc|}
\hline $\begin{array}{c}\text { Station } \\
\text { Number }\end{array}$ & \multicolumn{2}{c|}{ 3-Month Lead } & \multicolumn{2}{|c|}{$\mathbf{6 - M o n t h ~ L e a d ~}$} & \multicolumn{2}{c|}{ 9-Month Lead } \\
tau & p-value & tau & p-value & tau & p-value \\
\hline \hline 13185000 & -0.152 & 0.087 & 0.148 & 0.097 & & \\
13302500 & -0.308 & $\mathbf{0 . 0 0 1}$ & & & & \\
13313000 & -0.278 & $\mathbf{0 . 0 0 2}$ & 0.191 & $\mathbf{0 . 0 3 2}$ & & \\
13317000 & -0.243 & $\mathbf{0 . 0 0 6}$ & 0.173 & 0.052 & & \\
13336500 & -0.263 & $\mathbf{0 . 0 0 3}$ & 0.171 & 0.054 & & \\
13337000 & -0.259 & $\mathbf{0 . 0 0 4}$ & 0.182 & $\mathbf{0 . 0 4 1}$ & & \\
13342500 & -0.289 & $\mathbf{0 . 0 0 1}$ & & & & \\
14044000 & 0.250 & $\mathbf{0 . 0 0 5}$ & & & & \\
14046500 & 0.280 & $\mathbf{0 . 0 0 2}$ & & & & \\
14105700 & -0.369 & $\mathbf{0 . 0 0 0}$ & & & & \\
14137000 & 0.159 & 0.074 & 0.185 & $\mathbf{0 . 0 3 7}$ & & \\
14154500 & & & 0.164 & 0.065 & -0.230 & $\mathbf{0 . 0 1 0}$ \\
14185000 & & & & & -0.178 & $\mathbf{0 . 0 4 6}$ \\
14191000 & & & & & -0.331 & $\mathbf{0 . 0 0 0}$ \\
14301000 & 0.154 & 0.084 & & & -0.157 & 0.077 \\
14301500 & & & & & -0.377 & $\mathbf{0 . 0 4 3}$ \\
14306500 & & & 0.149 & 0.093 & -0.314 & $\mathbf{0 . 0 0 0}$ \\
14308000 & & & & & -0.354 & $\mathbf{0 . 0 0 0}$ \\
14321000 & & & & & -0.337 & $\mathbf{0 . 0 0 0}$ \\
14325000 & & & & & \\
14359000 & & & & & & \\
14362000 & & & & & & \\
\hline
\end{tabular}




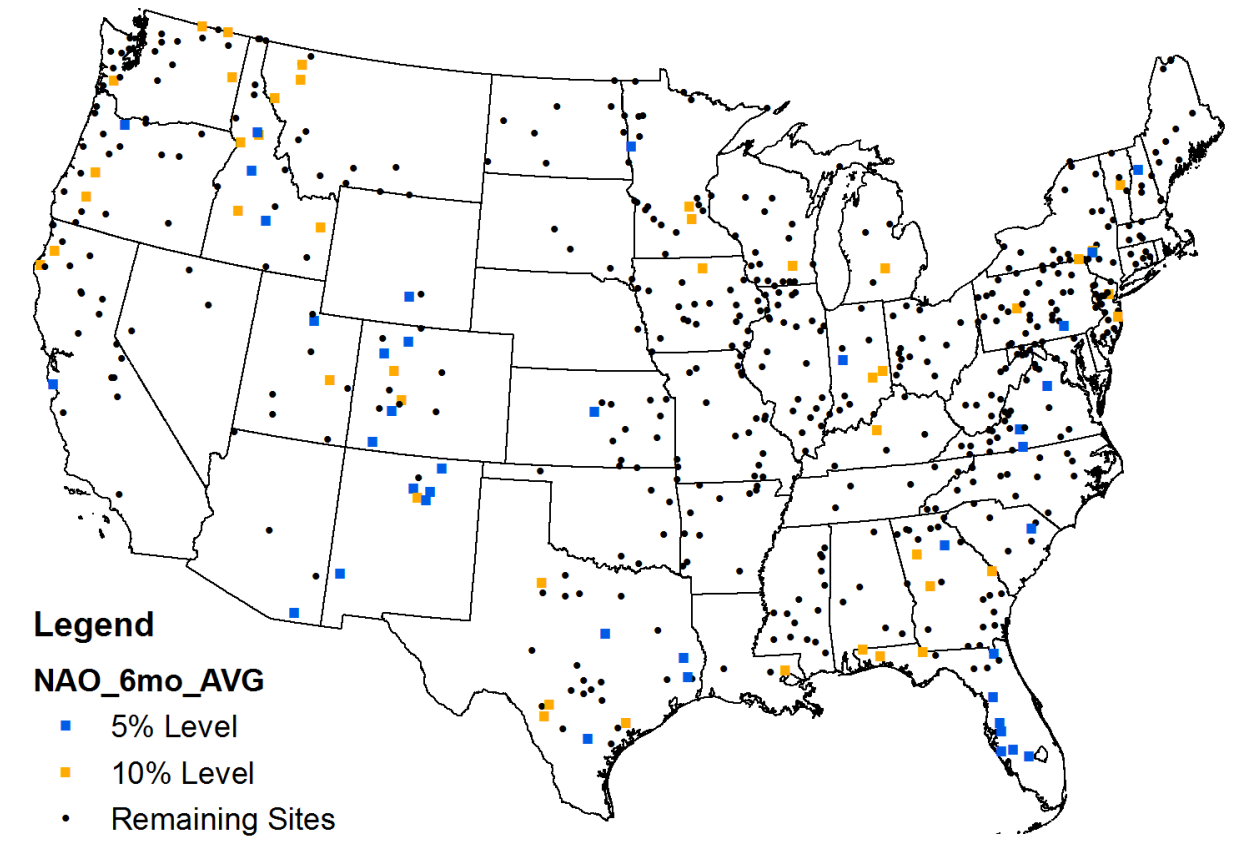

Figure E.7 Locations of sites with significant Kendall's tau correlation between 10-year moving average of log-transformed flood flows and 3-month average NAO anomalies with 6-month lead.

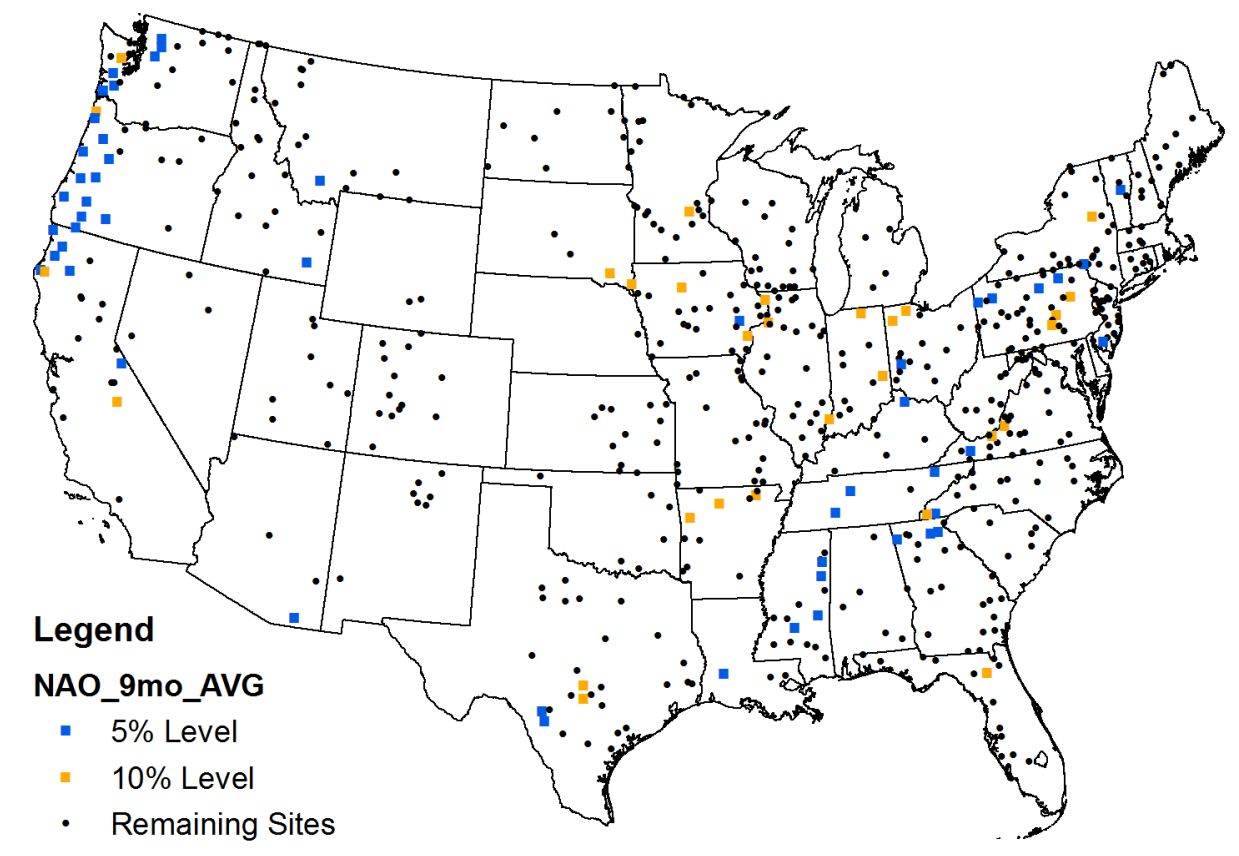

Figure E. 8 Locations of sites with significant Kendall's tau correlation between 10-year moving average of log-transformed flood flows and 3-month average NAO anomalies with 9-month lead. 


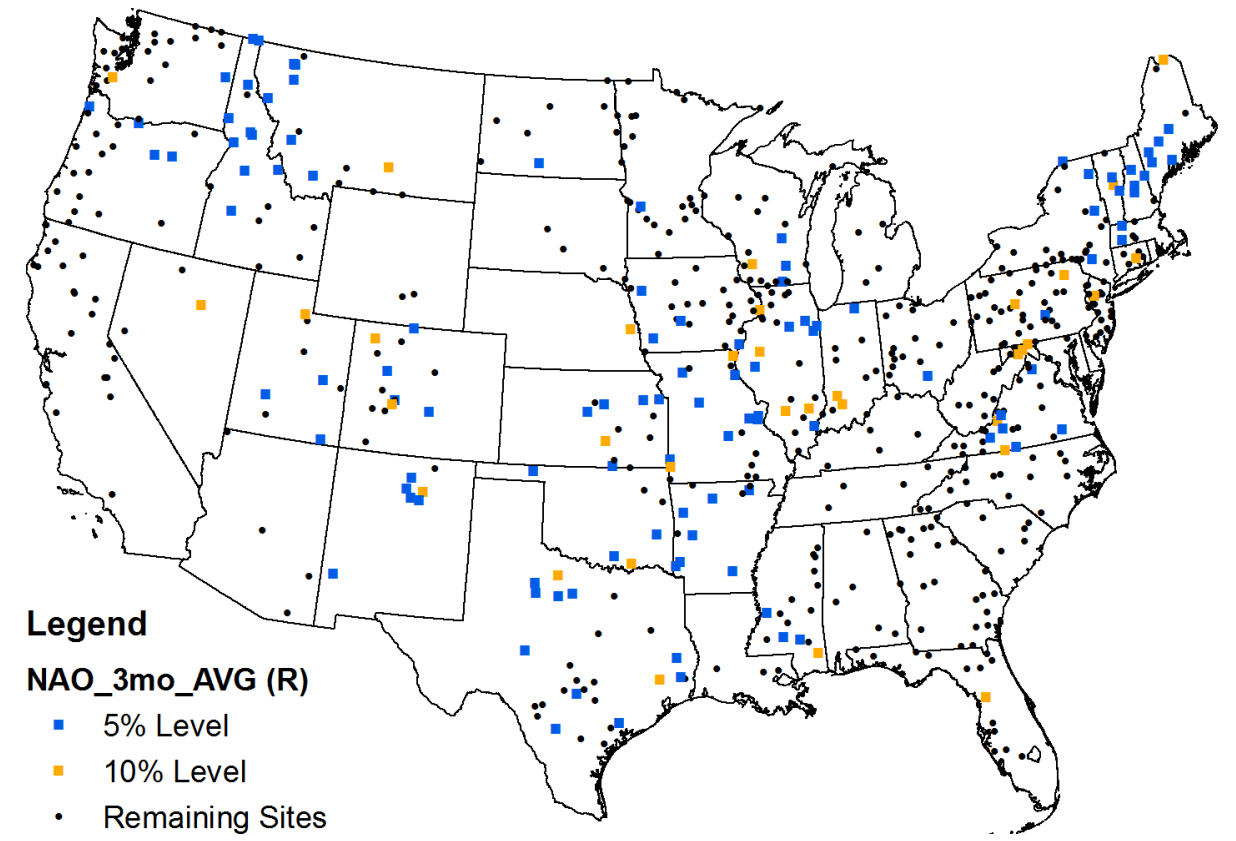

Figure E.9 Locations of sites with significant Pearson's $r$ correlation between 10-year moving average of log-transformed flood flows and 3-month average NAO anomalies with 3-month lead.

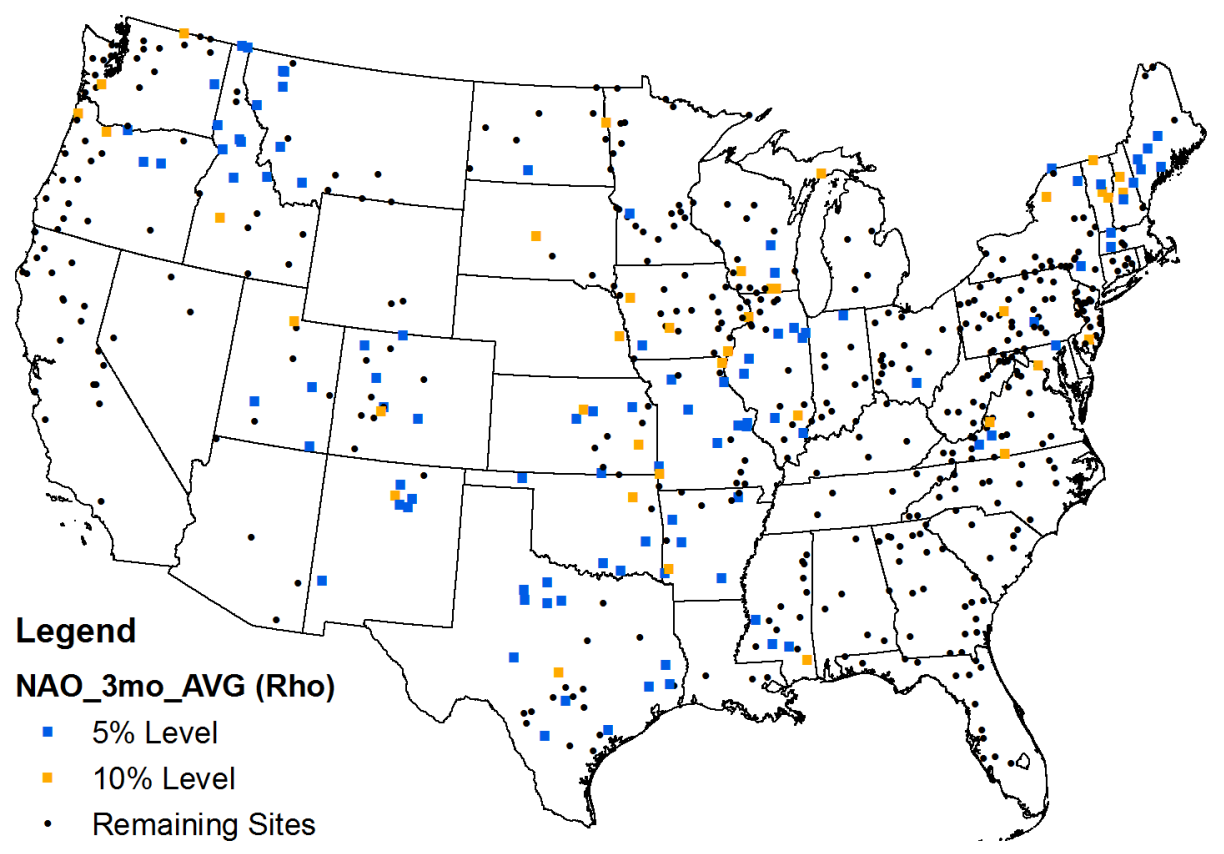

Figure E.10 Locations of sites with significant Spearman's rho correlation between 10year moving average of log-transformed flood flows and 3-month average NAO anomalies with 3-month lead. 


\section{E.4 NINO 3.4 Correlation Results}

Table E.5

Results of Kendall's tau analyses (significant at 10\% level) between 10-year moving average of log-transformed flood flows and 3-month average Nino3.4 anomalies with 3-, 6-, and 9-month leads.

\begin{tabular}{|c|c|c|c|c|c|c|}
\hline \multirow{2}{*}{$\begin{array}{c}\text { Station } \\
\text { Number }\end{array}$} & \multicolumn{2}{|c|}{ 3-Month Lead } & \multicolumn{2}{|c|}{ 6-Month Lead } & \multicolumn{2}{|c|}{ 9-Month Lead } \\
\hline & tau & $\mathrm{p}$-value & tau & $\mathrm{p}$-value & tau & $\mathrm{p}$-value \\
\hline 1064500 & & & & & 0.154 & 0.083 \\
\hline 1459500 & & & & & -0.164 & 0.065 \\
\hline 1520500 & & & & & -0.149 & 0.093 \\
\hline 2083000 & & & & & 0.148 & 0.096 \\
\hline 2083500 & & & & & 0.175 & 0.049 \\
\hline 2231000 & -0.152 & 0.089 & & & & \\
\hline 2317500 & & & & & 0.170 & 0.056 \\
\hline 3010500 & & & & & -0.149 & 0.093 \\
\hline 3080000 & & & & & -0.218 & 0.014 \\
\hline 3118500 & 0.150 & 0.091 & & & & \\
\hline 3144000 & & & 0.209 & 0.020 & 0.194 & 0.031 \\
\hline 3326500 & & & 0.155 & 0.081 & & \\
\hline 3360500 & & & 0.161 & 0.070 & & \\
\hline 3373500 & & & 0.154 & 0.083 & & \\
\hline 3374000 & & & 0.150 & 0.092 & & \\
\hline 4112500 & & & -0.153 & 0.086 & -0.168 & 0.059 \\
\hline 5084000 & & & & & -0.206 & 0.020 \\
\hline 5131500 & & & & & -0.163 & 0.067 \\
\hline 5288500 & & & & & -0.151 & 0.090 \\
\hline 5418500 & & & & & -0.174 & 0.050 \\
\hline 5419000 & & & -0.151 & 0.090 & & \\
\hline 5432500 & & & -0.155 & 0.081 & & \\
\hline 5434500 & & & -0.161 & 0.070 & -0.148 & 0.096 \\
\hline 5435500 & & & -0.149 & 0.095 & & \\
\hline 6214500 & & & & & -0.179 & 0.044 \\
\hline 6335500 & & & & & -0.167 & 0.060 \\
\hline 6337000 & & & & & -0.174 & 0.050 \\
\hline 6340500 & & & & & -0.169 & 0.058 \\
\hline 6354000 & & & & & -0.152 & 0.089 \\
\hline 6876900 & & & & & -0.159 & 0.074 \\
\hline 7050500 & 0.153 & 0.086 & & & & \\
\hline 7291000 & & & & & 0.155 & 0.082 \\
\hline 7378500 & & & & & 0.161 & 0.071 \\
\hline 8013500 & & & & & 0.215 & 0.015 \\
\hline 8033500 & & & & & 0.161 & 0.070 \\
\hline 8095000 & & & & & 0.155 & 0.081 \\
\hline 8151500 & & & 0.148 & 0.096 & & \\
\hline 8153500 & & & 0.176 & 0.047 & & \\
\hline
\end{tabular}


Table E.5, continued

\begin{tabular}{|c|c|c|c|c|c|c|}
\hline \multirow{2}{*}{$\begin{array}{c}\text { Station } \\
\text { Number }\end{array}$} & \multicolumn{2}{|c|}{ 3-Month Lead } & \multicolumn{2}{|c|}{ 6-Month Lead } & \multicolumn{2}{|c|}{ 9-Month Lead } \\
\hline & tau & $\mathrm{p}$-value & tau & $\mathrm{p}$-value & tau & $\mathrm{p}$-value \\
\hline 8158000 & & & 0.180 & 0.043 & 0.150 & 0.092 \\
\hline 8167000 & 0.162 & 0.068 & 0.156 & 0.079 & & \\
\hline 8167500 & & & 0.157 & 0.077 & & \\
\hline 8171000 & 0.181 & 0.042 & 0.216 & 0.015 & 0.241 & 0.007 \\
\hline 9239500 & & & & & -0.149 & 0.095 \\
\hline 9304500 & & & & & -0.153 & 0.085 \\
\hline 9310500 & & & & & -0.153 & 0.085 \\
\hline 9379500 & & & & & -0.146 & 0.100 \\
\hline 10131000 & & & & & -0.212 & 0.017 \\
\hline 11532500 & -0.159 & 0.074 & & & & \\
\hline 12306500 & & & -0.153 & 0.086 & & \\
\hline 12332000 & & & & & -0.163 & 0.066 \\
\hline 12404500 & & & & & -0.150 & 0.092 \\
\hline 12414500 & & & & & -0.165 & 0.063 \\
\hline 12442500 & & & & & -0.168 & 0.059 \\
\hline 12451000 & & & -0.159 & 0.073 & & \\
\hline 12459000 & & & -0.162 & 0.069 & -0.176 & 0.048 \\
\hline 12488500 & & & & & -0.169 & 0.057 \\
\hline 13037500 & & & -0.175 & 0.049 & -0.233 & 0.009 \\
\hline 13269000 & & & & & -0.198 & 0.026 \\
\hline 13302500 & & & & & -0.155 & 0.081 \\
\hline 13317000 & & & & & -0.151 & 0.090 \\
\hline 14113000 & & & -0.176 & 0.048 & & \\
\hline 14178000 & -0.170 & 0.056 & -0.214 & 0.016 & & \\
\hline 14191000 & & & -0.195 & 0.028 & & \\
\hline 14301000 & & & -0.151 & 0.090 & & \\
\hline
\end{tabular}




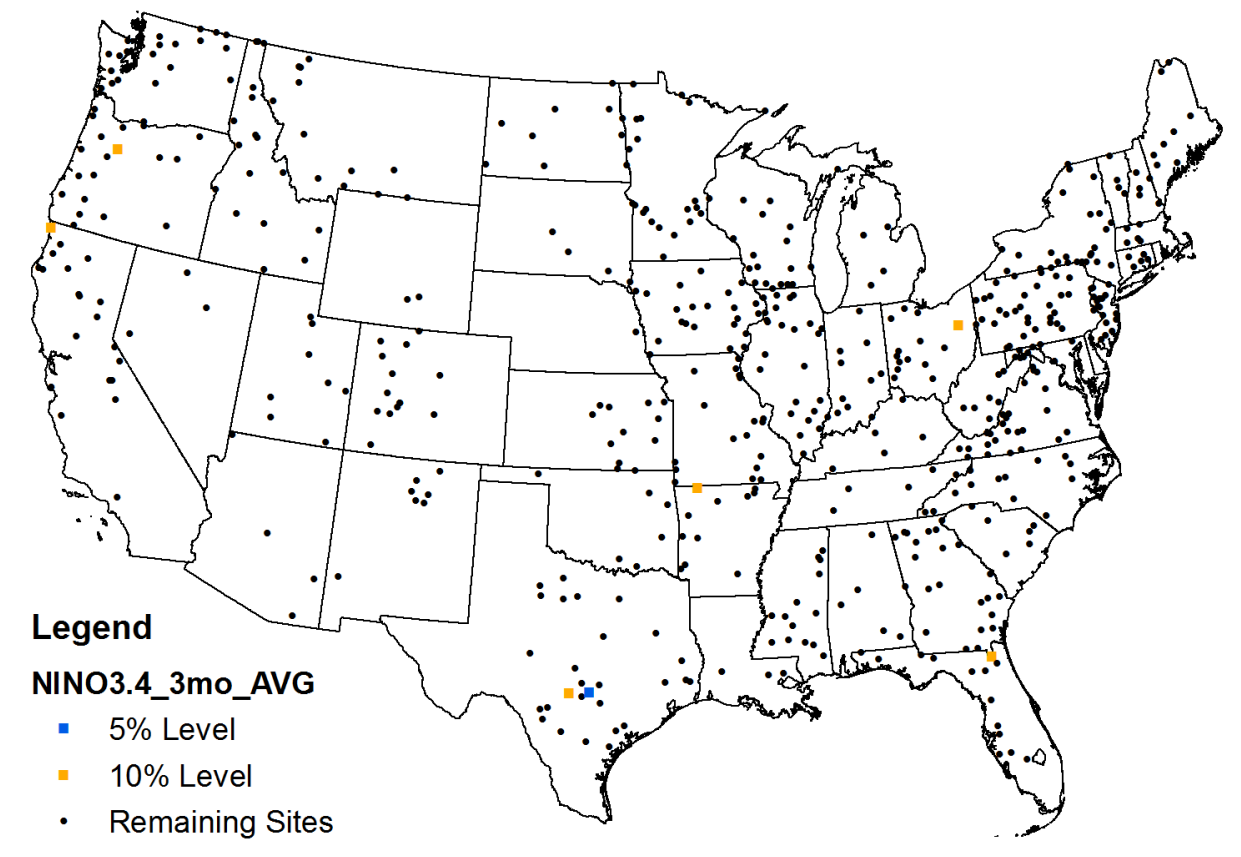

Figure E.11 Locations of sites with significant Kendall's tau correlation between 10-year moving average of log-transformed flood flows and 3-month average Nino3.4 anomalies with 3-month lead.

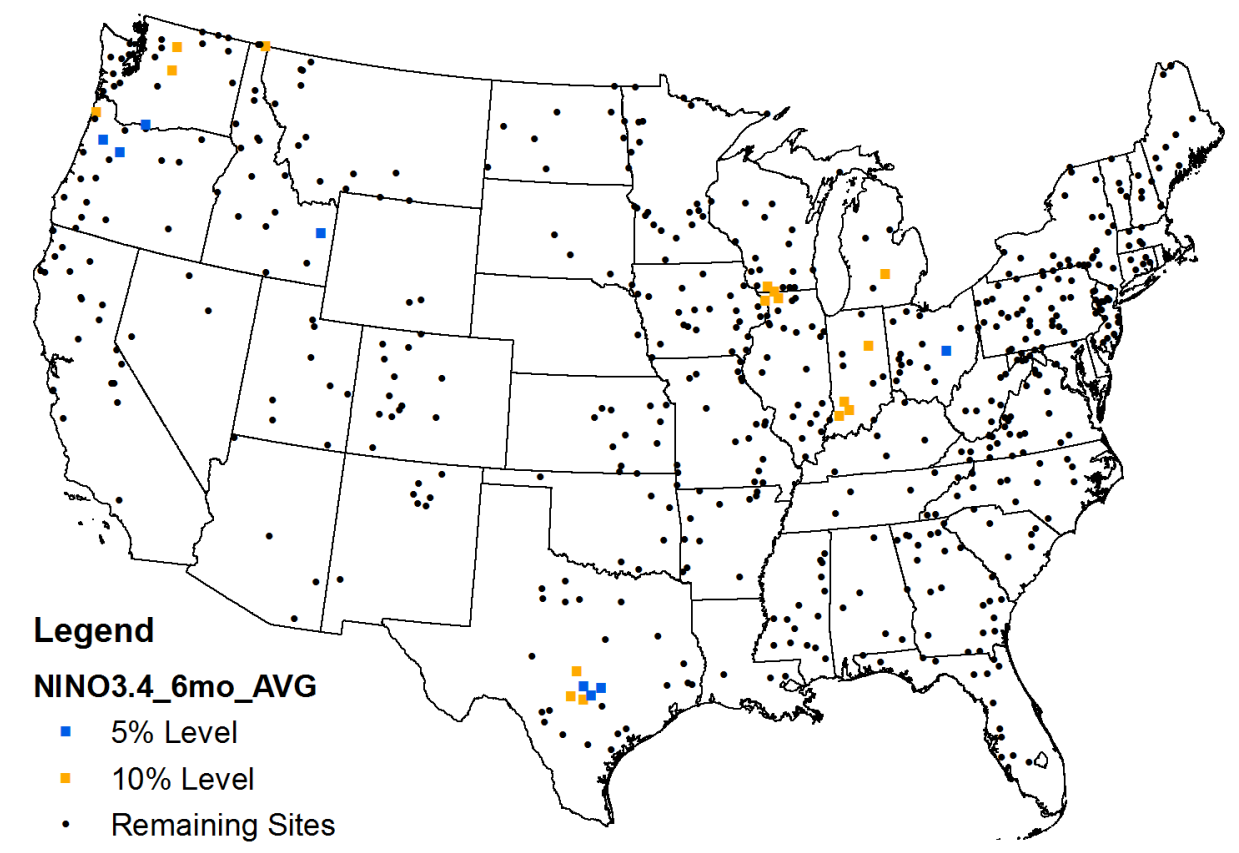

Figure E.12 Locations of sites with significant Kendall's tau correlation between 10-year moving average of log-transformed flood flows and 3-month average Nino3.4 anomalies with 6-month lead. 


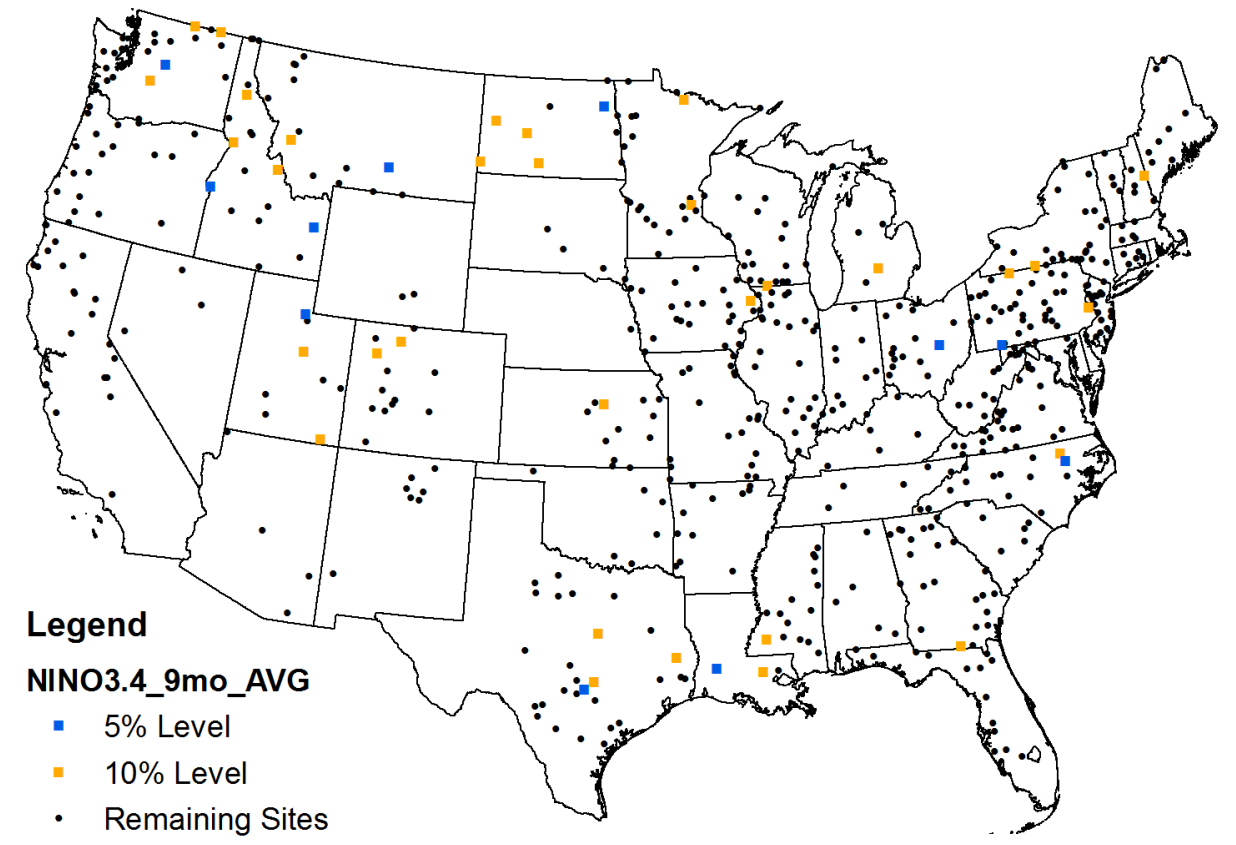

Figure E.13 Locations of sites with significant Kendall's tau correlation between 10-year moving average of log-transformed flood flows and 3-month average Nino3.4 anomalies with 9-month lead.

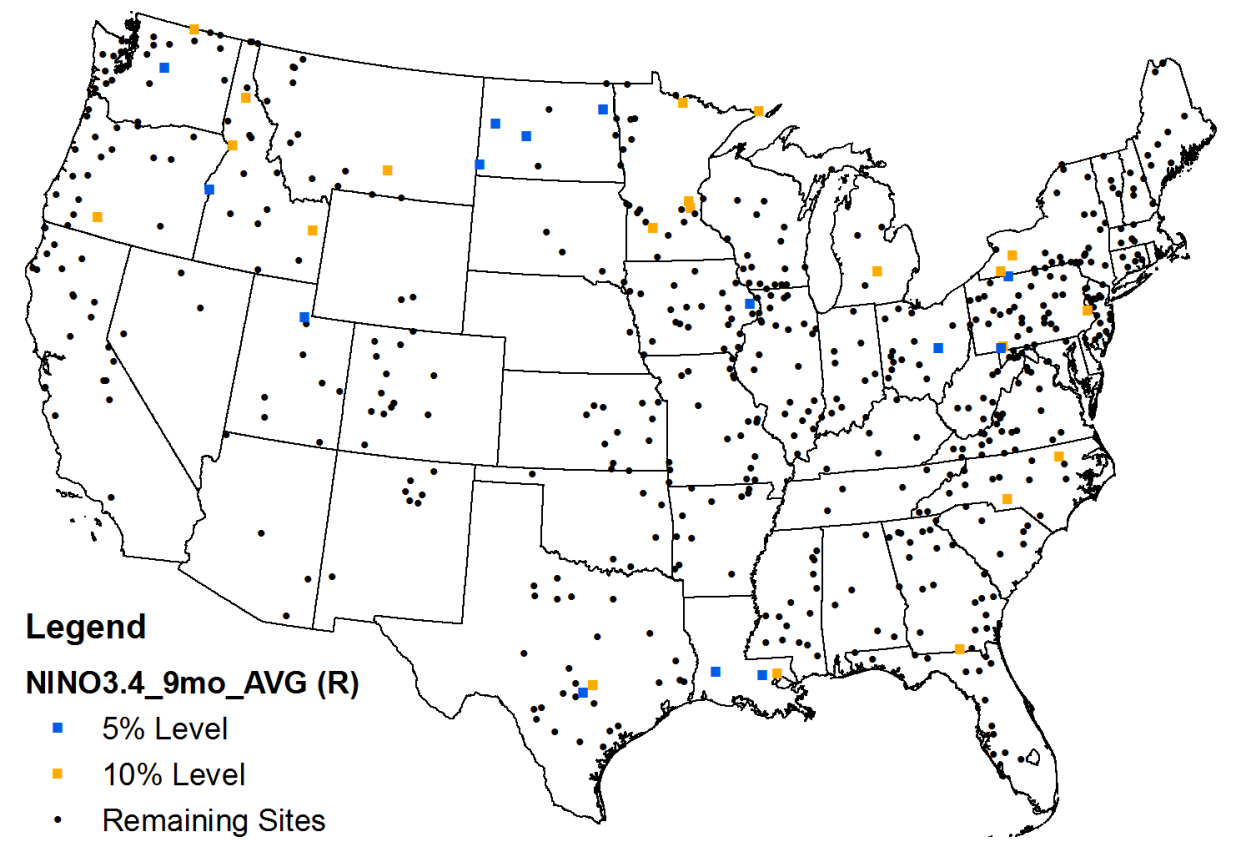

Figure E.14 Locations of sites with significant Pearson's $r$ correlation between 10-year moving average of log-transformed flood flows and 3-month average Nino3.4 anomalies with 9-month lead. 


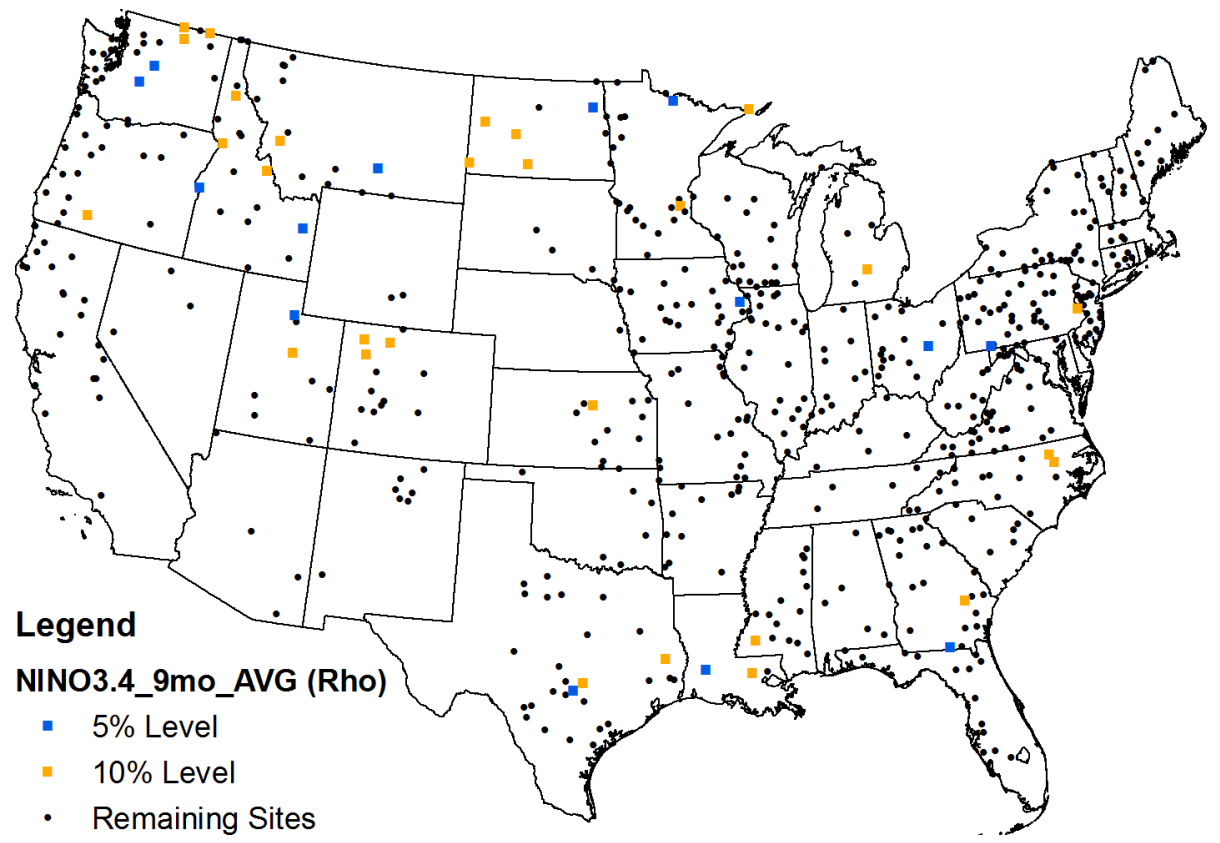

Figure E.15 Locations of sites with significant Spearman's rho correlation between 10year moving average of log-transformed flood flows and 3-month average Nino3.4 anomalies with 9-month lead.

\section{E.5 PDO Correlations Results}

Table E.6

Results of Kendall's tau analyses (significant 10\% level) between 10-year moving average of log-transformed flood flows and 3-month average PDO anomalies with 3-, 6-,

9-month leads.

\begin{tabular}{|c|cc|cc|cc|}
\hline $\begin{array}{c}\text { Station } \\
\text { Number }\end{array}$ & \multicolumn{2}{|c|}{ 3-Month Lead } & \multicolumn{2}{|c|}{ 6-Month Lead } & \multicolumn{2}{c|}{ 9-Month Lead } \\
tau & p-value & tau & p-value & tau & p-value \\
\hline \hline 1011000 & 0.234 & $\mathbf{0 . 0 0 8}$ & 0.226 & $\mathbf{0 . 0 1 1}$ & 0.150 & 0.092 \\
1013500 & 0.239 & $\mathbf{0 . 0 0 7}$ & 0.176 & $\mathbf{0 . 0 4 8}$ & & \\
1014000 & 0.266 & $\mathbf{0 . 0 0 3}$ & 0.249 & $\mathbf{0 . 0 0 5}$ & 0.193 & $\mathbf{0 . 0 3 0}$ \\
1031500 & & & 0.193 & $\mathbf{0 . 0 3 0}$ & 0.163 & 0.066 \\
1038000 & 0.226 & $\mathbf{0 . 0 1 1}$ & 0.245 & $\mathbf{0 . 0 0 6}$ & 0.240 & $\mathbf{0 . 0 0 7}$ \\
1047000 & 0.161 & 0.071 & & & 0.204 & $\mathbf{0 . 0 2 2}$ \\
1055000 & & & & & 0.234 & $\mathbf{0 . 0 0 8}$ \\
1057000 & 0.180 & $\mathbf{0 . 0 4 3}$ & 0.225 & $\mathbf{0 . 0 1 1}$ & 0.310 & $\mathbf{0 . 0 0 0}$ \\
1064500 & 0.214 & $\mathbf{0 . 0 1 6}$ & 0.255 & $\mathbf{0 . 0 0 4}$ & 0.372 & $\mathbf{0 . 0 0 0}$ \\
1073000 & 0.195 & $\mathbf{0 . 0 3 0}$ & & & 0.286 & $\mathbf{0 . 0 0 1}$ \\
1076500 & 0.158 & 0.077 & & & 0.179 & $\mathbf{0 . 0 4 6}$ \\
1078000 & 0.211 & $\mathbf{0 . 0 1 9}$ & 0.198 & $\mathbf{0 . 0 2 8}$ & 0.328 & $\mathbf{0 . 0 0 0}$
\end{tabular}


Table E.6, continued

\begin{tabular}{|c|c|c|c|c|c|c|}
\hline \multirow{2}{*}{$\begin{array}{l}\text { Station } \\
\text { Number }\end{array}$} & \multicolumn{2}{|c|}{ 3-Month Lead } & \multicolumn{2}{|c|}{ 6-Month Lead } & \multicolumn{2}{|c|}{ 9-Month Lead } \\
\hline & tau & $\mathrm{p}$-value & tau & $\mathrm{p}$-value & tau & $\mathrm{p}$-value \\
\hline 1119500 & 0.166 & 0.064 & 0.157 & 0.080 & 0.264 & 0.003 \\
\hline 1127500 & 0.233 & 0.009 & 0.274 & 0.002 & 0.261 & 0.004 \\
\hline 1137500 & & & & & 0.165 & 0.066 \\
\hline 1162500 & 0.205 & 0.022 & 0.211 & 0.019 & 0.196 & 0.028 \\
\hline 1169000 & 0.266 & 0.003 & 0.222 & 0.013 & 0.282 & 0.002 \\
\hline 1176000 & 0.160 & 0.074 & & & 0.185 & 0.039 \\
\hline 1181000 & 0.218 & 0.015 & 0.247 & 0.006 & 0.254 & 0.005 \\
\hline 1188000 & & & 0.161 & 0.073 & 0.220 & 0.014 \\
\hline 1193500 & 0.192 & 0.032 & 0.205 & 0.022 & 0.202 & 0.024 \\
\hline 1196500 & 0.249 & 0.005 & 0.334 & 0.000 & 0.401 & 0.000 \\
\hline 1318500 & 0.181 & 0.042 & & & 0.181 & 0.041 \\
\hline 1334500 & 0.205 & 0.021 & 0.248 & 0.005 & 0.211 & 0.017 \\
\hline 1350000 & 0.213 & 0.016 & 0.202 & 0.023 & 0.309 & 0.001 \\
\hline 1365000 & 0.278 & 0.002 & 0.211 & 0.017 & 0.253 & 0.004 \\
\hline 1379500 & 0.147 & 0.097 & 0.171 & 0.055 & & \\
\hline 1381500 & 0.244 & 0.006 & 0.331 & 0.000 & 0.344 & 0.000 \\
\hline 1387500 & 0.222 & 0.012 & 0.283 & 0.001 & 0.257 & 0.004 \\
\hline 1396500 & 0.240 & 0.007 & 0.308 & 0.001 & 0.293 & 0.001 \\
\hline 1397500 & & & 0.225 & 0.011 & 0.251 & 0.005 \\
\hline 1398000 & & & & & 0.193 & 0.030 \\
\hline 1398500 & 0.230 & 0.010 & 0.309 & 0.001 & 0.287 & 0.001 \\
\hline 1399500 & & & 0.164 & 0.065 & & \\
\hline 1408000 & 0.215 & 0.016 & 0.161 & 0.070 & 0.169 & 0.057 \\
\hline 1410000 & & & & & 0.149 & 0.093 \\
\hline 1411000 & 0.201 & 0.024 & 0.220 & 0.013 & 0.175 & 0.049 \\
\hline 1411500 & & & & & 0.162 & 0.068 \\
\hline 1413500 & & & & & 0.148 & 0.096 \\
\hline 1420500 & 0.186 & 0.036 & 0.275 & 0.002 & 0.305 & 0.001 \\
\hline 1426500 & & & -0.157 & 0.077 & & \\
\hline 1439500 & 0.146 & 0.100 & 0.157 & 0.077 & & \\
\hline 1445500 & 0.152 & 0.087 & 0.222 & 0.013 & 0.231 & 0.009 \\
\hline 1518000 & & & -0.198 & 0.026 & -0.188 & 0.035 \\
\hline 1520500 & & & -0.240 & 0.007 & -0.235 & 0.008 \\
\hline 1531000 & & & -0.173 & 0.052 & & \\
\hline 1532000 & & & & & 0.198 & 0.026 \\
\hline 1534000 & & & 0.154 & 0.084 & & \\
\hline 1538000 & & & 0.194 & 0.029 & 0.220 & 0.013 \\
\hline 1541000 & 0.173 & 0.051 & 0.182 & 0.041 & 0.149 & 0.093 \\
\hline 1555000 & 0.188 & 0.034 & 0.180 & 0.043 & 0.295 & 0.001 \\
\hline 1555500 & 0.221 & 0.013 & 0.263 & 0.003 & 0.230 & 0.010 \\
\hline 1556000 & & & -0.248 & 0.005 & & \\
\hline 1558000 & 0.159 & 0.074 & & & & \\
\hline 1560000 & 0.221 & 0.013 & 0.225 & 0.011 & 0.274 & 0.002 \\
\hline 1574000 & 0.151 & 0.090 & 0.179 & 0.045 & & \\
\hline
\end{tabular}


Table E.6, continued

\begin{tabular}{|c|c|c|c|c|c|c|}
\hline \multirow{2}{*}{$\begin{array}{l}\text { Station } \\
\text { Number }\end{array}$} & \multicolumn{2}{|c|}{ 3-Month Lead } & \multicolumn{2}{|c|}{ 6-Month Lead } & \multicolumn{2}{|c|}{ 9-Month Lead } \\
\hline & tau & $\mathrm{p}$-value & tau & $\mathrm{p}$-value & tau & $\mathrm{p}$-value \\
\hline 1601500 & 0.210 & 0.018 & 0.227 & 0.011 & 0.326 & 0.000 \\
\hline 1604500 & -0.154 & 0.083 & -0.261 & 0.003 & -0.277 & 0.002 \\
\hline 1608500 & 0.222 & 0.012 & 0.300 & 0.001 & 0.272 & 0.002 \\
\hline 1610000 & & & 0.211 & 0.017 & & \\
\hline 1614500 & 0.306 & 0.001 & 0.300 & 0.001 & 0.246 & 0.006 \\
\hline 1631000 & 0.186 & 0.036 & 0.223 & 0.012 & 0.173 & 0.052 \\
\hline 1632000 & 0.150 & 0.092 & 0.147 & 0.099 & 0.172 & 0.053 \\
\hline 1634000 & 0.210 & 0.018 & 0.227 & 0.011 & 0.220 & 0.013 \\
\hline 1634500 & 0.280 & 0.002 & 0.347 & 0.000 & 0.409 & 0.000 \\
\hline 1645000 & 0.263 & 0.003 & 0.322 & 0.000 & 0.213 & 0.016 \\
\hline 1667500 & 0.323 & 0.000 & 0.262 & 0.003 & 0.158 & 0.076 \\
\hline 2013000 & 0.194 & 0.029 & 0.285 & 0.001 & 0.224 & 0.012 \\
\hline 2016000 & 0.177 & 0.047 & 0.241 & 0.007 & 0.231 & 0.009 \\
\hline 2017500 & 0.173 & 0.051 & 0.155 & 0.082 & 0.219 & 0.014 \\
\hline 2018000 & 0.238 & 0.007 & 0.327 & 0.000 & 0.373 & 0.000 \\
\hline 2035000 & 0.146 & 0.100 & 0.185 & 0.037 & & \\
\hline 2045500 & 0.245 & 0.006 & 0.285 & 0.001 & 0.341 & 0.000 \\
\hline 2051500 & 0.213 & 0.017 & 0.280 & 0.002 & 0.335 & 0.000 \\
\hline 2055000 & 0.244 & 0.006 & 0.304 & 0.001 & 0.319 & 0.000 \\
\hline 2059500 & 0.361 & 0.000 & 0.152 & 0.087 & 0.178 & 0.045 \\
\hline 2061500 & 0.205 & 0.021 & 0.278 & 0.002 & 0.312 & 0.000 \\
\hline 2070000 & & & 0.227 & 0.011 & 0.171 & 0.055 \\
\hline 2074500 & 0.323 & 0.000 & 0.202 & 0.023 & 0.170 & 0.057 \\
\hline 2083000 & & & 0.150 & 0.091 & 0.271 & 0.002 \\
\hline 2091500 & & & -0.154 & 0.084 & & \\
\hline 2116500 & 0.166 & 0.062 & & & & \\
\hline 2118000 & 0.158 & 0.075 & & & 0.192 & 0.031 \\
\hline 2126000 & & & & & 0.199 & 0.025 \\
\hline 2138500 & 0.202 & 0.023 & & & 0.159 & 0.073 \\
\hline 2154500 & & & -0.175 & 0.049 & -0.180 & 0.043 \\
\hline 2213500 & 0.226 & 0.011 & 0.264 & 0.003 & 0.310 & 0.000 \\
\hline 2225500 & & & 0.164 & 0.065 & 0.163 & 0.067 \\
\hline 2231000 & -0.354 & 0.000 & -0.397 & 0.000 & -0.233 & 0.009 \\
\hline 2246000 & -0.246 & 0.006 & -0.277 & 0.002 & -0.163 & 0.066 \\
\hline 2256500 & -0.289 & 0.001 & -0.309 & 0.001 & -0.199 & 0.025 \\
\hline 2296750 & -0.302 & 0.001 & -0.256 & 0.004 & -0.207 & 0.020 \\
\hline 2298830 & & & -0.153 & 0.086 & -0.162 & 0.068 \\
\hline 2301500 & -0.244 & 0.006 & -0.330 & 0.000 & -0.201 & 0.024 \\
\hline 2303000 & -0.233 & 0.009 & -0.280 & 0.002 & & \\
\hline 2313000 & -0.227 & 0.011 & -0.194 & 0.029 & & \\
\hline 2314500 & & & & & -0.181 & 0.042 \\
\hline 2317500 & & & 0.171 & 0.055 & 0.189 & 0.034 \\
\hline 2320500 & & & 0.178 & 0.046 & 0.153 & 0.086 \\
\hline 2321500 & -0.196 & 0.028 & -0.286 & 0.001 & & \\
\hline
\end{tabular}


Table E.6, continued

\begin{tabular}{|c|c|c|c|c|c|c|}
\hline \multirow{2}{*}{$\begin{array}{l}\text { Station } \\
\text { Number }\end{array}$} & \multicolumn{2}{|c|}{ 3-Month Lead } & \multicolumn{2}{|c|}{ 6-Month Lead } & \multicolumn{2}{|c|}{ 9-Month Lead } \\
\hline & tau & $\mathrm{p}$-value & tau & $\mathrm{p}$-value & tau & $\mathrm{p}$-value \\
\hline 2329000 & & & 0.213 & 0.017 & 0.166 & 0.062 \\
\hline 2333500 & & & -0.195 & 0.028 & & \\
\hline 2339500 & -0.167 & 0.060 & -0.249 & 0.005 & -0.305 & 0.001 \\
\hline 2353500 & 0.163 & 0.066 & 0.162 & 0.069 & 0.194 & 0.029 \\
\hline 2369000 & 0.153 & 0.085 & 0.192 & 0.031 & 0.312 & 0.000 \\
\hline 2375500 & 0.194 & 0.029 & 0.235 & 0.008 & 0.161 & 0.070 \\
\hline 2383500 & & & -0.215 & 0.016 & -0.265 & 0.003 \\
\hline 2387500 & & & -0.207 & 0.020 & -0.261 & 0.003 \\
\hline 2431000 & & & -0.148 & 0.096 & -0.174 & 0.050 \\
\hline 2441000 & & & -0.157 & 0.077 & -0.201 & 0.024 \\
\hline 2467000 & 0.160 & 0.072 & 0.216 & 0.015 & 0.294 & 0.001 \\
\hline 2472500 & 0.179 & 0.045 & 0.275 & 0.002 & 0.322 & 0.000 \\
\hline 2479000 & 0.214 & 0.016 & 0.264 & 0.003 & 0.296 & 0.001 \\
\hline 2484500 & 0.151 & 0.090 & & & & \\
\hline 2486000 & 0.202 & 0.023 & 0.210 & 0.018 & 0.163 & 0.066 \\
\hline 2487500 & & & 0.172 & 0.053 & 0.220 & 0.013 \\
\hline 2488500 & 0.263 & 0.003 & 0.298 & 0.001 & 0.323 & 0.000 \\
\hline 3010500 & -0.189 & 0.033 & -0.285 & 0.001 & -0.298 & 0.001 \\
\hline 3011020 & -0.179 & 0.044 & -0.282 & 0.002 & -0.280 & 0.002 \\
\hline 3015500 & 0.185 & 0.038 & 0.181 & 0.042 & 0.193 & 0.030 \\
\hline 3024000 & & & -0.226 & 0.011 & -0.290 & 0.001 \\
\hline 3034500 & & & 0.162 & 0.068 & 0.178 & 0.046 \\
\hline 3049500 & & & -0.233 & 0.009 & -0.302 & 0.001 \\
\hline 3079000 & & & -0.217 & 0.015 & -0.266 & 0.003 \\
\hline 3080000 & -0.218 & 0.014 & -0.271 & 0.002 & -0.392 & 0.000 \\
\hline 3102500 & & & -0.188 & 0.034 & -0.190 & 0.033 \\
\hline 3106000 & & & -0.163 & 0.067 & -0.161 & 0.071 \\
\hline 3118500 & 0.279 & 0.002 & 0.336 & 0.000 & 0.338 & 0.000 \\
\hline 3144000 & 0.157 & 0.081 & 0.264 & 0.003 & 0.347 & 0.000 \\
\hline 3164000 & 0.176 & 0.047 & 0.216 & 0.015 & 0.341 & 0.000 \\
\hline 3167000 & & & -0.211 & 0.017 & -0.274 & 0.002 \\
\hline 3170000 & 0.197 & 0.026 & 0.218 & 0.014 & 0.207 & 0.020 \\
\hline 3182500 & & & 0.219 & 0.014 & 0.272 & 0.002 \\
\hline 3186500 & & & 0.168 & 0.058 & 0.257 & 0.004 \\
\hline 3198500 & 0.147 & 0.097 & & & & \\
\hline 3219500 & & & 0.183 & 0.041 & & \\
\hline 3230500 & & & -0.225 & 0.012 & & \\
\hline 3234500 & -0.252 & 0.005 & -0.261 & 0.004 & -0.378 & 0.000 \\
\hline 3253500 & -0.207 & 0.021 & -0.303 & 0.001 & -0.257 & 0.004 \\
\hline 3266000 & -0.153 & 0.089 & & & & \\
\hline 3269500 & -0.171 & 0.057 & -0.264 & 0.003 & -0.261 & 0.004 \\
\hline 3274000 & -0.167 & 0.062 & & & & \\
\hline 3275000 & -0.223 & 0.012 & -0.165 & 0.063 & -0.296 & 0.001 \\
\hline 3281500 & & & & & -0.169 & 0.060 \\
\hline
\end{tabular}


Table E.6, continued

\begin{tabular}{|c|c|c|c|c|c|c|}
\hline \multirow{2}{*}{$\begin{array}{c}\text { Station } \\
\text { Number }\end{array}$} & \multicolumn{2}{|c|}{ 3-Month Lead } & \multicolumn{2}{|c|}{ 6-Month Lead } & \multicolumn{2}{|c|}{ 9-Month Lead } \\
\hline & tau & $\mathrm{p}$-value & tau & $\mathrm{p}$-value & tau & $\mathrm{p}$-value \\
\hline 3294500 & & & -0.167 & 0.063 & -0.256 & 0.004 \\
\hline 3301500 & & & 0.148 & 0.099 & & \\
\hline 3307000 & 0.248 & 0.006 & 0.365 & 0.000 & 0.399 & 0.000 \\
\hline 3326500 & & & & & 0.178 & 0.045 \\
\hline 3339500 & -0.194 & 0.029 & & & & \\
\hline 3360500 & -0.167 & 0.061 & & & & \\
\hline 3363500 & -0.215 & 0.015 & & & -0.199 & 0.025 \\
\hline 3373500 & -0.197 & 0.026 & & & -0.191 & 0.032 \\
\hline 3380500 & & & 0.166 & 0.062 & 0.202 & 0.023 \\
\hline 3381500 & 0.166 & 0.062 & & & 0.214 & 0.016 \\
\hline 3434500 & & & & & 0.157 & 0.077 \\
\hline 3438000 & 0.234 & 0.009 & 0.281 & 0.002 & 0.256 & 0.004 \\
\hline 3465500 & & & & & 0.159 & 0.073 \\
\hline 3479000 & 0.195 & 0.028 & 0.187 & 0.036 & 0.278 & 0.002 \\
\hline 3524000 & & & -0.165 & 0.063 & -0.181 & 0.042 \\
\hline 3528000 & & & -0.168 & 0.058 & & \\
\hline 3604000 & & & & & 0.152 & 0.089 \\
\hline 3612000 & & & & & -0.157 & 0.080 \\
\hline 4056500 & & & 0.235 & 0.008 & & \\
\hline 4087000 & 0.149 & 0.095 & & & & \\
\hline 4100500 & 0.190 & 0.033 & 0.173 & 0.052 & 0.306 & 0.001 \\
\hline 4191500 & 0.148 & 0.098 & 0.195 & 0.030 & 0.206 & 0.021 \\
\hline 4193500 & & & 0.215 & 0.015 & 0.220 & 0.013 \\
\hline 4198000 & 0.177 & 0.047 & 0.164 & 0.065 & & \\
\hline 4223000 & & & -0.183 & 0.040 & -0.178 & 0.045 \\
\hline 4234000 & & & & & 0.164 & 0.065 \\
\hline 4262500 & 0.199 & 0.025 & & & 0.282 & 0.001 \\
\hline 4264331 & 0.278 & 0.002 & 0.263 & 0.003 & 0.336 & 0.000 \\
\hline 4269000 & & & & & 0.161 & 0.070 \\
\hline 4275000 & 0.251 & 0.005 & 0.214 & 0.016 & 0.350 & 0.000 \\
\hline 4287000 & 0.156 & 0.082 & 0.220 & 0.014 & 0.210 & 0.019 \\
\hline 4293500 & 0.160 & 0.075 & 0.174 & 0.053 & 0.256 & 0.004 \\
\hline 5078000 & & & & & -0.189 & 0.034 \\
\hline 5078500 & & & & & -0.166 & 0.063 \\
\hline 5084000 & -0.194 & 0.029 & -0.191 & 0.032 & -0.340 & 0.000 \\
\hline 5100000 & & & -0.177 & 0.046 & -0.170 & 0.056 \\
\hline 5112000 & -0.156 & 0.079 & -0.208 & 0.019 & -0.225 & 0.011 \\
\hline 5131500 & & & & & -0.161 & 0.071 \\
\hline 5286000 & & & & & -0.254 & 0.004 \\
\hline 5288500 & -0.147 & 0.099 & -0.195 & 0.028 & -0.283 & 0.001 \\
\hline 5304500 & 0.185 & 0.037 & & & 0.214 & 0.016 \\
\hline 5316500 & 0.167 & 0.061 & 0.231 & 0.009 & 0.283 & 0.001 \\
\hline 5340500 & & & & & -0.207 & 0.020 \\
\hline 5379500 & & & -0.158 & 0.075 & & \\
\hline
\end{tabular}


Table E.6, continued

\begin{tabular}{|c|c|c|c|c|c|c|}
\hline \multirow{2}{*}{$\begin{array}{l}\text { Station } \\
\text { Number }\end{array}$} & \multicolumn{2}{|c|}{ 3-Month Lead } & \multicolumn{2}{|c|}{ 6-Month Lead } & \multicolumn{2}{|c|}{ 9-Month Lead } \\
\hline & tau & $\mathrm{p}$-value & tau & $\mathrm{p}$-value & tau & $\mathrm{p}$-value \\
\hline 5407000 & & & 0.220 & 0.014 & & \\
\hline 5408000 & & & -0.213 & 0.017 & -0.261 & 0.003 \\
\hline 5410490 & & & -0.242 & 0.006 & -0.297 & 0.001 \\
\hline 5412500 & -0.207 & 0.020 & -0.259 & 0.004 & -0.336 & 0.000 \\
\hline 5414000 & & & -0.180 & 0.043 & -0.185 & 0.037 \\
\hline 5418500 & & & -0.209 & 0.019 & -0.282 & 0.002 \\
\hline 5419000 & & & -0.172 & 0.053 & -0.231 & 0.009 \\
\hline 5421000 & & & -0.149 & 0.093 & -0.215 & 0.016 \\
\hline 5431486 & & & & & -0.149 & 0.093 \\
\hline 5432500 & -0.146 & 0.100 & -0.257 & 0.004 & -0.265 & 0.003 \\
\hline 5434500 & -0.161 & 0.070 & -0.241 & 0.007 & -0.263 & 0.003 \\
\hline 5435500 & -0.207 & 0.020 & -0.277 & 0.002 & -0.240 & 0.007 \\
\hline 5436500 & -0.180 & 0.045 & -0.267 & 0.003 & -0.253 & 0.005 \\
\hline 5447500 & & & 0.189 & 0.034 & 0.231 & 0.009 \\
\hline 5459500 & & & -0.167 & 0.060 & -0.164 & 0.065 \\
\hline 5474000 & 0.205 & 0.021 & 0.149 & 0.095 & & \\
\hline 5482500 & -0.253 & 0.004 & -0.198 & 0.026 & -0.189 & 0.034 \\
\hline 5484500 & -0.270 & 0.002 & -0.189 & 0.033 & -0.182 & 0.041 \\
\hline 5495000 & 0.261 & 0.003 & 0.165 & 0.063 & 0.177 & 0.047 \\
\hline 5497000 & & & 0.151 & 0.096 & & \\
\hline 5501000 & 0.303 & 0.001 & 0.216 & 0.015 & 0.304 & 0.001 \\
\hline 5520500 & 0.289 & 0.001 & 0.245 & 0.006 & 0.236 & 0.008 \\
\hline 5526000 & 0.332 & 0.000 & 0.181 & 0.041 & 0.286 & 0.001 \\
\hline 5527500 & 0.297 & 0.001 & 0.282 & 0.001 & 0.318 & 0.000 \\
\hline 5555300 & 0.187 & 0.036 & 0.169 & 0.057 & 0.266 & 0.003 \\
\hline 5570000 & 0.168 & 0.058 & 0.147 & 0.097 & & \\
\hline 5572000 & 0.215 & 0.015 & 0.207 & 0.020 & 0.169 & 0.057 \\
\hline 5585000 & 0.240 & 0.007 & 0.198 & 0.026 & 0.203 & 0.022 \\
\hline 5593000 & & & -0.198 & 0.026 & -0.163 & 0.067 \\
\hline 5597000 & & & -0.180 & 0.043 & -0.205 & 0.021 \\
\hline 6019500 & 0.221 & 0.013 & 0.202 & 0.023 & 0.193 & 0.030 \\
\hline 6191500 & & & & & -0.162 & 0.069 \\
\hline 6214500 & & & & & -0.170 & 0.057 \\
\hline 6335500 & -0.186 & 0.036 & -0.303 & 0.001 & -0.383 & 0.000 \\
\hline 6337000 & -0.180 & 0.043 & -0.300 & 0.001 & -0.387 & 0.000 \\
\hline 6340500 & & & -0.193 & 0.030 & -0.275 & 0.002 \\
\hline 6441500 & -0.166 & 0.063 & -0.225 & 0.011 & -0.242 & 0.006 \\
\hline 6600500 & & & 0.163 & 0.067 & 0.190 & 0.033 \\
\hline 6606600 & -0.180 & 0.043 & & & & \\
\hline 6809500 & -0.218 & 0.014 & -0.203 & 0.022 & -0.206 & 0.021 \\
\hline 6864500 & -0.318 & 0.000 & -0.227 & 0.011 & -0.198 & 0.026 \\
\hline 6876900 & -0.214 & 0.016 & & & -0.194 & 0.029 \\
\hline 6889500 & 0.278 & 0.002 & 0.194 & 0.029 & 0.308 & 0.001 \\
\hline 6899500 & & & & & -0.148 & 0.097 \\
\hline
\end{tabular}


Table E.6, continued

\begin{tabular}{|c|c|c|c|c|c|c|}
\hline \multirow{2}{*}{$\begin{array}{l}\text { Station } \\
\text { Number }\end{array}$} & \multicolumn{2}{|c|}{ 3-Month Lead } & \multicolumn{2}{|c|}{ 6-Month Lead } & \multicolumn{2}{|c|}{ 9-Month Lead } \\
\hline & tau & $\mathrm{p}$-value & tau & p-value & tau & $\mathrm{p}$-value \\
\hline 6933500 & & & 0.147 & 0.097 & 0.153 & 0.086 \\
\hline 7016500 & 0.174 & 0.051 & 0.188 & 0.034 & 0.223 & 0.012 \\
\hline 7019000 & & & & & 0.178 & 0.045 \\
\hline 7067000 & & & 0.194 & 0.029 & & \\
\hline 7069500 & & & -0.255 & 0.004 & -0.384 & 0.000 \\
\hline 7072000 & & & & & -0.171 & 0.055 \\
\hline 7074000 & -0.224 & 0.012 & & & -0.244 & 0.006 \\
\hline 7096000 & -0.249 & 0.005 & & & -0.174 & 0.050 \\
\hline 7144200 & 0.182 & 0.041 & & & & \\
\hline 7176000 & -0.236 & 0.008 & -0.193 & 0.030 & -0.170 & 0.056 \\
\hline 7186000 & 0.164 & 0.065 & & & 0.218 & 0.014 \\
\hline 7187000 & & & -0.199 & 0.025 & -0.251 & 0.005 \\
\hline 7203000 & -0.171 & 0.059 & -0.161 & 0.075 & & \\
\hline 7218000 & -0.196 & 0.029 & -0.184 & 0.040 & & \\
\hline 7234000 & -0.285 & 0.001 & & & -0.219 & 0.014 \\
\hline 7247000 & -0.249 & 0.005 & & & & \\
\hline 7247500 & -0.199 & 0.025 & -0.195 & 0.028 & -0.292 & 0.001 \\
\hline 7261500 & & & & & 0.149 & 0.095 \\
\hline 7290000 & 0.185 & 0.037 & 0.231 & 0.009 & & \\
\hline 7291000 & 0.270 & 0.002 & 0.375 & 0.000 & 0.355 & 0.000 \\
\hline 7331000 & & & & & 0.186 & 0.036 \\
\hline 7332500 & & & 0.199 & 0.025 & 0.175 & 0.049 \\
\hline 7340000 & -0.280 & 0.002 & -0.166 & 0.063 & -0.259 & 0.004 \\
\hline 7340500 & -0.267 & 0.003 & & & -0.276 & 0.002 \\
\hline 7363500 & -0.171 & 0.055 & & & -0.157 & 0.078 \\
\hline 7375500 & 0.247 & 0.005 & 0.259 & 0.004 & 0.271 & 0.002 \\
\hline 7378500 & 0.183 & 0.040 & 0.320 & 0.000 & 0.334 & 0.000 \\
\hline 8013500 & 0.228 & 0.010 & 0.340 & 0.000 & 0.150 & 0.092 \\
\hline 8033500 & & & & & 0.190 & 0.033 \\
\hline 8041500 & 0.213 & 0.017 & 0.191 & 0.032 & 0.311 & 0.000 \\
\hline 8055500 & -0.331 & 0.000 & -0.207 & 0.020 & -0.224 & 0.012 \\
\hline 8080500 & -0.257 & 0.004 & & & -0.200 & 0.024 \\
\hline 8082000 & -0.246 & 0.006 & & & -0.223 & 0.012 \\
\hline 8082500 & -0.238 & 0.007 & & & -0.167 & 0.060 \\
\hline 8128000 & & & -0.183 & 0.040 & -0.203 & 0.022 \\
\hline 8151500 & 0.366 & 0.000 & 0.293 & 0.001 & 0.258 & 0.004 \\
\hline 8153500 & 0.361 & 0.000 & 0.311 & 0.000 & 0.290 & 0.001 \\
\hline 8158000 & 0.272 & 0.002 & & & 0.179 & 0.045 \\
\hline 8164000 & 0.250 & 0.005 & & & & \\
\hline 8167000 & 0.255 & 0.004 & 0.289 & 0.001 & 0.227 & 0.011 \\
\hline 8167500 & 0.317 & 0.000 & 0.302 & 0.001 & 0.287 & 0.001 \\
\hline 8171000 & 0.179 & 0.044 & & & 0.169 & 0.057 \\
\hline 8176500 & 0.173 & 0.051 & & & & \\
\hline 8189500 & & & 0.197 & 0.027 & & \\
\hline
\end{tabular}


Table E.6, continued

\begin{tabular}{|c|c|c|c|c|c|c|}
\hline \multirow{2}{*}{$\begin{array}{c}\text { Station } \\
\text { Number }\end{array}$} & \multicolumn{2}{|c|}{ 3-Month Lead } & \multicolumn{2}{|c|}{ 6-Month Lead } & \multicolumn{2}{|c|}{ 9-Month Lead } \\
\hline & tau & $\mathrm{p}$-value & tau & $\mathrm{p}$-value & tau & $\mathrm{p}$-value \\
\hline 8195000 & 0.202 & 0.023 & 0.367 & 0.000 & 0.271 & 0.003 \\
\hline 8210000 & -0.229 & 0.010 & -0.151 & 0.090 & & \\
\hline 8276500 & & & 0.188 & 0.035 & 0.190 & 0.032 \\
\hline 8291000 & 0.345 & 0.000 & 0.269 & 0.003 & 0.227 & 0.011 \\
\hline 8378500 & 0.256 & 0.004 & 0.170 & 0.059 & 0.247 & 0.006 \\
\hline 8380500 & -0.209 & 0.020 & -0.156 & 0.083 & & \\
\hline 9085000 & -0.196 & 0.028 & & & -0.175 & 0.049 \\
\hline 9110000 & -0.217 & 0.015 & & & -0.242 & 0.006 \\
\hline 9180500 & -0.147 & 0.097 & & & -0.158 & 0.075 \\
\hline 9379500 & -0.274 & 0.002 & & & -0.204 & 0.022 \\
\hline 9430500 & 0.322 & 0.000 & 0.210 & 0.018 & 0.267 & 0.003 \\
\hline 9448500 & 0.198 & 0.026 & 0.177 & 0.047 & 0.246 & 0.006 \\
\hline 9471000 & -0.176 & 0.048 & & & & \\
\hline 9508500 & & & & & 0.203 & 0.022 \\
\hline 10174500 & & & 0.166 & 0.063 & & \\
\hline 10234500 & 0.157 & 0.078 & 0.146 & 0.100 & 0.180 & 0.043 \\
\hline 10296000 & & & -0.174 & 0.050 & & \\
\hline 10310000 & & & -0.193 & 0.030 & & \\
\hline 10396000 & & & 0.163 & 0.067 & & \\
\hline 11160500 & -0.165 & 0.066 & & & & \\
\hline 11381500 & & & & & -0.155 & 0.082 \\
\hline 11383500 & -0.187 & 0.035 & -0.171 & 0.055 & -0.186 & 0.036 \\
\hline 11413000 & -0.168 & 0.061 & & & -0.159 & 0.076 \\
\hline 11425500 & -0.188 & 0.034 & & & & \\
\hline 11477000 & -0.221 & 0.013 & -0.253 & 0.004 & -0.265 & 0.003 \\
\hline 11478500 & -0.158 & 0.075 & -0.205 & 0.021 & -0.192 & 0.031 \\
\hline 11522500 & & & -0.196 & 0.028 & & \\
\hline 11525500 & & & -0.227 & 0.011 & & \\
\hline 11530000 & -0.153 & 0.086 & -0.225 & 0.011 & -0.259 & 0.004 \\
\hline 11532500 & -0.202 & 0.023 & -0.254 & 0.004 & -0.217 & 0.015 \\
\hline 12035000 & 0.188 & 0.034 & 0.296 & 0.001 & 0.327 & 0.000 \\
\hline 12039500 & & & & & 0.216 & 0.015 \\
\hline 12048000 & & & 0.179 & 0.045 & 0.188 & 0.035 \\
\hline 12054000 & & & & & 0.215 & 0.016 \\
\hline 12056500 & & & & & 0.190 & 0.033 \\
\hline 12134500 & 0.248 & 0.005 & 0.225 & 0.011 & 0.300 & 0.001 \\
\hline 12186000 & 0.240 & 0.007 & 0.191 & 0.032 & 0.216 & 0.015 \\
\hline 12189500 & 0.285 & 0.001 & 0.204 & 0.022 & 0.304 & 0.001 \\
\hline 12306500 & -0.308 & 0.001 & -0.212 & 0.017 & -0.292 & 0.001 \\
\hline 12322000 & -0.279 & 0.002 & -0.257 & 0.004 & -0.334 & 0.000 \\
\hline 12332000 & -0.200 & 0.024 & & & -0.225 & 0.011 \\
\hline 12354500 & -0.198 & 0.026 & & & -0.225 & 0.011 \\
\hline 12355500 & -0.239 & 0.007 & -0.149 & 0.093 & -0.267 & 0.003 \\
\hline 12358500 & -0.229 & 0.010 & & & -0.208 & 0.019 \\
\hline
\end{tabular}


Table E.6, continued

\begin{tabular}{|c|c|c|c|c|c|c|}
\hline \multirow{2}{*}{$\begin{array}{c}\text { Station } \\
\text { Number }\end{array}$} & \multicolumn{2}{|c|}{ 3-Month Lead } & \multicolumn{2}{|c|}{ 6-Month Lead } & \multicolumn{2}{|c|}{ 9-Month Lead } \\
\hline & tau & $\mathrm{p}$-value & tau & $\mathrm{p}$-value & tau & $\mathrm{p}$-value \\
\hline 12370000 & & & & & -0.225 & 0.011 \\
\hline 12409000 & -0.161 & 0.071 & -0.284 & 0.001 & -0.184 & 0.039 \\
\hline 12413000 & -0.196 & 0.027 & -0.227 & 0.011 & -0.204 & 0.022 \\
\hline 12422500 & -0.263 & 0.003 & -0.161 & 0.070 & -0.284 & 0.001 \\
\hline 12442500 & -0.259 & 0.003 & & & -0.236 & 0.008 \\
\hline 12445000 & -0.273 & 0.002 & & & -0.223 & 0.012 \\
\hline 12451000 & -0.270 & 0.002 & -0.166 & 0.063 & & \\
\hline 12459000 & -0.159 & 0.074 & & & & \\
\hline 12488500 & & & 0.163 & 0.066 & & \\
\hline 13185000 & -0.187 & 0.036 & -0.161 & 0.071 & -0.209 & 0.019 \\
\hline 13302500 & & & & & -0.172 & 0.053 \\
\hline 13313000 & -0.266 & 0.003 & -0.236 & 0.008 & -0.311 & 0.000 \\
\hline 13317000 & -0.192 & 0.031 & & & -0.247 & 0.005 \\
\hline 13336500 & -0.191 & 0.032 & & & -0.249 & 0.005 \\
\hline 13337000 & -0.205 & 0.021 & & & -0.238 & 0.007 \\
\hline 13342500 & -0.230 & 0.010 & & & -0.261 & 0.003 \\
\hline 14044000 & 0.147 & 0.099 & 0.164 & 0.065 & 0.185 & 0.038 \\
\hline 14105700 & -0.260 & 0.003 & -0.167 & 0.061 & -0.272 & 0.002 \\
\hline 14185000 & & & & & -0.151 & 0.089 \\
\hline 14191000 & -0.246 & 0.006 & -0.268 & 0.003 & -0.272 & 0.002 \\
\hline 14301000 & & & -0.236 & 0.008 & -0.177 & 0.047 \\
\hline 14301500 & -0.167 & 0.060 & -0.207 & 0.020 & & \\
\hline 14306500 & -0.213 & 0.017 & -0.298 & 0.001 & -0.196 & 0.028 \\
\hline 14308000 & -0.164 & 0.065 & -0.189 & 0.033 & -0.213 & 0.017 \\
\hline 14321000 & -0.180 & 0.043 & -0.219 & 0.014 & -0.216 & 0.015 \\
\hline 14325000 & -0.189 & 0.034 & -0.241 & 0.007 & & \\
\hline 14359000 & -0.209 & 0.019 & -0.294 & 0.001 & -0.225 & 0.011 \\
\hline 14362000 & -0.235 & 0.008 & -0.284 & 0.001 & -0.190 & 0.033 \\
\hline
\end{tabular}




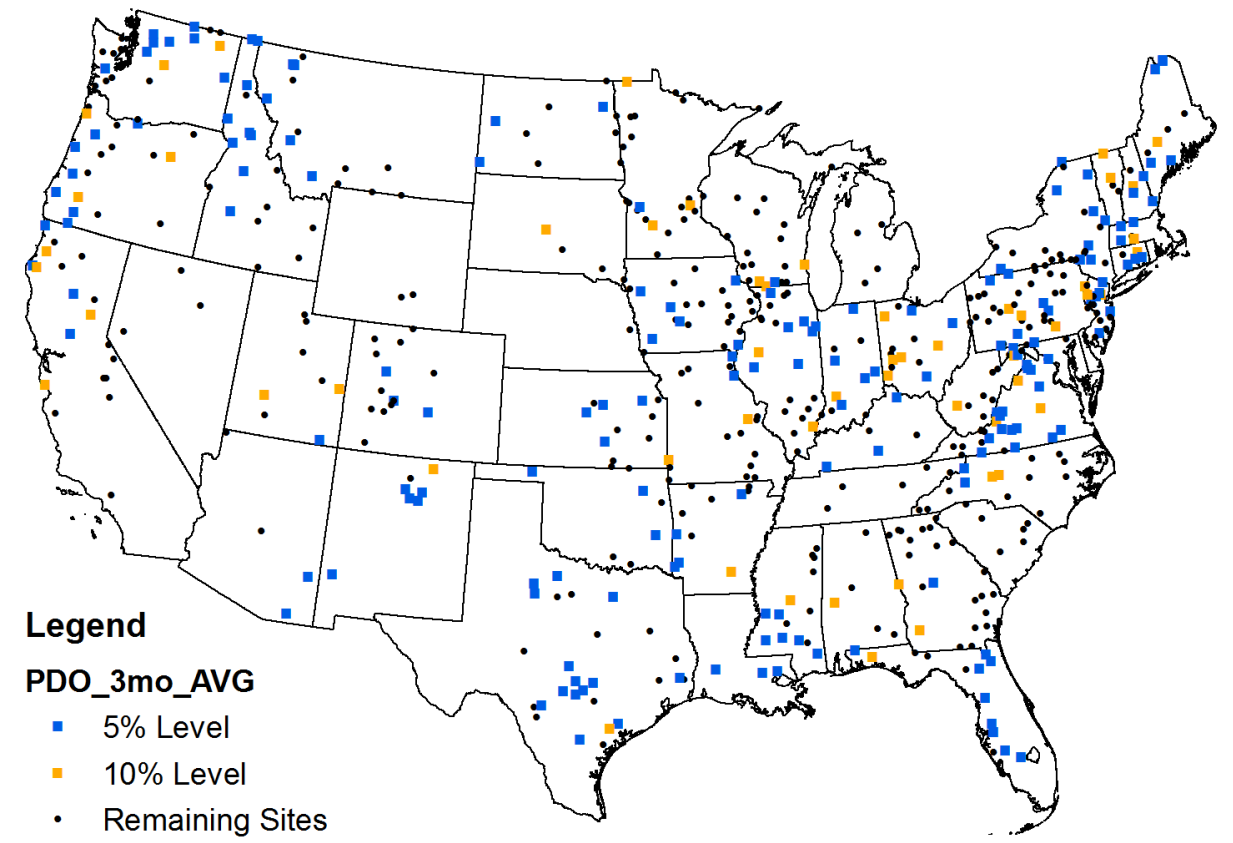

Figure E.16 Locations of sites with significant Kendall's tau correlation between 10-year moving average of log-transformed flood flows and 3-month average PDO anomalies with 3-month lead.

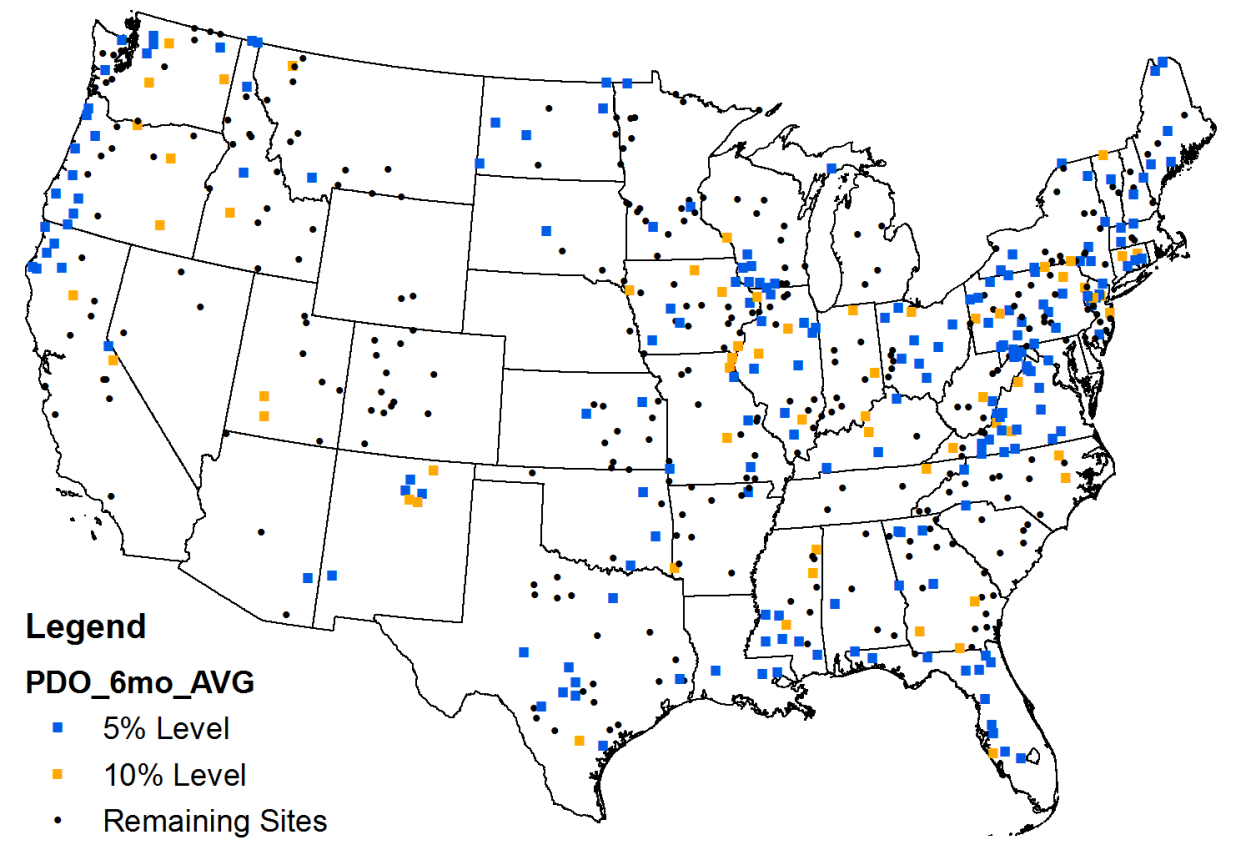

Figure E.17 Locations of sites with significant Kendall's tau correlation between 10-year moving average of log-transformed flood flows and 3-month average PDO anomalies with 6-month lead. 


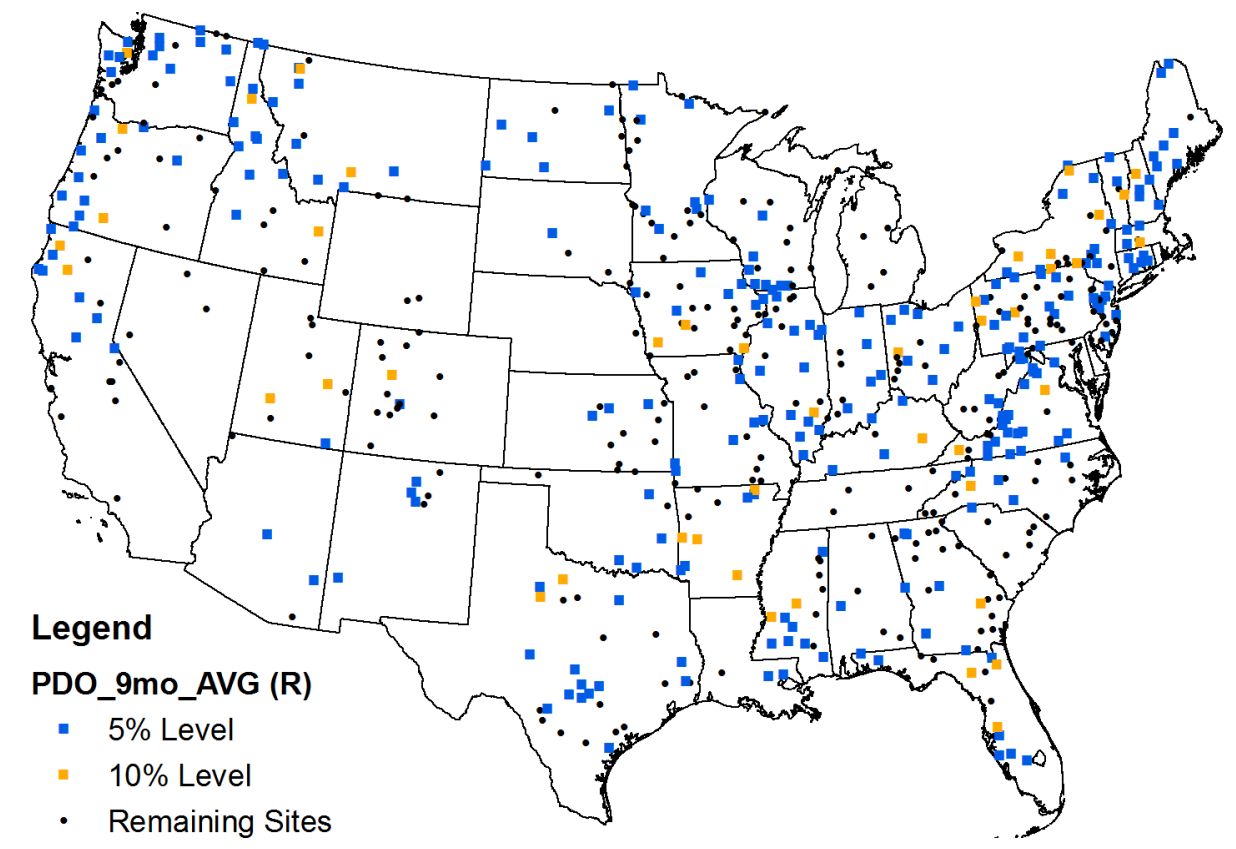

Figure E.18 Locations of sites with significant Pearson's r correlation between 10-year moving average of log-transformed flood flows and 3-month average PDO anomalies with 9-month lead.

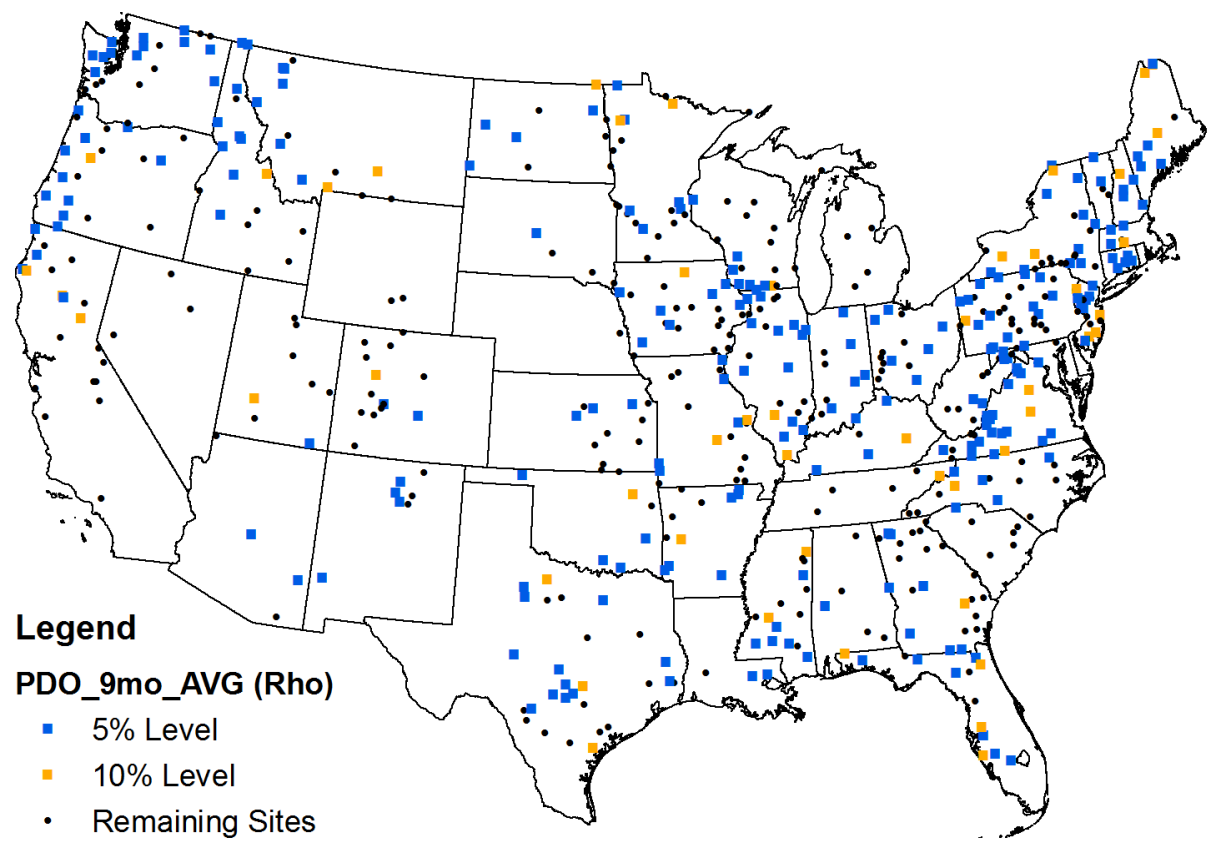

Figure E.19 Locations of sites with significant Spearman's rho correlation between 10year moving average of log-transformed flood flows and 3-month average PDO anomalies with 9-month lead. 


\section{APPENDIX F CORRELATION ANAYLSIS RESULTS BETWEEN 10 YEAR MOVING STANDARD DEVIATION OF LOGS OF FLOOD FLOWS AND CLIMATE ANOMALIES}

This appendix contains tables and figures summarizing Kendall's tau correlation analyses between the 10-year moving standard deviation of log-transformed flood flows and 3month average AMO, MEI, NAO, Nino3.4, and PDO anomalies with 3-, 6-, and 9-month leads. Tables include results only for sites with significant relationships on the $10 \%$ level (sites significant on the 5\% level are in bold). Results are omitted (blank spaces) when p-values greater than $10 \%$ were obtained. Note that results of the Kendall's tau analyses for AMO, MEI, NAO, and PDO with lead times of 3-, 9-, 3-, and 9-months, respectively, are illustrated in Chapter 3. Figures for Pearson's $r$ and Spearman's rho with the same lead times are included herein. The table below summarizes the number of sites where significant results were obtained using the Pearson's $r$ and Spearman's rho analyses for all cases considered.

Table F.1

Number of sites with significant Pearson's $r$ and Spearman's rho correlations ( 5 and 10\% levels) between 10-yr moving standard deviation of log-transformed flood peaks and for AMO, MEI, NINO 3.4, NAO, and PDO indices with specified lead times.

\begin{tabular}{|c|cc|cc|cc|cc|cc|}
\hline $\begin{array}{c}\text { Lead Time } \\
\text { (months) }\end{array}$ & \multicolumn{2}{|c|}{ AMO } & \multicolumn{2}{c|}{ MEI } & \multicolumn{2}{c|}{ Nino 3.4 } & \multicolumn{2}{c|}{ NAO } & \multicolumn{2}{c|}{ PDO } \\
\hline \multicolumn{10}{|c|}{ Pearson's $r$ Correlation } \\
\hline 3 & $10 \%$ & $5 \%$ & $10 \%$ & $5 \%$ & $10 \%$ & $5 \%$ & $10 \%$ & $5 \%$ & $10 \%$ \\
\hline 6 & 257 & 299 & 42 & 82 & 3 & 6 & 85 & 114 & 152 & 200 \\
9 & 257 & 300 & 60 & 114 & 0 & 13 & 21 & 45 & 174 & 231 \\
\hline \multicolumn{10}{|c|}{ Spearman's rho Correlation } \\
\hline 3 & 215 & 264 & 128 & 175 & 15 & 32 & 43 & 91 & 215 & 268 \\
\hline 6 & 234 & 287 & 41 & 77 & 3 & 11 & 77 & 104 & 155 & 206 \\
9 & 230 & 283 & 55 & 94 & 5 & 18 & 29 & 48 & 178 & 223 \\
\hline
\end{tabular}




\section{F.1 AMO Correlation Results}

Table F.2

Results of Kendall's tau analyses (significant 10\% level) between 10-year moving standard deviation of log-transformed flood flows and 3-month average AMO anomalies with 3-, 6-, and 9-month leads.

\begin{tabular}{|c|c|c|c|c|c|c|}
\hline \multirow{2}{*}{$\begin{array}{c}\text { Station } \\
\text { Number }\end{array}$} & \multicolumn{2}{|c|}{ 3-Month Lead } & \multicolumn{2}{|c|}{ 6-Month Lead } & \multicolumn{2}{|c|}{ 9-Month Lead } \\
\hline & tau & $\mathrm{p}$-value & tau & p-value & tau & p-value \\
\hline 21011000 & $2-0.301$ & 0.001 & -0.279 & 0.002 & $2-0.180$ & 0.043 \\
\hline 1013500 & -0.168 & 0.058 & -0.226 & 0.011 & -0.165 & 0.063 \\
\hline 1030500 & -0.242 & 0.006 & -0.185 & 0.037 & & \\
\hline 1038000 & -0.315 & 0.000 & -0.250 & 0.005 & -0.183 & 0.039 \\
\hline 1073000 & 0.274 & 0.002 & 0.299 & 0.001 & 0.233 & 0.009 \\
\hline 1076500 & & & & & -0.164 & 0.067 \\
\hline 1078000 & 0.282 & 0.002 & 0.288 & 0.001 & 0.199 & 0.027 \\
\hline 1127500 & & & 0.151 & 0.093 & & \\
\hline 1169000 & 0.188 & 0.036 & 0.167 & 0.062 & 0.148 & 0.099 \\
\hline 1175500 & 0.196 & 0.028 & 0.217 & 0.015 & 0.258 & 0.004 \\
\hline 1176000 & 0.171 & 0.056 & & & & \\
\hline 1181000 & 0.207 & 0.021 & 0.148 & 0.098 & 0.148 & 0.099 \\
\hline 1188000 & 0.160 & 0.075 & & & & \\
\hline 1318500 & 0.159 & 0.074 & & & & \\
\hline 1321000 & 0.222 & 0.013 & 0.193 & 0.030 & & \\
\hline 1334500 & -0.174 & 0.050 & -0.219 & 0.014 & -0.216 & 0.015 \\
\hline 1350000 & 0.391 & 0.000 & 0.284 & 0.001 & 0.270 & 0.002 \\
\hline 1365000 & 0.404 & 0.000 & 0.327 & 0.000 & 0.329 & 0.000 \\
\hline 1381500 & 0.242 & 0.006 & 0.163 & 0.066 & & \\
\hline 1387500 & 0.166 & 0.062 & & & & \\
\hline 1396500 & 0.192 & 0.031 & 0.244 & 0.006 & 0.161 & 0.070 \\
\hline 1398000 & 0.409 & 0.000 & 0.372 & 0.000 & 0.308 & 0.001 \\
\hline 1398500 & 0.201 & 0.024 & 0.168 & 0.059 & & \\
\hline 1408000 & 0.299 & 0.001 & 0.373 & 0.000 & 0.340 & 0.000 \\
\hline 1410000 & -0.401 & 0.000 & -0.287 & 0.001 & -0.325 & 0.000 \\
\hline 1411500 & -0.277 & 0.002 & -0.321 & 0.000 & -0.328 & 0.000 \\
\hline 1413500 & 0.421 & 0.000 & 0.464 & 0.000 & 0.360 & 0.000 \\
\hline 1414500 & 0.497 & 0.000 & 0.485 & 0.000 & 0.441 & 0.000 \\
\hline 1420500 & 0.271 & 0.002 & 0.242 & 0.006 & 0.199 & 0.025 \\
\hline 1421000 & 0.369 & 0.000 & 0.320 & 0.000 & 0.287 & 0.001 \\
\hline 1439500 & 0.246 & 0.006 & 0.179 & 0.044 & 0.199 & 0.025 \\
\hline 1440000 & 0.240 & 0.007 & 0.279 & 0.002 & 0.212 & 0.017 \\
\hline 1445500 & 0.186 & 0.036 & & & & \\
\hline 1459500 & 0.360 & 0.000 & 0.380 & 0.000 & 0.358 & 0.000 \\
\hline 1463500 & 0.339 & 0.000 & 0.307 & 0.001 & 0.285 & 0.001 \\
\hline 1514000 & -0.293 & 0.001 & -0.283 & 0.001 & -0.270 & 0.002 \\
\hline 1518000 & -0.330 & 0.000 & -0.384 & 0.000 & -0.353 & 0.000 \\
\hline 1520500 & -0.279 & 0.002 & -0.329 & 0.000 & -0.284 & 0.001 \\
\hline
\end{tabular}


Table F.2, continued

\begin{tabular}{|c|c|c|c|c|c|c|}
\hline \multirow{2}{*}{$\begin{array}{c}\text { Station } \\
\text { Number }\end{array}$} & \multicolumn{2}{|c|}{ 3-Month Lead } & \multicolumn{2}{|c|}{ 6-Month Lead } & \multicolumn{2}{|c|}{ 9-Month Lead } \\
\hline & tau & $\mathrm{p}$-value & tau & $\mathrm{p}$-value & tau & $\mathrm{p}$-value \\
\hline 1531000 & -0.261 & 0.003 & -0.303 & 0.001 & -0.279 & 0.002 \\
\hline 1532000 & -0.360 & 0.000 & -0.261 & 0.003 & -0.329 & 0.000 \\
\hline 1538000 & & & 0.202 & 0.023 & & \\
\hline 1539000 & -0.409 & 0.000 & -0.334 & 0.000 & -0.342 & 0.000 \\
\hline 1548500 & -0.163 & 0.067 & & & -0.194 & 0.029 \\
\hline 1558000 & 0.285 & 0.001 & 0.254 & 0.004 & 0.170 & 0.056 \\
\hline 1560000 & -0.236 & 0.008 & & & -0.225 & 0.011 \\
\hline 1564500 & 0.462 & 0.000 & 0.458 & 0.000 & 0.372 & 0.000 \\
\hline 1570500 & -0.271 & 0.002 & -0.185 & 0.038 & -0.246 & 0.006 \\
\hline 1599000 & 0.240 & 0.007 & 0.245 & 0.006 & 0.175 & 0.049 \\
\hline 1601500 & 0.189 & 0.034 & 0.281 & 0.002 & 0.179 & 0.044 \\
\hline 1604500 & 0.210 & 0.018 & 0.214 & 0.016 & 0.218 & 0.014 \\
\hline 1631000 & 0.153 & 0.086 & 0.273 & 0.002 & & \\
\hline 1632000 & & & 0.268 & 0.003 & 0.183 & 0.040 \\
\hline 1634000 & & & 0.255 & 0.004 & 0.153 & 0.085 \\
\hline 1645000 & -0.355 & 0.000 & -0.393 & 0.000 & -0.359 & 0.000 \\
\hline 1667500 & & & & & 0.156 & 0.079 \\
\hline 2016000 & 0.175 & 0.049 & 0.287 & 0.001 & 0.173 & 0.051 \\
\hline 2035000 & -0.268 & 0.003 & -0.190 & 0.032 & -0.299 & 0.001 \\
\hline 2045500 & & & & & -0.162 & 0.068 \\
\hline 2059500 & & & & & 0.173 & 0.052 \\
\hline 2061500 & & & 0.213 & 0.016 & & \\
\hline 2074500 & -0.301 & 0.001 & -0.376 & 0.000 & -0.341 & 0.000 \\
\hline 2083500 & 0.164 & 0.065 & 0.294 & 0.001 & 0.218 & 0.014 \\
\hline 2091500 & 0.288 & 0.001 & 0.324 & 0.000 & 0.280 & 0.002 \\
\hline 2102000 & & & 0.246 & 0.006 & 0.162 & 0.068 \\
\hline 2116500 & -0.172 & 0.053 & & & & \\
\hline 2118000 & -0.222 & 0.012 & -0.176 & 0.047 & -0.231 & 0.009 \\
\hline 2126000 & 0.184 & 0.038 & 0.235 & 0.008 & & \\
\hline 2131000 & & & 0.195 & 0.028 & & \\
\hline 2132000 & 0.381 & 0.000 & 0.439 & 0.000 & 0.340 & 0.000 \\
\hline 2134500 & 0.279 & 0.002 & 0.376 & 0.000 & 0.274 & 0.002 \\
\hline 2138500 & 0.216 & 0.015 & 0.177 & 0.046 & & \\
\hline 2154500 & & & 0.155 & 0.081 & & \\
\hline 2173500 & 0.324 & 0.000 & 0.306 & 0.001 & 0.288 & 0.001 \\
\hline 2192000 & 0.251 & 0.005 & 0.290 & 0.001 & 0.196 & 0.027 \\
\hline 2198000 & 0.392 & 0.000 & 0.314 & 0.000 & 0.268 & 0.003 \\
\hline 2202500 & 0.406 & 0.000 & 0.415 & 0.000 & 0.354 & 0.000 \\
\hline 2203000 & 0.148 & 0.096 & 0.183 & 0.040 & & \\
\hline 2213500 & 0.223 & 0.012 & 0.163 & 0.067 & & \\
\hline 2217500 & 0.358 & 0.000 & 0.362 & 0.000 & 0.279 & 0.002 \\
\hline 2226000 & 0.379 & 0.000 & 0.361 & 0.000 & 0.284 & 0.001 \\
\hline 2226500 & 0.316 & 0.000 & 0.354 & 0.000 & 0.305 & 0.001 \\
\hline 2228000 & 0.456 & 0.000 & 0.431 & 0.000 & 0.417 & 0.000 \\
\hline 2231000 & 0.341 & 0.000 & 0.425 & 0.000 & 0.461 & 0.000 \\
\hline
\end{tabular}


Table F.2, continued

\begin{tabular}{|c|c|c|c|c|c|c|}
\hline \multirow{2}{*}{$\begin{array}{c}\text { Station } \\
\text { Number }\end{array}$} & \multicolumn{2}{|c|}{ 3-Month Lead } & \multicolumn{2}{|c|}{ 6-Month Lead } & \multicolumn{2}{|c|}{ 9-Month Lead } \\
\hline & tau & p-value & tau & $\mathrm{p}$-value & tau & p-value \\
\hline 2246000 & 0.238 & 0.007 & 0.284 & 0.001 & 0.288 & 0.001 \\
\hline 2296750 & 0.343 & 0.000 & 0.322 & 0.000 & 0.366 & 0.000 \\
\hline 2298830 & 0.214 & 0.016 & 0.200 & 0.025 & 0.202 & 0.023 \\
\hline 2301500 & 0.412 & 0.000 & 0.491 & 0.000 & 0.492 & 0.000 \\
\hline 2303000 & 0.393 & 0.000 & 0.344 & 0.000 & 0.380 & 0.000 \\
\hline 2313000 & 0.417 & 0.000 & 0.525 & 0.000 & 0.481 & 0.000 \\
\hline 2314500 & & & 0.149 & 0.095 & & \\
\hline 2320500 & 0.181 & 0.042 & 0.202 & 0.023 & & \\
\hline 2321500 & 0.301 & 0.001 & 0.378 & 0.000 & 0.416 & 0.000 \\
\hline 2329000 & 0.202 & 0.023 & 0.212 & 0.017 & 0.167 & 0.061 \\
\hline 2331600 & & & & & -0.154 & 0.083 \\
\hline 2333500 & & & -0.180 & 0.043 & & \\
\hline 2337000 & & & 0.169 & 0.057 & & \\
\hline 2339500 & 0.553 & 0.000 & 0.518 & 0.000 & 0.471 & 0.000 \\
\hline 2347500 & 0.436 & 0.000 & 0.427 & 0.000 & 0.336 & 0.000 \\
\hline 2353500 & 0.240 & 0.007 & 0.258 & 0.004 & 0.193 & 0.030 \\
\hline 2358000 & 0.524 & 0.000 & 0.499 & 0.000 & 0.409 & 0.000 \\
\hline 2361000 & 0.258 & 0.004 & 0.319 & 0.000 & 0.216 & 0.015 \\
\hline 2369000 & 0.318 & 0.000 & 0.361 & 0.000 & 0.242 & 0.006 \\
\hline 2371500 & 0.165 & 0.063 & 0.166 & 0.063 & & \\
\hline 2375500 & 0.336 & 0.000 & 0.305 & 0.001 & 0.244 & 0.006 \\
\hline 2387500 & & & 0.146 & 0.100 & & \\
\hline 2392000 & -0.155 & 0.081 & & & & \\
\hline 2398000 & & & & & -0.179 & 0.044 \\
\hline 2436500 & -0.173 & 0.052 & -0.206 & 0.020 & -0.169 & 0.057 \\
\hline 2437000 & -0.365 & 0.000 & -0.327 & 0.000 & -0.298 & 0.001 \\
\hline 2467000 & -0.210 & 0.018 & -0.172 & 0.053 & & \\
\hline 2472500 & -0.254 & 0.004 & -0.255 & 0.004 & -0.174 & 0.050 \\
\hline 2474500 & -0.149 & 0.095 & -0.206 & 0.020 & -0.151 & 0.089 \\
\hline 2486000 & & & -0.198 & 0.026 & -0.150 & 0.091 \\
\hline 2488500 & -0.167 & 0.061 & -0.152 & 0.087 & & \\
\hline 3011020 & & & -0.178 & 0.045 & -0.158 & 0.076 \\
\hline 3015500 & 0.321 & 0.000 & 0.218 & 0.014 & 0.285 & 0.001 \\
\hline 3020500 & 0.234 & 0.008 & & & 0.198 & 0.026 \\
\hline 3034500 & 0.207 & 0.020 & 0.150 & 0.091 & & \\
\hline 3049500 & 0.185 & 0.037 & & & 0.154 & 0.083 \\
\hline 3079000 & 0.286 & 0.001 & 0.289 & 0.001 & 0.253 & 0.004 \\
\hline 3102500 & 0.202 & 0.023 & 0.180 & 0.043 & 0.319 & 0.000 \\
\hline 3106000 & 0.408 & 0.000 & 0.375 & 0.000 & 0.354 & 0.000 \\
\hline 3109500 & 0.335 & 0.000 & 0.223 & 0.013 & 0.298 & 0.001 \\
\hline 3118500 & 0.167 & 0.061 & & & & \\
\hline 3164000 & & & & & -0.245 & 0.006 \\
\hline 3167000 & & & 0.188 & 0.034 & & \\
\hline 3170000 & -0.200 & 0.024 & & & -0.178 & 0.045 \\
\hline 3173000 & & & 0.146 & 0.100 & & \\
\hline
\end{tabular}


Table F.2, continued

\begin{tabular}{|c|c|c|c|c|c|c|}
\hline \multirow{2}{*}{$\begin{array}{c}\text { Station } \\
\text { Number }\end{array}$} & \multicolumn{2}{|c|}{ 3-Month Lead } & \multicolumn{2}{|c|}{ 6-Month Lead } & \multicolumn{2}{|c|}{ 9-Month Lead } \\
\hline & tau & p-value & tau & p-value & tau & p-value \\
\hline 3182500 & $\begin{array}{l}-0.193 \\
\end{array}$ & 0.030 & & & -0.158 & 0.076 \\
\hline 3183500 & -0.172 & 0.053 & & & & \\
\hline 3186500 & -0.199 & 0.025 & & & & \\
\hline 3193000 & 0.297 & 0.001 & 0.203 & 0.022 & 0.239 & 0.007 \\
\hline 3198500 & & & -0.187 & 0.035 & & \\
\hline 3230500 & 0.353 & 0.000 & 0.233 & 0.009 & 0.193 & 0.031 \\
\hline 3234500 & 0.168 & 0.061 & & & & \\
\hline 3253500 & 0.353 & 0.000 & 0.342 & 0.000 & 0.375 & 0.000 \\
\hline 3265000 & 0.206 & 0.022 & 0.161 & 0.072 & 0.178 & 0.047 \\
\hline 3266000 & 0.246 & 0.006 & 0.225 & 0.012 & 0.348 & 0.000 \\
\hline 3281500 & & & -0.184 & 0.041 & & \\
\hline 3294500 & 0.337 & 0.000 & 0.237 & 0.008 & 0.265 & 0.003 \\
\hline 3301500 & -0.264 & 0.003 & -0.148 & 0.098 & -0.217 & 0.015 \\
\hline 3307000 & -0.181 & 0.044 & & & & \\
\hline 3326500 & & & & & 0.198 & 0.026 \\
\hline 3360500 & 0.201 & 0.024 & & & & \\
\hline 3363500 & 0.181 & 0.042 & & & 0.239 & 0.007 \\
\hline 3373500 & 0.360 & 0.000 & 0.289 & 0.001 & 0.325 & 0.000 \\
\hline 3374000 & 0.413 & 0.000 & 0.368 & 0.000 & 0.328 & 0.000 \\
\hline 3377500 & 0.427 & 0.000 & 0.370 & 0.000 & 0.327 & 0.000 \\
\hline 3380500 & -0.177 & 0.047 & -0.188 & 0.034 & -0.147 & 0.099 \\
\hline 3381500 & 0.402 & 0.000 & 0.317 & 0.000 & 0.251 & 0.005 \\
\hline 3434500 & -0.215 & 0.016 & -0.179 & 0.044 & & \\
\hline 3438000 & 0.150 & 0.094 & 0.198 & 0.028 & 0.154 & 0.085 \\
\hline 3465500 & -0.179 & 0.045 & & & -0.189 & 0.033 \\
\hline 3504000 & 0.240 & 0.007 & 0.151 & 0.089 & & \\
\hline 3524000 & -0.202 & 0.023 & & & & \\
\hline 3528000 & -0.183 & 0.039 & -0.155 & 0.081 & & \\
\hline 3540500 & -0.290 & 0.001 & -0.236 & 0.008 & -0.406 & 0.000 \\
\hline 3604000 & -0.233 & 0.009 & -0.174 & 0.051 & -0.184 & 0.039 \\
\hline 4010500 & 0.236 & 0.008 & & & 0.165 & 0.063 \\
\hline 4073500 & & & -0.195 & 0.029 & & \\
\hline 4079000 & 0.311 & 0.001 & 0.233 & 0.009 & 0.182 & 0.043 \\
\hline 4087000 & 0.426 & 0.000 & 0.391 & 0.000 & 0.315 & 0.000 \\
\hline 4105000 & -0.262 & 0.003 & -0.283 & 0.001 & -0.214 & 0.016 \\
\hline 4112500 & -0.276 & 0.002 & -0.338 & 0.000 & -0.216 & 0.015 \\
\hline 4193500 & -0.173 & 0.051 & -0.149 & 0.093 & & \\
\hline 4214500 & -0.237 & 0.008 & -0.288 & 0.001 & -0.228 & 0.010 \\
\hline 4223000 & -0.245 & 0.006 & -0.243 & 0.006 & -0.260 & 0.003 \\
\hline 4234000 & -0.218 & 0.014 & -0.153 & 0.085 & & \\
\hline 4262500 & -0.205 & 0.021 & -0.258 & 0.004 & -0.206 & 0.021 \\
\hline 4264331 & & & & & -0.155 & 0.081 \\
\hline 4275000 & 0.285 & 0.001 & 0.294 & 0.001 & 0.255 & 0.004 \\
\hline 4287000 & & & -0.166 & 0.064 & -0.160 & 0.075 \\
\hline 5053000 & -0.419 & 0.000 & -0.351 & 0.000 & -0.262 & 0.003 \\
\hline
\end{tabular}


Table F.2, continued

\begin{tabular}{|c|c|c|c|c|c|c|}
\hline \multirow{2}{*}{$\begin{array}{c}\text { Station } \\
\text { Number }\end{array}$} & \multicolumn{2}{|c|}{ 3-Month Lead } & \multicolumn{2}{|c|}{ 6-Month Lead } & \multicolumn{2}{|c|}{ 9-Month Lead } \\
\hline & tau & p-value & tau & p-value & tau & p-value \\
\hline 5062000 & -0.431 & 0.000 & -0.418 & 0.000 & -0.371 & 0.000 \\
\hline 5062500 & -0.228 & 0.010 & & & & \\
\hline 5066500 & -0.212 & 0.017 & -0.223 & 0.012 & & \\
\hline 5082500 & -0.327 & 0.000 & -0.309 & 0.000 & -0.245 & 0.006 \\
\hline 5084000 & 0.282 & 0.001 & 0.220 & 0.013 & 0.221 & 0.013 \\
\hline 5131500 & & & 0.182 & 0.041 & & \\
\hline 5133500 & 0.211 & 0.018 & 0.191 & 0.032 & 0.190 & 0.032 \\
\hline 5280000 & -0.237 & 0.008 & -0.262 & 0.003 & -0.218 & 0.014 \\
\hline 5286000 & -0.255 & 0.004 & -0.215 & 0.015 & -0.155 & 0.082 \\
\hline 5288500 & -0.281 & 0.002 & -0.262 & 0.003 & -0.205 & 0.021 \\
\hline 5291000 & 0.219 & 0.014 & 0.263 & 0.003 & 0.215 & 0.015 \\
\hline 5293000 & & & 0.199 & 0.025 & 0.161 & 0.070 \\
\hline 5313500 & -0.237 & 0.008 & -0.246 & 0.006 & -0.198 & 0.026 \\
\hline 5316500 & & & -0.189 & 0.033 & & \\
\hline 5317000 & -0.400 & 0.000 & -0.359 & 0.000 & -0.334 & 0.000 \\
\hline 5330000 & -0.153 & 0.085 & -0.251 & 0.005 & -0.231 & 0.009 \\
\hline 5331000 & -0.202 & 0.023 & -0.210 & 0.018 & -0.205 & 0.021 \\
\hline 5340500 & & & 0.193 & 0.030 & 0.192 & 0.031 \\
\hline 5362000 & -0.237 & 0.008 & -0.276 & 0.002 & -0.251 & 0.005 \\
\hline 5379500 & & & -0.193 & 0.030 & & \\
\hline 5394500 & -0.148 & 0.096 & -0.283 & 0.001 & -0.258 & 0.004 \\
\hline 5399500 & -0.187 & 0.035 & & & & \\
\hline 5408000 & -0.159 & 0.073 & -0.248 & 0.005 & -0.152 & 0.087 \\
\hline 5410490 & & & -0.146 & 0.100 & & \\
\hline 5412500 & 0.260 & 0.003 & 0.323 & 0.000 & 0.266 & 0.003 \\
\hline 5414000 & 0.314 & 0.000 & 0.324 & 0.000 & 0.256 & 0.004 \\
\hline 5418500 & 0.344 & 0.000 & 0.319 & 0.000 & 0.329 & 0.000 \\
\hline 5420500 & -0.291 & 0.001 & -0.383 & 0.000 & -0.305 & 0.001 \\
\hline 5422000 & & & -0.162 & 0.068 & & \\
\hline 5426000 & -0.241 & 0.007 & -0.331 & 0.000 & -0.245 & 0.006 \\
\hline 5434500 & -0.234 & 0.008 & -0.265 & 0.003 & -0.209 & 0.019 \\
\hline 5435500 & -0.224 & 0.012 & -0.307 & 0.001 & -0.205 & 0.021 \\
\hline 5436500 & 0.272 & 0.002 & 0.157 & 0.081 & 0.200 & 0.026 \\
\hline 5438500 & 0.298 & 0.001 & 0.194 & 0.029 & 0.245 & 0.006 \\
\hline 5444000 & & & 0.158 & 0.076 & & \\
\hline 5447500 & -0.151 & 0.089 & -0.196 & 0.027 & & \\
\hline 5451500 & & & -0.150 & 0.092 & -0.185 & 0.037 \\
\hline 5459500 & -0.262 & 0.003 & -0.285 & 0.001 & -0.166 & 0.063 \\
\hline 5465500 & & & -0.149 & 0.095 & & \\
\hline 5470000 & 0.231 & 0.009 & 0.267 & 0.003 & 0.193 & 0.030 \\
\hline 5474000 & & & -0.160 & 0.071 & -0.230 & 0.010 \\
\hline 5476000 & -0.201 & 0.024 & -0.267 & 0.003 & -0.249 & 0.005 \\
\hline 5479000 & & & & & -0.184 & 0.039 \\
\hline 5486490 & & & & & 0.170 & 0.056 \\
\hline 5500000 & -0.260 & 0.003 & -0.178 & 0.045 & -0.229 & 0.010 \\
\hline
\end{tabular}


Table F.2, continued

\begin{tabular}{|c|c|c|c|c|c|c|}
\hline \multirow{2}{*}{$\begin{array}{c}\text { Station } \\
\text { Number }\end{array}$} & \multicolumn{2}{|c|}{ 3-Month Lead } & \multicolumn{2}{|c|}{ 6-Month Lead } & \multicolumn{2}{|c|}{ 9-Month Lead } \\
\hline & tau & $\mathrm{p}$-value & tau & p-value & tau & p-valu \\
\hline 5501000 & -0.203 & 0.022 & -0.150 & 0.091 & & \\
\hline 5520500 & -0.318 & 0.000 & -0.301 & 0.001 & -0.207 & 0.020 \\
\hline 5527500 & -0.254 & 0.004 & -0.307 & 0.001 & -0.255 & 0.004 \\
\hline 5556500 & -0.340 & 0.000 & -0.365 & 0.000 & -0.277 & 0.002 \\
\hline 5592500 & 0.259 & 0.004 & 0.202 & 0.023 & 0.259 & 0.003 \\
\hline 5593000 & 0.204 & 0.022 & & & & \\
\hline 6289000 & 0.169 & 0.057 & 0.191 & 0.032 & 0.263 & 0.003 \\
\hline 6452000 & 0.165 & 0.064 & 0.169 & 0.057 & 0.223 & 0.012 \\
\hline 6478500 & -0.166 & 0.062 & -0.192 & 0.031 & & \\
\hline 6485500 & -0.224 & 0.012 & -0.247 & 0.005 & -0.310 & 0.000 \\
\hline 6600500 & & & -0.146 & 0.100 & & \\
\hline 6620000 & & & & & 0.152 & 0.087 \\
\hline 6630000 & & & & & 0.146 & 0.100 \\
\hline 6635000 & -0.215 & 0.016 & -0.201 & 0.024 & & \\
\hline 6710500 & -0.289 & 0.002 & -0.318 & 0.000 & -0.350 & 0.000 \\
\hline 6800500 & -0.373 & 0.000 & -0.410 & 0.000 & -0.437 & 0.000 \\
\hline 6809500 & -0.237 & 0.008 & -0.153 & 0.086 & & \\
\hline 6810000 & -0.161 & 0.070 & & & & \\
\hline 6889500 & & & 0.179 & 0.045 & & \\
\hline 6892000 & 0.425 & 0.000 & 0.456 & 0.000 & 0.361 & 0.000 \\
\hline 6897500 & 0.398 & 0.000 & 0.433 & 0.000 & 0.446 & 0.000 \\
\hline 6899500 & 0.250 & 0.005 & 0.242 & 0.006 & 0.232 & 0.009 \\
\hline 6908000 & -0.149 & 0.095 & -0.199 & 0.025 & & \\
\hline 6913500 & 0.370 & 0.000 & 0.379 & 0.000 & 0.282 & 0.001 \\
\hline 6933500 & 0.364 & 0.000 & 0.379 & 0.000 & 0.374 & 0.000 \\
\hline 7018500 & -0.236 & 0.008 & -0.208 & 0.019 & -0.172 & 0.053 \\
\hline 7019000 & -0.168 & 0.059 & -0.206 & 0.020 & & \\
\hline 7050500 & -0.166 & 0.063 & -0.197 & 0.026 & & \\
\hline 7056000 & -0.361 & 0.000 & -0.367 & 0.000 & -0.296 & 0.001 \\
\hline 7067000 & -0.149 & 0.095 & & & & \\
\hline 7069500 & -0.146 & 0.100 & & & & \\
\hline 7074000 & -0.313 & 0.000 & -0.205 & 0.021 & -0.180 & 0.043 \\
\hline 7096000 & & & & & 0.203 & 0.022 \\
\hline 7144200 & 0.234 & 0.009 & 0.215 & 0.016 & 0.192 & 0.031 \\
\hline 7146500 & 0.157 & 0.078 & & & & \\
\hline 7147800 & 0.277 & 0.002 & 0.216 & 0.015 & & \\
\hline 7176000 & 0.158 & 0.076 & & & & \\
\hline 7180500 & 0.376 & 0.000 & 0.359 & 0.000 & 0.219 & 0.014 \\
\hline 7183000 & 0.453 & 0.000 & 0.467 & 0.000 & 0.385 & 0.000 \\
\hline 7186000 & 0.364 & 0.000 & 0.394 & 0.000 & 0.360 & 0.000 \\
\hline 7187000 & 0.148 & 0.097 & & & & \\
\hline 7189000 & -0.219 & 0.017 & -0.236 & 0.010 & & \\
\hline 7196500 & & & -0.192 & 0.031 & & \\
\hline 7218000 & 0.174 & 0.053 & 0.178 & 0.048 & 0.163 & 0.070 \\
\hline 7234000 & & & & & 0.158 & 0.076 \\
\hline
\end{tabular}


Table F.2, continued

\begin{tabular}{|c|c|c|c|c|c|c|}
\hline \multirow{2}{*}{$\begin{array}{c}\text { Station } \\
\text { Number }\end{array}$} & \multicolumn{2}{|c|}{ 3-Month Lead } & \multicolumn{2}{|c|}{ 6-Month Lead } & \multicolumn{2}{|c|}{ 9-Month Lead } \\
\hline & tau & p-value & tau & p-value & tau & p-value \\
\hline 7247000 & & & -0.217 & 0.015 & -0.289 & 0.001 \\
\hline 7252000 & -0.406 & 0.000 & -0.378 & 0.000 & -0.273 & 0.002 \\
\hline 7261500 & -0.222 & 0.012 & -0.175 & 0.049 & & \\
\hline 7291000 & 0.151 & 0.089 & 0.172 & 0.053 & & \\
\hline 7331000 & 0.163 & 0.067 & 0.241 & 0.007 & 0.263 & 0.003 \\
\hline 7332500 & 0.193 & 0.030 & 0.214 & 0.016 & 0.234 & 0.008 \\
\hline 7340000 & -0.161 & 0.071 & -0.220 & 0.013 & -0.277 & 0.002 \\
\hline 7340500 & -0.374 & 0.000 & -0.344 & 0.000 & -0.325 & 0.000 \\
\hline 7363500 & -0.210 & 0.018 & -0.169 & 0.057 & -0.197 & 0.027 \\
\hline 8013500 & 0.210 & 0.018 & 0.198 & 0.026 & 0.248 & 0.005 \\
\hline 8041000 & 0.212 & 0.017 & & & & \\
\hline 8055500 & -0.168 & 0.058 & -0.215 & 0.016 & -0.149 & 0.093 \\
\hline 8070000 & 0.394 & 0.000 & 0.302 & 0.001 & 0.267 & 0.003 \\
\hline 8080500 & -0.168 & 0.059 & -0.179 & 0.045 & -0.219 & 0.014 \\
\hline 8082500 & & & 0.149 & 0.093 & & \\
\hline 8085500 & -0.431 & 0.000 & -0.423 & 0.000 & -0.328 & 0.000 \\
\hline 8128000 & -0.313 & 0.000 & -0.280 & 0.002 & -0.251 & 0.005 \\
\hline 8153500 & 0.376 & 0.000 & 0.374 & 0.000 & 0.342 & 0.000 \\
\hline 8158000 & 0.216 & 0.015 & 0.156 & 0.079 & 0.172 & 0.053 \\
\hline 8164000 & 0.329 & 0.000 & 0.424 & 0.000 & 0.349 & 0.000 \\
\hline 8167500 & 0.283 & 0.001 & 0.365 & 0.000 & 0.360 & 0.000 \\
\hline 8171000 & 0.253 & 0.004 & 0.321 & 0.000 & 0.206 & 0.021 \\
\hline 8172000 & 0.182 & 0.041 & 0.211 & 0.017 & 0.254 & 0.004 \\
\hline 8176500 & 0.191 & 0.032 & 0.270 & 0.002 & 0.295 & 0.001 \\
\hline 8189500 & 0.168 & 0.058 & & & 0.213 & 0.018 \\
\hline 8195000 & 0.290 & 0.001 & 0.204 & 0.022 & 0.276 & 0.002 \\
\hline 8276500 & 0.466 & 0.000 & 0.437 & 0.000 & 0.353 & 0.000 \\
\hline 8378500 & 0.431 & 0.000 & 0.414 & 0.000 & 0.296 & 0.001 \\
\hline 9085000 & 0.167 & 0.061 & & & & \\
\hline 9124500 & 0.264 & 0.003 & 0.292 & 0.001 & 0.287 & 0.001 \\
\hline 9310500 & -0.259 & 0.004 & -0.221 & 0.013 & & \\
\hline 9415000 & & & & & 0.174 & 0.050 \\
\hline 9430500 & 0.181 & 0.041 & 0.153 & 0.086 & 0.275 & 0.002 \\
\hline 9448500 & & & -0.159 & 0.073 & & \\
\hline 9471000 & 0.164 & 0.064 & & & 0.164 & 0.065 \\
\hline 9508500 & -0.146 & 0.100 & -0.217 & 0.015 & & \\
\hline 10174500 & & & 0.203 & 0.022 & 0.163 & 0.067 \\
\hline 10296000 & 0.160 & 0.072 & 0.169 & 0.057 & 0.167 & 0.061 \\
\hline 10310000 & 0.236 & 0.008 & 0.234 & 0.008 & 0.159 & 0.073 \\
\hline 10312000 & -0.150 & 0.091 & & & & \\
\hline 11098000 & 0.302 & 0.001 & 0.301 & 0.001 & 0.174 & 0.052 \\
\hline 11152000 & -0.182 & 0.041 & -0.200 & 0.024 & -0.158 & 0.076 \\
\hline 11160500 & -0.341 & 0.000 & -0.286 & 0.001 & -0.290 & 0.001 \\
\hline 11237500 & 0.243 & 0.007 & 0.252 & 0.005 & 0.202 & 0.024 \\
\hline 11381500 & -0.265 & 0.003 & -0.245 & 0.006 & -0.327 & 0.000 \\
\hline
\end{tabular}


Table F.2, continued

\begin{tabular}{|c|c|c|c|c|c|c|}
\hline \multirow{2}{*}{$\begin{array}{c}\text { Station } \\
\text { Number }\end{array}$} & \multicolumn{2}{|c|}{ 3-Month Lead } & \multicolumn{2}{|c|}{ 6-Month Lead } & \multicolumn{2}{|c|}{ 9-Month Lead } \\
\hline & tau & p-value & tau & p-value & tau & p-value \\
\hline 11383500 & -0.238 & 0.007 & -0.223 & 0.012 & -0.274 & 0.002 \\
\hline 11402000 & -0.148 & 0.096 & -0.157 & 0.077 & -0.206 & 0.020 \\
\hline 11413000 & -0.206 & 0.021 & -0.168 & 0.061 & & \\
\hline 11425500 & -0.206 & 0.021 & -0.154 & 0.084 & -0.253 & 0.004 \\
\hline 11525500 & -0.389 & 0.000 & -0.488 & 0.000 & -0.459 & 0.000 \\
\hline 12020000 & 0.190 & 0.032 & & & & \\
\hline 12035000 & & & & & 0.157 & 0.077 \\
\hline 12039500 & 0.353 & 0.000 & 0.322 & 0.000 & 0.312 & 0.000 \\
\hline 12056500 & 0.166 & 0.063 & & & & \\
\hline 12134500 & 0.292 & 0.001 & 0.329 & 0.000 & 0.360 & 0.000 \\
\hline 12186000 & 0.448 & 0.000 & 0.385 & 0.000 & 0.314 & 0.000 \\
\hline 12189500 & 0.409 & 0.000 & 0.352 & 0.000 & 0.290 & 0.001 \\
\hline 12306500 & 0.231 & 0.009 & 0.235 & 0.008 & 0.228 & 0.010 \\
\hline 12330000 & -0.299 & 0.001 & -0.258 & 0.004 & & \\
\hline 12332000 & & & & & 0.183 & 0.040 \\
\hline 12358500 & -0.180 & 0.043 & -0.233 & 0.009 & -0.262 & 0.003 \\
\hline 12401500 & 0.148 & 0.096 & 0.150 & 0.091 & & \\
\hline 12409000 & -0.211 & 0.018 & -0.209 & 0.019 & -0.159 & 0.073 \\
\hline 12413000 & -0.161 & 0.071 & & & & \\
\hline 12422500 & -0.164 & 0.065 & & & & \\
\hline 12451000 & 0.232 & 0.009 & 0.293 & 0.001 & 0.293 & 0.001 \\
\hline 12459000 & & & 0.168 & 0.058 & 0.157 & 0.077 \\
\hline 13037500 & 0.224 & 0.012 & 0.232 & 0.009 & 0.246 & 0.006 \\
\hline 13082500 & -0.250 & 0.005 & -0.338 & 0.000 & -0.275 & 0.002 \\
\hline 13120500 & & & 0.159 & 0.073 & 0.199 & 0.025 \\
\hline 13185000 & -0.312 & 0.000 & -0.267 & 0.003 & -0.211 & 0.018 \\
\hline 13269000 & & & 0.201 & 0.024 & 0.182 & 0.041 \\
\hline 13313000 & -0.174 & 0.050 & & & & \\
\hline 13317000 & -0.215 & 0.016 & & & & \\
\hline 13342500 & -0.192 & 0.031 & -0.252 & 0.005 & -0.261 & 0.003 \\
\hline 14020000 & -0.188 & 0.034 & & & & \\
\hline 14046500 & -0.343 & 0.000 & -0.359 & 0.000 & -0.344 & 0.000 \\
\hline 14137000 & -0.161 & 0.070 & -0.189 & 0.034 & -0.217 & 0.015 \\
\hline 14325000 & 0.201 & 0.024 & & & & \\
\hline 14359000 & 0.185 & 0.038 & 0.166 & 0.063 & 0.209 & 0.019 \\
\hline 14362000 & 0.168 & 0.059 & & & & \\
\hline
\end{tabular}




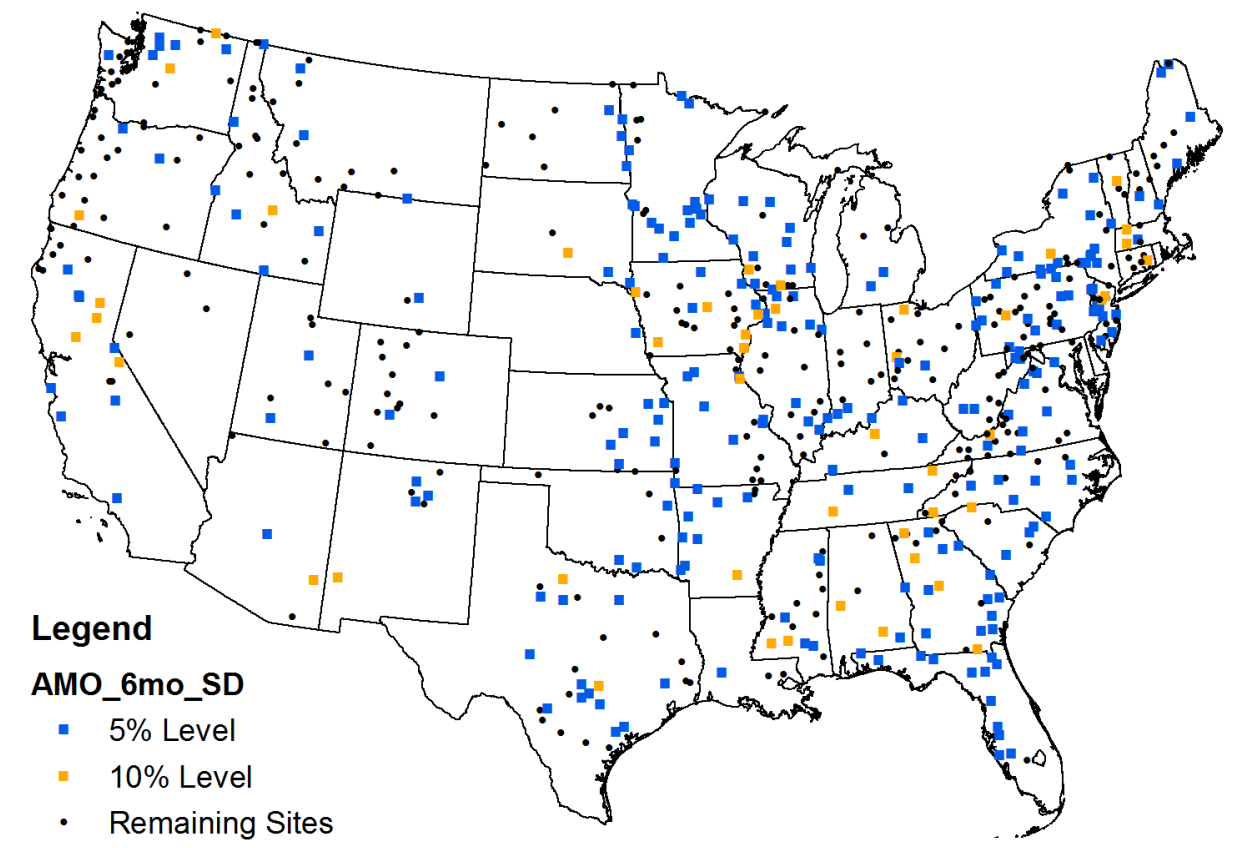

Figure F.1 Locations of sites with significant Kendall's tau correlation between 10-year moving standard deviation of log-transformed flood flows and 3-month average AMO anomalies with 6-month lead.

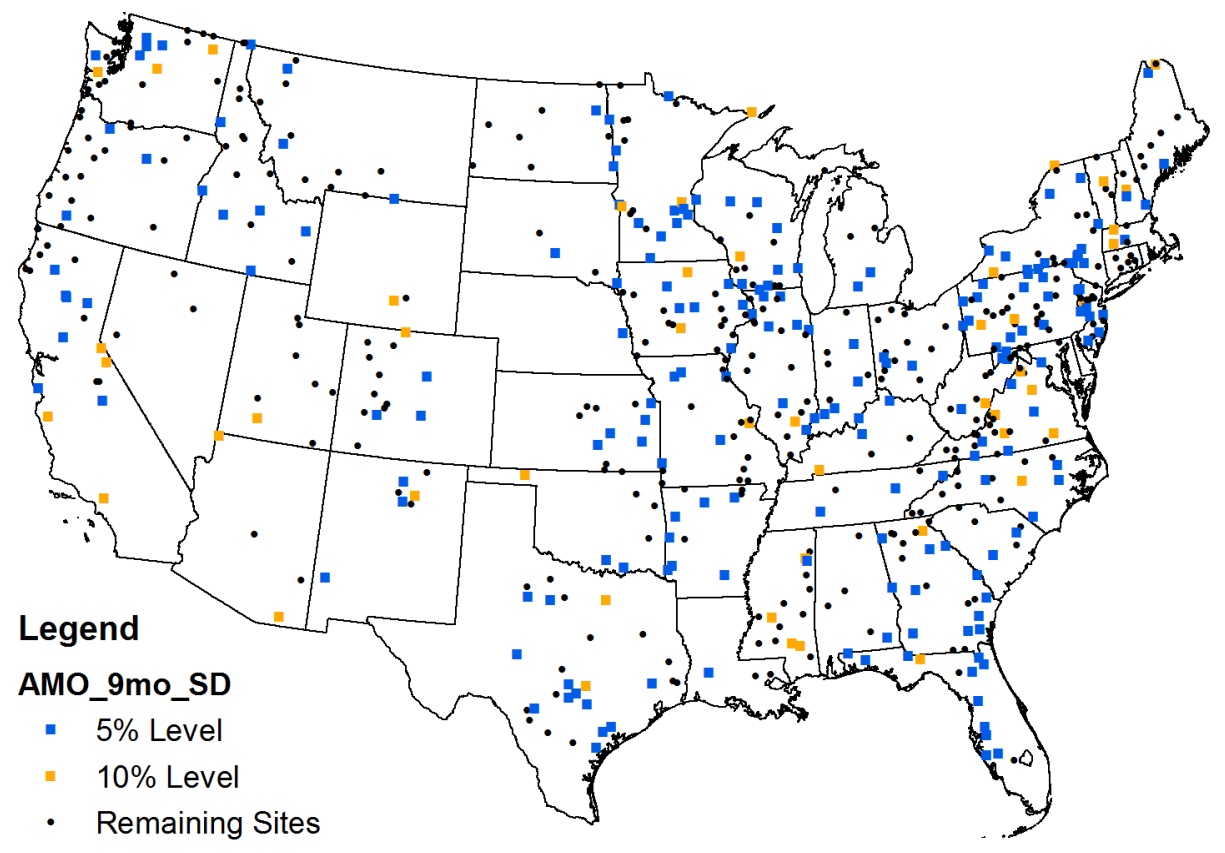

Figure F.2 Locations of sites with significant Kendall's tau correlation between 10-year moving standard deviation of log-transformed flood flows and 3-month average AMO anomalies with 9-month lead. 


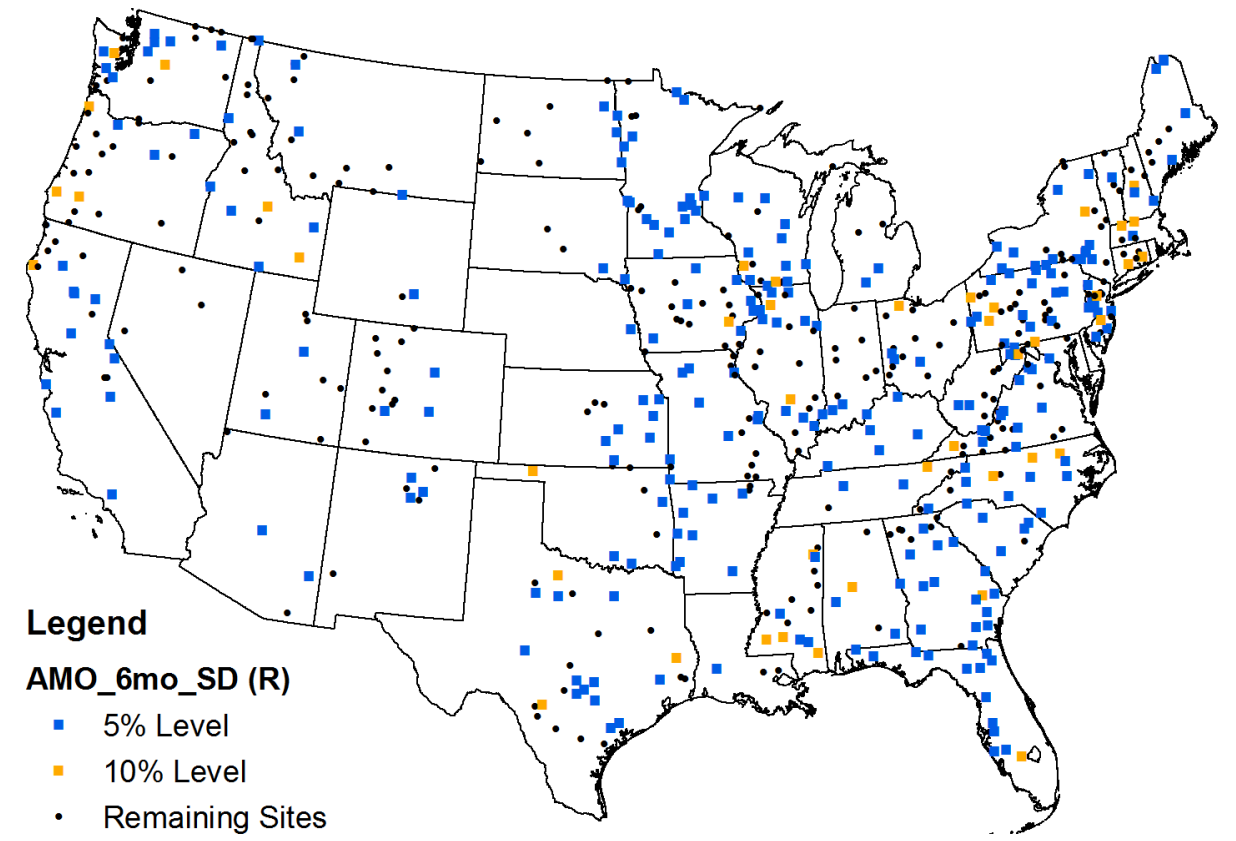

Figure F.3 Locations of sites with significant Pearson's r correlation between 10-year moving standard deviation of log-transformed flood flows and 3-month average AMO anomalies with 6-month lead.

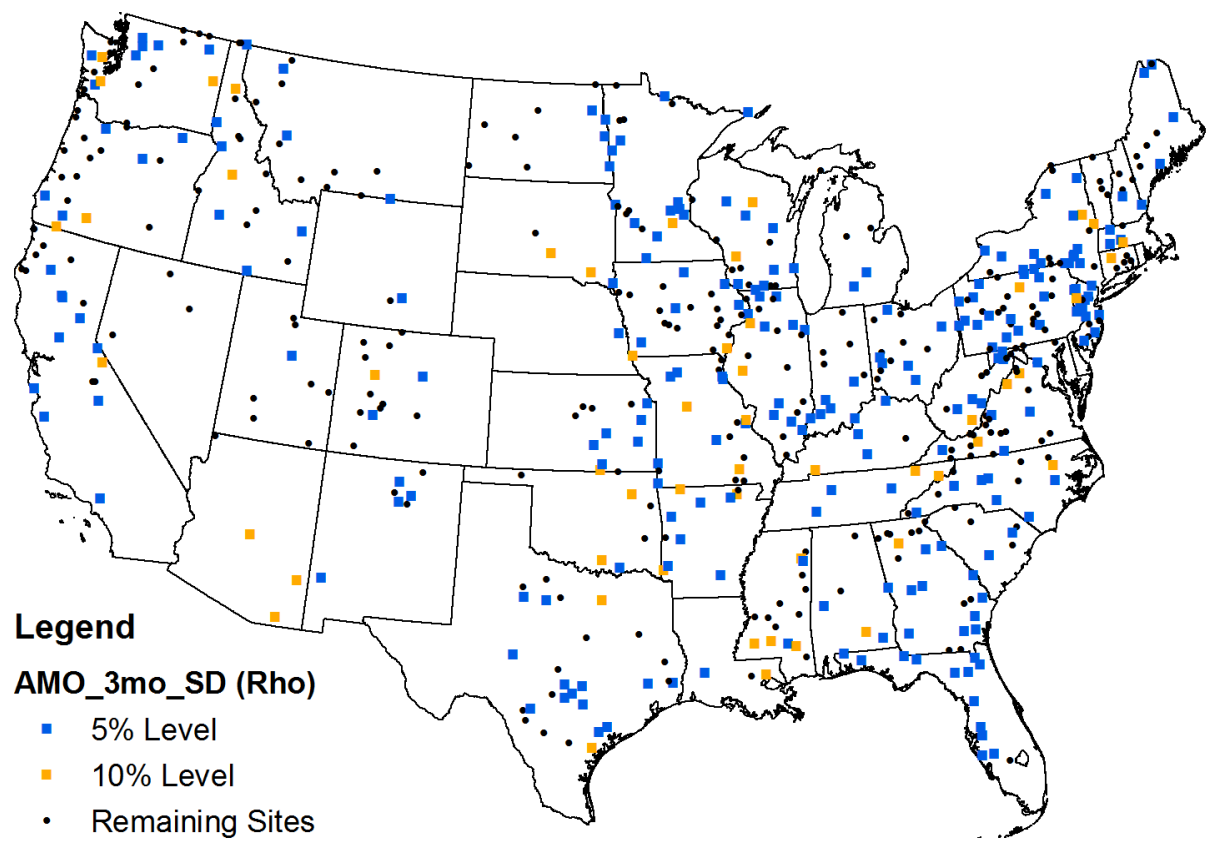

Figure F.4 Locations of sites with significant Spearman's rho correlation between 10-year moving standard deviation of log-transformed flood flows and 3-month average AMO anomalies with 3-month lead. 


\section{F.2 MEI Correlation Results}

Table F.3

Results of Kendall's tau analyses (significant at 10\% level) between 10-year moving standard deviation of log-transformed flood flows and 3-month average MEI anomalies with 3-, 6-, and 9-month leads.

\begin{tabular}{|c|c|c|c|c|c|c|}
\hline \multirow{2}{*}{$\begin{array}{c}\text { Station } \\
\text { Number }\end{array}$} & \multicolumn{2}{|c|}{ 3-Month Lead } & \multicolumn{2}{|c|}{ 6-Month Lead } & \multicolumn{2}{|c|}{ 9-Month Lead } \\
\hline & tau & p-value & tau & $\mathrm{p}$-value & tau & $\mathrm{p}$-value \\
\hline 21013500 & & & & & $2-0.150$ & 0.091 \\
\hline 1055000 & & & & & -0.154 & 0.083 \\
\hline 1064500 & & & & & -0.164 & 0.065 \\
\hline 1127500 & & & & & 0.186 & 0.038 \\
\hline 1137500 & & & & & -0.155 & 0.084 \\
\hline 1169000 & & & -0.169 & 0.060 & -0.170 & 0.058 \\
\hline 1181000 & & & -0.181 & 0.044 & -0.182 & 0.043 \\
\hline 1188000 & -0.232 & 0.010 & -0.219 & 0.014 & -0.198 & 0.028 \\
\hline 1196500 & -0.158 & 0.077 & -0.178 & 0.047 & & \\
\hline 1334500 & & & & & -0.179 & 0.044 \\
\hline 1372500 & & & -0.149 & 0.093 & -0.163 & 0.066 \\
\hline 1381500 & -0.251 & 0.005 & -0.215 & 0.016 & -0.227 & 0.011 \\
\hline 1387500 & -0.162 & 0.069 & & & & \\
\hline 1397500 & -0.147 & 0.099 & & & & \\
\hline 1398500 & -0.181 & 0.042 & -0.165 & 0.063 & -0.176 & 0.048 \\
\hline 1399500 & -0.174 & 0.050 & -0.158 & 0.075 & -0.152 & 0.087 \\
\hline 1408500 & 0.154 & 0.084 & 0.173 & 0.052 & 0.249 & 0.005 \\
\hline 1410000 & 0.148 & 0.096 & & & 0.212 & 0.017 \\
\hline 1439500 & -0.228 & 0.010 & -0.219 & 0.014 & -0.216 & 0.015 \\
\hline 1440000 & & & & & -0.154 & 0.084 \\
\hline 1518000 & & & & & -0.199 & 0.025 \\
\hline 1520500 & & & & & -0.172 & 0.053 \\
\hline 1531000 & & & & & -0.183 & 0.040 \\
\hline 1541500 & & & & & -0.159 & 0.074 \\
\hline 1543500 & -0.186 & 0.036 & -0.207 & 0.020 & -0.268 & 0.003 \\
\hline 1560000 & & & & & 0.146 & 0.100 \\
\hline 1580000 & 0.231 & 0.009 & 0.152 & 0.087 & & \\
\hline 1601500 & & & & & 0.196 & 0.027 \\
\hline 1634000 & & & & & 0.147 & 0.097 \\
\hline 2018000 & & & & & 0.183 & 0.040 \\
\hline 2051500 & & & & & 0.157 & 0.077 \\
\hline 2055000 & 0.156 & 0.079 & 0.161 & 0.071 & 0.202 & 0.023 \\
\hline 2059500 & 0.232 & 0.009 & & & & \\
\hline 2061500 & & & & & 0.173 & 0.051 \\
\hline 2074500 & 0.149 & 0.095 & & & & \\
\hline 2083000 & & & & & 0.188 & 0.034 \\
\hline 2083500 & & & & & 0.173 & 0.051 \\
\hline 2085500 & & & 0.202 & 0.023 & 0.199 & 0.025 \\
\hline
\end{tabular}


Table F.3, continued

\begin{tabular}{|c|c|c|c|c|c|c|}
\hline \multirow{2}{*}{$\begin{array}{c}\text { Station } \\
\text { Number }\end{array}$} & \multicolumn{2}{|c|}{ 3-Month Lead } & \multicolumn{2}{|c|}{ 6-Month Lead } & \multicolumn{2}{|c|}{ 9-Month Lead } \\
\hline & tau & p-value & tau & $\mathrm{p}$-value & tau & p-value \\
\hline 2102000 & & & 0.165 & 0.063 & 0.228 & 0.010 \\
\hline 2131000 & & & 0.155 & 0.082 & & \\
\hline 2134500 & & & & & 0.183 & 0.040 \\
\hline 2138500 & & & 0.162 & 0.069 & & \\
\hline 2154500 & & & & & 0.186 & 0.036 \\
\hline 2156500 & 0.195 & 0.030 & 0.214 & 0.017 & 0.276 & 0.002 \\
\hline 2213500 & & & -0.152 & 0.087 & & \\
\hline 2320500 & -0.181 & 0.042 & -0.181 & 0.042 & -0.253 & 0.004 \\
\hline 2329000 & -0.180 & 0.043 & -0.186 & 0.036 & -0.247 & 0.005 \\
\hline 2333500 & & & -0.214 & 0.016 & & \\
\hline 2361000 & & & & & 0.199 & 0.025 \\
\hline 2431000 & & & & & 0.228 & 0.010 \\
\hline 2474500 & & & & & -0.212 & 0.017 \\
\hline 2479000 & & & & & -0.267 & 0.003 \\
\hline 2486000 & & & & & -0.189 & 0.034 \\
\hline 3010500 & -0.188 & 0.035 & -0.212 & 0.017 & -0.233 & 0.009 \\
\hline 3011020 & -0.179 & 0.045 & -0.212 & 0.017 & -0.274 & 0.002 \\
\hline 3015500 & -0.154 & 0.084 & -0.185 & 0.037 & -0.261 & 0.003 \\
\hline 3020500 & & & & & -0.179 & 0.044 \\
\hline 3118500 & & & & & -0.148 & 0.096 \\
\hline 3164000 & & & 0.166 & 0.062 & & \\
\hline 3167000 & & & 0.211 & 0.017 & 0.221 & 0.013 \\
\hline 3175500 & & & & & 0.161 & 0.070 \\
\hline 3182500 & & & & & 0.231 & 0.009 \\
\hline 3183500 & & & & & 0.152 & 0.087 \\
\hline 3186500 & & & & & 0.240 & 0.007 \\
\hline 3193000 & & & & & -0.229 & 0.010 \\
\hline 3198500 & & & & & -0.196 & 0.027 \\
\hline 3234500 & & & -0.154 & 0.087 & -0.255 & 0.004 \\
\hline 3269500 & & & -0.160 & 0.093 & -0.206 & 0.030 \\
\hline 3272000 & & & -0.149 & 0.097 & -0.227 & 0.011 \\
\hline 3274000 & -0.163 & 0.069 & -0.174 & 0.053 & -0.191 & 0.034 \\
\hline 3275000 & -0.160 & 0.071 & -0.219 & 0.014 & -0.189 & 0.034 \\
\hline 3281500 & & & & & -0.182 & 0.042 \\
\hline 3294500 & -0.176 & 0.050 & -0.158 & 0.077 & -0.199 & 0.027 \\
\hline 3301500 & & & & & 0.207 & 0.021 \\
\hline 3307000 & & & -0.162 & 0.071 & & \\
\hline 3345500 & & & & & -0.194 & 0.029 \\
\hline 3360500 & & & & & -0.152 & 0.087 \\
\hline 3363500 & -0.216 & 0.015 & -0.234 & 0.008 & -0.246 & 0.006 \\
\hline 3379500 & & & & & -0.171 & 0.055 \\
\hline 3438000 & & & 0.174 & 0.053 & 0.235 & 0.009 \\
\hline 3473000 & & & 0.180 & 0.043 & 0.201 & 0.024 \\
\hline 3524000 & 0.150 & 0.091 & 0.184 & 0.038 & 0.160 & 0.072 \\
\hline 3540500 & & & 0.159 & 0.073 & 0.147 & 0.099 \\
\hline
\end{tabular}


Table F.3, continued

\begin{tabular}{|c|c|c|c|c|c|c|}
\hline \multirow{2}{*}{$\begin{array}{c}\text { Station } \\
\text { Number }\end{array}$} & \multicolumn{2}{|c|}{ 3-Month Lead } & \multicolumn{2}{|c|}{ 6-Month Lead } & \multicolumn{2}{|c|}{ 9-Month Lead } \\
\hline & tau & $\mathrm{p}$-value & tau & $\mathrm{p}$-value & tau & $\mathrm{p}$-value \\
\hline 3550000 & 0.155 & 0.082 & 0.225 & 0.011 & 0.228 & 0.010 \\
\hline 4105000 & & & & & -0.161 & 0.071 \\
\hline 4223000 & & & -0.163 & 0.066 & -0.168 & 0.058 \\
\hline 4262500 & & & & & -0.203 & 0.022 \\
\hline 5053000 & & & & & 0.188 & 0.035 \\
\hline 5062500 & 0.205 & 0.021 & 0.215 & 0.016 & 0.302 & 0.001 \\
\hline 5082500 & & & & & 0.198 & 0.026 \\
\hline 5112000 & 0.240 & 0.007 & 0.232 & 0.009 & 0.303 & 0.001 \\
\hline 5131500 & & & & & 0.166 & 0.063 \\
\hline 5133500 & & & 0.166 & 0.062 & 0.195 & 0.028 \\
\hline 5286000 & 0.164 & 0.065 & & & & \\
\hline 5288500 & 0.168 & 0.058 & 0.156 & 0.079 & & \\
\hline 5293000 & & & & & 0.151 & 0.090 \\
\hline 5316500 & & & -0.147 & 0.099 & -0.183 & 0.040 \\
\hline 5394500 & & & -0.167 & 0.061 & -0.238 & 0.007 \\
\hline 5399500 & 0.168 & 0.058 & 0.224 & 0.012 & 0.277 & 0.002 \\
\hline 5412500 & 0.158 & 0.075 & 0.188 & 0.035 & 0.285 & 0.001 \\
\hline 5418500 & & & & & 0.150 & 0.092 \\
\hline 5436500 & & & & & -0.226 & 0.012 \\
\hline 5593000 & & & & & -0.232 & 0.009 \\
\hline 5597000 & & & -0.153 & 0.086 & -0.153 & 0.085 \\
\hline 6191500 & 0.159 & 0.074 & 0.179 & 0.045 & 0.190 & 0.033 \\
\hline 6192500 & 0.177 & 0.047 & 0.199 & 0.025 & 0.192 & 0.031 \\
\hline 6214500 & 0.159 & 0.074 & 0.199 & 0.025 & 0.194 & 0.029 \\
\hline 6289000 & & & 0.148 & 0.096 & 0.148 & 0.096 \\
\hline 6335500 & & & & & 0.249 & 0.005 \\
\hline 6337000 & & & & & 0.245 & 0.006 \\
\hline 6340500 & & & & & 0.210 & 0.018 \\
\hline 6478500 & & & 0.167 & 0.061 & 0.167 & 0.061 \\
\hline 6600500 & & & -0.149 & 0.093 & -0.220 & 0.013 \\
\hline 6606600 & & & -0.162 & 0.069 & -0.173 & 0.052 \\
\hline 6620000 & 0.153 & 0.085 & 0.148 & 0.096 & 0.171 & 0.055 \\
\hline 6630000 & 0.179 & 0.044 & 0.147 & 0.099 & 0.147 & 0.099 \\
\hline 6635000 & 0.176 & 0.047 & 0.194 & 0.029 & 0.169 & 0.057 \\
\hline 6864500 & 0.214 & 0.016 & 0.174 & 0.050 & 0.186 & 0.036 \\
\hline 6889500 & -0.146 & 0.100 & -0.172 & 0.053 & -0.172 & 0.053 \\
\hline 7013000 & & & & & 0.147 & 0.099 \\
\hline 7018500 & 0.149 & 0.093 & & & 0.186 & 0.036 \\
\hline 7061500 & & & & & 0.177 & 0.046 \\
\hline 7096000 & 0.204 & 0.022 & 0.183 & 0.039 & 0.206 & 0.021 \\
\hline 7203000 & 0.288 & 0.002 & 0.180 & 0.053 & & \\
\hline 7247000 & & & & & -0.216 & 0.015 \\
\hline 7340000 & & & & & -0.179 & 0.045 \\
\hline 7375500 & & & -0.167 & 0.060 & -0.241 & 0.007 \\
\hline 7378500 & & & & & -0.157 & 0.078 \\
\hline
\end{tabular}


Table F.3, continued

\begin{tabular}{|c|c|c|c|c|c|c|}
\hline \multirow{2}{*}{$\begin{array}{c}\text { Station } \\
\text { Number }\end{array}$} & \multicolumn{2}{|c|}{ 3-Month Lead } & \multicolumn{2}{|c|}{ 6-Month Lead } & \multicolumn{2}{|c|}{ 9-Month Lead } \\
\hline & tau & $\mathrm{p}$-value & tau & $\mathrm{p}$-value & tau & $\mathrm{p}$-value \\
\hline 8032000 & & & & & -0.150 & 0.091 \\
\hline 8033500 & -0.157 & 0.077 & -0.194 & 0.029 & -0.251 & 0.005 \\
\hline 8041000 & -0.227 & 0.011 & -0.231 & 0.009 & -0.324 & 0.000 \\
\hline 8041500 & -0.158 & 0.075 & -0.159 & 0.073 & -0.246 & 0.006 \\
\hline 8070000 & -0.183 & 0.039 & -0.160 & 0.071 & -0.171 & 0.055 \\
\hline 8082000 & & & & & 0.176 & 0.047 \\
\hline 8095000 & & & & & 0.214 & 0.016 \\
\hline 8167000 & 0.193 & 0.030 & & & & \\
\hline 8167500 & & & & & 0.185 & 0.037 \\
\hline 9110000 & 0.185 & 0.038 & 0.153 & 0.086 & 0.166 & 0.062 \\
\hline 9112500 & 0.195 & 0.028 & 0.176 & 0.047 & 0.199 & 0.025 \\
\hline 9119000 & & & & & 0.162 & 0.069 \\
\hline 9132500 & 0.178 & 0.046 & 0.174 & 0.050 & 0.244 & 0.006 \\
\hline 9147500 & 0.184 & 0.039 & & & 0.147 & 0.099 \\
\hline 9180500 & 0.183 & 0.039 & 0.166 & 0.062 & 0.241 & 0.007 \\
\hline 9251000 & 0.167 & 0.061 & 0.157 & 0.078 & 0.242 & 0.006 \\
\hline 9304500 & 0.252 & 0.005 & 0.253 & 0.004 & 0.323 & 0.000 \\
\hline 9310500 & 0.188 & 0.035 & 0.195 & 0.028 & 0.270 & 0.002 \\
\hline 9315000 & 0.184 & 0.039 & 0.188 & 0.035 & 0.190 & 0.033 \\
\hline 9448500 & 0.197 & 0.027 & & & & \\
\hline 9471000 & 0.189 & 0.034 & & & & \\
\hline 10128500 & 0.183 & 0.047 & 0.187 & 0.043 & 0.196 & 0.033 \\
\hline 10131000 & 0.201 & 0.024 & 0.207 & 0.020 & 0.268 & 0.003 \\
\hline 10234500 & 0.193 & 0.030 & 0.190 & 0.033 & 0.249 & 0.005 \\
\hline 10312000 & & & & & 0.167 & 0.060 \\
\hline 10329500 & 0.154 & 0.084 & & & & \\
\hline 10396000 & & & & & 0.160 & 0.072 \\
\hline 11266500 & & & & & -0.155 & 0.081 \\
\hline 11383500 & & & 0.149 & 0.093 & 0.164 & 0.065 \\
\hline 11402000 & 0.165 & 0.063 & 0.194 & 0.029 & 0.175 & 0.049 \\
\hline 11413000 & 0.155 & 0.084 & & & & \\
\hline 11425500 & & & 0.193 & 0.030 & 0.167 & 0.060 \\
\hline 11478500 & 0.224 & 0.012 & 0.275 & 0.002 & & \\
\hline 11501000 & & & & & 0.238 & 0.007 \\
\hline 11530000 & 0.167 & 0.060 & 0.173 & 0.052 & & \\
\hline 12010000 & & & 0.171 & 0.054 & & \\
\hline 12020000 & 0.166 & 0.062 & 0.216 & 0.015 & & \\
\hline 12027500 & & & 0.250 & 0.005 & & \\
\hline 12039500 & & & 0.173 & 0.051 & & \\
\hline 12048000 & 0.245 & 0.006 & 0.205 & 0.021 & & \\
\hline 12054000 & 0.166 & 0.062 & 0.162 & 0.068 & & \\
\hline 12189500 & & & 0.155 & 0.081 & & \\
\hline 12306500 & & & & & 0.153 & 0.086 \\
\hline 12413000 & & & & & 0.212 & 0.017 \\
\hline 12459000 & & & & & 0.176 & 0.047 \\
\hline
\end{tabular}


Table F.3, continued

\begin{tabular}{|c|cc|cc|cc|}
\hline Station & \multicolumn{2}{|c|}{ 3-Month Lead } & \multicolumn{2}{|c|}{ 6-Month Lead } & \multicolumn{2}{c|}{ 9-Month Lead } \\
Number & tau & p-value & tau & p-value & tau & p-value \\
\hline \hline 13185000 & & & & & 0.215 & $\mathbf{0 . 0 1 5}$ \\
13269000 & & & & & 0.272 & $\mathbf{0 . 0 0 2}$ \\
13313000 & & & & & 0.188 & $\mathbf{0 . 0 3 5}$ \\
13317000 & & & & & 0.195 & $\mathbf{0 . 0 2 8}$ \\
14301000 & & & 0.208 & $\mathbf{0 . 0 1 9}$ & & \\
14301500 & 0.147 & 0.099 & 0.195 & $\mathbf{0 . 0 2 8}$ & & \\
\hline
\end{tabular}

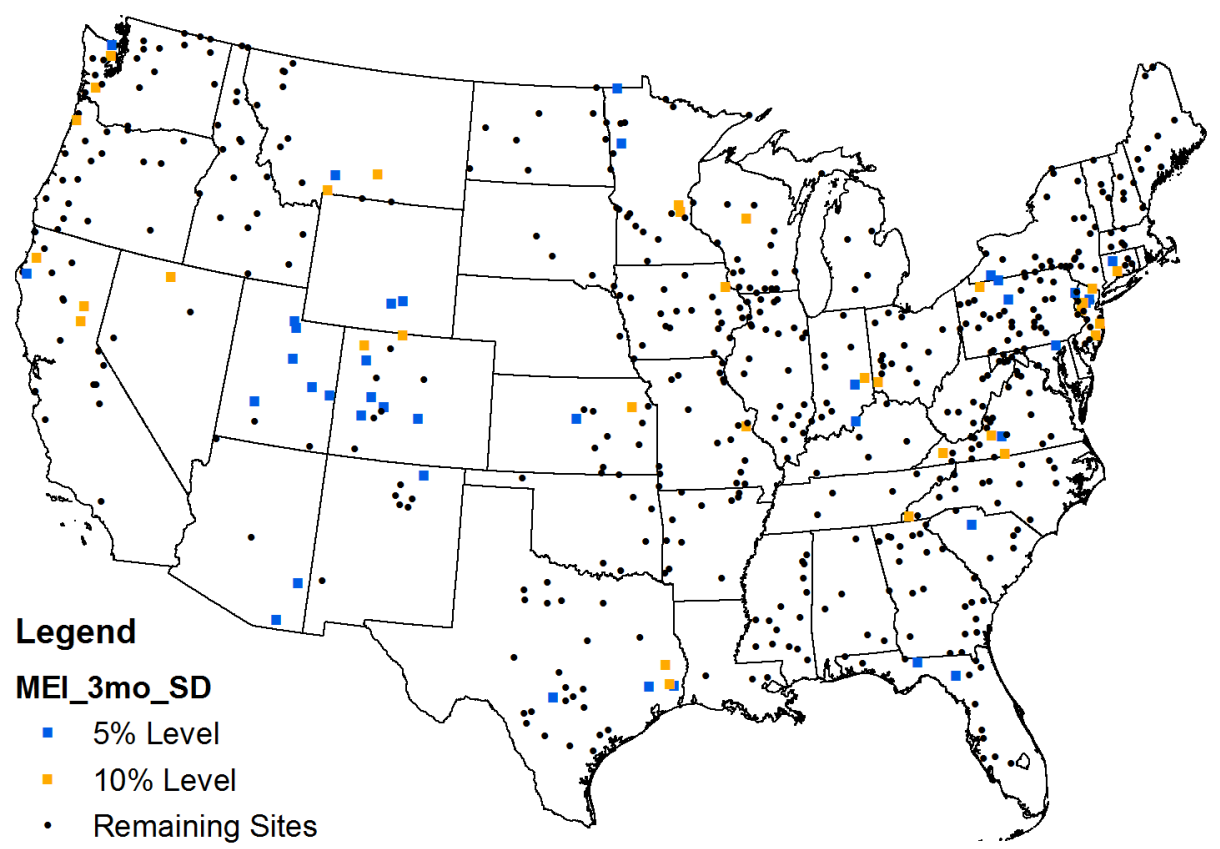

Figure F-5 Locations of sites with significant Kendall's tau correlation between 10-year moving standard deviation of log-transformed flood flows and 3-month average MEI anomalies with 3-month lead. 


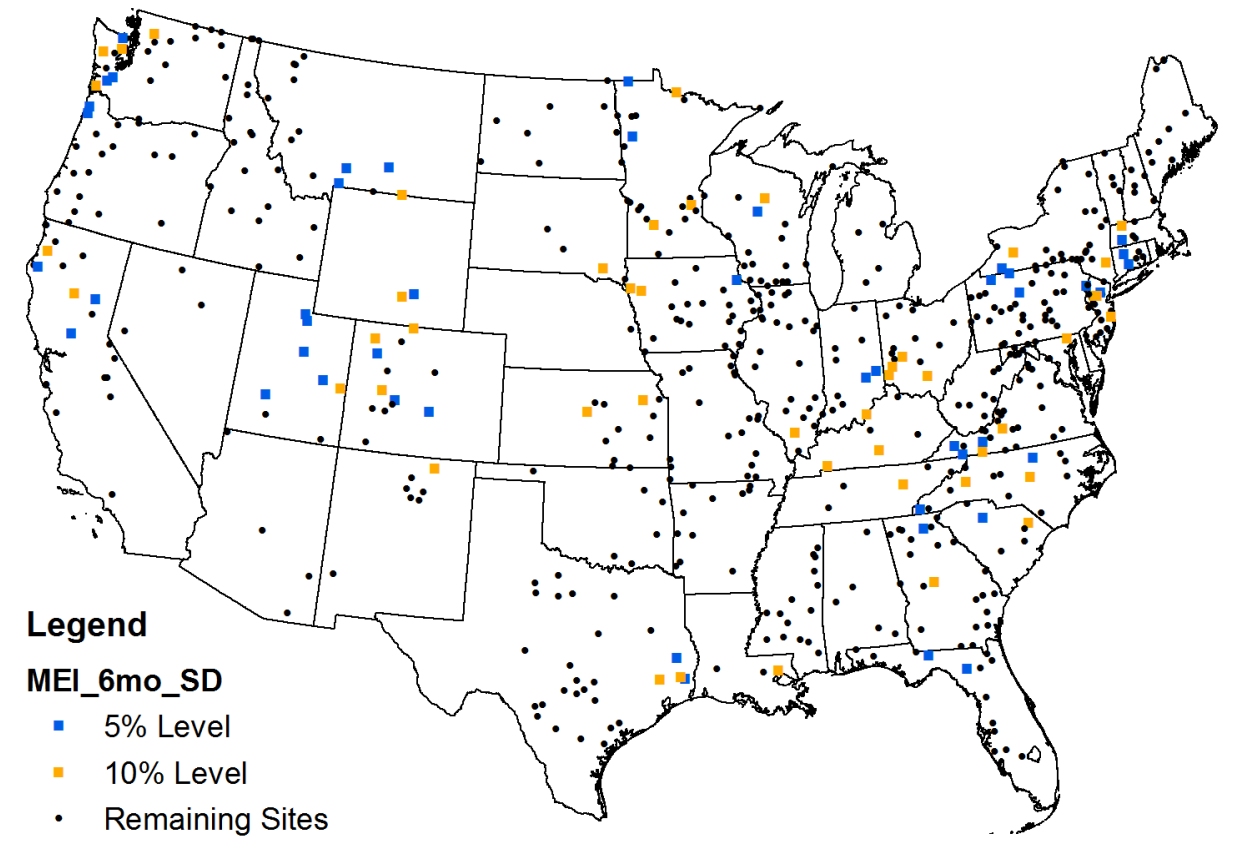

Figure F-6 Locations of sites with significant Kendall's tau correlation between 10-year moving standard deviation of log-transformed flood flows and 3-month average MEI anomalies with 6-month lead.

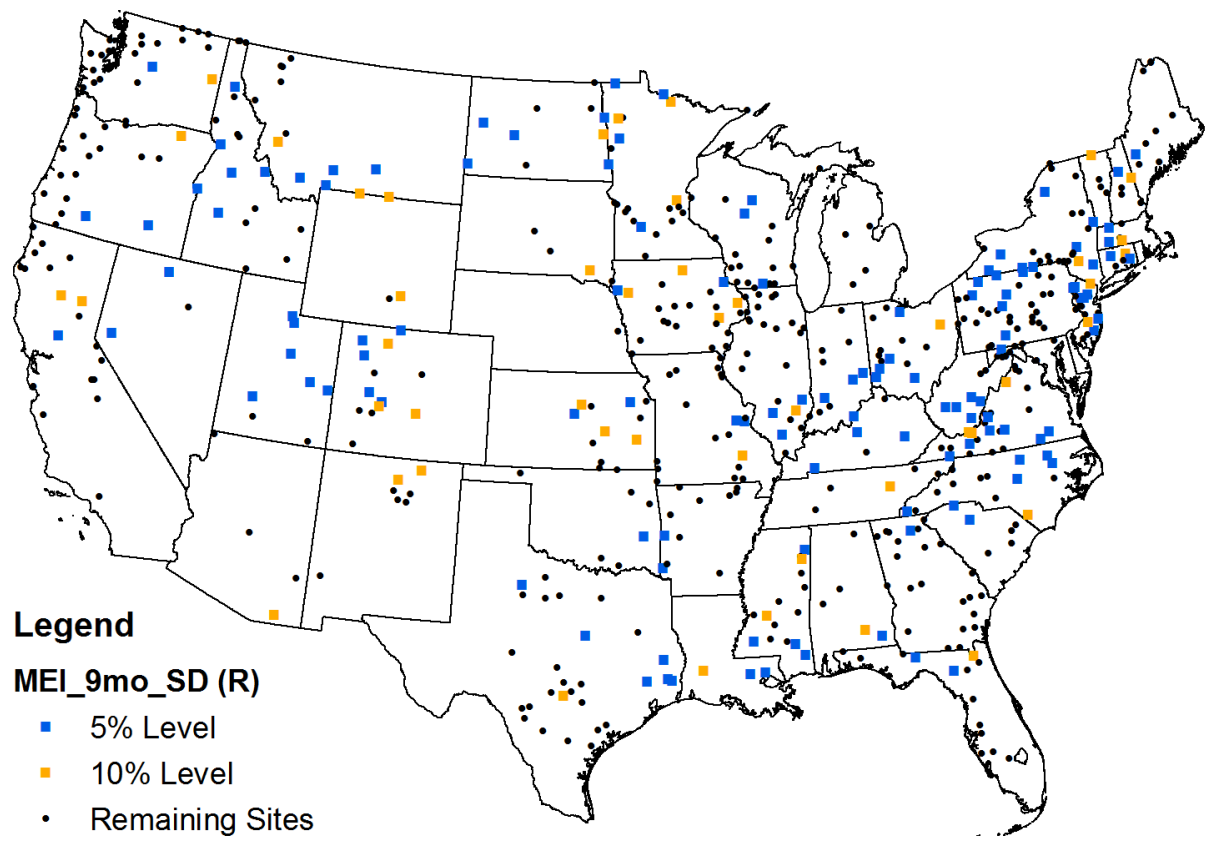

Figure F.7 Locations of sites with significant Pearson's r correlation between 10-year moving standard deviation of log-transformed flood flows and 3-month average MEI anomalies with 9-month lead. 


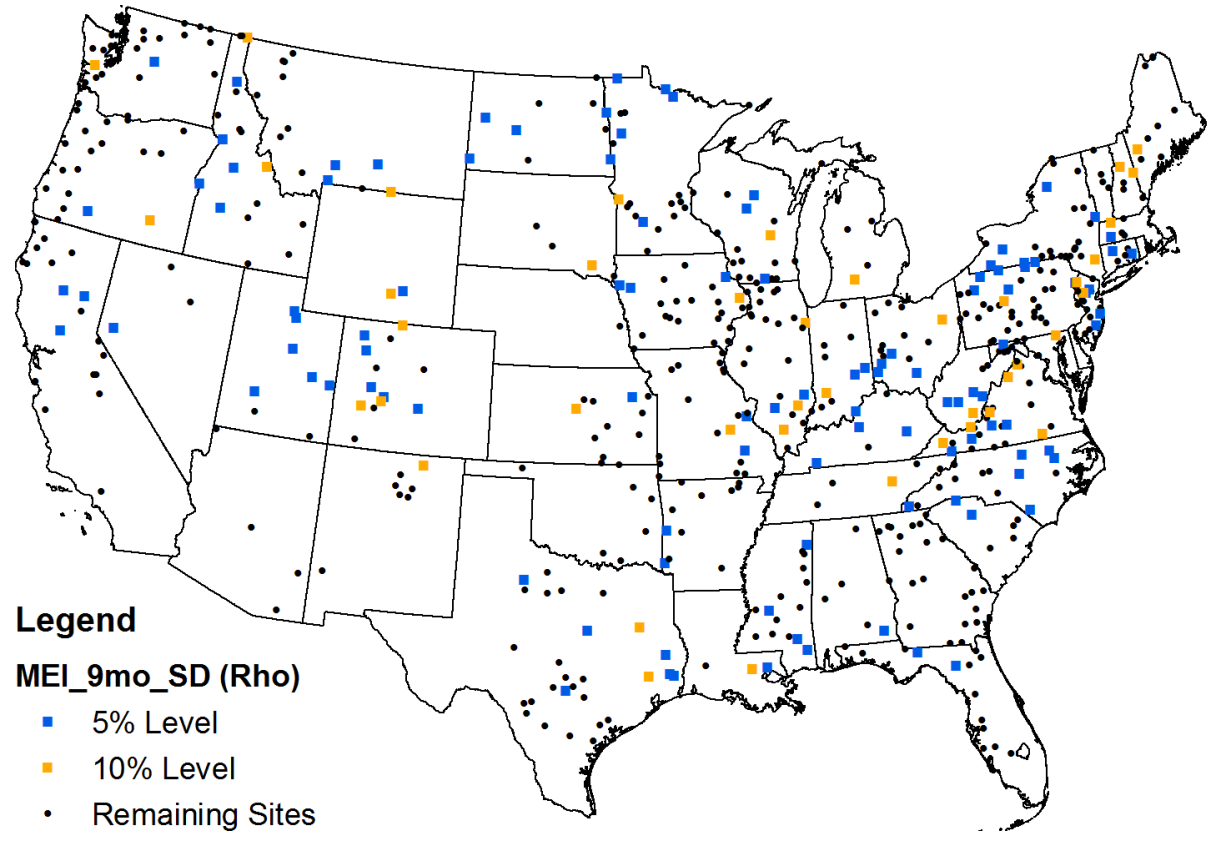

Figure F.8 Locations of sites with significant Spearman's rho correlation between 10-year moving standard deviation of log-transformed flood flows and 3-month average MEI anomalies with 9-month lead.

\section{F.3 NAO Correlation Results}

Table F.4

Results of Kendall's tau analyses (significant at 10\% level) between 10-year moving standard deviation of log-transformed flood flows and 3-month average NAO anomalies with 3-, 6-, and 9-month leads.

\begin{tabular}{|c|cc|cc|cc|}
\hline $\begin{array}{c}\text { Station } \\
\text { Number }\end{array}$ & \multicolumn{2}{|c|}{ 3-Month Lead } & \multicolumn{2}{|c|}{ 6-Month Lead } & \multicolumn{2}{c|}{ 9-Month Lead } \\
tau & p-value & tau & p-value & tau & p-value \\
\hline \hline 1038000 & 0.242 & $\mathbf{0 . 0 0 6}$ & & & & \\
1064500 & -0.219 & $\mathbf{0 . 0 1 4}$ & & & 0.148 & 0.096 \\
1137500 & -0.267 & $\mathbf{0 . 0 0 3}$ & & & & \\
1142500 & & & -0.181 & $\mathbf{0 . 0 4 4}$ & & \\
1144000 & & & & & 0.151 & 0.093 \\
1334500 & 0.162 & 0.068 & & & & \\
1357500 & & & & & 0.149 & 0.093 \\
1408500 & 0.190 & $\mathbf{0 . 0 3 2}$ & & & & \\
1414500 & & & -0.179 & $\mathbf{0 . 0 4 4}$ & & \\
1514000 & & & 0.210 & $\mathbf{0 . 0 1 8}$ & &
\end{tabular}


Table F.4, continued

\begin{tabular}{|c|c|c|c|c|c|c|}
\hline \multirow{2}{*}{$\begin{array}{c}\text { Station } \\
\text { Number }\end{array}$} & \multicolumn{2}{|c|}{ 3-Month Lead } & \multicolumn{2}{|c|}{ 6-Month Lead } & \multicolumn{2}{|c|}{ 9-Month Lead } \\
\hline & tau & $\mathrm{p}$-value & tau & $\mathrm{p}$-value & tau & $\mathrm{p}$-value \\
\hline 1538000 & & & & & -0.150 & 0.091 \\
\hline 1541000 & & & & & -0.154 & 0.084 \\
\hline 1555500 & & & & & -0.188 & 0.035 \\
\hline 1560000 & & & 0.171 & 0.054 & & \\
\hline 1567000 & & & & & -0.198 & 0.026 \\
\hline 1580000 & & & 0.313 & 0.000 & & \\
\hline 2059500 & & & 0.263 & 0.003 & & \\
\hline 2070000 & 0.183 & 0.040 & & & & \\
\hline 2074500 & & & 0.174 & 0.051 & & \\
\hline 2083000 & 0.170 & 0.056 & & & & \\
\hline 2126000 & & & & & -0.158 & 0.075 \\
\hline 2132000 & & & -0.175 & 0.049 & & \\
\hline 2138500 & & & & & 0.318 & 0.000 \\
\hline 2192000 & & & -0.160 & 0.072 & & \\
\hline 2217500 & & & -0.221 & 0.013 & & \\
\hline 2226000 & & & -0.167 & 0.061 & & \\
\hline 2231000 & & & -0.222 & 0.012 & & \\
\hline 2256500 & & & -0.147 & 0.100 & & \\
\hline 2298830 & & & & & -0.168 & 0.059 \\
\hline 2303000 & & & 0.148 & 0.097 & & \\
\hline 2321500 & & & & & -0.154 & 0.083 \\
\hline 2333500 & & & & & -0.252 & 0.005 \\
\hline 2339500 & & & -0.195 & 0.029 & & \\
\hline 2353500 & -0.150 & 0.092 & & & & \\
\hline 2358000 & & & -0.161 & 0.070 & & \\
\hline 2398000 & & & & & 0.165 & 0.064 \\
\hline 2474500 & -0.178 & 0.045 & & & & \\
\hline 2479000 & -0.189 & 0.033 & & & & \\
\hline 2486000 & -0.152 & 0.087 & & & & \\
\hline 2487500 & 0.165 & 0.064 & & & & \\
\hline 3032500 & -0.186 & 0.036 & & & & \\
\hline 3102500 & & & & & -0.153 & 0.086 \\
\hline 3164000 & & & & & 0.317 & 0.000 \\
\hline 3230500 & -0.241 & 0.007 & & & & \\
\hline 3234500 & -0.240 & 0.007 & & & & \\
\hline 3272000 & -0.256 & 0.004 & & & & \\
\hline 3275000 & & & & & -0.160 & 0.072 \\
\hline 3301500 & & & 0.225 & 0.012 & & \\
\hline 3335500 & & & & & 0.155 & 0.082 \\
\hline 3363500 & & & & & -0.193 & 0.030 \\
\hline 3379500 & -0.154 & 0.083 & & & & \\
\hline 3381500 & -0.191 & 0.032 & & & -0.214 & 0.016 \\
\hline 3434500 & & & & & 0.163 & 0.067 \\
\hline 3540500 & & & & & 0.286 & 0.001 \\
\hline 3550000 & & & & & 0.226 & 0.011 \\
\hline
\end{tabular}


Table F.4, continued

\begin{tabular}{|c|c|c|c|c|c|c|}
\hline \multirow{2}{*}{$\begin{array}{c}\text { Station } \\
\text { Number }\end{array}$} & \multicolumn{2}{|c|}{ 3-Month Lead } & \multicolumn{2}{|c|}{ 6-Month Lead } & \multicolumn{2}{|c|}{ 9-Month Lead } \\
\hline & tau & p-value & tau & p-value & tau & p-value \\
\hline 4010500 & -0.246 & 0.006 & & & & \\
\hline 4087000 & & & -0.165 & 0.064 & & \\
\hline 4198000 & & & & & 0.147 & 0.099 \\
\hline 4234000 & & & 0.167 & 0.061 & & \\
\hline 4262500 & & & & & 0.188 & 0.035 \\
\hline 4275000 & & & -0.185 & 0.038 & & \\
\hline 5062000 & & & 0.172 & 0.053 & & \\
\hline 5078000 & -0.231 & 0.009 & & & & \\
\hline 5078500 & -0.196 & 0.027 & & & & \\
\hline 5120500 & & & & & -0.157 & 0.078 \\
\hline 5280000 & & & & & 0.205 & 0.021 \\
\hline 5286000 & & & & & 0.150 & 0.091 \\
\hline 5288500 & & & & & 0.192 & 0.031 \\
\hline 5291000 & & & & & 0.166 & 0.062 \\
\hline 5300000 & & & & & 0.167 & 0.060 \\
\hline 5313500 & & & & & 0.165 & 0.063 \\
\hline 5317000 & & & 0.161 & 0.070 & 0.168 & 0.058 \\
\hline 5330000 & -0.231 & 0.009 & & & 0.197 & 0.027 \\
\hline 5331000 & & & & & 0.184 & 0.038 \\
\hline 5394500 & -0.314 & 0.000 & & & 0.160 & 0.072 \\
\hline 5399500 & 0.162 & 0.068 & & & & \\
\hline 5420500 & -0.168 & 0.059 & & & & \\
\hline 5421000 & & & & & 0.153 & 0.086 \\
\hline 5422000 & -0.146 & 0.100 & 0.159 & 0.074 & & \\
\hline 5434500 & & & 0.158 & 0.076 & 0.194 & 0.029 \\
\hline 5455500 & -0.193 & 0.030 & & & & \\
\hline 5476000 & -0.215 & 0.015 & & & 0.167 & 0.060 \\
\hline 5484000 & 0.269 & 0.002 & & & & \\
\hline 5484500 & 0.400 & 0.000 & & & & \\
\hline 5486490 & 0.175 & 0.049 & & & & \\
\hline 5497000 & 0.328 & 0.000 & & & 0.204 & 0.028 \\
\hline 5501000 & 0.257 & 0.004 & & & & \\
\hline 5527500 & & & 0.226 & 0.011 & & \\
\hline 5555300 & -0.155 & 0.081 & 0.158 & 0.076 & & \\
\hline 5570000 & 0.246 & 0.006 & & & & \\
\hline 5585000 & 0.167 & 0.060 & & & & \\
\hline 5593000 & -0.291 & 0.001 & & & & \\
\hline 6019500 & 0.191 & 0.032 & & & & \\
\hline 6191500 & 0.352 & 0.000 & & & & \\
\hline 6192500 & 0.346 & 0.000 & & & & \\
\hline 6207500 & 0.300 & 0.001 & & & & \\
\hline 6214500 & 0.239 & 0.007 & & & & \\
\hline 6289000 & 0.225 & 0.012 & & & & \\
\hline 6441500 & 0.298 & 0.001 & & & & \\
\hline 6478500 & 0.243 & 0.006 & & & & \\
\hline
\end{tabular}


Table F.4, continued

\begin{tabular}{|c|c|c|c|c|c|c|}
\hline \multirow{2}{*}{$\begin{array}{l}\text { Station } \\
\text { Number }\end{array}$} & \multicolumn{2}{|c|}{ 3-Month Lead } & \multicolumn{2}{|c|}{ 6-Month Lead } & \multicolumn{2}{|c|}{ 9-Month Lead } \\
\hline & tau & $\mathrm{p}$-value & tau & $\mathrm{p}$-value & tau & $\mathrm{p}$-value \\
\hline 6485500 & & & & & 0.166 & 0.063 \\
\hline 6630000 & 0.177 & 0.047 & & & & \\
\hline 6635000 & 0.191 & 0.032 & & & & \\
\hline 6710500 & 0.168 & 0.067 & & & & \\
\hline 6800500 & -0.147 & 0.100 & & & 0.158 & 0.076 \\
\hline 6809500 & 0.225 & 0.012 & & & & \\
\hline 6864500 & 0.305 & 0.001 & 0.230 & 0.010 & & \\
\hline 6869500 & -0.168 & 0.058 & & & & \\
\hline 6889500 & -0.269 & 0.002 & & & & \\
\hline 6933500 & & & & & -0.185 & 0.038 \\
\hline 7013000 & 0.240 & 0.007 & & & & \\
\hline 7061500 & 0.272 & 0.002 & & & & \\
\hline 7067000 & 0.206 & 0.020 & & & & \\
\hline 7068000 & 0.242 & 0.006 & & & & \\
\hline 7071500 & 0.175 & 0.049 & & & & \\
\hline 7074000 & & & 0.148 & 0.097 & & \\
\hline 7096000 & 0.180 & 0.043 & & & & \\
\hline 7144200 & & & & & -0.194 & 0.029 \\
\hline 7146500 & & & & & -0.182 & 0.041 \\
\hline 7176000 & -0.148 & 0.097 & & & & \\
\hline 7180500 & -0.278 & 0.002 & & & -0.175 & 0.049 \\
\hline 7183000 & & & & & -0.201 & 0.024 \\
\hline 7186000 & & & & & -0.154 & 0.083 \\
\hline 7187000 & -0.195 & 0.028 & & & & \\
\hline 7196500 & -0.153 & 0.086 & & & & \\
\hline 7203000 & 0.161 & 0.085 & 0.187 & 0.045 & & \\
\hline 7234000 & 0.153 & 0.085 & & & & \\
\hline 7247000 & -0.327 & 0.000 & & & & \\
\hline 7331000 & & & & & -0.239 & 0.007 \\
\hline 7340000 & -0.263 & 0.003 & & & & \\
\hline 7340500 & & & & & 0.184 & 0.039 \\
\hline 8032000 & -0.211 & 0.017 & & & & \\
\hline 8070000 & & & & & -0.204 & 0.022 \\
\hline 8082000 & 0.209 & 0.019 & & & & \\
\hline 8082500 & & & & & -0.151 & 0.090 \\
\hline 8085500 & & & 0.150 & 0.091 & & \\
\hline 8095000 & 0.324 & 0.000 & & & & \\
\hline 8153500 & & & & & -0.160 & 0.072 \\
\hline 8158000 & & & & & -0.152 & 0.087 \\
\hline 8167000 & & & 0.258 & 0.004 & 0.150 & 0.095 \\
\hline 8195000 & & & 0.187 & 0.036 & 0.205 & 0.022 \\
\hline 8205500 & 0.284 & 0.001 & & & & \\
\hline 8210000 & & & & & -0.181 & 0.042 \\
\hline 8276500 & & & & & -0.151 & 0.089 \\
\hline 8380500 & -0.155 & 0.085 & -0.163 & 0.069 & & \\
\hline
\end{tabular}


Table F.4, continued

\begin{tabular}{|c|c|c|c|c|c|c|}
\hline \multirow{2}{*}{$\begin{array}{l}\text { Station } \\
\text { Number }\end{array}$} & \multicolumn{2}{|c|}{ 3-Month Lead } & \multicolumn{2}{|c|}{ 6-Month Lead } & \multicolumn{2}{|c|}{ 9-Month Lead } \\
\hline & tau & $\mathrm{p}$-value & tau & $\mathrm{p}$-value & tau & $\mathrm{p}$-value \\
\hline 9110000 & 0.243 & 0.006 & & & & \\
\hline 9119000 & 0.168 & 0.058 & & & & \\
\hline 9147500 & 0.217 & 0.015 & & & & \\
\hline 9180500 & 0.172 & 0.053 & & & & \\
\hline 9251000 & 0.146 & 0.100 & & & & \\
\hline 9304500 & 0.179 & 0.045 & & & & \\
\hline 9315000 & 0.229 & 0.010 & & & & \\
\hline 9379500 & -0.214 & 0.016 & & & & \\
\hline 9415000 & & & 0.235 & 0.008 & & \\
\hline 9430500 & & & 0.234 & 0.008 & & \\
\hline 9448500 & 0.195 & 0.028 & 0.320 & 0.000 & & \\
\hline 9471000 & & & 0.173 & 0.052 & & \\
\hline 9508500 & & & 0.208 & 0.019 & & \\
\hline 10128500 & 0.305 & 0.001 & & & & \\
\hline 10131000 & 0.225 & 0.011 & & & & \\
\hline 10234500 & 0.171 & 0.055 & & & & \\
\hline 10312000 & 0.151 & 0.089 & & & & \\
\hline 10329500 & & & & & 0.163 & 0.067 \\
\hline 11098000 & & & -0.151 & 0.093 & & \\
\hline 11152000 & & & & & -0.159 & 0.074 \\
\hline 11160500 & & & 0.178 & 0.048 & & \\
\hline 11237500 & -0.175 & 0.051 & & & & \\
\hline 11264500 & -0.201 & 0.024 & & & & \\
\hline 11266500 & -0.214 & 0.016 & & & & \\
\hline 11381500 & & & 0.166 & 0.062 & & \\
\hline 11383500 & & & 0.187 & 0.035 & & \\
\hline 11425500 & & & & & 0.162 & 0.068 \\
\hline 11478500 & & & & & 0.167 & 0.060 \\
\hline 11525500 & -0.164 & 0.065 & & & 0.186 & 0.036 \\
\hline 12010000 & & & & & 0.229 & 0.010 \\
\hline 12020000 & & & & & 0.393 & 0.000 \\
\hline 12027500 & & & & & 0.340 & 0.000 \\
\hline 12048000 & & & & & 0.227 & 0.011 \\
\hline 12054000 & & & & & 0.260 & 0.003 \\
\hline 12056500 & & & & & 0.148 & 0.097 \\
\hline 12134500 & -0.211 & 0.018 & & & & \\
\hline 12186000 & -0.210 & 0.018 & -0.206 & 0.021 & & \\
\hline 12189500 & -0.222 & 0.012 & -0.175 & 0.049 & 0.205 & 0.021 \\
\hline 12321500 & & & -0.147 & 0.099 & & \\
\hline 12330000 & 0.326 & 0.000 & & & & \\
\hline 12332000 & 0.264 & 0.003 & & & & \\
\hline 12355500 & & & -0.182 & 0.041 & & \\
\hline 12414500 & & & -0.182 & 0.041 & & \\
\hline 12422500 & 0.148 & 0.096 & & & & \\
\hline 12451000 & & & & & -0.169 & 0.057 \\
\hline
\end{tabular}


Table F.4, continued

\begin{tabular}{|c|c|c|c|c|c|c|}
\hline \multirow{2}{*}{$\begin{array}{c}\text { Station } \\
\text { Number }\end{array}$} & \multicolumn{2}{|c|}{ 3-Month Lead } & \multicolumn{2}{|c|}{ 6-Month Lead } & \multicolumn{2}{|c|}{ 9-Month Lead } \\
\hline & tau & $p$-value & & $\mathrm{p}$-value & tau & $\mathrm{p}$-value \\
\hline 12459000 & 0.200 & 0.024 & & & & \\
\hline 13073000 & & & & & 0.153 & 0.085 \\
\hline 13082500 & & & & & 0.239 & 0.007 \\
\hline 13120500 & 0.223 & 0.012 & & & & \\
\hline 13139510 & 0.260 & 0.003 & & & & \\
\hline 13185000 & & & & & 0.206 & 0.021 \\
\hline 13302500 & 0.309 & 0.000 & & & & \\
\hline 13313000 & 0.190 & $\mathbf{0 . 0 3 3}$ & & & & \\
\hline 13317000 & 0.220 & 0.013 & & & & \\
\hline 14113000 & -0.176 & 0.047 & & & & \\
\hline 14301000 & & & & & 0.309 & 0.001 \\
\hline 14301500 & & & & & 0.297 & 0.001 \\
\hline 14306500 & & & & & 0.167 & 0.061 \\
\hline 14325000 & & & & & 0.204 & 0.022 \\
\hline
\end{tabular}

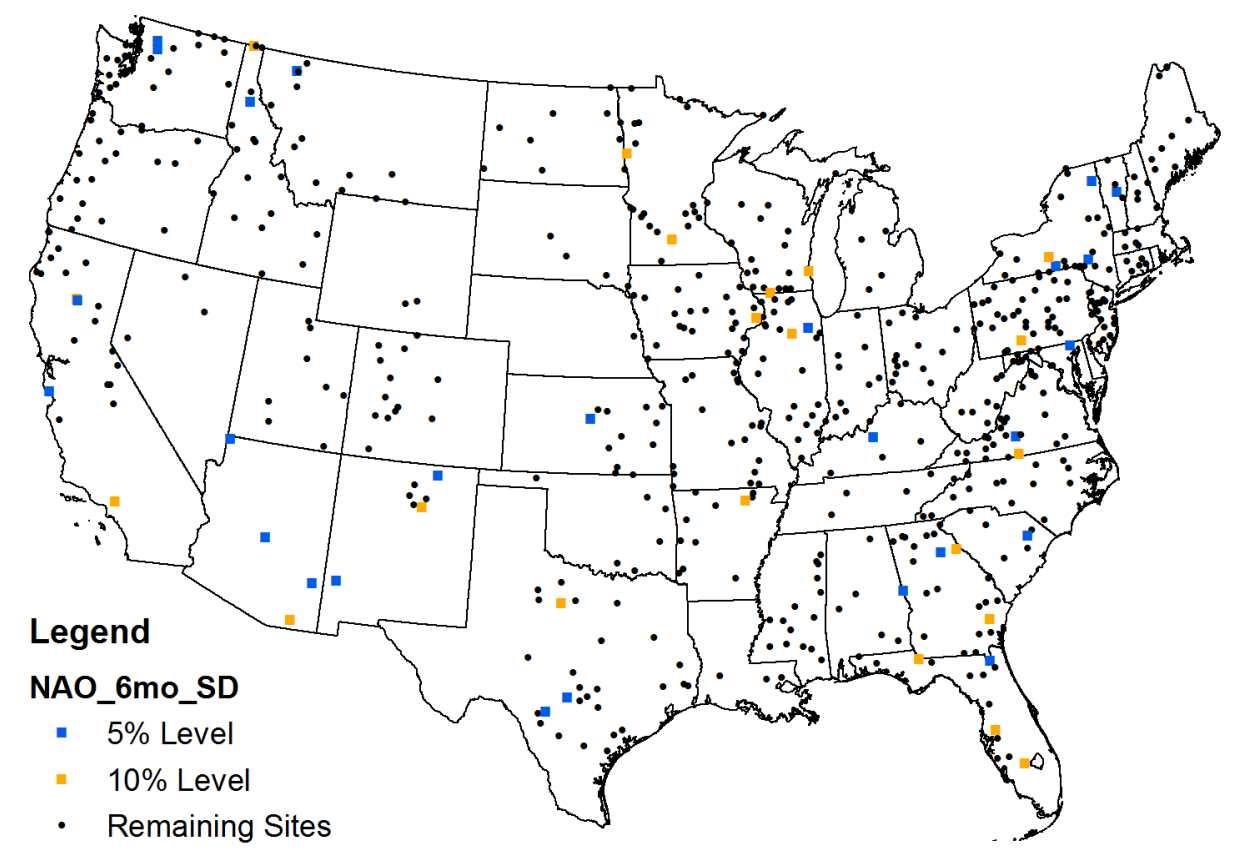

Figure F-9 Locations of sites with significant Kendall's tau correlation between 10-year moving standard deviation of log-transformed flood flows and 3-month average NAO anomalies with 6-month lead. 


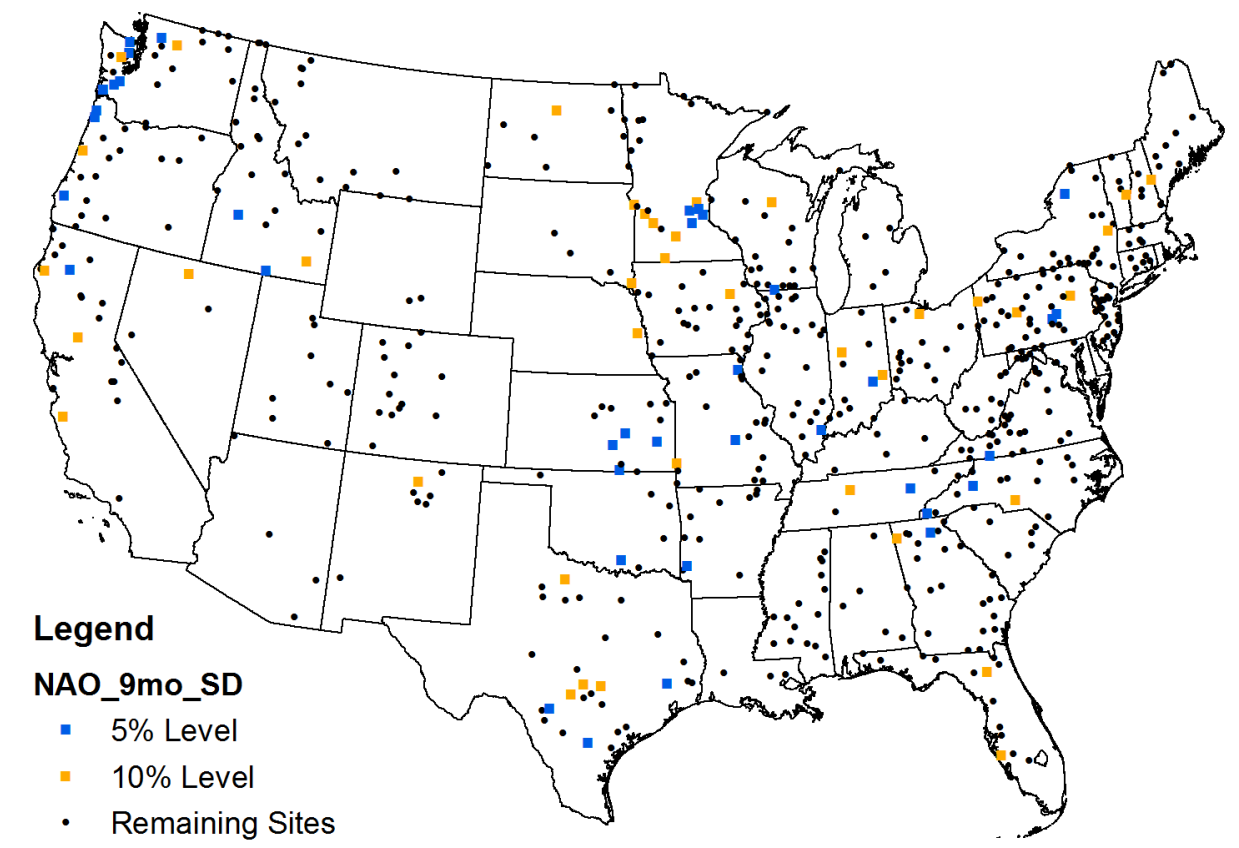

Figure F-10 Locations of sites with significant Kendall's tau correlation between 10-year moving standard deviation of log-transformed flood flows and 3-month average NAO anomalies with 9-month lead.

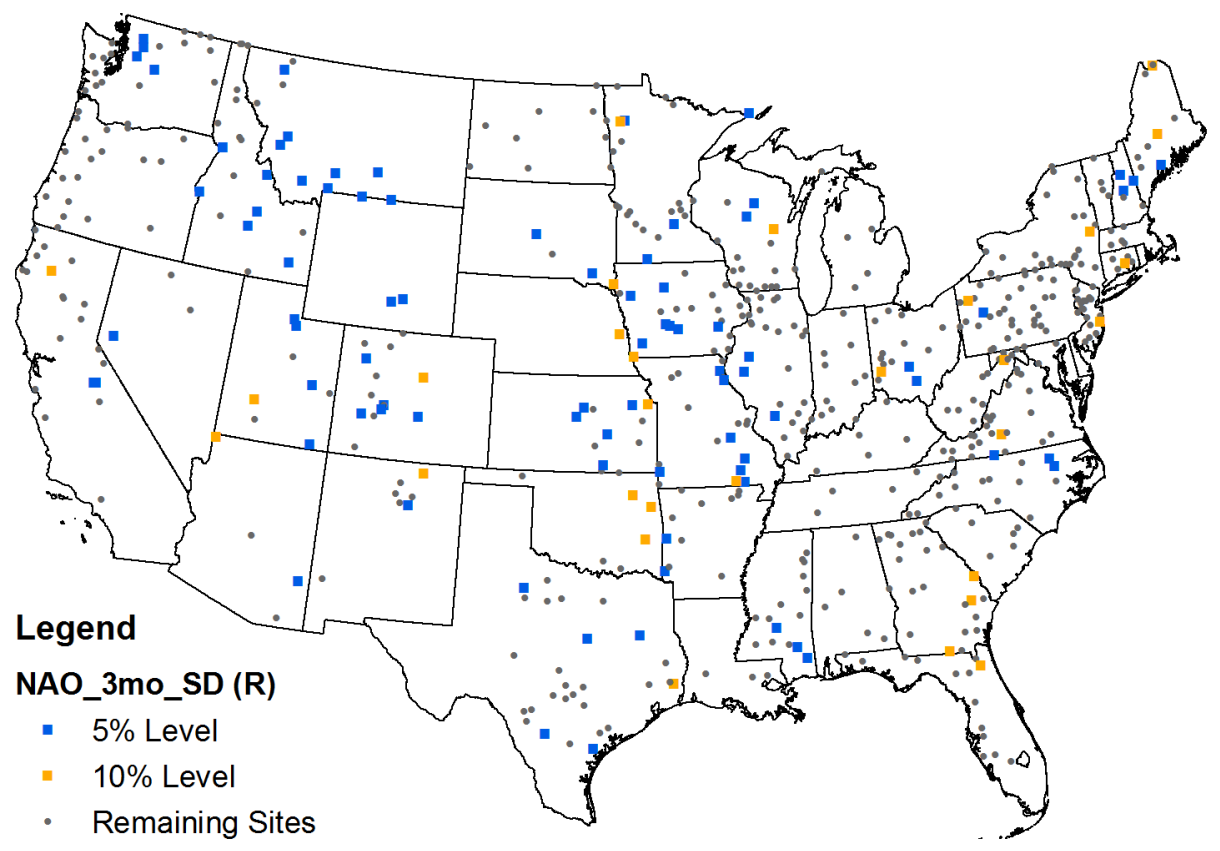

Figure F.11 Locations of sites with significant Pearson's $r$ correlation between 10-year moving standard deviation of log-transformed flood flows and 3-month average NAO anomalies with 3-month lead. 


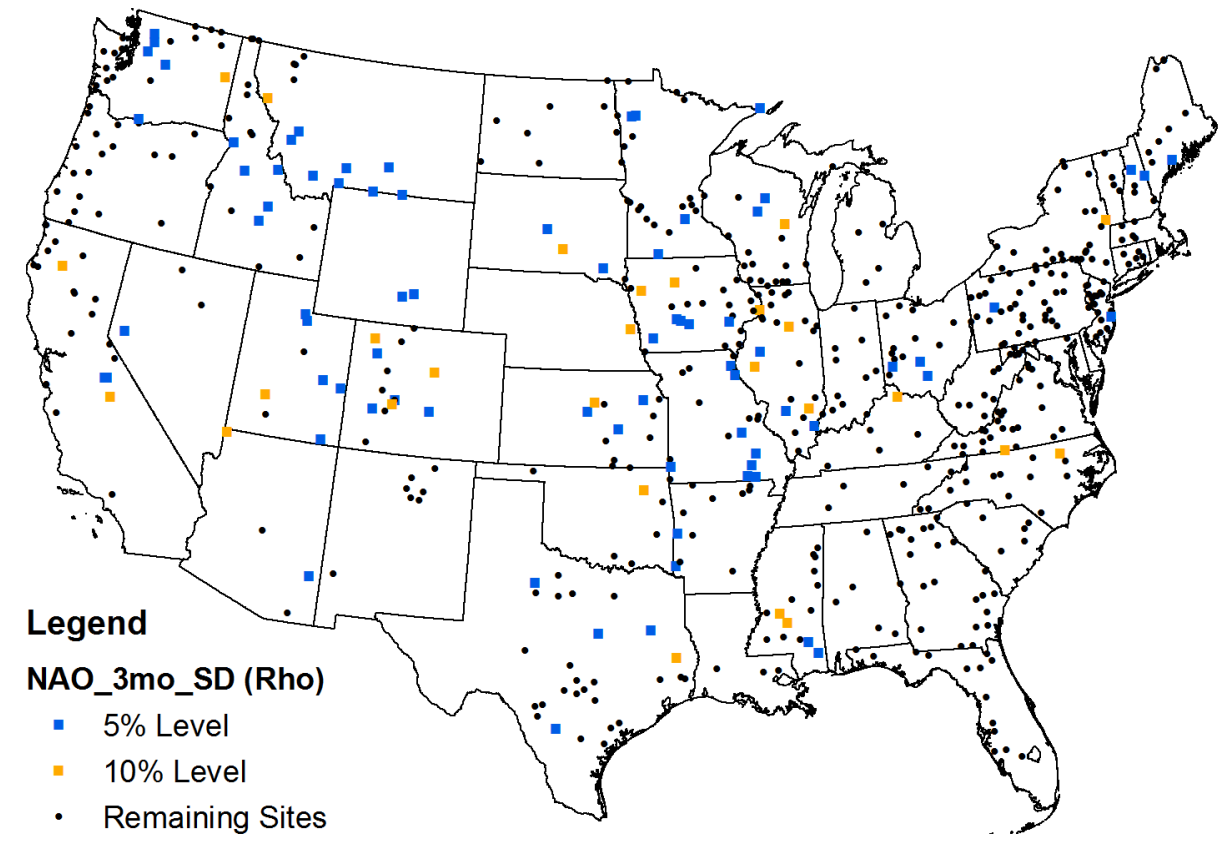

Figure F.12 Locations of sites with significant Spearman's rho correlation between 10year moving standard deviation of log-transformed flood flows and 3-month average

NAO anomalies with 3-month lead.

\section{F.4 NINO 3.4 Correlation Results}

Table F.5

Results of Kendall's tau analyses (significant at 10\% level) between 10-year moving standard deviation of log-transformed flood flows and 3-month average Nino3.4 anomalies with 3-, 6-, and 9-month leads.

\begin{tabular}{|c|cc|cc|cc|}
\hline $\begin{array}{c}\text { Station } \\
\text { Number }\end{array}$ & \multicolumn{2}{|c|}{ 3-Month Lead } & \multicolumn{2}{|c|}{ 6-Month Lead } & \multicolumn{2}{c|}{ 9-Month Lead } \\
tau & p-value & tau & p-value & tau & p-value \\
\hline 1196500 & -0.156 & 0.083 & -0.184 & $\mathbf{0 . 0 4 1}$ & -0.169 & 0.060 \\
1381500 & -0.155 & 0.081 & & & & \\
1541500 & & & & & -0.161 & 0.071 \\
1543500 & & & & & -0.201 & $\mathbf{0 . 0 2 4}$ \\
1548500 & & & & & -0.147 & 0.099 \\
2156500 & & & 0.173 & 0.054 & 0.160 & 0.075 \\
2217500 & & & 0.192 & $\mathbf{0 . 0 3 1}$ & & \\
2320500 & & & & & -0.190 & $\mathbf{0 . 0 3 3}$ \\
2329000 & & & & & -0.188 & $\mathbf{0 . 0 3 5}$ \\
3010500 & & & -0.202 & $\mathbf{0 . 0 2 3}$ & -0.236 & $\mathbf{0 . 0 0 8}$ \\
3011020 & & & 0.157 & 0.078 & -0.202 & $\mathbf{0 . 0 2 3}$ \\
3262000 & & & 0.178 & $\mathbf{0 . 0 4 8}$ & 0.152 & 0.090 \\
3488000 & 0.162 & 0.068 & & & &
\end{tabular}


Table F.5, continued

\begin{tabular}{|c|c|c|c|c|c|c|}
\hline \multirow{2}{*}{$\begin{array}{c}\text { Station } \\
\text { Number }\end{array}$} & \multicolumn{2}{|c|}{ 3-Month Lead } & \multicolumn{2}{|c|}{ 6-Month Lead } & \multicolumn{2}{|c|}{ 9-Month Lead } \\
\hline & & p-value & tau & $p$-value & tau & p-value \\
\hline 4223000 & & & & & -0.154 & 0.083 \\
\hline 5062500 & & & & & 0.147 & 0.097 \\
\hline 5078500 & & & & & 0.147 & 0.097 \\
\hline 5112000 & 0.187 & 0.036 & 0.169 & 0.057 & 0.219 & 0.014 \\
\hline 5133500 & & & 0.177 & 0.047 & 0.185 & 0.038 \\
\hline 5280000 & & & & & 0.151 & 0.090 \\
\hline 5412500 & & & & & 0.196 & 0.028 \\
\hline 5418500 & & & & & 0.155 & 0.082 \\
\hline 5431486 & & & -0.147 & 0.097 & & \\
\hline 6214500 & & & 0.167 & 0.061 & 0.168 & 0.059 \\
\hline 6289000 & & & & & 0.171 & 0.054 \\
\hline 6620000 & & & 0.149 & 0.095 & 0.216 & 0.015 \\
\hline 6630000 & & & 0.170 & 0.056 & 0.213 & 0.016 \\
\hline 6635000 & & & 0.156 & 0.079 & 0.165 & 0.063 \\
\hline 7096000 & & & 0.170 & 0.056 & 0.179 & 0.044 \\
\hline 7203000 & 0.221 & 0.018 & & & & \\
\hline 7375500 & & & & & -0.166 & 0.063 \\
\hline 8033500 & & & -0.160 & 0.071 & -0.201 & 0.024 \\
\hline 8041000 & & & -0.148 & 0.097 & -0.186 & 0.036 \\
\hline 8041500 & & & & & -0.177 & 0.047 \\
\hline 8070000 & & & & & -0.165 & 0.064 \\
\hline 8167000 & 0.154 & 0.083 & & & & \\
\hline 8167500 & & & & & 0.162 & 0.068 \\
\hline 9180500 & & & & & 0.153 & 0.085 \\
\hline 9304500 & & & 0.190 & 0.033 & 0.160 & 0.072 \\
\hline 9315000 & & & & & 0.175 & 0.049 \\
\hline 10329500 & & & 0.161 & 0.070 & & \\
\hline 10396000 & & & & & 0.158 & 0.075 \\
\hline 12035000 & 0.158 & 0.075 & & & -0.149 & 0.093 \\
\hline 12048000 & 0.192 & 0.031 & & & & \\
\hline 13269000 & & & & & 0.206 & 0.020 \\
\hline
\end{tabular}




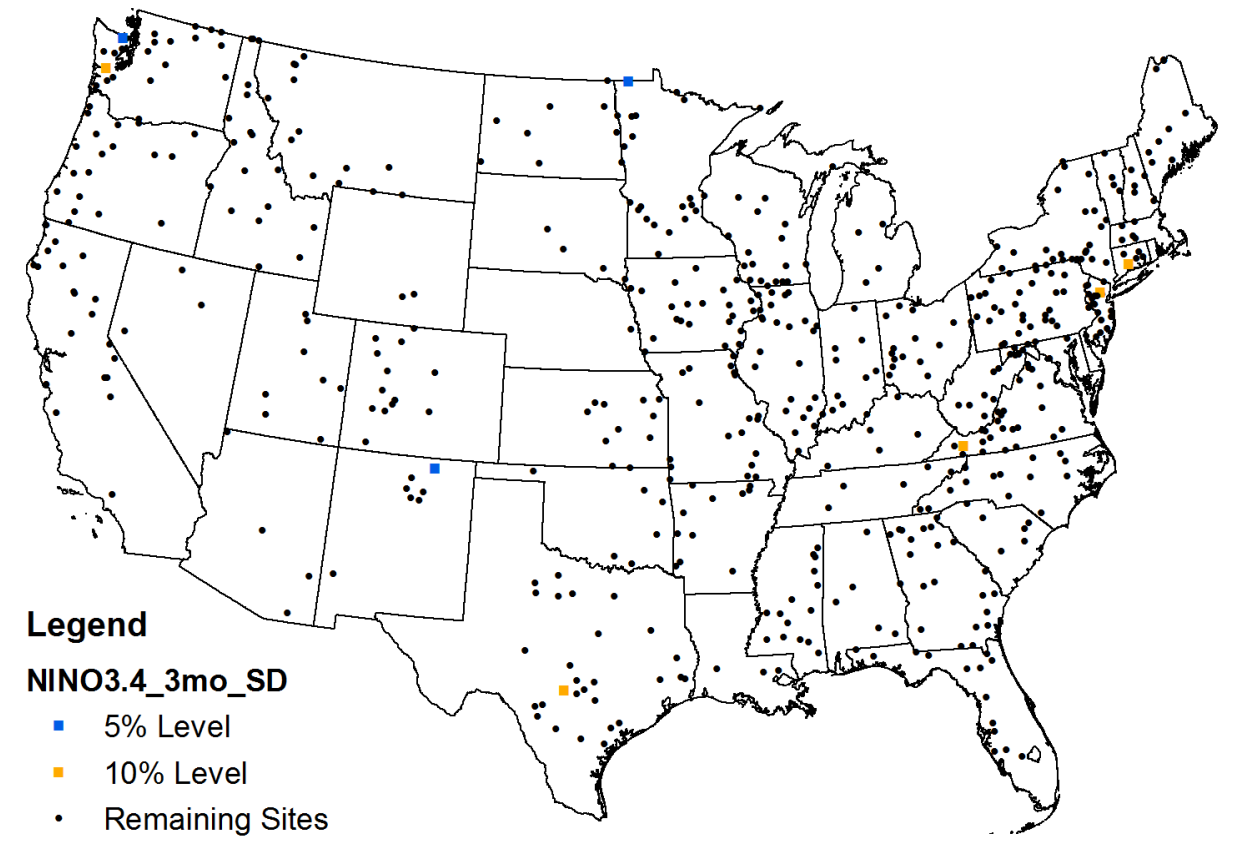

Figure F-13 Locations of sites with significant Kendall's tau correlation between 10-year moving standard deviation of log-transformed flood flows and 3-month average Nino3.4 anomalies with 3-month lead.

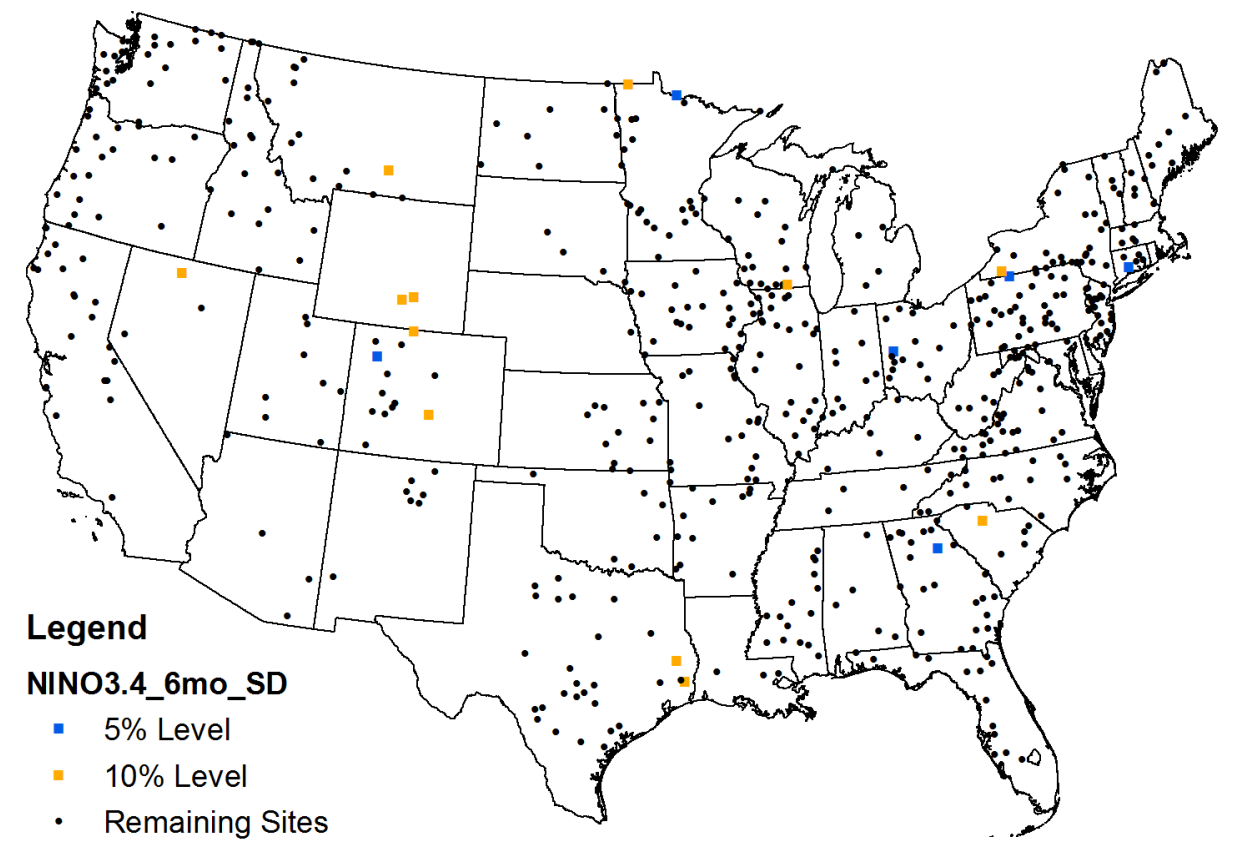

Figure F-14 Locations of sites with significant Kendall's tau correlation between 10-year moving standard deviation of log-transformed flood flows and 3-month average Nino3.4 anomalies with 6-month lead. 


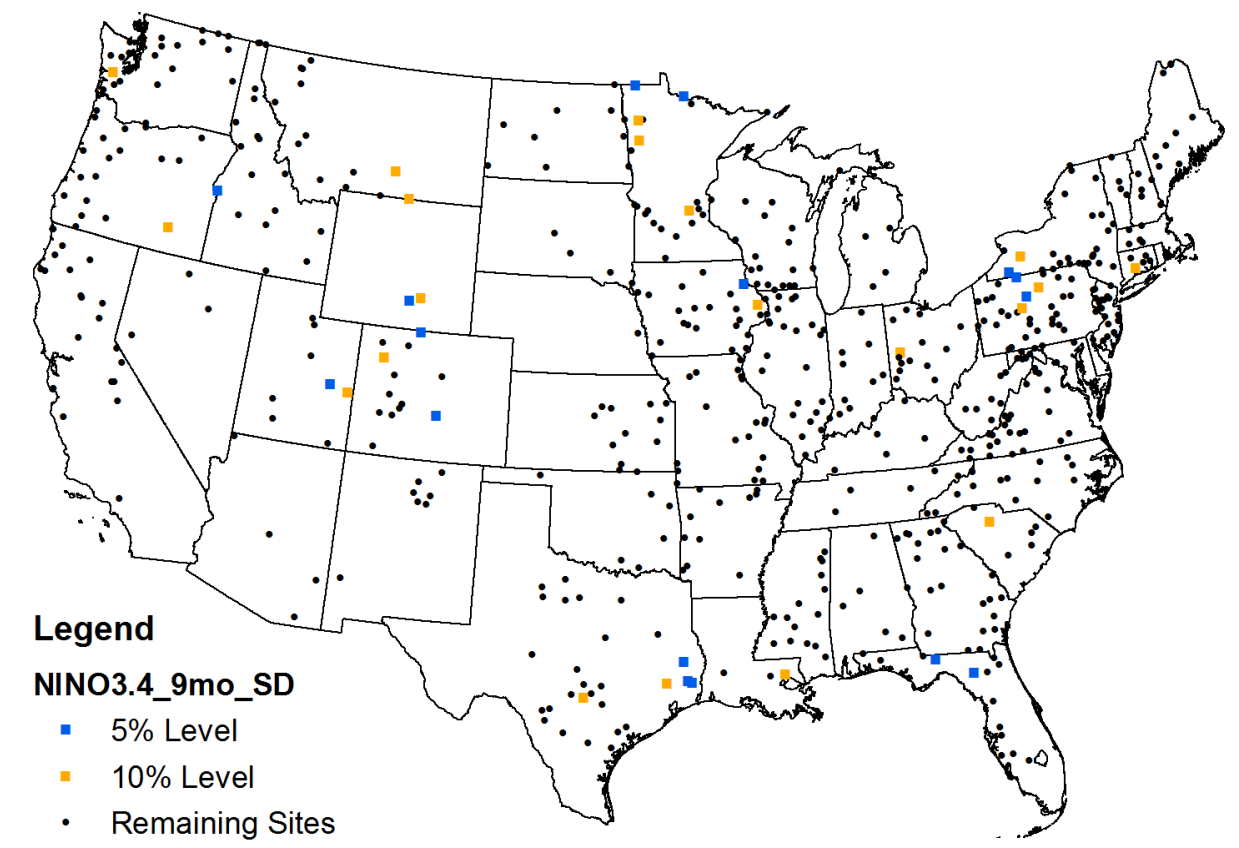

Figure F-15 Locations of sites with significant Kendall's tau correlation between 10-year moving standard deviation of log-transformed flood flows and 3-month average Nino3.4 anomalies with 9-month lead.

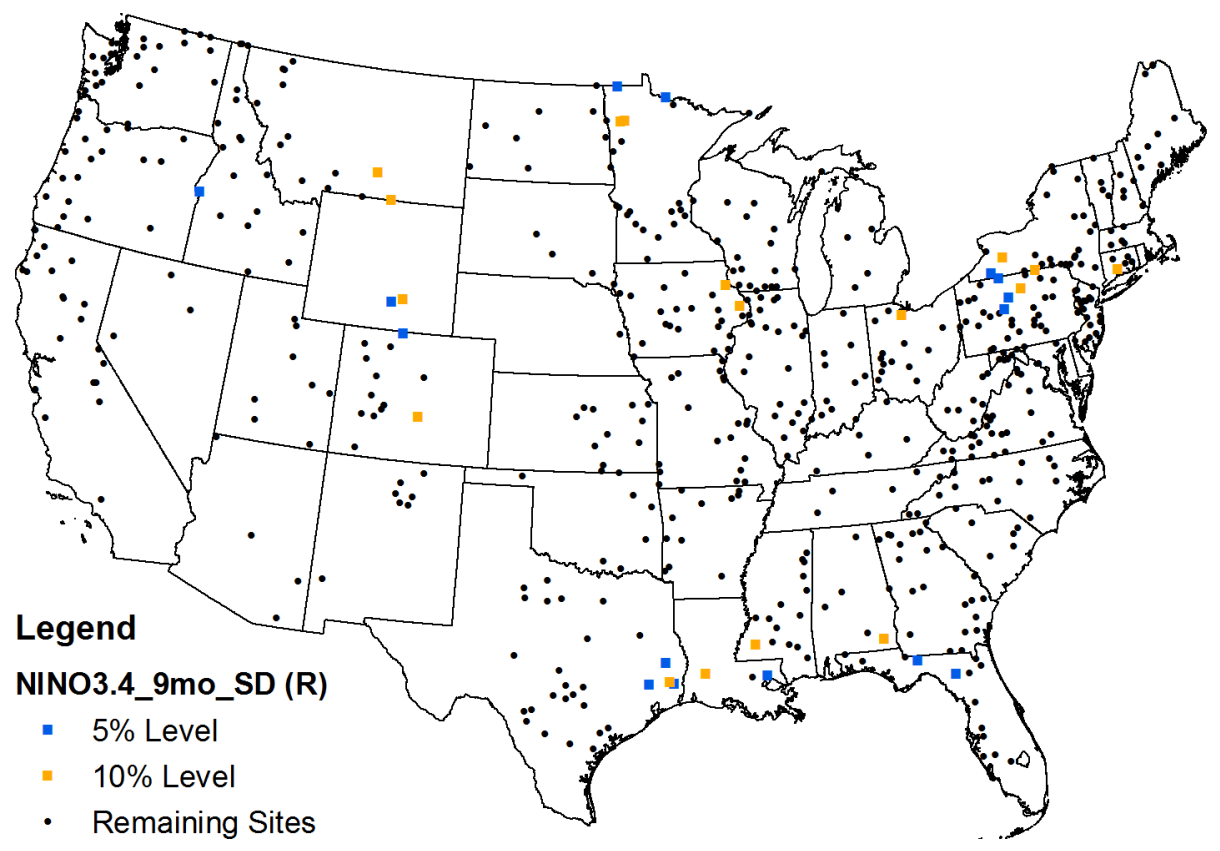

Figure F.16 Locations of sites with significant Pearson's $r$ correlation between 10-year moving standard deviation of log-transformed flood flows and 3-month average Nino3.4 anomalies with 9-month lead. 


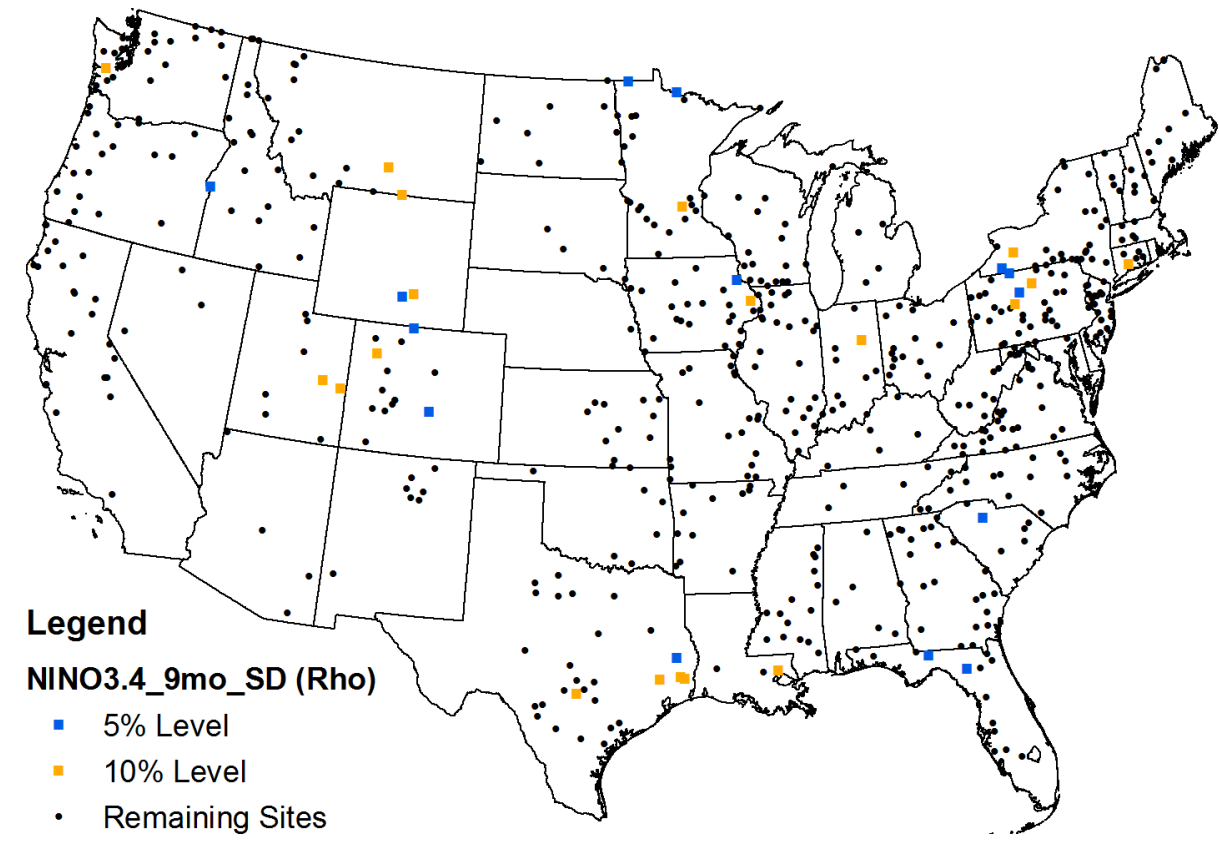

Figure F.17 Locations of sites with significant Spearman's rho correlation between 10year moving standard deviation of log-transformed flood flows and 3-month average

Nino3.4 anomalies with 9-month lead.

\section{F.5 PDO Correlations Results}

Table F.6

Results of Kendall's tau analyses (significant at 10\% level) between 10-year moving standard deviation of log-transformed flood flows and 3-month average PDO anomalies with 3-, 6-, and 9-month leads.

\begin{tabular}{|c|cc|cc|cc|}
\hline $\begin{array}{c}\text { Station } \\
\text { Number }\end{array}$ & \multicolumn{2}{|c|}{ 3-Month Lead } & \multicolumn{2}{|c|}{ 6-Month Lead } & \multicolumn{2}{c|}{ 9-Month Lead } \\
tau & p-value & tau & p-value & tau & p-value \\
\hline \hline 1030500 & & & & & 0.187 & $\mathbf{0 . 0 3 6}$ \\
1038000 & 0.175 & $\mathbf{0 . 0 4 9}$ & 0.277 & $\mathbf{0 . 0 0 2}$ & 0.231 & $\mathbf{0 . 0 0 9}$ \\
1055000 & -0.196 & $\mathbf{0 . 0 2 7}$ & -0.167 & 0.061 & & \\
1057000 & & & & & 0.173 & 0.051 \\
1064500 & & & -0.160 & 0.071 & -0.189 & $\mathbf{0 . 0 3 3}$ \\
1073000 & & & -0.171 & 0.056 & & \\
1127500 & 0.157 & 0.081 & 0.220 & $\mathbf{0 . 0 1 4}$ & 0.301 & $\mathbf{0 . 0 0 1}$ \\
1137500 & & & & & -0.210 & $\mathbf{0 . 0 1 9}$ \\
1142500 & & & & & -0.186 & $\mathbf{0 . 0 3 8}$ \\
1169000 & -0.223 & $\mathbf{0 . 0 1 3}$ & -0.182 & $\mathbf{0 . 0 4 3}$ & -0.156 & 0.083 \\
1175500 & & & & & 0.164 & 0.068 \\
1176000 & -0.154 & 0.085 & & & & \\
1181000 & -0.260 & $\mathbf{0 . 0 0 4}$ & -0.226 & $\mathbf{0 . 0 1 2}$ & -0.159 & 0.076
\end{tabular}


Table F.6, continued

\begin{tabular}{|c|c|c|c|c|c|c|}
\hline \multirow{2}{*}{$\begin{array}{c}\text { Station } \\
\text { Number }\end{array}$} & \multicolumn{2}{|c|}{ 3-Month Lead } & \multicolumn{2}{|c|}{ 6-Month Lead } & \multicolumn{2}{|c|}{ 9-Month Lead } \\
\hline & tau & $\mathrm{p}$-value & tau & $\mathrm{p}$-value & tau & $\mathrm{p}$-value \\
\hline 1188000 & -0.223 & 0.013 & -0.237 & 0.008 & -0.206 & 0.021 \\
\hline 1334500 & & & & & -0.296 & 0.001 \\
\hline 1350000 & -0.210 & 0.018 & -0.206 & 0.021 & -0.201 & 0.024 \\
\hline 1372500 & & & -0.178 & 0.046 & -0.235 & 0.008 \\
\hline 1381500 & -0.229 & 0.010 & -0.319 & 0.000 & -0.276 & 0.002 \\
\hline 1387500 & & & & & -0.147 & 0.099 \\
\hline 1397500 & & & -0.179 & 0.045 & & \\
\hline 1398000 & -0.153 & 0.086 & -0.151 & 0.090 & & \\
\hline 1398500 & -0.195 & 0.028 & -0.235 & 0.008 & -0.226 & 0.011 \\
\hline 1399500 & & & -0.149 & 0.093 & -0.164 & 0.065 \\
\hline 1408500 & 0.296 & 0.001 & 0.261 & 0.003 & 0.262 & 0.003 \\
\hline 1410000 & 0.283 & 0.001 & 0.343 & 0.000 & 0.294 & 0.001 \\
\hline 1411000 & 0.167 & 0.060 & & & & \\
\hline 1411500 & & & & & 0.187 & 0.035 \\
\hline 1420500 & -0.150 & 0.092 & -0.151 & 0.089 & & \\
\hline 1421000 & -0.170 & 0.056 & -0.171 & 0.055 & & \\
\hline 1439500 & -0.238 & 0.007 & -0.292 & 0.001 & -0.208 & 0.019 \\
\hline 1440000 & & & -0.175 & 0.049 & & \\
\hline 1445500 & & & & & -0.176 & 0.047 \\
\hline 1459500 & & & & & 0.176 & 0.047 \\
\hline 1518000 & & & & & -0.218 & 0.014 \\
\hline 1520500 & & & & & -0.215 & 0.016 \\
\hline 1531000 & & & & & -0.262 & 0.003 \\
\hline 1532000 & 0.179 & 0.044 & 0.187 & 0.036 & & \\
\hline 1541500 & & & & & -0.234 & 0.008 \\
\hline 1543500 & -0.203 & 0.022 & -0.251 & 0.005 & -0.374 & 0.000 \\
\hline 1548500 & & & & & -0.192 & 0.031 \\
\hline 1560000 & & & 0.223 & 0.012 & 0.182 & 0.041 \\
\hline 1568000 & & & 0.252 & 0.005 & & \\
\hline 1580000 & 0.276 & 0.002 & 0.282 & 0.002 & 0.159 & 0.074 \\
\hline 1599000 & -0.147 & 0.097 & & & -0.159 & 0.073 \\
\hline 1601500 & & & 0.209 & 0.019 & 0.250 & 0.005 \\
\hline 1632000 & & & 0.205 & 0.021 & 0.172 & 0.053 \\
\hline 1634000 & & & 0.198 & 0.026 & 0.193 & 0.030 \\
\hline 2013000 & & & & & -0.155 & 0.082 \\
\hline 2018000 & & & 0.167 & 0.060 & 0.174 & 0.050 \\
\hline 2045500 & & & 0.213 & 0.017 & & \\
\hline 2051500 & & & 0.196 & 0.027 & 0.180 & 0.043 \\
\hline 2055000 & & & 0.288 & 0.001 & 0.221 & 0.013 \\
\hline 2059500 & 0.285 & 0.001 & 0.194 & 0.029 & 0.184 & 0.039 \\
\hline 2061500 & & & 0.210 & 0.018 & 0.172 & 0.053 \\
\hline 2070000 & 0.167 & 0.061 & 0.226 & 0.011 & & \\
\hline 2074500 & 0.240 & 0.007 & 0.161 & 0.071 & 0.257 & 0.004 \\
\hline 2083000 & 0.202 & 0.023 & 0.279 & 0.002 & 0.313 & 0.000 \\
\hline 2083500 & 0.153 & 0.085 & 0.222 & 0.013 & 0.279 & 0.002 \\
\hline
\end{tabular}


Table F.6, continued

\begin{tabular}{|c|c|c|c|c|c|c|}
\hline \multirow{2}{*}{$\begin{array}{c}\text { Station } \\
\text { Number }\end{array}$} & \multicolumn{2}{|c|}{ 3-Month Lead } & \multicolumn{2}{|c|}{ 6-Month Lead } & \multicolumn{2}{|c|}{ 9-Month Lead } \\
\hline & tau & p-value & tau & p-value & tau & p-value \\
\hline 2085500 & 0.179 & 0.045 & 0.265 & 0.003 & 0.292 & 0.001 \\
\hline 2102000 & 0.168 & 0.059 & 0.252 & 0.005 & 0.269 & 0.002 \\
\hline 2116500 & & & 0.192 & 0.031 & & \\
\hline 2131000 & & & 0.149 & 0.093 & & \\
\hline 2134500 & & & & & 0.198 & 0.026 \\
\hline 2138500 & & & 0.199 & 0.025 & 0.208 & 0.019 \\
\hline 2154500 & & & 0.189 & 0.034 & 0.208 & 0.019 \\
\hline 2156500 & 0.160 & 0.074 & 0.272 & 0.002 & 0.291 & 0.001 \\
\hline 2198000 & -0.190 & 0.032 & -0.180 & 0.043 & & \\
\hline 2202500 & -0.152 & 0.087 & & & & \\
\hline 2213500 & -0.220 & 0.013 & -0.278 & 0.002 & -0.201 & 0.024 \\
\hline 2226000 & -0.197 & 0.026 & -0.192 & 0.031 & -0.176 & 0.047 \\
\hline 2228000 & -0.149 & 0.095 & -0.183 & 0.039 & & \\
\hline 2231000 & -0.192 & 0.031 & -0.159 & 0.073 & -0.188 & 0.034 \\
\hline 2301500 & & & -0.190 & 0.033 & -0.193 & 0.030 \\
\hline 2313000 & & & & & -0.158 & 0.076 \\
\hline 2320500 & -0.168 & 0.059 & -0.211 & 0.017 & -0.322 & 0.000 \\
\hline 2321500 & & & & & -0.207 & 0.020 \\
\hline 2329000 & -0.180 & 0.043 & -0.226 & 0.011 & -0.302 & 0.001 \\
\hline 2333500 & -0.156 & 0.079 & -0.327 & 0.000 & -0.275 & 0.002 \\
\hline 2339500 & -0.193 & 0.030 & & & & \\
\hline 2347500 & -0.180 & 0.043 & & & & \\
\hline 2358000 & -0.155 & 0.081 & & & & \\
\hline 2361000 & & & & & 0.187 & 0.036 \\
\hline 2371500 & & & & & -0.210 & 0.018 \\
\hline 2375500 & -0.237 & 0.008 & -0.252 & 0.005 & -0.201 & 0.024 \\
\hline 2431000 & 0.192 & 0.031 & 0.284 & 0.001 & 0.360 & 0.000 \\
\hline 2437000 & 0.176 & 0.048 & 0.226 & 0.011 & 0.231 & 0.009 \\
\hline 2441000 & & & 0.162 & 0.069 & & \\
\hline 2474500 & -0.156 & 0.079 & -0.164 & 0.065 & -0.283 & 0.001 \\
\hline 2479000 & -0.267 & 0.003 & -0.272 & 0.002 & -0.374 & 0.000 \\
\hline 2488500 & & & 0.179 & 0.045 & 0.207 & 0.020 \\
\hline 3010500 & & & -0.171 & 0.055 & -0.260 & 0.003 \\
\hline 3011020 & -0.175 & 0.049 & -0.232 & 0.009 & -0.332 & 0.000 \\
\hline 3015500 & -0.320 & 0.000 & -0.344 & 0.000 & -0.352 & 0.000 \\
\hline 3020500 & -0.164 & 0.064 & -0.213 & 0.017 & -0.235 & 0.008 \\
\hline 3024000 & & & -0.188 & 0.034 & & \\
\hline 3049500 & -0.187 & 0.035 & & & & \\
\hline 3102500 & -0.228 & 0.010 & & & -0.149 & 0.093 \\
\hline 3106000 & -0.168 & 0.059 & & & & \\
\hline 3109500 & -0.253 & 0.005 & -0.210 & 0.019 & & \\
\hline 3118500 & & & -0.226 & 0.011 & -0.222 & 0.012 \\
\hline 3144000 & & & -0.150 & 0.094 & & \\
\hline 3164000 & 0.188 & 0.035 & 0.209 & 0.019 & 0.220 & 0.013 \\
\hline 3167000 & 0.196 & 0.027 & 0.241 & 0.007 & 0.249 & 0.005 \\
\hline
\end{tabular}


Table F.6, continued

\begin{tabular}{|c|c|c|c|c|c|c|}
\hline \multirow{2}{*}{$\begin{array}{c}\text { Station } \\
\text { Number }\end{array}$} & \multicolumn{2}{|c|}{ 3-Month Lead } & \multicolumn{2}{|c|}{ 6-Month Lead } & \multicolumn{2}{|c|}{ 9-Month Lead } \\
\hline & tau & p-value & tau & p-value & tau & p-value \\
\hline 3170000 & & & 0.165 & 0.063 & & \\
\hline 3175500 & & & 0.159 & 0.073 & 0.172 & 0.053 \\
\hline 3182500 & 0.216 & 0.015 & 0.337 & 0.000 & 0.305 & 0.001 \\
\hline 3183500 & 0.152 & 0.087 & 0.275 & 0.002 & 0.207 & 0.020 \\
\hline 3186500 & 0.224 & 0.012 & 0.347 & 0.000 & 0.352 & 0.000 \\
\hline 3193000 & -0.178 & 0.045 & -0.266 & 0.003 & -0.302 & 0.001 \\
\hline 3198500 & -0.175 & 0.049 & -0.208 & 0.019 & -0.267 & 0.003 \\
\hline 3230500 & & & -0.237 & 0.008 & -0.189 & 0.035 \\
\hline 3234500 & -0.211 & 0.019 & -0.274 & 0.002 & -0.309 & 0.001 \\
\hline 3266000 & & & & & -0.148 & 0.099 \\
\hline 3269500 & & & -0.183 & 0.054 & -0.209 & 0.028 \\
\hline 3272000 & & & & & -0.202 & 0.024 \\
\hline 3274000 & & & -0.185 & 0.039 & -0.217 & 0.016 \\
\hline 3275000 & & & -0.261 & 0.003 & -0.314 & 0.000 \\
\hline 3281500 & & & & & -0.181 & 0.044 \\
\hline 3294500 & -0.174 & 0.052 & -0.307 & 0.001 & -0.258 & 0.004 \\
\hline 3301500 & 0.249 & 0.005 & 0.316 & 0.000 & 0.274 & 0.002 \\
\hline 3339500 & & & & & -0.191 & 0.032 \\
\hline 3345500 & & & -0.174 & 0.050 & -0.261 & 0.003 \\
\hline 3360500 & -0.209 & 0.019 & -0.260 & 0.003 & -0.256 & 0.004 \\
\hline 3363500 & -0.255 & 0.004 & -0.319 & 0.000 & -0.375 & 0.000 \\
\hline 3374000 & & & -0.164 & 0.065 & & \\
\hline 3377500 & & & -0.166 & 0.063 & & \\
\hline 3379500 & & & -0.158 & 0.075 & & \\
\hline 3381500 & & & -0.163 & 0.067 & & \\
\hline 3438000 & 0.224 & 0.012 & 0.233 & 0.009 & 0.341 & 0.000 \\
\hline 3465500 & & & & & 0.181 & 0.042 \\
\hline 3473000 & 0.191 & 0.032 & 0.224 & 0.012 & 0.273 & 0.002 \\
\hline 3504000 & -0.162 & 0.069 & -0.177 & 0.047 & -0.154 & 0.084 \\
\hline 3524000 & 0.230 & 0.010 & 0.312 & 0.000 & 0.226 & 0.011 \\
\hline 3540500 & 0.294 & 0.001 & 0.189 & 0.033 & 0.174 & 0.050 \\
\hline 3550000 & 0.155 & 0.081 & 0.231 & 0.009 & 0.346 & 0.000 \\
\hline 3604000 & & & 0.188 & 0.035 & & \\
\hline 4073500 & & & -0.156 & 0.082 & -0.208 & 0.021 \\
\hline 4079000 & & & -0.176 & 0.050 & & \\
\hline 4087000 & -0.167 & 0.061 & -0.201 & 0.024 & & \\
\hline 4105000 & & & & & -0.179 & 0.044 \\
\hline 4121500 & -0.161 & 0.071 & & & & \\
\hline 4142000 & -0.151 & 0.090 & & & & \\
\hline 4198000 & & & 0.186 & 0.037 & 0.183 & 0.039 \\
\hline 4214500 & & & & & -0.193 & 0.030 \\
\hline 4223000 & & & & & -0.234 & 0.009 \\
\hline 4234000 & & & 0.178 & 0.046 & & \\
\hline 4264331 & -0.165 & 0.063 & & & -0.172 & 0.053 \\
\hline 4293500 & 0.155 & 0.084 & & & & \\
\hline
\end{tabular}


Table F.6, continued

\begin{tabular}{|c|c|c|c|c|c|c|}
\hline \multirow{2}{*}{$\begin{array}{c}\text { Station } \\
\text { Number } \\
\end{array}$} & \multicolumn{2}{|c|}{ 3-Month Lead } & \multicolumn{2}{|c|}{ 6-Month Lead } & \multicolumn{2}{|c|}{ 9-Month Lead } \\
\hline & tau & p-value & tau & p-value & tau & p-value \\
\hline 5053000 & 0.242 & 0.006 & 0.313 & 0.000 & 0.290 & 0.001 \\
\hline 5062500 & 0.345 & 0.000 & 0.373 & 0.000 & 0.336 & 0.000 \\
\hline 5066500 & 0.194 & 0.029 & 0.246 & 0.006 & 0.232 & 0.009 \\
\hline 5082500 & 0.204 & 0.022 & 0.249 & 0.005 & 0.203 & 0.022 \\
\hline 5100000 & 0.243 & 0.006 & 0.175 & 0.049 & & \\
\hline 5112000 & 0.293 & 0.001 & 0.342 & 0.000 & 0.290 & 0.001 \\
\hline 5131500 & 0.177 & 0.047 & & & & \\
\hline 5133500 & 0.263 & 0.003 & & & 0.148 & 0.096 \\
\hline 5286000 & 0.151 & 0.089 & 0.215 & 0.016 & 0.185 & 0.038 \\
\hline 5288500 & 0.215 & 0.016 & 0.269 & 0.002 & 0.149 & 0.095 \\
\hline 5293000 & & & 0.178 & 0.046 & 0.194 & 0.029 \\
\hline 5316500 & -0.168 & 0.059 & -0.219 & 0.014 & -0.208 & 0.019 \\
\hline 5394500 & -0.154 & 0.083 & -0.180 & 0.043 & -0.291 & 0.001 \\
\hline 5399500 & 0.284 & 0.001 & 0.323 & 0.000 & 0.323 & 0.000 \\
\hline 5408000 & & & & & -0.179 & 0.045 \\
\hline 5410490 & & & & & -0.170 & 0.057 \\
\hline 5412500 & & & 0.204 & 0.022 & 0.336 & 0.000 \\
\hline 5418500 & & & & & 0.207 & 0.020 \\
\hline 5420500 & & & 0.164 & 0.065 & & \\
\hline 5426000 & & & & & -0.167 & 0.060 \\
\hline 5436500 & -0.219 & 0.015 & -0.316 & 0.000 & -0.293 & 0.001 \\
\hline 5454500 & -0.216 & 0.015 & & & -0.219 & 0.014 \\
\hline 5459500 & & & 0.178 & 0.046 & 0.165 & 0.063 \\
\hline 5464500 & -0.207 & 0.020 & -0.178 & 0.046 & -0.171 & 0.055 \\
\hline 5482500 & 0.232 & 0.009 & & & 0.153 & 0.086 \\
\hline 5484000 & 0.261 & 0.003 & & & 0.148 & 0.096 \\
\hline 5484500 & 0.258 & 0.004 & & & 0.250 & 0.005 \\
\hline 5490500 & -0.161 & 0.071 & & & & \\
\hline 5497000 & & & & & 0.217 & 0.020 \\
\hline 5500000 & & & 0.171 & 0.055 & & \\
\hline 5501000 & & & & & 0.161 & 0.071 \\
\hline 5520500 & & & 0.193 & 0.030 & & \\
\hline 5555300 & & & & & -0.177 & 0.047 \\
\hline 5572000 & -0.186 & 0.036 & -0.196 & 0.027 & -0.216 & 0.015 \\
\hline 5593000 & -0.249 & 0.005 & -0.198 & 0.026 & -0.271 & 0.002 \\
\hline 5597000 & & & -0.219 & 0.014 & -0.182 & 0.041 \\
\hline 6019500 & & & & & 0.181 & 0.042 \\
\hline 6191500 & 0.313 & 0.000 & 0.159 & 0.074 & 0.295 & 0.001 \\
\hline 6192500 & 0.286 & 0.001 & 0.177 & 0.047 & 0.302 & 0.001 \\
\hline 6207500 & 0.348 & 0.000 & 0.173 & 0.051 & 0.251 & 0.005 \\
\hline 6214500 & 0.352 & 0.000 & 0.159 & 0.074 & 0.256 & 0.004 \\
\hline 6289000 & 0.185 & 0.037 & & & 0.164 & 0.065 \\
\hline 6335500 & 0.263 & 0.003 & 0.313 & 0.000 & 0.380 & 0.000 \\
\hline 6337000 & 0.223 & 0.012 & 0.309 & 0.001 & 0.376 & 0.000 \\
\hline 6340500 & & & 0.179 & 0.045 & 0.157 & 0.077 \\
\hline
\end{tabular}


Table F.6, continued

\begin{tabular}{|c|c|c|c|c|c|c|}
\hline \multirow{2}{*}{$\begin{array}{c}\text { Station } \\
\text { Number }\end{array}$} & \multicolumn{2}{|c|}{ 3-Month Lead } & \multicolumn{2}{|c|}{ 6-Month Lead } & \multicolumn{2}{|c|}{ 9-Month Lead } \\
\hline & tau & p-value & tau & p-value & tau & p-value \\
\hline 6441500 & 0.167 & 0.061 & 0.195 & 0.028 & 0.288 & 0.001 \\
\hline 6452000 & 0.254 & 0.004 & 0.263 & 0.003 & 0.266 & 0.003 \\
\hline 6478500 & 0.326 & 0.000 & 0.220 & 0.013 & 0.291 & 0.001 \\
\hline 6600500 & & & -0.234 & 0.008 & -0.283 & 0.001 \\
\hline 6606600 & -0.179 & 0.045 & -0.183 & 0.040 & -0.214 & 0.016 \\
\hline 6620000 & 0.235 & 0.008 & & & 0.155 & 0.082 \\
\hline 6630000 & 0.178 & 0.046 & & & 0.216 & 0.015 \\
\hline 6635000 & 0.230 & 0.010 & 0.168 & 0.058 & 0.263 & 0.003 \\
\hline 6864500 & 0.345 & 0.000 & 0.213 & 0.017 & 0.227 & 0.011 \\
\hline 6869500 & -0.211 & 0.018 & -0.149 & 0.095 & & \\
\hline 6889500 & -0.180 & 0.043 & & & -0.202 & 0.023 \\
\hline 6892000 & -0.207 & 0.020 & -0.171 & 0.054 & -0.151 & 0.089 \\
\hline 6913500 & -0.303 & 0.001 & -0.254 & 0.004 & -0.225 & 0.011 \\
\hline 7013000 & 0.247 & 0.005 & 0.188 & 0.034 & 0.175 & 0.049 \\
\hline 7016500 & 0.151 & 0.090 & & & 0.205 & 0.021 \\
\hline 7018500 & 0.322 & 0.000 & 0.289 & 0.001 & 0.271 & 0.002 \\
\hline 7019000 & & & 0.168 & 0.058 & & \\
\hline 7061500 & 0.263 & 0.003 & 0.228 & 0.010 & 0.222 & 0.012 \\
\hline 7074000 & & & 0.260 & 0.003 & & \\
\hline 7096000 & 0.306 & 0.001 & 0.190 & 0.032 & 0.239 & 0.007 \\
\hline 7146500 & -0.251 & 0.005 & & & -0.223 & 0.012 \\
\hline 7180500 & -0.274 & 0.002 & -0.237 & 0.008 & -0.291 & 0.001 \\
\hline 7183000 & -0.180 & 0.043 & -0.220 & 0.013 & & \\
\hline 7187000 & -0.206 & 0.021 & & & & \\
\hline 7203000 & 0.248 & 0.008 & 0.183 & 0.049 & 0.194 & 0.037 \\
\hline 7218000 & & & & & -0.178 & 0.047 \\
\hline 7234000 & 0.182 & 0.041 & & & & \\
\hline 7247000 & -0.267 & 0.003 & -0.167 & 0.061 & -0.310 & 0.000 \\
\hline 7247500 & -0.240 & 0.007 & & & & \\
\hline 7252000 & & & 0.223 & 0.012 & & \\
\hline 7261500 & 0.223 & 0.012 & 0.234 & 0.008 & & \\
\hline 7291000 & & & -0.159 & 0.073 & -0.163 & 0.067 \\
\hline 7340000 & -0.180 & 0.043 & & & -0.272 & 0.002 \\
\hline 7375500 & -0.175 & 0.049 & -0.223 & 0.012 & -0.187 & 0.035 \\
\hline 7378500 & & & & & -0.211 & 0.017 \\
\hline 8013500 & -0.149 & 0.095 & & & & \\
\hline 8032000 & -0.249 & 0.005 & -0.192 & 0.031 & -0.246 & 0.006 \\
\hline 8033500 & -0.275 & 0.002 & -0.179 & 0.044 & -0.254 & 0.004 \\
\hline 8041000 & -0.327 & 0.000 & -0.357 & 0.000 & -0.314 & 0.000 \\
\hline 8041500 & & & & & -0.166 & 0.063 \\
\hline 8055500 & & & 0.189 & 0.033 & 0.181 & 0.042 \\
\hline 8070000 & -0.258 & 0.004 & -0.202 & 0.023 & -0.203 & 0.022 \\
\hline 8082000 & & & & & 0.159 & 0.073 \\
\hline 8082500 & 0.210 & 0.018 & & & 0.147 & 0.099 \\
\hline 8085500 & 0.168 & 0.059 & 0.289 & 0.001 & 0.210 & 0.018 \\
\hline
\end{tabular}


Table F.6, continued

\begin{tabular}{|c|c|c|c|c|c|c|}
\hline \multirow{2}{*}{$\begin{array}{c}\text { Station } \\
\text { Number }\end{array}$} & \multicolumn{2}{|c|}{ 3-Month Lead } & \multicolumn{2}{|c|}{ 6-Month Lead } & \multicolumn{2}{|c|}{ 9-Month Lead } \\
\hline & tau & p-value & tau & p-value & tau & p-value \\
\hline 8088000 & & & 0.184 & 0.039 & 0.175 & 0.049 \\
\hline 8095000 & 0.279 & 0.002 & 0.203 & 0.022 & 0.249 & 0.005 \\
\hline 8128000 & & & 0.219 & 0.014 & & \\
\hline 8167000 & 0.185 & 0.038 & 0.271 & 0.002 & 0.163 & 0.069 \\
\hline 8167500 & 0.155 & 0.081 & & & 0.159 & 0.073 \\
\hline 8171000 & & & -0.194 & 0.029 & & \\
\hline 8189500 & & & -0.321 & 0.000 & -0.220 & 0.014 \\
\hline 8190000 & & & -0.252 & 0.005 & & \\
\hline 8205500 & 0.163 & 0.066 & & & 0.220 & 0.013 \\
\hline 8210000 & & & -0.153 & 0.085 & & \\
\hline 8276500 & & & -0.159 & 0.073 & & \\
\hline 8291000 & 0.219 & 0.015 & 0.194 & 0.030 & & \\
\hline 9085000 & 0.170 & 0.057 & & & & \\
\hline 9110000 & 0.366 & 0.000 & 0.196 & 0.027 & 0.283 & 0.001 \\
\hline 9112500 & 0.465 & 0.000 & 0.285 & 0.001 & 0.272 & 0.002 \\
\hline 9119000 & 0.306 & 0.001 & 0.232 & 0.009 & 0.305 & 0.001 \\
\hline 9132500 & 0.345 & 0.000 & 0.266 & 0.003 & 0.303 & 0.001 \\
\hline 9147500 & 0.243 & 0.006 & 0.231 & 0.009 & 0.284 & 0.001 \\
\hline 9180500 & 0.297 & 0.001 & 0.219 & 0.014 & 0.312 & 0.000 \\
\hline 9239500 & 0.277 & 0.002 & 0.210 & 0.018 & 0.197 & 0.027 \\
\hline 9251000 & 0.347 & 0.000 & 0.249 & 0.005 & 0.355 & 0.000 \\
\hline 9304500 & 0.391 & 0.000 & 0.299 & 0.001 & 0.363 & 0.000 \\
\hline 9310500 & 0.328 & 0.000 & 0.255 & 0.004 & 0.301 & 0.001 \\
\hline 9315000 & 0.272 & 0.002 & 0.152 & 0.087 & 0.258 & 0.004 \\
\hline 9379500 & & & & & -0.162 & 0.069 \\
\hline 9430500 & 0.163 & 0.066 & & & & \\
\hline 9448500 & 0.293 & 0.001 & 0.154 & 0.083 & 0.180 & 0.043 \\
\hline 9471000 & 0.389 & 0.000 & 0.361 & 0.000 & & \\
\hline 9508500 & 0.359 & 0.000 & 0.280 & 0.002 & 0.204 & 0.022 \\
\hline 10128500 & 0.299 & 0.001 & 0.168 & 0.068 & 0.304 & 0.001 \\
\hline 10131000 & 0.342 & 0.000 & 0.273 & 0.002 & 0.416 & 0.000 \\
\hline 10234500 & 0.291 & 0.001 & 0.215 & 0.015 & 0.236 & 0.008 \\
\hline 10296000 & 0.201 & 0.024 & & & & \\
\hline 10310000 & & & -0.223 & 0.012 & -0.153 & 0.086 \\
\hline 10312000 & 0.205 & 0.021 & 0.166 & 0.063 & 0.236 & 0.008 \\
\hline 10329500 & & & & & 0.157 & 0.077 \\
\hline 11264500 & & & -0.183 & 0.040 & -0.168 & 0.058 \\
\hline 11367500 & & & & & 0.168 & 0.058 \\
\hline 11381500 & 0.190 & 0.033 & 0.161 & 0.070 & 0.259 & 0.004 \\
\hline 11383500 & 0.206 & 0.020 & 0.218 & 0.014 & 0.337 & 0.000 \\
\hline 11402000 & 0.188 & 0.034 & 0.214 & 0.016 & 0.306 & 0.001 \\
\hline 11413000 & 0.160 & 0.074 & & & 0.221 & 0.014 \\
\hline 11425500 & 0.250 & 0.005 & 0.242 & 0.006 & 0.343 & 0.000 \\
\hline 11477000 & & & & & 0.216 & 0.015 \\
\hline 11478500 & 0.201 & 0.024 & 0.206 & 0.020 & 0.370 & 0.000 \\
\hline
\end{tabular}


Table F.6, continued

\begin{tabular}{|c|c|c|c|c|c|c|}
\hline \multirow{2}{*}{$\begin{array}{c}\text { Station } \\
\text { Number }\end{array}$} & \multicolumn{2}{|c|}{ 3-Month Lead } & \multicolumn{2}{|c|}{ 6-Month Lead } & \multicolumn{2}{|c|}{ 9-Month Lead } \\
\hline & tau & p-value & tau & $\mathrm{p}$-value & tau & p-value \\
\hline 11501000 & 0.208 & 0.019 & 0.197 & 0.027 & 0.209 & 0.019 \\
\hline 11522500 & & & & & 0.168 & 0.058 \\
\hline 11530000 & & & & & 0.259 & 0.004 \\
\hline 12010000 & & & 0.148 & 0.096 & & \\
\hline 12020000 & 0.217 & 0.015 & 0.227 & 0.011 & 0.157 & 0.077 \\
\hline 12027500 & 0.174 & 0.050 & 0.220 & 0.013 & 0.208 & 0.019 \\
\hline 12039500 & & & 0.260 & 0.003 & 0.192 & 0.031 \\
\hline 12048000 & 0.262 & 0.003 & 0.219 & 0.014 & 0.168 & 0.058 \\
\hline 12054000 & 0.286 & 0.001 & 0.271 & 0.002 & 0.251 & 0.005 \\
\hline 12056500 & 0.164 & 0.065 & & & & \\
\hline 12186000 & 0.167 & 0.060 & 0.213 & 0.017 & & \\
\hline 12189500 & & & 0.200 & 0.024 & & \\
\hline 12306500 & 0.190 & 0.032 & & & & \\
\hline 12330000 & 0.284 & 0.001 & 0.257 & 0.004 & 0.326 & 0.000 \\
\hline 12332000 & 0.217 & 0.015 & & & 0.159 & 0.073 \\
\hline 12354500 & 0.178 & 0.045 & & & & \\
\hline 12401500 & -0.227 & 0.011 & -0.252 & 0.005 & -0.285 & 0.001 \\
\hline 12404500 & -0.183 & 0.040 & -0.229 & 0.010 & -0.293 & 0.001 \\
\hline 12413000 & 0.240 & 0.007 & 0.239 & 0.007 & 0.210 & 0.018 \\
\hline 12422500 & 0.226 & 0.011 & 0.154 & 0.083 & & \\
\hline 12459000 & 0.189 & 0.033 & & & 0.157 & 0.077 \\
\hline 12488500 & 0.256 & 0.004 & & & & \\
\hline 13037500 & 0.269 & 0.002 & & & & \\
\hline 13185000 & 0.271 & 0.002 & 0.232 & 0.009 & 0.178 & 0.045 \\
\hline 13269000 & 0.153 & 0.086 & & & 0.246 & 0.006 \\
\hline 13302500 & 0.245 & 0.006 & & & 0.223 & 0.012 \\
\hline 13313000 & 0.275 & 0.002 & 0.197 & 0.026 & 0.193 & 0.030 \\
\hline 13317000 & 0.236 & 0.008 & 0.214 & 0.016 & 0.206 & 0.021 \\
\hline 13342500 & & & & & -0.175 & 0.049 \\
\hline 14020000 & & & 0.156 & 0.079 & & \\
\hline 14105700 & 0.191 & 0.032 & & & & \\
\hline 14113000 & & & & & 0.193 & 0.030 \\
\hline 14154500 & & & & & 0.191 & 0.032 \\
\hline 14185000 & & & & & 0.184 & 0.038 \\
\hline 14301000 & 0.189 & 0.033 & 0.228 & 0.010 & 0.230 & 0.010 \\
\hline 14301500 & 0.222 & 0.013 & 0.204 & 0.022 & 0.248 & 0.005 \\
\hline 14308000 & & & & & 0.207 & 0.020 \\
\hline 14325000 & & & 0.150 & 0.091 & 0.206 & 0.021 \\
\hline 14359000 & & & & & 0.182 & 0.041 \\
\hline
\end{tabular}




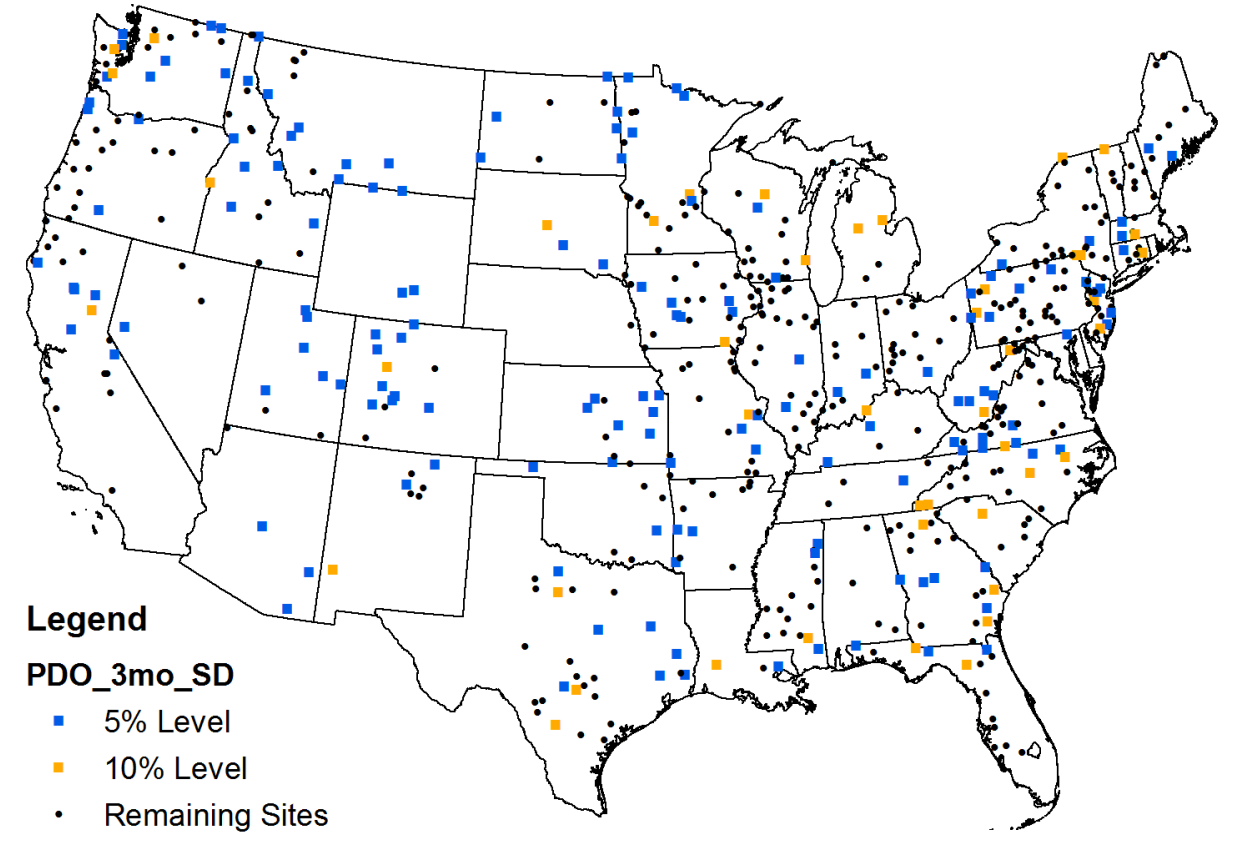

Figure F-18 Locations of sites with significant Kendall's tau correlation between 10-year moving standard deviation of log-transformed flood flows and 3-month average PDO anomalies with 3-month lead.

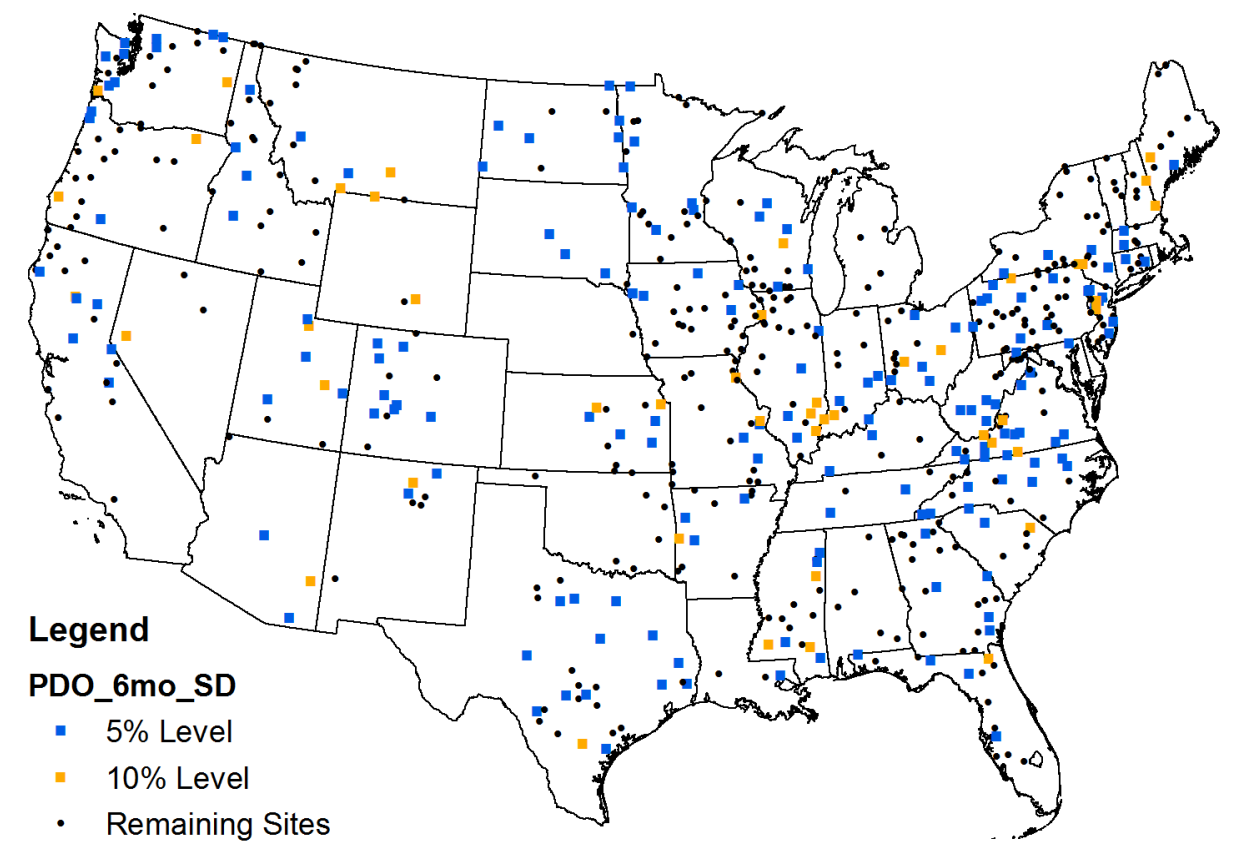

Figure F-19 Locations of sites with significant Kendall's tau correlation between 10-year moving standard deviation of log-transformed flood flows and 3-month average PDO anomalies with 6-month lead. 


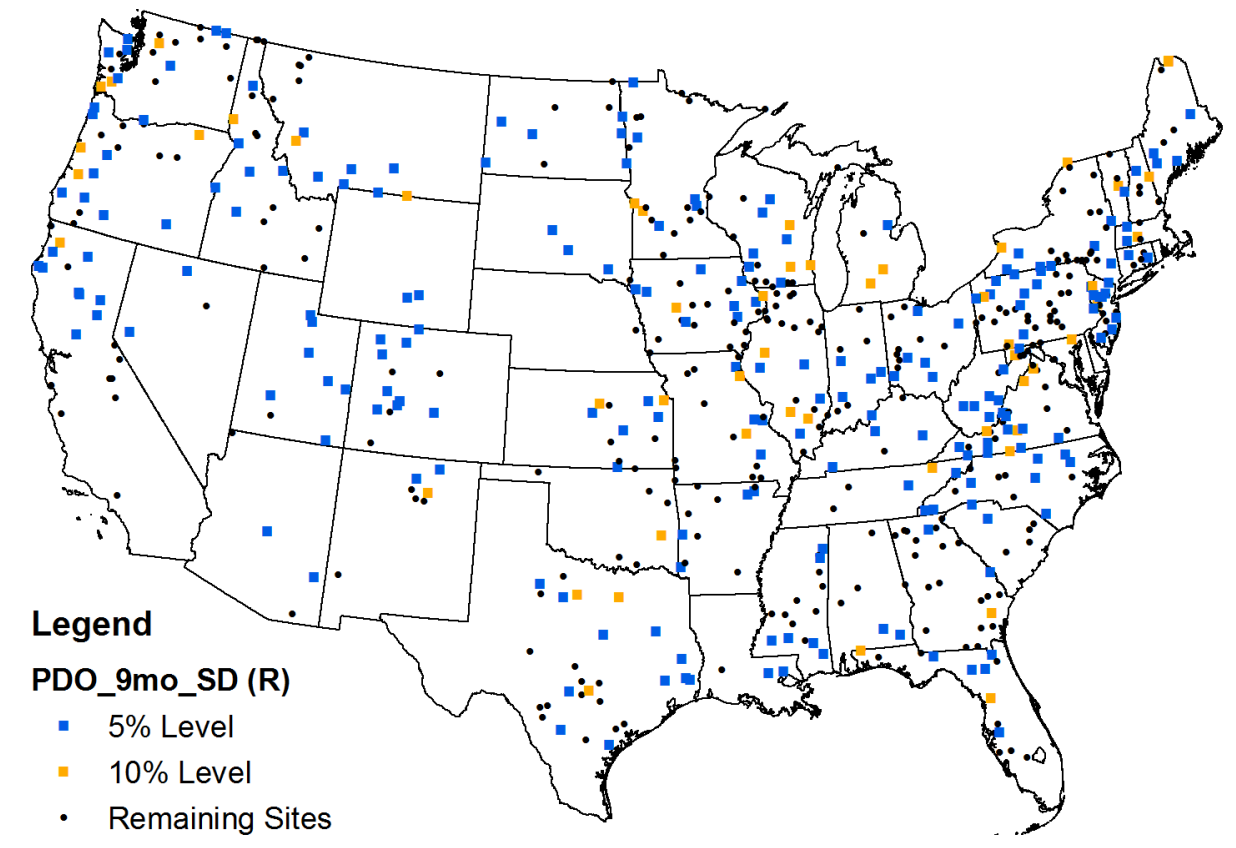

Figure F.20 Locations of sites with significant Pearson's r correlation between 10-year moving standard deviation of log-transformed flood flows and 3-month average PDO anomalies with 9-month lead.

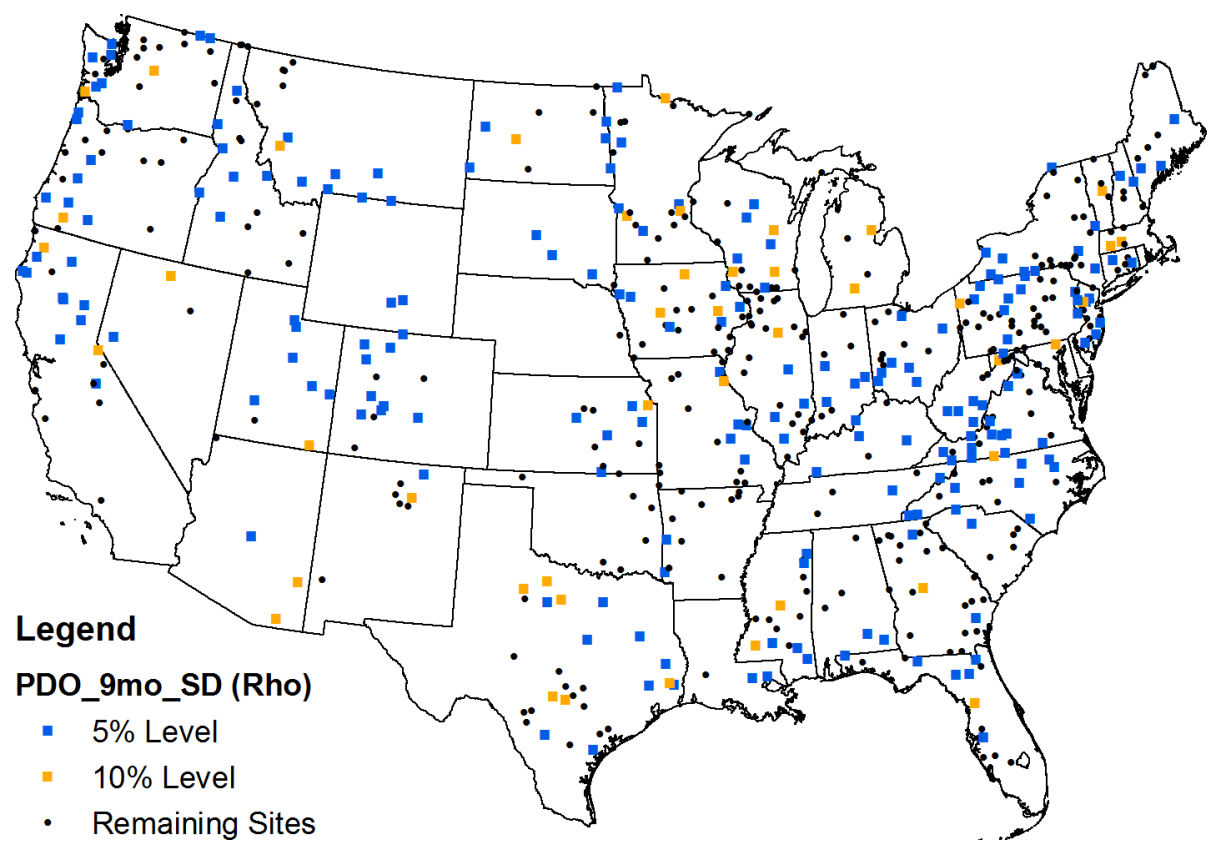

Figure F.21 Locations of sites with significant Spearman's rho correlation between 10year moving standard deviation of log-transformed flood flows and 3-month average PDO anomalies with 9-month lead. 


\section{APPENDIX G CORRELATION ANAYLSIS RESULTS BETWEEN ANNUAL MAXIMUM FLOOD SERIES AND FLOOD GENERATING HYDROCLIMATIC SERIES}

This appendix summarizes results of Pearson's correlation analyses between annual maximum flood (AMF) series and the associated flood generating precipitation and temperature series constructed using 1/8 degree gridded data and the best X-day lead time as described in Chapter 3. The association between temperature and AMF series is assessed with respect to both the magnitude and timing of AMF peaks. Only sites for which results are significant on the $10 \%$ level are included in the following tables (results significant on the 5\% level are in bold). Results are omitted (blank spaces) when pvalues greater than $10 \%$ level were obtained.

Table G.1

Results of Pearson's correlation analyses between magnitude of AMF peaks and associated flood generating hydroclimatic series with best lead times.

\begin{tabular}{|c|c|c|c|c|c|c|c|c|c|}
\hline \multirow[b]{2}{*}{$\begin{array}{c}\text { Site } \\
\text { Number }\end{array}$} & \multicolumn{3}{|c|}{ Precipitation } & \multicolumn{3}{|c|}{ Maximum Temperature } & \multicolumn{3}{|c|}{ Minimum Temperature } \\
\hline & $\begin{array}{c}\text { Lead } \\
\text { Time } \\
\text { (days) }\end{array}$ & $\mathrm{r}$ & $\begin{array}{c}\mathrm{p}- \\
\text { value }\end{array}$ & $\begin{array}{c}\text { Lead } \\
\text { Time } \\
\text { (days) }\end{array}$ & $\mathrm{r}$ & $\begin{array}{c}\text { p- } \\
\text { value }\end{array}$ & $\begin{array}{c}\text { Lead } \\
\text { Time } \\
\text { (Days) }\end{array}$ & $\mathrm{r}$ & $\begin{array}{c}\mathrm{p}- \\
\text { value }\end{array}$ \\
\hline 1011000 & 2 & 0.545 & 0.000 & & & & 2 & 0.299 & 0.024 \\
\hline 1013500 & 4 & 0.399 & 0.002 & 7 & 0.272 & 0.041 & 3 & 0.401 & 0.002 \\
\hline 1030500 & 5 & 0.402 & 0.002 & & & & 7 & 0.410 & 0.002 \\
\hline 1031500 & 2 & 0.709 & 0.000 & & & & & & \\
\hline 1038000 & 4 & 0.631 & 0.000 & & & & & & \\
\hline 1047000 & 4 & 0.612 & 0.000 & & & & & & \\
\hline 1055000 & 2 & 0.519 & 0.000 & & & & & & \\
\hline 1057000 & 4 & 0.644 & 0.000 & & & & & & \\
\hline 1064500 & 4 & 0.617 & 0.000 & & & & & & \\
\hline 1073000 & 3 & 0.774 & 0.000 & & & & 2 & 0.369 & 0.005 \\
\hline 1076500 & 4 & 0.543 & 0.000 & & & & & & \\
\hline 1078000 & 4 & 0.618 & 0.000 & 7 & 0.389 & 0.003 & 6 & 0.473 & 0.000 \\
\hline 1119500 & 7 & 0.770 & 0.000 & 7 & 0.284 & 0.032 & 6 & 0.372 & 0.004 \\
\hline 1127500 & 7 & 0.770 & 0.000 & 7 & 0.244 & 0.067 & & & \\
\hline 1137500 & 7 & 0.479 & 0.000 & 4 & -0.307 & 0.020 & 4 & -0.262 & 0.049 \\
\hline 1142500 & 3 & 0.570 & 0.000 & 6 & 0.532 & 0.000 & 7 & 0.487 & 0.000 \\
\hline 1144000 & 7 & 0.455 & 0.000 & 7 & 0.362 & 0.006 & 7 & 0.348 & 0.008 \\
\hline 1162500 & 7 & 0.463 & 0.000 & & & & & & \\
\hline
\end{tabular}


Table G.1, continued

\begin{tabular}{|c|c|c|c|c|c|c|c|c|c|}
\hline \multirow[b]{2}{*}{$\begin{array}{c}\text { Site } \\
\text { Number }\end{array}$} & \multicolumn{3}{|c|}{ Precipitation } & \multicolumn{3}{|c|}{ Maximum Temperature } & \multicolumn{3}{|c|}{ Minimum Temperature } \\
\hline & $\begin{array}{c}\text { Lead } \\
\text { Time } \\
\text { (days) }\end{array}$ & $\mathrm{r}$ & $\begin{array}{c}\mathrm{p}- \\
\text { value }\end{array}$ & $\begin{array}{c}\text { Lead } \\
\text { Time } \\
\text { (days) }\end{array}$ & $\mathrm{r}$ & $\begin{array}{c}\mathrm{p}- \\
\text { value }\end{array}$ & $\begin{array}{c}\text { Lead } \\
\text { Time } \\
\text { (Days) }\end{array}$ & $\mathrm{r}$ & $\begin{array}{c}\mathrm{p}- \\
\text { value }\end{array}$ \\
\hline 1169000 & $\overline{5}$ & 0.705 & 0.000 & 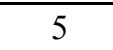 & 0.256 & 0.055 & $\overline{6} 6$ & 0.243 & 0.069 \\
\hline 1175500 & 7 & 0.450 & 0.000 & & & & & & \\
\hline 1176000 & 4 & 0.761 & 0.000 & 5 & 0.284 & 0.032 & 3 & 0.396 & 0.002 \\
\hline 1181000 & 7 & 0.773 & 0.000 & 6 & 0.234 & 0.080 & 5 & 0.271 & 0.042 \\
\hline 1188000 & 7 & 0.839 & 0.000 & & & & 7 & 0.328 & 0.013 \\
\hline 1193500 & 6 & 0.683 & 0.000 & & & & & & \\
\hline 1196500 & 7 & 0.665 & 0.000 & & & & & & \\
\hline 1318500 & 2 & 0.302 & 0.023 & & & & & & \\
\hline 1321000 & 2 & 0.530 & 0.000 & & & & 2 & 0.265 & 0.046 \\
\hline 1334500 & 2 & 0.619 & 0.000 & & & & & & \\
\hline 1350000 & 2 & 0.669 & 0.000 & & & & & & \\
\hline 1365000 & 2 & 0.642 & 0.000 & 6 & 0.221 & 0.099 & 7 & 0.226 & 0.091 \\
\hline 1372500 & 2 & 0.687 & 0.000 & 2 & 0.306 & 0.021 & 7 & 0.330 & 0.012 \\
\hline 1379500 & 4 & 0.615 & 0.000 & 7 & 0.306 & 0.021 & 2 & 0.350 & 0.008 \\
\hline 1381500 & 7 & 0.717 & 0.000 & & & & & & \\
\hline 1387500 & 2 & 0.798 & 0.000 & 5 & 0.335 & 0.011 & 2 & 0.342 & 0.009 \\
\hline 1396500 & 2 & 0.521 & 0.000 & & & & & & \\
\hline 1398000 & 2 & 0.779 & 0.000 & 3 & 0.323 & 0.014 & 2 & 0.273 & 0.040 \\
\hline 1398500 & 5 & 0.833 & 0.000 & 3 & 0.280 & 0.035 & 2 & 0.264 & 0.047 \\
\hline 1399500 & 5 & 0.676 & 0.000 & & & & 2 & 0.229 & 0.087 \\
\hline 1408000 & 4 & 0.524 & 0.000 & & & & & & \\
\hline 1408500 & 3 & 0.725 & 0.000 & & & & 2 & 0.316 & 0.017 \\
\hline 1410000 & 7 & 0.658 & 0.000 & 7 & 0.350 & 0.008 & 2 & 0.428 & 0.001 \\
\hline 1411000 & 4 & 0.548 & 0.000 & & & & & & \\
\hline 1411500 & 5 & 0.655 & 0.000 & 7 & 0.236 & 0.078 & 4 & 0.308 & 0.020 \\
\hline 1413500 & 2 & 0.590 & 0.000 & & & & & & \\
\hline 1414500 & 2 & 0.538 & 0.000 & & & & & & \\
\hline 1420500 & 4 & 0.654 & 0.000 & & & & 2 & 0.249 & 0.061 \\
\hline 1421000 & 4 & 0.633 & 0.000 & & & & 2 & 0.259 & 0.052 \\
\hline 1426500 & 4 & 0.518 & 0.000 & & & & 2 & 0.261 & 0.050 \\
\hline 1439500 & 7 & 0.799 & 0.000 & 2 & 0.431 & 0.001 & 7 & 0.407 & 0.002 \\
\hline 1440000 & 2 & 0.641 & 0.000 & & & & & & \\
\hline 1445500 & 6 & 0.509 & 0.000 & & & & & & \\
\hline 1459500 & 7 & 0.610 & 0.000 & 4 & 0.453 & 0.000 & 3 & 0.433 & 0.001 \\
\hline 1463500 & 5 & 0.600 & 0.000 & 2 & 0.410 & 0.002 & 3 & 0.371 & 0.005 \\
\hline 1467000 & 4 & 0.615 & 0.000 & 7 & 0.251 & 0.059 & 2 & 0.364 & 0.005 \\
\hline 1503000 & 4 & 0.559 & 0.000 & 2 & 0.375 & 0.004 & 2 & 0.396 & 0.002 \\
\hline 1512500 & 4 & 0.398 & 0.002 & 6 & 0.282 & 0.034 & 4 & 0.313 & 0.018 \\
\hline 1514000 & 3 & 0.449 & 0.000 & & & & & & \\
\hline 1518000 & 2 & 0.768 & 0.000 & 7 & 0.242 & 0.070 & 3 & 0.288 & 0.030 \\
\hline 1520500 & 3 & 0.677 & 0.000 & & & & 4 & 0.235 & 0.079 \\
\hline 1531000 & 4 & 0.677 & 0.000 & 4 & 0.329 & 0.013 & 4 & 0.351 & 0.007 \\
\hline 1532000 & 3 & 0.671 & 0.000 & & & & 2 & 0.229 & 0.086 \\
\hline
\end{tabular}


Table G.1, continued

\begin{tabular}{|c|c|c|c|c|c|c|c|c|c|}
\hline \multirow[b]{2}{*}{$\begin{array}{c}\text { Site } \\
\text { Number }\end{array}$} & \multicolumn{3}{|c|}{ Precipitation } & \multicolumn{3}{|c|}{ Maximum Temperature } & \multicolumn{3}{|c|}{ Minimum Temperature } \\
\hline & $\begin{array}{l}\text { Lead } \\
\text { Time } \\
\text { (days) } \\
\end{array}$ & $\mathrm{r}$ & $\begin{array}{c}\mathrm{p}- \\
\text { value }\end{array}$ & $\begin{array}{l}\text { Lead } \\
\text { Time } \\
\text { (days) }\end{array}$ & $\mathrm{r}$ & $\begin{array}{c}\mathrm{p}- \\
\text { value }\end{array}$ & $\begin{array}{l}\text { Lead } \\
\text { Time } \\
\text { (Days) }\end{array}$ & $\mathrm{r}$ & $\begin{array}{c}\mathrm{p}- \\
\text { value }\end{array}$ \\
\hline 1534000 & 2 & 0.691 & 0.000 & 6 & 0.235 & 0.078 & 6 & 0.285 & 0.032 \\
\hline 1538000 & 5 & 0.594 & 0.000 & 2 & 0.343 & 0.009 & 2 & 0.257 & 0.053 \\
\hline 1539000 & 4 & 0.734 & 0.000 & 2 & 0.375 & 0.004 & 7 & 0.412 & 0.001 \\
\hline 1541000 & 3 & 0.663 & 0.000 & 6 & 0.401 & 0.002 & 7 & 0.412 & 0.001 \\
\hline 1541500 & 3 & 0.638 & 0.000 & & & & & & \\
\hline 1543500 & 4 & 0.701 & 0.000 & & & & & & \\
\hline 1548500 & 3 & 0.787 & 0.000 & & & & 3 & 0.238 & 0.075 \\
\hline 1555000 & 4 & 0.707 & 0.000 & & & & & & \\
\hline 1555500 & 2 & 0.852 & 0.000 & 2 & 0.241 & 0.071 & 3 & 0.277 & 0.037 \\
\hline 1556000 & 2 & 0.653 & 0.000 & & & & & & \\
\hline 1558000 & 3 & 0.780 & 0.000 & & & & & & \\
\hline 1560000 & 2 & 0.630 & 0.000 & 2 & 0.394 & 0.002 & 5 & 0.353 & 0.007 \\
\hline 1564500 & 2 & 0.665 & 0.000 & & & & & & \\
\hline 1567000 & 3 & 0.765 & 0.000 & & & & 6 & 0.221 & 0.099 \\
\hline 1568000 & 3 & 0.690 & 0.000 & & & & 4 & 0.221 & 0.098 \\
\hline 1574000 & 5 & 0.825 & 0.000 & 7 & 0.266 & 0.046 & 7 & 0.337 & 0.010 \\
\hline 1580000 & 2 & 0.450 & 0.000 & & & & & & \\
\hline 1599000 & 2 & 0.754 & 0.000 & 2 & 0.279 & 0.036 & 2 & 0.381 & 0.003 \\
\hline 1601500 & 3 & 0.292 & 0.028 & & & & & & \\
\hline 1604500 & 2 & 0.662 & 0.000 & & & & & & \\
\hline 1608500 & 3 & 0.779 & 0.000 & & & & & & \\
\hline 1610000 & 3 & 0.776 & 0.000 & & & & 4 & 0.236 & 0.077 \\
\hline 1613000 & 4 & 0.651 & 0.000 & & & & & & \\
\hline 1614500 & 3 & 0.770 & 0.000 & & & & 5 & 0.261 & 0.050 \\
\hline 1631000 & 5 & 0.877 & 0.000 & & & & 2 & 0.353 & 0.007 \\
\hline 1632000 & 4 & 0.720 & 0.000 & & & & & & \\
\hline 1634000 & 5 & 0.761 & 0.000 & & & & 2 & 0.241 & 0.070 \\
\hline 1634500 & 4 & 0.652 & 0.000 & 4 & 0.360 & 0.006 & 2 & 0.407 & 0.002 \\
\hline 1645000 & 2 & 0.618 & 0.000 & 7 & 0.289 & 0.029 & 7 & 0.328 & 0.013 \\
\hline 1667500 & 3 & 0.825 & 0.000 & 3 & 0.344 & 0.009 & 2 & 0.415 & 0.001 \\
\hline 2013000 & 2 & 0.702 & 0.000 & & & & 6 & 0.347 & 0.008 \\
\hline 2016000 & 3 & 0.793 & 0.000 & 2 & 0.302 & 0.022 & 2 & 0.388 & 0.003 \\
\hline 2017500 & 2 & 0.561 & 0.000 & & & & & & \\
\hline 2018000 & 2 & 0.599 & 0.000 & & & & & & \\
\hline 2035000 & 7 & 0.754 & 0.000 & 4 & 0.236 & 0.077 & 3 & 0.332 & 0.012 \\
\hline 3010500 & 2 & 0.847 & 0.000 & & & & 4 & 0.226 & 0.091 \\
\hline 3011020 & 4 & 0.676 & 0.000 & & & & & & \\
\hline 3015500 & 3 & 0.277 & 0.037 & & & & & & \\
\hline 3020500 & 3 & 0.529 & 0.000 & & & & & & \\
\hline 3024000 & 2 & -0.246 & 0.065 & 2 & -0.225 & 0.092 & 2 & -0.253 & 0.058 \\
\hline 3032500 & 7 & 0.713 & 0.000 & 7 & 0.415 & 0.001 & 7 & 0.460 & 0.000 \\
\hline 3034500 & 2 & 0.570 & 0.000 & 7 & 0.319 & 0.016 & 6 & 0.336 & 0.011 \\
\hline 3051000 & 3 & 0.770 & 0.000 & & & & & & \\
\hline
\end{tabular}


Table G.1, continued

\begin{tabular}{|c|c|c|c|c|c|c|c|c|c|}
\hline \multirow[b]{2}{*}{$\begin{array}{c}\text { Site } \\
\text { Number }\end{array}$} & \multicolumn{3}{|c|}{ Precipitation } & \multicolumn{3}{|c|}{ Maximum Temperature } & \multicolumn{3}{|c|}{ Minimum Temperature } \\
\hline & $\begin{array}{l}\text { Lead } \\
\text { Time } \\
\text { (days) }\end{array}$ & $\mathrm{r}$ & $\begin{array}{c}\mathrm{p}- \\
\text { value }\end{array}$ & $\begin{array}{l}\text { Lead } \\
\text { Time } \\
\text { (days) }\end{array}$ & $\mathrm{r}$ & $\begin{array}{c}\mathrm{p}- \\
\text { value }\end{array}$ & $\begin{array}{c}\text { Lead } \\
\text { Time } \\
\text { (Days) }\end{array}$ & $\mathrm{r}$ & $\begin{array}{c}\mathrm{p}- \\
\text { value }\end{array}$ \\
\hline 3069500 & $\overline{20}$ & 0.700 & $\overline{0.000}$ & & & & & & \\
\hline 3079000 & 2 & 0.488 & 0.000 & & & & & & \\
\hline 3080000 & 2 & 0.730 & 0.000 & 5 & 0.355 & 0.007 & 4 & 0.420 & 0.001 \\
\hline 3102500 & 6 & 0.453 & 0.000 & & & & & & \\
\hline 3106000 & 3 & 0.661 & 0.000 & & & & & & \\
\hline 3109500 & 6 & 0.684 & 0.000 & & & & & & \\
\hline 3118500 & 2 & 0.631 & 0.000 & 2 & 0.331 & 0.012 & 2 & 0.337 & 0.010 \\
\hline 3144000 & 3 & 0.766 & 0.000 & & & & & & \\
\hline 3164000 & 2 & 0.718 & 0.000 & 2 & 0.292 & 0.028 & 2 & 0.370 & 0.005 \\
\hline 3167000 & 3 & 0.491 & 0.000 & & & & & & \\
\hline 3170000 & 2 & 0.672 & 0.000 & 7 & 0.276 & $\mathbf{0 . 0 3 7}$ & 7 & 0.349 & 0.008 \\
\hline 3173000 & 2 & 0.678 & 0.000 & & & & & & \\
\hline 3175500 & 2 & 0.569 & 0.000 & & & & & & \\
\hline 3182500 & 2 & 0.711 & 0.000 & & & & & & \\
\hline 3183500 & 3 & 0.577 & 0.000 & & & & & & \\
\hline 3186500 & 2 & 0.546 & 0.000 & 2 & 0.276 & $\mathbf{0 . 0 3 7}$ & 2 & 0.297 & 0.025 \\
\hline 3193000 & 2 & 0.650 & 0.000 & & & & & & \\
\hline 3198500 & 3 & 0.667 & 0.000 & & & & & & \\
\hline 3219500 & 5 & 0.446 & 0.001 & 6 & -0.239 & 0.073 & & & \\
\hline 3230500 & 5 & 0.584 & 0.000 & 6 & -0.304 & 0.021 & 7 & -0.300 & 0.023 \\
\hline 3234500 & 4 & 0.762 & 0.000 & 2 & -0.384 & 0.003 & 2 & -0.380 & 0.004 \\
\hline 3253500 & 4 & 0.716 & 0.000 & & & & & & \\
\hline 3262000 & 6 & 0.603 & 0.000 & & & & & & \\
\hline 3265000 & 2 & 0.626 & 0.000 & & & & & & \\
\hline 3266000 & 7 & 0.525 & 0.000 & & & & & & \\
\hline 3269500 & 2 & 0.537 & 0.000 & 5 & -0.331 & 0.013 & 4 & -0.337 & 0.011 \\
\hline 3272000 & 3 & 0.662 & 0.000 & 2 & -0.236 & 0.078 & & & \\
\hline 3274000 & 3 & 0.684 & 0.000 & 5 & -0.288 & 0.030 & 5 & -0.295 & 0.026 \\
\hline 3275000 & 3 & 0.543 & 0.000 & & & & & & \\
\hline 3281500 & 6 & 0.718 & 0.000 & & & & & & \\
\hline 3301500 & 6 & 0.856 & 0.000 & & & & & & \\
\hline 3307000 & 3 & 0.781 & 0.000 & & & & & & \\
\hline 3326500 & 5 & 0.537 & 0.000 & 2 & 0.276 & 0.038 & 2 & 0.324 & 0.014 \\
\hline 3335500 & 7 & 0.517 & 0.000 & & & & & & \\
\hline 3339500 & 3 & 0.693 & 0.000 & & & & & & \\
\hline 3345500 & 4 & 0.737 & 0.000 & & & & & & \\
\hline 3360500 & 7 & 0.792 & 0.000 & & & & & & \\
\hline 3363500 & 3 & 0.735 & 0.000 & 3 & -0.304 & 0.022 & 5 & -0.280 & 0.035 \\
\hline 3373500 & 7 & 0.451 & 0.000 & & & & & & \\
\hline 3374000 & 7 & 0.502 & 0.000 & 7 & -0.243 & 0.068 & & & \\
\hline 3379500 & 4 & 0.746 & 0.000 & & & & & & \\
\hline 3380500 & 6 & 0.884 & 0.000 & & & & & & \\
\hline 3381500 & 7 & 0.369 & 0.005 & & & & & & \\
\hline
\end{tabular}


Table G.1, continued

\begin{tabular}{|c|c|c|c|c|c|c|c|c|c|}
\hline \multirow[b]{2}{*}{$\begin{array}{c}\text { Site } \\
\text { Number }\end{array}$} & \multicolumn{3}{|c|}{ Precipitation } & \multicolumn{3}{|c|}{ Maximum Temperature } & \multicolumn{3}{|c|}{ Minimum Temperature } \\
\hline & $\begin{array}{c}\text { Lead } \\
\text { Time } \\
\text { (days) }\end{array}$ & $\mathrm{r}$ & $\begin{array}{c}\mathrm{p}- \\
\text { value }\end{array}$ & $\begin{array}{c}\text { Lead } \\
\text { Time } \\
\text { (days) } \\
\end{array}$ & $\mathrm{r}$ & $\begin{array}{c}\mathrm{p}- \\
\text { value }\end{array}$ & $\begin{array}{c}\text { Lead } \\
\text { Time } \\
\text { (Days) }\end{array}$ & $\mathrm{r}$ & $\begin{array}{c}\mathrm{p}- \\
\text { value }\end{array}$ \\
\hline 3434500 & 3 & 0.705 & 0.000 & & & & & & \\
\hline 3438000 & 2 & 0.754 & 0.000 & & & & & & \\
\hline 3612000 & 5 & 0.834 & 0.000 & & & & & & \\
\hline 4056500 & 3 & 0.484 & 0.000 & & & & 3 & 0.269 & 0.043 \\
\hline 4073500 & 2 & 0.225 & 0.092 & & & & & & \\
\hline 4079000 & 7 & 0.371 & 0.004 & & & & & & \\
\hline 4087000 & 7 & 0.351 & $\mathbf{0 . 0 0 7}$ & & & & & & \\
\hline 4100500 & 2 & 0.428 & 0.001 & & & & & & \\
\hline 4105000 & 4 & 0.544 & 0.000 & & & & & & \\
\hline 4112500 & 6 & 0.304 & 0.022 & & & & & & \\
\hline 4191500 & 4 & 0.301 & 0.023 & & & & & & \\
\hline 4193500 & & & & 7 & -0.223 & 0.096 & 7 & -0.232 & 0.083 \\
\hline 4214500 & 4 & 0.581 & 0.000 & & & & & & \\
\hline 4223000 & 5 & 0.724 & 0.000 & & & & & & \\
\hline 4234000 & 3 & 0.508 & 0.000 & & & & 2 & 0.230 & 0.085 \\
\hline 4262500 & 2 & 0.552 & 0.000 & & & & 2 & 0.298 & 0.025 \\
\hline 4269000 & 6 & 0.304 & 0.021 & & & & & & \\
\hline 4275000 & 3 & 0.412 & 0.001 & & & & & & \\
\hline 4287000 & 2 & 0.546 & 0.000 & & & & & & \\
\hline 5291000 & 3 & 0.360 & 0.006 & & & & & & \\
\hline 5293000 & & & & 5 & -0.230 & 0.085 & & & \\
\hline 5300000 & 3 & 0.239 & 0.073 & 2 & -0.312 & 0.018 & 2 & -0.273 & 0.040 \\
\hline 5304500 & 2 & 0.245 & 0.067 & & & & & & \\
\hline 5313500 & 3 & 0.399 & 0.002 & 7 & -0.231 & 0.084 & & & \\
\hline 5316500 & 4 & 0.373 & 0.004 & & & & & & \\
\hline 5317000 & 7 & 0.278 & 0.037 & & & & & & \\
\hline 5340500 & 4 & 0.332 & 0.012 & & & & & & \\
\hline 5362000 & 2 & 0.264 & 0.048 & & & & & & \\
\hline 5379500 & 3 & 0.240 & 0.072 & & & & & & \\
\hline 5399500 & 3 & 0.504 & 0.000 & 3 & 0.244 & 0.068 & 5 & 0.235 & 0.078 \\
\hline 5408000 & 2 & 0.539 & 0.000 & & & & 2 & 0.225 & 0.092 \\
\hline 5412500 & 3 & 0.478 & 0.000 & & & & & & \\
\hline 5414000 & 4 & 0.360 & 0.006 & 6 & 0.312 & 0.018 & 7 & 0.286 & 0.031 \\
\hline 5419000 & 3 & 0.450 & 0.000 & & & & & & \\
\hline 5421000 & 3 & 0.519 & 0.000 & & & & & & \\
\hline 5422000 & 5 & 0.348 & 0.008 & & & & & & \\
\hline 5432500 & 2 & 0.546 & 0.000 & 2 & 0.388 & 0.003 & 2 & 0.388 & 0.003 \\
\hline 5434500 & 4 & 0.392 & 0.003 & & & & & & \\
\hline 5436500 & 3 & 0.312 & 0.018 & & & & & & \\
\hline 5438500 & 3 & 0.280 & 0.035 & & & & & & \\
\hline 5440000 & 3 & 0.322 & 0.014 & & & & & & \\
\hline 5444000 & 5 & 0.500 & 0.000 & & & & & & \\
\hline 5446500 & 6 & 0.387 & 0.003 & & & & & & \\
\hline
\end{tabular}


Table G.1, continued

\begin{tabular}{|c|c|c|c|c|c|c|c|c|c|}
\hline \multirow[b]{2}{*}{$\begin{array}{c}\text { Site } \\
\text { Number }\end{array}$} & \multicolumn{3}{|c|}{ Precipitation } & \multicolumn{3}{|c|}{ Maximum Temperature } & \multicolumn{3}{|c|}{ Minimum Temperature } \\
\hline & $\begin{array}{c}\text { Lead } \\
\text { Time } \\
\text { (days) }\end{array}$ & $\mathrm{r}$ & $\begin{array}{c}\mathrm{p}- \\
\text { value }\end{array}$ & $\begin{array}{c}\text { Lead } \\
\text { Time } \\
\text { (days) }\end{array}$ & $\mathrm{r}$ & $\begin{array}{c}\text { p- } \\
\text { value }\end{array}$ & $\begin{array}{c}\text { Lead } \\
\text { Time } \\
\text { (Days) }\end{array}$ & $\mathrm{r}$ & $\begin{array}{c}\mathrm{p}- \\
\text { value }\end{array}$ \\
\hline 5447500 & 2 & 0.443 & 0.001 & & & & & & \\
\hline 5451500 & 4 & 0.301 & 0.023 & & & & & & \\
\hline 5454500 & 2 & 0.229 & 0.087 & & & & & & \\
\hline 5455500 & 4 & 0.528 & 0.000 & & & & & & \\
\hline 5459500 & 2 & 0.339 & 0.010 & & & & & & \\
\hline 5464500 & 7 & 0.312 & 0.018 & & & & & & \\
\hline 5465500 & 2 & 0.352 & 0.007 & & & & & & \\
\hline 5470000 & 4 & -0.256 & 0.055 & & & & & & \\
\hline 5479000 & 5 & 0.452 & 0.000 & 3 & -0.241 & 0.071 & & & \\
\hline 5482500 & 7 & 0.375 & 0.004 & & & & & & \\
\hline 5484000 & 5 & 0.452 & 0.000 & & & & 4 & 0.229 & 0.086 \\
\hline 5484500 & 5 & 0.444 & 0.001 & & & & & & \\
\hline 5486490 & 4 & 0.468 & 0.000 & & & & & & \\
\hline 5490500 & 2 & 0.235 & 0.079 & & & & & & \\
\hline 5495000 & 5 & 0.489 & 0.000 & & & & & & \\
\hline 5497000 & 4 & 0.482 & 0.000 & & & & & & \\
\hline 5500000 & 7 & 0.594 & 0.000 & & & & & & \\
\hline 5501000 & 2 & 0.647 & 0.000 & 2 & 0.235 & 0.079 & 3 & 0.267 & 0.045 \\
\hline 5520500 & 5 & 0.262 & 0.049 & & & & & & \\
\hline 5526000 & 7 & 0.344 & 0.009 & & & & & & \\
\hline 5527500 & 4 & 0.418 & 0.001 & & & & & & \\
\hline 5555300 & 4 & 0.425 & 0.001 & & & & & & \\
\hline 5556500 & 3 & 0.469 & 0.000 & & & & & & \\
\hline 5570000 & 5 & 0.429 & 0.001 & & & & & & \\
\hline 5572000 & 4 & 0.664 & 0.000 & & & & & & \\
\hline 5585000 & 7 & 0.624 & 0.000 & & & & & & \\
\hline 5592500 & 3 & 0.791 & 0.000 & & & & & & \\
\hline 5593000 & 7 & 0.699 & 0.000 & & & & & & \\
\hline 5597000 & 7 & 0.694 & 0.000 & & & & & & \\
\hline 7013000 & 3 & 0.713 & 0.000 & & & & & & \\
\hline 7016500 & 5 & 0.820 & 0.000 & & & & 4 & 0.225 & 0.092 \\
\hline 7018500 & 7 & 0.763 & 0.000 & & & & 5 & 0.225 & 0.092 \\
\hline 7019000 & 6 & 0.817 & 0.000 & & & & & & \\
\hline
\end{tabular}


Table G.2

Results of Pearson's correlation analyses between timing of AMF peaks and associated flood generating temperature (minimum and maximum) series with best lead times.

\begin{tabular}{|c|c|c|c|c|}
\hline $\begin{array}{c}\text { Site } \\
\text { Number }\end{array}$ & $\begin{array}{l}\text { Minimum 1 } \\
\text { Lead Time } \\
\text { (days) }\end{array}$ & $\begin{array}{l}\text { perature } \\
\text { p-value }\end{array}$ & $\begin{array}{l}\text { Maximum T } \\
\text { Lead Time } \\
\text { (days) }\end{array}$ & $\begin{array}{l}\text { iperature } \\
\text { p-value }\end{array}$ \\
\hline 01011000 & & & 7 & 0.000 \\
\hline 01013500 & 3 & 0.013 & 7 & 0.000 \\
\hline 01030500 & 2 & 0.002 & 2 & 0.000 \\
\hline 01031500 & 6 & 0.000 & 7 & 0.000 \\
\hline 01038000 & 5 & 0.000 & 6 & 0.000 \\
\hline 01047000 & 5 & 0.000 & 7 & 0.000 \\
\hline 01055000 & 7 & 0.000 & 7 & 0.000 \\
\hline 01057000 & 6 & 0.000 & 5 & 0.000 \\
\hline 01064500 & 7 & 0.000 & 7 & 0.000 \\
\hline 01073000 & 4 & 0.000 & 7 & 0.000 \\
\hline 01076500 & 7 & 0.000 & 7 & 0.000 \\
\hline 01078000 & 3 & 0.000 & 6 & 0.000 \\
\hline 01119500 & 7 & 0.000 & 6 & 0.000 \\
\hline 01127500 & 5 & 0.001 & 7 & 0.001 \\
\hline 01137500 & 7 & 0.000 & 7 & 0.000 \\
\hline 01142500 & 4 & 0.000 & 4 & 0.000 \\
\hline 01144000 & 5 & 0.000 & 5 & 0.000 \\
\hline 01162500 & 5 & 0.000 & 7 & 0.000 \\
\hline 01169000 & 3 & 0.000 & 5 & 0.000 \\
\hline 01175500 & 2 & 0.000 & 3 & 0.000 \\
\hline 01176000 & 3 & 0.000 & 6 & 0.000 \\
\hline 01181000 & 7 & 0.000 & 2 & 0.000 \\
\hline 01188000 & 6 & 0.000 & 5 & 0.000 \\
\hline 01193500 & 7 & 0.000 & 4 & 0.000 \\
\hline 01196500 & 7 & 0.000 & 5 & 0.000 \\
\hline 01318500 & 7 & 0.005 & 7 & 0.000 \\
\hline 01321000 & 4 & 0.002 & 4 & 0.000 \\
\hline 01334500 & 5 & 0.000 & 6 & 0.000 \\
\hline 01350000 & 2 & 0.000 & 3 & 0.000 \\
\hline 01365000 & 3 & 0.000 & 3 & 0.000 \\
\hline 01372500 & 7 & 0.000 & 4 & 0.000 \\
\hline 01379500 & 2 & 0.000 & 3 & 0.000 \\
\hline 01381500 & 7 & 0.000 & 7 & 0.000 \\
\hline 01387500 & 2 & 0.000 & 3 & 0.000 \\
\hline 01396500 & 7 & 0.000 & 3 & 0.000 \\
\hline 01398000 & 7 & 0.000 & 4 & 0.000 \\
\hline 01398500 & 7 & 0.000 & 4 & 0.000 \\
\hline 01399500 & 7 & 0.000 & 7 & 0.000 \\
\hline 01408000 & 2 & 0.000 & 2 & 0.000 \\
\hline
\end{tabular}


Table G.2, continued

\begin{tabular}{|c|c|c|c|c|}
\hline $\begin{array}{c}\text { Site } \\
\text { Number }\end{array}$ & $\begin{array}{l}\text { Minimum T } \\
\text { Lead Time } \\
\text { (days) }\end{array}$ & $\begin{array}{l}\text { perature } \\
\text { p-value }\end{array}$ & $\begin{array}{c}\text { Maximum } \\
\text { Lead Time } \\
\text { (days) }\end{array}$ & $\begin{array}{l}\text { iperature } \\
\text { p-value }\end{array}$ \\
\hline 01408500 & 4 & 0.000 & 3 & 0.000 \\
\hline 01410000 & 3 & 0.000 & 3 & 0.000 \\
\hline 01411000 & 4 & 0.000 & 5 & 0.000 \\
\hline 01411500 & 4 & 0.000 & 4 & 0.000 \\
\hline 01413500 & 7 & 0.000 & 3 & 0.000 \\
\hline 01414500 & 7 & 0.000 & 2 & 0.000 \\
\hline 01420500 & 7 & 0.000 & 3 & 0.000 \\
\hline 01421000 & 7 & 0.000 & 3 & 0.000 \\
\hline 01426500 & 5 & 0.000 & 7 & 0.000 \\
\hline 01439500 & 7 & 0.000 & 4 & 0.000 \\
\hline 01440000 & 2 & 0.000 & 3 & 0.000 \\
\hline 01445500 & 7 & 0.000 & 2 & 0.000 \\
\hline 01459500 & 7 & 0.000 & 4 & 0.000 \\
\hline 01463500 & 2 & 0.000 & 4 & 0.000 \\
\hline 01467000 & 4 & 0.000 & 7 & 0.000 \\
\hline 01503000 & 5 & 0.000 & 4 & 0.000 \\
\hline 01512500 & 4 & 0.000 & 5 & 0.000 \\
\hline 01514000 & 2 & 0.000 & 5 & 0.000 \\
\hline 01518000 & 7 & 0.009 & 2 & 0.024 \\
\hline 01520500 & 7 & 0.000 & 7 & 0.000 \\
\hline 01531000 & 7 & 0.000 & 7 & 0.000 \\
\hline 01532000 & 7 & 0.000 & 7 & 0.000 \\
\hline 01534000 & 2 & 0.000 & 7 & 0.000 \\
\hline 01538000 & 7 & 0.000 & 7 & 0.000 \\
\hline 01539000 & 7 & 0.000 & 2 & 0.000 \\
\hline 01541000 & 2 & 0.000 & 2 & 0.000 \\
\hline 01541500 & 2 & 0.000 & 6 & 0.000 \\
\hline 01543500 & 7 & 0.000 & 5 & 0.000 \\
\hline 01548500 & 7 & 0.000 & 7 & 0.000 \\
\hline 01555000 & 2 & 0.000 & 2 & 0.000 \\
\hline 01555500 & 7 & 0.000 & 7 & 0.000 \\
\hline 01556000 & 2 & 0.000 & 7 & 0.000 \\
\hline 01558000 & 2 & 0.000 & 7 & 0.000 \\
\hline 01560000 & 2 & 0.000 & 2 & 0.000 \\
\hline 01564500 & 6 & 0.003 & 2 & 0.008 \\
\hline 01567000 & 3 & 0.003 & 6 & 0.008 \\
\hline 01568000 & 4 & 0.000 & 7 & 0.000 \\
\hline 01574000 & 5 & 0.000 & 7 & 0.000 \\
\hline 01580000 & 7 & 0.000 & 4 & 0.000 \\
\hline 01599000 & 7 & 0.000 & 7 & 0.000 \\
\hline 01601500 & 5 & 0.000 & 7 & 0.000 \\
\hline 01604500 & 6 & 0.000 & 3 & 0.000 \\
\hline
\end{tabular}


Table G.2, continued

\begin{tabular}{|c|c|c|c|c|}
\hline \multirow{2}{*}{$\begin{array}{c}\text { Site } \\
\text { Number }\end{array}$} & \multicolumn{2}{|c|}{ Minimum Temperature } & \multicolumn{2}{|c|}{ Maximum Temperature } \\
\hline & $\begin{array}{l}\text { Lead Time } \\
\quad \text { (days) }\end{array}$ & p-value & $\begin{array}{l}\text { Lead Time } \\
\quad \text { (days) }\end{array}$ & p-value \\
\hline 01608500 & 7 & 0.000 & 7 & 0.000 \\
\hline 01610000 & 7 & 0.000 & 7 & 0.000 \\
\hline 01613000 & 7 & 0.000 & 7 & 0.000 \\
\hline 01614500 & 7 & 0.002 & 7 & 0.008 \\
\hline 01631000 & 2 & 0.000 & 5 & 0.000 \\
\hline 01632000 & 6 & 0.000 & 7 & 0.000 \\
\hline 01634000 & 7 & 0.000 & 7 & 0.000 \\
\hline 01634500 & 4 & 0.000 & 7 & 0.000 \\
\hline 01645000 & 7 & 0.000 & 7 & 0.000 \\
\hline 01667500 & 7 & 0.000 & 2 & 0.000 \\
\hline 02013000 & 2 & 0.000 & 2 & 0.000 \\
\hline 02016000 & 7 & 0.000 & 7 & 0.000 \\
\hline 02017500 & 7 & 0.000 & 7 & 0.000 \\
\hline 02018000 & 7 & 0.000 & 5 & 0.000 \\
\hline 02035000 & 3 & 0.000 & 2 & 0.000 \\
\hline 03010500 & 6 & 0.000 & 6 & 0.000 \\
\hline 03011020 & 2 & 0.000 & 5 & 0.000 \\
\hline 03015500 & 7 & 0.000 & 7 & 0.000 \\
\hline 03020500 & 6 & 0.000 & 7 & 0.000 \\
\hline 03024000 & 2 & 0.000 & 7 & 0.000 \\
\hline 03032500 & 5 & 0.000 & 5 & 0.000 \\
\hline 03034500 & 2 & 0.000 & 3 & 0.000 \\
\hline 03051000 & 2 & 0.000 & 3 & 0.000 \\
\hline 03069500 & 7 & 0.000 & 7 & 0.000 \\
\hline 03079000 & 7 & 0.000 & 7 & 0.000 \\
\hline 03080000 & 7 & 0.000 & 7 & 0.000 \\
\hline 03102500 & 2 & 0.000 & 3 & 0.000 \\
\hline 03106000 & 2 & 0.000 & 6 & 0.000 \\
\hline 03109500 & 2 & 0.000 & 6 & 0.000 \\
\hline 03118500 & 2 & 0.000 & 7 & 0.000 \\
\hline 03144000 & 2 & 0.000 & 4 & 0.000 \\
\hline 03164000 & 2 & 0.000 & 3 & 0.000 \\
\hline 03167000 & 6 & 0.000 & 6 & 0.000 \\
\hline 03170000 & 2 & 0.000 & 7 & 0.000 \\
\hline 03173000 & 7 & 0.000 & 5 & 0.000 \\
\hline 03175500 & 6 & 0.000 & 7 & 0.000 \\
\hline 03182500 & 2 & 0.001 & 3 & 0.000 \\
\hline 03183500 & 5 & 0.000 & 5 & 0.000 \\
\hline 03186500 & 6 & 0.000 & 3 & 0.000 \\
\hline 03193000 & 6 & 0.000 & 6 & 0.000 \\
\hline 03198500 & 7 & 0.000 & 7 & 0.000 \\
\hline 03219500 & 3 & 0.000 & 3 & 0.000 \\
\hline
\end{tabular}


Table G.2, continued

\begin{tabular}{|c|c|c|c|c|}
\hline $\begin{array}{c}\text { Site } \\
\text { Number }\end{array}$ & $\begin{array}{l}\text { Minimum T } \\
\text { Lead Time } \\
\text { (days) }\end{array}$ & $\begin{array}{l}\text { perature } \\
\text { p-value }\end{array}$ & $\begin{array}{c}\text { Maximum } \\
\text { Lead Time } \\
\text { (days) }\end{array}$ & $\begin{array}{l}\text { iperature } \\
\text { p-value }\end{array}$ \\
\hline 03230500 & 2 & 0.000 & 6 & 0.000 \\
\hline 03234500 & 3 & 0.000 & 3 & 0.000 \\
\hline 03253500 & 2 & 0.000 & 2 & 0.000 \\
\hline 03262000 & 7 & 0.000 & 7 & 0.000 \\
\hline 03265000 & 7 & 0.000 & 3 & 0.000 \\
\hline 03266000 & 3 & 0.000 & 3 & 0.000 \\
\hline 03269500 & 3 & 0.000 & 3 & 0.000 \\
\hline 03272000 & 2 & 0.000 & 2 & 0.000 \\
\hline 03274000 & 2 & 0.000 & 4 & 0.000 \\
\hline 03275000 & 2 & 0.000 & 7 & 0.000 \\
\hline 03281500 & 3 & 0.000 & 5 & 0.000 \\
\hline 03301500 & 4 & 0.000 & 4 & 0.000 \\
\hline 03307000 & 2 & 0.000 & 2 & 0.000 \\
\hline 03326500 & 2 & 0.000 & 2 & 0.000 \\
\hline 03335500 & 4 & 0.000 & 7 & 0.000 \\
\hline 03339500 & 2 & 0.000 & 2 & 0.000 \\
\hline 03345500 & 2 & 0.000 & 2 & 0.000 \\
\hline 03360500 & 4 & 0.000 & 3 & 0.000 \\
\hline 03363500 & 7 & 0.000 & 7 & 0.000 \\
\hline 03373500 & 3 & 0.000 & 7 & 0.000 \\
\hline 03374000 & 3 & 0.000 & 5 & 0.000 \\
\hline 03379500 & 4 & 0.000 & 6 & 0.000 \\
\hline 03380500 & 5 & 0.000 & 6 & 0.000 \\
\hline 03381500 & 5 & 0.000 & 5 & 0.000 \\
\hline 03434500 & 7 & 0.000 & 7 & 0.000 \\
\hline 03438000 & 7 & 0.000 & 2 & 0.000 \\
\hline 03612000 & 4 & 0.000 & 4 & 0.000 \\
\hline 04056500 & 3 & 0.045 & 7 & 0.008 \\
\hline 04073500 & 6 & 0.000 & 6 & 0.000 \\
\hline 04079000 & 7 & 0.000 & 5 & 0.000 \\
\hline 04087000 & 4 & 0.000 & 5 & 0.000 \\
\hline 04100500 & 6 & 0.000 & 7 & 0.000 \\
\hline 04105000 & 2 & 0.000 & 6 & 0.000 \\
\hline 04112500 & 6 & 0.000 & 6 & 0.000 \\
\hline 04121500 & 7 & 0.000 & 7 & 0.000 \\
\hline 04142000 & 2 & 0.000 & 6 & 0.000 \\
\hline 04191500 & 7 & 0.000 & 7 & 0.000 \\
\hline 04193500 & 2 & 0.000 & 7 & 0.000 \\
\hline 04198000 & 2 & 0.000 & 7 & 0.000 \\
\hline 04214500 & 7 & 0.000 & 5 & 0.000 \\
\hline 04223000 & 7 & 0.000 & 7 & 0.000 \\
\hline 04234000 & 7 & 0.010 & 7 & 0.004 \\
\hline
\end{tabular}


Table G.2, continued

\begin{tabular}{|c|c|c|c|c|}
\hline \multirow{2}{*}{$\begin{array}{c}\text { Site } \\
\text { Number }\end{array}$} & \multicolumn{2}{|c|}{ Minimum Temperature } & \multicolumn{2}{|c|}{ Maximum Temperature } \\
\hline & $\begin{array}{l}\text { Lead Time } \\
\quad \text { (days) }\end{array}$ & p-value & $\begin{array}{l}\text { Lead Time } \\
\quad \text { (days) }\end{array}$ & p-value \\
\hline 04262500 & 7 & 0.054 & 7 & 0.000 \\
\hline 04269000 & 7 & 0.000 & 7 & 0.000 \\
\hline 04275000 & 7 & 0.000 & 5 & 0.000 \\
\hline 04287000 & 4 & 0.000 & 5 & 0.000 \\
\hline 05280000 & 7 & 0.000 & 7 & 0.000 \\
\hline 05286000 & 7 & 0.000 & 7 & 0.000 \\
\hline 05291000 & 5 & 0.000 & 7 & 0.000 \\
\hline 05293000 & 4 & 0.000 & 7 & 0.000 \\
\hline 05300000 & 7 & 0.000 & 7 & 0.000 \\
\hline 05304500 & 7 & 0.000 & 7 & 0.000 \\
\hline 05313500 & 7 & 0.000 & 6 & 0.000 \\
\hline 05316500 & 7 & 0.000 & 7 & 0.000 \\
\hline 05317000 & 5 & 0.000 & 7 & 0.000 \\
\hline 05340500 & 4 & 0.000 & 7 & 0.000 \\
\hline 05362000 & 3 & 0.000 & 4 & 0.000 \\
\hline 05379500 & 6 & 0.000 & 7 & 0.000 \\
\hline 05394500 & 4 & 0.000 & 7 & 0.000 \\
\hline 05399500 & 3 & 0.000 & 4 & 0.000 \\
\hline 05408000 & 4 & 0.000 & 7 & 0.000 \\
\hline 05412500 & 2 & 0.000 & 2 & 0.000 \\
\hline 05414000 & 7 & 0.000 & 7 & 0.000 \\
\hline 05418500 & 3 & 0.000 & 5 & 0.000 \\
\hline 05419000 & 3 & 0.000 & 3 & 0.000 \\
\hline 05421000 & 6 & 0.000 & 6 & 0.000 \\
\hline 05422000 & 7 & 0.000 & 7 & 0.000 \\
\hline 05426000 & 7 & 0.000 & 7 & 0.000 \\
\hline 05430500 & 7 & 0.000 & 7 & 0.000 \\
\hline 05432500 & 3 & 0.000 & 4 & 0.000 \\
\hline 05434500 & 7 & 0.000 & 7 & 0.000 \\
\hline 05435500 & 5 & 0.000 & 7 & 0.000 \\
\hline 05436500 & 2 & 0.000 & 2 & 0.000 \\
\hline 05438500 & 7 & 0.000 & 7 & 0.000 \\
\hline 05440000 & 7 & 0.000 & 7 & 0.000 \\
\hline 05444000 & 7 & 0.000 & 7 & 0.000 \\
\hline 05446500 & 7 & 0.000 & 2 & 0.000 \\
\hline 05447500 & 7 & 0.000 & 7 & 0.000 \\
\hline 05451500 & 7 & 0.000 & 7 & 0.000 \\
\hline 05454500 & 7 & 0.000 & 7 & 0.000 \\
\hline 05455500 & 7 & 0.000 & 2 & 0.000 \\
\hline 05459500 & 4 & 0.000 & 4 & 0.000 \\
\hline 05464500 & 6 & 0.000 & 7 & 0.000 \\
\hline 05465500 & 7 & 0.000 & 6 & 0.000 \\
\hline
\end{tabular}


Table G.2, continued

\begin{tabular}{|c|cc|cc|}
\hline $\begin{array}{c}\text { Site } \\
\text { Number }\end{array}$ & \multicolumn{2}{|c|}{$\begin{array}{c}\text { Minimum Temperature } \\
\text { Lead Time } \\
\text { (days) }\end{array}$} & p-value & \multicolumn{2}{|c|}{$\begin{array}{c}\text { Maximum Tead Time } \\
\text { (days) }\end{array}$} & p-value \\
\hline \hline 05470000 & & & & \\
05474000 & 5 & $\mathbf{0 . 0 0 0}$ & 6 & $\mathbf{0 . 0 0 0}$ \\
05476000 & 7 & $\mathbf{0 . 0 0 0}$ & 7 & $\mathbf{0 . 0 0 0}$ \\
05479000 & 6 & $\mathbf{0 . 0 0 0}$ & 6 & $\mathbf{0 . 0 0 0}$ \\
05482500 & 4 & $\mathbf{0 . 0 0 0}$ & 7 & $\mathbf{0 . 0 0 0}$ \\
05484000 & 2 & $\mathbf{0 . 0 0 0}$ & 5 & $\mathbf{0 . 0 0 0}$ \\
05484500 & 7 & $\mathbf{0 . 0 0 0}$ & 7 & $\mathbf{0 . 0 0 0}$ \\
05486490 & 4 & $\mathbf{0 . 0 0 0}$ & 6 & $\mathbf{0 . 0 0 0}$ \\
05490500 & 7 & $\mathbf{0 . 0 0 0}$ & 6 & $\mathbf{0 . 0 0 0}$ \\
05495000 & 4 & $\mathbf{0 . 0 0 0}$ & 5 & $\mathbf{0 . 0 0 0}$ \\
05497000 & 2 & $\mathbf{0 . 0 0 0}$ & 5 & $\mathbf{0 . 0 0 0}$ \\
05500000 & 3 & $\mathbf{0 . 0 0 0}$ & 4 & $\mathbf{0 . 0 0 0}$ \\
05501000 & 3 & $\mathbf{0 . 0 0 0}$ & 4 & $\mathbf{0 . 0 0 0}$ \\
05520500 & 7 & $\mathbf{0 . 0 0 0}$ & 7 & $\mathbf{0 . 0 0 0}$ \\
05526000 & 3 & $\mathbf{0 . 0 0 0}$ & 2 & $\mathbf{0 . 0 0 0}$ \\
05527500 & 6 & $\mathbf{0 . 0 0 0}$ & 7 & $\mathbf{0 . 0 0 0}$ \\
05555300 & 5 & $\mathbf{0 . 0 0 0}$ & 6 & $\mathbf{0 . 0 0 0}$ \\
05556500 & 7 & $\mathbf{0 . 0 0 0}$ & 7 & $\mathbf{0 . 0 0 0}$ \\
05570000 & 6 & $\mathbf{0 . 0 0 0}$ & 6 & $\mathbf{0 . 0 0 0}$ \\
05572000 & 5 & $\mathbf{0 . 0 0 0}$ & 6 & $\mathbf{0 . 0 0 0}$ \\
05585000 & 7 & $\mathbf{0 . 0 0 0}$ & 7 & $\mathbf{0 . 0 0 0}$ \\
05592500 & 2 & $\mathbf{0 . 0 0 0}$ & 2 & $\mathbf{0 . 0 0 0}$ \\
05593000 & 5 & $\mathbf{0 . 0 0 0}$ & 5 & $\mathbf{0 . 0 0 0}$ \\
05597000 & 7 & $\mathbf{0 . 0 0 0}$ & 3 & $\mathbf{0 . 0 0 0}$ \\
07013000 & 6 & $\mathbf{0 . 0 0 0}$ & 7 & $\mathbf{0 . 0 0 0}$ \\
07016500 & 2 & $\mathbf{0 . 0 0 0}$ & 2 & $\mathbf{0 . 0 0 0}$ \\
07018500 & 2 & $\mathbf{0 . 0 0 0}$ & 2 & $\mathbf{0 . 0 0 0}$ \\
07019000 & 3 & $\mathbf{0 . 0 0 0}$ & 2 & $\mathbf{0 . 0 0 0}$ \\
\hline & & & & \\
\hline & & & 6 & 2 \\
\hline
\end{tabular}

